\title{
GRAIN GROWTH IN THORIA AND THORIA-BASE FUEL PELLETS \\ (LWBR DEVELOPMENT PROGRAM)
}

R. J. SMID

CONTRACT NO. E(36-1)-GEN-14

JANUARY 1976

BETTIS ATOMIC POWER LABORATORY, WEST MIFFLIN, PA., OPERATED FOR THE U.S. ENERGY RESEARCH AND DEVELOPMENT ADMINISTRATION BY WESTINGHOUSE ELECTRIC CORPORATION 


\section{DISCLAIMER}

This report was prepared as an account of work sponsored by an agency of the United States Government. Neither the United States Government nor any agency Thereof, nor any of their employees, makes any warranty, express or implied, or assumes any legal liability or responsibility for the accuracy, completeness, or usefulness of any information, apparatus, product, or process disclosed, or represents that its use would not infringe privately owned rights. Reference herein to any specific commercial product, process, or service by trade name, trademark, manufacturer, or otherwise does not necessarily constitute or imply its endorsement, recommendation, or favoring by the United States Government or any agency thereof. The views and opinions of authors expressed herein do not necessarily state or reflect those of the United States Government or any agency thereof. 


\section{DISCLAIMER}

Portions of this document may be illegible in electronic image products. Images are produced from the best available original document. 


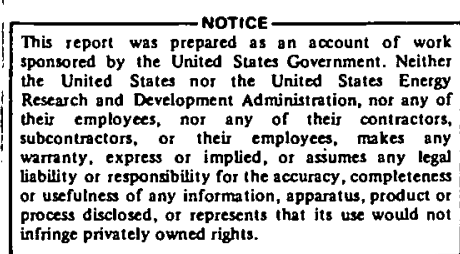

infringe privately owned rights.

GRAIN GROWTH IN THORIA AND THORIA-BASE FUEL PELLETS

(LWBR Development Program)

R. J. Smid

Contract No. $E(36-1)-G E N-14$

January 1976

Priated in the United States of America Avallable from the

Nationel Technical Iuformation Service

U. S. Department of Comerce 5285 Port Royal Roed

Springfield, Virginia 22151

\section{NOTE}

Th1s document is an interim memorandum prepared primarily for internal reference sind does not represent final expression of the opinton of lestinghoust. When th 18 memorandum is distributed externally, it is with the express understanding that westinghouse makes no representation 88 to completeness, accuracy, or usability of information contalned the rein. 

TABLE OF CONTENTS

$\underline{\text { Page }}$

I. INTRODUCTION

II. SUMMARY

A. Observations of Sintered Pellets With Uncontrolled Microstructure

1. Structural Nonuniformity

2. Sintering Kinetics of $\mathrm{ThO}_{2}$ Pellets, 0.53 Inch Diameter

3. Recrystallization Kinetics

4. Effects of Sintering Temperature and Atmosphere and $\mathrm{ThO}_{2}$ Composition

5. Impurities Responsible for Grain Growth Inhibition

6. Effects of Particle Size and Pellet Green Density

B. Effect of Powder Calcining on Grain Growth

III. ANALYTICAL METHODS AND PRODUCTION PROCEDURES

A. Powder Preparation for Pressing

1. Liquid/Solids (L/S) Blending

2. Slurry Agglomeration

12

i. 3. Dry Pressing

B. Presses

1. Baldwin Lima Hamilton (BLH) Prese 12

2. Stokes Press

C. Density Determinations

1. Geometric Density

2. Immersion Density

D. Pretreatment Furnaces

1. Laboratory Facility

2. Thoria Production Facility

E. Sintering Furnaces

1. Laboratory Furnace

2. Thoria Facility Development Furnace

3. Thoria Production Furnace

4. Vacuum Furnace

F. Powder Calcining

1. $1100^{\circ} \mathrm{C}$ Air Calcine

2. $1100^{\circ} \mathrm{C}$ Hydrogen Calcine

3. 1200 and $1400^{\circ} \mathrm{C}$ Hydroger Calcine 
TABLE OF CONTENTS (CONT'D.)

$\underline{\text { Page }}$

III. G. Grain Size Measurements 18

H. Granular Segregation Rating System · 19

I. Scanning Electron Microscope (SEM), Electron Microprobe 19 (EMP), and Quantimet

J. Pellet Description . 20

IV. SINTERING THEORY AS APPIIED TO $\mathrm{ThO}_{2}$ AND $\mathrm{ThO}_{2}-\mathrm{UO}_{2} \quad \cdot \quad$. 21

A. Introduction to. Sintering and Grain Growth . 21

B. Crain Growth Mochanism . . 2?

1. Normal Grain Growth : . 23

2. Secondary Recrystallization (Discontinuous Grain Growth) 25

3. Pore-Cortrolled Grain Growth 30

4. Grain Growth in the Presence of' a Liquid Phase 32

C. Atmosphere and Additives. . . 34

D. Surface Area . . . 36

V. KINETIC SINTERING SERIES · 37

A. Introduction . . 37

B. Sintering Kinetics 37

1. Laboratory Pretreatment and Siriteririg Procedures 37

2. Results of Laboratory Kinetic Studies 38

C. Effects of Sintering Atmosphere and Solarization of 55

Sintered $\mathrm{ThO}_{2}$ Pellets

D. Interpretations ' ' 59

1. Secondary Recrystallization . 59

2. Ilold Timc, Craclrc, and Mcchanically Expodod Surfaooc 60

3. Green Density and Powder Type 60

4. Sintering Time and Temperature 61

5. Thinmorphis Grains 61

6. Atmosphere and Additives 62

VI. RECRYSTALLIZATION MEASUREMENTS $\quad 62$ VII. EFFECT OF CALCINATION AND POWDER SURFACE AREA ON GRAIN GROWTH
IN SINTERED COMPACTS

A. Air-Calcined Powder $-1100^{\circ} \mathrm{C}$

1. Dry Pressing Procedure : 66

2. Dry Press Results . 67

3. Slurry Agglomeration Procedure 74

4. Slurry Agglomerated Pellet Results 75 
TABLE OF CONTENTS (CONT'D.)

Page

VII. B. Hydrogen-Calcined Powder $-1100^{\circ} \mathrm{C} \quad 78$

1. Dry Pressing Procedure 78

2. Dry Press Results 78

3. Slurry Agglomerated Procedure 83

4. Slurry Agglomerated Results 84

C. Hydrogen-Calcined Powder -1200 and $1400^{\circ} \mathrm{C} \quad 89$

1. Dry Pressed Results -1200 and $1400^{\circ} \mathrm{C} \quad 90$

2. Dry Pressed and Pretreated Results -1200 and $1400^{\circ} \mathrm{C}$

3. L/S Agglomerated Results -1200 and $1400^{\circ} \mathrm{C}$

D. Powder Blends 98

1. Blended Calcined and As-Received Lot 136 Powder 99

2. Blended Calcined and As-Received Lot 136 Powder-Pretreated 100

3. Blended Calcined Lot 136 and As-Received Lot 096 Powder 101

4. Porosity Distribution of Blended Powder Pellets 103

5. Grain Boundary Curvature 106

6. Density of Pellets Fabricated from Calcined Powder ". 107

E. Effects of Powder Processing Parameters on Grain Growth -. . 109

Thoria 0.53 Inch Diameter Pellets

VIII. WESTINGHOUSE RESEARCH LABORATORY (WRL) SUBCONTRACT 111

- IX, POSSIBLE FUTURE EXPERIMENTS 116

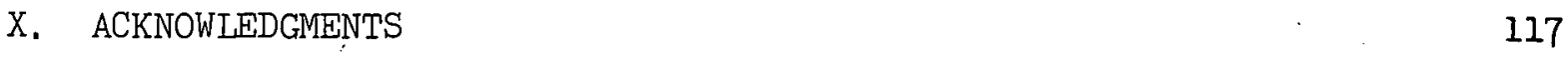

REFERENCES

APPENDIX A 
Table No. Title

$\underline{\text { Page }}$

1 Pretreatment and Sintering Schedules for the Production of $100 \% \mathrm{ThO}_{2}$ Pellets

2 Pretreatment and Sintering Schedules for the Production of Binary $\mathrm{ThO}_{2} / \mathrm{UO}_{2}$ Pellets

3 Sintering and Density Data for Pellet Structure Study \#1

123

4 . Sintering and Density Data for Pellet Structure Study \#2

124

5 Sintering and Lensity Data for Pellet Structure Study \#3

125

6 Sintering and Dencity Data for Tellet Structure Sbudy \#4

126

$7 \quad$ Sintering and Density Data for Fuel Pellets

127 Kinetio Study. $\#$ ?

8. Sintering and Density Data for Fuel Pellets Kinetic Study \#9

9 Thoria Pellet Densities After Thermal Exposure in Wet Hydrogen

10 Thoria Pellet Densities After Thermal Exposure in Vacuum $\left(4.10^{-6}\right.$ torr $)$

11 Recrystallization Around Hardness Indentations

12 Recrystallization Around Hardness Indentations in Thoria Fuel Pellets

13 Summary of Thoria Pellet and Powder Properties

14 Spark Source Mass Spectrographic Analyses of As-Received and Calcined ( 48 Hours, $1100^{\circ} \mathrm{C}$ in Hydrogen and Air)

140 $\mathrm{ThO}_{2}$ Powders

15 Thoria and Thoria-Urania Pellets Used by WRL to Perform Diagnostic txaminations

16 Estimated Grain Size of $\mathrm{ThO}_{2}$ Fuel Pellets Fabricated at WRL and Sintered at $1750^{\circ} \mathrm{C}$ for 12 . Hrs in $\mathrm{H}_{i}$ (Dry) 
2 Kinetic Study No. 1: Change in Density as a Function of

3. Kinetic Study No. 1 Effect of Sintering Time at $1750^{\circ} \mathrm{C}$ in Wet Hydrogen on Grain Growth in $\mathrm{ThO}_{2}$ Pellets Fabricated From Powder Lot 088, L/S Agrlomerated With $1.0 \mathrm{w} / \mathrm{O}$ Carbowax-0.2 w/o Sterotex (Added Dry), and Pressed to a Green Density of $55 \%$

4 : Relationship Between Grain Growth Zone and Time for Kinetic Study No. 1

Kinetic Study No. 1, Effect of Sintering Time at $1750^{\circ} \mathrm{C}$ on Grain Growth in $\mathrm{ThO}_{2}$ Pellets Fabricated From Powder Lot 088, L/S Agglomerated With $1.0 \mathrm{w} / \mathrm{o}$ Carbowax-0.2 w/o Sterotex (Added Dry), and Pressed to a Green Density of $55 \%$

6 Kinetic Study No. 1 Effect of Sintering Time at $1750^{\circ} \mathrm{C}$ on Grain Growth in $\mathrm{ThO}_{2}$ Pellets Fabricated From Powder Lot 088, I/ $/ \mathrm{s}$ Agglonmerated With $1.0 \mathrm{w} / \mathrm{o}$ Carbowax $-0.2 \mathrm{w} / \mathrm{o}$ Sterotex (Added Dry), and Pressed to a Green Density of $55 \%$

Kinetic Study No, 2: Change in Density as a Function of Tille and Temperature in ThO 2 Pcllote, Fabricated From Powder Iot 097, L/S Agglomerated With $1.0 \mathrm{w} / 0$ Carbowax$0.2 \mathrm{w} / \mathrm{O}$ Sterotex (Added Dry), and Pressed to a Green Density of $62 \%$

Kinetic Study No. 2: Effect of Sintering Time at $1750^{\circ} \mathrm{C}$ on Grain Growth in $\mathrm{ThO}_{2}$ Pellets Fabricated From Powder Lot 097, L/S Agglomerated With $1.0 \mathrm{w} / \mathrm{o}$ Carbowax - 0.2 w/o Sterotex (Added Dry), and Pressed to a Green Density of $62 \%$ in Dry Hydrogen for 13 Hours at $1750^{\circ} \mathrm{C}$ 
Figure No.

13 Area 4 in Figure 9

18 Electron Microprobe Examination of ThO 2 Pellet, 6-2,

a thru d Blend 097-1-01A in Area of Idiomorphic Grain Structure

Showing Presence of' 'Th $(0,5)_{2}$ Phase: Kinetic Study \#'2

19 Electron Microprobe, Semi-Quantitative X-Ray Trace of White Second Phase, Th $(0,5)_{2}$ Shown in Figure 18. - Kinetic Study \#2 097-1-01A, in Area of Idiomorphic Grain Structure Showing Presence of $\operatorname{Th}(0, \mathrm{~S})_{2}$ Phase: Kinetic Study \#2

Electron Microprobe, SSemi Quantitative X-Ray 'Trace of' Grey Second Yhase, 'l'h $(U, S)_{2}$ S'hown in F'igure $2 U$ - Kinetic Study \#2 on lirain lirowth in 'l'hl, 'Peldets Fabricated From Powder Lot 0,97 , L/S Agglomerated With $1.0 \mathrm{w} / 0$ Carbowax - $0.2 \mathrm{w} / \mathrm{o}$ Sterotex (Added Dry), and Pressed to a Green Density of $62 \%$

23 Time Dependent Grain Growth at $1655^{\circ} \mathrm{C}$ in $\mathrm{ThO}_{2}$ Pellets, 088-1-11, at Surface Exposed to the Sintering. Atmosphere Hold Time on Grain Growth in ThO Pellets Fabricated From Powder Lot 097 , L/S Agglomerated With $1.0 \mathrm{w} / \mathrm{o}$ Carbowax$0.2 \cdot \mathrm{w} / \mathrm{o}$ Storotox (Added Dry), and Prececd to a Crecn Density of $62 \%$

25 Kinetic Study No. 6: Effect of Heating Rate $\left(400^{\circ} \mathrm{C} / \mathrm{Hr}\right.$ ) and Sintering Time at $1750^{\circ} \mathrm{C}$ on Grain Growth in $\mathrm{ThO}_{2}$ Pellets Pauricated Trom Fowder Lot.088, L/S Agglonerated With 1.0 w/o Carbowax - 0.2 w/o S.terotex (Added Dry), and Fressed to a Green Density of $55 \%$ 
LIST OF FIGURES (Cont'd.)

Figure No.

26

27

a thru d

29

a thru i

30

31

32

33

34
Title

$\underline{\text { Page }}$

Time and Temperature in $\mathrm{ThO}_{2}$ Pellets Fabricated From Powder Lot 088, L/S Agglomerated With $1.0 \mathrm{w} / \mathrm{o}$ Carbowax0.2 w/o Sterotex (Added Dry), and Pressed to a Green Density of $55 \%$

Kinetic Study No. 7: Effect of Sintering Time at $1750^{\circ} \mathrm{C}$ on Grain Growth in ThO Pellets Fabricated From Powder Lot 088, L/S Agglomerated With $1.0 \mathrm{w} / 0$ Carbowax. - $0.2 \mathrm{w} / \mathrm{o}$ Sterotex (Added Dry), and Pressed to a Green Density of $55 \%$

Kinetic Study \#7 Photomicrographs of Pellet, 8-7,

Sintered For 5 Hrs at $1750^{\circ} \mathrm{C}$

Kinetic Study \#7: Photomicrographs of Thoria Pellet, $6-7$, Sintered for 20 Hours at $1750^{\circ} \mathrm{C}$

Kinetic Study No. 9: Effect of Sintering Time at $1750^{\circ} \mathrm{C}$ in Wet Hydrogen on Grain Growth in ThO Pellets Fabricated From Powder Lot 088, L/S Agglomerated fith $1.0 \mathrm{w} / \mathrm{o}$ Carbowax - $0.2 \mathrm{w} / \mathrm{o}$ Sterotex (Added Dry), and Pressed to a Green Density of $55 \%$

Effect of Sintering Atmosphere on the Grain Growth in $\mathrm{ThO}_{2}$ Pellets Fabricated From Powder Lot 088, I/S Agglomerated With $1.0 \mathrm{w} / 0$ Carbowax - $0.2 \mathrm{w} / 0$ Sterotex (Added Dry), Fressed to a Green Density (of 56\% and Previously Sintered at $1750^{\circ} \mathrm{C}$ for $12 \mathrm{Hrs}$ in $\mathrm{H}_{2}$ (Wet)

Photomicrograph of Sectioned Pellet, Powder Lot 088, Which Previously Had Been Sintered at $1750^{\circ} \mathrm{C}$ and Then Heat Treated at $1800^{\circ} \mathrm{C}$ in a Wet $\left(25^{\circ} \mathrm{C}\right)$ Hydrogen Atmosphere

Variation Grain Growth as a Function of $\mathrm{ThO}_{2}$ Pellet Cross Section for a Vacuum Sintered Pellet Fabricated From Powder Lot 097, L/S Agglomerated With 1.0 w/o Carbowax 0.2 w/o Sterotex (Added Dry)

Photomicrograph Showing Recrystallized Grains in Area Plastically Deformed by Knoop Indentation

Effect of Calcining $\left(1100^{\circ} \mathrm{C}-48 \mathrm{Hrs}-\mathrm{Air}\right)$ and Micronizing (1-Double Pass) on Grain Growth in ThO, Pelleto Dry Fressed Without Binder or Lubricant From Powder Lot 096 and Sintered at $1750^{\circ} \mathrm{C}-1-1 / 2$ Hrs in $\mathrm{H}_{2}$ (Dry) 
I.TST OF. FIGURES (Cont'd. )

Figure No.

Title

$\underline{\text { Page }}$

36

Effect of Calcining $\left(1100^{\circ} \mathrm{C}-48 \mathrm{Hrs}-\mathrm{Air}\right)$ and Micronizing

179 (1-Double Pass) on Grain Growth in ThO 2 Pellets Dry Pressed Without Binder or Lubricant From Powder Lot 096 and Sintered at $1750^{\circ} \mathrm{C}-12 \mathrm{Hrs}_{2} \mathrm{H}_{2}$ (Dry) .

37

Center Microstructure Showing Intragranular Porosity

$180-181$

a thru c

38

Effecl of Calcining $\left(1100^{\circ} \mathrm{C}-48 \mathrm{Hrz}-\mathrm{Air}\right)$ and Micronizing

182

(1-Double Pass) on Grain Growth in ThO Pellets Dry Pressed

Wi liout Dinder or Lubricant. From Powder̃ fot 136 and

Sintered at $1750^{\circ} \mathrm{C}-1-1 / 2$ Hrs in $\mathrm{H}_{2}$ (Dry)

39

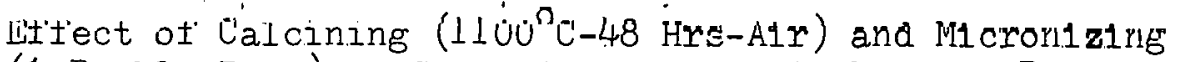

(1-Double Pass) on Grain Growth in ThO Pellets Dry

Pressed Without Binder or Lubricant From Powder Lot 136

and Sintered at $1750^{\circ} \mathrm{C}-12 \mathrm{Hrs}-\mathrm{H}_{2}$ (Dry)

40

Microstructure of Slurry Agglomerated Thoria Pellets

Showing Severe Granular Segregation

a thru d

41

Effect of Micronization and Sintering Time on Grain Growth in $\mathrm{ThO}_{2}$ Pellets Dry Pressed Without Binder or Lubricant

186 From Calcined $\left(1100^{\circ} \mathrm{C}-48 \mathrm{Hrs}-\mathrm{H}_{2}\right.$ (Dry), Powder Lot 096

42

a thru $d$

Thoria Pelfet, :4AA, Dry Pressed From Calcined $\left(1100^{\circ} \mathrm{C}-48\right.$

$187-188$

$\mathrm{Hrs}-\mathrm{H}_{2}$ (Dry)) 096 Thoria Powder and Sintered at $1750^{\circ} \mathrm{C}$ in $\mathrm{H}_{2}{ }^{2}$ for 12 Hes

Effect of Micronization and Sintering Time on Grain Growth in ThO; Pellets Dry Pressed Without Binder or Lubricant From Calcined $\left(1100^{\circ} \mathrm{C}-48 \mathrm{Hrs}_{2} \mathrm{H}_{2}\right.$ (Dry), Powder Lot 136

44 Porosity Distribution in Thoria Pellets F'abricated From a thru d Calcined $\left(1100^{\circ} \mathrm{C}-48 \mathrm{Hrs}-\mathrm{H}_{2}\right)$ Powder

Effect of Sintering Time at $1750^{\circ} \mathrm{C}$ on Grain Growth in 192 $\mathrm{ThO}_{2}$ Pellets Fabricated From Pqwder Lot 096, Micronized, $\mathrm{Calc}$ ined $\left(1100^{\circ} \mathrm{C}-48 \mathrm{Hrs}-\mathrm{H}_{2}\right.$ (Iry), Slumy Agglomerated With

$190-191^{\circ}$ $1.75 \mathrm{w} / \mathrm{o}$ Carbowax - $0.2 \mathrm{w} \%$ Sterotex (Added Dry) and Pressed to a. Target Green Density of $57 \%$

46

Effect of Sintering Time at $1750^{\circ} \mathrm{C}$ on Grain Growth in $\mathrm{ThO}_{2}$ Pellets Fabricated From Pqwder Lot 096, Micronized, $\mathrm{Cal}$ cined $\left(1100^{\circ} \mathrm{C}-48 \mathrm{Hrs}-\mathrm{H}_{2}\right.$ (Dry). Slurry Agglomerated With 1.75 w/o Carbowax - $0.2 \mathrm{w} \%$. Sterotex (Added Dry) and Pressed to a Target Green Density of $61 \%$ 
LIST OF FTGURES (Cont'd.)

Figure No.

Title

Page

47

Effect of Sintering Time at $1750^{\circ} \mathrm{C}$ on Grain Growth in $\mathrm{ThO}_{2}$

Pellets Fabricated From Powder Lot 136 , Calcined $\left(1100^{\circ} \mathrm{C}-{ }^{2}\right.$ $48 \mathrm{Hrs}-\mathrm{H}_{2}$ (Dry), Micronized, Slurry Agglomerated With 1.75 w/o Carbowax-0.2 w/o Sterotex (Added Dry), and Pressed to a Green Target Density of 57\%

48 Effect of Sintering Time at $1750^{\circ} \mathrm{C}$ on Grain Growth in $\mathrm{ThO}_{2}$ Pellets Fabricated From Powder Lot 136, Calcined $\left(1100^{\circ} \mathrm{C}-{ }^{2}\right.$ $48 \mathrm{Hrs}-\mathrm{H}_{2}$ (Dry), Micronized, Slurry Agglomerated With 1.75 w/o Carbowax-0.2 w/o Sterotex (Added Dry), and Pressed to a Green Target Density of $61 \%$

49 Effect of Pressed Density on Grain Growth in ThO Pellets Pressed From $1100^{\circ} \mathrm{C}-48 \mathrm{Hrs}-\mathrm{H}_{2}$ (Dry) Calcined, Micronized, Powder Lot 096 Slurry Agglomerated With 1.75 w/o Carbowax$0.2 \mathrm{w} / 0$ Sterotex (Added Dry) and Sintered at $1750^{\circ} \mathrm{C}$ for 12 Hours

50 Effect of Pressed Density on Grain Growth in $\mathrm{ThO}_{2}$ Pellets .. 197 Pressed From $1100^{\circ}$ C 48 Hrs-Hi. (Dry.) Calcined, Micronized, Powder Lot 136 Slurry Agglomerated With 1.75 w/o Carbowax$0.2 \mathrm{w} / \mathrm{o}$ Sterotex (Added Dry) and Sintered at $1750^{\circ} \mathrm{C}$ for $12 \mathrm{Hrs}$

Effect of Pressed Density on Grain Growth in ThO Peliets Pressed From Micronized, As-Received Powder Lot 096, Slurry Agglomerated With $1.75 \mathrm{w} / \mathrm{O}$ Carbowax-0.2 w/o Sterotex (Added Dry) and Sintered at $1750^{\circ} \mathrm{C}$ for $12 \mathrm{Hrs}$

Effect of Calcining Time and Temperature on Grain Growth in $\mathrm{ThO}_{2}$ Pellets Fabricated Without Binder From Powder Lot 136, and Dry Pressed to a Green Density of 60\% Sintering Condition: $1750^{\circ} \mathrm{C}-1 \frac{1}{2} \operatorname{Hrs}-\mathrm{H}_{2}$ (Dry)

53 Effect of Calcining Time and Temperature on Grain Growth in $\mathrm{ThO}_{2}$ Pellets Fabricated Without Binder From Powder Lot 136 and Dry Pressed to a Green Density of $60 \%$ Sintering Conditions: $1750^{\circ} \mathrm{C}-12 \mathrm{Hrs}_{2}$ (Dry)

54 Effect of Calcining Time and Temperature on Grain Growth in Pretreated $\left(925^{\circ} \mathrm{C}-3 \mathrm{Hrs}-\mathrm{CO}_{2}\right) \mathrm{ThO}_{2}$ Pellets Fabricated Without Binder From Powder Lot 136, Dry Pressed to a Green Density of $60 \%$ and Sintered at $1750^{\circ} \mathrm{C}$ in $\mathrm{H}_{2}$ (Dry) for $1 \frac{1}{2} \mathrm{Hrs}$

55 Effect of Calcining Time and Temperature on Grain Growth in Pretreated $\left(925^{\circ} \mathrm{C}-3 \mathrm{Hrs}-\mathrm{CO}_{2}\right)$ ThO Pellets Fabricated Without Binder From Powder Lot 136, Dry Pressed to a Green Density of $60 \%$ and Sintered at $1750^{\circ} \mathrm{C}$ in $\mathrm{H}_{2}$ (Iry) for $12 \mathrm{Hrs}$ 
Figure No.

56
Title

Effect of Sintering Time at $1750^{\circ} \mathrm{C}-\mathrm{H}_{2}$ (Dry) on Grain Growth in $\mathrm{ThO}_{2}$ Pellets Fabricated From Powder Lot 136, Micronized, Calcined $\left(1200^{\circ} \mathrm{C}-8 \mathrm{Hrs}-\mathrm{H}_{2}\right.$ (Dry), L/S Agglomerated With 1.5 w/o Carbowax-0.2 w/o Sterotex (Added Dry), and Pressed to a Green Density of 60\%

Effect of Sintering Time at $1750^{\circ} \mathrm{C}-\mathrm{H}_{2}$ (Dry) on Grain Growth in ThO Pellets Fabricated From Powder Lot 136, Micronized, Calcined (1200 $\mathrm{C}-8$ Hrs-H, (Dry), L/S Agslomerated With 1.5 w/o Carbowax-0.2 w/o Sterotex (Added Dry), and Pressed to a. Cireen lensity of $62 \%$

Effect of Sintering Time at $1750^{\circ} \mathrm{C}-\mathrm{H}_{2}$ (Dry) on Grain Growth in ThO Pcllctg Tabricaley Fıull Puwder Lot 196 Micronized, Calcined $\left(1400^{\circ} \mathrm{C}-3 \mathrm{Hrs}-\mathrm{H}_{2}\right.$ (Dry)), L/S Agglomerated With 1.5 w/o Carbowax-0.2 w/o Sterotex (Added Dry), and Pressed to a Green Density of $60 \%$

Effect of Sintering Time at $1750^{\circ} \mathrm{C}-\mathrm{H}_{2}$ (Dry) on Grain Growth in ThO 2 Pellets Fabricated From Powder Lot 136, Micronized, Calcined $\left(1400^{\circ} \mathrm{C}-3 \mathrm{Hrs}-\mathrm{H}_{2}\right.$ (Dry), L/S Agglomerated. With $1.5 \mathrm{w} / \mathrm{o}$ Carbowax-0.2 w/O Sterotex (Added Dry), and Pressed to a Green Density of $65 \%$

Effect of Blending Calcined and As-Received 136 Powder on Grain Growth in Tho Pellets Dry Pressed Without Bindor at $60 \%$ Green Density arid Sintered at. $1750^{\circ} \mathrm{C}$ in $\mathrm{H}_{2}$ (Dry) for $1 \frac{1}{2}$ Hrs

Effect of Blending Calcined and As-Received 136 Powders on Grain Growth in ThO 2 Pellets Dry Pressed Without Binder at $60 \%$ Green Density and Sintered at $1750^{\circ} \mathrm{C}$ in $\mathrm{H}_{2}(\overline{D r y})$
for $12 \mathrm{Hrs}$

Effect of Sintering Time at $1750^{\circ} \mathrm{C}$ in $\mathrm{H}^{\prime}$ (Dry) on Grain Growth in Pretreated $\left(925^{\circ} \mathrm{C}-3 \mathrm{Hrs}-\mathrm{CO}_{2}\right)$ ThO ${ }_{2}$. Pellets Dry Pressed Without Binder From a Blend of Calcined and As-Rereived 136 Powder

Effect of Sintering Time at $1750^{\circ} \mathrm{C}$ in $\mathrm{H}_{2}$ (Dry) on Grain Growth in $\mathrm{ThO}_{2}$ Pellets Dry Pressed Without Binder From a Blend of Calcined 136 and As-Received 096 Powder

Effect of Blending Calcined 136 and As-Received 096 Powder on Grain Growth in ThO Dry Pellets Pressed Without Binder and Sintered at $1750^{\circ} \mathrm{C}^{2}$ in $\mathrm{H}_{2}$ (Dry) for $1 \frac{1}{2} \mathrm{Hrs}$

Effect of Blending Calcined 136 and As-Received 096 Powder on Grain Growth in ThO, Pellets Dry Pressed Without 
Figure No.

66

$\mathrm{a}$ and $\mathrm{b}$

67

$a$ and $b$

68.

69

a thru c

70

71

72

A-1

A-3
A-2 Effect of Sintering Time at $1750^{\circ} \mathrm{C}$ ' on Grain Growth in

Title

Page

Metallographic Section at the Surface and Pellet Center Along the Diameter of the Thoria Pellet Fabricated Without Binder From Equal Quantities of Calcined $\left(1400^{\circ}-3 \mathrm{Hrs}-\mathrm{H}_{2}\right)$, Micronized and As-Received Micronized Thoria 136 Powder and Sintered at $1750^{\circ} \mathrm{C}$ for $12 \mathrm{Hrs}$

Metallographic Section at the Surface and Pellet Center Along the Diameter of the Thoria Pellet Fabricated Without Binder From Equal Quantities of Calcined (1400-3 Hrs- $\mathrm{H}_{2}$ ), Micronized and As-Received, Micronized Thoria 136 Powdêr. Sintering Temperature $1750^{\circ} \mathrm{C}-1 \frac{1}{2} \mathrm{Hrs}-\mathrm{H}_{2}$

Variation in Porosity Along the Diameter of a Thoria Pellet Fabricated Without Binder From Equal Quantities of Calcined and As-Received 136 Powder Sintered at $1750^{\circ} \mathrm{C}$ in $\mathrm{H}_{2}$

Grain Boundary Curvature at a Free Surface

Sintered Density of Binderless $\mathrm{ThO}_{2}$ Pellets (Lot 136)

Sintered for $12 \mathrm{Hrs}$ at $1750^{\circ} \mathrm{C}$ in Dry $\mathrm{H}_{2}$

Effect of Surface Area and Calcination on Grain Growth in $\mathrm{ThO}_{2}$ Pellets

Effect of Surface Area and Calcination on Grain Growth in $\mathrm{ThO}_{2}$ Pellets Sintered at $1750^{\circ} \mathrm{C}$ in $\mathrm{H}_{2}$ For $1.2 \mathrm{Hrs}$

Effect of Sintering Time at $1750^{\circ} \mathrm{C}$ on Grain Growth in $\mathrm{ThO}_{2}$ Pellets Fabricated From Powder Lot 096, Micronized, As-Received, Slurry Agglomerated With 1.75 w/o Carbowax0.2 w/o Sterotex (Added Dry) and Pressed to a Green Target Density of $57 \%$ $\mathrm{ThO}_{2}$ Pellets Fabricated From Powder Lot 096 Air Calcined at $1100^{\circ} \mathrm{C}$ for $48 \mathrm{Hrs}$, Micronized, Slurry Agglomerated With $1.75 \mathrm{w} / \mathrm{o}$ Carbowax-0.2 w/o Sterotex (Added Dry) and Pressed to a Green Target Density of $5 \% \%$

Effect of Sintering Time at $1750^{\circ} \mathrm{C}$ on Grain Growth in $\mathrm{ThO}_{2}$ Pellets Fabricated From Powder Lot 096, Micronized, AsReceived, Slurry Agglomerated With 1.75 w/o Carbowax0.2 w/o Sterotex (Added Dry) and Pressed to a Green Target Density of $61 \%$ 
Figure No. A-4 $A-5$ $A-6$
Title

Page

Effect of Sintering Time at $1750^{\circ} \mathrm{C}$ on Grain Growth in $\mathrm{ThO}_{2}$ Pellets Fabricated From Powder Lot 096 Air Calcined at $1100^{\circ} \mathrm{C}$ for $48 \mathrm{Hrs}$, Micronized, Slurry Agglomerated With 1.75 w/o Carbowax-0.2 w/o Sterotex (Added Dry) and Pressed to a Green Target Density of $61 \%$

Effect of Sintering Time at $1750^{\circ} \mathrm{C}$ on Grain Growth in $\mathrm{ThO}_{2}$ Pelletc Fabricatcd From Powder Iot 136, Micronizcd, $\Lambda$. Received, Slumry Agglomerated With 1.75 w/o Carbowax-0.2 w/o Sterotex (Added Dry) and Pressed to a Green Target Lensity of' $57 \%$

Effect of Sintering Time at $1750^{\circ} \mathrm{C}$ on Grain Growth in $\mathrm{ThO}_{2}$ Pellets Fabricated From Powder Lot 136 Air Calcined at $1100^{\circ} \mathrm{C}$ for $48 \mathrm{Hrs}$, Micronized, Slurry Agglomerated With 1.75 w/o Carbowax-0.2 w/o Stcrotex (Added Dry) and Pressed to a Green Target Density of $57 \%$

Effect of Sintering Time at $1750^{\circ} \mathrm{C}$ on Grain Growth in $\mathrm{ThO}_{2}$ Pellets Fabricated From Powder Lot 136, Micronized, AsReceived, Slurry Agglomerated With 1.75 w/o Carbowax$0.2 \mathrm{w} / \mathrm{o}$ Sterotex (Added Dry) and Pressed to a Green Target Density of $61 \%$

Effect of Sintering Time at $1750^{\circ} \mathrm{C}$ on Grain Growth in $\mathrm{ThO}_{2}$ Pellets Fabricated From Powder Lot 136 Air Calcined at $1100^{\circ} \mathrm{C}$ for $48 \mathrm{Hrs}$, Micronized, Slurry Agglomerated With 1.75 w/o Carbowax-0.2 w/o Sterotex (Added Dry) and Pressed to a Green Density of $61 \%$

Effect of Pressed Density on Grain Growth in ThO Pellets Pressed From Micronized, As-Received Powder Lot 696 SIurry Agg Lomerated With $1.75 \mathrm{w} / \mathrm{O}$ Carbowax $-0.2 \mathrm{w} / \mathrm{O}$ Sterotex (Added Dry) and Sjntered at $1750^{\circ} \mathrm{C}$ for 12 Hrs

Effect of Pressed Density on Grain Growth in ThO Pellets Pressed From $1100^{\circ} \mathrm{C}-48 \mathrm{Hrs}$ Air Calcined, Micronized Powder Lot 096 Slurry Agglomerated With $1.75 \mathrm{w} / \mathrm{o}$ Carbowax-0.2 w/o Sterotex (Added Dry) and Sintered at $1750^{\circ} \mathrm{C}$ for 12 Hrs

Effect of Pressed Density on Grain Growth in ThO Pellets Pressed From Micronized As-Received Powder Lot 136 Slurry Agglomerated With 1.75 w/o Carbowax-0.2 w/o Sterotex (Added Dry) and Sintered at $1750^{\circ} \mathrm{C}$ for $12 \mathrm{Hrs}$ Pressed From Air Calcined $1100^{\circ} \mathrm{C}-48 \mathrm{Hrs}$, Micronized Powder Lot 136, Slurry Agglomerated With 1.75 w/o Carbowax-0.2 w/o Sterotex (Added Dry) and Sintered at $1750^{\circ} \mathrm{C}$ for $12 \mathrm{Hrs}$ 


\section{GRAIN GROWTH IN THORIA AND THORIA-BASE FUEL FELLETS}

(LWBR Development Program)

$$
\text { R. J. Smid }
$$

\section{INTRODUCTION}

This investigation was undertaken by the Bettis Atomic Power Laboratory (Bettis) to determine the influence of powder and processing parameters on grain growth in LWBR 0.53 inch diameter thoria and thoria-urania fuel pellets. Although the overall pellet manufacturing process incorporates numerous specifications, procedures, and controls, it is difficult to determine what effect any single parameter has on grain growth since the variations observed in the control parameters are typically small and frequently within the error of the measurement. It was therefore concluded that it was desirable to delineate the basic mechanisms of grain growth in thoria-base LWBR fuel pellets so that grain size variations and the sensitivity of the control parameters could be evaluated.

The results of this investigation point to the presence of an as yet unidentified impurity (or impurities) in $\mathrm{ThO}_{2}$ powder which is not completely volatilized by conventional calcining treatments. The trace impurity is removed from the exterior of the pellet during heating to sintering temperatures, resulting in the formation of a "picture frame" on the outside of pellets which has "normal" grain growth characteristics. On the inside of the pellet, some distance from the surface, the trace impurity inhibits normal grain growth and changes the behavior to discontinuous grain coarsening. This leads to large variations in grain size within a single pellet or between pellets with only very small changes in sintering time, temperature, atmosphere, green density, and impurity content, thereby explaining why defined controls do not always adequately predict the final grain size. The impurity can be volatilized by heating the $\mathrm{ThO}_{2}$ powder to temperatures somewhat above those initially utilized for production powder; changes in powder particle surface area and density caused by this recalcination, however, deteriorate "granulation, pressing and densification properties using initial LWBR production parameters for these operations. These results suggested three courses of action: 1) Blend calcined (impurity free) and as-received 
(impurity containing) powder to obtain the optimum characteristics of each. 2) Increase the grain boundary mobility so that grain growth proceeds in spite of the presence of the inhibiting impurity. 3) Alter the production of the original starting thoria powder so that the inhibiting impurity is either not present or its influence on grain growth reduced (may be accomplished by optimizing impurity removal and surface area).

After investigating the kinetic nature of grain growth and the influence of calcining, the first two actions were examined because of the potential immediate results. It was concluded that the third course of action would not be undertaken since it would require a long range develupment effort.

Two additional variables which were identified as having significant influence on grain growth in $\mathrm{ThO}_{2}$ fuel were the surface area of the starting powder and the oxygen partial pressure of the sintering furnace.

\section{SUMMARY}

A. Observations of Sintered Pellets With Uncontrolled Microstructure 1. Structural Nonuniformity.

A feature which is striking to anyone examining the crosssectional microstructure of a sintered $\mathrm{ThO}_{2}$ pellet with the grain growth variation that prompted this investigation is its structural nonuniformity best described as a picture-frame structure; possible even more unusual is the reproducibility of this nonuniformity. The periphery of the pellet to a depth which varies with powder lot of 0.050 to 0.100 inches consists of grains of size normally in the range ASTM \#5 to \#8 whereas the remainder of the pellet normally has a grain size of ASTM \#10 or finer. As pellets are pressed to ever-higher green densities, the grain size of the periphery remains unchanged or, at most, reduces by one or two ASTM grain size numbers, while the grain size of the interior increases to levels equal or greater than those of the picture frame. This structural nonuniformity persisted during initial peliet fabrication operations irrespective of powder source, or subsequent handling. Significantly, the borders of cracks which are formed in green pellets prior to sintering have the grain size characteristics of the periphery even when they penetrate to the center of the pellet. Two separate experiments, Section V.B, one involving a low temperature hold in the sintering cycle, the other using mechanically drilled holes in the pellet 
surface, proved that the picture-frame of the structure nonuniformity was not in fact some unique property of the exterior of the pellet (such as green density) but rather access of the pellet to the atmosphere.

\section{Sintering Kinetics of $\mathrm{ThO}_{2}$ Pellets, 0.53 Inch Diameter}

Observations of grain size development in initial production or development $\mathrm{ThO}_{2}$ pellets were customarily confined to examination after the normal 12 hour at $1750^{\circ} \mathrm{C}$ sintering cycle; when grain sizes were less than specification levels, the pellets would be re-examined after each repetition of the standard cycle. This practice was premised not only upon production practicality but also on the assumption that the various grain growth mechanisms defined in Section IV.B of this report operated and that the 12 hour (or subsequent 24 hour) structures were in fact only extensions of the structures which would be observed at shorter times as predicted from (time $)^{\frac{1}{2}-1 / 5}$ relationships. However, there were occasional observations of grains much larger than specification in the center of pellets whose grain size was otherwise "normal." Further, it was noted that resintering often resulted in grain sizes far coarser than could be explained by extrapolation of "normal" grain growth kinetics. These observations motivated a more careful and detailed study of structure development in $\mathrm{ThO}_{2}$ pellets as a function of sintering time, temperature, atmosphere, powder compaction, etc. (Section V). These studies revealed the true differences between the picture frame and the pellet core; specifically they identified the grain growth characteristics of the former to be "normal" and those of the latter to be "discontinuous."

In addition, the identification of exaggerated grain growth as a result of the phenomena of secondary recrystallization documented the existence of an inhibiting species. From the kinetic studies alone it was not clear whether the impurity existed as a second phase, remained in solid solution, or was present as a gas trapped in pores. Nevertheless, there appeared to be little doubt of 1 ts presence.

Based on the conclusion that a grain growth inhibiting impurity was present, and review of several articles in the literature indicating that under special conditions CO-filled pores could inhibit graln growth, it was considered probable that residual carbon, as co gas-filled pores, was the prime impurity. Attention was directed toward more effectual procedures for its removal from the original power and from the green pellet. A serles 
of experiments where production $\mathrm{ThO}_{2}$ pellets were heated to $18 \mathrm{~b}^{\circ} \mathrm{C}$ in a vacuum ("solarization" experiments, Section V.C, Figure 31) wi thout. increasing the grain size, causing pore growth, or decreasing the density raised considerable doubt about the presence or at leașt the importance of gas-filled pores. Even more conclusive were the observations (Section VII.B, Figure 44 ) where pore-free grains bordered grains with extensive necklace porosity; the grain size in both areas was identical. Finally, it was shown that the thoria pellets when pulverized as part of the standard procedure prior to analysis adsorbed $\mathrm{CO}_{2}$ from the atmosphere onto the $\mathrm{ThO}_{2}$. linis adsorbed $\mathrm{CO}_{2}$ could be driven off at relatively low temperatures, $<400^{\mathrm{U}} \mathrm{C}$, and therefore could contribute little to structural development in $\mathrm{ThO}_{2}$ pellets. It is apparent that large amounts of carbon deliberately intruduced in peliets can affect the grain size, but such observations are not germane to normal practice. Thus, the role of carbon and gas-filled pores in the normal $\mathrm{ThO}_{2}$ pellet production process was determined to be unimportant to the discontinuous grain size problem.

\section{Recrystallization Kinetics}

The driving force for grain growth, namely grain boundary. energy, is known to be very small. It was considered that, if the driving force for grain growth could be increased, differences between picture frame and core of sintered pellets or between pellets. sintered to different grain size levels or different material lots could be demonstrated in an independent manner. A method for increasing the propensity for grain growth is to locally plastically deform the oxide by hardness indentation. A volume of material underneath the indenter is plastically deformed, (Ket. I), and the deformation energy contained in that volume then causes recrystulli-. zation and grain growth upon reheating the indented specimen. It was estimated that the deformation energy stored in the plastic zone beneath a I $\mathrm{kg}$ load knoop indentation in $\mathrm{ThO}_{2}$ is about 500 dyme $-\mathrm{cm}$ as compared with about 0.1 dyne-cm grain boundary energy in the same volume. Most of the former strain energy will be recovered by mechanisms other than recrystailization during heating. The experimental method and results are described in Section VI. These experiments showed that the grains in the picture frame region recrystallized readily around the indentation whereas the fine- 
grained core region was resistant to recrystallization unless the temperature was raised to $1800^{\circ} \mathrm{C}$. Recrystallization, even in the core of the pellets, was noted when the grain size was increased to a size greater than ASTM $\not \$ 8.5$ in the core region by increasing green density.

These results are believed to be interpretable only on the basis that a grain growth inhibitor is present in the interior of pellets (but is eliminated in the picture frame region upon heating to sintering temperature) which prevents recrystallization around the indentation even with the added stored energy of plastic deformation. The fact that, even in the pellet interior, recrystallization is noted when the grain size is increased is interpreted as indicating that the inhibitor is not an immobile dispersed phase or pore but more probably an impurity in solid solution which retards the grain boundary but is eventually swept up by advancing grain boundaries by a process analogous to zone refining to an extent that recrystallization around indentations is unhampered by the presence in bulk of the impurity.

The fact that both sintering kinetic studies and recrystallization results indicate that grain growth occurs more readily with increased temperature also tends to favor the impurity drag hypothesis and hence the presence of an impurity in solid solution; however a significant increase in the self-diffusion rates with increase in temperature may impart sufficient energy to grain boundaries to enable them to move past even immobile dispersed phases.

4. Effects of Sintering Temperature and Atmosphere and $\mathrm{ThO}_{2}$ Composition

In the course of performing the "solarization" experiments previously described, the observation was made (reported in Section V.C) that grain growth in a conventional production $\mathrm{ThO}_{2}$ pellet made from powder containing about $100 \mathrm{ppm} \mathrm{Ca}$ and initially sintered 12 hours at $1750^{\circ} \mathrm{C}$ was markedly enhanced by resintering for an additional 12 hours in wet hydrogen at $1800^{\circ} \mathrm{C}$, but unchanged by resintering for 12 hours at $1850^{\circ} \mathrm{C}$ in a high vacuum. An explanation was postulated for this observation based on changes in the defect structure 1nduced in $\mathrm{ThO}_{2}$ by equilibration with the atmosphere. It is apparent that factors which increase the self-diffusion rate of $\mathrm{ThO}_{2}$, such as equilibration with an oxidizing or less reducing atmosphere 
such as air or wet hydrogen rather than a highly reducing atmosphere such as pure hydrogen, or higher temperatures of sintering would increase grain boundary mobility and thus. permit grain growth even in the presence of inhibiting phases or elements.

\section{Impurities Responsible for Grain Growth Inhibition}

Various impurities have been postulated as being responsible for grain growth inhibition. The reasons for discarding carbon as a suspect were previously discussed. Sulfur was also a prime candidate since, unlike carbon, its presence in the powder and not as an adsorbed gas is real and it is not driven off at low temperatures but requires high temperatures for its removal (See Table 14). The presence of a thorium oxysulfide phase in an area where large idiomorphic grains were detected directed attention initially. to this impurity; however, the absence of this phase in the areas where exaggerated grain growth was observed cast considerable doubt on its possible role as an inhibiting impurity.

It was also shown in Section VII that marked changes can be produced in the sintering characteristics of $\mathrm{ThO}_{2}$ pellets by calcining the powder at temperatures which have little or no effect on the sulfur content. For these reasons, sulfur is no longer regarded as a prime suspect.

Sanples of $\mathrm{THO}_{2}$ powder's which have been calcined at $1100^{\circ} \mathrm{C}$ in air and hydrogen and which have shown corresponding changes in grain growth behavior upon subsequent compaction and sintering have been examined by spark source mass spectrography. to detect differences in impurity levels. Of the elements detected, only sodium and fluorine are present in sufficient quantity and are reduced by calcining in a manner consistent with the postulate. Cross sections of fine-grained and coarse-grained $\mathrm{ThO}_{2}$ peliets examined at the Westinghouse Research Laboratory using an ion probe detected $\mathrm{Na}$ and $\mathrm{K}$ as impurities in the $\mathrm{ThO}_{2}-\mathrm{U}^{233} \mathrm{O}_{2}$ samples. However, at this time positive identification of the specific grain growth inhibiting agents is unavailable.

\section{Effects of Particle Size and Pellet Green Density}

Increasing green density has been known to increase grain size at $\mathrm{ThO}_{2}$ fuel pellet centers whereas a general correlation has been noted 
between $\mathrm{ThO}_{2}$ powder particle surface area and grain size, the latter increasing directly with the former. The latter effect was found to be even more prominent in the calcined materials than in the as-received powders, Section VII. Possible relationships between particle size and grain size have been confounded by the presence of internal porosity in the particles. Since the major effect of finer particles is the increased surface area, the parameter of prime importance with regard to grain growth is the powder surface area rather than the particle size. The manner in which these observations tie in with impurity inhibition of grain growth is discussed below.

Increased pellet green density may influence grain growth in the following ways:

(a) With increasing green density the interparticle void volume obviously decreases, and sintered densities at which grain growth can occur rapidiy are achieved earlier in the sintering cycle. This effect may be*large at short times of sintering but is expected to decrease in importance with sintering times approaching 12 hours.

(b) With better interparticle contact in the green pellet, discontinuous grain growth can initiate earlier in the sintering cycle and proceed from more nuclei. Thus a grain size coarser than that achieved at lower green densities but finer than the grain size attained after grain coarsening has occured in the low green density bodies may occur.

(c) Pellet density may be higher at the pellet surface than at the center at low green densities but the opposite at higher green density levels. Thus grain size may reflect density variations in the green pellet. This explanation is deemed inconsistent with the early attempts to measure green pellet density variations reported in Ref. 2 which showed no consistent trends or showed a density variation inconsistent with formation of a picture frame, nor does it agree with the results of the experiment where grain growth was detected along the surface of holes drilled into a pellet prior to sintering.

(d) With increasing green density, particles may be increasingly fractured during compacting and the grain growth pattern and trends with increasing green density may reflect particle size variations in the green 
pellet. Available results reported in Ref. 2 show only. small effects of compacting or green density on particle size (or surface area).

With increasingly fine $\mathrm{ThO}_{2}$ particles, grain growth is expected to be affected in the following manner.

(a). At constant green density, interparticle çontacts are more numerous and remnant voids smaller the smaller the particle size. This should result in more rapid sintering to levels of density at which grain growth can occur unimpeded by the presence of voids. Thus a small improvement in grain size is anticipated by this mechanism.

(b) 'l'he greater the number of' interparticle cuntucts the sooner nuclei for discontinuous grain growth can form and the greater the number. Thus again grain sizes will be intermediate between those of inhibited and those of grain coarsened compacts.

(c) Substructurés and sub-boundaries may form as adjacent particles coalesce and grow. Such substructures, remnants of the original particle structure, are expected to eniance self-diffusion rates and hence improve grain boundary mobility as described in Section II.A. Alternatively substructure boundaries may entrap inhibiting impurities and reduce the concentration at migrating boundaries and thus reduce the impurity drag effect. These mechanisms are completely speculative and have not been demonstrated experimentally; they are attractive however in that they are the only ones, of all the preceding speculations, capable of predicting an effect of the original powder size. (surface area) and green density persisting into the very late stages of sintering.

It is convenient to regard the ellects of increasing green density and of finer particle size (greater surface area) in the same light... as that of increasing temperature on grain coarsening. It has been shown in steels that grain size is a maximum at a temperature just above that at "which grain coarsening initiates and decreases with increasing annealing temperat.ure a.s more nuclei become activated, Ref. 3. Similarly, the higher the green density and the finer the initial particle size (greater the surface area) the lower sintering temperature at which pronounced grain coarsening may be noted. It is apparent that much. more experimentation and evaluation 
are required to sort out the effects of all these variables. In any case, the sensitivity of grain size to these factors is in itself strong evidence of the presence of inhibiting impurities, since no mechanism for such sensitivity has been devised for a very pure powder.

\section{B. Effect of Powder Calcining on Grain Growth}

As described in Section II.A.2 calcining of the $\mathrm{ThO}_{2}$ powder was proposed to remove what was originally considered to be the principal contaminant, namely carbon. For this reason there was employed an extended time of 48 hours in air at $1038^{\circ} \mathrm{C}$, the highest calcining temperature employed by the powder producer, National Lead of Ohio (NLO), with a thinner bed depth accompanied by rabbling to expose a maximum amount of powder surface. As reported in Section VIII, Westinghouse Research Laboratory (WRL) found that in sintering compacts from these powders a marked improvement in pellet grain size resulted as compared with compacts made from uncalcined powders, even though by this time carbon was beginning to be : agardad $\because:$ l:?ikeiv to contribute to grain growth inhibition.

In light of these promising results, additional. $\mathrm{ThO}_{2}$ powder lots, Oof and 136, wise calcined in air at $1100^{\circ} \mathrm{C}$ for 48 hours in $2 \mathrm{~kg}$ batches. Ni-Cr-Fe Alioy 600 boats were used in the hope that little additional contamination would arise from their use at a $60^{\circ} \mathrm{C}$ higher temperature; unfortunately considerable contamination occurred from oxidation produi of of the boats, although the grain size results obtained are believed to be unaffected since the major alloying elements in this material are readily reduced in sintering and are present, albeit to a lesser extent, in the original powder. As noted it became apparent that carbon which would most readily be removed by oxidation was not the culprit element. Also as evidenced by the formation of normal grain size picture frames on compact surfaces, the impurity can be removed by heating in a hydrogen atmosphere. Therefore since production feasibility of calcining is enhanced by use of hydrogen atmosphere facilities particularly if temperatures higher than $1100^{\circ} \mathrm{C}$ are required, a parallel set of powders was calcined at $1100^{\circ} \mathrm{C}$ for 48 hours in hydrogen. The available grain size results from these powders are contained in Section VII.B. 
WAPD-TM-1311

Two different levels of $\mathrm{CaO}$ in ThÖ 2 were used in this investigation. Thoria powder lot 096 which was typically used for the production of $\mathrm{ThO}_{2}$ (no $\mathrm{UO}_{2}$ ) pellets contained $100 \mathrm{ppm} \mathrm{CaO}$. The addition of the $\mathrm{CaO}$ was used as a sintering aid for the thoria pellets by increasing the diffusion coefficient of the thorium ion, rather than the usual method of inhibiting the mobility of the higher energy grain boundaries (see Section IV.C). Since the addition of $\mathrm{UO}_{2}$ to $\mathrm{ThO}_{2}$ acts as a sintering aid, the $\mathrm{ThO}_{2}$ powder used in the production of the $\mathrm{ThO}_{2}-\mathrm{UO}_{2}$ pellets did not require a CaO addition (normal trace CaO is approximately $4 \mathrm{ppm}$ ).

The principal conclusions are that, with the powder containing 100 ppm CaO, calcining both in air and hydrogen improved grain growth relative to the as-received powder, with the latter less effective than the former: With the powder free of $\mathrm{CaO}$, again calcining improved grain growth over the as-received powder, but here the hydrogen-calcining was more effective than air calcining. These results concerning the effect of CaO are tentative since the surface areas (and hence particle sizes) of the various powders were not the same which made direct comparison difficult; however, it was clear that calcining improved grain growth.

Since a picture frame was still present in cross sections of the calcined pellets, it is concluded that the impurity content was reduced, but not however to a level sufficient to eliminate the discontinuous grain growth behavior of the peilet. To attempt to ensure the removal of the impurity phase, CaO free powder was calcined at $1200^{\circ} \mathrm{C}$ for 8 and 24 hours and at $1400^{\circ} \mathrm{C}$ for 3 and 9 hours. The resulting powders were subjected to multi-pass micronization to normalize the very strong influence of the powder surface area. The results of these tests showed that it was extremely difficult to mechanically reduce the particle size below about $\alpha_{\downarrow}$. The grain growth results indicated that shorter calcining times at higher temperatures were effective in increasing the grain growth. However, the beneficial effects of increasing the calcining temperature to promote additional impurity removal were diminished by the increased diffusion distance resulting from particle densification. It was therefore concluded that high temperature calcining was not a practical method of impurity removal because of the reduced powder surface area and increased contamination from 
the calcining crucible. It is possible that long time calcining at low temperatures, $<982^{\circ} \mathrm{C}$, may be worthwhile, but further experimentation would be required (See Section $\mathrm{IX}$ ).

In an effort to overcome the influence of the reduced surface area of the calcined powders on grain growth, calcined ( $1400^{\circ} \mathrm{C}-3$ hours) powder was blended with as-received (calcine of $1038^{\circ} \mathrm{C}$ at vendor) powder. It was considered that the pure, large coarse or higher density particles of the calcined powders would act as nucleation sites and be able to grow at the expense of the smaller or lower density impure particles. The grain growth results obtained from these powder blends, Section VII.D, were different than expected. Grain growth in the blended powder pellets was consistently greater than that observed in either pellets fabricated solely from the calcined or as-received powder. This synergistic effect was explained in terms of a high purity particle with low surface energy able to grow at the expense of an inhibited particle with high surface energy.

III. ANALVPTCAL METIODE AND FROUUCPION FROSEDURES

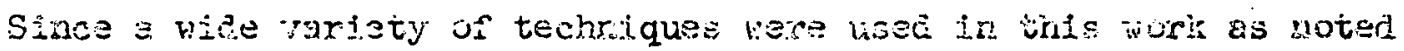
thrcughout this report and, in ingny cases, more than one proaedire was used to geasure a single pargmeter; a brief sumary of the various methols with attention being focussed on the differences between nethoos is given below.

\section{A. Powder Preparation for Pressing}

1. Liquid/Solids (I/S) Blending

All of the pellets studied in the section on grain growth kinetics, Section V, and selected pellets fabricated from powder calcined at 1200 and $1400^{\circ} \mathrm{C}$ were produced in the thoria production facility by the liquid/solias ( $I / S$ ) blending process. The powder was mixed in a vee-blendez while a solution of Oxylene ana binder was spreyed into the blender. Approximately 1.0 v/ $/ 0$ Carbowkx 6000 was lised as the bindex for the kinetic studies and $i .5 \mathrm{w} / 0$ Carbowax 6000 ; wes used for the calcined powders. The Carbowax/Oxylene mixture was adaed at such a rate that the powder is dampened only slightly (e.g., the powder should never become wet). The granuies produced by this process were passed through a 16 mesh screen. After screening, $0.2 \mathrm{w} / 0$ Sterotex (- 100 mesh) Iubricant was dry blended 
WAPD-TM-1311

with the granules.

2. Slurry Agglomeration

The Carbowax/Oxylene solution was added to the $\mathrm{ThO}_{2}$ powder in large enough quantities to thoroughly wet the powder to the extent that the mixture was almost fluid. Mixing was accomplished with a bladed paddle. When the mixture was sufficiently dry that it was pliable and may be formed, it was mechanically forced through a 24 mesh screen thus forming granules. In this study the granules made by this process contained $1.75 \mathrm{w} / 0$ Carbowax. Many of the calcined pellets were f'abricated from slurry agglomerated granules. Like the L/S blended granules $0.2 \mathrm{w} / 0$ Sterotex was dry blended with the granules for die wall lubrication during pressing.

\section{Dry Pressing}

The powder to be dry pressed was not processed into granules. No binder or lubricant was added directly to the powder. The die walls and punch faces were merely wiped clean with a $2 \mathrm{v} / \mathrm{o}$ solution of SterotexOxylene prior to hand filling of the die with the dry, binderless thoria powder. In those cases when the pellet broke upon ejection from the die, the pieces were put back into the die and repressed. Most pressing included a 1 to 2 minute hold at the maximum load. Depending on the powder pressing characteristic, the green dry pressed pellet had varying degrees of surface defects. Geometric density determinations of the green dry pressed pellets were less precise than the green pellets which contained a binder and lubricant.

\section{B. Presses}

1. Baldwin Lima Hamilton (BLH) Press

The Baldwin Lima Hamilton (BLH) is a mechanical press that

achieves a dual pressing action of both top and bottom punch by a pneumatic flotation of the die table. Ejection of the pressed pellet is accomplished by raising the bottom punch. A wide variety of adjustments is possible with the most desirable condition being where both top and bottom punches impart equal loads to the pellet. All of the peliets fabricated from granules produced by the L/S process were pressed on the BLH Press. 


\section{Stokes Press}

The Stokes press is also a mechanical press which operates in an identical fashion to the BLH except that the die is floated by die support springs. Consequently the travel of the die is controlled by the die wall friction forces. In spite of this feature, load distribution between top and bottom punches was relatively equal. Pellets pressed from the same mix and to the same green density on both the Stokes and BLH required about the same load. The Stokes press was used for the production of all the pellets fabricated from slurry agglomerated powder and the dry pressed powder.

C. Density Determinations

1. Geometric Density

The geometric densities were determined by dividing the dry pellet weight by the calculated (measured height and diameter excluding. $0.0302 \mathrm{cc}$ for both end dishes in the sintered pellet) pellet volume. All of the green densities were determined by this procedure as well as the sintered pellets from the kinetic study and the pellets fabricated from the slurry agglomerated powder. The weight was measured to $\pm 0.0001 \mathrm{gm}$ and the dimensions to $\pm 0.0005 \mathrm{~cm}$. The density was therefore accurate to $\pm 0.0003 \mathrm{gm} / \mathrm{cc}$. However, small cracks or chips in the pellet surface would influence the precision of the measureilert. The geometric density includes both open and closed pores.

\section{Immersion Density}

By determining the peliet weight dry, water saturated, and saturated suspended, the density of the pellet both including and excluding the open pores was calculated. The accuracy of this tecinique is not hampered by surface imperfections and was therefore used to determine the sintered density of ail thë. dry pressed pellets. Occasionally a chip would be lost from the pellet during the determination of the saturated weight, thereby resulting in the density of the pellet excluding the open porosity to be less than the density including the open porosity. Table 12. In trose cases where this happened, the results were flagged. This method is accurate to approximately $\pm 0.0002 \mathrm{gm} / \mathrm{cc}$. 


\section{Pretreatment Furnaces}

\section{Laboratory Facility}

Pellets pretreated in the laboratory furnaces were heated $\left(50^{\circ} \mathrm{C} / \mathrm{hr}\right)$ to temperature in a quartz container which was part of a closed system. The carbon dioxide gas flow rate was $8-10.1 \% \mathrm{~min}$. Instrument grade $\mathrm{CO}_{2}$ which contained only 10-15 ppm oxygen as measured at the bottle and approximately $10-25 \mathrm{ppm}$ as measured in the furnace hot zone at. temperature was used for every laboratory pretreatment run.

\section{I'horia Froduct1or Fucilily}

The thoria probullun pielieatment equipmont is a Harper batsh type, bell furnace which uses $\mathrm{CO}_{2}$ containing approximately 250 ppm oxygen as an in-line contaminant. All of the calcined powder pellets fabricated from $\mathrm{I} / \mathrm{S}$ granules were pretreated in this furnace.

\section{E. Sintering Furnaces}

\section{Laboratory Furnace}

A smaīi resistance wound hydrogen tube furpace capdule uf a. maximum temperature of $1900^{\circ} \mathrm{C}$ for a relatively short time period was used for all of the kinetic. experiments, Section V, ard those pellets rabricated from a blend of pretreated calcined powder lot 136 and as-received powder lot 096. Above $1000^{\circ} \mathrm{C}$ an optical pyrometer is used to determine the temperature by sighting on the samples. The temperature in this range is accurate to about $\pm 25^{\circ} \mathrm{C}$. Below $1000^{\circ} \mathrm{C}$ a chromel-alumel thermocouple is used which is accurate to approximately $\pm 5^{\circ} \mathrm{C}$. The furnace dew point is difficult to control. Truly dry hydrogen atmospheres were not possible. The dew point as measured by pumping a sample of the gas into an Alnor Type 7000 Dew Point indicator showed that at the hydrogen bottle the dew point was approximately $-51^{\circ} \mathrm{C}\left(-60^{\circ} \mathrm{F}\right)$; however, in the hot zone of the furnace the measured dew point was $15^{\circ} \mathrm{C}\left(59^{\circ} \mathrm{F}\right)$. The water content of the hydrogen increased from $\sim 40 \mathrm{ppm}$ to $\sim 18,000 \mathrm{ppm}$. This very large increase in dew point was probably the result of back streaming from the flame curtain at the furnace tube exit. The furnace exit is only about 24 inches away from the furnace hot zone. The "wet" hydrogen condition was produced by passing the dry incoming hydrogen through a water bubbler. 
This method proved effective and the measured hot zone dew point of the hydrogen was $25^{\circ} \mathrm{C}\left(77^{\circ} \mathrm{F}\right), 33,000 \mathrm{ppm} \mathrm{H}_{2} \mathrm{O}$.

The operating procedure consisted of initially loading the furnace hot zone with pretreated 0.53 inch diameter pellets while the dew point of the incoming hydrogen was established as either wet or dry, depending on whether it was bubbled through a $25^{\circ} \mathrm{C}$ water bath or passed directly from the bottle to the furnace. In both cases the entire hydrogen flow was treated uniformly for the entire duration of the test, and the flow rate was generally held to $2.6^{+}-0.6 \mathrm{l} / \mathrm{min}$. The pellets were heated at the rate of $100^{\circ} \mathrm{C} / \mathrm{hr}$ to $1750^{\circ} \mathrm{C}$ or to the prescribed sintering temperature. At the first desired time and temperature setting, i.e. $1600^{\circ} \mathrm{C}-0$ hours, a pellet would be removed from the furnace hot zone as soon as a hot zone temperature reading of $1600^{\circ} \mathrm{C}$ was achieved: The rate at which the selected pellet was removed from the hot zone of the furnace to a cold zone in the furnace determined the cooling rate. The distance to the furnace cold zone was previously calibrated so that a cooling rate of $150^{\circ} \mathrm{C} / \mathrm{hr}$ could be achieved with the pellet being withdrawn while the remainder of the pellets continued to increase in temperature at the rate of $100^{\circ} \mathrm{C} / \mathrm{hr}$. Once the maximum temperature was attained, usually $1750^{\circ} \mathrm{C}$, pellets were withdrawn from the furnace hot zone at selected time intervals $\left(0, \frac{1}{2}, 1 \frac{1}{2}\right.$, 5,12 hours) according to the procedure described for the $1600^{\circ} \mathrm{C}$ sample. For example, five hours @ $1750^{\circ} \mathrm{C}$ means the pellet was heated from room temperature to $1750^{\circ} \mathrm{C}$ at the rate of $100^{\circ} \mathrm{C} / \mathrm{hr}$, held at $1750^{\circ} \mathrm{C}$ for 5 hours, and withdrawn from the hot zone so that the cooling rate was $150^{\circ} \mathrm{C} / \mathrm{hr}$ from $1750^{\circ} \mathrm{C}$ to room temperature:

\section{2: Thoria Facility Development Furnace}

The Hevi-Duty/Lindberg furnace \#1 was used for all "dry" hydrogen sintering runs excluding those of the kinetic studies. This includes all of the runs with pellets made from calcined or blended powders and those muns made with slumy agglomerated and $\mathrm{L} / \mathrm{S}$ blended powders, the one exception being the one run made with blended powder, pretreated, calcined 136/as-receiver 096 which was sintered in the small laboratory furnace. 
'lhe temperature of this furnace was controlied by a thermocouple located in the furnace hot zone; however, the furnace thermal profile was monitored with an optical pyrometer. The dew point of the inlet hydrogen from the bulk storage facility was determined to be approximately $-47^{\circ} \mathrm{C}\left(-52^{\circ} \mathrm{F}\right)$ which contains $50 \mathrm{ppm} \mathrm{H}_{2} \mathrm{O}$ by volume. However, the dew point of the same hydrogen in the hot zone a full six hours after the furnace attained a.. temperature of $1400^{\circ} \mathrm{C}$ was approximately $11.5^{\circ} \mathrm{C}\left(+53^{\circ} \mathrm{F}\right)$. This atmosphere contains $13,000 \mathrm{ppm} \mathrm{H}_{2} \mathrm{O}$ by volume. The hot zone is approximately 6 feet. from the furnace exit: At a point 3 feet from the exit the dew point was $18^{\circ} \mathrm{C}$ $\left(-1.65^{\mathrm{U}} \mathrm{F}\right), 21,500 \mathrm{ppm} \cdot \mathrm{H}_{2} \mathrm{O}$.

\section{Thoria Production Furnace}

This large Harper furnace was used for only a few pellets fabricated from 1200 and $1400^{\circ} \mathrm{C}$ calcined $\mathrm{L} / \mathrm{s}$ blended pellets. The dry $\left(-60^{\circ} \mathrm{F}\right)$ hydrogen was passed through a $110^{\circ} \mathrm{F}$ bubbler and, without cooling, piped into the furnace. Although not measured in the furnace hot zone, the water content at a dew point of $110^{\circ} \mathrm{F}\left(47^{\circ} \mathrm{C}\right)$ would be $\sim 86,000 \mathrm{ppm} \mathrm{H}_{2} \mathrm{O}$.

\section{Vacuum Furnace}

An R. D. Brew vacuum furnace, Model \#420, was used for the vacuum sintering runs in Section V.C; Kinetic Sintering Series, and in Section VI, Recrystallization Measurements. 'l'he sample is surroupleid by "d tantalum resistance heating element which getters the oxygen from the furnace atmosphere so that the oxygen partial pressure is very low, probably $<10^{-10}$ torr, even though the overall furnace pressure is $\sim 1 u^{-6}$ torr. "The temperaluis of the pellet in the vacuum furnace was measured with an optical pysulleler by sighting through a quartz window directly on the pellel. The reflectivity of the pellet was compensated by the absorption of the quartz window so that the true temperature was read directly from the pyrometer. The temperature reading is accurate to $\pm 10^{\circ} \mathrm{C}$.

F. Powder Calcining

\section{1. $1100^{\circ} \mathrm{C}$ Air Calcine}

The $1100^{\circ} \mathrm{C}$ air-calcined powder was heated in a resistance element Glo-Bar box type furnace to $1100^{\circ} \mathrm{C}$ and held at temperature for 48 hours. 
Powder batches of approximately $2 \mathrm{~kg}$ were heated in Inconel crucibles and rabbled with an Inconel rake every 30 minutes. Powder depth in the crucible was approximately 2 inches and the heating rate to temperature was approximately $500^{\circ} \mathrm{C} / \mathrm{hr}$. The temperature was determined by a calibrated chromelalumel thermocouple. The temperature reading. is accurate to $\pm 5^{\circ} \mathrm{C}$.

\section{2. $1100^{\circ} \mathrm{C}$ Hydrogen Calcine}

The $1100^{\circ} \mathrm{C}$ hydrogen calcining took place in a resistance wound tube furnace. The thoria powder lots were calcined for 48 hours in a closed furnace system at $1100^{\circ} \mathrm{C}$ in flowing dry $\left(-60^{\circ} \mathrm{F}\right.$ dew point) hydrogen. Temperature was controlled to $\pm 2^{\circ} \mathrm{C}$ by a series of thermocouples located along the length of the furnace hot zone. The effluents were monitored with a gas chromatograph. Except for the initial release of adsorbed water, the combined $\mathrm{H}_{2} \mathrm{O}$ and $\mathrm{O}_{2}$ in the effluent gas was less than $15 \mathrm{ppm}$. The maximum powder depth in the quartz crucibles was 2 inches. Since it was a closed system, the sample was not rabbled as was the air-calcined powder. The total powder charge per boat was only $1100 \mathrm{gms}$ and required two separate calcining runs per composition to produce the required amount of material. The two $1100 \mathrm{gm}$ batches of each composition were mechanically biended prior to micronization. "Subsequent mass-spectrographic analysis of this powder showed it to be of higher purity than the starting powder.

\section{1200 and $1400^{\circ} \mathrm{C}$ Hydrogen Calcine}

The powder which was calcined at $1200^{\circ} \mathrm{C}$ for 8 and 24 hours and the powder calcined at $1400^{\circ} \mathrm{C}$ for 3 and 9 hours was heated in the large Hevi-Duty/Lindberg furnace \#2 normally used in production tor sintering of $100 \% \mathrm{ThO}_{2}$ pellets. The line hydrogen used for this work had a dew point of - 55 F. Molybdenum boats were filled to a depth of approximately 2 inches. Since this Lindberg is a continuous furnace and the lowest gear ratio would result in a hot zone exposure of only 12 hours, the $1200^{\circ} \mathrm{C}-24$ hour calcine was achieved by sending the powder through the furnace twice.

The heating rate of all four calcining conditions was different since, the time spent in the furnace hot zone was different. The heating rates for the $1200^{\circ} \mathrm{C}-8$ and 24 hour and the $1400^{\circ} \mathrm{C}-3$ and 9 hour calcines were approximately $70^{\circ} \mathrm{C} / \mathrm{hr}$ and $30^{\circ} \mathrm{C} / \mathrm{hr}, 1.40^{\circ} \mathrm{C} / \mathrm{hr}$ and $60^{\circ} \mathrm{C} / \mathrm{hr}$, respectively. 
Temperature control was achieved by a fixed optical pyrometer and calibrated by sightings on a flag boat. The temperature was controlled to $\begin{aligned} & +40^{\circ} \mathrm{C} \\ - & 0^{\circ} \mathrm{C}\end{aligned}$

\section{G. Grain Size Measurements}

The ASTM calibrated eyepiece was used for all of the grain size measurements except some of the measurements in Kinetic Study No. 1 where an electron microscope was used in addition to the optical microscope to resolve the very fine grains in the center of a few pellets. The ASTM calibrated eyepiece yields an average grain size by simultaneously comparing the majority of the grains in a field of view with a calibrated field in the eyepiece of the viewer. The results obtained by this technique are accurate to within one ASTM number and may be compared directly with values obtained by the line intercept method if. the ASTM numbers are converted to the number of grain per unit area according to the equation $\dot{n}=2^{N-1}$ where $n=$ number of grains/in. ${ }^{2}$ at $100 X$ and $N=A S T M$ grain size number. The number of grains per in. ${ }^{2}$ may be used to calculate the average diameter by the equation $100 \mathrm{~d} / 2=(\mathrm{n} \pi)^{-\frac{1}{2}}$. A table with the diameter of the average grain in millimeters and inches as well as the nominal grains per in. ${ }^{2}$ at $100 \mathrm{X}$ is given in Ref. 4 . The values in this report were obtained from the table for grain sizes between ASTM 00 and 16. ASTM grain size numbers greater than 16. were calculated.

Those grains which were finer than could be determined optically with the ASTM eyepiece were, in a few cases, examined with the electron microscope. Carbon replicas were extracted from the sample surface and examined with the transmission electron microscope. In order to determine the exact location of a specific grain formation, the replica had to extend from the pellet surface since this was the point of reference for use of the calibrated microscope stage. While the ASTM calibrated eyepiece was used to determine the average grain size directly in the optical determination, the number of grains in a given area as determined by counting from a photographic enlargement was used to determine the ASTM grain size for the electron microscope examination. Considering the differences in technique, possible errors in magnification and photographic enlargement, and variations in grain size as a function of location, the agreement between the optical and electron microscope was considered reasonably good. 


\section{H. Granular Segregation Rating System}

The granular segregation rating system was devised at Bettis to quantify this sintered pellet attribute. A reting of 1 represents a structure free from granular segregation. None of the original green powder granule morpholiogy may be detected in the sample metallography. A rating of 7 represents the: most severe granular segregation. The entire perimeter of the original granule is clearly delineated when viewing a metallographic section of the sintered pellet. A series of photomicrographs which typify these two conditions and five intermediate degrees of granular segregation have been established and designated one through seven. This series of photomicrographs representing the seven degrees of granular segregation have become the standard by, which other microstructures are classified.

The granular segregation rating of a sample is determined by scanning with a microscope the longitudinal and transverse axes of metallographically prepared pellets and assigning the number of the standard microstructure which most closely represents the degree of granular segregation observed in the sample. A granular segregation rating of greater than three is considered unacceptable.

\section{Scanning Electron Microscope (SEM), Electron Microprobe (EMP), and Quantimet}

Samples examined with the SEM, EMP, and Quantimet were prepared according to standard ceramographic techniques (polishing accomplished by using a progressively finer grinding media); however, the samples were not etched prior to examination when phase identification or pore distribution was desired. Since the $\mathrm{ThO}_{2}$ pellet is a poor electronic conductor and carbon was an element of interest, a thin layer of aluminum or gold rather than carbon was vapor deposited on the sample surface prior to analysis. The compositional analyses were for the most part qualitative or semi-quantitative where the peak height was compared to the peak height from a known standard. No adjustments were made to the peak height to account for absorption and fluorescence. 
WAPD-TM-1311

J. Pellet Description

The as-pressed thoria compact may be approximated by a 0.610 in. $(1.55 \mathrm{~cm})$ to $0.635 \mathrm{in.}(1.61 \mathrm{~cm})$ diameter by $0.75 \mathrm{in.}(1.90 \mathrm{~cm})$. hi.gh right circular. cylinder. A dish and chamfer were pressed into each end such that the as-sintered dish had a radius of $1.439 \mathrm{in}$. and the chamfer was $0.006 \pm 0.004 \mathrm{in}$. The as-sintered diameter was $0.52 \mathrm{in.}(1.32 \mathrm{~cm})$ to $0.53 \mathrm{in.}(1.35 \mathrm{~cm})$ with an overall height of $0.615 \mathrm{in.}(1.56 \mathrm{~cm})$. 
IV. SINTERING THEORY AS APPLIED TO $\mathrm{ThO}_{2}$ AND $\mathrm{ThO}_{2}-\mathrm{UO}_{2}$

A. Introduction to Sintering and Grain Growth

Sintering and grain growth are two material properties which have received extensive investigation, Refs. 5-22. Most studies of sintering on an atomistic level are restricted to the "initial" stages since neck growth in spherical models, pure metal spheres or wires lends.itself to a mathematical analysis. During the initial sintering stage necks are formed at points of contact between adjacent particles and grow until they begin to impinge on each other. Approximately 3 to $5 \%$ linear shrinkage occurs during the initial sintering stage, Ref. 13. A major objection to these model experiments is that the predominant mechanism of material transport changes as a function of particle size. The particles used in a powder compact are not only orders of magnitude smaller than the spheres and wires used in the model studies, they also have an irregular shape. Finally, in practice it is difficult to determine when initial stage sintering ceases and intermediate sintering begins.

"Intermediate" sintering kinetics are characterized by a pore structure having interconnected channel porosity with pores lying primarily along three grain edges, Ref. 14. The pore phase is continuous and the pores are intersected by grain boundaries. During the intermediate sintering stage the pores continue to shrink until a significant amount of closed porosity is formed. During densification in this intermediate stage the average pore size may increase as the result of grain-boundary migration and pore coalescence; however, the total porosity decreases. The mechanism of mass transport would likely include vapor transport, volume, grain-boundary and surface diffusion, and, under. very unusual circumstances, plastic deformation by dislocation motion. The general reduced shrinkage with the occurrence of discontinuous grain growth has been taken by Coble, Ref. 21, as phenomenological evidence that a diffusional rather than plastic flow process takes place during densification. The intermediate stage usually continues until approximately only 5 to $7 \%$ porosity remains, Ref. 13.

Final stage sintering is assumed to begin when the pore channels change from continuous to discontinuous. The energetically favored structure is realized when the pores occupy four-grain corners rather than the 
intersection of three grain boundaries as is the case in the intermediate stage sintering. The pore configuration in final stage sintering can lead to total pore elimination in a stable fashion. The formation of discontinuous porosity may also result in gas being trapped within the pores which may prohibit their complete closure, Ref. 21. The "final" stage of sintering and grain growth which may take place to some degree during all three sintering stages in oxide ceramics is practically important but geometrically more complex and not nearly as well understood as either the intermediate or initial sintering stages.

To complicate the picture even further, an alternate final stage of sintering exists. This additional final sintering stage, variously called exaggerated or discontinuous growth or secondary recrystallization, occurs before all the porosity is removed and is characterized by a relatively few large grains growing very rapidly at the expense of the majority of the remaining microstructure. The resultant structure has closed, spherical pores located within the grains (intragranular porosity) not intersected by any grain boundaries. Continued heating at temperature after the recrystaliization process has proceeded to completion can lead to pore elimination only by diffusion to the grain boundaries, leaving a pore-free region near the boundaries with greater porosity concentration in the center of the grain. (Ref. 23), or by the migration of the boundaries in a direction toward the center of the grain boundary curvature and the consequent sweeping out of pores. These mechanisms are generally slow and the phenomenon of exaggerated grain growth is generally density limiting. Exaggerated grain growth occurs when the size and volume traction of some dispersed second phase is capable of preventing the movement of the matrix grains of uniform size, but is mobile enough to allow the migration of the more sharply curved grain boundaries of the large grains. The presence of an impurity or pore phase is a necessary requirement for exaggerated grain growth, Ref. 22 .

\section{B. Grain Growth Mechanism}

The only driving force for grain growth in a sintered solid such as a strain-free $\mathrm{ThO}_{2}$ pellet or in a well-annealed metal is the minimization of the excess free energy tied up in grain boundaries. This energy is quite minute. Thus, in $\mathrm{ThO}_{2}$ pellet $0.53 \mathrm{in.}(1.345 \mathrm{~cm})$ diameter $\times 0.6 \mathrm{in} .(1.524 \mathrm{~cm})$ 
height with a uniform grain size of ASTM \#13 (grain diameter $=4.10^{-4} \mathrm{~cm}$ ), with a grain boundary energy of $1150 \mathrm{erg} / \mathrm{cm}^{2}$, Ref. 24, and a specific heat at $1750^{\circ} \mathrm{C}$ of $0.076 \mathrm{cal} / \mathrm{g}^{\circ} \mathrm{C}$, Ref. 25 , only sufficient energy would be released by removal of all grain boundaries and conversion of the pellet to a single crystal to raise its temperature less than $0.6^{\circ} \mathrm{C}$. Hence, it is quite understandable that minute deviations in composition, porosity, sintering time temperature, atmosphere, etc., are adequate to upset this delicate, balance and cause apparent loss of grain size control.

\section{Normal Grain Growth}

Ideal grain growth is defined as grain diameter change with time such that the driving force for minimization of grain boundary energy is limited only by bàse material grain boundary or volume self diffusion rates; hence,. according to Burke, Ref. 22,

$$
M=M_{0} \exp \left(\frac{-Q b}{R T}\right)
$$

where $\mathrm{Qb}=$ is the activation energy for grain boundary diffusion

$\mathrm{M}=$ grain boundary mobility.

Since grain growth also involves the progressive movement of grain boundaries, the velocity of an individual grain boundary is given by

$$
\mathrm{V}=\mathrm{MP}
$$

where $\mathrm{V}=$ grain boundary velocity

$M=$ grain boundary mobility

$P=$ force acting on the grain boundary.

The force acting on a grain boundary causing the area to decrease by moving toward the center of curvature is:

$$
P=2 \sigma\left(\frac{1}{\rho_{1}}+\frac{1}{\rho_{2}}\right)
$$

where

$$
\sigma=\text { the interfacial energy of the grain boundary }
$$

$$
\rho_{1} \text { and } \rho_{2}=\text { principal radii of curvature. }
$$

Substituting equation 3 into 2 we have

$$
V=2 M \sigma\left(\frac{1}{\rho_{1}}+\frac{1}{\rho_{2}}\right) .
$$

*An approximation originally derived by Dr. B. Lustman, 
Making the following assumptions Burke, Ref. 22, derived an expression for the rate of grain growth rather than the velocity of an individual grain boundary:

1. The mobility is constant for all grains, regardless of grain size.

2. The surface energy of all grain boundaries is constant, regardless of grain size.

3. The shape of the grain size distribution curve is independent uf yidill size.

4. 'I'he principal radii of' curvature ( $\rho_{1}$ and $\rho_{2}$ ) of a. grain. boundary are proportional to the average grain diameter (D).

5. Grain growth will continue indef'initely.

Therefore $V^{\prime}=K_{1}$ dD/dt and $\left(\frac{1}{\rho_{1}}+\frac{1}{\rho_{2}}\right)=K_{2}\left(\frac{1}{D}\right)$.

Substituting into equation 4 gives

$$
\begin{aligned}
\mathrm{V}=\mathrm{K}_{1} \mathrm{dD} / \mathrm{dt} & \left.=\mathrm{K}_{2} \mathrm{M} \sigma \mid \frac{1}{\mathrm{D}}\right) \text { or } \\
\because & \mathrm{K}_{3} \mathrm{M} \sigma \\
\mathrm{dD} / \mathrm{dt} & =\frac{3}{\mathrm{D}} \quad \therefore
\end{aligned}
$$

Integrating equation (5) we have the well known equation:

$$
D^{2}-D_{0}^{2}=K M \sigma t
$$

where $D_{0}=$ grain diameter at zero time

$\mathrm{D}=$ grain diameter at time, $t$

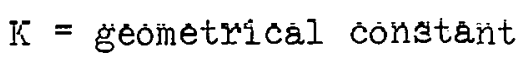

Extending equation (6) to include the effect of temperature we have upon substituting equation (1) into (6)

$$
D^{2}-D_{0}^{2}=\mathrm{kM}_{0} \sigma t \exp \left|\frac{-Q b}{R T}\right|
$$

Equation (7) predicts that the grain diameter increases with time to the $1 / 2$ power and the activation energy of the process is equivalent to that of grain boundary diffusion. These values can only be achieved in crystalline solids of high purity and nearly theoretical density. In practice, 
as discussed in subsequent sections, this simple relationship is disturbed by a number of factors resulting in an exponent of the time variable of less than 0.5 and the activation energy for growth greater than the activation energy of grain boundary diffusion.

\section{Secondary Recrystallization (Discontinuous Grain Growth)}

Probably the single most insidious perturbation of the relationship for uninhibited, normal grain growth is the effect of impurities. Until recently the impurity level in most ceramic systems was relatively high and the intrinsic behavior of the host material was rarely observed. The " impuritty phase 'frequently was not homogeneously distributed, formed an eutectic with the host material or other impurities, and altered the sintering kinetics by pinning grain boundaries, forming gas-filled pores, or low temperature melting liquid phases. Over the past 10-12 years relatively high purity ceramic powders have been manufactured and the phenomenon of secondary recrystallization has been detected in $\mathrm{Al}_{2} \mathrm{O}_{3}, \mathrm{MgO}, \mathrm{ThO}_{2}, \mathrm{MgAl}_{2} \mathrm{O}_{4}$, Ferrites, $\mathrm{UO}_{2}$, etc. What once was a rather rare occurrence has now become common in many fine particle oxide powders as well as in many metal systems. Whether final sintering is controlled by uninhibited grain boundary surface tension forces or exhibits secondary recrystallization is not readily predictable from the material parametexs.

Initial densification and grain growth depends almost entirely on volume diffusion with almost no contribution from grain boundary diffusion, Ref. 26. The presence of a grain growth inhibitor has little effect on grain growth until sufficient porosity is removed to allow annihilation. of pores and the beginning of final stage sintering because the impurity or additive segregates to the grain boundary (it may or may not precipitate as a separate phase) and does not influence the volume diffusion. During final-stage sintering, densification increases only slightly and "normal" grain growth is relatively slow. Hore shrinkage and grain growth are controlled mainly by grain boundary diffusion, Ref. 26. In spite of the presence of numerous impurities grain growth may still proceed by uninhibited grain boundary diffusion since the transfer rate from the source to the sink is so slow that the impediment caused by the impurities is not enough to influence the normal rate of grain growth, Ref. 27. Consequently it is 
. possible to make an oxide ceramic from impure powder and experience normal, i.e. $t^{\frac{1}{2}}=t^{\frac{1}{4}}$, grain growth kinetics. Increased impurity quantities or different impurity types may inhibit the material transfer down to the point that grain boundary movement is stopped. Impurities may, because of atomic size differences or other factors, tend to concentrate at grain boundaries in quantities out of all proportion to their bulk concentration. Hence grain boundary mobility rather than occurring by local transfer of like atoms across the boundary requires, on a microscopic scale, the movement of rather gross amounts of the segregated material. 'In ionic-bonded ceramic materials such as $\mathrm{ThO}_{2}$ the charge difference between an impurity element dissolved in the oxide and the thorium or oxygen ions is an additional factor leading to segregation of the impurity at grain boundaries which is not present in metallic systems, Ref. 28. An example of this grain boundary segregation in a ceramic oxide system was recently reported by Taylor, Coad, and Brook (Ref. 29) who found in $\mathrm{Al}_{2} \mathrm{O}_{3}$ containing an $\mathrm{MgO}$ additive, a calcium content of $0.6 \%$ at the grain boundaries, even though the bulk content of $\mathrm{Ca}$ was only $0.001-0.0015 \%$. Similarly, it can be estimated that the grain boundary surface of a $\mathrm{ThO}_{2}$ pellet with a grain size of ASTM \#13 can be completely covered with a twodimensional network of $\mathrm{Na}^{+}-\mathrm{O}^{=}$ions at a sodium content of $25 \mathrm{ppm}$. Under these circumstances, grain growth will be controlled by what is known as the "impirit.y drag" effest.

.. If the impurity is present, not in solution, but precipitated as a dispersed phase, inhibition of grain growth may also occur; in fact, grain growth may be completely stopped by the presence of a dispersed phase and the surtace tension forces between the phase and the intersecting grain.boundary. A "l1m1t1ng" grain size, $1 \mathrm{~m}$, may be reached and equation (6) thus modified to

$$
\frac{\mathrm{dD}}{\mathrm{dt}}=\mathrm{K}\left(\frac{1}{\bar{D}}-\frac{1}{\mathrm{Dm}}\right), \text { Ref. } 22 \text {. }
$$

The amount and size of dispersed phase leading to such inhibition was analyzed by Zener (Ref. 30) who derived the expression

$$
D m=\frac{8 r}{3 f}
$$

where $r$ is the radius of the dispersed phase particles (assumed immobile in the material) and $f$ its volume fraction. If purely for the purpose of 
illustration, since sodium will undoubtedly be soluble in $\mathrm{ThO}_{2}$ at such levels, the $25 \mathrm{ppm}$ of sodium previously discussed to be present in $\mathrm{ThO}_{2}$ were present precipitated as $\mathrm{Na}_{2} \mathrm{O}$ with a density of $2.27 \mathrm{gm} / \mathrm{cc}$ and hence a volume fraction $f$ of $1.1 \cdot 10^{-4}$, the diameter of $\mathrm{Na}_{2} \mathrm{O}$ particles required to limit the grain size of $\mathrm{ThO}_{2}$ to ASTM \#10 ( $\left.\cong 10 \cdot 10^{-4} \mathrm{~cm}\right)$ would be about $1.6 \cdot 10^{-7} \mathrm{~cm}$, a value approaching the limit of resolution of even the best transmission electron microscopy.

Equation (9) does provide a good explanation for the fact that coarse porosity, such as that introduced by Sterotex additions, does not affect grain size. Assuming voids due to Sterotex additions are present to a volume fraction of about 0.01 and their diameter to be $0.01 \mathrm{~cm}$, the limiting grain diameter is of the order of $2 \mathrm{~cm}$; i.e., voids of such grossness have no practical effect on grain growth in agreement with observation. For all practical purposes these large voids are not removed by extended time at temperature.

Grain boundary segregated impurity phases which may not be present in sufficient quantity to inhibit initial grain growth when the grains are small and there are numerous grain boundaries or when the impurity is not of an adequate size to anchor a grain boundary, may be swept along by the grain boundary movement during grain growth. Boundary movement may therefore concentrate the impurity so that greater energy is required for continued grain boundary movement. In addition, as grains grow the number of grain boundaries decreases and the number of impurity anchors necessary to stop grain growth also decreases. Consequently normal grain growth may proceed for a period of time prior to being inhibited.

Since different impurity types, size, number and location have different capacities to inhibit grain growth, and since the grain boundaries in a typical ceramic compact are, contrary to the simplifying assumptions of Section IV.B above, not all the same size and energy, it is almost the rule. rather than the exception that certain size grains with similar grain boundary energies will be inhibited, stopped completely or the boundary mobility reduced to some degree, while other grains within the same compact with, higher energy grain boundaries will not be inhibited at all. This situation can directly result in secondary recrystallization. The few grains which have 
sufficient energy to overcome the inhibiting influence of the impurity grow extremely rapidly because they may consume the inhibited grains and do not have to compete with bordering grains. This entire process depends on the presence of grain growth inhibitors (there is no reason why more than one inhibitor could not be operating simultaneously).

That discontinuous grain growth has been noted in $\mathrm{ThO}_{2}$ pellets is of importance not only in that grain sizes may be thus achieved which exceed maximum grain size specification values but also that the phenomenon points to the presence of grain growth inhibition under normal circumstances which may result also in failure to meet minimum grain size sperification.

Booaurc dencifioation coccntially ccaoco after exagrenated grain growth, since the pores are trapped inside the individual grains after the grain boundaries sweep past them, several investigators (Refs. 31, 12, and 32) have experimentally shown that exaggerated grain growth in sintered $\mathrm{ThO}_{2}$ compacts can be actually eliminated by the addition of significant quantities, 0.5 to $10 \mathrm{~m} / \mathrm{o}$, of sintering additives, e.g. $\mathrm{CaO}$ or $\mathrm{Y}_{2} \mathrm{O}_{3}$ to $\mathrm{ThO}_{2}$. The sintering additive or dopant acts as a grain growth inhibitor by segregating to the grain boundaries where it may remain in solution and reduce the rate of grain boundary migration by exerting a drag on the grain boundary motion and/or precipitates as a second phase and pins the grain boundary. The explosive growth of isolated grains associated with the phennmennn nf secondary renrystallization is restricted due to the presence of the inhibitor. Grain growth may still continue; however, the rate of grain boundary movement would be quite slow compared to the rapid movement associated with secondary recrystallization. The presence of trace amounts of impurities which inhibit normal grain boundary mobility is the cause of secondary recrystallization. The deliberate addition of larger quantities of specific additives which inhibit the rapid movement of the higher energy grain boundaries is a possible cure for secondary recrystallization. (Obviously the best cure would be to produce a starting powder without any grain growth inhibiting impurities.) The addition of a dopant to eliminate the possibility of secondary recrystallization may also act as a sintering aid. Since the grain boundary movement is retarded, the distance for vacancy diffusion from the remaining pores to the grain boundary is short and therefore the vacancy flux from the pores to the grain boundaries 
and consequently densification are maintained at a high level. Whether the impurity addition actually accelerates the diffusion of the vacancies, thereby also increasing the sintering rate, is not entirely clear. Investigators in the field of sintering kinetics are not in agreement whether the sintering kinetics are actually increased or the reduced grain boundary mobility results in a pseudo-increase resulting from the restricted diffusion distances. It appears that during the early stage of sintering when the amount of porosity is significant, impurity additions which remain in solution retard densification by reducing the surface energy and the bulk diffusion coefficient of the rate controlling species. In the later stages of sintering an increase in the sintering rate may be realized because of the reduced grain size of the doped sample relative to the undoped sample which results in shorter diffusion paths for the vacancies (Ref. 11). In addition, the vacancy concentration gradient formed during the initial stages would act as a driving force.

In summary, for pressed and sintered powdered oxide pellets, grain growth inhibition must result either from an element in solid solution which retards grain growth by the impurity drag effect or from an immobile dispersed phase or gas-filled pore, unlikely as the latter is to be immobile throughout the entire sintering process. 


\section{WAPD-TM-1311}

Another factor which may also cause deviations from the normal grain growth kinetics but which is of little importance for $\mathrm{ThO}_{2}(0.53$ inch diameter) pellets is interference with external surfaces of the specimens.

\section{Pore-Controlled Grain Growth}

A special case of grain growth inhibition by dispersed phases is afforded by the presence of pores in sintered ceramic or metallic bodies. Nichols (Ref. 33) has analyzed the kinetics of grain growth where grain boundary mobility is limited by pore mobility; the kinetics of grain growth are then a Function of the processes for pore migration. Equation (7) then takes the following torms.

$$
\begin{aligned}
D^{4}-D_{0}^{4}= & \text { Kt for volume diffusion or vapor } \\
& \text { transport when pressure within pores } \\
& \text { is constant } \\
D^{5}-D_{0}^{5}= & \text { Kt for surface diffusion } . \\
D^{3}-D_{0}^{3}= & \text { Kt for vapor transport where pore } \\
& \text { size dill yds pressure àre controlled } \\
& \text { by surface tension }
\end{aligned}
$$

where $K=k \exp -\mathrm{Q} / \mathrm{RT}$; $\mathrm{Q}$ being the activation energy for volume, surfaro or vapor transport, respectively.

It was the conclusion of this work that. the cubic rate law best explained the experimental evidence observed for $\mathrm{UO}_{2}$ and $\mathrm{Al}_{2} \mathrm{O}_{3}$. Tn a subsequent paper Nichols (Ref. 34) examined the effect. nf pores on grain boundary mobility and concluded that some scatter about a cubic growth law should be expected but that cubic kinetics provided a good model for "average" behavior. Cohen (Ref. 35) found for $\mathrm{ThO}_{2}$ pellets with a $\mathrm{D}_{\mathrm{o}}$ of $\sim 44 \mu$ (ASTM \#6) grain growth to follow equation (10a) with a temperature dependence of $K$ consistent with volume diffusion. 
That porosity affects the grain growth kinetics of $\mathrm{ThO}_{2}$ pellets is unquestionable and is vividly.illustrated by the "necklace" porosity sporadically present in $\mathrm{ThO}_{2}$ pélilets fabricated without binder additions, regardless of degassing prior to sintering, as well as in $\mathrm{ThO}_{2}$ and binary pellets fabricated with binders up to $1.75 \mathrm{w} / \mathrm{o}$ organic binder. This porosity is characteristically strung along grain boundaries, particularly at triple point junctions between grains. The larger the grain size, the coarser the pores and the greater the fraction located along grain boundaries or triple points. Since the pellet density remained constant or increased slightly, this implies that the pores have grown as they migrated along with the grain boundary by sweeping up pores which were encountered during migration. The stability of pores at grain boundaries implies that they are filled with a gas having limited solubility in the pellet; otherwise the pores would collapse by normal densification as vacancies escape to the grain boundaries. The pore size-limiting grain size-volume fraction relationship $\mathrm{Dm}=8 \mathrm{r} / 3 \mathrm{f}$ derived by. Zener appeared to reasonably predict the limiting grain size in the few cases where this effect was examined, Section VII.D. The establishment of a possible relationship between pore size, density, and limiting grain size would be beneficial even though the observation of "necklace" porosity indicates that the gas-filled pores are not immobile. Burke, Ref. 22, among othore, has indicated that. pores are capable of inhibiting grain growth and may even result in exaggerated grain growth or secondary recrystallization when the volume fraction of the dispersed phase is sufficient to prevent or. . retard movement. of the relatively flat boundaries between grains of uniform size, but insufficient to prevent the migration of strongly curved boundaries of the large grains. Hoge and Pask (Ref. 17) also indicate, based on a thermodynamic analysis, that the presence of a lenticular pore with any dihedral angle on a planar grain boundary will always pin the grain boundary or the pore will move with the boundary. A curved grain boundary can move away from a pore if the curvature is above a critical value, Experiments with $\mathrm{ThO}_{2}$ pellets have shown that the curvature and therefore the mobility of grain boundaries are influenced by powder purity and sintering time, Section VII.D.

A pore phase may also be capable of retarding or inhibiting grain growth during the intermediate and part of the final stages of sintering; however, the growth inhibiting pores may disappear by a combination of diffusion 
of the trapped gases and subsequent vacancy dift'usion. Under these circumstances pore-free regions may appear that allow select grains to grow. If these select grains have the required number of sides and the required grain boundary curvature for movement past the inhibiting pores, discontinuous or exaggerated grain growth may result.

The presence of carbon in the form of trapped CO gas could possibly limit grain growth as defined by the Zener equation (9) if the pores were immobile or reduce grain boundary mobility to the extent that growth of grains of a given size is retarded. Using equation (9), and assuming further that the pressure of $\mathrm{CO}$ in pores (assumed present to a volume fraction of 0.02 ) is con-. trolled by surface tension by the equation $P=2 Y / r$, where $Y$ is the surface tension (1150 dyne/cm), $r$, the gas pore radius, and $P$, the pressure; the carbon content of a pellet required to limit grain size to ASTM \#10 (10 $\mu$ grain diameter) is about $45 \mathrm{ppm} \mathrm{C}$ and the pore radius about $1500 \mathrm{~A}$. U. Of course if pores are swept up and are collected at grain boundaries the pore sizes may be greater than those calculated above, the pressure within the pores will be lower than that dictated by surface tension restraint, the number of pores required to be visible on metallographic examination will be less, and the carbon contents required for the appearance of grain boundary porosity may be much lower than the levels estimated above for immobile pores. Since, as evidenced by the formation of necklace porosity, gas-f'illed pores are not immobile, and, hence, may reduce but not stop grain growth, it was concluded that the carbon "contamination hypothesis as discussed later was of secondary importance and that carbon in the pellets at the normal production levels (< 100 ppm.) was capable of retarding but not of stopping grain growth.

\section{Grain Growth in the Presence of a Liquid Phase}

A special case of discontinuous grain growth is afforded by the observation of the formation in $\mathrm{ThO}_{2}$ ( 0.53 inch diameter) pellets of coarse idiomorphic grains. Such structures, although very unusual, have been noted previously in ceramics sintered ostensibly in the solid state. W. Kingery. (Ref. 36) included in his text book a photograph of a ceramic microstructure containing idiomorphic grain boundaries; he there interpreted their formation as requiring a critical concentration of a grain boundary contaminant.

Subsequently, Dr. Kingery, and Dr. R. Coble, have indicated a refinement. 
of this postulate to require the presence of a liquid phase in order to form idiomorphic boundaries rather than the non-crystallographic grain boundaries customarily produced by normal grain growth processes. Jorgensen and Westbrook (Ref. 11) have proposed an alternate explanation to: the requirement of a liquid phase to satisfy the energy requirements of idiomorphic crystalline microstructure. The preferential adsorption of solute, either impurity or dopant, on selected boundary types or orientations could possibly encourage growth in a particular direction and/or inhibit growth in other directions.

The identification of a thorium sulfide or oxysulfide phase (Section V.B) which probably forms an eutectic with $\mathrm{ThO}_{2}$ during sintering; Ref. 37, indicates that liquid phase postulate is the applicable mechanism in $\mathrm{ThO}_{2}$-base fuel pellets with trace quantities of sulfur $50-100 \mathrm{ppm}$. The sulfide results from sulfate impurities in oxalic acid and is not removed during normal calcining operations. Even elevated temperature calcinations $\left(1200^{\circ} \mathrm{C}\right)$ in hydrogen or air were not adequate to completely remove all of the sulfur phase, Section V.C.

Idiomorphic grain formation is believed related to the discontinuous grain growth in $\mathrm{ThO}_{2}$ pellets'in the following manner. "When discontinuous grain growth occurs in $\mathrm{ThO}_{2}$ peliets upon prolonged sintering, the advancing grain boundaries sweep up isolated pools of $\mathrm{ThOS}^{-\mathrm{KhO}_{2}}$ eutectic. These spread along the advanc1ng grain boundary: As a result of the high grain boundary mobility conferred by the rapid diffusion in the liquid phase as well as satisfaction of surface tension forces afforded by its presence, low energy crystallographic faces can develup or the growlrg grains, resulting in the appearance of idiomorphic grain structures in the sintered compact. Where two grains with idiomorphic boundaries intersect, the resulting grain boundary is free of the sulphide phase and is non-crystallographic in shape, further confirming the postulated mechanism.

Based on the preceding analysis of the mechanism required for the production of idiomorphic grains, as well as subsequent experimental evidence; it has been concluded that the sulfur impurity does not signiticantly inhibit grain growth, nor is it the cause of exaggerated grain growth. It has been concluded that sulfur does form a liquid eutectic phase which under specific conditions promotes idiomorphic crystalline growth. The exact role 


\section{JAPD-TM-1311}

of sulfur as well as other common contaminants, C, Fe, Ni, Cr, etc., on densification and grain growth was not pursued; such work may be worthy of additional investigation.

\section{Atmosphere and Additives}

Much has been written about the variable valence of $\mathrm{UO}_{2}$ and the possible defect structures resulting from the sintering atmospheres and various additives, Refs. 38, 39, and 27. Thoria, on the other hand, has been considered very stable, thereby prompting little interest into the investigation of possible defect structures. This changed once $R$. L. Coble made known his results on the effects of adding small quantities of $\mathrm{MgO}$ to $\mathrm{Al}_{2} \mathrm{O}_{3}$, Ref. 9 . Soon others investigated the effect of adding $\mathrm{Y}_{2} \mathrm{O}_{3}$ and $\mathrm{CaO}$ to $\mathrm{ThO}_{2}$, and the ensuing thoria defect structures, Refs, 12, 32, 40, and 41. Based on a few of these observations and other more general information, a defect structure caused by the atmosphere is hypothesized. The pertinent observations in Refs. 42, 43, and 32 which bear on the proposed lattice structure are the following.

1. Oxygen-deficient fluorite structure crystals (such as $\mathrm{ZrO}_{2-\mathrm{x}}$ ) produced by heating in very dry hydrogen or in contact with zirconium metal are black in color and. become white as they are oxidized. On the other hand, oxygen-deficient fluorite crystals such as $\mathrm{ThO}_{2}$ or $\mathrm{ZrO}_{2}$ produced by alloying with $\mathrm{CaO}$ retain the white coloration.

2. P-type electrical conductivity (i.e. electron hole conductivity) is predominant in $\mathrm{ThO}_{2}$ equilibrated at high oxygen pressures, n-type (electron conductivity) is inferred (although never actually measured) at low oxygen preceurec. Ionle elcotrioal conductivity (due to oxygen ion conduction) would be observed at intermediate oxygen pressures, is probably very limited in pure $\mathrm{ThO}_{2}$, but is enhanced by $\mathrm{CaO}$ additions.

3. At high oxygen pressure, electrical conductivity of pure $\mathrm{ThO}_{2}$ increases with increasing partial pressure of oxygen. 
Putting these observations together, the defect structures of Figure 1 are postulated. Figure 1a shows the lattice structure postulated for "stoichiometric" $\mathrm{ThO}_{2}$, i.e. equilibrated with an oxygen pressure $\cong 10^{-10}$ at. at $1850^{\circ} \mathrm{C}$. The lattice is hypothesized to show a small concentration of "Schottky" defects, i.e. compensating concentrations of Th and 0 ion sublattice vacancies. Because of the charge equalization, no color change is anticipated and self-diffusivity" of both Th and 0 is greatiy enhanced by the presence of the lattice vacancies. A "stoichiometric" oxide containing $\mathrm{CaO}$ is not shown; but would demonstrate a defect complex similar to that shown on the left of Figure $1 \mathrm{~d}$ where the $\mathrm{Ca}$ ion on the lattice site is charge-compensated by a vacancy in the oxygen sub-lattice. In the stoichiometric lattice, the presence of $\mathrm{CaO}$ will greatly enhance oxygen ion diffusion rates, but would not be predicted to have much of an influence on the thorium ion diffusion rate. Since the rate of all atom transport which involves the movement of boundaries is controlled by the slower-moving species, and the thorium ion is the'slower moving species by many orders of magnitude, the increase in oxygen ion "vacancies by itself would not increase the grain boundary mobility. However, it is possible that the thorium ion diffusion coefficient increases as the result of the $\mathrm{CaO}$ addition in a manner similar to the increase in U-ion diffusion rates when the $\mathrm{UO}_{2+x}$ is equilibrated with an oxidizing atmosphere, Ref. 39. :Additions of $\mathrm{CaO}$ to $\mathrm{ThO}_{2}$ over the range of $0.2 \mathrm{w} / \mathrm{o}$ to $8.8 \mathrm{w} / \mathrm{o}$ showed a reduction in the resulting grain size, Ref. 41. In a vacuum or an atmosphere with a very low partial pressure of oxygen, it is hypothesized that the thorium oxide becomes sub-stoichiometric in oxygen content by filling of thorium lattice vacancies, thus greatly reducing self-diffusivity of thorium. Because of the charge imbalance, free electrons are associated with this structure, leading to the black coloration due to free electron/light interactions. As indicated in Figure 1d; it would appear reasonable that $\mathrm{Ca}$ ions would tend to associate with these defects, causing a reduction in the free electron concentration; such a complex defect may lead to even further reduced self-diffusion rates and subsequent grain boundary mobility. Upon wet-hydrogen treatment, an oxygen enriched structure is hypothesized to form by increase in thorium ion lattice vacancy concentration. The charge imbalance is compensated by the formation of electron holes, which empirically are not observed to absorb visible light. 
The increase in Th and 0 sub-lattice vacancy concentrations leads to the observed increases in self-diffusivity. The CaO lattice defects probably would not associate with these postulated defects as shown in Figure $1 \mathrm{e}$ because of the increased resulting charge imbalance and in the low concentrations used in this report (100 ppm) the $\mathrm{CaO}$ would have no detectable influence on grain growth.

This sequence of defect structures is postulated rather than firmly supported and is presented primarily to reconcile observations in part III on grain growth as affected by atmosphere and $\mathrm{CaO}$ content.

D. Surface Area

'Probably the most cont'using aspect of' grain growth is the role of the starting particle size or surface area. As shown in Section IV.B, the driving force for grain growth is the minimization of the excess free energy tied up in grain boundaries. Consequently, the smaller the starting particle size, and hence the smaller the initial grain size, the greater the energy available for grain growth. In practice it is observed that the finer the particle size, the more rapid the initial densification and initial grain growth (a bulk diffusion model predicts the rate of sintering should be inversely proportional to the third power of the diameter). In practice, it is also frequentiy observed that the compact with the smaller initial particle size and/or greatest surface area results in the compact with the largest sintered grain size. This is a difficult observation to understand based on simple surface considerations. Kingery, Ref. 36, suggests that secondary recrystallization is the only mechanism by which this could occur. It is also reasonable that secondary recrystallization would occur more frequently in compacts with finer particles since the particle size distribution of the very fine particles would probably be wider than the coarser particles (particles $0.01 \mathrm{H}$ to $1 \mathrm{H}$ have a $100 / 1 \mathrm{spread}$ whereas particles $5-25 \mu$ only have a $5 / 1$ spread). The wider the particle size distribution, the greater the probability of secondary recrystallization providing an inhibiting phase is present.

The sintering kinetics of active powders, $<0.5 \mu$ diameter, surface area $>1.2 \mathrm{~m}^{2} / \mathrm{gm}$, are currently receiving considerable attention throughout the ceramic industry. It is anticipated that the literature will soon reflect the increased activity in this area. 


\section{KINETIC SINTERING SERIES}

\section{A. Introduction}

Observations of grain size development in production or development $\mathrm{ThO}_{2}$ pellets have usually been confined to examination after the normal 12 hour at $1750^{\circ} \mathrm{C}$ sintering cycle; when grain sizes were less than specification levels, the pellets "would be re-examined after each repetition, of the standard cycle. This practice was based on production practicality and also on the assumption that the normal grain growth mechanisms defined in

Section IV of this report operated and that the 12 hour (or subsequent 24 hour) structures were, in fact, only extensions of the structures which would be observed at shorter time as predicted from (time) $1 / 2-1 / 5$ relationships. Occasional observations were made of grains much larger than specification in the center of pellets whose grain size was otherwise "normal." Further, it was noted that resintering resulted often in grain sizes far coarser than could be explained by extrapolation of "normal" grain growth kinetics. These facts motivated a more careful and detailed study of structure development in $\mathrm{ThO}_{2}$ peliets as a function of sintering time, temperature, atmosphere, powder compaction, etc.

\section{B. Sintering Kinetics}

\section{Laboratory Pretreatment and Sintering Procedures}

The initially established pretreatment and sintering. schedules for the production of $\mathrm{ThO}_{2}$ and $\mathrm{ThO}_{2} / \mathrm{UO}_{2}, 0.53$ inch diameter, pellets are shown in. Tables 1 and 2, respectively. The procedures are significantly different. with the sintering time and temperature being the only parameters constant to both procedures. The inlet dew point of the. "wet" hydrogen used during the sintering of $\mathrm{ThO}_{2}$ peilets is approximately $45^{\circ} \mathrm{C}\left(\sim 110^{\circ} \mathrm{F}\right)$, while the inlet dew point of the "dry" hydrogen used with the binary pellets was. approximately $-48^{\circ} \mathrm{C}\left(-55^{\circ} \mathrm{F}\right)$. The respective water contents of the atmospheres are 70,000 and $50 \mathrm{ppm}$, respectively. Because of the nature of the equipment, it was difficult to duplicate these atmospheric conditions in the laboratory. For example, the larger size of the production sintering furnace permits a more effective purging of water back-diffusing from the fiame" curtain's at the charging and exit ends.' The wet and dry hydrogen used 
during the laboratory sintering runs had dew points in the hot zone of the furnace of approximately $25^{\circ} \mathrm{C}\left(77^{\circ} \mathrm{F}\right)$ and $15^{\circ} \mathrm{C}\left(59^{\circ} \mathrm{F}\right)$, respectively, $33,000 \mathrm{ppm}$ and $17,000 \mathrm{ppm} \mathrm{H}_{2} \mathrm{O}$. Consequently the atmosphere was relatively wet even" when a "dry" hydrogen run was attempted.

Heating rates and maximum temperatures were closely duplicated in the laboratory. However, samples which were pretreated in the laboratory generally resulted in higher residual carbon contents than those pretreated in the thoria or binary facilities. Caution must be exercised in comparing carbon contents in $\mathrm{ThO}_{2}$-base pellets since thoria powder readily adsorbs carbon from the atmosphere in the form of $\mathrm{CO}_{2}$. The carbon content of a given sample may vary by 150 to $300 \mathrm{ppm}$ depending on the exposure to the atmosphere and the surface area of the sample. Nevertheless, the differences in carbon conten'ts 'between the laboratory and production pretreated pellets were of such a magnitude that simple adsorption of $\mathrm{CO}_{2}$ could not readily account for the difference detected. Typical residual carbon after the $425^{\circ} \mathrm{C}-3$ hour pretreatment in the thoria facility varies between $1200 \mathrm{ppm}$ and $3000 \mathrm{ppm}$. The $2800 \mathrm{ppm}$ value observed in the laboratory experiments is high but still within range. The binary facility $925^{\circ} \mathrm{C}-3$ hour pretreatment typically results in residual pellet carbon contents of $150 \mathrm{ppm}$. The $464 \mathrm{ppm}-$ $925 \mathrm{ppm}$ observed from the laboratory experiments is well above this range. Since the laboratory experiments were performed under relatively stringent conditions with new furnace muffles, instrument grade $\mathrm{CO}_{2}$ (15 ppm or less oxygen), and an air-tight batch furnace, it was concluded that the lack of impurity oxygen in the system may have been partially responsible for the high residual carbon. The binary facility typically has contamination at levels sufficiently high to oxidize the $\mathrm{UO}_{2}$. Typical $\mathrm{O} / \mathrm{U}$ values are 2.15 to 2.5. In addition to oxidizing the $\mathrm{UO}_{2}$, the oxygen impurity also oxidizes the carbon, forming $C O$ gas. The oxygen is a more efficient reagent for removing carbon than the $\mathrm{CO}_{2}$. The lack of oxygen in the pretreating atmosphere is reflected in higher residual carbon contents.

\section{Results of Laboratory Kinetic Studies}

Nine 0.53 inch diameter pellets fabricated from powder lot 088 ( $100 \mathrm{ppm} \mathrm{CaO})$, Iiquid/solids agglomerated with $1.0 \mathrm{w} / 0$ Carbowax 6000 and $0.2 \mathrm{w} / \mathrm{o}$ Sterotex, pressed to a green density of $55 \%$, and pretreated at $425^{\circ} \mathrm{C}$ 
for 3 hours, were obtained from the $\mathrm{ThO}_{2}$ facility. These pellets were sintered in the laboratory furnace according to the schedule shown in Table 3. The density versus temperature and time plot, Figure 2, shows only nominal densification up to $1000^{\circ} \mathrm{C}$ after which densification proceeds rapidly up to $1750^{\circ} \mathrm{C}$. Extended time at $1750^{\circ} \mathrm{C}$ increased the density only an additional $0.4 \%$ absolute. The flat initial portion of the curve (below $1200^{\circ} \mathrm{C}$ ) represents the initial sintering stage, while the rapidly changing portion between $1200^{\circ} \mathrm{C}$, and $1750^{\circ} \mathrm{C}$ represents the latter stages of the initial sintering kinetics and intermediate stage sintering kinetics. Final. stage sintering. begins at some point after the rapid densification typical of the intermediate stage moderates. Final stage sintering kinetics are typified by the small increase in density observed. in. Figure 2, with increasing time at $1750^{\circ} \mathrm{C}$. It is difficult to delineate each sintering stage, especially since they overlap and more than one mechanism might be operating at any given time. Nevertheless, Figure 2 represents what might be termed a typical densification curve.

The metallography of the individual pellets shows that the sintering process was not nearly as classical as the density versus time curve indicated. Examination of the $1000^{\circ} \mathrm{C}$. sintered pellet showed that, although it was initially completely black after pretreatment because of its high carbon content (see Table 3) it now had a white exterior. A section through the center of the pellet showed that the center was stili black; however, the pellet cracked through the center during sintering and the pellet was white on each side of the crack, even in the middle portion of the pellet. This indicates that the wet hydrogen atmosphere which was effective in removing carbon from the exterior of the pellet also removed carbon from the material on each side of the crack. At $1400^{\circ} \mathrm{C}$ the pellets were completely white, interior and exterior. The grain size of these two pellets was extremely fine; < ASTM \#14, and could not be measured by optical metallography. At $1600^{\circ} \mathrm{C}$ the pellet showed visible darkening on the exterior surfaces, forming a faint picture frame when viewed from the mid-plane section. This picture frame darkened and became larger (the dark color proceeded inward) as the temperature and time at temperature increased. Metallographic examination of these samples showed that grain growth initially took place at the pellet surface and proceeded toward the interior in a pattern similar to the dark picture-frame effect. The grain size 
was measured as a function of the distance from the pellet surface for several of the conditions investigated, Figure 3. It becomes apparent from Figure 3 that a fine-grained pellet center may exist even though a relatively high density has been achieved which is not significantly changing with increasing time at temperature. The center grain size of the samples sintered for $1 / 2,1-1 / 2$, and 12 hours at $1750^{\circ} \mathrm{C}$ was considerably finer than could be determined optically with the ASTM eyepiece. Replicas were extracted from these two samples and examined with the electron microscope and are included in Figure 3 for comparison: A difference of approximately one to two ASTM numbers exists between the grain size number as determined by the electron and optical microscopes. This difference may. arise from the fact that the grain size was determined by the two methuds. at slightly different locations on the same sample and the grain size did vary as a function of pusition. In addition, an ASTM calibrated eyepiece was used to determine the average grain size in the optical determination while.. the number of grains in a given area as determined by counting from a photographic enlargment was used to determine the ASTM grain size number for the electron microscopy examination. Finally the magnification of the electron microscope is known with less certainty than the optical microscope. In any case, these results show that even though the center grain size of the pellet was considerably finer than the exterior portion, the grains did show growth with increasing time at temperature. Since the heating and cooling rates of these samples were not as closely controlled as desirable, the pellets frequently were cracked. Those cracks which occurred during the initial portion of the sintering experiment showed a darkening and grain growth on either side of the crack, even if the crack extended through the center of the pellet. Since this type of behavior is indicative of diffusion-related phenomena, the distance from the pellet surface at which the grain size could be readily measured (ASTM \#14) was plotted as a function of time on a log-log. plot, Figure 4. A straight line provided an excellent fit for the data. Substituting for the variables in the equation, the following relationship was derived: .

$$
\cdot \mathrm{d}=\mathrm{K} \mathrm{t}^{\mathrm{m}}
$$


where $K=$ constant of 8.1 (dependent on the units of the variables.)

$m=0.45$

$t=$ time in seconds

$\mathrm{d}=$ diffusion distance from the pellet surface in centimeters.

Figure 5 is a plot of the actual grain diameter in microns as a function of time for four different locations in the pellet. At the pellet surface the grain growth is "well behaved" in that it grows as the square root of time indicating grain growth control by uninhibited grain boundary surface tension forces. The grain growth toward the interior of the pellet departs from the classical time relationship and actually shows the presence of discontinuous grain growth, $m>1$, implying grain boundary mobility is initially limited by pinning obstacles and then breaks away. At a distance of 0.20 inch from the . pellet exterior, the log grain diameter versus log time plot is no longer a straight line, indicating the simplified equation $\mathrm{D}=\mathrm{Kt}^{\mathrm{n}}$ is no longer a good approximation of the data: This lack of fit was anticipated since the condition of the approximation for the equation of Figure 5 was that the final grain diameter, $\mathrm{D}$, is considerably larger than $\mathrm{D}_{\mathrm{O}}$, the initial grain diameter. Using the equation $D^{2}-D_{0}^{2}=K t$ so that the results will be corrected for the initial grain size, and a value for $D_{0}=0.5 \mu$, the average diameter of the initial powder particle, Ref. 44, a plot (Figure 6) is obtained which shows that, even making this correction, the exponent of $t$ is still not one, corresponding to normal grain growth, but rather 1.84 which is close to two, indicative of discontinuous grain growth.

I'hese results indicate that grain.growth at the pellet edge grows as the square root of time, indicating growth by uninhibited surface tension forces whereas, as the center is approached, a different mode of grain growth controls. Since the heating rate is relatively siow $\left(\sim 100^{\circ} \mathrm{C} / \mathrm{hr}\right)$ and the thermal conductivity of even a partially dense $\mathrm{ThO}_{2}$ compact is relatively high $\left(0.5 \mathrm{Btu} / \mathrm{hr}-\mathrm{ft}-{ }^{\circ} \mathrm{F}\right)$, the temperature differential between the pellet interior and exterior would be only $\approx 2^{\circ} \mathrm{C}$. It appears that the delayed center grain growth is not the result of a temperature differential.or lag. The temperature differential from the exterior to the interior of the pellet is quickly eliminated $(\sim 5 \mathrm{~min})$ at the steady state temperature of $1750^{\circ} \mathrm{C}$; however, the grain size duplex structure remains for extended times at temperature $\left(\sim 12 \mathrm{hrs}^{+}\right)$. The step-wise function of the grain growth coupled 
with the increasing.zone of normal grain growth at the surface are good indications that some contaminant phase or impurity segregation in the pellet interior resulted in the abnormal or discontinuous grain growth.

The pretreatment and sintering schedules of Kinetic Study \#1 closely parallel the standard conditions of the thoria facility. Kinetic Study \#2 was an attempt to duplicate the pretreatment and sintering schedules used in the binary facility (see Table 4). It should be noted, however, that no $\mathrm{U}^{235}$ addition was made to the $\mathrm{ThO}_{2}$ powder and the $\mathrm{ThO}_{2}$ powder contained 100. ppm CaO, a characteristic of the powder usually used in the $\mathrm{ThO}_{2}$ facility rather than the binary facility. Since grain size problems were common to both facilities, these differences were not considered significant to the success of these initial sintering studies.

The pellets of Kinetic Study \#2 were initially pretreated at $450^{\circ} \mathrm{C}$ in flowing $\mathrm{CO}_{2}$ and then at $925^{\circ} \mathrm{C}$ in flowing $\mathrm{CO}_{2}$. The carbon content after the $450^{\circ} \mathrm{C}$ pretreatment was 2000 to $3000 \mathrm{ppm}$ with radial and axial shrinkages of approximately 0.3 and $0.03 \%$, respectively. The total shrinkage after the $925^{\circ} \mathrm{C}$ pretreatment in the radial and axial directions was approximately 1.4 and $1.12 \%$, respectively (actual pellet values in Table 4), with a carbon content of $800 \mathrm{ppm}$. The shrinkage after pretreatment was relatively greater than that which could be compensated for by the weight loss of the Carbowax. The density of the pretreated pellet is approximately $1.7 \%$ greater than that of the green pellet and may indicate that initial sintering may be in process. Densification during sintering is practically complete when the maximum temperature of $1750^{\circ} \mathrm{C}$ is reached, Figure ?.

Examination of the sintered pellets showed that a darkening took place at the surface and proceeded toward the pellet interior. However, at a given time at temperature the darkening was considerably more extensive than was observed in the first kinetic study. In fact, at the end of five hours, the pellet was completely gray. The grain growth again proceeded from the exterior inward, Figure 8. Samples examined at the end of $0, \frac{1}{2}, 1 \frac{1}{2}$, and $5 \frac{1}{2}$ hours at temperature had relatively coarse grains at the surface and finegrained interiors. The sample sintered for 13 hours at $1750^{\circ} \mathrm{C}$ had a unique microstructure. Selected grains in the pellet interior grew extremely large, Figure 8. In addition, selected grains near the very center of the pellet 
were idiomorphic in external shape, Figure 9. Figures 10 through 16 are higher magnification photomicrographs showing the structure at various locations in the sectioned pellet of Figure 9.

Figures 10,11, and 16 (areas 1,2, and 7 along the pellet surface) show normal size and shaped grains. Figures 12 and 15 (areas 3 and 6) show a transition from normal grain growth to exaggerated grain growth. Extensive exaggerated grain growth is shown in area 4, Figure 13. Almost at the center of the pellet there are large idiomorphic grains, Figure 14 (area 5) which are bordering on very fine idiomorphic grains, Figure 17 (area 8).

Exaggerated grain growth is an indication that the normal grain boundary mobility was inhibited to some degree. The exact inhibiting media, e.g. porosity, secondary phase, solid solution segregation, etc.; may be open for discussion; however its presence is not. Exaggerated grain growth is considered to be the direct result of grain boundary inhibition and is not attributed to variations in temperature, pressing stresses, or density. The presence of idiomorphic grain growth is an indication of a liquid phase existing at the grain boundaries. The exaggerated grain growth and the idiomorphic grain growth may be attributed to the same mechanism, but they could both co-exist as a result of separate mechanisms, e.g. liquid phase and solid solution segregetion.

Since the presence of a second phase consisting of a specific quantity of a liquid phase, generally located along the grain boundaries, is required for the formation of idiomorphic grains, the sample shown in Figure 9 was investigated in more detail, both optical and with the scanning electron microscope and the electron probe. Examination of the unetched sample showed what appeared to be three separate phases in the thoria matrix. All three were present in the area where the idiomorphic grains were detected, but only one of the phases was dispersed throughout the entire sample.

A highly reflective phase which was common to both the regular and idiomorphic structure was identified as a transition metal sulfide. Chromium was most frequently, associated with the sulfur; however, $\mathrm{Fe}$ and $\mathrm{Ni}$ were also detected. This phase was previously detected by SEM techniques in thoria microstructures at which time it was concluded that it had no influence on grain growth. 
A light gray phase which frequently had one or more straight sides was determined to be composed of $T h, S$, and possibly $\mathrm{O}_{2}$, Figures 18 and 19. The presence of $\mathrm{Cr}, \mathrm{Fe}, \mathrm{Ni}$, or $\mathrm{Co}$ was not detected. The reflectivity of this phase was considerably less than the previously detected $\mathrm{Cr}-\mathrm{S}$ phase. The morphology of the two sulfur-containing phases also differed. The Th-S phase was almost always longer than it was thick and at least one side was straight. The Cr-S or transition metal sulfide was generally bulkier and less idiomorphic in appearance.

Although the thorium sulfide phase was detected in the area where idiomorphic grains were present and both the idiomorphic grains and the Th-S phase have straight sides, the Th-S phase did not exist exclusively at the grain boundaries. In fact, there appeared to be as many Th-S areas within the idiomorphic grains as there were along the grain boundaries. It is thus apparent that, while the thorium sulfide phase was associated with the formation of idiomorphic grains (since this phase could be detected only in pellet areas showing idiomorphic grains), they were not a permanent barrier to grain growth since grain boundaries could grow around them. In addition, this phase was associated only with the formation of idiomorphic grains and was not detected where the grain growth was inhibited or where exaggerated grain growth touk place.

The third phase in this sample was, also present where idiomorphic grain growth had resulted and its morphology was very, similar to the Th-S. phase, except the reflectivity was still less and it appeared: somewhat darker, Figure 20. The same quantitative electron microprobe analysis of this phase showed it to also be composed of Th and $S$ with a slightly higher oxygen content than the previous Th-S phase, Figure 21. It was concluded that the difference between the two Th-S phases was probably only the degree of exsolution from the host phase.

Kinetic Study \#3 (Table 5) was similar to \#2 except that the maximum sintering temperature was $1800^{\circ} \mathrm{C} .-1$ - In this case, idiomorphic grains were detected after only $1 \frac{1}{2}$ hours at $1800^{\circ} \mathrm{C}$ and exaggerated grain growth began after 6 hours at temperature, Figure 22. After 12 hours at $1800^{\circ} \mathrm{C}$ the large idiomorphic grains had impinged on each other and then appeared only . as grains typical of exaggerated grain growth. Only a few very small areas 
of idiomorphic grains remained. The occurrence of idiomorphic grains independently of exaggerated grain growth strengthened the hypothesis that the sulfur content influenced the formation of idiomorphic grains, but when uniformly dispersed in quantities typically found in the starting powder, $<120 \mathrm{ppm}$, did not inhibit grain growth and was not responsible for the picture-frame structure.: Subsequent calcining experiments further strengthened this belief (Section VII). It was therefore concluded that as a consequence of the rapid growth of the large grains resulting from secondary recrystallization the sulfur was swept toward the pellet center. A critical concentration of a liquid phase, presumably a eutectic of $\mathrm{Th}(\mathrm{O}, \mathrm{S})_{2}$ with $\mathrm{ThO}_{2}$, led to the formation of idiomorphic grain structure. The $\operatorname{Th}(0, S)_{2}$ phase, however, was not the grain growth inhibiting phase which resulted in the initial secondary recirystallization: :

The structure nonuniformity frequently described as picture framing which results in grains of size normally in the range of ASTM. \#5 to \#8 in a band approximately 0.050 to 0.100 inch around the periphery of the pellet with the remainder of the grains ASTM \#10 or finer has been reproduced in these initial experiments. A comparison of the grain size data of Kinetic Studies \#1 and \#2 shows that increasing the green density of the pellet from 55 to almost $64 \%$; respectively, has little effect on the grain size of the periphery (it should also be noted that Kinetic Studies \#1 and \#2 use pellets from different powder lots); however, the thickness of the "normal" grain growth region increases for a given time at temperature as well as the grain size in the pellet interior.

As a result of the preceding kinetic studies it was shown that the thickness of this border of normal grain growth is dependent on time as well as pellet green density. In fact, the periphery of normal grain growth appears to be a diffusion-related phenomenon with a square root of time dependence of its thickness. Again the borders of cracks which are formed in green pellets prior to sintering have the grain size characteristic of the periphery even when they extend to the pellet center. Based on this information it was postulated that an impurity element or phase was acting as a grain growth inhibitor during sintering. To determine if the normal grain growth at the pellet exterior was the result of residual strain imparted during the pressing operation (the added energy in the form of residual strain being enough 
to overcome the retarding effects of the impurity phase) or the result of reduced impurity levels due to impurity removal resulting from a reaction with the pretreatment or sintering atmosphere, $1 / 8$ inch diameter holes were drilled $1 / 4$ inch deep into the ends of six 0.53 inch diameter pellets, 088-1-11. Three of the pellets were drilled after they were pretreated in $\mathrm{CO}_{2}$ at $925^{\circ} \mathrm{C}$ for 3 hours; the remaining three pellets were drilled in the as-pressed condition and were pretreated in $\mathrm{CO}_{2}$ : at. $925^{\circ} \mathrm{C}$. for 3 hour.s.. Consequently, before sintering, both sets of pellets were subjected to identical pretreatments; however, one set of pellets was drilled before pretreatment and the other set after pretreatment.

The pellets were sintered at $1655^{\circ} \mathrm{C}$ in nominally "dry" hydrogen. The actual dew point was not measured. The measured dew point of the incoming hydrogen was $-60^{\circ} \mathrm{F}$; however, the dew point in the furnace hot zone was considerably higher and is estimated from subsequent measurements under similax conditions to be approximately $+60^{\circ} \mathrm{F}\left(15^{\circ} \mathrm{C}\right)$. One of each set of pellets was removed from the furnace after $1 \frac{1}{2}, 9$, and 16 hours, respectively. The pellets from both sets were sectioned longitudinally through the mid-plane of the pellet and drilled end holes.

Normal grain growth was detected along the pellet section closest to the walls of the drilled hole as well as along the exterior portion of the pellet:-surface, Figure 23. Both sets of pellets showed normal grain growth along the walls of the drilled holes, and the extent of grain growth appeared to be dependent on the time at temperature rather than whether the pellets were drilled before or after pretreatment. The grain growth data. for the two sets of pellets are remarkably similar and show that the impurity element or phase which inhibits grain growth is not removed at the low temperatures typical of the pretreatment process. Further, this experiment demonstrates that it is unlikely that strain energy or density variations resulting from the pressing operation are the causes of the duplex microstructure. This experiment also clearly showed that the hydrogen atmosphere promotes normal grain growth by reacting with the impurity phase. The pellets were placed in the furnace on end, thus reducing the access of the hydrogen atmosphere (and possibly the associated water vapor) with the bottom surface of the pellet and the bottom drilled hole. In all cases the extent of normal grain 
growth was less on the pellet bottom than on the top. It was also observed that for times at temperature in excess of 9 hours the grain growth of the free surface was somewhat greater than in the drilled hole, Figure 23. This may be due to the ease with which the atmosphere at the pellet surface can be recycled, whereas in the drilled hole movement of the atmosphere is more restricted. Higher flow rates in the sintering furnace with turbulent rather than laminar flow may be helpful to reduce localized buildup of effluents. These data correlate very well with the previous observations that normal grain growth occurred in the areas bordering cracks which formed prior or during the sintering cycle, and that the picture frame on small ( 0.25 inch) diameter pellets is of the same order of thickness as that on the larger ( 0.53 inch) diameter pellets. The previous experiment clearly demonstrates that the unique feature of the structural nonuniformity was not, in fact, the picture frame, but rather access of the pellet to the atmosphere.

To further demonstrate that the pellet microstructural nonuniformity was the result of effusion of a grain growth inhibiting impurity from the pellet surface during heating of the pellet to sintering temperatures prior to densification to an extent that release of the impurity stopped (less probable that an impurity could diffuse into the pellet from the sintering atmosphere which can change the grain growth characteristics of the picture frame), an experiment incorporating an initial hold time at a reduced temperature was performed, Kinetic Study \#4. By holding the pellets for a long time period at a temperature in the sintering atmosphere below that at which almost complete densification takes place, the thickness of the picture frame (area of "normal" growth) should be increased. Therefore, Kinetic Study \#4 included a $1300^{\circ} \mathrm{C}-$. 48 hour hold time. The hold time of $1300^{\circ} \mathrm{C}$ was selected because it was determined from the previous studies, Kinetic Study \#1, that densification extensive enough to limit severely access of the sintering atmosphere to the pellet interior by reduction of open porosity would not take place at this temperature. Also at this temperature, reaction of $\mathrm{C}$ with even dry hydrogen occurs at an appreciable rate. The 48 hour exposure time was estimated from the rate of thickening of the normal grain growth rim shown in Figure 4. Note, however, that the powder used in Kinetic Study \#1, lot 088, was different from that uscd in Kinetic Study 14 , lot $09 \%$, and the compact green dencity of the former was $55 \%$, of the latter $62 \%$. The pellets were given a 4 hour, $450^{\circ} \mathrm{C}$ 
pretreat in $\mathrm{CO}_{2}$. 'The pellets were then heated to $1300^{\circ} \mathrm{C}$ in wel $\mathrm{H}_{2}$ for $4 \dot{8}$ hours. At the end of 48 hours the pellet density was approximately $8.83 \mathrm{gm} / \mathrm{cc}$, Table 6. All pellets were heated to $1750^{\circ} \mathrm{C}$ and sampled as a function of time (see Figure 24). A control sample was included which did not receive the 48 hour, $1300^{\circ} \mathrm{C}$ hold time. While the rim showing normal grain. growth was not as extensive as was predicted from Kinetic Study \#1, a comparison of the pellets sintered at $1750^{\circ} \mathrm{C}$ for 12 hours wi.th and without the $1300^{\circ} \mathrm{C}-$ 48 hour hold time shows that the hold time appreciably increases the distance into the pellet where normal grain growth occurs from 0.042 inch. (at. ASIN G.S. \#12) to 0.096 inch. Nevertheless, the $1300^{\circ} \mathrm{C}$ hold time, while promoting grain uniformity, was insufficient to promote grain size uniformity all across the pellet.

L'ven though Kinetic Study \#4 did not provide a ready process for the production of 0.53 inch diameter pellets with uniform grain size, it did provide additional evidence for the hypothesis that an impurity could be removed to some degree by free communication with a hydrogen atmosphere.

It was also learncd from Kinetic Study \#4 that the removal of the grain growth inhibiting impurity was very slow when the powder was heattreated in the compacted pellet. Con'sequently higher temperature, longer time pretreatments did not lippear" to be a fruitful course for future experiments. Calcination of the fine powder $(\sim 0.5 \mu$ diameter $)$, on the other hand, where the diffusion distances were very short, appeared to be a promising area and several calcining experiments were initiated (Section VII).

In view of the data incicating the presence of a grain grow w inhibiting impurity being responsibie for part, if rot ali dí the grain growth problems (irinibited grain growth ana/or exaggerated grair growti), a kinetic stuay emplcying a rapid heatirg rate to temperature vas conducted. Although a rapid heeting rate would not be a prectical proaiction tecmique, it was considered that at the elevated temperatures tne impurity phase would possioly react with the atmosphere before extensive densificetion ard ciosure of the open pores colida limit the free communication of the atmosphere with the peliet interior. Kinetic study 466 consisted of neating five pellets (produced from 088 powder pressed to $55 \%$ green density and pretreated at $925^{\circ} \mathrm{C}$ for 3 hours) at an accelerated neating rate of $400 \mathrm{C} / \mathrm{hour}$ from room: 
semerd ture to 17500 . Semples were removed at the end of $0.1 / 2,1-1 \% 2$ and 12 hours at temperature.

The results of this experiment were difficult to evaluate since the pellets fractured extensively during the rapid heatup; as a result no density measurements could be obtained. From the grain growth results, Figure 25, it was not clear whether the open porosity at the pellet surface remained open at the high temperatures to allow for increased impurityatmosphere contact or the fractured pellets produced an increased surface area and therefore "normal" grain growth was slightly more extensive. The "normal" grain growth at the surface of the pellets examined after $0, \frac{1}{2}, 1 \frac{1}{2}$, and 5 hours exposure at $1750^{\circ} \mathrm{C}$ could be approximated by an equation with the square root of time dependence. The grain growth at the interior of these pellets was inhibited in much the same way as the pellets in Kinetic Study \#1. The increased heating rate did not significantly influence the grain growth in these samples. The sample which was at temperature for 12 hours had such large increases in surface area due to thermal fracture of the pellet that all of the pieces exhibited significant grain growth across the reduced cross section. Because of the increased exposure to the atmosphere at temperature, the reduced differential in grain size between the pellet exterior and interior was felt to be nonrepresentative of a 12 hour, $1750^{\circ} \mathrm{C}$ sinter, Figure 25. It was therefore concluded that the rapid heating rate did not increase the grain growth rate or result in increased communication of the atmosphere with the pellet interior by maintaining a higher amount of open porosity.

To determine the influence of moisture in the hydrogen atmosphere on grain growth and to replicate a kinetic study as a measure of reproducibility, Kinetic Studies \#7 and \#9 (Tables 7 and 8) were run in "dry" and "wet". hydrogen, respectively. Although the dew points of the inlet hydrogen gas for these two runs were $-60^{\circ} \mathrm{F}\left(-51^{\circ} \mathrm{C}\right)$ and $+77^{\circ} \mathrm{F}\left(+25^{\circ} \mathrm{C}\right)$, respectively, the dew points in the hot zone of the furnace were approximately $+59^{\circ} \mathrm{F}\left(15^{\circ} \mathrm{C}\right)$ and $77^{\circ} \mathrm{F}\left(25^{\circ} \mathrm{C}\right)$, respectively. The large increase in the dew point of the dry hydrogen is most probably the result of back streaming from the flame curtain at the exit end of the furnace. 
Kinetic Study \#? used 0.53 inch diameter pellets produced in the thoria facility from powder lot 088 ( $55 \%$ green density) which were pretreated in flowing instrument grade $\mathrm{CO}_{2}$ at $925^{\circ} \mathrm{C}$. The carbon content of these pellets as determined by chemical analysis was approximately $860 \mathrm{ppm}$. This is a value considerably higher than reported for pellets pretreated in $\mathrm{CO}_{2}$ in the binary facility production furnace. An identical pretreatment $\left(925^{\circ} \mathrm{C}\right.$, resulting in $890 \mathrm{ppm} \mathrm{C}$ ) and sintering schedule (dry hydrogen--dew point $\approx 15^{\circ} \mathrm{C}$ ) were used for Kinetic Study \#2 which resulted in the formation of an idiomorphic microstructure. The pellets were removed from the hot zone according to the schedule shown in Tahlee $?$ which also 1.ists the grepn and. sintered densities. The change in density as a function of time and temperature is show in Figure 26. The pellet density increased rapidly from the initial $5.6 \mathrm{gm} / \mathrm{cc}$ to $9.16 \mathrm{gm} / \mathrm{cc}$ as soon as the sintering temperature of $1750^{\circ} \mathrm{C}$ was attained. Additional time at temperature resulted in a maximum density of $9.38 \mathrm{gm} / \mathrm{cc}$ at the end of 5 hours and only $9.30 \mathrm{gm} / \mathrm{cc}$ at the end of 20 hours. The sintering kinetics, density versus time and temperature for Kinetic Studies \#? and \#1 were similar in spite of the differences in pretreatment times and temperatures and the dew point of the sintering atmosphere.

Grain size as a function of pellet cross section for Kinetic Study \#7 is shown in Figure 27. The rate of grain growth up to a maximum grain size of approximately $90 \mu$ (ASTM \#4) near the pellet surface and the rate of growth from the pellet surface toward the pellet center out to a distance of approximately $100 \mathrm{mils}(2540 \mu)$ could be approximated by a function of the square root of time. Grain growth in this area is therefore most likely controlled by uninhibited grain boundary surface tension forces. Similar to previous tests, the pellet center consisted of very fine grains, the growth of which is considered to be inhibited by an impurity phase. However, unlike previous kinetic studies, the pellet center was porous (Figure 28a-d) and soft, based on Knoop hardness measurements. Pellets 11-7 through 8-7 with sintering times at $1750^{\circ} \mathrm{C}$ of 0 to 5 hours had soft centers. Pellet $8-7$, 5 hours at $1750^{\circ} \mathrm{C}$, had a grain structure unresolvable with the optical microscope, Figure 28c, and a knoop Hardness No. of 60 . The exterior surface of this same pellet showed normal hardness levels, Knoop No. 900, and the average grain size at the surface was ASTM $\not 15(\sim 60 \mu)$, Figure $28 \mathrm{~b}$. This sample also showed the presence of exaggerated grain growth very 
near the fine-grained pellet center, Figures 27 and $28 \mathrm{~d}$. Since the densities of the pellets having the soft centers were comparable with those of the pellets which showed a more normal, uniform densification, and since the volume of the soft portion of the pellet was a significant fraction of the total pellet volume, it became obvious that although soft and granular, the pellet centers were not significantly. less dense than the harder, peripheral material. It has been previously demonstrated, Ref. 44, that the as-received thoria powder is porous. .The porosity in each individual particle may be removed or reduced by thermal treatment yielding a powder with the same particle size but with a reduced surface area. It is therefore considered that the individual powder particles in the center of the pellet are densifying, but densification and growth between particles in this area are not taking place. In fact, even the initial stage of sintering, neck formation between particles, is severely retarded. The reason for this is not entirely clear. It may be postulated that during the heat-treating process the exterior portion of the pellet leads the peliet center in the densification process. As a result, the exterior initially shrinks more than the interior and puts the center in compression and the surface in tension. The hot pressing action is probably small compared. to the normal surface-tension induced densification and in most cases is not separable experimentally. Once the exterior portion of the pellet has. densified and the shrinkage has stopped, densification of the center portion, which is lagging behind, continues. The center material is therefore subjected to hydrostatic tensile stresses. The surface tension forces of the pellet interior are quite small while the compressive strength of the sintered pellet exterior is quite large, even at temperature; therefore shrinkage as a result of neck formation and densification between particles is inhibited. With extended time at temperature the driving force for densification may be adequate to cause actual physical separation of the pellet interior from the exterior shell as shown in Figure 29. In addition to the larger intergranular separation between the interior and exterior, extremely. large grain boundary separations have formed to further alleviate the stress resulting from the differential shrinkage, Figures $29 a$ and $b$. The preceding explanation of the soft pellet centers and intergranular separations is an lilustration that the purification of the external portion of the peliet 
by impurity volatilization or impurity-atmosphere interaction, not only normalizes grain growth but also promotes densification vis-a-vis portions of the pellet which are not thus purified.

To recapitulate, it is postulated that the phenomenon of secondary grain growth dictates the presence of an inhibiting species. Normal grain growth at the pellet surface indicates that the inhibiting impurity. was either removed completely or reduced below a threshold value. Since there was either no impurity phase to inhibit grain growth or secondary recrystallization took place when the grains were still quite small, grain growth proceeded in a normal fashion, i.e. at a rate decreasing with time. At a somewhat greater impurity concentration selected grains were able to grow at the expense of the other grains in the immediate area. Exaggerated grain growth resulted when the growth of all but a few grains were retarded. Closer to the pellet center the impurity concentration was high enough that the growth of all the particles was inhibited.

The pellet sintered at $1750^{\circ} \mathrm{C}$ for 12 hours shows a distinct columnar structure with the longitudinal axis of the large grains extending radially out from the pellet center. In addition, what appeared to be a second phase was distributed as very thin equaliy spaced plates within several of the large columnar grains. Based on previous work it was at first tentatively assumed that the secondary phase conlained sulfur; however, the regular morphology of the secondary phase observed is unique to this stiddy. From an examination of the microstructure, Figure 29c, it was suspected that the plate-like phase may not be a separate phase but a different. orientation of the same phase which could result as stress induced twins. Subsequent energy-dispersive analysis in the scanning electron microscope (SEM) of this sample confirmed that no foreign elements were present in quantities sufficient to account for the formation of the plate-like phase in. Figure $29 \mathrm{c}$ and that it was indeed a twin. This would tend to support the speculation discussed above of the presence of tensile stresses between the core and the outside of the pellet and may also help explain the formation of columnar grains. 
Kinetic Study \#9 was undertaken to evaluate the effect of sintering atmosphere dew point. Therefore, unlike the other sintering kinetic studies, the pellet pretreatment and sintering were different from the procedures used by either the thoria or binary facilities, consisting of a combination of the $925^{\circ} \mathrm{C}$ binary facility pretreatment and the thoria facility wet hydrogen sintering. In addition, it should be noted that while the inlet dew points of the wet and dry hydrogen were $77^{\circ} \mathrm{F}\left(25^{\circ} \mathrm{C}\right)$ and $-60^{\circ} \mathrm{F}$ $\left(-51^{\circ} \mathrm{C}\right)$, respectively, the same dew point values in the hot zone of the sintering furnace were $25^{\circ} \mathrm{C}$ and $15^{\circ} \mathrm{C}$. Consequently; both atmospheres were relatively wet with somewhat similar dew points. Therefore it is not surprising that the density of these pellets; Table $8\left(25^{\circ} \mathrm{C}\right.$ dew point), are similar to those in Table ? $\left(15^{\circ} \mathrm{C}\right.$ dew point). Nevertheless, after 12 hours at temperature the density of wet hydrogen sintered pellet, 6-9, was measured at $9.453 \mathrm{gm} / \mathrm{cc}$ and the density of the "not so wet" hydrogen sintered pellet was $9.35 \mathrm{gm} / \mathrm{cc}$. The axial and radial shrinkages are also somewhat larger for the pellets sintered in the hydrogen with the higher dew point. What was surprising was the grain growth of the pellets in this study.

The grain growth data of Kinetic Study \#9 is shown in Figure 30. Grain growth was initiated at the pellet surface and proceeded to increase in diameter and in total penetration toward the pellet center as observed in earlier studies. Close comparison of the grain sizes as a tunction of time during the first 5 hours at temperature and in the exterior $160 \mathrm{mils}$, Figures 27 and 30 , shows little difference, implying that removal of the inhibiting impurities differs little as would be expected between hot zone dew points of 15 and $25^{\circ} \mathrm{C}$. At some time in excess of 5 hours at $1750^{\circ} \mathrm{C}$ the center grains overcame the inhibiting effects of the secondary phase and underwent significant growth. The growth was extensive enough to result in a relatively uniform grain size, ASTM \#3.5 to \#6 across the entire cross section of the pellet at the end of 12 hours at $1750^{\circ} \mathrm{C}$. It is highly significant that no additional grain growth resulted after 20 hours at temperature. If the initial results at 5 hours and less had been unavailable, the secondary recrystallization phenomenon would not have been detected from just the 12 or 20 hour results. Pellets from the same blend sintered in "dry" hydrogen ( $15^{\circ} \mathrm{C}$ hot zone dew point) showed exaggerated grain growth after 12 and 20 hours. These results indicate that the grain boundary diffusion in 
a wet $\left(25^{\circ} \mathrm{C}\right)$, or more properly, wetter hydrogen atmosphere, is greater or more efficient than in a drier hydrogen atmosphere. The wet hydrogen increased the mobility of the grain boundaries so that after 5 hours at temperature the boundaries of even the relatively small grains were able to move beyond the inhibiting phase or had sufficient energy, to drag the inhibiting phase. Consequently all of the grains were able to grow in a normal fashion. On the other hand, the more inhibited grain growth in the drier hydrogen atmosphere, Figure 27, allowed discontinuous grain growth, where only a few grain boundaries had sufficient energy to move appreciably, thereby resulting in a t'ew very large center grains.

A comparison of Kinetic Studies \#1 and \#9 is in order since these experiments differed only in the maximum pretreatment temperatures used, 425 and $925^{\circ} \mathrm{C}$, respectively; the results indicate that the higher pretreatment temperature may be beneficial. Secondary recrystallization was observed in both studies; however, in Kinetic Study \#9 ( $925^{\circ} \mathrm{C}$ pretreat) the center grain boundaries were able to overcome the inhibiting impurity sometime between 5 and 12 hours at $1750^{\circ} \mathrm{C}$, whereas in Kinetic Study $\# 1$ ( $425^{\circ} \mathrm{C}$ pretreatment) center grain boundary mobility became sufficient to migrate past the inhibiting impurity only after 12 to 20 hours. Since the carbon contents of the 425 and $925^{\circ} \mathrm{C}$ pretreated pellets are approximately $3000 \mathrm{ppm}$ and $860 \mathrm{ppm}$, respectively, the possibility that carbon in large amounts may act as a grain growth inhibiting phase was given greater emphasis.

As a consequence of the results obtained from the preceding two kinetic studies, it was concluded that the sintering atmosphere had a major influence on grain growth and warranted further investigation. Less clear cut is the effect of the pretreatment and residual carbon on subsequent grain growth. The higher carbon content (3000 ppm) of the $425^{\circ} \mathrm{C}$ pretreatment versus the $860 \mathrm{ppm}$ content of the $925^{\circ} \mathrm{C}$ pretreatment may have resulted in more gas-filled pores in the pellets used in Kinetic Study \#1 as compared to Kinetic Study \#9. However their effectiveness as a grain growth inhibitor has not been proven (see Section V). In any case, as discussed in Section IV above, the higher carbon levels delayed rather than prevented grain growth. 


\section{Effects of Sintering Atmosphere and Solarization of Sintered $\mathrm{ThO}_{2}$ Pellets}

These two topics are not normally companions; however, in the course of testing the postulate which suggests that gas-filled pores inhibited pellet grain growth, information was obtained simultaneously on the effect of the sintering atmosphere on grain growth.

Incorrect functioning and mal-operation of the pretreatment furnaces in the production facility, as well as some initial indications that carbon may not be readily eliminated by powder calcination, Section VII, caused suspicion to be directed toward carbon or its reaction products with $\mathrm{ThO}_{2}$ as being responsible for structural nonuniformities. The analyzed carbon content of the as-received powders was 100 to $500 \mathrm{ppm}$ and large amounts $(2-3 \mathrm{w} / 0$ which is equivalent to 4 to 5 times as much $\mathrm{v} / \mathrm{O})$ of carbonaceous materials are added as binders and lubricants or by erosion of the rubber liners in the micronizing equipment. Not all of this carbon was eliminated in the pretreatment and sintering steps since pellets pretreated in the laboratory in high purity $\mathrm{CO}_{2}$ gas at $925^{\circ} \mathrm{C}$ for 3 hours analyzed 460-900 ppm carbon and pellets sintered in the laboratory or production facility analyzed 50-100 ppm carbon. Based on information in the literature, Ref. 45, which attributed "necklace" porosity in $\mathrm{UO}_{2}$ similar to that often observed in the thoria fuel pellets to the reaction of residual carbon to form insoluble gases in the matrix as well as on the relatively high carbon analyses reported for as-sintered pellets, it was reasonable to suspect carbon in the form of CO gas trapped in pores as being the major grain growth inhibitor. This postulate lost credibility since it was shown that the carbon analyses, both from Bettis and NLO laboratories, were misleading and that the bulk of the carbon detected in the incoming powder, pretreated pellets, and sintered pellets was chemically adsorbed as $\mathrm{CO}_{2}$ from the air atmosphere onto the powder surface. Since the technique employed the crushing in air of the pretreated and sintered pellets, even those samples with initially. low surface area could indicate abnormally high carbon results. This adsorbed carbon dioxide was loosely held and could be removed by a $400^{\circ} \mathrm{C}$ calcine, Ref. 44 . Ușing a refined analytical technique where the pellets were ground in an inert atmosphere and not exposed to the air atmosphere prior to analysis, 
less than $10 \mathrm{ppm}$ carbon was retained in the sintered pellet. The $\mathrm{CO}_{2}$ adsorbed on the pretreated pellet prior to sintering would therefore be driven off at very low temperatures and could contribute little to the structure development in the $\mathrm{ThO}_{2}$ pellets. That which did remain was at such a low level that it could no longer be considered a primary effect responsible for grain growth inhibition. On the other hand, in pellets pretreated at $425^{\circ} \mathrm{C}$ with residual carbon contents greater than $1700 \mathrm{ppm}$ (Table 3), much of the carbon is probably present as elemental carbon. or incompletely pyrolyzed hydrocarbons and could well lead to the presence of insoluble carbonaceous gases in pores, particulariy when stritered in a truly dry hydrogen atmosphere. In fact, residual carbides can be formed during sintering under such conditions. Thus it is credible that grain boundary porosity in the sintered pellets resulting from pore stabilization via a, gas phase is detected by metallographic observation and most probably consists of carbonaceous gases. It was therefore still deemed important to establish the presence of gas-filled pores by determining if density decreases occurred in the sintered pellets after prolonged times at high temperatures caused by the coalescence and growth of gas-filled pores. In $\mathrm{UO}_{2}$, as well as in some other ceramics known to contain large amounts of gas-filled pores, these thermal treatments (so-called solarization experiments) have been shown to result in density decreases due to the pressure of the gas in the pores, Refs. $46-48$.

Initially as-sintered (12 hours at $1750^{\circ} \mathrm{C}$, wet $110^{\circ} \mathrm{F}(\sim 70,000 \mathrm{ppm}$ $\mathrm{H}_{2} \mathrm{O}$ ) hydrogen) pellets (from $\mathrm{ThO}_{2}$ lot 088 which showed a variation in grain size from ASTM \#4 at the surfiace to about \#y at the center) were resintered for 12 hours in wet $77^{\circ} \mathrm{F}\left(33,000 \mathrm{ppm} \mathrm{H}_{2} \mathrm{O}\right)$ hydrogen at $1800^{\circ} \mathrm{C}$. Two of the three pellets tested decreased in density $-0.717 \%$ and $-1.05 \%$; the third increased $+0.35 \%$, the change in each case being small, Table 9. This experiment was repeated with three additional pellets from the same lot, except using a vacuum atmosphere, $4 \times 10^{-6}$ torr at temperature, to preclude any possibility for gas formation by reaction with the atmosphere and a temperature of $1850^{\circ} \mathrm{C}$ for 12 hours. The results are shown in Table 10. The maximum geometric increase in density was $0.346 \%$, while the maximum increase in density as measured by immersion techniques was found to be only $0.153 \%$ 
(interestingly. the density change for the same pellet as determined. by geometric measurements was only $0.030 \%$ ). The fact that a density increase was recorded for each pellet, rather than the anticipated decrease, if the gas-filled pores were growing, does not completely exclude the possibility that solarization is, in fact, occurring since some densification would be: expected as a result of sintering of nongas-filled pores. which would be counteracted by bloating due to swelling. of the gas-filled pores. Lacking. quantitative information on the relative distribution of the several types of porosity, the results obtained to date do not rule out the presence of gas-filled pores.

Some interesting observations were made of the microstructures obtained in these two experiments. The pellets sintered at $1800^{\circ} \mathrm{C}$ in wet hydrogen showed the growth of very large grains, > ASTM.\#2, Figure 31, which; during their growth, collected and precipitated large collections of second. phases and pores, presumably gas-filled, Figure 32. Analysis by SEM of the phase shown in Figure. 32 has shown the presence of a. strong peak identified as aluminum. An approximate composition of the impurity phase was estimated at $0.7 \mathrm{w} / 0 \mathrm{Cr}, 7 \mathrm{w} / 0 \mathrm{Al}$ and the remainder. $\mathrm{ThO}_{2}$. Since the starting $\mathrm{ThO}_{2}$ powder was low in $A I$, it is assumed that the $A I$ was adsorbed during sintering at $1800^{\circ} \mathrm{C}$ in the $\mathrm{Al}_{2} \mathrm{O}_{3}$ muffle furnace. The dirty grey color and the pictureframe microstructure were more or less similar to that of the original pellet.:!:

The samples sintered at $1850^{\circ} \mathrm{C}$ in a vacuum were almost jet-black upon removal from the furnace, showed the same black coloration throughout the " $:$. pellet cross section, and demonstrated almost no grain size increase from. that of the original pellet. The as-received pellet, sintered at $1750^{\circ} \mathrm{C}$ in . wet hydrogen, was ASTM \#8 at the surface and ASTM \#9.5 at the pellet center. The grain size after resintering in vacuum at $1850^{\circ} \mathrm{C}$ at the same two locations was identical, ASTM \#8 and \#9.5.

It is postulated that the wet hydrogen exposure at $1800^{\circ} \mathrm{C}$, corresponding to a partial pressure of oxygen of about $10^{-10}$ at., produces a defect lattice with enhanced grain boundary mobility (arising from increased self-diffusion rates of both Th and $O$ ions); the mobility is sufficiently enhanced to overcome the anchoring effect of the impurity phase at the center of the pellet. While the partial pressure of oxygen at the nominal pressure of the vacuum 
treatment, $\sim 10^{-8}$ at., appears higher than that in the wet hydrogen treatment, it is probably many orders of magnitude lower because of the gettering of oxygen by the tantalum heating element and the niobium crucible in which the vacuum-sintered pellet was contained. Thus the vacuum-sintered pellet is believed to have been exposed to a partial pressure of oxygen less than $10^{-10}$ at. A defect structure has been postulated (Section IV.C) to form which reduces the volume and grain boundary self-diffusion rates (and hence grain boundary mobility) of the Th or 0 ions to a level such that not only is no grain size increase observed at the pellet center where an inhibiting impurity is believed to be present, but also no change is apparent at the surface where the impurity is believed to be absent. The diffusion rate. change due to the defect lattice change thus is more than adequate to overcome the normal increase in diffusion rate by a factor of 3 to 4 due to elevation in temperature from $1750^{\circ} \mathrm{C}$ to $1850^{\circ} \mathrm{C}$. Furthermore, the black coloration of the vacuum sintered pellet also indicates a change in defect lattice configuration. The observation that the coloration is uniform through the pellet indicates that the defect lattice probably arises by a readily diffusible species, the oxygen ion.

A practical application is suggested by these hypotheses. The critical oxygen pressure at which a change occurs from high to low selfdiffusion rates corresponds to a dew point in the hydrogen atmosphere of $25^{\circ} \mathrm{C}$ or less. The inlet hydrogen dew point initially utilized in the binary production facility was far lower and, uncontaminated, may yield oxygen partial. pressures in the low diffusion-rate defect structure range. Normally, sufficient reaction will occur with impurities in the brickwork or back-streaming from the flames at the entrance or exit ends to establish an adequately high oxygen level; however it is conceivable that with variation in age of the brickwork, furnace temperature in the approved range, or mode of door operation, uncontrolled variations in water content level will occur, leading to changes in pellet defect structure and hence variability in grain size from this source alone. Thus it was concluded that some minimum dew point, e.g. $25^{\circ} \mathrm{C}$, be established for the inlet hydrogen to remove this potential source of grain size variability. 
Since all of the pellets used for the solarization and atmosphere studies had been sintered previously, a green pellet was sintered in a. vacuum atmosphere. Unfortunately the pellet selected for this study was not fabricated from the same powder lot or to the same green density as the pellets used in the previous study. The powder lot was 09? and the green density was $6.245 \mathrm{gm} / \mathrm{cc}$ (the increased green density of this pellet would have a tendency to result in an increase in the final grain size). Nevertheless, the grain growth results as a function of pellet cross section, Figure 33, are still quite informative. The maximum grain size observed across the mid-plane diameter of a longitudinal section was ASTM \#10 (11.2 $\mu$ ), a value slightly smaller than the ASTM \#9-\#9.5 (15.9-13.4 $\mu$ ) which was observed as a center value for the pellets sintered in wet hydrogen and then sintered in vacuum. More informative, however, is the lack of grain growth at the pellet surface. The pellet initially sintered in wet hydrogen had a surface grain size of ASTM \#8 $(22.4 \mu)$, Figure 31 , whereas the pellet sintered only in a vacuum had a surface grain size of ASTM \#12 $(5.6 \mu)$. These results again indicate that the initial exposure to oxygen in the form of wet hydrogen promoted grain growth in the former case while the absence and possible creation of an oxygen deficient structure at the surface in the latter case inhibited grain growth.

\section{Interpretations}

\section{Secondary Recrystallization}

It has been demonstrated that sintering and grain growth are kinetic processes. The confusing nature of the grain size observations taken in the production facility resulted from observations being made only at fixed times. The kinetic experiments showed that inferences about grain growth being a monotonic function of time were incorrect and that the production data was readily explainable" within the framework of secondary recrystallization grain growth kinetics. The observed exaggerated grain growth resulting from the phenomena of secondary recrystallization is considered conclusive proof of the presence of a grain growth inhibitor. This impurity is removed from the pellet exterior during 'sintering resulting in a "picture frame" of normal grain growth on the outside of the pellet. On the inside of the pellet the impurity inhibits normal grain growth and results in discontinuous grain growth which, depending on sintering time, temperature, and 
oxidation potential of the atmosphere, leads either to a vcry fine grain size below specification limits or to a very coarse grain size exceeding the upper grain size limits.

\section{Hold Time, Cracks, and Mechanically Exposed Surfaces}

Extended exposure time to the hydrogen sintering atmosphere at temperatures $\left(\sim 1300^{\circ} \mathrm{C}\right)$ where a significant amount of porosity remained open, increased the thickness of the picture frame of normal grain growth when the pel.7et was subsequently sintered at $1750^{\circ} \mathrm{C}$ for 12 hours. Exposing the pellet interior to the hydrogen sintering atmosphere either by thermally-formed cracks or mechanically-formed holes resulled in low al grain growth in tho adjnining material. These results have been interpreted as supportive of the impurity inhibition conclusion and negate the possibility that the surface structure was the result of residual pressing stresses. Finally these results also suggested the possibility of calcining the powder so that exposure to the atmosphere is maximized and diffusion distances are minimized.

\section{Green Density and Powder Type}

Only a limited amount of data was collected on these

parameters. An increase in green density provides more particle-to-particle contact and therefore densification and grain growth appear to occur sooner in the sintering cycle than would a less dense compact. After a biven time at temperature this usually results in larger grain size for the pellet with the greater green density. However, the'final grain size is most strongly dependent on the inhibiting effect of the impurity and the very rapid growth associated' with secondary recrystallization.

Only thoria powder which contained approximately $100 \mathrm{ppm} \mathrm{CaO} \mathrm{was}$ investigated in this part of the evaluation. The effect of the different calcia containing thoria powder lots or grain growth, if any, was confounded by variations in the pellet green density. Small variations in the thickness of the picture frame of normal grain growth as a result of powder lot variations in the production facility have been attributed to slight differences in impurity content. 


\section{Sintering Time and Temperature}

Increasing the sintering temperature from 1750 to $1800^{\circ} \mathrm{C}$ decreased the exponent derived for the time variable in the equation $\mathrm{D}=\mathrm{Kt} \mathrm{n}^{\mathrm{n}}$ at the pellet surface from 0.55 to 0.13 . This would tend to indicate that the growth mechanism changed from uninhibited grain boundary diffusion to something akin to surface diffusion, Section IV. A meaningful activation energy can only be calculated when the time exponent in the above equation is constant. Consequently a value of 0.5 was selected based on the grain growth observations at $1750^{\circ} \mathrm{C}$ in the area where the inhibiting impurity was removed by vaporization. Using the measured grain diameter after one hour at $1750^{\circ} \mathrm{C}$, constants of 14.1 and 41 were calculated for $\mathrm{K}$ at $1750^{\circ} \mathrm{C}$ and $1800^{\circ} \mathrm{C}$, respectively. Substituting into the equation below and solving for $Q$ an activation energy

$$
\left.\ln \left(\frac{\mathrm{K}_{1}}{\mathrm{~K}_{2}}\right)=\frac{\mathrm{Q}}{\mathrm{R}} \cdot \mid \frac{1}{\mathrm{~T}_{2}}-\frac{1}{\mathrm{~T}_{1}}\right)
$$

of $185 \mathrm{kcal} / \mathrm{mole}$ was calculated. This value is larger than the $142 \mathrm{kcal} / \mathrm{mole}$ reported, Ref. 50, for the activation energy of surface diffusion in $\mathrm{ThO}_{2}$ and even larger than the $168 \mathrm{kcal} / \mathrm{mole}$ reported, Ref. 35, for the heat of "vaporization in $\mathrm{ThO}_{2}$. The variability in grain size measurements, the limiting effect of a free surface and most importantly the presence of impurities could all have a large effect on the calculated activation energy. Nevertheless, the activation energy for grain growth in pure thoria is significantly greater than the 85-124 kcal/more, Refs. 39 and 33, for grain growth and the 138 $\mathrm{kcal} / \mathrm{mole}$, Ref. 33, for the heat of vaporization in $\mathrm{UO}_{2}$.

\section{Idiomorphic Grains}

The observation of idiomorphic grain growth and the detection of a thorium oxysulfide eutectic phase which would be liquid at the sintering temperature of $1750^{\circ} \mathrm{C}$ satisfied many of the requirements dictated by the results of the kinetic studies. However, the thorium oxysulfide phase could be found only in the regions of idiomorphic growth and never in areas of normal or exaggerated growth indicating that the sulfur impurity was responsible for the special case of idiomorphic grain growth but not for the general grain growth inhibition. 
WAPD-TM-1311

\section{Atmosphere and Additives}

It was shown that grain growth in thoria like that in $\mathrm{UO}_{2}$, Ref. 39, is influenced by the oxidation potential of the sintering atmosphere. Grain growth is faster in an oxidizing atmosphere and slower in a reducing atmosphere. The grain boundary mobility was reduced to such an extent that a fine grained ( ASTM \#12) pellet originally sintered in hydrogen at $1750^{\circ} \mathrm{C}$ for 12 hours did not show any additional growth when resintered at $1850^{\circ} \mathrm{C}$ in a vacuum for the same length of time. The actual oxygen potential ( < 10-10 at.) in the vacuum was considered to be much below the nominal vacuum level of $10^{-6}$. torr because of the gettering of residual oxygen by the tantalum resistance heating element surrounding the specimen. These results confirm the hypothesis that grain growth in $\mathrm{ThO}_{2}$ cannot ${ }^{r_{i}}$ only be frihibited by the presence of an impurity but can also be increased or decreased by changing the intrinsic grain boundary mobility which is a function of the equilibrium defect structure of the oxide as modified by the atmosphere with which the pellet is equilibrated or by additives such as cao.

\section{RECRYSTALIIZATION MEASUREMENTS}

As an additional demonstration of the presence of grain growth inhibition in the sintered $\mathrm{ThO}_{2}$. pellets, an experiment was devised to plastically deform, by Knoop and/or Diamond Pyramid indentation hardness measuremerits, the surface of a polished pellet section. Atter indentation the pellels would be annealed at temperatures above, and below those used in the original pellet sintering. It was anticipated that the driving force for recrystallization and grain growth, which was estimated to be as great as 490 dyne-cm in the plastic zone around the hardness indentations (as compared with the grain boundary energy of about 0.1 dyne-cm available from grain boundary energy alone) would be adequate to cause grain growth in regions of the pellet free of grain growth inhibition (the pellet surface). On the other hand, at the pellet centers where the presence of grain growth inhibition is suspected, 
even the additional energy available from plastic deformation may be inadequate to cause recrystallization or, if it occurs, should be sharply reduced.

The initial experiments consisted of making indentations (both $1 \mathrm{~kg}$ Knoop and $1 \mathrm{~kg}$ Diamond Pyramid) at fixed intervals across the center diameter of longitudinally sectioned and polished thoria 0.53 inch diameter pellets (powder lot $087 ; \mathrm{R} / \mathrm{C} 74-3256 \mathrm{~A}$ ). The samples were heated for one hour at . $1700^{\circ} \mathrm{C}, 1750^{\circ} \mathrm{C}$; and $1800^{\circ} \mathrm{C}$, respectively, repolished and re-etched, and examined for evidence of recrystallization in the plastic zone around each hardness indentation. The results are shown in Table 11.

At $1700^{\circ} \mathrm{C}$ and $1750^{\circ} \mathrm{C}$ no recrystallization was observed at the centers of pellets where grain sizes were less than $14 \mu$ (about ASTM \#9); however, in the impurity free area near the pellet exterior, recrystallization and grain growth in the plastic zone around the indentation was obvious, figure 34 . At $1800^{\circ} \mathrm{C}$, where grain boundary mobility has been shown to be adequate to achieve grain growth upon sintering even, in the presence of grain growth inhibitors, recrystallization is, in fact, noted in the finer grain center region, albeit to a lesser extent than at the outside. These results confirmed in all respects the anticipated.results which were based on the initial premise that the grain growth at the pellet center was inhibited by some species or phase.

A second indentation experiment was devised to determine if, with the driving force of plastic deformation energy at the hardness indentation in addition to grain boundary energy, new grains could be made to grow around the indentations in spite of the presence of grain growth inhibitors. In this way it was hoped that differences between various $\mathrm{ThO}_{2}$ powder lots with respect to amount and distribution of grain growth inhibitors could be evaluated and newilight shed on the mechanism of grain growth as a furiction of green pellet density. The pellets listed in Table 12 were selected for this examination. Polished and etched transverse metallographic sections were indented with one row of $1 \mathrm{~kg}$ load knoop hardness indentations across one diameter and another row of $1 \mathrm{~kg}$ Vickers Diamond impressions across the orthogonal diameter. The indentations were spaced approximately 0.020 inch apart. Both Vickers and Knoop impressions were used to ensure that 
reproducible results were obtained independent of indentation shape or depth. In all cases the results with both indenters were identical, and thus no distinction is made in Table 12 between the observations with each set. The samples were then heat treated in a vacuum of $\sim 10^{-6}$ torr at $1750^{\circ} \mathrm{C}$ for 1 hour to cause recrystallization around the indentation. This thermal treatment was chosen as being adequate to secure recrystallization with no change in pellet grain size from that measured prior to the recrystallization treatment. However in one case, as shown in Table 12, the pellet grain size after the recrystallization treatment differed from that measured in the. as-sintered ( 12 hours at $1750^{\circ} \mathrm{C}$ ) condition.

It can. be concluded, from inspection of Table 12, that grain growth around hardness indentations is, without exception, completely consistent with the measured grain size; i.e., deformation-energy induced recrystallization is observed after 1 hour at $1750^{\circ} \mathrm{C}$ when the grain size is ASTM \#8.5 or coarser, and is not obtained at finer grain sizes.

It may further be inferred that the grain growth inhibitors interfering with' normal grain growth when the grain size is finer than ASTM.\#8.5 are '. swept up by the moving grain boundaries as grain growth proceeds such that the matrix, now reduced in inhibitor content, can freely grow new grains. around the hardness impressions. This is proposed in explanation for the observation that with increasing green density, both grain size and recrystallization propensity increase. Note that it is not unreasonable that grain growth inhibitors should be swept away by advancing grain boundaries, For example, on growing from a grain size of ASTM \#13 (grain diameter - $4 \mu$ ) to \#8.5 (grain diameter - $20 \mu$ ), the average grain volume will increase by a factor of 125 and, if grain growth is idealized as a process of successive absorptions of adjacent pairs of grains, an average grain will be swept by a grain boundary about seven times, thus affording ample opportunity for riding the grains of the responsible contaminant.

$\because 1.6$.

$\therefore$ The recrystallization results observed do not unequivocally point to dissollved elements or precipitated phases as being responsible for grain growth inhibition rather than porosity. Note, however, that similax porosity distributions should be obtained at the same green density levels. For this 
reason, one set of pellets in Table 12 was selected for examination which was pressed at a constant green density of about $60 \%$. Note that widely varying grain sizes were obtained at the pellet centers, a result difficult to reconcile with porosity distribution as an explanation for grain growth inhibjtion, but consistent with the contaminant hypothesis.

Of incidertial interest is the observation that the hardness of $\mathrm{ThO}_{2}$ pellets ( $760 \mathrm{Knoop,} \mathrm{I} \mathrm{kg;} 782 \mathrm{DPH}, 1 \mathrm{~kg}$ ) is appreciably higher than that of $\mathrm{UO}_{2}(666 \pm 14 \mathrm{KHN})$, not unexpected in light of the higher melting point of the former. No trend of hardness variation across a peliet diameter was noted, irrespective of the grain size for those samples used in the. recrystallization experiments, indicating that impurities responsible for grain growth inhibition are present in too small an amount to affect plastic properties.

VII. EFFECT OF CALCINATION AND POWDER SURFACE AREA ON GRAIN GROWTH IN SINTERED COMPACTS

Based on the results obtained from the sintering kinetic studies, it was concluded that a grain growth inhibiting impurity (or impurities) was present in the starting $\mathrm{ThO}_{2}$ powder. In an effort to test this hypothesis, a series of experiments was outlined with the intent of demonstrating that the impurity element could be removed by calcining the starting powder, thus volatilizing or reacting the impurity in air or hydrogen, and with the hope that 0.53 inch diameter pellets fabricated from such powder would exh.jibit normal grain growth. To obtain information on the effect of calcining. without being complicated by the effect of particle size, a number of different micronizations were attempted, especially for the powder which was calcined at the higher temperatures. The intent was to produce calcined powder with a particle size equivalent to the as-manufactured powder received from the vendor. This goal was not achieved because of the nature of the particle size reduction equipment available and the property changes of the powder itself as a result of recalcination which made it difficult to secure mechani-. cal particle size reduction below about $2 \mu$ (Ref. 44). The micronization procedures did result in the production of as-received and calcined powders at a variety of particle sizes. Although a direct comparison between 
as-received and calcined material at a specific particle size was in most cases not possible, the effect of calcining time and temperature as well as of particle size on grain growth was thoroughly explored. The powder selected for these experiments, the calcining times and temperatures, as well as surface area of the processed powders, and their chemistries are given in Tables 13 and 14 .

\section{A. Air-Calcined Powder $-1100^{\circ} \mathrm{C}$}

Thoria powder lots 096 (powder typically used for the production of $100 \% \mathrm{ThO}_{2}$ pellets. Which contains approximately $100 \mathrm{ppm} \mathrm{Ca}$ ) and 136 (powder typically used in the production of $\mathrm{ThO}_{2}-\mathrm{UO}_{2}$ pellets which contains approximately $4 \mathrm{ppm} \mathrm{(a)}$ ) were calcined at $1100^{\circ} \mathrm{C}$ in air for 48 hours. Inconel boats were filled with the powder to a depth of approximately 2 inches. The powder was rabbled with an Inconel rake every half hour. Four different powder variations--calcined, micronized-calcined, as-received, and micronized-asreceived (micronized in this case actually means a double micronization consisting of initially passing the powder through the micronizer at the rate of $150 \mathrm{gm} / \mathrm{min}$ and a second time at $50 \mathrm{gm} / \mathrm{min}$ )--of each powder lot were used to fabricate pellets which were sintered at $1750^{\circ} \mathrm{C}$.

\section{Dry Pressing Procedure}

Ungranulated powder lots 096 and 136, with and without the $1100^{\circ} \mathrm{C}$ air calcine and/or double micronization were:dry pressed into 0.53 inch diameter pellets using nei.ther Carbowax binder nor Sterotex lubricant in the powder. Sterotex was applied to the die and punch prior to pressing. each ungranulated powder pellet. Some difficulty was experienced in pressing the ungranulated powder, particularly the micronized-calcined lots. A 60second dwell was utilized and, in some cases, repressing was required. The green density of the repressed pellets was not very uniform. Occasionally cracks and areas of high pore concentration were observed at the pellet surface. The target green density of the pellets pressed from the ungranulated powder was $60 \%$; however, the actual values varied more widely than usual. The individual geometric values are tabulated in Table 13. 
These pellets were subsequently sintered at $1750^{\circ} \mathrm{C}$ in dry hydrogen ( $60^{\circ} \mathrm{F}$ tank dew point but $+53^{\circ} \mathrm{F}$ hot zone dew point) for $1 \frac{1}{2}$ and 12 hours. Because these pellets did not have any deliberate carbonaceous additions, the samples were not pretreated prior to sintering.

\section{.2. Dry Press Results.}

After sintering, the pellets were examined with the unaided eye for gross differences. The color of the pellets sintered at $1750^{\circ} \mathrm{C}$ for $1 \frac{1}{2}$ hours varied depending on the powder lot and powder processing. The asreceived and as-calcined samples of both powder lots were generally white with pellets produced from powder lot 136 having the whitest, most uniform color. Pellets which were fabricated from double micronized powder appeared mottled black and white or grey and white. Since the rubber liner in the powder micronizer was a possible source of carbon contamination (and possibly sulfur), a review of the powder chemistry was necessary. Examining the carbon analyses and the powder surface areas, shown below, it was clear that

Surface Area and Carbon Contents of Starting Powders Used to Evaluate the Effects of $1100^{\circ} \mathrm{C}-48 \mathrm{Hr}$ Air Calcine

\begin{tabular}{|c|c|c|c|c|}
\hline $\begin{array}{l}\text { Powder } \\
\text { Lot }\end{array}$ & Powder Treatment & $\begin{array}{l}\text { Surface } \\
\text { Area } \\
\left(\mathrm{m}^{2} / \mathrm{gm}\right) \\
\end{array}$ & $\begin{array}{l}\text { Carbon } \\
\text { Content } \\
\text { (ppm) }\end{array}$ & $\begin{array}{l}\text { Carbon Content } \\
\text { Surface Area } \\
\left(\begin{array}{c}\left.\text { (gm } \mathrm{C} / \mathrm{m}^{2} \mathrm{ThO}_{2}\right) \\
\times 10^{-6}\end{array}\right. \\
\end{array}$ \\
\hline $\begin{array}{c}096 \\
" ~ \\
" \\
136 \\
" ~ \\
" ~ \\
" ~\end{array}$ & $\begin{array}{l}\text { As-Received } \\
\text { As-Received + Double Micronized } \\
1100^{\circ} \mathrm{C} \text { Air Calcine } \\
1100^{\circ} \mathrm{C} \text { Air Calcine + Double Micronized } \\
\text { As-Received } \\
\text { As-Received + Double Micronized } \\
1100^{\circ} \mathrm{C} \text { Air Calcine } \\
1100^{\circ} \mathrm{C} \text { Air Calcine + Double Mïcronized }\end{array}$ & $\begin{array}{r}8.24 \\
10.28 \\
3.52 \\
5.29 \\
5.55 \\
8.10 \\
2.82 \\
5.27\end{array}$ & $\begin{array}{r}554 \\
790 \\
240 \\
508 \\
462 \\
624 \\
188 \\
360\end{array}$ & $\begin{array}{l}67.3 \\
76.7 \\
60.2 \\
96.0 \\
83.0 \\
77.0 \\
71.8 \\
68.3\end{array}$ \\
\hline
\end{tabular}

the dark color observed in some of' the sintered peliets was not the result of carbon contamination. The ratio of the analyzed carbon content (total carbon released at $1400^{\circ}$ ) to the surface area of the same powder is relatively constant for all the powders and conditions. The 096 double 
micronized as-received and calcined powders have a slightly higher ratio of carbon per square meter of powder surface area $76.7 \times 10^{-6}$ and $96.0 \times 10^{-6}$ than the respective nonmicronized powders at 67.3 and $68.2 \cdot 10^{-6} \mathrm{gms} / \mathrm{m}^{2}$; however, an opposite effect is observed with micronized and nonmicronized 136 powder. Variations in the carbon and surface area measurements could well account for the slight scatter in the ratio of carbon to surface area.

In addition to the fact that the carbon content varied as a function of the surface area, it was shown, Ref. 44, that the carbon was only weakly held and the majority of the carbon was released at temperatures below $400^{\circ} \mathrm{C}$. It was therefore concluded that the dark color which was typical of pellets made from micronized powder was not a function of the carbon content.

The samples which were sintered for 12 hours at $1750^{\circ} \mathrm{C}$ generally appeared to be a more uniform color throughout the entire pellet; however, the color of the pellets ranged from almost pure black to very white. The whitest sample was the pellet produced from as-received 136 powder and the blackest pellet was produced from 096 calcined-double IIILrronlized powaer.

The density after sintering was determined by the water 1mmersion technique and is listed in Table 13. That portion of Table 13 pertinent to the samples in Figures 35 and 36 is shown below. ASTM Center Grain Size Results for Pellets Fabricated From 096 Air Calcined and As-Received Powder

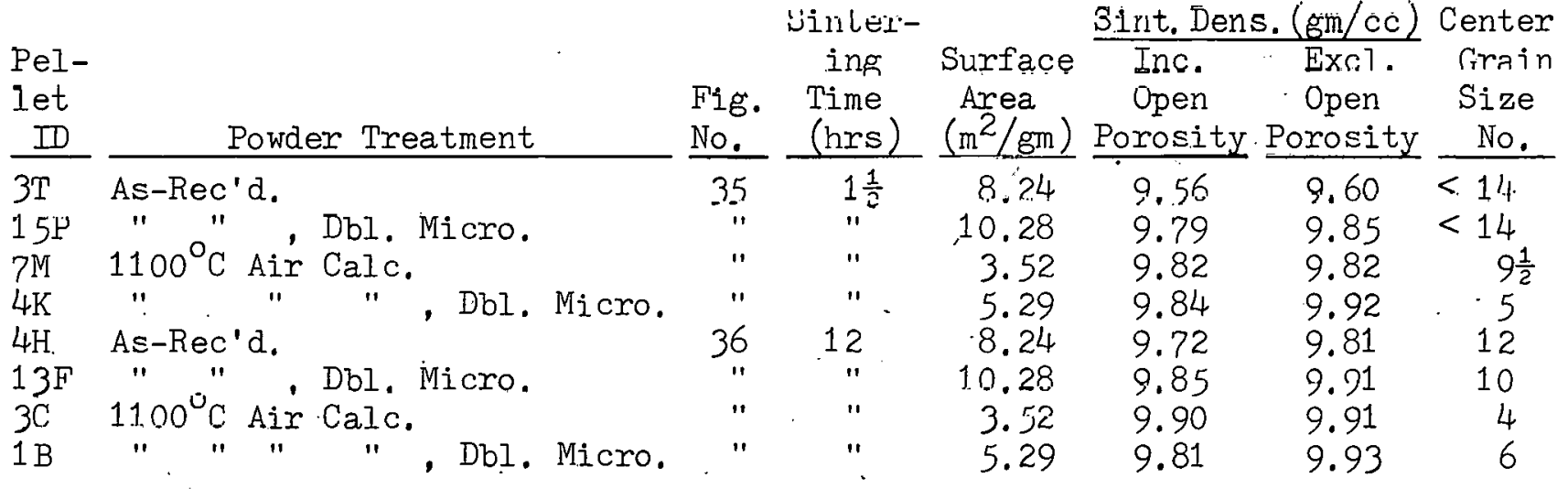


A comparison of the sintered densities and the surface area of the starting powder indicates only a small sensitivity to surface area after $1 \frac{1}{2}$ hours at temperature, and even less of a correlation between the two variables after 12 hours at temperature. With few exceptions, a sintered density in excess of $9.5 \mathrm{gm} / \mathrm{cc}$ was achieved after $1 \frac{1}{2}$ hours with little or no increase in density with 'increased 'time'to 12 hours. Part of the reason for these high density levels is the absence of the dry Sterotex lubricant. The densities are therefore approximately $1 \%$ higher than those of pellets fabricated according to production procedures which contain voids resulting from the burnout of the Sterotex. The insensitivity of density to sintering time was also observed in the kinetic sintering experiments.

A pellet from each condition was mounted longitudinally, polished, and the grain size determined as a function of distance from the pellet surface. Figure 35 shows the variation in grain size from the pellet surface for the 096,0.53-inch diameter, pellets fabricated from as-received, micronized-as-received, calcined, and micronized-calcined powder. Limited grain growth was recorded along the outer surface of the pellets fabricated from the as-received and micronized-as-received powder. The finer initial particle size of the micronized-as-received powder resulted in a more extensive rim of normal grain growth. However, the grain size observed in the center portion of both of these pellets was less than $2.8 \mu$ and could not be resolved with the optical microscope. As previously described in Section $V$, it was concluded that an impurity in the as-received material inhibits normal grain growth. At the pellet surface the concentration of this impurity is reduced below some critical level by reacting with the sintering atmosphere. Therefore, at the pellet surface the grain growth proceeded in a normal fashion because the inhibiting phase was below the critical level for grain growth inhibition.

As previously discussed, it was believed that the inhibiting impurity element concentration can be reduced by the $1100^{\circ} \mathrm{C}$ air calcine. Therefore, grain growth across the entire pellet cross section was anticipated in samples made from calcined powder and the results of the grain size measurements, Figure 35, confirm that prediction. The pellets produced from the calclred powder, $4 \mathrm{~K}$ and $7 \mathrm{M}$, exlibited grain growth across the 
entire pellet cross section which was, in all cases, greater than that observed in pellets produced from material which was not calcined. The pellet which was fabricated from powder which was both calcined and micronized, 4K, initially grew grains faster and possibly somewhat more uniformly. It has been recorded in the literature that coarse particles in the sintering powder do not result in as uniform a grain structure as do fine powders with the coarse particles removed. The extensive grain growth in the center portion of the pellet fabricated from the micronizedcalcined powder was greater than anticipated and may indicate that the impurity still resulted in some early grain inhibition. Jt may also be observed that the grain growt.h a.t. the surface of all the pollotc, rcgardless of the powder treatment, was similar. This indirates that, irrespective of initial treatment, grain growth at the pellet surface is controlled by the same type of reaction between the pellet and the sintering atmosphere. This is hardly surprising since purification by recalcination is limited to that which can occur at $1100^{\circ} \mathrm{C}$ whereas the pellet surface can eliminate contaminants at all temperatures up to $1750^{\circ} \mathrm{C}$.

Grain growth as a function of radial position for pellets fabricated from 096 powder and sintered at $1750^{\circ} \mathrm{C}$ for 12 hours is shown in Figure 36. The grain growth recorded in the pellets fabricated from the calcined and micronized-calcined powder, $13 \mathrm{C}$ and $1 \mathrm{~B}$, is again considerably more extensive than that of the pellet.s fabricated from eithor of the as-received powders. The grain size in the center of the pellets fabricated from the calcined powder is as large or larger than the grains observed at the pellet surface. The grain size in the center of the pellets which were produced from as-received or micronized-as-received powder is, in all cases, finer than the grain size at the pellet surface. It is not clear why the pellet produced from the calcined powder, $3 \mathrm{C}$, had larger grains thar the pellet produced from the micronized-calcined powder, 1B, or why the pellet produced from the micronized-calcined powder had larger grains at the end of $1 \frac{1}{2}$ hours than was recorded for a similar pellet sintered for 12 hours; however, some pellet-to-pellet variation should be anticipated.

The results presented in Figures 35 and 36 show that the grain growth at the pellet surface is very uniform. In the pellets made 
from the calcined powders it is postulated that the impurity element has been reduced. This assumption is strengthened by the fact that the pellets produced from the calcined and micronized-calcined powders consistently showed more extensive grain growth in spite of the significant difference in the surface area of the starting powders. The surface energy per gram of calcined and calcined-micronized powder is $4.1 .10^{7}$ and $6.1 \cdot 10^{7} \mathrm{ergs} / \mathrm{gm}$, respectively. The same values for the, as-received and as-received-micronized powders are $9.5 \cdot 10^{7}$ and $11.8 \cdot 10^{7}$ ergs/gm. These are the driving forces both for densification during sintering stages I to III (Section V) and for grain growth during sintering stage III. By far the greatest fraction of this energy is consumed in densification in stages I and II. For example, even with a grain size of ASTM \#14 which is barely resolvable by optical microscopy and may be the typical grain size at the beginning of stage III; the grain boundary energy is only about $10^{6} \mathrm{ergs} / \mathrm{gm}$; about one percent of the starting particle surface energy. Obviously there are many factors which might change the relative energies of the different powders before initiation of stage III sintering. For purposes of this discussion, it.is assumed that the energy available for grain growth at the beginning of the stage III is proportional to the initial particle surface energy. Thus, the driving force for grain growth in the pellets made from the calcined powder was, due to the coarser initial particle size or denser initial particle, only about one-half that of the as-received powder; however, the grain growth of the pellets fabricated from the calcined powder was greater beraluse the grain houndaries encountered less resistance to movement. In all probability the inhibiting impurity was not completely removed since the center grain growth did exceed, pellets $3 \mathrm{C}$ and $4 \mathrm{~K}$, the surface growth; however, the $1100^{\circ} \mathrm{C}$ calcine was sufficient to decrease the energy requirements for grain boundary movement by about $50 \%$. The reduced impurity content resulting from calcining presumably allowed more grains to break away; therefore, more grains were capable of growing and they could begin growth at a lower temperature or earlier in the sintering cycle. As a result of the larger number of nuclei, the ultimate grain size was only slightiy greater than the normal grain growth on the pellet surface. 
Another possible explanation for the observed grain growth in the pellets made from calcined powder is that the calcining was highly effective in removing all of the grain growth inhibiting phase. The grain 'growth in the center portion of the pellets fabricated from the calcined powder would then be normal and the lack of grain growth in the pellets fabricated from the as-received powders, the result of an impurity in the starting powder. The relatively uniform but somewhat smaller grain growth on the surface of all the pellets may then be the net result of removal of a very effective grain growth inhibitor from the powder at the peliet surface by a volatilization counteracted to a limited extent by contamination with a somewhat less effectively inhibiting impurity from the sintering atmosphere which diffused back into the pellet. The latter hypothesis appears to be unnecessarily involved; the former theory is.. supported by the presence of exaggerated grain growth in calcined powders reported in a subsequent experiment.

Examination of the microstructure shown in Figure 37a, b, and $c$ for pellets $3 \mathrm{C}, 1 \mathrm{~B}$, and 13F, respectively, indicates that the grains in pellet $3 \mathrm{C}$ contain the most intragranular porosity. (It appears to be more prominent because it is coarser. A grain with an equal volume of very fine porosity may not appear to contain as much because of the diffi. culty of fine pore resolution.) Quite apparently the grain boundaries had sufficient mobility to pass these pores without significant inhibition. Figure $37 \mathrm{~b}$ has a moderate amount of intragranular porosity. This pellet, $1 \mathrm{~B}$, had equal center and edge grain size. Higure $37 \mathrm{c}$ shows the center grain size for pellet $13 \mathrm{~F}$, as-received-micronized. The porosity is very fine and difficult to resolve. The grain boundaries are not nearly as well defined as the previous two samples, with many grains having less than six boundaries, hinting their mobility wäs restrained by effects other than normal surface tension.

The effect of calcining the starting powder is not nearly as obvious in the thoria powder which does not have the $100 \mathrm{ppm}$ calcia addition. Grain growth as a function of distance from the pellet surface for pellets fabricated from powder lot 136 is shown in Figure 38 and Figure 39 for pellets sintered for $1 \frac{1}{2}$ and 12 hours, respectively in dry hydrogen $\left(53^{\circ} \mathrm{F}\right.$ 
measured dew point in the furnace hot zone). A brief. summary of sintered pellet data is shown below. At the completion of $1 \frac{1}{2}$ hours at $1750^{\circ} \mathrm{C}$ the

ASTM Center Grain Size Results for Pellets Fabricated from 136 Calcined and As-Received Powder.

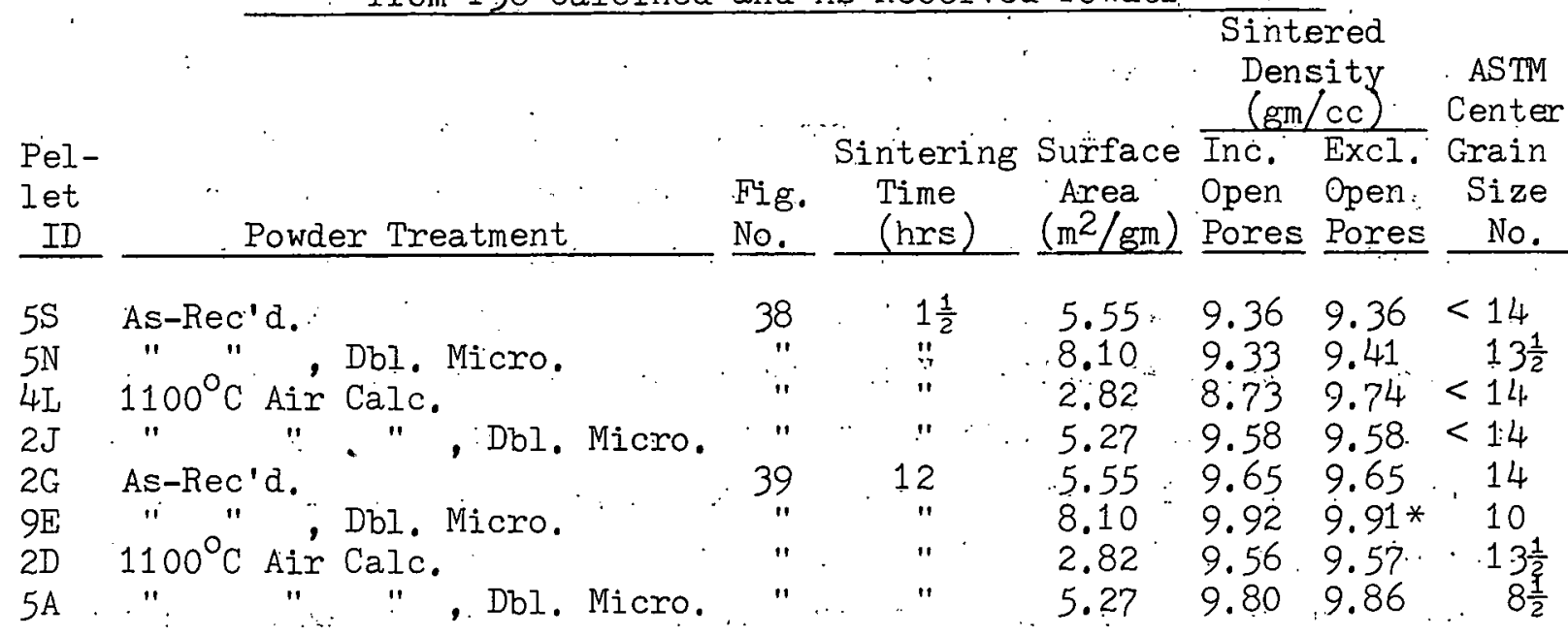

*Material lost during blotting

pellets fabricated from micronized-as-received powder actually showed larger grains at the pellet center than the pellet fabricated from micronizedcalcined powder, even though the largest grains recorded in any of the $1 \frac{1}{2}$ hour, lot 136 pcllets was observed in the pellets fabricated with the micronized-calcined powder approximately $30-40 \times 10^{-3}$ inches from the pellet surface. Since the as-received-micronized powder had a greater surface aroa $\left(8.10 \mathrm{~m}^{2} / \mathrm{gm}\right)$ than either the micronized-calcined $\left(5.27 \mathrm{~m}^{2} / \mathrm{gm}\right)$. or the calcined $\left(2.82 \mathrm{~m}^{2} / \mathrm{gm}\right)$ powder, the respective surface energies available for densification and subsequent grain growth are $9.3 \cdot 10^{7}, 6.0 \cdot 10^{7}$, and $3.2 \cdot 10^{7} \mathrm{ergs} / \mathrm{gm}$. In view of the respective powder surface energies, it becomes obvious that the only meaningful way to determine the effect of calcining is to compare pellets fabricated from powders of similar surface area and therefore similar surface energy. $\because$ As shown in Figure 38 , the pellet fabricated from the as-received powder, 5S, with a surface energy of $6.38 \cdot 10^{7} \mathrm{ergs} / \mathrm{gm}$, should be compared with the calcined, micronized sample, $2 \mathrm{~J}$, with a surface energy of $6.05 \cdot 10^{7} \mathrm{ergs} / \mathrm{gm}$; to clearly show the benefjoial. effect of calcining. 
Figure 39 shows the change in grain size as a function of pellet cross section for pellets sintered at $1750^{\circ} \mathrm{C}$ for 12 hours. As. shown above and by comparison of Figures 38 and 39 the effect of powder calcining on pellet grain growth became more significant and the influence of the initial particle size becomes less significant as the time at temperature is increased from $1 \frac{1}{2}$ to 12 hours at $1750^{\circ} \mathrm{C}$. At the end of 12 hours at $1750^{\circ} \mathrm{C}$ the pellets fabricated from calcined 136 powder exhibited greater grain growth than the pellets fabricated from as-received powder and the grain growth 'of the micronized-calcined was greater than the micronizedas-received. The beneficial effects of the $1100^{\circ} \mathrm{C}$ purification calcination are even greater when pellets made from powders with similar surface areas are compared. Pellet 5A fabricated from micronized-calcined powder had an initial powder surface area of $5.27 \mathrm{~m}^{2} / \mathrm{gm}$ and pellet. 2.4 fabricated from as-received powder had, an initial powder surface area of $5.55 \mathrm{~m}^{2} / \mathrm{gm}$. The pellets fabricated from the micronized-calcined 136 powder exhibited the greatest overall grain growth, which was also greater than the pellet fabricated from the micronized-as-received powder.

Figures 38 and 39 show that the effect of calcining $136 \mathrm{ThO}_{2}$ powder at $1100^{\circ} \mathrm{C}$ in air may not be as large as previously observed with 096 $\mathrm{ThO}_{2}$ powder. The reason for this difference may be that the impurity is Ilure edslly removed from $\mathrm{ThU}_{2}$ powder which has a higher $\mathrm{CaO}$ content. Another reason may be that the inhibiting impurity phase in both powder lots was reduced by approximately the same amount by the $1100^{\circ} \mathrm{C}$ air calcine; however, the observed difference may be due strictly to the differences in initial part1cle surface area since the surface energy for grain growth is derived from this initial energy. If the calcia-free powder, 136, was calcined at $982^{\circ} \mathrm{C}$ rather than $1032^{\circ} \mathrm{C}$, it may have resil, ter in grain growth cimilar to that observed for the $0.96 \mathrm{Th}_{2}$ powiter with the $100 \mathrm{ppm} \mathrm{CaO}$.

\section{Slurry Agglomeration Procedure}

In an effort to simulate by laboratory procedures on small quantities of powder a fabrication procedure which uses carbonaceous additives similar to the production facility, as well as to produce pellets with a wider range of green densities, 0.53 inch diameter pellets from 
lots 096 and 136 (as-received, as-received-double micronized, $1100^{\circ} \mathrm{C}$ air calcined, and $11.00^{\circ} \mathrm{C}$ air calcined, double micronized) were produced by a slurry agglomeration procedure. The various powders were wet mixed with oxylene and $1.75 \mathrm{w} / \mathrm{o}$ Carbowax 6000 and then granulated through a 24 mesh screen. Sterotex, $0.2 \mathrm{w} / 0$, was added to the granules and dry blended prior to pressing. A series of green densities between 55 and $65 \%$ T.D. were pressed on the Stokes press. The geometric density of the green pellets is included in Table 13. Almost consistently the actual measured green density is somewhat greater than the target density.

The pressed pellets were pretreated at $925^{\circ} \mathrm{C}$ for 3 hours in a flowing $\mathrm{CO}_{2}$ atmosphere. The $\mathrm{CO}_{2}$ gas was a high purity instrument grade with less than $15 \mathrm{ppm}$ oxygen. The carbon content of the resultant pellets analyzed $425+0-150 \mathrm{ppm}$. (Adsorbed $\mathrm{CO}_{2}$ from the atmosphere frequently approximated. $150 \mathrm{ppm}$ depending on length of exposure.) Again the high purity $\mathrm{CO}_{2}$ used to pretreat these pellets seemed to remove less carbion than the less pure ( 200 ppm. oxygen contamination) $\mathrm{CO}_{2}$ used in the production facility. The pellets were sintered at $1750^{\circ} \mathrm{C}$ for $0, \frac{1}{2}, 1 \frac{1}{2}, 5,12$, and, in some cases, 22 hours in. "dry". ( $53^{\circ} \mathrm{F}$ measured furnace hot zone dew point) hydrogen.

\section{Slumy Agglomerated Peliet Resüts}

The effect of sintering time at $1750^{\circ} \mathrm{C}$ on 0.53 inch diameter pellets fabricated by the slurry mix process from micronized-as-received and micronized $1100^{\circ} \mathrm{C}$ air-calcined 096 and 136 powders were confounded by extreme levels of granular segregation. Examples of the extensive granular segregation are shown in Figure 40a-d. The sintering within the granules was so extensive in pellet $3-15\left(1100^{\circ} \mathrm{C}-48\right.$ hour air calcine-double micronized lot 096, $6.1 \mathrm{gm} / \mathrm{cc}$ green density), Figure 40d, that physical separation had takcn plooe between the gramules. Almost all of the samples made from the 096 calcined-double micronized powder had a maximum segregation rating of 7. Table 13.

The reason why such extensive granular segregation resulted in the slurry-agglomerated powder is not completely clear. Shown below 
are crush loads for the slurry-agglomerated granules and the granular segregation rating for the pellets fabricated from the respective powders. There appears to be a weak correlation between

\section{Slurry Agglomerated Granule and Pellet Properties}

Pellet Segregation Rating at $1750^{\circ} \mathrm{C} \&$

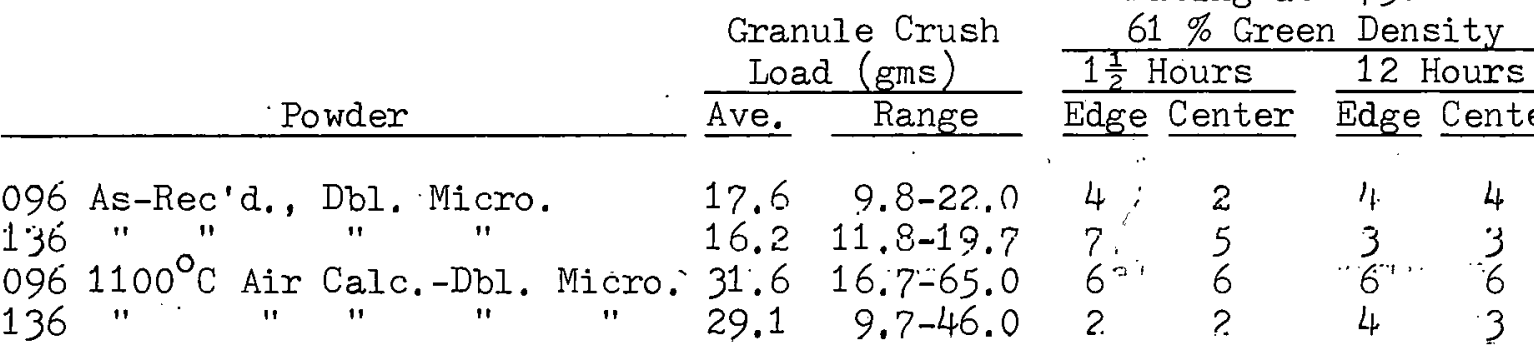

crush strength and granular segregation; however, it certainly is not clear cut, especially at. the $1 \frac{1}{2}$ hour sintering time. The strongest granules (096 calcined, 31.6. grams) resulted in the greatest granular segregation in the sintered pellet. The second strongest granules (136 calcined, 29.1 grams) also showed segregation when sintered, but it was not always grealer than that observed with some of the weaker granules. Since the lullye of crush loads tor each powder type were very wide, it is possible that the very strong and very weak granules may influence the granular segregation more than the simple average. If the integrily of the hard orullule: produced by this treatment were maintained during pressing better than granules prepared by conventional liquid/solids blending, a reduced granule-to-granule, contact may result. $\Lambda$ a consequence of such reduced contact, densification occurs primarị $7 \mathrm{y}$ within each granulc, resulliıly In granules shrinking apart and reducing their contact still further. If the slurry-agglomerated granule is strong and dense, the press load and springback for a given green compact density would decrease from the levels for weaker, less dense granules. Even the ejection load might decrease if for no other reason than the pellets were pressed to a lower ultimate density. However, pressing data shown below do not provide a definitive picture." Pressing load, springback, and ejection load are the lowest for the pellets fabricated from the $096,1100^{\circ} \mathrm{C}$ air-calcined granules and the granule segregation is the greatest as predicted from the 
Press Load, Springback, and Ejection Load for

0.53 Inch Diameter Pellets Fabricated From Slurry Agglomerated 096 and 136 Double Micronized, Air Calcined and As-Received Powder

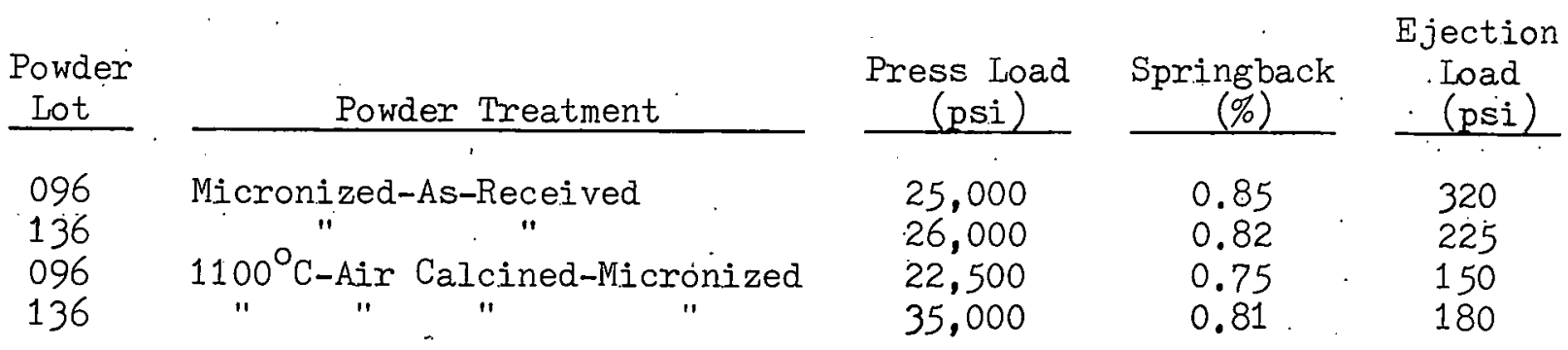

above. However the relationship between press load and granule segregation seems to break down with the other samples. The $136,1100^{\circ} \mathrm{C}$ air-calcined granules with a press load of 35,000 psi clearly do not show significantly less.igranular segregation than the other powders.

Regardless of the cause of the granular segregation, it did appear to influence the resulting pellet grain growth. To explain the observation that pellets fabricated from the slurry agglomerated, micronizedas-received showed greater grain growth than the same powder without binder and lubricant addition, it is proposed that the void around the granules visible in Figure 40 allowed permeation of the pellet with sintering atmosphere around each granule, and thus facilitated the removal of the grain growth inhibitor which normally is removed only at the pellet surface. The removal of the inhibitor thus promoted grain growth within the granules. The radius of the granule ( 0.014 inch) is much smaller than the thickness of the band of normal grain growth observed around the exterior of a typical duplex structure pellet; thus effusion of the inhibitor during sintering is relatively unimpeded. In the case of the calcined powder, access of the atmosphere in the void between granules is less important since the grain growth inhibitor has already been reduced in level. The density and grain size data for these slurry agglomerated samples have been included in. Table 13. The figures showing grain size as a function of pellet cross section and green density have been included in Appendix A. Due to the atypical nature of these samples, comparisons of the data may be misleading. They are included for cautious reference only. 


\section{B. Hydrogen-Calcined Powder $-1100^{\circ} \mathrm{C}$}

It was previously demonstrated with the use of $1100^{\circ} \mathrm{C}$-air-calcined powder that the powder history has a significant influence on grain growth kinetics. To study the effect of calcining atmosphere and to determine if the grain growth inhibiting impurity phase could be removed more effectively by calcining the starting thoria in dry hydrogen rather than in an air atmosphere, powder lots 096 and 136 were calcined for 48 hours in a closed furnace system at $1100^{\circ} \mathrm{C}$ in flowing dxy (-60\% $\mathrm{F}$ dew point) hydrogen. The maximum powder depth in the quartz crucibles was 2 inches. The sample was not rabbled as was the air-calcined powder. An analysis of the calcined powder is given in Table 14, along with the resulting surface area. The silicon content of one of the hydrogen-calcined powders (096) was signif'icantly greater than that of the air-calcined powder or the as-received powder, possibly as a consequence of the quartz crucible. The fact that the 136 powder showed no real change in Si content tends to cast doubt on the deviant analysis.

\section{Dry Pressing Procedure}

Similar to the experiment with the air-calcined powder, a number of pellets were pressed without binder from the calcined and double micronizedcalcined powder at approximately $60 \%$ compacted density. Processing pellets without the standard addition of Carbowax and the agglomeration of the powder into granules resulted in some pressing difficulties; however, at least two pellets were available for each variable. As before, these dry pressed binderless samples were not pretreated. The geometric green. density for each pellet sintered is included in Table 13. The pellets were sintered at $1750^{\circ} \mathrm{C}$ in a dry (furnace hot zone dew point $53^{\circ} \mathrm{F}$ ) hydrogen atmosphere.

\section{Dry Press Results}

After sintering, the pellets were examined with the unaided eye for gross differences. It was previously determined for pellets made from air-calcined powder that the darker colored pellets generally had larger grains than the lighter colored pellets. The darker pellets were generally those which were fạbricated from calcined and/or calcined-micronized powder. The same color trends were again observed with the pellets fabricated from the hydrogen-calcined powder and sintered for $1 \frac{1}{2}$ and 12 hours at $1750^{\circ} \mathrm{C}$. The 
only difference was that the pellets fabricated from hydrogen-calcined powders were generally lighter in color than the equivalent air-calcined powder pellet.

After the density of the sintered pellets was determined by the water immersion technique, Table 13, a pellet from each condition was mounted longitudinally, polished, etched, and the grain size determined as a function of distance from the pellet surface. The variation in grain size as a function of cross section for 096 0.53-inch diameter pellets $(\sim 100 \mathrm{ppm}$. CaO) fabricated from calcined and micronized-calcined powder sintered at $1750^{\circ} \mathrm{C}$ for $1 \frac{1}{2}$ and 12 hours is shown in Figure 41.

These results are to be compared with those shown in Figures 35 and 36 for $1 \frac{1}{2}$ and 12 hours sintering at $1750^{\circ} \mathrm{C}$, respectively, to evaluäte the effects of hydrogen calcining as well as to compare between the two calcining atmospheres. Comparing first with the as-received powder, it is apparent from the data in the table below that hydrogen calcining increased sintered grain size at the pellet center both after $1 \frac{1}{2}$ hours and 12 hours.

ASTM Center Grain Size Results for Pellets Fabricated From 096 Hydrogen-Calcined and As-Received Powder.

\begin{tabular}{|c|c|c|c|c|c|c|c|}
\hline & $\begin{array}{l}\therefore \\
\therefore \\
\therefore\end{array}$ & & Sinter- & & $\begin{array}{l}\text { Sir } \\
\text { Der } \\
\text { (gm }\end{array}$ & $\begin{array}{l}\text { red } \\
\text { ty } \\
\text { c) }\end{array}$ & $\begin{array}{c}\text { ASTM } \\
\text { Conter }\end{array}$ \\
\hline $\begin{array}{l}\text { el- } \\
\text { et }\end{array}$ & Powder Conditions & $\begin{array}{l}\text { Fig. } \\
\text { No. } \\
\end{array}$ & $\begin{array}{l}\text { ing } \\
\text { Time } \\
\text { (hrs) }\end{array}$ & $\begin{array}{c}\text { Surface } \\
\text { Area } \\
\left(\mathrm{m}^{2} / \mathrm{gm}\right)\end{array}$ & $\begin{array}{l}\text { Inc. } \\
\text { Open } \\
\text { Pores } \\
\end{array}$ & $\begin{array}{l}\text { Excl. } \\
\text { Open } \\
\text { Pores } \\
\end{array}$ & $\begin{array}{r}\text { Grain } \\
\text { Size } \\
\text { No:: } \\
\end{array}$ \\
\hline $\begin{array}{l}3 \mathrm{~T} \\
15 \mathrm{P} \\
2 \mathrm{EE} \\
2 \mathrm{FF} \\
4 \mathrm{H} \\
13 \mathrm{~F} \\
4 \mathrm{AA} \\
6 \mathrm{BB}\end{array}$ & 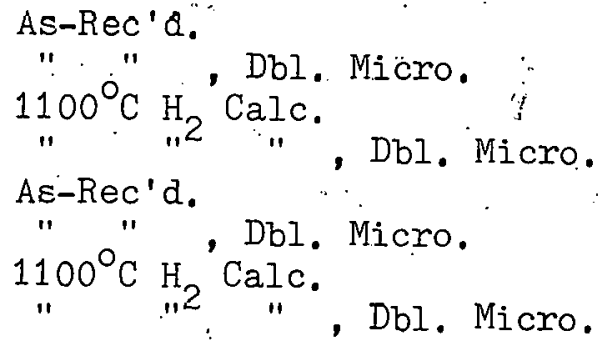 & $\begin{array}{r}35 \\
" 1 \\
41 \\
" 1 \\
36 \\
41 \\
41\end{array}$ & $\begin{array}{c}1 \frac{1}{2} \\
" 1 \\
" \\
12 \\
12 \\
" \\
" \\
"\end{array}$ & $\begin{array}{r}8.24 \\
10.28 \\
4.77 \\
5.82 \\
8.24 \\
10.28 \\
4.77 \\
5.82\end{array}$ & $\begin{array}{l}9.56 \\
9.79 \\
9.63 \\
9.68 \\
9.72 \\
9.85 \\
9.78 \\
9.82\end{array}$ & $\begin{array}{l}9.60 \\
9.85 \\
9.62^{*} \\
9.70 \\
9.81 \\
9.91 \\
9.78 \\
9.79 *\end{array}$ & $\begin{array}{c}<14 \\
<14 \\
13 \frac{1}{2} \\
9 \\
12 \\
10 \\
8-0 \\
9\end{array}$ \\
\hline
\end{tabular}

FMaterial lost during blotting

Thus, as previously shown for air-calcined 096 powder, dry hydrogen calcination at $1100^{\circ} \mathrm{C}$ for 48 hours improves pellet grain growth characteristics in spite of a reduccd ourface energy resulting from a reduced surface area. 
The efficacy of dry hydrogen calcining of 096 powder for 48 hours at $1100^{\circ} \mathrm{C}$ is confused by the formation, as indicated in Figure $4 \dot{1}$ and Figure $42 \mathrm{a}-\mathrm{d}$ for pellet $4 \mathrm{AA}$ ( 12 hours at $1750^{\circ} \mathrm{C}$ ) of large idiomorphic grains in the as-calcined powder. The large idiomorphic grains were in a field of finer grains. As shown in the kinetic studies, the formation of large idiomorphic grains can be attributed to the presence of a liquid phase at the idiomorphic grain boundaries, probably an eutectic between $\mathrm{ThO}_{2}$ and a thorium oxysulfide phase. The presence of microstructural constituents similar to those previously identified as thorium sulfides was detected in sample $4 \mathrm{AA}$ of Figures 41 and 42. The sulfur content of the hydrogen-calcined 0,6 powder was determined by mass spectrographic analysis to be $45 \mathrm{ppm}$, which is greater than that of the hydrogen-calcined 136 powder or either the 0,96 or 136 ai,r-. calcined powders whose sulfur contents were 18,37 , and 23 , respectively. However, the as-received 096 powdex had an analyzed sulfur content of 67 ppm. It is possible that the powder picked up small additional quantities of sulfur from the rubber liner of the micronizer (less than $1 \%$ sulfur in rubber liner); however, it is clear that the presence of sulfur alone does not determine if idiomorphic grains are formed.' The sulfur must be reacted with $\mathrm{ThO}_{2}$ to form $\operatorname{Th}(0, S)_{2}$; sulfur contamination from rubber, unless first reacted with $\mathrm{ThO}_{2}$ ' would probably not be effective. The process appears intricate, requiring critical quantities of the liquid phase. The formation of idiomorphis grains. is a rarity. Idiomorphic grains have been observed in initial production pellets only when the thoria powder contained the calcio addition (100 ppm) and the hydrogen atmosphere was relatively dry. The gross idiomorphic grain. growth shown in Figure 42 for sample $4 \mathrm{AA}, 12$ hour $-1750^{\circ} \mathrm{C}$ sinter of the pellet fabricated from hydrogen-calcined powder, is attributed to the presence of sulfur; the true grain size prior to growth of the idiomorphic grains is estimated to be ASTM \#8 from the size of the matrix grains.

With this assumption, it would appear from the comparison of air-vs. hydrogen-calcined 096 powders sintered at. $1750^{\circ} \mathrm{C}$ for $1 \frac{1}{2}$ hours, below,

\section{Fowder Treatment}

Air Calcined

Hydrogen Calcined

Air Calcined, Double Micronized

Hydrogen Calcined, Dbl. Micro.

ASTM Center
Grain Size No.

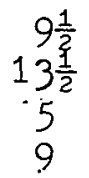

Figure

No.

35

41

35

41 
that both hydrogen and air calcining for 48 hours at $1100^{\circ} \mathrm{C}$ favor grain growth, but that the former is less effective than the latter for 096 powder. A similar trend is observed below for 096 powder air- and hydrogen-calcined and sintered for 12 hours at $1750^{\circ} \mathrm{C}$. A somewhat different picture is

\begin{tabular}{l} 
Powder Treatment \\
\hline Air Calcined \\
Hydrogen Calcined \\
Air Calcined, Double Micronized \\
Hydrogen Calcined, Dbl. Micro.
\end{tabular}

ASTM Center Grain Size No. 4. $8-0$

9
Figure

No.

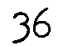

41

36

41

presented by the lot.136 powder (which contains approximately 4 ppm Ca).

\section{Lot 136 Powder}

\begin{tabular}{|c|c|c|c|c|}
\hline Powder Treatment & Sintering Condi & tion & $\begin{array}{r}\text { Grain } \\
\text { Size } \\
\end{array}$ & $\begin{array}{l}\text { Figure } \\
\text { No. }\end{array}$ \\
\hline $\begin{array}{l}\text { As-Received } \\
\text { As-Received + Micronized } \\
\mathrm{H}_{2} \text {-Calcined } \\
\mathrm{H}_{2} \text {-Calcined + Micronized } \\
\text { As-Received } \\
\text { As-Received + Micronized } \\
\mathrm{H}_{2} \text {-Calcined } \\
\mathrm{H}_{2}^{2} \text {-Calcined + Micronized }\end{array}$ & 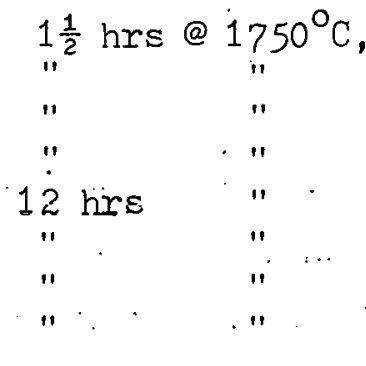 & $\begin{array}{r}\text { Dry } \mathrm{H}_{2} \\
\cdot \\
.\end{array}$ & $\begin{array}{c}<14 \\
13-14 \\
<14 \\
6-6.5 \\
13-14 \\
9.5-10 \cdot 5 \\
13-13.5 \\
4: 5-5:\end{array}$ & $\begin{array}{r}38 \\
" 1 " \\
43 \\
39 \\
39 \\
43\end{array}$ \\
\hline
\end{tabular}

Calcining the initial powder results in a definite increase in the center grain size of the sintered pellet, "in spite of the fact that the powder surface area and therefore the surface energy of the calcined powder is less than $75 \%$ of that of the as-received powder. It is probable that the beneficial effects of calcination (air or. hydrogen) on grain growth would be even more pronounced if the calcined and as-received powders were compared at the same particle size (or surface energy). Thus the pellets made from calcined-micronized 096 and 136 powder, surface area 5.82 and $5.91 \mathrm{~m}^{2} / \mathrm{gm}$, respectively, should be compared. with the pellets fabricated from the a.s-received 096 and 1.36 powder, surface area 8.24 and $5.55 \mathrm{~m}^{2} / \mathrm{gm}$, respectively. 
After $1 \frac{1}{2}$ hours at temperature the center grain size of the 096 and 136 calcined-micronized was 9 and 6-6.5, respectively; however, the same values for the as-received material were $<14$ and $<14$. After 12 hours at $1750^{\circ} \mathrm{C}$ the same comparison shows ASTM grain sizes of $8 \frac{1}{2}-9$ and $4.5-5$ for the micronized-calcined powder pellets and only 12 and 14, respectively, for the as-received powder pellets.

The ASTM grain size results for hydrogen-calcination are compared below with those for air-calcination. Thus for lot 136 powder, both

\section{Lot 136 Fowder}

\begin{tabular}{|c|c|c|c|}
\hline Powder Treatment & Sintering Condition & $\begin{array}{r}\Lambda \text { STM } \\
\text { Grain } \\
\text { Size } \\
\end{array}$ & $\begin{array}{l}\text { F'igure } \\
\text { No. } \\
\end{array}$ \\
\hline $\begin{array}{l}\text { Hydroger-Calciried } \\
\text { Hydrogen-Calc. + Micro. } \\
\text { Air-Calcined } \\
\text { Air-Calcined + Micro. } \\
\text { Hydrogen-Calcined. } \\
\text { Hydrogen-Calc. + Micro: } \\
\text { Air-Calcined } \\
\text { Air-Calcined + Micro. }\end{array}$ & 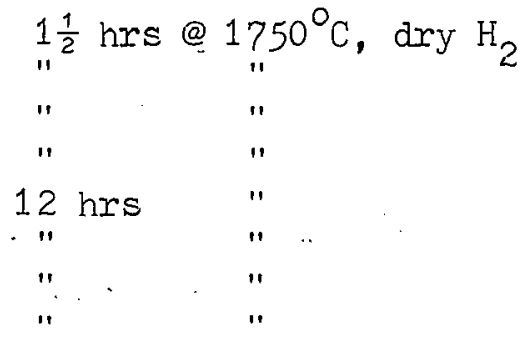 & $\begin{aligned} & 13 \\
& 6-6 \cdot 5 \\
&< 14 \\
&< 14 \\
& 13-13 \cdot 5 \\
& 4.5-5 \\
& 13-14 \\
& 6.5-10\end{aligned}$ & $\begin{array}{c}43 \\
" \\
38 \\
" 1 \\
43 \\
" 10 \\
39\end{array}$ \\
\hline
\end{tabular}

air and hydrogen calcining at $1100^{\circ} \mathrm{C}$ for 48 hours are effective in increasing grain growth over that noted with as-received powder, whereas hydrogen calcining appears to be somewhat more effective than air calcining for powder lot 136. These results made it clear that more attention must he given to the surface area of the powder since it determines the amount of surface energy available for densification and grain growth.

Examination of Figures: 41 and 43 and Figures 35,36 and 38, 39 reveals that, although hydrogen and air.calcining have improved grain growth characteristics of as-received $\mathrm{ThO}_{2}$ and binary powder samples, neither treatment has eliminated completely the grain size nonuniformity which is believed to demonstrate the effect of the presence of a grain growth inhibitor. Hence, whatever the identity or nature of the inhibitor, it has only been reduced. in level, but not eliminated, by $1100^{\circ} \mathrm{C}$ calcining. For this reason the experiments at higher calcining temperatures and those wi:th multiple micronizations have been performed. 
Some incidental observations were made in the course of examination of the pellets of Figures 41 and 43 which help to elucidate the relative roles of various factors which might affect sintered pellet grain size. It is apparent from earlier work that the carbon contents of the powders have increased upon double micronization. While undoubtedly most of this increase is attributable to the increased particle surface area for $\mathrm{CO}_{2}$ adsorption, part of the increase, up to $100-150 \mathrm{ppm} \mathrm{C}$, may be attributable to the inclusion in the powder of rubber from the micronizer liner, particularly since slow feed rates of 150 and $50 \mathrm{gm} / \mathrm{min}$ were used. It was noted upon examination of the micronized samples of Figures 41 and 43 that the centers of the pellets showed "necklace porosity", i.e. gas-filled pores at the grain boundaries, Figure 44. A thin rim ( 0.010-0.020 inch thick) at the pellet exterior and on the surface of pellet cracks was free of this type of porosity. It is believed that during heating of the pellets to sintering temperatures, the included carbonaceous gases from the rubber contaminant are released from a thin surface layer which sinters sufficiently to prevent the release of the rubber decomposition products from the remainder of the pellet. The entrapped rubber decomposes at sintering temperature and is concentrated at grain boundaries as gas-filled porosity as the advancing boundaries sweep up the pores. Note that this observation implies that gas-filled pores offer little obstacle to grain growth. Also observe in Figures $44 \mathrm{a}$ and $\mathrm{c}$ that the grain size in the areas with and without the porosity are the same. This further shows the negligible resistance offered by the gas-filled pores to grain growth.

\section{Slurry Agslomerated Procedure}

The procedure for fabricating the slurry agglomerated 0.53 inch diameter pellets from hydrogen-calcined 096 (100 ppm $\mathrm{Ca}$ ) and 136 (4 ppm. Ca) thoria powder was identical to the procedure used for the slurry agglomerated air-calcined powder. As a check on the reproducibility of the sintering cycle, duplicate pellets fabricated from the air-calcined powder were also included in the sintering boats. All pellets were evaluated in a similar fashion. 
WSPD-PM-I3II

\section{Slurry Agglomerated Results}

The green and sintered geometxic densities of the slurry agglomerated pellets are shown in Table 13. The sintered densities of the pellets fabricated from the hydrogen-calcined powder are greater than that observed for an air-calcined sample under equivalent conditions. The obvious reason for the density difference was the almost total absence of granular segregation in the pellets fabricated from the hydrogen-calcined powder. The greatest segregation reading on the scale of $1-7$ was 1 . The most characteristic microstructural feature of these samples was the presence of "necklace" porosity.

The sulfur content for the 096 and 136 powder was 45 ppm and $18 \mathrm{ppm}$, respectively, which is very similar to that recorded for the aircalcined pellets 37 and $23 \mathrm{ppm}$ and shows that sulfur is not readily removed at $1100^{\circ} \mathrm{C}$ in either a hydrogen or air atmosphere, Table 14.

The effect of sintering time on grain growth in 0.53 inch diameter pellets fabricated from hydrogen-calcined ( $1100^{\circ} \mathrm{C}-48$ hours) powder may be observed in Figures 45-48. As with the air-calcined powder, the surface area of the micronized hydrogen-calcined powder is considerably lower than that determined for the micronized-as-received powder. The surface areas of the micronized-as-received and micronized-hydrogen-calcined 096 powder are 10.28 and $5.82 \mathrm{~m} / \mathrm{gm}$, respectively. "The same numbers for the 136 powder are 8.1 and $5.91 \mathrm{~m}^{2} / \mathrm{gm}$. These differences coupled with the granular segregation and possible exposure of the interior of the as-received pellets to the sintering atmosphere make a direct comparison between the calcined and asreceived pellets (Figures 45 and $A-1,46$ and $A-3,47$ and $A-5,48$ and $A-7$ ) very difficult. Nevertheless, at the higher green densities the grain sizes of the pellets prepared from the calcined powders compare rather favorably, even though the particle surface energy is between $2 / 3$ and $1 / 2$ that available. in the pellets pressed from the as-received-micronized 136 and 096 powders. Pellets fabricated from micronized $\mathrm{H}_{2}$ calcined 096 and 136 powder with surface areas of 5.82 and $5.91 \mathrm{~m}^{2} / \mathrm{gm}$ respectively, pressed to $61 \%$ green density had a center ASTM grain size of 8 and $5 \frac{1}{2}$ after 12 hours at $1750^{\circ} \mathrm{C}$. The similar values for the micronized-as-received pellets were only $8 \frac{1}{2}$ and 9 although their surface areas were much greater, 10.28 and $8.1 \mathrm{~m}^{2} / \mathrm{gm}$ respectively. 
Due to the particle size difference (surface area), the data obtained from the agglomerated powder, Figures 46 and 48, were compared to the pellets made from the binderless as-received powder, Figures 35,36 and 38 and 39. The consistency of results was better than previously observed for the air-calcined powder although some differences were observed. The pellets made from the slurry-agglomerated micronized $\mathrm{H}_{2}$-calcined 136 powder had an ASTM grain size of only 13.5 after $1 \frac{1}{2}$ hours at $1750^{\circ} \mathrm{C}$; however the binderless pellets made from the same material and sintered for the same length of time had an ASTM grain size of 6.5. After 12 hours at temperature the respective grain sizes were 5.5 and 5 , respectively, and is considered excellent agreement. The grain size of the pellets made from 096 powder generally were in good agreement regardless of the time at temperature or whether or not a binder was used in the fabrication process. In all cases except where idiomorphic grains were detected, the pellets made from micronized-calcined powder showed greater grain growth than those made directly from as-caleined powder. In addition, the grain growth observed in the pellets fabricated from the: hydrogen-calcined powders, 096 and 136, had, in all cases, greater grain growth than the pellets fabricated from as-received or micronized-as-received powder, as shown below.

Comparison of Grain Growth in Dry Pressed Pellets Fabricated From As-Received 096 and 136 Powder With Slurry-Agglomerated Pellets Fabricated From Hydrogen Calcined 096 and 136 Powder

\begin{tabular}{|c|c|c|c|c|c|c|c|}
\hline $\begin{array}{l}\text { Pellet } \\
\text { ID } \\
\end{array}$ & $\begin{array}{l}\text { Powder } \\
\text { Lot } \\
\end{array}$ & Powder Treatment & $\begin{array}{l}\text { F1g. } \\
\text { No. }\end{array}$ & $\begin{array}{c}\text { Sinter- } \\
\text { ing } \\
\text { T1me } \\
\text { (hrs) } \\
\end{array}$ & $\begin{array}{l}\text { Surface } \\
\text { Area } \\
\left(\mathrm{m}^{2} / \mathrm{gm}\right)\end{array}$ & $\begin{array}{l}\text { Density } \\
\text { (gm/cc) } \\
\text { Inc. } \\
\text { Open } \\
\text { Pores } \\
\end{array}$ & $\begin{array}{l}\text { ASTM } \\
\text { Center } \\
\text { Grain } \\
\text { Size } \\
\text { No. } \\
\end{array}$ \\
\hline $3 T$ & 096 & As-Rec'd., Dry Press. & 35 & $1 \frac{1}{2}$ & 8.24 & 9.56 & $<14$ \\
\hline $8-61$ & 096 & $\begin{array}{l}\text { Micronized-Hydrogen } \\
\text { Calcined, Slurry Agg. }\end{array}$ & 46 & $1 \frac{1}{2}$ & 5.82 & 9.64 & 9 \\
\hline $\begin{array}{l}55 \\
5-61\end{array}$ & $\begin{array}{l}136 \\
136\end{array}$ & $\begin{array}{l}\text { As-Rec'd., Dry Press. } \\
\text { Micronized-Hydrogen } \\
\text { Calcined, Slurry Agg. }\end{array}$ & $\begin{array}{l}38 \\
48\end{array}$ & $\begin{array}{l}1 \frac{1}{2} \\
1 \frac{1}{2}\end{array}$ & $\begin{array}{l}5.35 \\
5.91\end{array}$ & $\begin{array}{l}9.36 \\
9.64\end{array}$ & $\begin{aligned}< & 14 \\
& 13 \frac{1}{2}\end{aligned}$ \\
\hline $4 \mathrm{H}$ & 096 & As-Rec'd., Dry Press. & 36 & 12 & 8.24 & 9.72 & 12 \\
\hline $10-61$ & 096 & $\begin{array}{l}\text { Micronized-Hydrogen } \\
\text { Calcined, Slumry Agg. }\end{array}$ & 46 & 12 & 5.82 & 9.68 & 8 \\
\hline $\begin{array}{l}2 \mathrm{G} \\
2-61\end{array}$ & $\begin{array}{l}136 \\
136\end{array}$ & $\begin{array}{l}\text { As-Rec'd., Dry Press. } \\
\text { Micronized-Hydrogen } \\
\text { Calcined, Slurry Agg. }\end{array}$ & $\begin{array}{l}39 \\
48\end{array}$ & $\begin{array}{l}12 \\
12\end{array}$ & $\begin{array}{l}5.55 \\
5.82\end{array}$ & $\begin{array}{l}9.65 \\
9.70\end{array}$ & $\begin{array}{r}14 \\
\ldots \quad 5.5\end{array}$ \\
\hline
\end{tabular}


The granular segregation in the hydrogen-calcined, slurryagglomerated peliets was much lower than that previously observed for the aircalcined, slurry-agglomerated pellets. Therefore, the confusion in the former caused by atmospheric interactions at the granule boundaries is avoided in the latter. As a consequence, the agreement between the results of pellets with and without binders is much better for the hydrogen-calcined material.

\section{All things being equal, it is difficult to determine which} calcining atmosphere is the most effective with all powders. The aix-calcined appeared more effective with the 096 powder; however, the hydrogen-calcined powder was possibly more effective in promoting grain growth in the 136 powder. Variations in green pellet properties, as well as variations in powder surface area, mask the slight dif'ferences between pellets promoted by the calcining atmosphere.

Like the pellets fabricated from air-calcined powder, the time dependency of grain growth did not follow any mathematical expression which modeled a specific mechanism. Generally the center grain size of the pellet increased with increasing time at temperature. In addition, the observed fluctuation in grain size between the pellet center and the exterior was similar to that previously noted for the air-calcined pellet samples. This effect, which is attributed to impurity removal by reaction with the atmosphere at the pellet surface, or possibly, the additional grain boundary mobility provided by the sintering atmosphere, is consistent with the conclusion of existence of an impurity phase. The effect is greatest for the lower green density and the shorter sintering times. Unlike the dry pressed pellet fabricated from 096 powder, hydrogen calcined, pressed to approximately $6.0 \mathrm{gm} / \mathrm{cc}$ and sintered at $1730^{\circ} \mathrm{C}$ tor $12 \mathrm{~L}$ hours, the slurry agglomerated equivalent did not show any idiomorphic grains.

The ef'ect of compacted green density on grain growth in pellets fabricated from slumry-agglomerated $1100^{\circ} \mathrm{C}-48$ hour- $\mathrm{H}_{2}$ (dry) calcined-micronized powder is shown in Figures 49 and 50.

The data presented in Figure 49 for thoria powder lot 096 (micronized) does not lead to any consistent trend between compaction density and grain growth. The ASTM center grain size of the pellets compacted to the 
four lowest green densities, $5.60,5.71,5.95$, and $6.18 \mathrm{gm} / \mathrm{cc}$, was $13.5,12$, 8.5, and 8, respectively. These results show the same trend observed with the pellets fabricated from the air-calcined powder in that the grain size increased regularly with increased density. What is not consistent with previous results is that the ASTM center grain size of the pellets compacted to a green density of 6.34 and $6.63 \mathrm{gm} / \mathrm{cc}$ decreased to 10 (11 $\mu$ diameter) and 11 ( $8 \mu$ diameter), respectively. The sintered densities of these samples also do not follow any consistent trend with grain size. In order of decreasing grain size the geometric densities were measured as $9.678,9.714,9.635,9.519,9.694$, and $9.638 \mathrm{gm} / \mathrm{cc}$.

Sintered in the same boat at the same time as the previous pellets were blanket pellets pressed from micronized 136 powder which had been calcined at $1100^{\circ} \mathrm{C}-48$ hours in $\mathrm{H}_{2}(\mathrm{dry})$, Figure 50. Although somewhat irregular, the grain size increases with green density... The grain size increased from $<$ ASTM \#14 (2.8 $\mu)$ to ASTM \#5 $(6 \mu)$ as the green density increased from 5.58 $\mathrm{gm} / \mathrm{cc}$ to $6.64 \mathrm{gm} / \mathrm{cc}$. With the exception of the sample compacted at $6.64 \mathrm{gm} / \mathrm{cc}$ which had a longitudinal crack that decreased the geometric density but did not have a significant effect on the grain growth in the center of the pellet, the fired density of these samples also increased from 9.512 to $9.743 \mathrm{gm} / \mathrm{cc}$, with increased grain size.

As a check on the reproducibility of the sintering cycie a limited number of pellets fabricated from powder lots 096 and 136 micronized-air calcined and micronized-as-received were sintered along with the pellets fabricated from the hydrogen-calcined powder, Table 13. The grain size as a function of pellet cross section was plotted for the replica pellets fabricated from micronizedas-received 096 powder, Figure 51. The grain size data of Figure 51 was compared with the data obtained from identical pellets sintered with the micronized-aircalcined powder pellets, Figure A-9. In Figure 51 the pellets with green densities of $5.98,6.38,6.52$, and $5.67 \mathrm{gm} / \mathrm{cc}$ had sintered center ASTM grain sizes of $11,1.0,9.5$, and 8, respectively. In Figure A-9 pellets of similar green densities had grain sizes of $11,9,8 \frac{1}{2}$, and 7 , respectively. The agreement is relatively good arid the trends in grain size as a function of green density are almost identical, indicating the sintering cycles were very similar. 
Based on the grain size results obtained from pellets fabricated from $1100^{\circ} \mathrm{C}-48$ hour air or dry hydrogen-calcined powders, the following relationships were drawn:

1) Calcining the $\mathrm{ThO}_{2}$ prior to pellet fabrication improved grain growth. The method by which calcining improved the grain growth was postulated to be the result of the removal (most probably by: volatilization) of a grain growth inhibiting impurity. The removal of all or part of the impurity phase eliminated or . reduced secondary grain growth, thereby promoting a unifurlll grain structure less susceptible to variations resulting from small changes in sintering time or temperature.

2) The surface area of the starting powder had a large effect on the grain growth in the final pellet. The greater the surface area of the powder, the greater the surface entrgy of the powder.

3) The beneficial effect of calcining on grain growth was difficult to measure quantitatively since the calcining process decreased the surface area of the starting powder; the micronizstion process $(150-50 \mathrm{gm} / \mathrm{min})$ being used was not effective in increasing the calcined suriece aree ali tne wey oeck to the stariag size...

4) Cremiation (siurry mix process with i.75 w/o Carbowax 6000) afiected the grein growtin kinetics and the pellet microstructure of air-calcined powders. The greis yruwtin observed in pellets proccsscd from the air-celicined sterting powder with the edatilun ur $1.75 \mathrm{w} / \mathrm{o}$ Carocwex, gxanulction; ina co? pretreatrent has resulted in pellets with significantly aifierent pinel srain sizes ther in pellets presed from the ssme powiers with no orgenic adoitives crain sizes were usuelly coersen for the former process but jometimes were. finer. Graniler segregstion resultirg from intregrenuler sintering was observed ir most ot the peilets feoricated from grenulated $1100^{\circ} \mathrm{C}-a$ ir calcined powaer, but not with peilets feoricated pror the same powèr which hed not been grenulated. The granular segregation was so extensive tist tre peilet densirication was reauced ard therefore the epolicejility of resuis from these specimens is questoneble. 
5) Normal kinetic expressions for pore-limited grain growth,

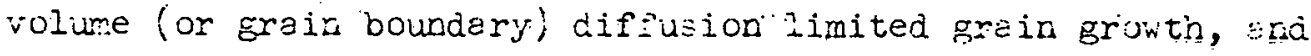
impurity limited, grain growth were inadequate to explain the pellet center grain growth characteristics.

6) The effects of the calcining atmosphere and the powder CaO content were secondary to those of surface area, green density. and exposure to calcination.

7) With the exception of those pellets with extensive granular segregation and open porosity, the pellet center grain size generally increased with increasing green density:

8) The air calcine may have been more effective in removing the grain growth impurities from 096 powder (contains approximately $100 \mathrm{ppm}(\mathrm{CaO})$, while the hydrogen calc̣ine wạs more effective in removing the inhibiting impurities from the 136 powder (approximately $2=4$ ppm CaO) as determined by grain size measurements on the sintered pellet.

C. Hydrogen-Calcined Powder $=1200$ and $1400^{\circ} \mathrm{C}$

It was observed in pellets prepared from both $1100^{\circ} \mathrm{C}$ air- and hydrogen-calcined powder that the center grain size was initially smaller and, with time, became larger than those grains near the:pellet surface where reaction with the sintering atmosphëre allowed growth to procèd without impurity inhibition: . It was therefore concluded that the $1100^{\circ} \mathrm{C}$ calcine was". inadequate to remove all of the inhibiting impurity. The inadequacy or lack'of" complete removal of the inhibiting impurities is not altogether surprising in view of the fact that the 096 and 136 powders were subjected to a purification calcination, only $118^{\circ} \mathrm{C}$ and $48^{\circ} \mathrm{C}$, respectively, above the calcination temperature (982 and $1032^{\circ} \mathrm{C}$ ) of the as-received powder at the vendor. Calcination temperatures of $1200^{\circ} \mathrm{C}$ and $1400^{\circ} \mathrm{C}$ were therefore evaluated on the basis that the higher temperatures mignt volatilize more of the inhibiting impurities. The times of 8 and 24 hours for the $1200^{\circ} \mathrm{C}$ calcine and 3 and 9 hours for the $1400^{\circ} \mathrm{C}$ calcine were selected based on the capacity of the production furnace and on the resultant powder surface area. Powder lot 136 was chosen so that the results of the calcination would not be confounded by the presence of the 
100 ppm CaO. Partial chemical analyses of the calcined powder, Ref. 44 , indicated that even the sulfur content was reduced to $10 \mathrm{ppm}$ or less.

In an effort to normalize the surface area effect, the calcined powder (surface area after calcining for $1200^{\circ} \mathrm{C}-8,1200^{\circ} \mathrm{C}-24,1400^{\circ} \mathrm{C}-3$, and $1400^{\circ} \mathrm{C}-9$ hours was $3.4,2.9,2.5$, and $2.0 \mathrm{~m}^{2} / \mathrm{gm}$, respectively) was subjected to :multi-micronizations. Based on the earlier results, an expression, $S=A 10^{B / T}$, relating surface area, $S$, and absolute calcining temperature, $T$, was used to predict that 5 and 6 passes through the micronizer would be required for the $1200^{\circ} \mathrm{C}$ ( 8 and 24 hours) and $1400^{\circ} \mathrm{C}$ ( 3 and 9 hours) calcire, respectively. The resultant surface areas of the 136 powder $1200^{\circ} \mathrm{C}, 8$ and 24 hour calcine after 5-pass micronization was 5.2 and $4.3 \mathrm{~m}^{2} / \mathrm{gm}$, respectively. The resultant surface area of the 136 powder $1400^{\circ} \mathrm{C}, 3$ and 9 hour calcine after 6-pass micronization was 4.4 and $3.3 \mathrm{~m}^{2} / \mathrm{gm}$; respectively. It became obvious that the previous equation did not accurately predict the effect of micronization. The surface area increased very little as a result of the additional passes through the micronizer. The effect of decreased surface area upon calcining was not neutralized by the additional micronization: The additional micronization did increase the carbon impurity levels from less than 50 ppm after calcination to almost $100 \mathrm{ppm}$ (this excludes carbon adsorbed as $\mathrm{CO}_{2}$ ), Ref. 44.

The calcined powder was used without any binder additions to press . blanket size pellets as described previously. As a control, pellets fabricated from double micronized, as-received 136 powder, surface area $8.1 \mathrm{~m}^{2} / \mathrm{gm}$ were also sintered with the pellets fabricated from the calcined powders.

1. Dry Pressed Results -1200 and $1400^{\circ} \mathrm{C}$

The green and sintexed densities of the pellets fabricated from the 1200 and $1400^{\circ} \mathrm{C}$ calcined powder are tabulated in Table 13. Since no dry Sterotex lubricant was used, the density values are approximately $1 \%$ higher than would have been obtained by typical production processing. Nevertheless, the densities were quite high and were representative of a good high density microstructure.

The grain growth results of the longitudinally sectioned samples are shown in Figures 52 and 53. The center grain size of all the pellets 
sintered at $1750^{\circ} \mathrm{C}$ for $1 \frac{1}{2}$ hours, Figure 52, regardless of calcining treatment, was smaller than that at the pellet surface. The center ASTM grain size of the pellet fabricated from the double micronized, as-received powder, surface area = $8.1 \mathrm{~m}^{2} / \mathrm{gm}$, and the pellet fabricated from the $1200^{\circ} \mathrm{C}-8$ hour $-\mathrm{H}_{2}$ calcined 5 -pass powder, surface area $=5.1 \mathrm{~m}^{2} / \mathrm{gm}$, was approximately the same at 13 . All of the other pellets had center grain sizes of ASTM \#14 or smaller. The grain size results of the as-received pellet agreed very well with the ASTM \#13.5 grain size obtained from a similar pellet sintered for the same time and temperature, Figure 37, showing that the sintering process is reproducible. The similarity in initial grain growth between the $1200^{\circ} \mathrm{C}-8$ hour calcined powder pellet and the micronized-as-received powder pellet in spite of their respective powder surface areas indicated that calcining at $1200^{\circ} \mathrm{C}-8$. hours may have removed more impurities.

The grain size as a function of pellet cross section for pellets fabricated from the same binderless, multimicronized powders and sintered at $1750^{\circ} \mathrm{C}$ for 12 hours in dry hydrogen is shown in Figure 53. The center ASTM grain size of the pellet along with the powder treatment and the resulting surface area is shown below.

Grain Size of Pellets Dry Pressed From Calcined Multipass Micronized Powder Lot 136

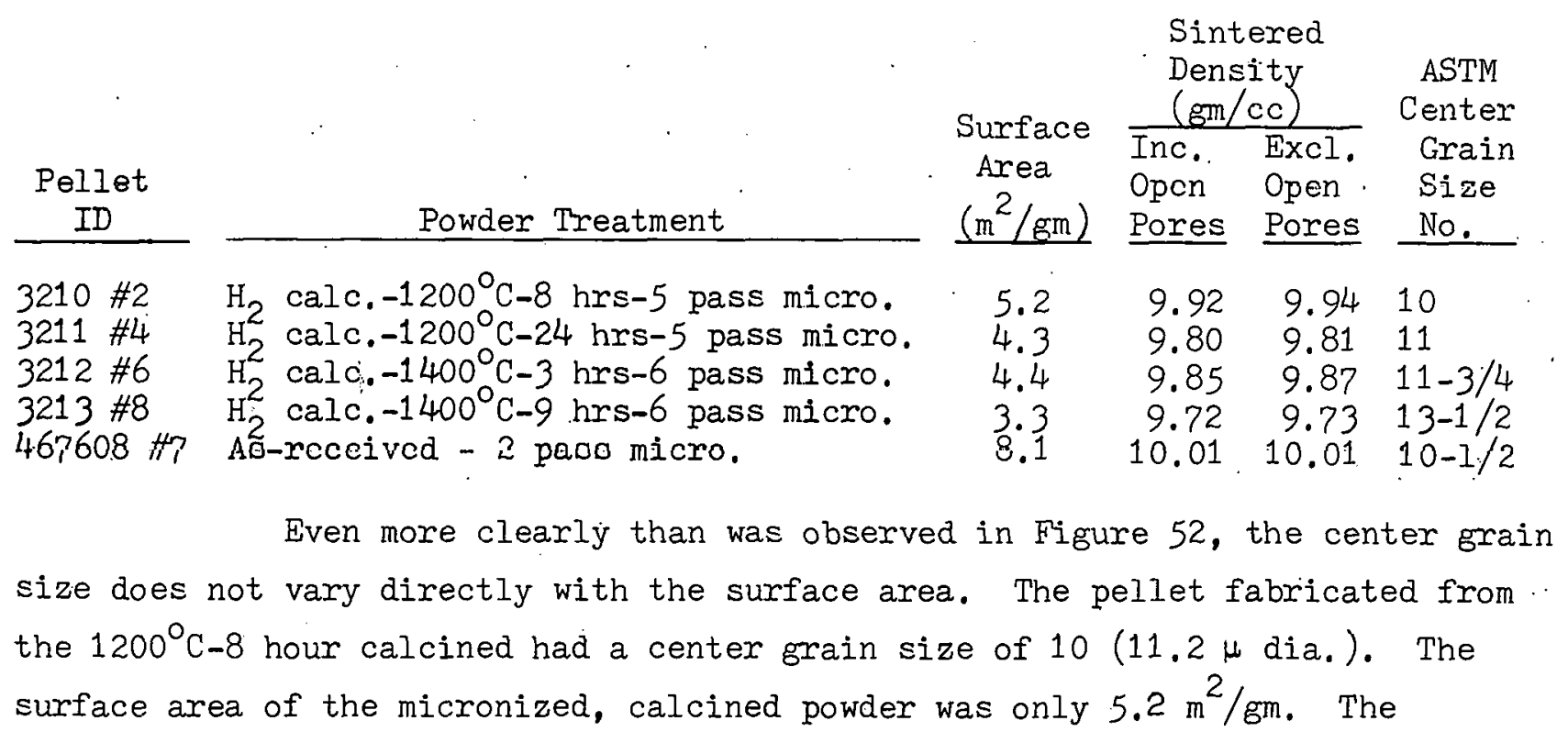


surface area of the micronized, as-received powder was $8.1 \cdot \mathrm{m}^{2} / \mathrm{gm}$, approximately 1.6 times greater, but the center grain size of the pellet fabricated from this powder was only $10.5(9.4 \mu)$, a value which agrees very well with previous results, ASTM \#10, Figure 39.

These results show thet percmeters ctrer then the surface area if trie powier and consequently the surface energy necesüry for densification infiuence grein growtr. The penalty accompenying the higher tempereture purificstion calcination is a reduced surface area winich is not readily increased by aditional micronizations.

Eecause of the counteracting effects of celcining on decreasing particle surtece area, winich reduces grein growth, end cn impurity removal, which increases grain growtin, the effects of calcining temperature and time et timpersture axe not atreightforwera. Thus the effect of increesec culcining time at trese eievated terrperatures is considered to have reduced Erain size in the sintered pellet because of particle densificaticr resulting in reduced surface area, even though more effective impurity removil would be expected. On the other hand, the eplect of impurity removai, is considered to have predomincted upon raisine the tempersture to $1400^{\circ} \mathrm{C}$ for three hours, compared to the caicinetion at $1200^{\circ} \mathrm{C}$ for twenty-folir rours.

\section{Dry Pressed and Pretreated Results $-1200^{\circ}$ and $1400^{\circ} \mathrm{C}$}

Since necklace porosity was observed in some of the pellets produced from $1100^{\circ} \mathrm{C}-48$ hour calcined powder, Figure 44 , as well as in the previous calcined samples, a number of the pellets fabricated from the 1200 and $1400^{\circ} \mathrm{C}$ calcined powder were pretreated at $925^{\circ} \mathrm{C}$ in $\mathrm{CO}_{2}$ prior to sintering, even though the pellet was fabricated without the addition of binder and lubricant in an effort to remove any possible gas forming impurities. Pel. Iets dry pressed to $60 \%$ green density from the four different calcined powders $\left(1200^{\circ} \mathrm{C}-8\right.$ and 24 hours and $1400^{\circ} \mathrm{C}-3$ and 9 hours) as well as pellets fabricated from as-received double micronized 136 powder were preheated in flowing $\mathrm{CO}_{2}$ for 3 hours, After pretreatment the pellets were sintered at $1750^{\circ} \mathrm{C}$ in $\mathrm{dry}$ ( $53^{\circ} \mathrm{F}$ dew point) hydrogen for $1 \frac{1}{2}$ and 12 hours. The green and sintered densities are tabulated in Tảbie 13. It was anticipated that the pretreatment would remove the cause 
of the necklace porosity thereby increasing the density. However, many of the sintered pretreated pellets were of a slightly lower final density than the identical peliets without the pretreatment. The difference may have been the result of a slight variation in the maximum temperature because the control sample for the pretreated batch of pellets is also less dense than an identical control sample in the nonpretreated pellets as shown below.

Density Variations in. Pretreated and Nonpretreated Pellets Fabricated From 1200 and $1400^{\circ} \mathrm{C}$ Micronized-Calcined 136 Powder

\begin{tabular}{|c|c|c|c|c|c|}
\hline & & Sint & red Des & sity ( & $\mathrm{m} / \mathrm{cc})$ \\
\hline$\cdots$ & . & $\begin{array}{r}\text { Pret: } \\
\text { Pel }\end{array}$ & $\begin{array}{l}\text { eated } \\
\text { ets }\end{array}$ & $\begin{array}{r}\mathrm{N} \\
\text { Pret: } \\
\text { Pel }\end{array}$ & $\begin{array}{l}\text { t } \\
\text { ea.ted } \\
\text { ets }\end{array}$ \\
\hline Powder Treatment & $\begin{array}{c}\text { Sintering } \\
\text { Time } \\
\text { (hrs) }\end{array}$ & $\begin{array}{l}\text { Inc. } \\
\text { Open } \\
\text { Pores } \\
\end{array}$ & $\begin{array}{l}\text { Excl. } \\
\text { Open } \\
\text { Pores } \\
\end{array}$ & $\begin{array}{l}\text { Inc. } \\
\text { Open } \\
\text { Pores } \\
\end{array}$ & $\begin{array}{l}\text { Excl. } \\
\text { Open } \\
\text { Pores } \\
\end{array}$ \\
\hline 2 calc. $1200^{\circ} \mathrm{C} / 8 \mathrm{hrs}+.5$ pass micro. & $12^{1.5}$ & $\begin{array}{l}9.69 \\
9.88\end{array}$ & $\begin{array}{l}9.70 \\
9.91\end{array}$ & $\begin{array}{l}9.77 \\
9.92\end{array}$ & $\begin{array}{l}9.78 \\
9.94\end{array}$ \\
\hline $\mathrm{H}_{2}$ calc. $1200^{\circ} \mathrm{C} / 24 \mathrm{hrs}+5$ pass micro. & $12 \cdot 5$ & $\begin{array}{l}9.46 \\
9.73\end{array}$ & $\begin{array}{l}9.48 \\
9.76\end{array}$ & $\begin{array}{l}9.43 \\
9.80\end{array}$ & $\begin{array}{l}9.46 \\
9.81\end{array}$ \\
\hline 2 calc. $1400 / 3$ hrs +6 pass micro. & $12 \cdot 5$ & 9.79 & 9.80 & $\begin{array}{l}9.56 \\
9.85\end{array}$ & $\begin{array}{l}9.57 \\
9.87\end{array}$ \\
\hline $\mathrm{I}_{2}$ calc. $1400 / 9 \mathrm{hre}+6$ pass micro. & $12 \cdot 5$ & $\begin{array}{l}9.50 \\
9.72\end{array}$ & $\begin{array}{l}9.53 \\
9.73\end{array}$ & $\begin{array}{l}9.32 \\
9.72\end{array}$ & $\begin{array}{l}9.32 \\
9.73\end{array}$ \\
\hline As-received + double micronizatio & $12 \cdot 5$ & $\begin{array}{l}9.89 \\
9.96\end{array}$ & $\begin{array}{l}9.89 \\
9.96\end{array}$ & $\begin{array}{r}9.88 \\
10.01\end{array}$ & $\begin{array}{r}9.89 \\
10.01\end{array}$ \\
\hline
\end{tabular}

Like the nonpretreated samples after $1 \frac{1}{2}$ hours at $1750^{\circ} \mathrm{C}$, the control pellet made from the as-received double micronized powder showed a greater center grain size than any of the pretreated calcined pellets, Figure 54. This result was anticipated since the surface area of the as-received double micronized powder was almost twice as great as any of the other powders used in the experiment. The very fine particles would have a greater surface energy. Rapid growth during the initial stages of sintering would proceed until the grains coarsened so that the concentration of impurities at the grain boundary increased to the point that it effectively. inhibited additional growth. 
Atter 12 hours at $1750^{\circ} \mathrm{C}$, Figure 55, the center grain size of the pellet fabricated from as-received powder, surface area $8.1 \mathrm{~m}^{2} / \mathrm{gm}$, and the pellet fabricated from the $1200^{\circ} \mathrm{C}-8$ hour calcined powder, surface area $5.2 \mathrm{~m}^{2} / \mathrm{gm}$, were almost identical in spite of the large differences in surface area of the respective powders. Interestingly, the pellet fabricated from the $1400^{\circ} \mathrm{C}-9$ hour powder which had a surface area of only $3.3 \mathrm{~m}^{2} / \mathrm{gm}$, showed the widest band of coarse grains around the pellet exterior. Being the pellet with probably the purest starting powder but the coarsest particle size, it might be postulated that the elimination of porosity along the grain boundaries starts at the pellet surface and proceeds toward the pellet interior. Since the $1400^{\circ} \mathrm{C}-9$ hour is the least inhibited, it has the greatest grain boundary mobility. . Therefore in the time available betore the pellet surtace becomes highly dense, porosity is eliminated and grains grow. Because of the high powder purity this process is more extensive in the high temperature calcined powders. However, because the higher tempexature calcined powder has a much lower surface area (denser particles), the driving force for initial stages of sintering is significantly reduced. Therefore the center grain size remains smaller even though the exterior of the pellet showed significant grain growth. It is therefore probable that additional time at temperature and/or increased temperature would have resulted in the coarse exterior grains extending across the entire pollot croec ecction.

A comparison of the center grain size of the pretreated and nonpretreated pellets fabricated from the multipass $\mathrm{H}_{2}$-calcined 1200 and $1400^{\circ} \mathrm{C}, 136$ powdex is shown on page 93.

It is clear that the pellet pretreatment did not result in large grains. Since the as-received double micronized control pellet also showed a reduced graiin size (larger ASTM grain size number), it is highly probable that a slightly reduced sintering temperature is the cause for the reduced ultimate grain size.

An examination of the resulting microstructure showed that the $925^{\circ} \mathrm{C} \mathrm{CO}_{2}$ pretreatment did not eliminate the formation of necklace porosity. The presence of the necklace porosity is not attributable to a slightly reduced sintering temperature. If the pores were the result of oxidation of carbonaceous impurities forming $C O$ gas which was trapped in pores during densification and 
Grain Size Variations in Pretreated and Nonpretreated :

Hydrogen Calcined 1200 and $1400^{\circ} \mathrm{C}$ Dry Pressed Pellets

\begin{tabular}{|c|c|c|c|c|c|c|}
\hline 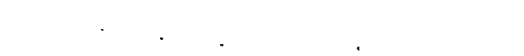 & & Sintering & Center & ASTM & rain Size No. & \\
\hline Powder Treatment & & $\begin{array}{l}\text { Time } \\
\text { (hrs) }\end{array}$ & Pretreated & $\begin{array}{l}\text { Fig. } \\
\text { No. }\end{array}$ & $\begin{array}{c}\text { Not } \\
\text { Pretreated }\end{array}$ & $\begin{array}{l}\text { Fig. } \\
\text { No. }\end{array}$ \\
\hline $\begin{array}{l}\mathrm{H}_{2} \text { calc. } 1200^{\circ} \mathrm{C} / 8 \mathrm{hrs}+ \\
5 \text { pass micro. }\end{array}$ & & $12 \cdot 5$ & $\begin{array}{l}<14 \\
11-1 / 2\end{array}$ & $\begin{array}{l}54 \\
55\end{array}$ & $\begin{array}{l}12-1 / 2 \\
10\end{array}$ & $\begin{array}{l}52 \\
53\end{array}$ \\
\hline${ }^{\mathrm{H}_{2} \text { calc. } 1200^{\circ} \mathrm{C} / 24 \text { hrs }+}$ & & $12^{2.5}$ & $\begin{aligned}< & 14 \\
& 13-1 / 2\end{aligned}$ & $\begin{array}{l}54 \\
55\end{array}$ & $\begin{aligned}< & 14 \\
& 11-3 / 4\end{aligned}$ & $\begin{array}{l}52 \\
53\end{array}$ \\
\hline $\begin{array}{l}\mathrm{H}_{2} \text { calc. } 1400^{\circ} \mathrm{C} / 3 \mathrm{hrs}+ \\
6 \text { pass micro. } \because\end{array}$ & . & $12^{1 \cdot 5}$ & $\begin{aligned} &< 14 \\
& 13-1 / 2\end{aligned}$ & $\begin{array}{l}54 \\
55\end{array}$ & $\begin{array}{l}13-1 / 2 \\
11\end{array}$ & $\begin{array}{l}52 \\
53\end{array}$ \\
\hline $\begin{array}{l}\mathrm{H}_{2} \text { calc. } 1400^{\circ} \mathrm{C} / 9 \mathrm{hrs}+ \\
6 \text { pass micro. }\end{array}$ & & $12 \cdot 5$ & $\begin{array}{l}<14 \\
<14\end{array}$ & $\begin{array}{l}54 \\
55\end{array}$ & $\begin{aligned}< & 14 \\
& 13-1 / 2\end{aligned}$ & $\begin{array}{l}52 \\
53\end{array}$ \\
\hline $\begin{array}{l}\text { As }- \text { received }+ \\
\text { double micronization }\end{array}$ &.. & $12 \cdot 5$ & $\begin{array}{l}13 \\
11-1 / 2\end{array}$ & $\begin{array}{l}54 \\
55\end{array}$ & $\begin{array}{l}12-1 / 2 \\
10-1 / 2\end{array}$ & $\begin{array}{l}52 \\
53\end{array}$ \\
\hline
\end{tabular}

grain growth, it is not clear why the $\mathrm{CO}_{2}$ pretreatment did not eliminate their formation. It may be that the instrument grade $\mathrm{CO}_{2}\left(10-15 \mathrm{ppm}_{2}\right)$ was too pure and did not effectively remove the carbon during pretreatment. Another possible explanation is that the necklace porosity is the result of entrapment of adsorbed $\mathrm{CO}_{2}$ within the particle pores; the $\mathrm{CO}_{2}$ from this source is much greater than that from carbonaceous impurities from the micronizer. In agreement with the latter, the necklace porosity was more apparent in the pellets made from the powder calcined at $1200^{\circ} \mathrm{C}$ for 8 hours and micronized ( 5 pass) with a surface area of $5.1 \mathrm{~m}^{2} / \mathrm{gm}$ than it was in the pellets made from powder calcined at $1400^{\circ} \mathrm{C}$. for 9 hours and micronized (6 pass) with a surface area of $3.3 \mathrm{~m}^{2} / \mathrm{gm}$. However, because grain growth is more extensive in the pellets fabricated from the $1200^{\circ} \mathrm{C}-8$ hour $-\mathrm{H}_{2}$ calcined powder, a greater amount of the porosity in the pellet would be swept to the grain boundaries, thereby resulting in more necklace porosity but a constant total porosity. Finally, it is possible that the necklace porosity is not the result of the decomposition of a carbonaceous material and the $\mathrm{CO}_{2}$ atmosphere is therefore ineffective in removing the gas-forming impurity. These results indicate that if other experimenters did further evaluations of $\mathrm{ThO}_{2}$ pellet sintering and grain growth behavior, it may be desirable to determine the quantity and aature of the atmosphere trapped within the pores of even the very high density pellets. 
WPL-TI:-1311

Certainly from a comparisor of the grain growtr between the pellet bedir. where necklace porosity is extensive and the area withir 0.10 inch or the pellet exterion where there does not apper to be mucn porosity of eny inind, one would have to conclude that the porosity does not irriuerce grain growth in any way. Nevertheless, knowledge of the type and gustity or ges in the pores roay well provide an improved insignt into the exect roie of impuritie: a : intering end greir growth kinetics in Tho,

\section{L/S Agglomerated Results -1200 and $1400^{\circ} \mathrm{C}$}

Granulation of the starting powder hy the liquid/solids frocess represents a duplication of a production process. It has been established that beneficial results were obtained by calcining the starting powder. However, it was also shown $\left(1100^{\circ} \mathrm{C}\right.$ air-calcined material) that the granulation method has a significant influence on the final sintered properties. To determine if the method of powder granulation used by the production facility was capable of using calcined powder and to determine if the multi-micronizations of the 1200 and $1400^{\circ} \mathrm{C}$ calcines were beneficial, 0.53 inch diameter pellets were pressed using 136 powder agglomerated by the L/S process from powder calcined at $1200^{\circ} \mathrm{C}-$ 8 hour $-\mathrm{H}_{2}(\mathrm{dry})$ and $1400^{\circ} \mathrm{C}-3$ hour $-\mathrm{H}_{2}$ (ary). The calcined powder used in these studies was micronized twice at the rate of $350 \mathrm{gm} / \mathrm{min}$ both before and after calcination. The powder is coarser (less surface energy) than that produced by an equivalent calcination but subjected to the multi-nass misconizatiinn. Pal- , lets fabricated from the $1200^{\circ} \mathrm{C}-8$ hour powder were pressed at 60 and $62 \%$ green density and pellets from the $1400^{\circ} \mathrm{C}-3$ hour powder were pressed at 60 and $65 \%$. green density. Grain sizes as a function of pellet cross section for the preceding four conditions are shown in Figures 56-59, respectively. In addition to the "dry" hydrogen $\left(53^{\circ} \mathrm{F}\right.$ dew point as measured in the furnace hot zone) results, a limited amount of data is included from identical pellets which were sintered in the production facility in a "wet" $\left(110^{\circ} \mathrm{F}\right.$ dew point as measured in the incoming hydrogen) hydrogen atmosphere.

The grain size across the center diameter of the pellets sintered in the latter atmosphere is larger and more uniform than that of an identical pellet sintered in the former atmosphere for the same length of time. This 
ef'ect is graphically illustrated by' the grain size variation shown in Figures $: \epsilon$ and 57. This result could have been anticipated in view of the kinetic grain growth studies (No. $\dot{7}$ and 9 ; Figures 27 and 30 ) and the information in Section IV.C. The wet hydrogen would have a tendency to promote a defect. structure in the $\mathrm{ThO}_{2}$ and increase the grain boundary mobility. The increased moiility of the grain boundaries would allow them to move more readily beyond the pinning impurities.

The grain size results from the $1200^{\circ} \mathrm{C}-8$ hour powder without granulation and micronized to a surface area of $5.1 \mathrm{~m}^{2} / \mathrm{gm}$ (Figure 53) had a larger center grain size, ASTM \#10 $(11.2 \mu)$, than that, ASTM \#12 $(5.6 \mu)$; (Figure 56) of the pellet fabricated from powder calcined in the same batch but granulated by the liquid/solids procëss and micronized to a surface area of $4.6 \mathrm{~m}^{2} / \mathrm{gm}$. Thus the effect of increased surface area on increasing grain growth is again illustrated regardless of agglomeration technique.

Figure 57 is similar to Figure 56 except the samples were pressed to a green density of approximately $62 \%$. The center grain size increases with increasing time at temperature, <14, <14, <14, $13,10.5$, and 9 for $0, \frac{1}{2}, 1 \frac{1}{2}$, 5, 12, and 22 hours at $1750^{\circ} \mathrm{C}$, respectively. Again the pellets sintered in "wet" hydrogen not only had larger grains than both the 12 hour and 22 hour "dry" hydrogen sintered pellets; but the grains across the "wet" hydrogen sintered pellet were more uniform. For any given condition the grains of the pellets pressed at $62 \%$ green density were larger than those pressed at $60 \%$ and sintered at equivalent times and temperatures." This may be the result of the additional time required for porosity elimination in the pellets of lower green density.

The effect of sintering time at $1750^{\circ} \mathrm{C}$ in dry hydrogen on pellets fabricated from L/S granulated, micronized, calcined. (1400-3. hours $\left.-\mathrm{H}_{2}\right)$ powder lot 136, Figures 58 and 59, showed that extended time (up to 22 hours) at temperature was not capable of increasing the grain size above ASTTM \#13..(4 4 ). regardless of green compaction density. Although the chemical impurity phase may have been removed, the low particle surface area did not provide sufficient grain boundary energy for high levels of grain growth or even densification. 
For pellet $\approx$ pressed to $a$ green density of $60 \%$ the sintered density varied from a low of $8.62 \mathrm{gm} / \mathrm{cc}$ at $O$ hours at $1750^{\circ} \mathrm{C}$ to a high of only $9.27 \mathrm{gm} / \mathrm{cc}$ after 22 hours at $1750^{\circ} \mathrm{C}$. Pressing at $62 \%$ green density did not significantly improve the grain sizes or densities. The sintered density varied from a low of $9.25 \mathrm{gm} / \mathrm{cc}$ to a maximum of $9.45 \mathrm{gm} / \mathrm{cc}$. The senter grain size of all the pellets fabricated from the $1400^{\circ} \mathrm{C}-3$ hour calcined powder, Figures 58 and 59 , by L/S agglomeration was ASTM \#13.5 or finer regardless of green density or time at $1750^{\circ} \mathrm{C}$.

\section{Powder Blends}

Experimental results have shown two important points relative to grain growth in $\mathrm{ThO}_{2}$ compacts: calcining the initial powder appears to remove impurities which may inhibit grain growth, and the powder surface area is critical to the formation of a uniform grain structure of acceptable size. Unfortunately calcining decreases the surface area. Calcining to higher temperatures appears to remove more impurity phase and thus reduces the forces $r \in s i s t i n g$ grain boundary movement; however, it further reduces the surface energy, the driving force for grain boundary movement. Several attempts have been made to increase the surface area of the calcined powder. Extending the number of micronization passes beyond the initial one or two was determined not to be a very effective means of increasing the surface area of the calcined powder (Section $V 1 \perp . B$ ), since the micronization process is basically a particle reduction process. Any attempt to increase the surface area by particle size reduction faces the same problem in that it is extremely difficult to reduce the particle size below 1 or $2 \mu$. The micronization process is further limited since it involves the impacting of like particles against each other. This process may effectively remove the irregular surface of the particles or fracture large agglomerates but probably does little to actually fracture large particles or produce the ultra fine solid particles necessary to have a surface area equivalent to the porous particles of the as-recelved powder. 
Relatively high surface areas were achieved by vibratory ball milling; however, extensive contamination of the powder sample resulted from attrition of the iron balls, Section VIII. Surprisingly, autogenous vibratory milling was unsatisfactory since the thoria balls were totally consumed in a. matter of a few minutes.

\section{Blended Calcined and As-Received Lot 136 Powder}

In an effort to increase the surface area of the powder and still maintain a low impurity content, it was decided to blend in equal proportions 2-pass micronized as-received 136 powder (surface area $6.5,8.8 \mathrm{~m}^{2} / \mathrm{gm}$ ) and 6-pass micronized $1400^{\circ} \mathrm{C}-3$ hour- $\mathrm{H}_{2}(\mathrm{dry})$ calcined 136 powder $\left(4.4 \mathrm{~m}^{2} / \mathrm{gm}\right)$. The resulting surface area of the mixed powders was $7.6,5.2 \mathrm{~m}^{2} / \mathrm{gm}$. This experiment was intended to determine if sufficient impurity-free material could be blended with sufficiently high surface area, as-received powder to dilute the impurity content of the mixture below some critical level while still maintaining a total surface areat approaching that of a 2-pass, as-received powder. The grain size of the blended powder pellet after $1 \frac{1}{2}$ hours at $1750^{\circ} \mathrm{C}$ is shown in Figure 60 . The pellet has a fine grained center; however, the grains are slightly coarser, ASTM \#1 $2 \frac{1}{4}$, than those of the pellet fabricated from as-received 2-pass powder

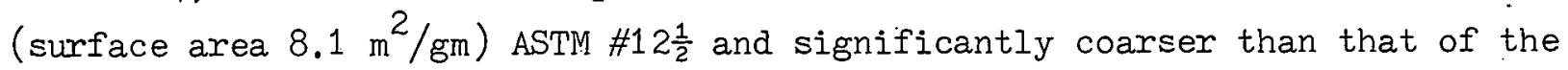
pellet made from $100 \%$ calcined powder 6-pass micronized, ASTM $13 \frac{1}{2}$. The sintered densities decreased in the same order, $9.89,9.88,9.56 \mathrm{gm} / \mathrm{cc}$ for pellets fabricated from the mixed powders, the as-received, and the as-calcined, respectively. The benefits of blending the calcined and as-received powders are even more apparent after 12 hours at $1750^{\circ} \mathrm{C}$, Figure 61 . The pellet fabricated from the blended powders had a center grain size of ASTM \#6 $\frac{1}{2}(38 \mu)$, that fabricated from the $100 \%$ as-received powders ASTM \#10 $\frac{1}{2}(9.4 \mu)$ and that fabricated from $100 \%$ calcined powder ASTM \#11 $(7.9 \mu)$. The sintered densities for the three powders are $9.97,10.01$, and $9.84 \mathrm{gm} / \mathrm{cc}$, respectively.

These results suggest that the dense impurity-free particles not reduced by micronization have high grain boundary mobility and are able to grow at the expense of the high surface energy but inhibited fine particles. Typically large particles or agglomerates are not desirable in a high quality ceramic since they may contain undeșirable porosity which is very difficult to remove, are generally detrimental to uniform grain growth, and may block shrinkage 
of the smallex particles. In this case, however, they may act as nucleation sites for grain growth. The large number of nucleation sites results in uniform grain growth. The high mobility of the grain boundaries results in significant grain development and high levels of densification.

The reason for the improved sintered density is not completely obvious. The density of the blended powder pellet, Figure 61, was $9.97 \mathrm{gm} / \mathrm{cc}$ which is even greater than the $9.92 \mathrm{gm} / \mathrm{cc}$ determined for the 5-pass micronized, calcined $1200^{\circ} \mathrm{C}-8$ hour powder of similar surface area and considerably greater than the $9.85 \mathrm{gm} / \mathrm{cc}$ determined for the 6-pass micronized, $1400^{\circ} \mathrm{C}-3$ hour $\mathrm{H}_{2}$. calcined powder pellets,. Figure 53. Standard techniques to increase the sintered density: by eliminating intragranular porosity, Refs. 9, 11, 12, and 27, generally limit grain boundary movement associated with secondary recrystallization. Grain growth inhibitors added for improved sintering generally result in a grain size smaller than that which is associated with the uninhibited structure of the material. It appears that the mechanism responsible for the increase in density with a concomitant increase in grain size is different in the case of these thoria powders.

The ability to improve grain. growth by blending powders of high purity and high surface area is significant since it also represents a process. which is feasible for large volume production.

\section{Blended Calcined and As-Received Lot 136 Powder - Pretreated}

To further substantiate the initial results obtained by blending calcined and as-received 136 powder and to determine the influence of the pretreatment process on density and grain growth, pellets fabricated from the same $50 / 50,1400^{\circ} \mathrm{C}-3$ hour/as-received blend of powder used in the preceding section were pretreated at $925^{\circ} \mathrm{C}$ for 3 hours in $\mathrm{CO}_{2}$ prior to sintering at $1750^{\circ} \mathrm{C}$. The time dependent grain growth results as a function of pellet cross section are shown in Figure 62. The pressed pellets were pretreated at $925^{\circ} \mathrm{C}$ in $\mathrm{CO}_{2}$ to eliminate any carbon possibly introduced during micronization. The grain size and uniformity increased as the time at temperature increased. The center ASTM grain size (260 × $10^{-3}$ inches in from the pellet surface) after $1 \frac{1}{2}, 5$, and 12 hours at temperature was $11 \frac{1}{4}(7.2 \mu), 10(11.2 \mu)$, and $6(45 \mu)$, respectively. The grain size $130 \times 10^{-3}$ inches from the surface for the same 
tixee peilets was $12(5.6 \mu), 7 \frac{1}{2}(27 \mu)$, and $5 \frac{1}{2}(53 \mu)$, respectively. In spite of the fact that considerable time had elapsed from the experiments described ir 1 above and the furnace temperature had been cycled in the interim, there was relatively good agreement between the data obtained for the pretreated and nonpretreated blends of calcined/as-received 136 powder. The center ASTM grain. size of the nonpretreated pellets after $1 \frac{1}{4}$ and 12 hours at $1750^{\circ} \mathrm{C}$ (Figures 60 and 61$)$ was $12 \frac{1}{4}(5.2 \mu)$ and $6 \frac{1}{2}(38 \mu)$, respectively. The same two values taken $130 \times 10^{-3}$ inches from the pellet surface were $12-3 / 4 .(4.3 \mu)$ and $7(32 \mu)$. The grain growth in the pretreated pellets may be slightly greater than observed in the earlier nonpretreated pellet; however, agreement within one ASTM number is probably reasonable.

Initial optical examination of the pellets used. in Figure 62 showed the microstructure to be similar to that previously observed for the nonpretreated pellets of the same composition and time at $1750^{\circ} \mathrm{C}$, i.e., "necklace" or grain boundary porosity was not eliminated by the pretreatment, indicating that residual carbon from rubber introduced by micronizing was not an important cause for this residual porosity.

\section{Blended Calcined Lot 136 and As-Received Lot 096 Powdex}

To determine"the influence of calcia addition on grain growth in the blended powder, a hlend of calcined $\left(1400^{\circ} \mathrm{C}-3\right.$ hour-3 double pass micronization) 136 powder and as-received ( 1 double pass micronization) 096 powder were fabricated into pellets by the dry press process (nio binder or lubricant) and sintered at $1750^{\circ} \mathrm{C}$ in "dry" hydrogen in the laboratory furnace. The effect of sintering time at $1750^{\circ} \mathrm{C}$. on grain growth as a function of pellet cross section is show in Figure 63. As previously demonstrated in Figure 62, grain size and grain uniformity increased with increasing time at temperature. The center grain size after $1 \frac{1}{2}, 5$, and 12 hours at $1750^{\circ} \mathrm{C}$ was ASTM $\# 11-3 / 4(6 \mu)$, $10 \frac{1}{2}(9.4 \mu)$, and $7 \frac{1}{4}(30 \mu)$, respectively. The same three values determined at a position $130 \times 10^{-3}$ inches from the surface were $12(5-6 \mu), 11(7.9 \mu)$, and $7(32 \mu)$. These results agree to within $3 / 4$ of an ASTM number with the nonpretreated pellet made from a blend of calcined/as-received 136 powder (Figures 60 and 61 ) and appear to be slightly smaller than the grains observed in the pretreated calcined/as-received 136 powder. It was anticipated that pellets 
fabricated from the biend of calcined 136/as-received 096 would produce larger grains since the suriace area of this blend was greater, $8.8 \mathrm{~m}^{2} / \mathrm{gm}$ versus $7.6 \mathrm{~m}^{2} / \mathrm{gm}$. Why this did not, in fact, take place is not clear. The influence of the calcia addition may have been reduced because the "dry" hydrogen sintering was, in fact, not very water free (dew point $+59^{\circ} \mathrm{F} \approx$ $18,000 \mathrm{ppm} \mathrm{H} \mathrm{H}^{\mathrm{O}}$ ); however, as shown in Section IV.C, CaO located at grain boundaries would retard grain growth.

Even though the $136 / 096$ blend pellet did not yield grains significantly larger than those observed in pellets produced from a blend of the 136 powder alone, the resultant grain growth was greater than in pellets fabricated solely from either of the components, as shown below and in Figures 64 and 65. (The as-received, not micronized 096 powder was included even though it was not one of the components of the blend because it had a surface area very close to that of the blend.)

Beneficial Influence of Blending Calcined and As-Received $\mathrm{ThO}_{2}$ Powder on Grain Growth in Pellets

\begin{tabular}{|c|c|c|c|c|}
\hline $\begin{array}{c}\text { Pellet } \\
\text { ID }\end{array}$ & Powder Treatmcnt & $\begin{array}{l}\text { Sintering } \\
\text { Timo } \\
\text { (hrs) } \\
\end{array}$ & $\begin{array}{l}\text { Surface, } \\
\wedge \text { roa } \\
\left(\mathrm{m}^{2} / g \mathrm{~m}\right)\end{array}$ & $\begin{array}{c}\text { ASTM } \\
\text { Center } \\
\text { Grain } \\
\text { Sizc } \\
\text { No. }\end{array}$ \\
\hline $3373 \# 1$ & $\mathrm{Blend}\left(\begin{array}{l}(50 \% \text { as-recd } 096,2-\text { pass micro. }) \\
\left(60 \% \text { calc. } 136,1400 \mathrm{C}-3 \mathrm{hr}-\mathrm{H}_{2}\right. \\
6 \text { pass micronization }\end{array}\right)$ & 1.5 & 8.8 & $11 \frac{1}{2}$ \\
\hline $3273 \#$ & $"$ & $1 \%$ & 8.8 & 7 \\
\hline $3212 \not 15$ & $\begin{array}{l}\text { Calc. } 136,1400^{\circ} \mathrm{C}-3 \text { hrs }-H_{2}, 6 \text {-pass } \\
\text { micronization }\end{array}$ & 1.5 & 4.4 & $13 \frac{1}{2}$ \\
\hline 3212,46 & $"$ & 12 & 4.4 & $11^{\circ}$ \\
\hline $15 \mathrm{P}$ & As-rec'd. 096, 2-pass micronization & 1.5 & 10.3 & $<14^{\prime}$. \\
\hline $13 F$ & $"$ & 12 & 10.3 & 10 \\
\hline $3 T$ & As-rec'd. 096 & 1.5 & 8.2 & $<14$ \\
\hline $4 \mathrm{H}$ & $"$ & 12 & 8.2 & 12 \\
\hline
\end{tabular}


Cleariy the pellet fabricated from the blend of calcined 136 and as-received 096 powder had more uniform and larger grains than those oibtained in pellets febricated from the individual powders.

- The results observed in the pellets made from the blended calcined/as-received powder are significant since they support a production spproach where only a fraction of the total amount of thorla powder necessary for large scale production of blanket size pellets needs to be calcined.

4. Porosity Distribution of Blended Powder Pellets

It was shown that the grain growth of the pellets fabricated from the blended powders was greater and more uniform than could be achieved solely with either powder. The resulting pellets were of very high density (> 99\% TD) and had a uniform microstructure relatively free from porosity. Surprisingly, in view of the relative surface areas of the calcined, micronized and asreceived, micronized starting 136 powders, 4.4 and $8 \mathrm{~m}^{2} / \mathrm{gm}$, respectively, there was relatively little porosity trapped within the grains of any of the blended pellets which were sintered at $1750^{\circ} \mathrm{C}$ for 12 hours. The porosity which was detected was located mostly at the grain boundaries. Figure 66a is a photomicrograph of sample $\mathrm{R} / \mathrm{C} 75-3372 \# 21400^{\circ} \mathrm{C}-3$. hour/as-received 136 powder, 12 hours at $1750^{\circ} \mathrm{C}$, showing the unetched pellet microstructure from the surface to a depth of approximately 0.018 inch along the pellet center diameter. The first $3-4 \times 10^{-3}$ inches are practically pore free and represent an area in which the inhibiting impurity was removed by contact with the sintering atmosphere and the porosity could diffuse to the surface. The remainder of the porosity was relatively coarse and located mostly at grain boundaries. This porosity distribution remained relatively uniform across the pellet to the pellet center, Figure 66b. Figure 67a is a photomicrograph of the $1 \frac{1}{2}$ hour pellet made from the same blended powdex and shows an area extending from the pellet surface approximately $18 \times 10^{-3}$ inches toward the pellet center. As in the 12 hour sample, a narrow band approximately $3-4 \times 10^{-3}$ inches of pore-free material existis around the exterior of the pellet. It is significant that the thickness of the pore-free band is not dependent on the sintering time. This would help support the possibility that the pore-free rim is the result 
of a surface effect, e.g. "residual pressing strains or a free surface. The latter is most probable in view of kinetic study results, Figure 23 . The area immediately after the pore-free surface rim shows the presence of both coarse and fine porosity; however, the porosity is relatively uniformly distributed and is not necessarily concentrated at. grain boundaries. This area extends approximately 30 to $40 \times 10^{-3}$ inches into the pellet from the surface. The. remainder of the pellet cross séction, Figure $67 \mathrm{~b}$, consists of relatively. fine porosity, uniformly distributed. The grains are small in this area, 3-4 $\mu$ in diameter, and hence the pores may be located primarily at grain boundaries.

Since the elimination of porosity is a normal part of the sintering process and because the elimination of porosity takes place by diffusion eventually to the pellet surface once residual porosity is closed, a finer-grained center with coarser grains at the pellet exterior would be expected to be the microstructure in any ceramic body made from fine powder tist was not sintered to completion. If other experimenters conduct further evaluation of sintering and grain growth of ThO? based pellets, it appears that additional studies of the pore morphology as a function of time would be desirable. The establishment of a relationship between density, grain growth snd porosity may help in better understanding the role of pores in densificasion and grain Erowth.

To quantify the variation in porosity as. a function. of time and pellet cross section in the pellets made from powder blends, photomicrographs of these two samples were analyzed with the epidiascope attachment to the Quantimet. At the magnification necessary to resolve the solid and pore phases. on the epidiascope $(1000 \mathrm{X})$, the contrast between the fine pores and the solid phases was only marginal. Especially for the sample sintered at $1750^{\circ} \mathrm{C}$ for. $1 \frac{1}{2}$ hours, it is possible that some of the smaller pores, especially at. the. pellet center, went undetected. The results of this investigation are shown in Figure 68. Both the $1 \frac{1}{2}$ hour and 12 hour samples showed an extremely low porosity content near $\left(3-4 \times 10^{-3}\right.$ inches) the exterior surface, $0.086 \mathrm{v} / 0$ and $0.060 \mathrm{v} / \mathrm{o}$, respectively. On the surface of the two pellets the ASTM grain sizes are almost equal to $11(7.9 \mu)$ and $10.5(9.4 \mu)$ respectively: The porosity of both samples increased rapidly in the next 5 to $10 \times 10^{-3}$ inches. 
A maximum porosity content of $2.1 \mathrm{v} / 0$ is reached $10 \times 10^{-3}$ inchess from the surface in the sample sintered $1 \frac{1}{2}$ hours. The grain size at this point was aiso a maximum of $9.5(13.4 \mu)$, Figure 60 . After reaching the maximum the porosity decreased as did the grain size in.moving toward the pellet center.. A low of $0.5 \mathrm{v} / 0$ porosity was detected $37 \times 10^{-3}$ inches from the exterior : $)$ surface. The minimum. grain size of \#13.5 (3.3. $\mu)$ was determined to be . approximately $45 \times 10^{-3}$ inches from the exterior surface. If the porosity measurements were extended across the entire pellet, cross section, the minimums in porosity varied widely, possibly the result of detection difficulty. In spite of the problems with the detection of fine porosity, it appears that the shorter sintering time results in a sample with greater porosi.ty. With increasing time the porosity is swept and concentrated at the grain boundaries.

The porosity of the pellet sintered for 12 , hours at $1750^{\circ} \mathrm{C}$. increased to approximately $0.97 \mathrm{v} / 0$ at $6 \times 10^{-3}$ inches from the surface and remained relatively constant for about $1.5 \times 10^{-3}$ inches. The maximum grain size of ASTM \#6 was recorded $30 \times 10^{-3}$ inches from the pellet surface, Figure 61. Some of the scatter experienced in the results may be due to poor statistics and fine porosity.

In splte of the difficulties noted above it has been concluded from this preliminary examination of the pore morphology that graln growin find pore shape, size and location are a function of the extent of grein growth and the time at temperature. $\because$

It is postulated that the very fine micronized, as-received powder (surface area $\approx 8-10 \mathrm{~m}^{2} / \mathrm{gm}$ lots 136 and.096) is highly sinterable as demonstrated by the fact that after: only $1 \frac{1}{2}$ hours at $1750^{\circ} \mathrm{C}$ the pellet surface was relative void free. The reason for a lack of grain growth at the pellet center may be partially due to the rapid reaction at the pellet surface. Because of the intimate contact with the sintering atmosphere, the porosity at or near the surface is quickly removed as are any possible grain growth inhibiting impurities. The large surface energy is a strong driving force causing densification and grain growth relatively early in the sintering cycle, A high density outer rim impedes the removal of porosity from the pellet interior and may also reduce communication with the sintering atmos- 
phere. The importance of the sintering atmosphere has been noted previously in this report. .Keeping the sintering atmosphere' away from the pellet interior by forming a high density outer rim may retard impurity elimination and grain boundary mobility. The oxidation and subsequent accelerated grain boundary movement resulting from a wet hydrogen atmosphere may be restricted to just a surface effect if a high density outer rim is formed early in the sintering cycle.

It may therefore be hypothesized that the mixture of $1400^{\circ} \mathrm{C}$ calcined powder containing high density but impurity-free particles with as-received and micronized powder with relatively fine but impurity-bearing particles results in a compact that does not form a high density siritered skin as early as the pellets made trom $100 \%$ as-received powder. Therefore, a greater amount of impurities may be removed by the sintering atmosphere, as well as provide increased grain boundary mobility. Pellets fabricated from $100 \%$ calcined powder also do not generally result in grains as large as those realized from the powder blends because the surface area of the calcined powder is significantly lower than the as-received or blended powder. If the surface area of the calcined powder could be increased to the same value as the as-received or, blended powders, it is predicted that the resulting grain size would be larger and more uniform.

\section{Grain Boundary Curvature}

Sterotex voids common to all of the pellets fabricated with the addition of dry.Sterotex powder after agglomeration typically had smooth void surfaces indicating no grain boundary curvature, Figure 69a. Even pellets fabricated from calcined powder which showed significant grain growth after a relatively short time period at $1750^{\circ} \mathrm{C}$, Figure $69 \mathrm{~b}$, had a similar sterotex void surface morphology. However, those pellets fabricated from the calcined powder and sintered at $1750^{\circ} \mathrm{C}$ for 12 hours, showed considerably more grain.boundary curvature at the free surface.left by the Sterotex lubricant, Figure.69c. The structure in Figure 69c represents"an equilibrium configuration determined by the surface energies. That the curved grain boundary surface is representative. 
of an equilibrium condition has been shown frequently, e.g. by Burke, Ref. 22, and may be represented by the equation:

$$
Y_{\text {ss }}=2 Y_{\text {sg }} \cos \varphi / 2
$$

where $Y_{s s}=$ surface energy between the two solid grains

$\therefore: \cdots \cdot y_{s g}=$ surface energy "bétween the solid grain and the gats or vacuum" phase in the void

$\varphi=$ dihedral angle between equivalent interphase boundaries : where $\varphi$ is some value less-than $180^{\circ}$ :

The practicé of thermal 'etching: usés this'concept to accentuate the grain boundaries. The solid surface is rapidly heated until the surface has sufficient energy to achieve its equilibrium position. This results in the solid-gas boundary curving downward as it intersects the solid-solid boundary. This type of surface relief results in the delineation of the grain boundaries by subsequent reflected light examinations.

The microstructures at the solid-gas interface in Figures $69 \mathrm{a}$ and $\mathrm{b}$ are unusual in that the boundary energy is not independent of the crystalline surface and represents a nonequilibrium condition. For this to occur and remain stable for an extended time period, Figure 69a, an inhibiting species must be present. This further supports the conclusion that an impurity is present which is capable of inhibiting grain growth.

The distribution of the fine porosity in Figures $69 \mathrm{~b}$ and $\mathrm{c}$ shows that the grain boundaries are able to move past the closed pores. After grain growth is nearly complete and the movement of grain boundaries is considerably. slower. :Figure 69c, the pores are swept by boundaries.

6. Density of Pellets Fabricated from Calcined Powder Calcining of the thoria powder was instituted to remove grain growth inhibiting impurities; however, some effect of this practice upon densification might also be detectable. The densities of pellets fabricated from as-received 136 pellets with a powder surface area of $5.55 \mathrm{~m}^{2} / \mathrm{gm}$ were determined to be, after $1 \frac{1}{2}$ hours at $1750^{\circ} \mathrm{C}, 9.357 \mathrm{gm} / \mathrm{cc}$ (ave) and; after 12 hours at $1750^{\circ} \mathrm{C}, 9.65 \mathrm{gm} / \mathrm{cc}$ (ave), Table 13. The comparable densities of 
pellets fabricated from calcined $\left(1200^{\circ} \mathrm{C}-8\right.$ hours $\left.-\mathrm{H}_{2}\right) 136$ powder micronized to a surface area of $5.17 \mathrm{~m}^{2} / \mathrm{gm}$ are 9.77 and $9.91 \mathrm{gm} / \mathrm{cc}$, respectively. Similarly, the corresponding densities of pellets fabricated from calcined $\left(1100^{\circ} \mathrm{C}-48\right.$ hours$\mathrm{H}_{2}$ ) 136 powder and double micronized to a surface area of $5.91 \mathrm{gm} / \mathrm{cc}$ are 9.79 and $9.82 \mathrm{gm} / \mathrm{cc}$, after $1 \frac{1}{2}$ and 12 hours of sintering, respectively. Pellets fabricated from a $50 / 50$ blend of calcined/as-received 'powder also showed an increase in density over both.the as-received and the calcined powder pellets, provided the surface areas were similar.

To further explore the effect of increased sinterability and grain growth resulting from powder calcination, the sintered density, values of the binderless pellets fabricated from the various conditions of lot 136 powder were plotted against the surface area of the powder in. Figure 70.

Each straightline segment for the various conditions joins only two data point pairs; the difference in initial surface area for the as-received and $1100^{\circ} \mathrm{C}$ calcined powders represents an effect of micronizing (as-calcined vs micronized) at constant calcining time and that for the $1200^{\circ}$ and $1400^{\circ}$ materials was developed by increased time at temperature $\left(1200^{\circ} \mathrm{C} / 8\right.$ and 24 hours and $1400^{\circ} \mathrm{C} / 3$ and 9 hours), all materials being similarly micronized.. It is clearly demonstrated that with lower impurity level resulting from higher temperature calcining, a given tired density can be developed with less active powders, i.e., at lower surface area. A similar trend is noted for lot 096 powder (data for as-received and $1100^{\circ} \mathrm{C}$ calcined only) except that the slope of density vs surface area is only about one-third of that observed for lot 136. However, this may simply be a manifestation of (1) higher surface area in the. initial powder since as-received lot 096 was micronized once at $350 \mathrm{gm} / \mathrm{min}$ prior to any other processing, (2) "a possible beneficial effect of the $\mathrm{CaO}$ addition resulting in somewhat higher fuel density at lower surface areas ( $\mathrm{CaO}$ additions have been used as densifying agents in $\mathrm{ThO}_{2}$, Ref. 12); (3) the fact that an ultimate density near. $9.9 \mathrm{~g} / \mathrm{cc}$ was attained for both the CaO-free and CaO-containing materials at the highest surface areas, and (4) the possibility that additional data at intermediate surface areas would show all materials to have similar initial slopes and then reduced slopes approaching the theoretical maximum density. 


\section{E. Eifects of Powder Processing Parameters on Grain Growth -} Thoria 0.53 Inch Diameter Pellets

In light of all of the data collected on pellets made from different powders calcined for various times at several temperatures, Table 13, an initial effort was made to correlate some of these data to determine the relative effects of calcining temperature, particle size, and fabrication technique on sintered grain diameters. With the existing data it was extremely difficult to make a correlation betweén sintered grain diameter and calcining temperature because the surface area of each calcination varied. Even after differing amounts of micronization, the surface areas of the powders varied widely. In addition to having variable surface areas, the time at temperature of each calcination also was not held constant. The calcining times and temperatures were selected in an effort to produce the maximum grain size rather than to produce a balanced, unconfounded experiment. The inability to promote significant grain growth at $1750^{\circ} \mathrm{C}$ in pellets made from powders with surface areas. less than $4.4 \mathrm{~m}^{2} / \mathrm{gm}$ was unanticipated and limited the selection of calcining conditions.

A comelation between surface area and final sintered grain size was observed for the calcined and the as-received powder, Figure 71. For any eiven surface area, the pellets fabricated from powder which had beer salcined at $1100^{\circ} \mathrm{C}$ or higher had larger grains after 12 hours at $1750^{\circ} \mathrm{C}$ in dry hydrogen than pellets fabricated from as-received powder. Plotting the data from a wide variety of calcining times, temperatures, powder compositions, and fabrication techniques on semi-log paper. (Figure 72) surprisingly good straight line fit of the data was obtained. The three populations (as-received, calcined, and calcined and sintered in wet hydrogen) were not tested for statistical differences. however, it appears that the differences between the two populations of calcined and as-received are real within approximately $80 \%$ confidence levels. From the data the equation log (grain size $(\mu))=0.318$ (surface area $\mathrm{m}^{2} / \mathrm{gm}$ ) - 0.621 was derived which predicts the sintered grain size for 0.53 inch diameter pellets pressed to $60 \%$ green density from powder calcined to $1100^{\circ} \mathrm{C}$ or greater and sintered at $1750^{\circ} \mathrm{C}$ in $\mathrm{H}_{2}$ (dry) for 12 hours. Interestingly it may be observed from Figure 72 that the center grain size of 
the sintered pellet doubles for each square meter per gram surface area of the starting calcined powder. With starting surface areas of 4, 5, 6, 7, and $8 \mathrm{~m}^{2} / \mathrm{gm}$ the resulting center grain sizes are predicted to be $4.5,9.5,20,40$, and $80 \mu$, respectively.

Another interesting result was that with one exception all of the center grain sizes of the pellets fabricated from $50 / 50$ blends of calcined/ as-received powder, sintered for 12 hours in $\mathrm{H}_{2}$ (dry), fell on the curve generated by the equation $\log \mu=0.318$ (SA) - 0.621 representing calcined starting powder. The lone exception was the pellets fabricated from the $136 / 096$ powder blend. The center grain size of these pellets was significantly smaller than what would be predicted from the generated equation. A possible explanation for the reduction is that the pellets were only pressed to approximately $58 \%$ green density. In addition, the sintering temperature was probably lower, as confirmed by the fine grain size of the pretreated $136 / 136$ blend, Figure 52, than that of the unpretreated blend; the former was sintered along with the $136 / 096$ blend.

What may be a more difficult question is why any of the pellets made from 096 powder lie on the same line as the pellets made from calcined 136 powder. It was postulated, Section IV.C, that in the stoichiometric $\mathrm{ThO}_{2}$ lattice, the presence of $\mathrm{CaO}$ could enhance oxygen ion diffusion rates. Since it has been shown in other material systems, Refs. 9, 12, and 29, that the trace element addition may concentrate at or near the grain boundaries, grain boundary mobility could be altered by even very small concentrations of additives or impurities. If, however, the $\mathrm{ThO}_{2}$ lattice was substoichiometric in oxygen content the self-diffusivity of thorium may be greatly reduced and the $\mathrm{Ca}$ ions may associate with the defect, thereby additionally reducing grain boundary mobility. It has also been postulated, Section IV.C, that with increase in the oxygen activity in the hydrogen atmosphere the structure would become more oxygen-enriched which may occur by an increase in thorium ion lattice vacancy concentration. The increase in Th defect concentration leads to an increased self-diffusivity. The CaO lattice defects would be associated with the thorium ion defect. The exact nature of these defects is not fully understood; however, the influence of calcia on densification of $\mathrm{ThO}_{2}$ as a 
function of the sintering atmosphere has been reported, Ref. 49. Approximately $\frac{1}{2} \mathrm{w} / \mathrm{O} \mathrm{CaO}$ added as the carbonate or fluoride increased the density of $\mathrm{ThO}_{2}$ from 99 to $100 \% \mathrm{TD}$ when sintered in air or argon but had no effect when the compact was sintered in dry hydrogen.

It is hypothesized that the beneficial effects of $\mathrm{CaO}$ and possibly even $\mathrm{UO}_{2}$ on the grain growth... in $\mathrm{ThO}_{2}$ will be realized only when sintering is performed in an atmosphere of higher oxygen potential than that corresponding to dew points of $-50^{\circ} \mathrm{F}$ as existed during this study in the Binary Production Facility or even $+53^{\circ} \mathrm{F}$ as existed during this study in the Thoria Production Experimental Furnace. The detrimental effects of a highly reducing atmosphere have been demonstrated, as have the beneficlal effects of a more oxidizing atmosphere.

Finally, two batches of pellets were fabricated by the liquid/solids process from calcined 136 powder. The powder used in the first batch was. calcined at $1200^{\circ} \mathrm{C}-8$ hours $-\mathrm{H}_{2}$ and the second batch $1400^{\circ} \mathrm{C}-3$ hours $-\mathrm{H}_{2}$. Pellets from each batch were sintered at $1750^{\circ} \mathrm{C}$ in hydrogen with dew points of $110^{\circ} \mathrm{F}$ and approximately $53^{\circ} \mathrm{F}$... The center grain size from each batch of pellets sintered in the hydrogen with the higher dew point had larger center grain sizes. The differencesin the center grain size were approximately two ASTM numbers. These results further demonstrate the benefits of a more oxidizing atmosphere for grain growth in thoria without any additives.

\section{VIII. ' WESTINGHOUSE RESEARCH LABORATORY (WR.L) SUBCONTRACT .}

\section{A program was instituted with Westinghouse Research Laboratory to} perform supplemental experiments on both the pure thoria and the thoria-U. 233 pellets. The nature of the program with WRL was two-fold. The first phase of the program consisted of examining $\mathrm{ThO}_{2}$ and $\mathrm{ThO}_{2}-\mathrm{UO}_{2}$ pellets fabricated at the Bettis Laboratory that showed characteristic microstructures (i.e., medium sized gralus on exterior and very large or very fine grains at pellet interior). Examinations consisted of optical metallography, ion probe, electron microprobe, and $X$-ray microfocus diffraction to detect stoichiometry differences between surface and center of pellets. The second phase of the program con- 
sisted of fabricating 0.53 inch diameter size pellets from as-received and calcined thoria provided by the Bettis Laboratory and adding $\mathrm{UO}_{2}$ to simulate actual binary pellet compositions. In addition, pellets would be fabricated from extra high purity $\mathrm{ThO}_{2}$ produced by WRL. Grain growth determinations would be made as a function of atmosphere and pellet composition.

The pellets sent to WRL, the green and sintered densities, for each pellet, and the ASTM grain size at the pellet edge, middle, and center are shown in Table 15. Samples 74-3462-7 and 74-3410 were examined in the greatest deta1l. Of the elements considered most likely to be responsible for grain size variability, definite evidence was detected only for carbon with both ion probe and electron microprobe examination. Most direct evidence for carbon was observed in large pores which are presumed to be remnants of the Sterotex additives. In a few cases calcium was associated with the carbon in these pores. No evidence for calcium or carbon was noted in small grain boundary pores, indicating either that carbon was present as a volatile gas which escaped during metallographic preparation or that undetected impurity elements. were contained therein. A further investigation of the content and quantity of the gas-filled pores was not done at this time. Such an investigation may be worthy of future experiments. Small concentrations of Al were detected at the surface of some of the pellets. The trace quantity nf alumina is most likely due to vaporization of the alumina refractories during sintering.

Electron microprobe and ion probe analysis of the two $\mathrm{ThO}_{2}-1.66 \% \mathrm{U}^{233} \mathrm{O}_{2}$ binary pellets, Table 15, substantiated the results obtained for the pure thorla pellets with two additional findings. The $\mathrm{UO}_{2}$, concentration at the grair boundaries was above the matrix concentration. Most important was the detection of low level quantities of sodium and potassium. These results are of particular inlerest since these two elements were observed to decrease as a rêsult of calcining experiments conducted at the Bettis Laboratory at $1100^{\circ} \mathrm{C}$ in both air and hydrogen atmospheres, Table 14. It was also reported by WRL 
that the shape of the thorium and uranium peaks at the center of the pellet where the grains were very fine were different from the shape of the peaks obtained at the pellet surface where the grains were considerably larger. It was hypothesized that the observed variation in peak shape may be related to. the stoichiometry of the two oxides.

$X$-ray diffraction examination using a microfocus camera showed no difference in lattice parameters between the surface $(5.4970 \pm 0.0001 \AA)$ and the center $(5.4976 \pm 0.0005 \AA)$ indicating again that impurities are insoluble or are present at very smail levels.

Thermogravimetric analysis of green pellets heated to $450^{\circ} \mathrm{C}$ at $50^{\circ} \mathrm{C} /$ hour in air and $\mathrm{CO}_{2}$ showed $1.64 \%$ weight loss in the former and $1.43 \mathrm{w} / \mathrm{O}$ in the latter atmosphere. On sintering in wet hydrogen total weight loss in both cases was $1.8 \mathrm{w} / \mathrm{o}$ indicating that the $450^{\circ} \mathrm{C}$ pretreat removes only a fraction of all volatiles.

The conclusion drawn from this series of diagnostic tests was that the inhibiting impurities were at extremely low levels making identification very difficult.

The second phase of the work consisted of fabricating pellets from powders supplied by the Bettis Laboratory. Pellets were pressed to $62 \%$ green density with no bindex or Iubricant additions using both CaO-free (lot 136) and CaO-containing (lot 095) powders, as well as the latter recalcined in air at $1900^{\circ} \mathrm{F}\left(1038^{\circ} \mathrm{C}\right)$ for 48 hours. This powder initially received the normal $1800^{\circ} \mathrm{F}\left(982^{\circ} \mathrm{C}\right)-24$ hour air calcine at the manufacture. The pellets were sintered in wet hydrogen, with no pretreatment, for 12 hours at $1750^{\circ} \mathrm{C}$. The heating rate to temperature was $70^{\circ} \mathrm{C} /$ hour. Initial examination revealed the following.

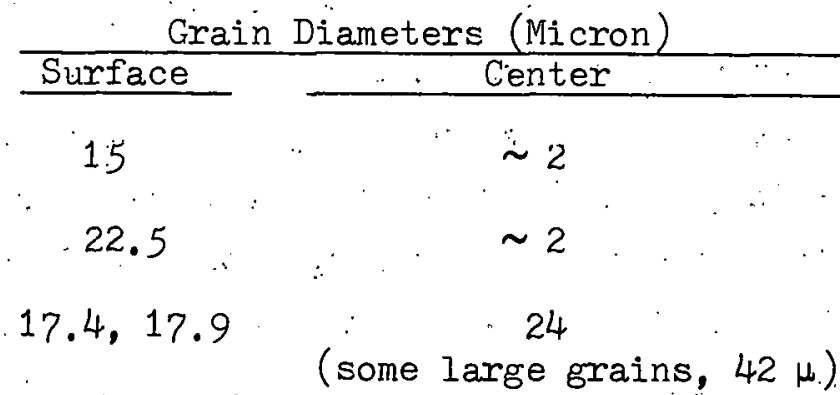


WAPD-TM-1311

These results helped to confirm the earlier Bettis conclusions concerning the presence of an inhibiting impurity. In addition, some initial examinations

normal additives made of lot 087 ( $\mathrm{R} / \mathrm{C} \# 3256, \mathrm{~A}-1$ ). As-sintered at Bettis in wet hydrogen, these pellets showed grain sizes of $44 \mu$ at the surface and $9.5 \mu$ at the center. However, when sintered at the Research Lab in wet nitrogen, the surface and center grain sizes were identical, $14 \mu$. Apparently, relative to center grain size, the higher oxygen potential of the wet nitrogen atmosphere yielded little benefit compared to the wet hydrogen atmosphere. The reduction in grain size of the surface in wet nitrogen suggests some inhibition due to this atmosphere.

In an effort to minimize the confounding effects of a decreasing surface area with increasing calcination temperature, Section VII.C, calcined powders were sent to WRL and the average particle size was decreased by vibratory milling. Vibratory milling appeared to be the one particle size reduction method which was effective in the micron and submicron particle size range, Ref. 44. Unfortunately, a significant amount of contamination resulted from the iron balls used in the mill. As a result, all of the milled powders had to be leached with $\mathrm{HCl}$ and washed with distilled water. After the powder was dried, the cake was returned to the mill for approximately one minute.

A preliminary review of the grain size data obtained from 0.53 inch diameter pellets fabricated at WRL from as-received and calcined 096 and 136 thoria powder, Table 16, indicates that the addition of urania and trace quantities of phosphorus promoted grain growth. Initial data show that in spite of the decrease in particle size resulting from milling and leaching, pellets fabricated from this powder did not show an increase in grain growth. Samples fabricated from as-received and calcined 096 powder which had heen milled and leached with $\mathrm{HCl}$ actually showed a reduction in center grain size as compared to the results obtained from pellets fabricated from identical powders which were not subjected to the additional processing. The lack of grain growth resulting from the use of milled and leached thoria powder was attributed to the leaching process. It was postulated that trace elements which influenced grain growth were either added or removed. It has been previously established that trace impurities in the as-received powder 
inhibit grain growth. Additional impurities imparted to the powder by the acid leach could retard grain growth even further.

To demonstrate the influence of impurities in the starting powder on grain growth in thoria fuel pellets, high purity thoria was precipitated from the oxalate and calcined at $900^{\circ} \mathrm{C}$ for 2 hours. This powder was subsequently used in the fabrication of 0.53 inch diameter pellets by dry pressing to $52 \%$ green density and sintering at $1750^{\circ} \mathrm{C}$ in dry hydrogen. (Dew point of the source hydrogen was $-70^{\circ} \mathrm{F}$; however, the dew point in the furnace hot zone has not been measured.) Pellets produced from this powder had a uniform grain structure with an average grain diameter of approximately $30 \mu$ ( ASTM \#7).

Results of a spark source mass spectrographic analysis of the WRL produced $\mathrm{ThO}_{2}$ powder along with the 136 as-received $\left(1038^{\circ} \mathrm{C}\right.$ air calcined) and the 136 calcined $\left(1100^{\circ} \mathrm{C}-\mathrm{H}_{2}-48\right.$ hour $)$ powders are shown in Table 17. With the exception of sodium and fluorine, the WRL produced powder was lower in impurities than either the as-received or calcined 136 powder. The presence of $40 \mathrm{ppm}$ sodium and $20 \mathrm{ppm}$ fluorine in the oxide powder is difficult to understand since the starting oxalate contained only $10 \mathrm{ppm}$ of these two elements. Since the precipitation process and subsequent calcination generally result in a purification of the powder, lower levels were anticipated. It was suggested by cognizant W4L personnel that the sample taken for spectrographic analysis was contaminated.

The surface area of the WRL-thoria powder was $13.2 \mathrm{~m}^{2} / \mathrm{gm}$ which is considerably greater than even the milled and leached, as-received 136 powder; however, the average particle diameter was approximately $1 \mu$. The high surface area and relatively large particle size is inconsistent unless the particles themselves are porous. This result is very significant in that it helps confirm earlier results at Bettis and may explain the relatively poor fabricability of calcined powder. Calcining the starting powder removes the impurities that inhibit grain grnwth in the compacted pellet; however, calcining may also reduce the internal porosity of the thoria particles, as indicated by a comparison of the average particle diameter calculated from the particle size distribution data and the gàs adsorption data. It has been shown, Ref. 44 , 
WAPD-TM-1311

that calcining results in significantly larger decreases in surface area than in increases in average particle size. This result can only be explained by assuming a decrease in surface roughness or internal porosity. Electron micrographs of the calcined particles show only a moderate rounding of sharp corners and almost no change iñ shape. A decrease in internal porosity therefore seems to be more reasonable.

It may be postulated that as a result of the reduced porosity the calcined thoria particle is stronger and less friable than an equivalent asreceived particle. During pellet compaction the as-received particles fracture, thereby changing the plate-like morphology and increasing the mechanical interlocking of particles.

\section{POSSIBLE FUTURE EXPERIMENTS}

Not having absolutely identified the impurity or impurities responsible for the grain growth inhibition observed in the $\mathrm{ThO}_{2}$ and $\mathrm{ThO}_{2}-\mathrm{UO}_{2}$ pellets leaves an obvious phase of the investigation incomplete. Therefore additional analytical work could be directed toward a more definitive identification of the amount and location of $\mathrm{Na}$ and $\mathrm{K}$ in the sintered pellet and powder. However, it is very possible that the concentration of the impurity phase is at or very near the limits of detection of the best anslytical tools available. To overcome this obstacle, production of a very high purity thoria starting from the initial $\mathrm{Th}\left(\mathrm{NO}_{3}\right)_{4}$ could be accomplished. This may require some time to develop the necessary techniques; however, it would be easier to produce an impurity-free thoria than it would to purify the contaminated powder. Varying amounts of suspect elements could be added to the pure powder; and the resultant pellet grain size could then be correlated to the additive. This experiment could not only identify the inhibiting impurity, hut it. could also indicate the quantity responsible for inhibition.

Because the thoria particles densified with increasing calcining temperature, the distance the inhibiting impurity had to diffuse prior to volatilization increased thereby reducing the effectiveness of the inereased calcining temperature. This suggests that for further experiments thorium oxalate be heated for extended time periods at temperatures below $982^{\circ} \mathrm{C}$. 
Since the blending of equal quantities of calcined and as-received powders was so successful in promoting grain growth in the sintered compact, a series of experiments could be designed to determine the amount of calcined powder, the time and temperature for calcination and the number of micronization passes necessary for optimum grain growth.

Finally three further experiments discussed in the report that are designed to determine the amount and nature of the gases trapped in closed pores, to determine the growth mechanisms of exaggerated grains, and to explore the mechanisms responsible for grain growth as a function of particle size could provide considerable insight into the mechanisms responsible for grain growth in $\mathrm{ThO}_{2}$.

\section{ACKNOWLEDGMENTS}

The author is extremely gratefui to Dr. B. Lustman whose personal guidance and contributions to every phase of this document were extremely... helpful. Thanks are also extended to Mr. C. C. Busby who was instrumental in the fabrication of the many samples used in thị report; to Mr. P. A. Antonella who made most of the physical property measurements; to Mr. C. P. Gamber. and the metallography personnel who prepared the samples and performed the numerous grain size measurements; to Dr. 0. 0. Gamba for the electron microprohe analysis; to Mr. I. Cohen for the Quantimet work; to Mr. C. E. Campbell and Mr. R. H. Nagy for the SEM examinations; to Dr. J. S. Bryner for the grain size measurements. with the electron microscope; to Dr. W. D. Kingery and Dr. R. L. Coble for their views on idiomorphic grain growth; and to Ms. E. M. Bonnell for her effort in converting a handwritten paper into a manuscript. 
WAPD -TM-1311

\section{REFERENCES}

1. D. Tabor, "The Hardness of Metals," Oxford, 1951.

2. C.C. Busby and J.C. Clayton, "Thorium Oxide Granule and Compact Properties which are Important to $\mathrm{ThO}_{2}$ and $\mathrm{ThO}_{2}-\mathrm{UO}_{2}$ Fuel Pellet Fabrication (IWBR Development Program)," WAPD-TM-1231 ianuary, 1976.

3. J. May and D. E. Turribull, "Secondary Recrystallization in Silicon Iron," Trans. AIME 212, 769-781 (1958).

4. ASTM Standard E-112-63, "Micro Grain Size Relationships" in ASTM Standards (1Y74), Part II, Metallography, p.209, American Society for Testing Materials, Easton Md., 1974.

5. I. Amato, "Discontinuous Grain Growth in Sintered "TO?," T. Am. Cer. Sos. $48,53(1965)$.

6. P. J. Jorgensen, "Modification of Sintering Kinetics by Solute Segregation in $\mathrm{Al}_{2} \Theta_{3}, "$ J. Am. Cer. Soc. 48, 207-10 (1965).

7. R. I. Taylor, J. P. Coad, and R. J. Brook, "Crain Boundary Segregation in $\mathrm{Al}_{2} \mathrm{O}_{3}$ " J. Am. Cer. Soc. 57, 539-40 (1974).

8. J. B. Ainscough, B. W. Uldfield, and J. O Ware, "Isothermal Grain Growth Kinetics"in Sintered $\mathrm{UO}_{2}$ Peliets," J. Nuc. Mat. 49, 117-128 (1973).

9. R. I. Coble, "Sintering Crystalline Solids: I," J. Appl. Phys, 22 . $787-92(1.961)$,

10. R. I. Coble, "Intermediate-Stage Sintering: Modification and Correction of a Lattice-Diffusion Model," J. Appl. Phys, 36, 2327 (1965).

11. ․ J. Jorgensen and J. H. Westbrook, "Role of Solute Segregation at Grain Boundarles During Final-Stage Sintering of Alumina," J. Am. Cer. Soc. 47, 332-338 (i964).

12. L.. J. Jorgensen ard W. G. Schmidt, "kinal Stage Sintering of ThO 2 ," J. Am. Cer. Soc. 53, 24-27 (1970).

13. D. L. Johnson, "A General Model for the Intermediate Stage of Sintering," J. Am. Cer. Soc. 53, 574-577 (1970).

14. R. L. Coble, "Effects of Particle-Size Distribution in Initial-Stage Sintering," J. Am. Cer. Soc. 56, $461-466$ (1973). 
15. N. A. Haroun and D. W. Budworth, "Effects of Additions of MgO, ZnO and NiO on Grain Growth in Dense Alumina," Trans. Brit. Cer. Soc. 69, 73-79 $(1970)$.

16. I. D. Prendergast, D. W. Budworth, and. N. H. Brett, "Densification and Grain Size Control in Alumina," Brit. Cer. Soc. 71, 31-36 (1972).

17. C. E. Hoge and J. A. Pask, "Thermodynamics of Solid State Sintering," Phys. of Sinter. 5, 109-142 (1973).

18. R. L. Coble, "Ceramic and Metal Sintering: Mechanisms of Material Transport and Density-Limiting Characteristics" in "Fundamental Phenomena in the Material Sciences," Volume 1, Chapt. 2, L. J. Bonis and H. H. Hausner, Eds., pp. 11-23, Plenum Press, New York, 1964.

19. D. I. Johnson and I. Cutler, "Diffusion Sintering: I, Initial Stage Sintering Models ard Their Application to Shrinkage of Power Compacts," J. Am. Cer. Soc. $46,541-544$ (1963).

20. D. L. Johnson and I. Cutler, "Diffusion Sintering: II, Sintering Kinetics of Aiumina," Ibid. 545-550 (1963).

21. R. L. Coble, "Development of Microstructures in Ceramic Systems" in "Ceramic Microstructures," Chapt. 32, R. M. Fulrath and J. A. Pask, Eds., pp. 658-680, John Wiley \& Sons, New York, 1968.

22. J. E. Burke, "Grain Growth" in "Ceramic Microstructures," Chapt. 33, R. M. Fulrath and J. A. Pask, Eds., pp. 681-700, John Wiley \& Sons, New York, 1968.

23. J. E. Burke, "Role of Grain Boundaries in Sintering," J. Am. Cer. Soc. 40 , 80-85 (1957).

24. G. C. Benson, P. I. Freeman, and E. Dempsey, "Calculation of Cohesive and Surface Energies of Thorium and Uranium Dioxide," J. Am. Cer. Soc. 46, 43-4?. (1963).

25. J. F. Lynch, C. G. Rudèrer, and W. H. Duckworth, "Engineering Properties of Selected Ceramic Materials,". Chapt. 5.4, published by the Am. Cer. Soc, Inc, Columbus, Ohio, 1966. 
26. J. H. Rosolowski and C.'Greskovich, "Theory of the Dependence of Densification on Grain Growth During Intermediate-Stage Sintering," J. Am. Cer. Soc. 58, 177-182 (1975).

27. R. I. Coble and J. E. Burke, "Sintering in Ceramics," in "Progress in Ceramic Science, Vol. 3, Chapt. 4, J. E. Burke, Ed., pp. 197-251, Pergamon Press, New York, 1964.

28. F. A. Koreger, "Chemistry of Imperfect Crystals," p. 776, North Holland, 1964.

29. R. I. Taylor, J. P. Coad, and R. J. Brook, "Grain Boundary Segregation in $\mathrm{Al}_{2} \mathrm{O}_{3}$ " "I. Am. Cer. Soc. 57, 539-40 (19'74).

30. C. Zener; reported by C. S. Smith, "Grains, Phases, and Interfaces: An Interpretation of Microstructure," Trans. AIME, 175, 15-51 (1948).

31. G. P. Halbfinger and M. Kolodney, "Activated Sintering of $\mathrm{ThO}_{2}$ and $\mathrm{ThO}_{2}-\mathrm{Y}_{2} \mathrm{O}_{3}$ with $\mathrm{NiO}, " \mathrm{~J}$. Am. Cer. Soc. 55, 519-524 (1972).

32. R. C. Anderson, "Thoria and Yttria" in "High Temperature Oxides - Part II," Chapt. 1, A. M. Alper, Ed., pp. 1-40, Academic Press, New York, 1970.

33. F. A. Nichols, "Theory of Grain Growth in Porous Compacts," J. Appl. Phys. 32, 4599-4602 (1966).

34. F. A. Nichols, "Further Comments on the 'Theory of Grain Growth in Pnrnus Compacts," J. Am. Cer. Soc. 51, 468-69 (1968).

35. I. Cohen, "Effects of Thermal Gradients in Oxide Fuels," WAPD-TM-1092, March 1973.

36. W. D. Kingery, Introduction to Ceranlics, John W1ley, New York, 1960.

37. P. D. Shalek, "Preparation and Properties of Uranium and Thorium. Morioeulfidce," J. Am. Cer. Boe. 46, 155-161 (1963).

38. J. Belle, "Uranium Dioxide," U. S. Gov. Printing Office, Washington, D. C., 1961 .

39. I. Amato, R. L. Colombo, and A. M. Protti, "Influence of Stoichiometry on the Rate of Grain Growth in $\mathrm{UO}_{2}$," J. Am. Cer. Soc. 407 (1963). 
40. P: J. Jorgensen, "Final-Stage Sintering and Grain Growth in Oxides" in "Defects and Transport in Oxides," M. S. Seltzer and R. I. Jaffee, Eds., pp. 379-395, Plenum Press, New York, 1973.

41. S. N. Kaha and A. R. Das, "Isothermal Grain Growth and Sintering in Pure $\mathrm{ThO}_{2}$ and $\mathrm{ThO}_{2}-\mathrm{CaO}$ Compositions," J. Nuc. Mat. 39, 285-291 (1971).

42. H. M. Lee, "Electrical Conductivity of $\mathrm{UO}_{2}-\mathrm{ThO}_{2}$ Solid Solutions," J. Nuc. Mat. $48,107-117$ (1973).

43. M. F. Lasker and R. A. Rapp, Zeit. Phy. Chem. 49, 198 (1966), as reported by R. C. Anderson, "Thoria and Yttria" in. "High Temperature Oxides, Part "II," Chapt. 1, A. M. Alper, Ed., pp. 1-40, Academic Press, Neiw York, 1970.

44. $\therefore$ C. Cleyton, "Thorium Oxide Powder Properties winich are Importent to $\mathrm{ThO}_{2}-\mathrm{ThO}_{2}-\mathrm{UO}_{2}$ Fuel Pellet Fabrication," WAPD-TM-1230, January" 1 y ic.

45. B. Francois and W. D. Kingery, "The Sintering of Crystalline Oxides, II Densification and Microstructure Development in $\mathrm{UO}_{2}$ " in "Sintering and Related Phenomena," G. C. Kuczynski, N. A. Hooton, and C. F. Gibbon, Eds., pp. 499-525, Gordon and Breach, New York, 1967.

46. I. Amato, R. I. Colombo, and A. M. Protti, "On a Case of Solarization During. Steam Sinterlng of UO 2. Pellets,". J. Nuc. Mat. 8, $271-272$ (1963).

47\%. I. Amato and R. L. Colombo, "The Influence of Organic Additions on the $y$ : Solarizätion and Grain Growth of Sintered $\mathrm{UO}_{2}$," ibid. 11, 348-50 (1964).

48. I. Amato, Rit. L. Colombo, and A. M. Protti, "Pore Growth During Solarization of Sintered UO ${ }^{\prime}$ " ibid, 13, 265-68 (1964):

49. C. E. Curtis, "Calcination of Thorium Oxide for Slurries and Suspensions," BNL-483 Thorium-U ${ }^{233}$ Symposium, pp. 119-120, January 9, 1958.

50. R. M. Berman, "Surface Diffusion Measurements in $\mathrm{ThO}_{2}$, $\mathrm{UO}_{2}$ and $\mathrm{ThO}_{2}-\mathrm{UO}_{2}$," WAPD-TM-843, July 1969. 
TABLE 1

Pretreatment and Sintering Schedules for the Production of $100 \% \mathrm{ThO}_{2}$ Pellets

Pretreatment Schedüle

Heating Ra.te
$\left(\mathrm{O}_{\mathrm{C} / \mathrm{hr}}\right)$

50

70

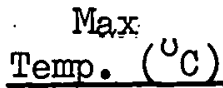
425
Time at Temp. (hrs) 3

\section{Atmosphere}

$\mathrm{CO}_{2}$

Sintering Schedule

1750

12

TABLE 2

Protreatment and sinterine scherlutas for the Production of Binary ThO $2 / \mathrm{UO}_{2}$ Pellets

Pretreatment Schedule

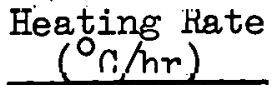

50

50

100

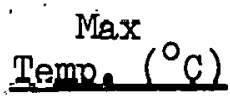

450

925 'lime

Temp. (hrs)

4

3

Sintering Schedule 1750

12
60.2

Atmosphere

$\mathrm{CO}_{2}$

$\mathrm{H}_{2}$ (dry) 


\section{TABLE 3}

\section{Sintering and Density Data for Pellet Structure Study \#1}

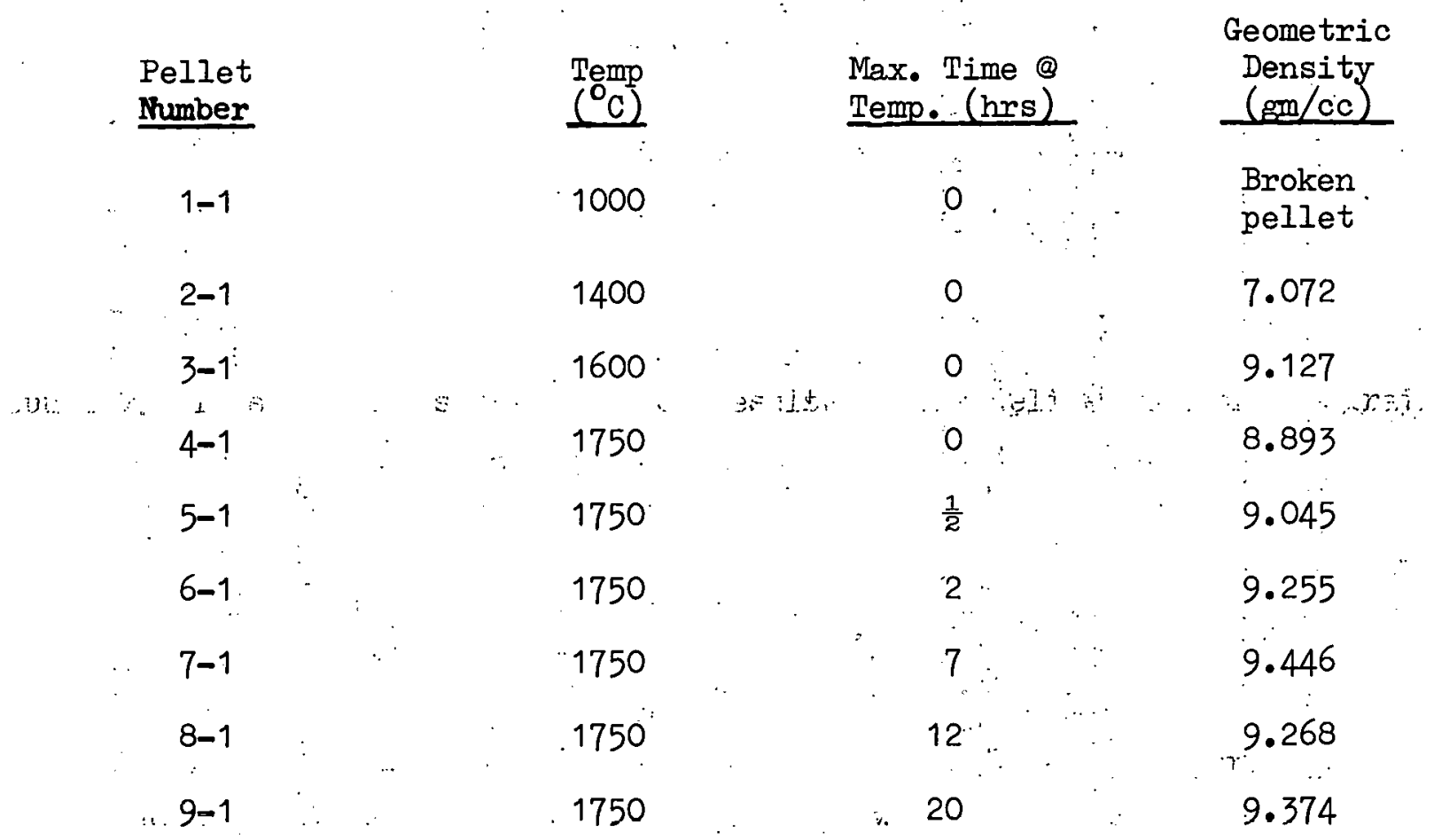

Material: 0.53 inch diameter pellets, Tho $/ \mathrm{CaO}$, Lot $088-1-11$.

Binder/Lubricant: it w/o Carivowax;6000/0.2 w/o. Storotex Ave." Compấcted Green Dénsity: $55 \% \mathrm{TD}$ Pretreatment: ${ }_{50}^{\circ} \mathrm{C} / \mathrm{hr}, 20^{\circ} \mathrm{C}$ to $425^{\circ} \mathrm{C}$ in $\mathrm{CO}_{2}, 3 \mathrm{hrs}$ @ Temp. Ave. Carbon Content after Pretreatment: $1700-3000 \mathrm{ppm}$ Sintering Cond.: : $100^{\circ} \mathrm{C} / \mathrm{hr}, 20^{\circ} \mathrm{C}$ to $1750^{\circ} \mathrm{C}$ in $\mathrm{H}_{2}$, (wet) cooling not controlled 
Sintering and Density Data for Pellet Strucure Study \#2

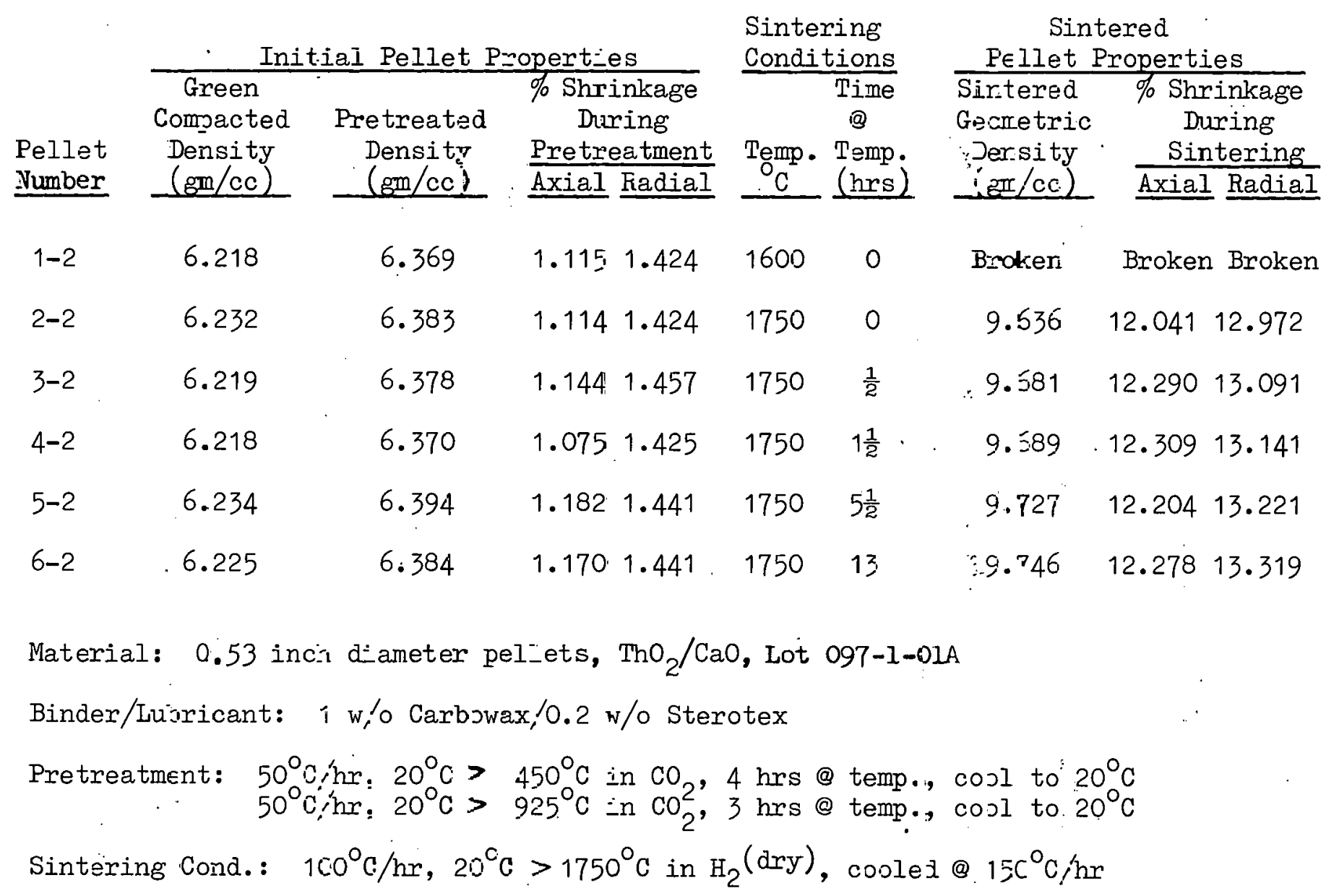


TABLE 5.

Sintering and Density Data for Pellet Structure

Study \#3

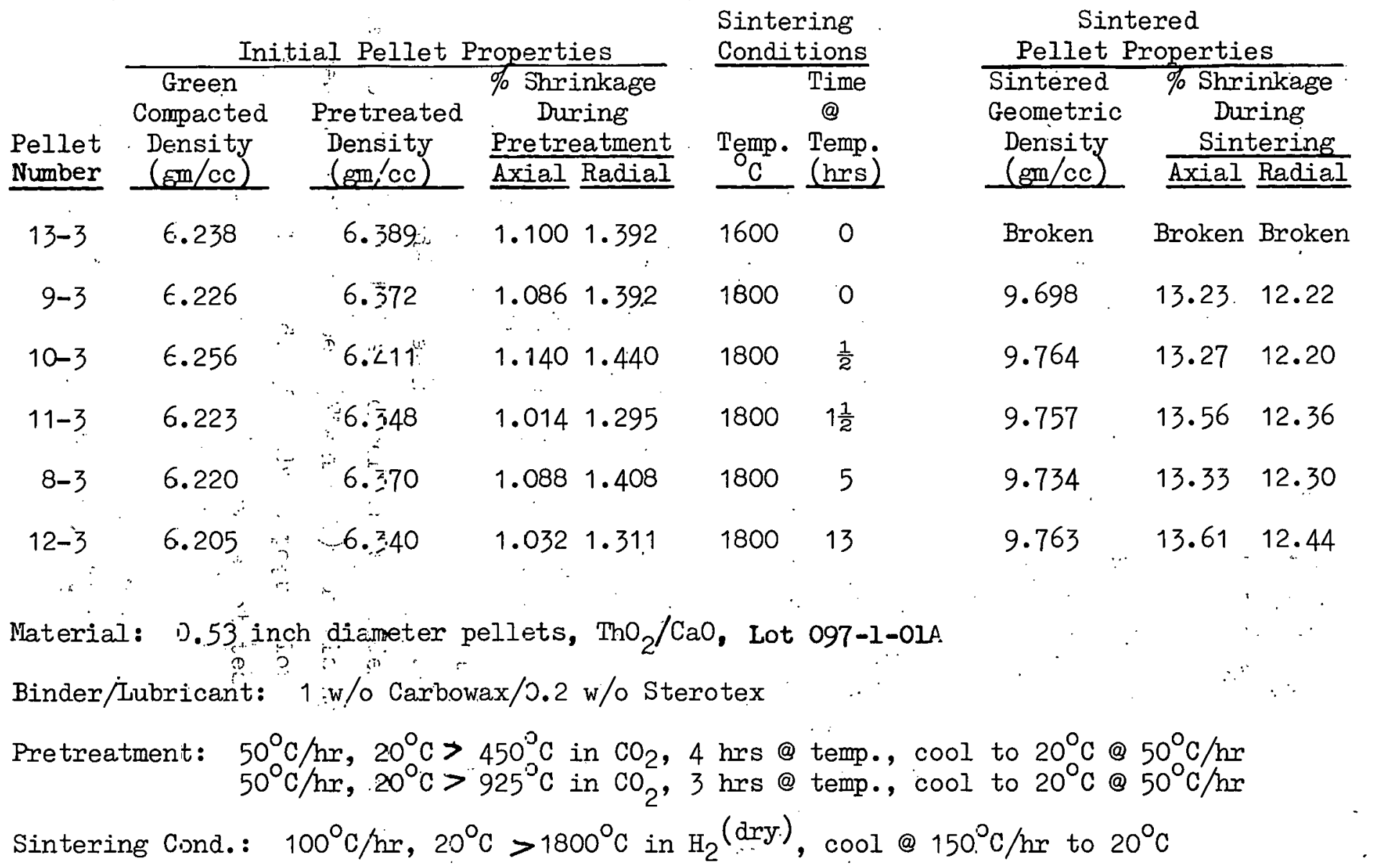


With $48 \mathrm{Hr} ., 1300^{\circ} \mathrm{C}$ Hold Time

\begin{tabular}{|c|c|c|c|c|c|c|c|c|c|}
\hline \multirow[b]{2}{*}{$\begin{array}{l}\text { Pellet } \\
\text { Number }\end{array}$} & \multicolumn{3}{|c|}{ Initial Pellet Properties } & \multicolumn{2}{|c|}{$\begin{array}{l}\text { Sintering } \\
\text { Conditions }\end{array}$} & \multicolumn{4}{|c|}{ Sintered } \\
\hline & $\begin{array}{l}\text { Green } \\
\text { Ccimpacted } \\
\text { Iensity } \\
(\text { sm'cc) }\end{array}$ & $\begin{array}{c}\text { Pretreated } \\
\text { Density } \\
(\mathrm{gm} / \mathrm{cc}) \\
\end{array}$ & $\begin{array}{c}\text { \% Shrinkage } \\
\text { During } \\
\text { Pretreatment } \\
\text { Axial Radial }\end{array}$ & $\begin{array}{c}\text { Temp. } \\
\mathrm{C} \\
\end{array}$ & $\begin{array}{l}\text { Time } \\
\text { @ } \\
\text { Temp. } \\
\text { (hrs) }\end{array}$ & 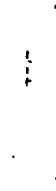 & $\begin{array}{l}\text { Sintered } \\
\text { Geometric } \\
\text { Density } \\
\text { (gm/cc) } \\
\end{array}$ & $\begin{array}{r}\% \text { Sh } \\
\text { D } \\
\text { Sir } \\
\text { Axial } \\
\end{array}$ & $\begin{array}{l}\text { cinkage } \\
\text { lring } \\
\text { tering } \\
\text { Radial } \\
\end{array}$ \\
\hline $24-4$ & 5.237 & 6.185 & 0.04180 .259 & 1300 & 48 & $"$ & 8.867 & - & - \\
\hline $25-4$ & 5.240 & 6.193 & 0.04170 .2751 & 1300 & 48 & 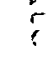 & 8.809 & - & - \\
\hline $26-4$ & 5.196 & 6.167 & $0.028 \quad 0.436$ & 1750 & $\frac{1}{2}$ & $\therefore$ & 9.376 & - & - \\
\hline $29-4$ & 5.211 & 6.154 & 0.06970 .1781 & 1750 & $1 \frac{1}{2}$ & $i$ & 9.372 & - & - \\
\hline $27-4$ & 5.244 & 6.197 & 0.09720 .2590 & 1750 & 5 & & 9.395 & - & - \\
\hline $28-4$ & 5.240 & 6.195 & 0.06950 .2752 & 1750 & 12 & & 9.395 & - & - \\
\hline $30-4^{*}$ & 6.212 & 6.160 & 0.02790 .2266 & $1750^{*}$ & $12^{*}$ & & 9.229 & - & - \\
\hline $31-4^{*}$ & 6.230 & 6.177 & 0.02790 .2104 & $1750^{*}$ & $12^{*}$ & ;. & Broken & Broken & Broken \\
\hline
\end{tabular}

Material: 0.53 inch diameter pellets, $\mathrm{ThC}_{2} / \mathrm{CaO}$, Lot 097-1-01A

Binder/Lubricant: $1 \mathrm{w} / \mathrm{o}$ Carbovax/0.2 w/o Sterotex

Pretreated: $50^{\circ} \mathrm{C} / \mathrm{hr}, 20^{\circ} \mathrm{C}>450^{\circ} \mathrm{C}$ in $\mathrm{CO}_{2}, 4 \mathrm{hrs} @$ temp., co.jl to $20^{\circ} \mathrm{C} @ 50^{\circ} \mathrm{C} / \mathrm{hr}$

Sintering Cond.: $10 \mathrm{C}^{\circ} \mathrm{C} / \mathrm{hr}, 20^{\circ} \mathrm{C}>1300^{\circ} \mathrm{C}$ in $\mathrm{H}_{2}$ (wet), hold for $48 \mathrm{hrs}$ $10 \mathrm{C}^{\circ} \mathrm{C} / \mathrm{hr}, 1300^{\circ} \mathrm{C}>1750^{\circ} \mathrm{C}$ in $\mathrm{H}_{2}$ (wet), cool a $150^{\circ} \mathrm{C} / \mathrm{hr}$ to $20^{\circ} \mathrm{C}$

* Not subjected to $48 \mathrm{hr} ., 1300^{\circ} \mathrm{C}$ hold time. 
Sintering and Density Data for Fuel Pellets Kinetic Study \#?

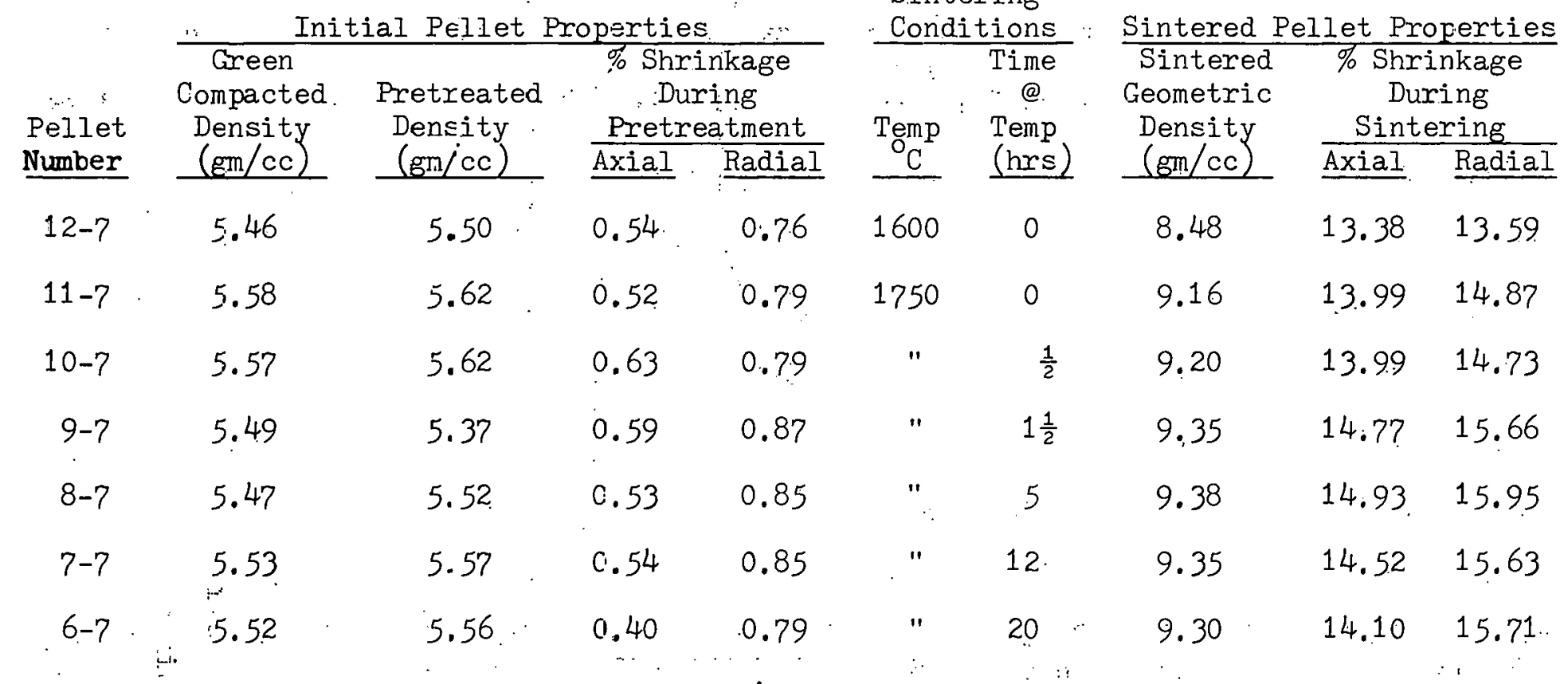

Material: 0.53 inch diamater pellets, $\mathrm{ThO}_{2} / \mathrm{CaO}$, Lot $088-1-16$

Agglomeration: Liquid/Solịds, 1 w/o Cärbowax plus 0.2 w/o Sterotex (added dry).

Pretreatment: $\quad 50^{\circ} \mathrm{C} / \mathrm{hr} 20^{\circ} \mathrm{C}$ to $450^{\circ} \mathrm{C}$ in $\mathrm{CO}_{2}, 4 \mathrm{hrs} @$ temp, cool to $20^{\circ} \mathrm{C}$ $50^{\circ} \mathrm{C} / \mathrm{hr} 20^{\circ} \mathrm{C}$ to $925^{\circ} \mathrm{C}$ in $\mathrm{CO}_{2}^{2}, 3 \mathrm{hrs} @$ temp, cool to $20^{\circ} \mathrm{C}$

Sintering Conditions: $100^{\circ} \mathrm{C} / \mathrm{hr} 20^{\circ} \mathrm{C}$ to $1750^{\circ} \mathrm{C}$ in $\mathrm{H}_{2}($ dry $) \cdots \operatorname{cool} @ 150^{\circ} \mathrm{C} / \mathrm{hr}$ 


\begin{tabular}{|c|c|c|c|c|c|c|c|c|c|}
\hline \multirow[b]{3}{*}{$\begin{array}{l}\text { Pellet } \\
\text { Nunber }\end{array}$} & \multicolumn{4}{|c|}{ nitia: Pellet Frojerti } & \multicolumn{2}{|c|}{$\begin{array}{l}\text { Sintering } \\
\text { Conditions }\end{array}$} & \multirow{3}{*}{$\begin{array}{l}\text { Sintered } \\
\text { Sintered } \\
\text { Jeometric } \\
\text { Density } \\
\text { (gm/cc) }\end{array}$} & \multirow{2}{*}{\multicolumn{2}{|c|}{$\begin{array}{l}\text { 1let Properties } \\
\text { \% Shrinkage } \\
\text { During } \\
\text { Sintering }\end{array}$}} \\
\hline & \multirow{2}{*}{$\begin{array}{c}\text { Green } \\
\text { Compacted } \\
\text { Derisity } \\
\text { (g:n/oc) } \\
\end{array}$} & \multirow{2}{*}{$\begin{array}{l}\text { Pretreated } \\
\text { Density } \\
(\mathrm{gm} / \mathrm{cc}) \\
\end{array}$} & \multirow{2}{*}{\multicolumn{2}{|c|}{$\begin{array}{l}\text { \% Shrinkage } \\
\text { During } \\
\text { Pretreatment }\end{array}$}} & \multirow[b]{2}{*}{$\begin{array}{l}\text { Temp } \\
{ }^{\circ} \mathrm{C} \\
\end{array}$} & \multirow{2}{*}{$\begin{array}{l}\text { Time } \\
@ \\
\text { Temp } \\
\text { (hrs) } \\
\end{array}$} & & & \\
\hline & & & & & & & & $\frac{\text { Sint }}{\text { Axial }}$ & $\frac{\text { ring }}{\text { Radial }}$ \\
\hline $1-9$ & 5.52 & 5.56 & .55 & .86 & 1600 & 0 & 8.610 & 13.42 & 13.90 \\
\hline $2-9$ & 5.52 & 5.56 & .51 & .80 & 1750 & 0 & 9.038 & 14.61 & 15.25 \\
\hline $3-9$ & 5.48 & 5.52 & .57 & .79 & " & $\frac{1}{2}$ & 9.183 & 15.08 & 15.98 \\
\hline $4-9$ & 5.47 & 5.52 & .65 & .87 & $"$ & $1 \frac{1}{2}$ & .9 .323 & 15.48 & 16.44 \\
\hline $5-7$ & 5.51 & 5.57 & .69 & .93 & " & 5 & 9.407 & 15.48 & 16.39 \\
\hline $6-9$ & 5.46 & 5.50 & .58 & .87 & " & 12 & 9.453 & 15.83 & 16.90 \\
\hline $7-9$ & 5.46 & 5.50 & .61 & .79 & " & 20 & $\because 9.4013$ & 15.59 & 16.93 \\
\hline
\end{tabular}

Material: 0,5: inci d"ameter pellets, Thi $2 / \mathrm{CaO}$, Lot 088-1-16

Agglomeration: Liquid/Solids, 1 w/o Carbjwax plus D.2 w/o Sterotex (added dry)

Pretreatment: $\quad 50^{\circ} \mathrm{C} / \mathrm{hr} 20^{\circ} \mathrm{C}$ to $450^{\circ} \mathrm{C}$ in CO, 4 hrs 2 temp, coal to $20^{\circ} \mathrm{C}$ $50^{\circ} \mathrm{C} / \mathrm{hr} 20^{\circ} \mathrm{C}$ to $925^{\circ} \mathrm{C}$ in $\mathrm{CO}_{2}^{2}, 3 \mathrm{hrs}$ temp; coal to $20^{\circ} \mathrm{C}$

Sintering Conditions: $100^{\circ} \mathrm{C} / \mathrm{hr} 20^{\circ} \mathrm{C}$ to $1750^{\circ} \mathrm{C}$ in $\mathrm{H}_{2}{ }^{\left(w e^{\circ}\right)}$; cool @ $150^{\circ} \mathrm{C} / \mathrm{hr}$ 
TABLE 9.

Thoria Pellet Densities

After Thermal Exposure in-Wet Hydrogen

Material: : :Thoria Pellets Produced from Powder Lot 088 and

Pressed to a Green Density of $57 \%$ According to

Standard Thorie Production Procedures

Initial Sinter: $1750^{\circ} \mathrm{C}-12 \mathrm{Hrs}-\mathrm{H}_{2}$ (wet), Dew Point $\approx 43^{\circ} \mathrm{C}$

Second Sinter: $\quad 1800^{\circ} \mathrm{C}-12 \mathrm{Hrs}-\mathrm{H}_{2}$ (wet) , Dew Point $\approx 25^{\circ} \mathrm{C}$

\begin{tabular}{|c|c|c|c|}
\hline $\begin{array}{l}\text { Pellet } \\
\text { Number } \\
\end{array}$ & $\begin{array}{l}\text { Density (gm/cc) } \\
\text { After Exposure } \\
\text { to } 1750^{\circ} \mathrm{C} \text { for } 12^{\prime} \text { Hrs } \\
\end{array}$ & $\begin{array}{l}\text { Density }(\mathrm{gm} / \mathrm{cc}) \text { After } \\
\text { Additional Exposure } \\
\text { to } 1800^{\circ} \mathrm{C} \text { for } 12 \text { Hrs } \\
\end{array}$ & $\begin{array}{c}\text { Change in } \\
\text { Density } \\
(\%) \\
\end{array}$ \\
\hline 1 & 9.763 & 9.693 & -0.717 \\
\hline 2 & 9.885 & 9.781 & -1.05 \\
\hline 3 & 9.883 & 9.916 & +0.35 \\
\hline
\end{tabular}

TABLE 10

Thoria Pellet Densities

After Thermal Exposure iri Vacuum $\left(4.10^{-6}\right.$ torr $)$

Material: $\therefore$ Thoria Pellets Lot 088-1-16ARS Pressed to Green Density of $56 \%$ According to Standard Thoria Production: Frocedures

Initial Sinter: $1750^{\circ}-24 \mathrm{Hrs}-\mathrm{H}_{2}{ }^{\text {(wet) }}$, Dew Point $43^{\circ} \mathrm{C}$

Second Sinter: $1850^{\circ} \mathrm{C}-12 \mathrm{Hrs}-4.10^{-6}$ torr @ Temp

\begin{tabular}{|c|c|c|c|c|c|c|}
\hline \multirow[b]{2}{*}{$\begin{array}{l}\text { Pellet } \\
\text { Number }\end{array}$} & \multicolumn{2}{|c|}{$\begin{array}{l}\text { As-Sintered } \\
\text { Condition }(\mathrm{gm} / \mathrm{cc})\end{array}$} & \multicolumn{2}{|c|}{$\begin{array}{l}\text { Vacuum Heat-Treated } \\
\text { at } 1850^{\circ} \mathrm{C}(\mathrm{gm} / \mathrm{cc})\end{array}$} & \multicolumn{2}{|c|}{$\begin{array}{c}\text { Change in Density } \\
(\%)\end{array}$} \\
\hline & $\begin{array}{l}\text { Geometric } \\
\text { Density }\end{array}$ & $\begin{array}{c}\text { Wet } \\
\text { Density }\end{array}$ & $\begin{array}{l}\text { Geometric } \\
\text { Density }\end{array}$ & $\begin{array}{c}\text { Wet } \\
\text { Density }\end{array}$ & $\begin{array}{l}\text { Geometric } \\
\text { Density }\end{array}$ & $\begin{array}{c}\text { Wet } \\
\text { Density }\end{array}$ \\
\hline 4 & 9.833 & 9.841 & 9.868 & 9.852 & .10 .346 & +0.111 \\
\hline 5 & 9.882 & 9.870 & 9.908 & 9.876 & +0.264 & +0.061 \\
\hline 6 & 9.866 & 9.830 & 9.869 & 9.845 & +0.030 & +0.153 \\
\hline
\end{tabular}




\section{Recrystallization Around Hardness Indentations}

Material: $\mathrm{ThO}_{2}$ Pellets, $0.53 \mathrm{In}$. Dia., Fabricated from

Powder Lot 087 - Green Density $=55 \%$; Sintered Density $=96 \%$

Grain Diameter.

Microns

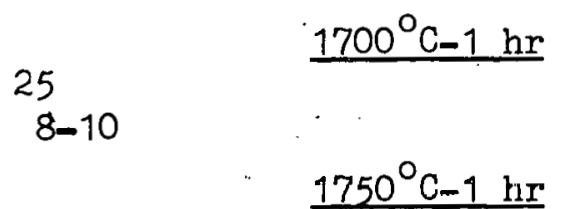

2.5

22.8

13.9

8.3

8.6

7

25

25

31

25

25

25

18

8.2

8

7.4

30

28

19

11

6.5

7.1

7.1

8.3

7.1

7.6

7.1

7.7

7.1

9.1

8.4

19

16.7

25

22

28

22
Ratio of Length of Recrystallized

Zone to Iength of Indentation

Knoop Indentation DPH Indentation

1.38

No recrys. zone

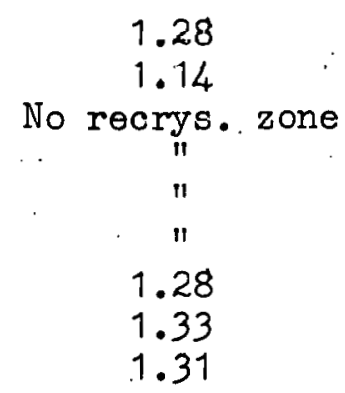

2.2

2.5

1.64

1.43

1.67

1.5

1.4

1.7

1.6

1.8

1.8

1.5

1.3

1.33

1.3

1.3

1.3

1.3

1.4

1.5

1.5

1.7

2

2

2.

1.67

1.67

1.9 
TABLE 12

Recrystallization Around Hardness Indentations in Thorla Fuel Pellets

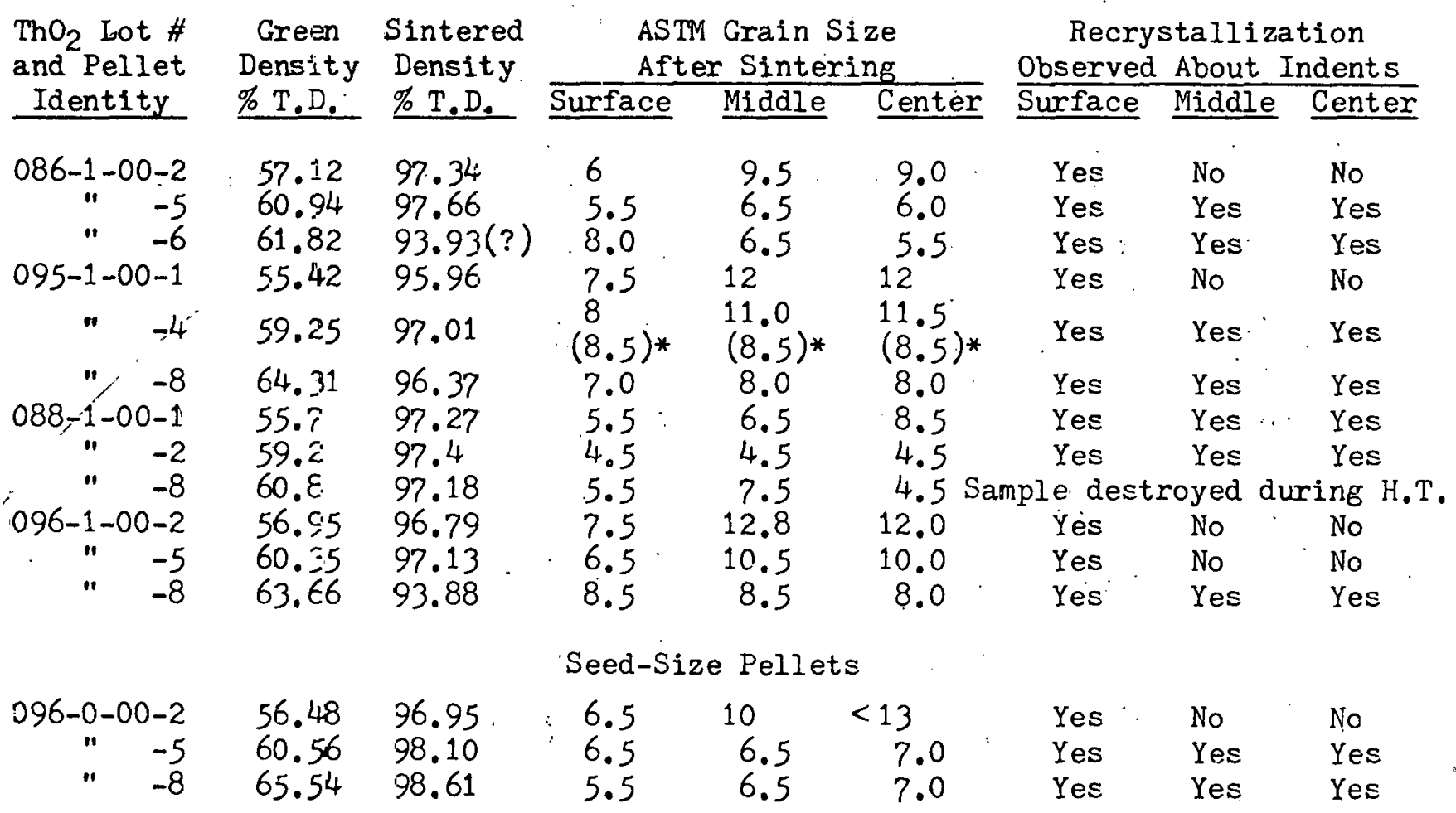

*Grain size measured after recrystalliza.tion treatment. 


\begin{tabular}{|c|c|c|c|c|c|c|c|c|c|c|c|c|c|c|c|c|}
\hline \multirow[b]{2}{*}{$\begin{array}{l}\text { Pellet } \\
\text { Number }\end{array}$} & \multirow[b]{2}{*}{$\begin{array}{l}\text { Pcwder } \\
\text { Lot } \\
\end{array}$} & \multicolumn{3}{|c|}{$\begin{array}{c}\text { Calcine } \\
\text { Corditions } \\
\end{array}$} & \multicolumn{2}{|c|}{$\begin{array}{c}\text { Surface frea } \\
\left(\mathrm{m}^{2} / \mathrm{g}\right) \\
\end{array}$} & \multicolumn{2}{|c|}{$\begin{array}{c}\text { Zabrication } \\
\text { Procedure } \\
\end{array}$} & \multirow{2}{*}{$\begin{array}{l}\text { Green } \\
\text { Jensity: } \\
\text { (gm/cc }\end{array}$} & \multicolumn{3}{|c|}{$\begin{array}{r}\text { Sintering } \\
\text { Conditions } \\
\end{array}$} & \multirow{2}{*}{$\begin{array}{l}\text { Sintered } \\
\text { Densi.ty* } \\
\text { (gm/cc) }\end{array}$} & \multicolumn{2}{|c|}{ Grain Size } & \multirow{2}{*}{$\begin{array}{l}\text { Segregation } \\
\text { Rating } \\
\text { Edge Center }\end{array}$} \\
\hline & & $\begin{array}{l}\text { Temp } \\
\left({ }^{0} \mathrm{C}\right)\end{array}$ & $\begin{array}{r}\text { Time } \\
\text { (hrs) } \\
\end{array}$ & $\underline{\mathrm{Atm}}$ & $\begin{array}{l}\text { After } \\
\text { Calcine }\end{array}$ & $\begin{array}{l}\text { Aftex } \\
\text { Micrc }\end{array}$ & $\begin{array}{l}\text { Binder- } \\
\text { lass } \\
\end{array}$ & $\begin{array}{c}\text { With } \\
\text { Binder } \\
\end{array}$ & & $\begin{array}{r}\begin{array}{r}\text { Time } \\
\text { (hrs) }\end{array} \\
\end{array}$ & $\begin{array}{l}\text { Temp } \\
\text { (c) }\end{array}$ & Atm & & $\begin{array}{c}\text { ESTM \# } \\
0,130,260\end{array}$ & $\begin{array}{c}\text { Diameter } \\
\mu\end{array}$ & \\
\hline $\begin{array}{l}11-57 \\
11-61\end{array}$ & 136 & 1100 & 48 & $\mathrm{H}_{2}$ & 4.42 & 5.91 & & Slurry & $\begin{array}{l}5.820 \\
6.278\end{array}$ & $\begin{array}{l}\text { a } \\
G\end{array}$ & & $\mathrm{H}_{\tilde{z}}(53)$ & $\begin{array}{l}9.22 c, \\
9.51 \varepsilon\end{array}$ & $\begin{array}{l}-0 \frac{1}{2}<14,<14 \\
0,<14,<14\end{array}$ & $\begin{array}{l}9.4,<2.8,<2.8 \\
11.2,<2.8,<2.8\end{array}$ & \\
\hline $\begin{array}{l}9-57 \\
9-61\end{array}$ & & & & & & & & - & $\begin{array}{l}5.876^{\prime} \\
6.204\end{array}$ & $\begin{array}{l}0.5 \\
0.5\end{array}$ & & & $\begin{array}{l}9.350 \\
9.60 .2\end{array}$ & $\begin{array}{l}3 ;<14,<14 \\
y_{i}<14,<14\end{array}$ & $\begin{array}{l}15.9,<2.8,<2.8 \\
15.9,<2.8,<2.8\end{array}$ & \\
\hline $\begin{array}{l}6-57 \\
6-61\end{array}$ & & & & & & & & & $\begin{array}{l}5.837 \\
6.160\end{array}$ & $\begin{array}{l}1 \\
1\end{array}$ & & & $\begin{array}{l}9.468 \\
9.5: 5\end{array}$ & & & 1 \\
\hline $\begin{array}{l}5-57 \\
5-61\end{array}$ & & & & & & . & & & $\begin{array}{l}5.842 \\
6.191\end{array}$ & $\begin{array}{l}1.5 \\
1.5\end{array}$ & . & & $\begin{array}{l}9.431 \\
9.636\end{array}$ & $\begin{array}{l}3 \frac{1}{2}, \therefore 14,<14 \\
10, \therefore 3 \frac{1}{2},-3 \frac{1}{2}\end{array}$ & $\begin{array}{l}18.9,<2.8,<2.8 \\
11.2,3.3 .3 .3\end{array}$ & \\
\hline $\begin{array}{l}7-57 \\
7-61\end{array}$ & & & & & & . & & & $\begin{array}{l}5.837 \\
6.241\end{array}$ & $\begin{array}{l}5 \\
5\end{array}$ & & & $\begin{array}{l}9.5=2 \\
9.6 .54\end{array}$ & $\begin{array}{l}7 \frac{1}{2},=4,14 \\
10 \frac{1}{2} .12 \frac{1}{2}, 12\end{array}$ & $\begin{array}{l}13.4,2.8,2.8 \\
9.4,4.7,4.7\end{array}$ & 1 \\
\hline $\begin{array}{l}2-55 \\
3-57 \\
2-59 \\
3-61 \\
2-63 \\
2-65\end{array}$ & & & . & & & . & & & $\begin{array}{l}5.585 \\
5.841 \\
5.954 \\
6.256 \\
6.406 \\
6.644\end{array}$ & $\begin{array}{l}12 \\
12 \\
12 \\
12 \\
12 \\
12\end{array}$ & & & $\begin{array}{l}9.5-2 \\
9.6+9 \\
9.634 \\
9.750 \\
9.7+3 \\
9.6 .54\end{array}$ & $\begin{array}{l}12,=14,<14 \\
1 C,-4,1+4 \\
1 C \frac{1}{2},<1+,<14 \\
9 \frac{\pi}{2}, 5,5,5.5 \\
16,5,5 \\
11,5.5\end{array}$ & $\begin{array}{l}11.2,<2,8,<2.8 \\
11,2,2.8,2,8 \\
9.4,<2.8,<2.8 \\
13.4,53.4,53.4 \\
11.2,64,64 \\
7.9,64,64\end{array}$ & 1 \\
\hline $\begin{array}{l}1-57 \\
1-61\end{array}$ & & & & & : & & & & $\begin{array}{l}5.819 \\
6.197\end{array}$ & $\begin{array}{l}22 \\
22\end{array}$ & & & $\begin{array}{l}9.627 \\
9.657\end{array}$ & $\begin{array}{l}1\left(\frac{1}{2}, 12 \frac{1}{2}, 12\right. \\
10,5,5,5\end{array}$ & $\begin{array}{l}9.4,4.7,5.6 \\
11.2,64,64\end{array}$ & 1 \\
\hline $\begin{array}{l}1-57 \\
2-61\end{array}$ & 096 & 1100 & 48 & $\mathrm{H}_{2}$ & 4.?? & 5.82 & & Slurry & $\begin{array}{l}5.726 . \\
6.139\end{array}$ & $\begin{array}{l}j \\
0\end{array}$ & & $\mathrm{H}_{2}^{(53)}$ & $\begin{array}{l}9.301 \\
9.630\end{array}$ & $\begin{array}{l}8,<14,<14 \\
0 \div, 13,12\end{array}$ & $\begin{array}{l}22.4,<2.8,<2.8 \\
13.4,4.0,5.6\end{array}$ & \\
\hline $\begin{array}{l}2-57 \\
4-51\end{array}$ & & & & & & 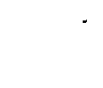 & & & $\begin{array}{l}5.830 \\
6.232\end{array}$ & $\begin{array}{l}0.5 \\
0.5\end{array}$ & & & $\begin{array}{l}9 . \dot{3} 4 \\
9.18\end{array}$ & $8 \frac{1}{2}, 10, \frac{1}{2}$ & $18.9,11.2,13.4$ & \\
\hline $\begin{array}{l}3-57 \\
5-61\end{array}$ & & & & & & . & & & $\begin{array}{l}5.778 \\
6.21 \varepsilon\end{array}$ & $\stackrel{1}{1}$ & & & $\begin{array}{l}9.512 \\
9 . \leqslant 27\end{array}$ & . & · & \\
\hline $\begin{array}{l}4-5 ? \\
8-61\end{array}$ & & & & & & & . & & $\begin{array}{l}5.76 c \\
\epsilon .21 \varepsilon\end{array}$ & $\begin{array}{l}1.5 \\
1.5\end{array}$ & $!$ & & $\begin{array}{l}9.246 \\
9.641\end{array}$ & $\begin{array}{l}7,14,14 \\
9, \frac{-2}{2}, 5\end{array}$ & $\begin{array}{l}32,2.8,2.8 \\
-, 13.4,15.9\end{array}$ & \\
\hline $\begin{array}{l}5-57 \\
6-61\end{array}$ & $\stackrel{\vec{N}}{0}$ & & & & & & & & $\begin{array}{l}.6 .65 c \\
6.25 \varepsilon\end{array}$ & $\begin{array}{l}5 \\
5\end{array}$ & & & $\begin{array}{l}9.619 \\
9.6266\end{array}$ & $\begin{array}{l}5,13,13 \\
8 \frac{1}{2}, 8 \frac{1}{2}, 8 \frac{1}{2}\end{array}$ & $\begin{array}{l}64.0,4 \cdot 0,4 \cdot 0 \\
18 \cdot 9,18 \cdot 9,18.9\end{array}$ & \\
\hline
\end{tabular}


Summary of Thoria Pellet and Powder Properties

\begin{tabular}{|c|c|c|c|c|c|c|c|c|c|c|c|c|c|c|c|c|}
\hline \multirow[b]{2}{*}{$\begin{array}{l}\text { Pelle: } \\
\text { Number }\end{array}$} & \multirow[b]{2}{*}{$\begin{array}{l}\text { Fowder } \\
\text { Lot } \\
\end{array}$} & \multicolumn{3}{|c|}{$\begin{array}{c}\text { Calcine } \\
\text { Conditions }\end{array}$} & \multicolumn{2}{|c|}{$\begin{array}{l}\text { Surface Area } \\
\left(\mathrm{m}^{2} / g\right)\end{array}$} & \multicolumn{2}{|c|}{$\begin{array}{c}\text { Fabrication } \\
\text { Procedure }\end{array}$} & \multirow{2}{*}{$\begin{array}{l}\text { Green } \\
\text { Density* } \\
\text { (gm/cc) }\end{array}$} & \multicolumn{2}{|c|}{$\begin{array}{r}\text { Sintering } \\
\text { Conditions } \\
\end{array}$} & \multirow{2}{*}{$\begin{array}{l}\text { Sintered } \\
\text { Density* } \\
(\mathrm{gm} / \mathrm{cc})\end{array}$} & \multicolumn{2}{|c|}{ Grain Size } & \multirow{2}{*}{\multicolumn{2}{|c|}{$\begin{array}{l}\text { Segregation } \\
\text { Rating } \\
\end{array}$}} \\
\hline & & $\begin{array}{l}\text { Temp } \\
\left({ }^{\circ} \mathrm{C}\right)\end{array}$ & $\begin{array}{l}\text { Tine } \\
\text { (hrs) }\end{array}$ & At.m & $\begin{array}{l}\text { After } \\
\text { Calcine } \\
\end{array}$ & $\begin{array}{l}\text { After } \\
\text { Micro }\end{array}$ & $\begin{array}{l}\text { Binder- } \\
\text { less } \\
\end{array}$ & $\begin{array}{c}\text { Wi=h } \\
\text { Binder }\end{array}$ & & $\begin{array}{r}\text { Time Temp } \\
\text { (hrs) } \\
\left.\text { ( }{ }^{\circ} \mathrm{C}\right)\end{array}$ & Atm & & $\begin{array}{c}\text { ASTM \# } \\
0,130,260 \\
\end{array}$ & $\begin{array}{c}\text { Diameter } \\
\mu\end{array}$ & & \\
\hline $\begin{array}{l}2-55 \\
P \\
2-59 \\
10-6= \\
4-63 \\
4-65\end{array}$ & 096 & 1100 & 48 & $\mathrm{H}_{2}$ & $4.7 ?$ & 5.82 & . & Slurry & $\begin{array}{l}5.600 \\
5.712 \\
5.954 \\
6.185 \\
6.337 \\
6.630\end{array}$ & $\begin{array}{l}12 \\
12 \\
12 \\
12 \\
12 \\
12\end{array}$ & $\mathrm{H}_{2}(53)$ & $\begin{array}{l}9.638 \\
9.694 \\
9.714 \\
9.678 \\
9.635 \\
9.519\end{array}$ & $\begin{array}{l}8 \frac{1}{2}, 13 \frac{1}{2}, 13 \frac{1}{2} \\
8 \frac{1}{2}, 12,12 \\
8 \frac{1}{2}, 10,8 \frac{1}{2} \\
8 \frac{1}{2}, 8,8 \\
10 \frac{1}{2}, 10,10 \\
10 \frac{1}{2}, 11,11\end{array}$ & $\begin{array}{l}18.9,3 \cdot 3,3.3 \\
18.9,5.6,5.6 \\
18.9,11.2,18.9 \\
18.9,22.4,22.4 \\
9.4,11.2,11.2 \\
9.4,7.9,7.9\end{array}$ & & 1 \\
\hline$\stackrel{T}{11-6:}$ & & & & & & & & & $\begin{array}{l}5.827 \\
6.195\end{array}$ & $\begin{array}{l}22 * * * \\
22\end{array}$ & & $\begin{array}{l}9.669 \\
9.639\end{array}$ & $\begin{array}{l}8,7 \frac{1}{2}, 7 \frac{1}{2} \\
8,8,8\end{array}$ & $\begin{array}{l}22,4,27,27 \\
22.4,22,4,22,4\end{array}$ & & $\begin{array}{l}1 \\
1\end{array}$ \\
\hline $\begin{array}{l}4-3 \\
4-15\end{array}$ & 136 & 1100 & 48 & Air & 2.82 & 5.55 & & Sluery & $\begin{array}{l}5.705 \\
6.150\end{array}$ & $\begin{array}{l}0 \\
0\end{array}$ & $\mathrm{H}_{2}{ }^{(53)}$ & $\begin{array}{l}8.997 \\
9.247\end{array}$ & $\begin{array}{l}11,<14,<14 \\
10 \frac{1}{2},<14,<14\end{array}$ & $\begin{array}{l}7.9,<2.8,<2.8 \\
9.4,<2.8,<2.8\end{array}$ & $\begin{array}{l}1 \\
2\end{array}$ & $\begin{array}{l}3 \\
1\end{array}$ \\
\hline $\begin{array}{l}4-5 \\
4-17\end{array}$ & & & & & & & & & $\begin{array}{l}5.729 \\
6.153\end{array}$ & $\begin{array}{l}0.5 \\
0.5\end{array}$ & & $\begin{array}{l}9.029 \\
9.312\end{array}$ & $\begin{array}{l}11,<14,<14 \\
9 \frac{1}{2},<14,<14\end{array}$ & $\begin{array}{l}7.9,<2.8 .<2.8 \\
13.4,<2.8,<2.8\end{array}$ & $\begin{array}{l}4 \\
1\end{array}$ & $\begin{array}{l}6 \\
1\end{array}$ \\
\hline $\begin{array}{l}4-9 \\
4-2\end{array}$ & & & & & & & & & $\begin{array}{l}5.714 \\
6.110\end{array}$ & $\begin{array}{l}1.5 \\
1.5\end{array}$ & & $\begin{array}{l}9.182 \\
8.952\end{array}$ & $\begin{array}{l}9,<14,<14 \\
9,<14,<14\end{array}$ & $\begin{array}{l}15.9,<2.8,<2.8 \\
15.9,<2.8,<2.8\end{array}$ & $\begin{array}{l}2 \\
2\end{array}$ & $\begin{array}{l}1 \\
2\end{array}$ \\
\hline $\begin{array}{l}4-1 i \\
4-23\end{array}$ & & & & & & & & & $\begin{array}{l}5.666 \\
6.133\end{array}$ & $\begin{array}{l}5 \\
5\end{array}$ & & $\begin{array}{l}9.334 \\
9.542\end{array}$ & $\begin{array}{l}10 \frac{1}{2}, 14,<14 \\
10 \frac{1}{2}, 13,13\end{array}$ & $\begin{array}{l}9.4,2.8,<2.8 \\
9.4,4.0,4.0\end{array}$ & $\begin{array}{l}2 \\
4\end{array}$ & $\begin{array}{l}1 \\
3\end{array}$ \\
\hline $\begin{array}{l}4-25 \\
4-1 \\
4-29 \\
4-13 \\
4-33 \\
4-3 ?\end{array}$ & & & & & & & & & $\begin{array}{l}5.574 \\
5.702 \\
5.954 \\
6.114 \\
6.334 \\
6.544\end{array}$ & $\begin{array}{l}12 \\
12 \\
12 \\
12 \\
12 \\
12\end{array}$ & & $\begin{array}{l}9.418 \\
9.420 \\
9.424 \\
9.521 \\
9.577 \\
9.554\end{array}$ & $\begin{array}{l}9,12 \frac{1}{2}, 12 \frac{1}{2} \\
9 \frac{1}{2}, 12,12 \frac{1}{2} \\
10 \frac{1}{2}, 11,11 \\
10 \frac{1}{2}, 10 \frac{1}{2}, 10 \frac{1}{2} \\
9,7 \frac{1}{2}, 7 \frac{1}{2} \\
9 \frac{1}{2}, 6,6\end{array}$ & $\begin{array}{l}15.9,4 \cdot 7,4.7 \\
13.4,5.6,6.7 \\
9.4,7 \cdot 9,7.9 \\
9.4,9.4,9.4 \\
15.9,27,27 \\
13.4,45,45\end{array}$ & $\begin{array}{l}3 \\
3 \\
3 \\
4 \\
3 \\
1\end{array}$ & $\begin{array}{l}4 \\
3 \\
3 \\
3 \\
2 \\
1\end{array}$ \\
\hline $\begin{array}{l}4-6 \\
4-18\end{array}$ & & & & & & & & & $\begin{array}{l}5.694 \\
6.212\end{array}$ & $\begin{array}{l}22 \\
22\end{array}$ & & - & $\begin{array}{l}8 \frac{1}{2}, 9 \frac{1}{2}, 10 \\
9 \frac{1}{2}, 5,9 .\end{array}$ & $\begin{array}{l}18.9,13 \cdot 4,11.2 \\
13.4,64,15.9\end{array}$ & $\begin{array}{l}4 \\
5\end{array}$ & $\begin{array}{l}6 \\
4\end{array}$ \\
\hline
\end{tabular}

Pellets Sintered in a Subsequent Sintering Run (With Pellets of $\mathrm{H}_{2}$ Calcined Material)

\begin{tabular}{|c|c|c|c|c|c|c|c|c|c|c|c|}
\hline $\begin{array}{l}4-26 \\
4-30 \\
4-34 \\
4-38\end{array}$ & 136 & 1100 & 48 & Air & 2.82 & $\begin{array}{c}5.55 \\
\therefore \quad:\end{array}$ & Slumry. & $\begin{array}{l}5.608 \\
5.943 \\
6.382 \\
6.521\end{array}$ & $\begin{array}{l}12 \\
12 \\
12 \\
12\end{array}$ & $\mathrm{H}_{2}{ }^{(53)}$ & $\begin{array}{l}9.315 \\
9.417 \\
9.515 \\
9.594\end{array}$ \\
\hline
\end{tabular}




\begin{tabular}{|c|c|c|c|c|c|c|c|c|c|c|c|c|c|c|c|c|c|}
\hline \multirow{2}{*}{$\begin{array}{l}\text { Pellet } \\
\text { Number }\end{array}$} & \multirow[b]{2}{*}{$\begin{array}{l}\text { Powder } \\
\text { Lot } \\
\end{array}$} & \multicolumn{3}{|c|}{$\begin{array}{l}\text { Calcine } \\
\text { Conditions }\end{array}$} & \multicolumn{2}{|c|}{$\begin{array}{l}\text { Surfice frea } \\
\left(n^{2} f i\right.\end{array}$} & \multicolumn{2}{|c|}{$\begin{array}{c}\text { Fabrication } \\
\text { Frocedure }\end{array}$} & \multirow{2}{*}{$\begin{array}{l}\text { Creen } \\
\text { Density } \\
\text { (gm/cc) }\end{array}$} & \multicolumn{3}{|c|}{$\begin{array}{r}\text { Sintering } \\
\text { Conditions }\end{array}$} & \multirow{2}{*}{$\begin{array}{l}\text { Sintezed } \\
\text { Iensi-z* } \\
\text { (gm/c } / 2)\end{array}$} & \multicolumn{2}{|c|}{ Grain Size } & \multirow{2}{*}{\multicolumn{2}{|c|}{$\begin{array}{l}\text { Segregation } \\
\text { Rating }\end{array}$}} \\
\hline & & $\begin{array}{l}\text { Temp } \\
\text { (C) }\end{array}$ & $\begin{array}{r}\text { Time } \\
(\mathrm{hrs}) \\
\end{array}$ & s.tm & $\begin{array}{l}\text { After } \\
\text { Calcine }\end{array}$ & $\begin{array}{l}\text { ifter } \\
\text { Micro }\end{array}$ & $\begin{array}{l}\text { Binder- } \\
\text { less }\end{array}$ & $\begin{array}{l}\text { With } \\
\text { Binjer }\end{array}$ & & $\begin{array}{l}\text { Time } \\
\text { (hrs) }\end{array}$ & $\begin{array}{l}\text { Temp } \\
\left({ }^{\circ} \mathrm{C}\right)\end{array}$ & Atm & & $\begin{array}{l}\text { ASTM \# } \\
130,260\end{array}$ & $\underset{\mu}{\substack{\text { Diameter } \\
\mu}}$ & & \\
\hline $\begin{array}{l}3-3 \\
3-15\end{array}$ & $\overline{096}$ & 1100 & 48 & $\operatorname{sir}$ & 3.52 & 5.29 & & Slurry & $\begin{array}{l}5.837 \\
6.101\end{array}$ & $\begin{array}{l}0 \\
0\end{array}$ & . & $\overline{\mathrm{H}_{2}} \overline{(53)}$ & $\begin{array}{l}8.243 \\
8.780\end{array}$ & 14,14 & $2.8,2.8$ & 7 & $\begin{array}{l}? \\
?\end{array}$ \\
\hline $\begin{array}{l}3-5 \\
3-17\end{array}$ & & & & & & & & & $\begin{array}{l}5.801 \\
6.185\end{array}$ & $\begin{array}{l}0.5 \\
0.5\end{array}$ & & & $\begin{array}{l}8.105 \\
8.930\end{array}$ & $\begin{array}{l}12 \frac{1}{2}, 12 \frac{1}{2} \\
12 \frac{\bar{m}}{2}, 13\end{array}$ & $\begin{array}{l}4.7 .4 . ? \\
4.7,4.0\end{array}$ & $\begin{array}{l}7 \\
7\end{array}$ & $\begin{array}{l}7 \\
7\end{array}$ \\
\hline $\begin{array}{l}3-7 \\
3-19\end{array}$ & & & & & & & & & $\begin{array}{l}5.848 \\
6.180\end{array}$ & $\begin{array}{l}1 \\
1\end{array}$ & & & $\begin{array}{l}8.19: 0 \\
9.055\end{array}$ & & . & $\begin{array}{l}? \\
?\end{array}$ & $\begin{array}{l}? \\
7\end{array}$ \\
\hline $\begin{array}{l}3-9 \\
3-21\end{array}$ & & & & & & & & & $\begin{array}{l}5.802 \\
6.12 C\end{array}$ & $\begin{array}{l}1.5 \\
1.5\end{array}$ & & & $\begin{array}{l}8.374 \\
9.110\end{array}$ & $\begin{array}{l}13 \frac{2}{2}, 13 \\
12,11 \frac{1}{2}\end{array}$ & $\begin{array}{l}3.3,4.0 \\
5.6,6.7\end{array}$ & $\frac{7}{6}$ & $\begin{array}{l}7 \\
6\end{array}$ \\
\hline $\begin{array}{l}3-11 \\
3-23\end{array}$ & & & & & & & & & $\begin{array}{l}5.856 \\
6.102\end{array}$ & $\begin{array}{l}5 \\
5\end{array}$ & & & $\begin{array}{l}8.35+ \\
9.21 .5\end{array}$ & $\begin{array}{l}11 \frac{3}{\frac{3}{2}}, 12 \\
10 \frac{2}{4}, 10 \frac{1}{4}\end{array}$ & $\begin{array}{l}6.7,5.6 \\
10.9,10.9\end{array}$ & $\begin{array}{l}7 \\
6\end{array}$ & $\begin{array}{l}? \\
6\end{array}$ \\
\hline $\begin{array}{l}3-25 \\
3-1 \\
3-29 \\
3-13 \\
3-33 \\
3-37\end{array}$ & & & & & & & & & $\begin{array}{l}5.610 \\
5.739 \\
5.940 \\
6.120 \\
6.350 \\
6.662\end{array}$ & $\begin{array}{l}12 \\
12 \\
12 \\
12 \\
12 \\
12\end{array}$ & & & $\begin{array}{l}8.259 \\
8.54 ! \\
9.005 \\
9.15+ \\
9.183 \\
9.217\end{array}$ & $\begin{array}{l}11,12 \frac{1}{2} \\
1 C \frac{1}{2}, 10 \frac{1}{2} \\
11,11 \frac{1}{2} \\
9,9 \\
7,7 \frac{1}{2} \\
7, ?\end{array}$ & $\begin{array}{l}7.9,4.7 \\
9.4,9.4 \\
79,6.7 \\
15.9,15.9 \\
32,27 \\
32.32\end{array}$ & $\begin{array}{r}7 \\
7 \\
7 \\
-6 \\
6 \\
3\end{array}$ & $\begin{array}{l}7 \\
7 \\
7 \\
6 \\
6 \\
3\end{array}$ \\
\hline $\begin{array}{l}2-3 \\
2-15\end{array}$ & 136 & $A s-R e$ & ceived & & & $3.1 c$ & & Slurry & $\begin{array}{l}5.81 ? \\
6.131\end{array}$ & $\begin{array}{l}0 \\
0\end{array}$ & 1750 & $\mathrm{H}_{\bar{\alpha}}(53)$ & $\begin{array}{l}9.455 \\
9.6 \pi \pi^{4}\end{array}$ & $11 \frac{1}{2}, 11 \frac{1}{2}$ & $6.7,6.7$ & $\begin{array}{l}? \\
?\end{array}$ & $\begin{array}{l}? \\
7\end{array}$ \\
\hline $\begin{array}{l}2-5 \\
2-17\end{array}$ & & & & & & & & & $\begin{array}{l}5.835 \\
5.135\end{array}$ & $\begin{array}{l}0.5 \\
0.5\end{array}$ & & & $\begin{array}{l}9.491 \\
9.6=4\end{array}$ & $\begin{array}{l}13,13 \\
12,12\end{array}$ & $\begin{array}{l}4.0,4.0 \\
5.6,5.6\end{array}$ & $\frac{7}{6}$ & $\begin{array}{l}6 \\
5\end{array}$ \\
\hline $\begin{array}{l}2-9 \\
2-21\end{array}$ & & & & & & & & & $\begin{array}{l}5.73 ? \\
5.176\end{array}$ & $\begin{array}{l}1.5 \\
1.5\end{array}$ & & & $\begin{array}{l}9.549 \\
9.659\end{array}$ & $\begin{array}{l}12 \frac{1}{2}, 12 \frac{1}{2} \\
10 \frac{1}{2}, 10\end{array}$ & $\begin{array}{l}4.7,4.7 \\
9.4,11.2\end{array}$ & $\begin{array}{l}7 \\
?\end{array}$ & $\begin{array}{l}7 \\
5\end{array}$ \\
\hline $\begin{array}{l}2-11 \\
2-23\end{array}$ & & & & & & & & & $\begin{array}{l}5.779 \\
5.196\end{array}$ & $\begin{array}{l}5 \\
5\end{array}$ & & & $\begin{array}{l}9.610 \\
9.74 .7 .\end{array}$ & 12,12 & $5.6,5.6$ & $\begin{array}{l}7 \\
4\end{array}$ & $\begin{array}{l}7 \\
4\end{array}$ \\
\hline & & & & & $s_{\text {ir }}$ & ered $=\mathrm{n}$ & a Subse & $t \leq 1:$ & ng Ru & Wi & el & 01 & Ilcined: & 1aterial) & & & \\
\hline $\begin{array}{l}3-26 \\
3-30 \\
3-34 \\
3-38\end{array}$ & 096 & 1100 & 48 & Air & 3.52 & 5.29 & & sluxry & $\begin{array}{l}5.623 \\
5.547 \\
6.356 \\
6.620\end{array}$ & $\begin{array}{l}12 \\
12 \\
12 \\
12\end{array}$ & & $\mathrm{H}_{2}{ }^{(53)}$ & $\begin{array}{l}8.487 \\
9.295 \\
9.483 \\
9.388\end{array}$ & & & $\begin{array}{l}\mathrm{N} / \mathrm{A} \\
" . \\
"\end{array}$ & $\begin{array}{c}6 \\
N / A \\
2 \\
N / A\end{array}$ \\
\hline
\end{tabular}


TABLE 13 (Cont'd.)

Summary of Thoria Pellet and Powder Properties

\begin{tabular}{|c|c|c|c|c|c|c|c|c|c|c|c|c|c|c|c|c|c|}
\hline \multirow[b]{2}{*}{$\begin{array}{l}\text { Pellet } \\
\text { Number }\end{array}$} & \multirow[b]{2}{*}{$\begin{array}{l}\text { Powder } \\
\text { Lot }\end{array}$} & \multicolumn{3}{|c|}{$\begin{array}{l}\text { Calcine } \\
\text { Conditions }\end{array}$} & \multicolumn{2}{|c|}{$\begin{array}{c}\text { Surface Area } \\
\left(\mathrm{m}^{2} / \mathrm{g}\right)\end{array}$} & \multicolumn{2}{|c|}{$\begin{array}{c}\text { Fatricaticn } \\
\text { Procedure }\end{array}$} & \multirow{2}{*}{$\begin{array}{l}\text { Green } \\
\text { Density* } \\
\text { (gm/cc) }\end{array}$} & \multicolumn{3}{|c|}{$\begin{array}{r}\text { Sintering } \\
\text { Conditions }\end{array}$} & \multirow{2}{*}{$\begin{array}{l}\text { Sintered } \\
\text { Density* } \\
(\mathrm{gm} / \mathrm{cc})^{*}\end{array}$} & \multicolumn{2}{|c|}{ Grain Size } & \multicolumn{2}{|c|}{$\begin{array}{l}\text { Segregatior } \\
\text { Rating }\end{array}$} \\
\hline & & $\begin{array}{l}\text { Tem? } \\
\left({ }^{\circ} \mathrm{C}\right)\end{array}$ & $\begin{array}{l}\text { Time } \\
\text { (hris) }\end{array}$ & Atm & $\begin{array}{l}\text { After } \\
\text { Calcine }\end{array}$ & $\begin{array}{l}\text { After } \\
\text { Micro } \\
\end{array}$ & $\begin{array}{l}\text { Binder- } \\
\text { less }\end{array}$ & $\begin{array}{c}\text { With } \\
\text { Birder }\end{array}$ & & $\begin{array}{l}\text { Time } \\
\text { (hrs) }\end{array}$ & $\begin{array}{l}\text { Temp } \\
\left.{ }^{\circ} \mathrm{C}\right) \\
\end{array}$ & $\mathrm{Atm}$ & & $\begin{array}{l}\text { ASTM \# } \\
130,260 \\
\end{array}$ & $\begin{array}{c}\text { Diameter } \\
\mu\end{array}$ & $\frac{\text { Rat }}{\text { Edge }}$ & $\frac{\text { ing }}{\text { Ceriter }}$ \\
\hline$\therefore \begin{array}{l}2-25 \\
2-1 \\
2-29 \\
2-13 \\
2-33 \\
2-37\end{array}$ & 136 & As-Re & $\begin{array}{l}\text { cèived } \\
:\end{array}$ & . & . & $8 . \therefore 0$ & . & Slurry & $\begin{array}{l}5.636 \\
5.796 \\
6.032 \\
6.165 \\
6.382 \\
6.511\end{array}$ & $\begin{array}{l}12 \\
12 \\
12 \\
12 \\
12 \\
12\end{array}$ & 1750 & $\mathrm{H}_{2}(5.3)$ & $\begin{array}{l}9.545 \\
9.598 \\
9.720 \\
9.759 \\
9.723 \\
9.706\end{array}$ & $\begin{array}{l}13,13 \\
11,10 \\
9 \frac{1}{2}, 9 \frac{1}{2} \\
9,9 \\
6 \frac{1}{2}, 6 \frac{1}{2} \\
6 \frac{1}{2}, 8\end{array}$ & $\begin{array}{l}4.0,4.0 \\
7.9,11.2 \\
13.4 .13 .4 \\
15.9,15.9 \\
38,38 \\
38,22.4\end{array}$ & $\begin{array}{l}6 \\
7 \\
5 \\
3 \\
3 \\
4\end{array}$ & $\begin{array}{l}6 \\
7 \\
5 \\
3 \\
3 \\
4\end{array}$ \\
\hline $\begin{array}{l}2-6 \\
2-18\end{array}$ & & : & $\because$ & $\therefore$ & & & . & & $\begin{array}{l}5.857 \\
6.161\end{array}$ & $\begin{array}{l}22 \\
22\end{array}$ & & & $\begin{array}{l}- \\
-\end{array}$ & $\begin{array}{l}10 \frac{1}{2}, 9 \frac{1}{2} \\
9,9\end{array}$ & $\begin{array}{l}9.4 .13 .4 \\
15: 9.15 .9\end{array}$ & 5. & $\begin{array}{l}5 \\
3\end{array}$ \\
\hline $\begin{array}{l}1-3 \\
1-15\end{array}$ & 096 & As-Re & ceived & $\because$ & & 10.28 & $\therefore$ & SI:urry & $\begin{array}{l}5.742 \\
6.195\end{array}$ & $\begin{array}{l}0 \\
0\end{array}$ & 1750 & $\mathrm{H}_{2}(53)$ & $\begin{array}{l}9.528 \\
9.605\end{array}$ & $\begin{array}{l}12,10 \frac{1}{2} \\
10,9 \frac{1}{2}\end{array}$ & $\begin{array}{l}5.6,9.4 \\
11.2,13.4\end{array}$ & $\begin{array}{l}4 \\
5\end{array}$ & $\begin{array}{l}4 \\
4\end{array}$ \\
\hline $\begin{array}{l}1-5 \\
1-17\end{array}$ & & 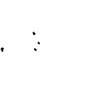 & & & & & . & & $\begin{array}{l}5.664 \\
6.218\end{array}$ & $\begin{array}{l}0.5 \\
0.5\end{array}$ & . & & $\begin{array}{l}9.529 \\
9.659\end{array}$ & $\begin{array}{l}11 \frac{1}{2}, 10 \\
9,8 \frac{1}{2}\end{array}$ & $\begin{array}{l}6.7 .11 .2 \\
15.9 .18 .9\end{array}$ & $\begin{array}{l}5 \\
4\end{array}$ & $\begin{array}{l}5 \\
4\end{array}$ \\
\hline $\begin{array}{l}1-7 \\
1-1 \ni\end{array}$ & & $\therefore$ & - & & & & & v & $\begin{array}{l}5.644 \\
6.162\end{array}$ & $\begin{array}{l}1 \\
1\end{array}$ & $\cdot$ & & $\begin{array}{l}9.565 \\
9.638\end{array}$ & & . & $\begin{array}{l}5 \\
4\end{array}$ & $\begin{array}{l}5 \\
4\end{array}$ \\
\hline $\begin{array}{ll}\because \quad 1-9 \\
\therefore & 1-21\end{array}$ & & & & & & & & & $\begin{array}{l}5.677 \\
6.164\end{array}$ & $\begin{array}{l}1.5 \\
1.5\end{array}$ & & & $\begin{array}{l}9.567 \\
9.609\end{array}$ & $\begin{array}{l}10 \frac{1}{2}, 9 \frac{1}{4} \\
8 \frac{1}{2}, 8 \frac{1}{2}\end{array}$ & $\begin{array}{l}9.4,13.4 \\
18.9,18.9\end{array}$ & $\begin{array}{l}5 \\
4\end{array}$ & $\begin{array}{l}4 \\
2\end{array}$ \\
\hline$\because \begin{array}{l}1-11 \\
1-23\end{array}$ & & & & & & & & & $\begin{array}{l}5.671 \\
6.152\end{array}$ & $\begin{array}{l}5 \\
5\end{array}$ & & & $\begin{array}{l}9.651 \\
9.645\end{array}$ & $\begin{array}{l}8 \frac{1}{2}, 7 \frac{1}{2} \\
8,8\end{array}$ & $\begin{array}{l}18.9,27 \\
22.4,22.4\end{array}$ & $\begin{array}{l}5 \\
5\end{array}$ & $\begin{array}{l}3 \\
3\end{array}$ \\
\hline $\begin{array}{l}1-25 \\
1-1 \\
1-29 \\
1-13 \\
1-33 \\
1-37\end{array}$ & & $\because$ & $: \cdot$ & & & ' & & & $\begin{array}{l}5.644 \\
5.726 \\
5.978 \\
6.226 \\
5.985 \\
6.513\end{array}$ & $\begin{array}{l}12 \\
12 \\
12 \\
12 \\
12 \\
12\end{array}$ & . & & $\begin{array}{l}9.614 \\
9.605 \\
9.683 \\
9.662 \\
9.639 \\
9.655\end{array}$ & $\begin{array}{l}8,8 \\
7 \frac{1}{2}, 7 \\
11,11 \\
9,8 \frac{1}{2} \\
9 \frac{1}{2}, 9 \\
8 \frac{1}{2}, 8 \frac{1}{2}\end{array}$ & $\begin{array}{l}22.4,22.4 \\
27,32 \\
7.9,7.9 \\
15.9,18.9 \\
13.4,15.9 \\
18.9,18.9\end{array}$ & $\begin{array}{l}3 \\
5 \\
4 \\
4 \\
2 \\
4\end{array}$ & $\begin{array}{l}3 \\
4 \\
4 \\
4 \\
2 \\
4\end{array}$ \\
\hline
\end{tabular}

Pellets Sintered in a Subsequent Sintering Run (With Pellets of $\mathrm{H}_{2}$ Calcined Material) .

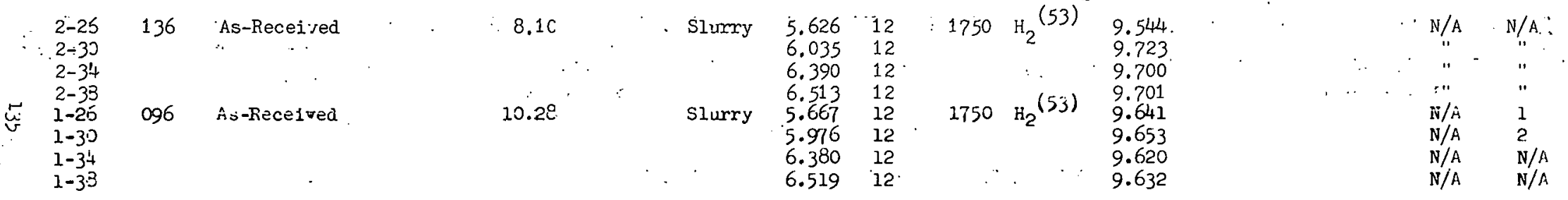

* Ge ometric Densi ity

* See Section III F. 


\begin{tabular}{|c|c|c|c|c|c|c|c|c|c|c|c|c|c|c|c|c|c|}
\hline \multirow{2}{*}{$\begin{array}{l}\text { Pelilet } \\
\text { Number. }\end{array}$} & \multirow[b]{2}{*}{$\begin{array}{l}\text { Powder } \\
\text { Lot }\end{array}$} & \multicolumn{3}{|c|}{$\begin{array}{l}\text { Calcine } \\
\text { Conditicns }\end{array}$} & \multicolumn{2}{|c|}{$\begin{array}{c}\text { Surf } \equiv \text { ce Area } \\
\left(T^{2} / g i\right.\end{array}$} & \multicolumn{3}{|c|}{ Fabrication Procedure } & \multirow{2}{*}{$\begin{array}{l}\text { Green } \\
\text { Density* } \\
\text { (gm/cc) }\end{array}$} & \multicolumn{3}{|c|}{ Sintering Eonjitions } & \multicolumn{2}{|c|}{$\begin{array}{l}\text { Sintered Density } \\
(\mathrm{gm} / \mathrm{cc}) * *\end{array}$} & \multicolumn{2}{|c|}{ Grain Size } \\
\hline & & $\begin{array}{l}\text { Temp } \\
\left({ }^{\mathrm{O}} \mathrm{C}\right) \\
\end{array}$ & $\begin{array}{l}\text { Time, } \\
\text { (hrs; }\end{array}$ & Atm & $\begin{array}{l}\mathrm{A}=\operatorname{ter} \\
\mathrm{C}_{\mathrm{a}}=\mathrm{cin} \equiv\end{array}$ & $\begin{array}{l}\text { After } \\
\text { Micro } \\
\end{array}$ & & nderless & $\begin{array}{c}\text { With } \\
\text { Binder }\end{array}$ & & $\begin{array}{l}\text { Time } \\
\text { (hrs) } \\
\end{array}$ & $\begin{array}{l}\text { Tenp } \\
\text { (O) } \\
\end{array}$ & Atm & $\begin{array}{c}\text { Inc. } \\
\text { Open Pores }\end{array}$ & $\begin{array}{c}\text { Exc. } \\
\text { Open Pores }\end{array}$ & $\begin{array}{l}\mathrm{ASTM} \# \\
130,260 \\
\end{array}$ & $\begin{array}{c}\text { Diameter } \\
\mu\end{array}$ \\
\hline $\begin{array}{l}\text { 2D-46́7611 } \\
\mathrm{Cal} \text {, Ho Micro }\end{array}$ & 136 & 1100 & 48 & Air & 2.82 & 2.82 & Dry & Fressed & . & 6.00 & 12 & 1751 & $I_{2}(53)$ & 9.563 & 9.573 & $11 \frac{1}{2}, 13 \frac{1}{2}$ & $6.7,3.3$ \\
\hline $\begin{array}{l}\text { 3C-467611 } \\
\text { Cal, Ho Micro }\end{array}$ & 096 & 1100 & 48 & Airr & 3.52 & 3.52 & & $" r$ & & 5.92 & $"$ & $"$ & " & 9.905 & 9.909 & 4,4 & $89.8,89.8$ \\
\hline $2 \mathrm{G}-469891$ & 136 & As-Red & eived & & 5.55 & 5.55 & & $"$ & & 5.98 & $"$ & $"$ & $"$ & 9.652 & 9.652 & 14,14 & $2,8,2.8$ \\
\hline $4 \mathrm{H}-469891$ & 096 & As-Rec & eived & & 8.24 & 8.24 & & " & & 5.53 & $"$ & " & $"$ & 9.721 & 9.814 & 12,12 & $5.6,5.6$ \\
\hline $\begin{array}{l}\text { 13F-467608 } \\
\text { Dbl Nicro }\end{array}$ & 096 & As-Rec & eived & & & 10.28 & & $"$ & & 5.95 & $"$ & $"$ & $"$ & 9.849 & 9.906 & 10,10 & $11.2,11.2$ \\
\hline $\begin{array}{l}1 \mathrm{~B}-467607 \\
\mathrm{Cal}, \text { Micro }\end{array}$ & 096 & 1100 & 48 & Air & & 5.29 & & " & & 6.17 & $"$ & $"$ & " & 9.806 & 9.928 & $7 \frac{1}{2}, 6$ & 27,45 \\
\hline $\begin{array}{l}9 \mathrm{E}-467608 \\
\text { Dbl Micro }\end{array}$ & 136 & As-Re & eived & & & 8.10 & & $"$ & & 5.99 & $"$ & $"$ & " & 9.923 & 9.908 & 10,10 & $11,2,11,2$ \\
\hline $\begin{array}{l}5 A-467607 \\
\text { Cal, Micro }\end{array}$ & 136 & 1100 & 48 & Air & & 5.27 & & " & & 5.99 & $"$ & $"$ & $"$ & 9.792 & 9.858 & $9,8 \frac{1}{2}$ & $15.9,18.9$ \\
\hline $\begin{array}{l}\text { 15P-467608 } \\
\text { Dbl Micro }\end{array}$ & 096. & As-Rec & eived & & & 10.28 & & $"$ & & 6.00 & $1 \frac{1}{2}$ & $"$ & ' & 9.790 & 9.851 & $<14,<14$ & $<2.8,<2.8$ \\
\hline $\begin{array}{l}5 \mathrm{~N}-467608 \\
\text { Dbl Micro }\end{array}$ & 136 & As-Re & eived. & & & 8.10 & & $"$ & . & 6.04 & $"$ & $"$ & ' & 9.331 & 9.414 & $13 \frac{1}{2}, 13 \frac{1}{2}$ & $3.3,3.3$ \\
\hline $\begin{array}{l}\text { 4K-467607 } \\
\text { Cal,Dbl Micro }\end{array}$ & 096 & 1100 & 48 & Air & & 5.29 & & " & & 6.11 & $"$ & $"$ & $\cdot \cdot$ & 9.844 & 9.925 & $5 \frac{1}{2}, 5$ & 53.4 .64 \\
\hline $5 S-469891$ & 136 & As-Re & eived & & 5.55 & 5.55 & & " & & 5.94 & $"$ & $"$ & $"$ & 9.357 & 9.363 & $<14,<14$ & $<2.8,<2.8$ \\
\hline $\begin{array}{l}2 \mathrm{~J}-467607 \\
\mathrm{Cal}, \mathrm{Dbl} \text { Micro }\end{array}$ & 136 & 1100 & 48 & Air & & 5.29 & & $"$ & & 5.96 & " & $"$ & - & 9.582 & 9.582 & $<14,<14$ & $2,8,2.8$ \\
\hline $\begin{array}{l}7 \mathrm{M}-467611 \\
\mathrm{Cal}, \text { No Micro }\end{array}$ & 096 & 1100 & 48 & Air & 3.52 & 3.52 & & $"$ & & 5.96 & $"$ & $"$ & - & 9.819 & $9.817^{* * *}$ & $9 \frac{1}{2}, 9 \frac{1}{2}$ & $13.4,13.4$ \\
\hline $\begin{array}{l}\text { 4I-467611 } \\
\text { Cal, No Micro }\end{array}$ & 136 & 1100 & 48 & $A i=$ & 2.32 & 2.82 & & " & & 5.98 & $"$ & $"$ & $n$ & 8.730 & 9.739 & $<14,<14$ & $<2.8,<2.8$ \\
\hline $3 \mathrm{~T}-467801$ & 096 & As-Re & eived & & 8.24 & 8.24 & & " & & 6.20 & $"$ & $"$ & " & 9.565 & 9.599 & $<14,<14$ & $<2.8,<2.8$ \\
\hline
\end{tabular}


TABLE 13 (Cont'd.)

Summary of Thoria Pellet and Powder Properties

\begin{tabular}{|c|c|c|c|c|c|c|c|c|c|c|c|c|c|c|c|c|c|}
\hline \multirow[b]{2}{*}{$\begin{array}{l}\text { Pellet } \\
\text { Number }\end{array}$} & \multirow[b]{2}{*}{$\begin{array}{l}\text { Powder } \\
\text { Lot } \\
\end{array}$} & \multicolumn{3}{|c|}{$\begin{array}{c}\text { Calcine } \\
\text { Ccnditions }\end{array}$} & \multicolumn{2}{|c|}{$\begin{array}{c}\text { Surface Area } \\
\left(\mathrm{m}^{2} / \mathrm{g}\right)\end{array}$} & \multicolumn{3}{|c|}{ Fabrication Procedure } & \multirow{2}{*}{$\begin{array}{l}\text { Green } \\
\text { Density* } \\
\text { (gm/cc) } \\
\end{array}$} & \multicolumn{3}{|c|}{ Sintering Conditions } & \multicolumn{2}{|c|}{$\begin{array}{c}\text { Sintered Density } \\
(\mathrm{gm} / \mathrm{cc})^{* *}\end{array}$} & \multicolumn{2}{|c|}{ Grain Size } \\
\hline & & $\begin{array}{l}\text { Temp } \\
\text { ( } \mathrm{C}) \\
\end{array}$ & $\begin{array}{l}\text { Time } \\
\text { (hrs) }\end{array}$ & Atm & $\begin{array}{l}\text { After } \\
\text { Calcine } \\
\end{array}$ & $\begin{array}{l}\text { After } \\
\text { Micro } \\
\end{array}$ & & incerless & $\begin{array}{c}\text { With } \\
\text { Binder } \\
\end{array}$ & & $\begin{array}{l}\text { Time } \\
\text { (hrs) } \\
\end{array}$ & $\begin{array}{l}\text { Temp } \\
\left({ }^{\circ} \mathrm{C}\right) \\
\end{array}$ & Atm & $\begin{array}{c}\text { Inc. } \\
\text { Open Pores }\end{array}$ & $\begin{array}{c}\text { Exc. } \\
\text { Open Pores }\end{array}$ & $\begin{array}{l}\text { ASTM \# } \\
130,260 \\
\end{array}$ & $\begin{array}{c}\text { Diameter } \\
\mu . \\
\end{array}$ \\
\hline $\begin{array}{l}\text { W/R } 467608 \text { 47 } \\
\text { Dbl Micro }\end{array}$ & 1.35 & As-Re & ceived & & & 8.1 & Dry & Pressed & & 5.98 & 12. & 1750 & $\pi_{2}(53)$ & 10.006 & 10.013 & $10 \frac{1}{2}, 10 \frac{1}{2}$ & 9.5 .9 .5 \\
\hline 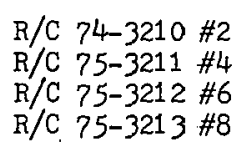 & " & $\begin{array}{l}1200 \\
" \ddot{400} \\
"\end{array}$ & $\begin{array}{r}8 \\
24 \\
3 \\
9\end{array}$ & $\begin{array}{l}\mathrm{H}_{2} \\
" 2 \\
"\end{array}$ & $\begin{array}{l}2.6-3.6 \\
2.4-3.2 \\
2.2-2.5 \\
1.9-2.1\end{array}$ & $\begin{array}{l}5.2 \\
4.3 \\
4.4 \\
3.3\end{array}$ & Dry & $\begin{array}{l}\text { Pressed } \\
" 1 \\
" \\
\text { " }\end{array}$ & & $\begin{array}{l}5.96 \\
5.97 \\
- \\
5.98\end{array}$ & $\begin{array}{l}" 1 \\
" 1 " \\
"\end{array}$ & " & $\begin{array}{l}" \\
" " \\
" 1\end{array}$ & $\begin{array}{l}9.919 \\
9.803 \\
9.846 \\
9.712\end{array}$ & $\begin{array}{l}9.943 \\
9.811 \\
9.867 \\
9.725\end{array}$ & $\begin{array}{l}10,10 \\
11 \frac{3}{4}, 11 \frac{3}{4} \\
11,11 \\
12 \frac{1}{2}, 13 \frac{1}{2}\end{array}$ & $\begin{array}{l}11.2,11.2 \\
6.0,6.0 \\
7 \cdot 9,7.9 \\
4: 7,3.3\end{array}$ \\
\hline $\begin{array}{l}\text { W/R } 46760848 \\
\text { Dbl Micro }\end{array}$ & " & $A \dot{s}-R \in$ & ceived & & & $\begin{array}{c}8.1 \\
:\end{array}$ & & $"$ & & 5.97 & $1 \frac{1}{2}$ & $"$ & $"$ & $\begin{array}{l}9.885 \\
\because .\end{array}$ & 9.890 & $12 \frac{1}{2}, 12 \frac{1}{2}$ & $4.7,4.7^{\circ}$ \\
\hline 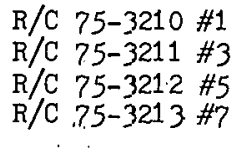 & $\begin{array}{l}" \\
" \\
"\end{array}$ & $\begin{array}{l}1200 \\
1 " \\
1400 \\
" 1\end{array}$ & $\begin{array}{r}8 \\
24 \\
3 \\
9\end{array}$ & $\begin{array}{l}" 1 \\
" 1 \\
"\end{array}$ & & $\begin{array}{l}5.2 \\
4.3 \\
4.4 \\
3.3\end{array}$ & & $\begin{array}{l}\text { " } \\
" 1 \\
"\end{array}$ & & $\begin{array}{l}6.0 \\
5.98 \\
- \\
5.71\end{array}$ & " & $\begin{array}{l}" \\
" \\
"\end{array}$ & " & $\begin{array}{l}9.773 \\
9.427 \\
9.561 \\
9.317\end{array}$ & $\begin{array}{l}9.785 \\
9.463 \\
9.566 \\
9.319\end{array}$ & $\begin{array}{l}12 \frac{1}{2}, 12 \frac{1}{2} \\
<14,<14 \\
13 \frac{1}{2}, 13 \frac{1}{2} \\
<14,<14\end{array}$ & $\begin{array}{l}4.7,4.7 \\
<2.8,<2.8 \\
3.3,3.3 \\
<2.8,<2.8\end{array}$ \\
\hline $\begin{array}{l}\text { W/R } 467608 \$ 11 \\
\text { Dbl Micro }\end{array}$ & $"$ & As-Rec & ceived & & & 8.1 & $\begin{array}{l}\text { Dry } \\
\text { Pret. }\end{array}$ & $\begin{array}{l}\text { Pressed } \\
\text { treated }\end{array}$ & & 5.9 & 12 & $"$ & $"$ & 9.958. & $9.958 * * *$ & $1.1 \frac{1}{2}, 11 \frac{1}{2}$ & $\begin{array}{l}6.7,7.9 \\
\cdot\end{array}$ \\
\hline $\begin{array}{l}\mathrm{R} / \mathrm{C} 75-3210 \# 8 \\
\mathrm{R} / \mathrm{C} 75-3211 \# 7 \\
\mathrm{R} / \mathrm{C} \text { 75-3212 \#1 } \\
\mathrm{R} / \mathrm{C} \text { 75-3213 \#6 }\end{array}$ & "" & $\begin{array}{l}1200 \\
" 1 \\
1400 \\
" ~\end{array}$ & $\begin{array}{r}8 \\
24 \\
3 \\
9\end{array}$ & " & & $\begin{array}{l}5.2 \\
4.3 \\
4.4 \\
3.3\end{array}$ & & " & . & $\begin{array}{l}6.0 \\
5.9 \\
6.0\end{array}$ & $\begin{array}{l}": \\
": " \\
":\end{array}$ & $\begin{array}{l}" 1 \\
\ddot{~} \\
" 1\end{array}$ & $\begin{array}{l}" \\
" " \\
" 1\end{array}$ & $\begin{array}{l}9.884 \\
9.732 \\
9.787 \\
9.719\end{array}$ & $\begin{array}{l}9.908 \\
9.755 \\
9.803 \quad 1 \\
9.727\end{array}$ & $\begin{array}{l}1,2 \frac{1}{2}, 11 \frac{1}{2} \\
<14,13 \frac{1}{2} \\
<14,13 \frac{1}{2} \\
<14,<14\end{array}$ & $\begin{array}{l}4.7,6.7 \\
<2.8,3.3 \\
<2.8,3.3 \\
<2.8,<2.8\end{array}$ \\
\hline $\begin{array}{l}\text { W/R } 4676.08 * 4 \\
\text { Dbl Micro }\end{array}$ & $"$ & As- $\operatorname{Rec}$ & ceived & & & 8.1 & & ". & & 6.0 & $1 \frac{1}{2}$ & $"$ & $"$ & 9.889 & $\begin{array}{l}9.888 * * * \\
\because\end{array}$ & $\begin{array}{l}13 \frac{1}{4}, 13 \frac{1}{4} \\
\because\end{array}$ & $3.7,3.7$ \\
\hline $\begin{array}{l}\mathrm{R} / \mathrm{C} \quad 75-5210 \# 5 \\
\mathrm{R} / \mathrm{C} \text { 75-5211 \#2 } \\
\mathrm{R} / \mathrm{C} \text { 75-5213 \#3 }\end{array}$ & " & $\begin{array}{l}1200 \\
1 " \\
1400\end{array}$ & $\begin{array}{r}8 \\
24 \\
9\end{array}$ & "" & & $\begin{array}{l}5.2 \\
4.3 \\
3.3\end{array}$ & & "." & & $\begin{array}{l}5.97 \\
5.98 \\
5.83\end{array}$ & " & " & " & $\begin{array}{l}9.694 \\
9.457 \\
9.495\end{array}$ & $\begin{array}{l}9.702 \\
9.477 \\
9.526\end{array}$ & $\begin{array}{l}<14,<14 \\
<14,<14 \\
<14,<14\end{array}$ & $\begin{array}{l}<2.8,<2.8 \\
<2.8,<2.8 \\
<2.8,<2.8\end{array}$ \\
\hline $\begin{array}{l}\text { 4AA } \\
\text { As-Calcine } \\
\text {.. }\end{array}$ & 096 & 1100 & 48 & $"$ & 4.77 & 4.77 & Dry & Pressed & & 6.03 & 12 & $"$ & $"$ & 9.776 & 9.777 & $<1,<1$ & $300+, 300+$ \\
\hline $\begin{array}{l}\text { 6BB } \\
\mathrm{Cal}, \mathrm{Dbl}, \mathrm{Mic}=0\end{array}$ & $"$ & $"$ & 48 & $"$ & & 5.82 & & $"$ & 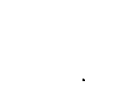 & 6.07 & ". & $!$ & ". & $9: 825$ & $9.788 * * *$ & 9,9 & $15.9,15.9$ \\
\hline As-Calcine & 136 & $"$ & 48 & $"$ & 4.42 & 4.4 & & " & & 6.00 & $\therefore$ & $\because$ & $\because$ & $\begin{array}{c}9.615 \\
\because\end{array}$ & 9.616 & 13,13 & $4: 0,4.0$ \\
\hline $\begin{array}{l}\text { 6DD } \\
\text { Cal,Dbl Micro }\end{array}$ & " & " & 48 & $"$ & & 5.91 & & $"$ & & 6.08 & $"$ & $"$ & $"$ & 9.816 & 9.868 & 5,5 & 64,64 \\
\hline
\end{tabular}

*Geometria Densit

**Irmersion Densitj

***Material lost during blotting

$\because \cdots$ 


\begin{tabular}{|c|c|c|c|c|c|c|c|c|c|c|c|c|c|c|c|c|}
\hline \multirow[b]{2}{*}{$\begin{array}{l}\text { Pellet } \\
\text { Number } \\
\end{array}$} & \multirow[b]{2}{*}{$\begin{array}{l}\text { Powder } \\
\text { Lot } \\
\end{array}$} & \multicolumn{3}{|c|}{$\begin{array}{l}\text { Calcine } \\
\text { Conditions }\end{array}$} & \multicolumn{2}{|c|}{$\begin{array}{c}\text { Surface Area } \\
\left(\mathrm{m}^{2} ; \mathrm{g}\right)\end{array}$} & \multicolumn{2}{|c|}{ Fabicication Prosedure } & \multirow{2}{*}{$\begin{array}{c}\text { Green } \\
\text { Density } \\
(\mathrm{gm} / \mathrm{cc}) \\
\end{array}$} & \multicolumn{3}{|c|}{ Sintering Conditicns } & \multicolumn{2}{|c|}{$\begin{array}{c}\text { Sintered Density } \\
(\mathrm{gm} / \mathrm{cc})^{* *}\end{array}$} & \multicolumn{2}{|c|}{ Grain Size } \\
\hline & & $\begin{array}{l}\overline{\mathrm{Temp}} \\
\left(\underline{\left.{ }^{\circ} \mathrm{C}\right)}\right. \\
\end{array}$ & $\begin{array}{l}\text { Time } \\
\text { (hrs) } \\
\end{array}$ & $\underline{\mathrm{Atm}}$ & $\begin{array}{l}\text { After } \\
\text { Calcine } \\
\end{array}$ & $\begin{array}{l}\text { After } \\
\text { Micro } \\
\end{array}$ & Bìnćerless & $\begin{array}{l}\text { With } \\
\text { Binder }\end{array}$ & & $\begin{array}{l}\text { Tine } \\
\text { (hrs) }\end{array}$ & $\begin{array}{l}\text { Temp } \\
\left(\begin{array}{l}\left.{ }^{\circ} \mathrm{C}\right) \\
\end{array}\right.\end{array}$ & At.r. & $\begin{array}{l}\text { Inc. } \\
\text { Cpen Pores }\end{array}$ & $\begin{array}{c}\text { Exc. } \\
\text { Open Pores }\end{array}$ & $\begin{array}{l}\text { ASTM \# } \\
130,260 \\
\end{array}$ & $\begin{array}{c}\text { Liameter } \\
\mu\end{array}$ \\
\hline $\begin{array}{l}2 \mathrm{EE} \\
\mathrm{As}-\mathrm{Cal} \text { cine }\end{array}$ & 096 & 1100 & 48 & $\mathrm{H}_{2}$ & 4.77 & 4.77 & Dry Pressed & & 6.00 & $1 \frac{1}{2}$ & 1750 & $\mathrm{H}_{2}(5 ;)$ & $9: 630$ & $9.620 * * *$ & $13 \frac{1}{2}, 13 \frac{1}{2}$ & $3.3,3.0$ \\
\hline $\begin{array}{l}2 \mathrm{FF} \\
\mathrm{Cal}, \mathrm{Dbl} \text { Micro }\end{array}$ & $"$ & $"$ & $"$ & ' & & 5.82 & 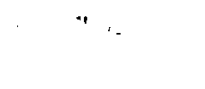 & & 5.99 & $"$ & $"$ & $"$ & 9.675 & 9.698 & 9.9 & $15.9,15.9$ \\
\hline $\begin{array}{l}4 G G \\
\text { As-Calcine }\end{array}$ & 136 & $"$ & ". & . & 4.4 & 4.4 & $"$ & & 6.03 & $"$. & $"$ & $"$. & 9.223 & 9.360 & $<14,<14$ & $<2.8,<2.8$ \\
\hline $\begin{array}{l}\text { 4HH } \\
\text { Cal,Dbl Micro }\end{array}$ & $"$ & $"$ & ". & " & & 5.9 & $"$ & & 6.09 & $"$ & $"$ & $"$ & 9.789 & 9.799 & $6 \frac{1}{2}, 6$ & 38,45 \\
\hline $494 / 901$ & $"$ & 1200 & 8 & $I_{2} \mathrm{I}$ & & 4.6 & & $\mathrm{~L} / \mathrm{S}$ & 6.133 & 0 & $"$ & $"$ & $9.110 *$ & & $<14<14$ & $<2,8<2,8$ \\
\hline 902 & $"$ & $"$ & $"$ & .2 & & $"$ & & $"$ & 6.017 & $\frac{1}{2}$ & " & " & $9.243 *$ & & $<14,<14$ & $<2.8,<2.8$ \\
\hline 903 & $"$ & $"$ & $"$ & : & & " & & $"$ & 6.126 & 1 & $"$ & $"$ & $9.208 *$ & & $<14,<14$ & $<2.8,<2.8$ \\
\hline 904 & $"$ & $"$ & $"$ & - & & ". & & $"$ & 6.062 & $1 \frac{1}{2}$ & $"$ & $"$ & $9.421 *$ & & $<14,<14$ & $<2.8,<2.8$ \\
\hline 905 & $"$ & $"$ & $"$ & ; & & $"$ & & $"$ & 6.125 & 5 & 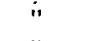 & " & $9.401 *$ & & $<14,<14$ & $<2.8,<2.8$ \\
\hline $90 ?$ & $"$ & " & $"$ & ' & & " & & "r & $6.10 \epsilon$ & 12 & " & " & $9.566^{*}$ & & 12,12 & $5.6,5.6$ \\
\hline 908 & $"$ & $"$ & $"$ & ' & & $"$ & & $"$ & 6.095 & 22 & $"$ & " & $9.534 *$ & & $9 \frac{1}{2}, 10$ & 13.4 .11 .2 \\
\hline $501 / 921$ & $"$ & $"$ & $"$ & ' & & $"$ & & " & $6.21 \bar{z}$ & 0 & " & " & $9.253^{*}$ & & $<14,<14$ & $<2,8,<2,8$ \\
\hline 922 & $"$ & $"$ & $"$ & . & & $"$ & & $"$ & 6.294 & $\frac{1}{2}$ & " & $"$ & $9.313^{*}$ & & $<14,<14$ & $<2.8<<2.8$ \\
\hline 923 & $"$ & $"$ & $"$ & $"$ & & $"$. & & " & $6.31 \%$ & 1 & "i & $"$ & $9.371 *$ & & $<14,<14$ & $<2.8,<2.8$ \\
\hline 924 & $"$ & $"$ & $"$ & " & & $"$ " & & $"$ & 6.275 & $1 \frac{1}{2}$ & " & $"$ & $9.381 *$ & & $<14,<14$ & $<2.8,<2.8$ \\
\hline 925 & $"$ & $"$ & $"$ & $"$ & & ." & & $"$ & 6.258 & $5^{2}$ & $"$ & $"$ & $9.433 \%$ & & 13,13 & $4.0,4.0$ \\
\hline 9206 & $"$ & $"$ & $"$ & ' & & " & & $"$ & 6.341 & 12 & " & $"$ & $9.546 *$ & & $10 \frac{1}{2}, 10 \frac{1}{4}$ & $9.4,9.4$ \\
\hline 927 & $"$ & $"$ & $"$ & ' & & " & & " & $6.27 \%$ & 22 & " & " & $9.545^{*}$ & & 8,9 & $22.4,15.9$ \\
\hline $480 / 101$ & " & 1400 & .3 & ' & & 3.4 & & " & 6.071 & 0 & $"$ & $"$ & $8.618^{*}$ & & $<14,<14$ & $<2.8,<2.8$ \\
\hline 102 & $"$ & " & $"$ & ' & & " & & $"$ & 6.072 & $\frac{1}{2}$ & " & " & $8.729^{*}$ & & $<14,<14$ & $<2.8,<2.8$ \\
\hline 103 & $"$ & $"$ & $"$ & ' & & $"$ & & $"$ & 6.098 & $1^{2}$ & " & " & $8.786 *$ & & $<14,<14$ & $<2.8,<2.8$ \\
\hline 104 & $"$ & $"$ & $"$ & " & & $"$ & & " & 6.074 & $1 \frac{1}{2}$ & " & $"$ & $8.827 *$ & & $<14,<14$ & $<2.8,<2.8$ \\
\hline 105 & $"$ & " & $"$ & $"$ & & " & & $"$ & 6.078 & $5^{6}$ & " & $"$ & $9.004 *$ & & 14,14 & $2.8,2.5$ \\
\hline $10 \sigma^{\prime}$ & $"$ & " & ." & $"$ & : & $"$ & & $"$ & $6.10 z$ & 12 & " & $"$ & $9.228^{*}$ & & 14,14 & $2.8,2.8$ \\
\hline $10 ?$ & $"$ & $"$ & $"$ & $"$ & & " & & " & 6.065 & 22 & " & :" & $9.272^{*}$ & & $13 \frac{1}{2}, 13 \frac{2}{4}$ & $3.34,3.0$ \\
\hline $487 / 132$ & " & $"$ & $"$ & , & & $"$ & & $"$ & 6.535 & 0 & $"$ & " & $8.865^{*}$ & & $<14,<14$ & $<2.8,<2.8$ \\
\hline 133 & $"$ & $"$ & $"$ & $"$ & & $"$ & & $"$ & 6.474 & $\frac{1}{2}$ & $"$ & $"$ & $8.993^{*}$ & & $<14,<14$ & $<2.8,<2.8$ \\
\hline 134 & " & $"$ & $"$ & 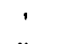 & & " & & " & 6.475 & $1^{2}$ & " & " & $9.099 *$ & & $<14,<14$ & $<2.8,<2.8$ \\
\hline 135 & $"$ & " & $"$ & 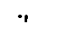 & & " & & " & 6.241 & $1 \frac{1}{2}$ & " & " & $9.022^{*}$ & & $<14,<14$ & $<2,8,<2.8$ \\
\hline 13.5 & $"$ & " & $"$ & $"$ & & " & & $"$ & 6.499 & $5^{\circ}$ & $"$ & " & $9.292^{*}$ & & 14,14 & $2.8,2.8$ \\
\hline 137 & $"$ & " & " & $"$ & & $"$ & & $"$ & 6.578 & 12 & $"$ & " & $9.430^{*}$ & & $13 \frac{3}{4}, 13 \frac{3}{4}$ & $3.0,3.0$ \\
\hline 133 & $"$ & $"$ & $"$ & $"$ & & $"$ & & $"$ & $6.56 \mathrm{C}$ & 22 & $"$ & & $9.439 \%$ & & $13 \frac{1}{2}, 13 \frac{1}{2}$ & $3.3,3.3$ \\
\hline $\begin{array}{l}R / C \quad 75-3195 \\
R / C \quad 75-3196\end{array}$ & $"$ & 1200 & $\begin{array}{l}8 \\
"\end{array}$ & $\ddot{~}$ & & $"$ & & " & $\begin{array}{l}6.0 \\
6.2\end{array}$ & 12 & " & $\mathrm{H}_{2 .}(-10)$ & & & $\begin{array}{l}9,8 \frac{1}{2} \\
4,4\end{array}$ & $\begin{array}{l}15.9 .18 .9 \\
89.889 .8\end{array}$ \\
\hline & & & & & & & & & & & & & & & & \\
\hline
\end{tabular}


Sumnary of Thoria Pellet and Powder Properties

\begin{tabular}{|c|c|c|c|c|c|c|c|c|c|c|c|c|c|c|c|c|}
\hline \multirow[b]{2}{*}{$\begin{array}{l}\text { Pellet } \\
\text { Number }\end{array}$} & \multirow[b]{2}{*}{$\begin{array}{l}\text { Poirder } \\
\text { Lot }\end{array}$} & \multicolumn{3}{|c|}{$\begin{array}{l}\text { Calcine } \\
\text { Conditions }\end{array}$} & \multicolumn{2}{|c|}{$\begin{array}{c}\text { Surface Area } \\
\left(\mathrm{m}^{2} / \mathrm{s}\right)\end{array}$} & \multicolumn{2}{|c|}{ Fakrication Procedure } & \multirow{2}{*}{$\begin{array}{c}\text { Green } \\
\text { Density } \\
\text { (gm/cc) } \\
\end{array}$} & \multicolumn{3}{|c|}{ Sintering Corditions } & \multicolumn{2}{|c|}{$\begin{array}{c}\text { Sintered Density } \\
(\mathrm{gm} / \mathrm{cc})^{* *}\end{array}$} & \multicolumn{2}{|c|}{ Grain Size } \\
\hline & & $\begin{array}{l}\text { Temp } \\
\left({ }^{\circ} \mathrm{C}\right) \\
\end{array}$ & $\begin{array}{l}\text { Time } \\
\text { (hrs) }\end{array}$ & $\underline{\text { Atm }}$ & $\begin{array}{l}\text { After } \\
\text { Calcine }\end{array}$ & $\begin{array}{l}\text { After } \\
\text { Micro }\end{array}$ & Binderless & $\begin{array}{c}\text { With } \\
\text { Binder }\end{array}$ & & $\begin{array}{l}\text { * Time } \\
\text { (hrs) } \\
\end{array}$ & $\begin{array}{l}\text { Temp } \\
\left({ }^{\circ} \mathrm{C}\right) \\
\end{array}$ & Atm & $\begin{array}{l}\text { Inc. } \\
\text { Open Pores }\end{array}$ & $\begin{array}{c}\text { Exc. } \\
\text { Open Pores }\end{array}$ & $\begin{array}{l}\text { ASTM \# } \\
130,260 \\
\end{array}$ & $\begin{array}{c}\text { Diameter } \\
\mu \\
\end{array}$ \\
\hline $\begin{array}{l}\text { R/C } 75-3373 \text { \#8 } \\
50 \% \text { As-Re='d } \\
50 \% \text { Cal }\end{array}$ & $\begin{array}{l}076 \\
136\end{array}$ & 1.460 & 3 & $\mathrm{H}_{2}$ & & $\begin{array}{r}8.8 \\
10.3 \\
4.4\end{array}$ & Dry Pressed & & 5.81 & 12 & 1750 & $\mathrm{H}_{2}{ }^{(60)}$ & 9.951 & $.9 .947^{* * *}$ & 7,7 & 32,32 \\
\hline $\begin{array}{l}\text { 3/C } 75-3373 \text { \#1 } \\
50 \% \text { As-Rec'd } \\
50 \% \text { Cal }\end{array}$ & $\begin{array}{l}096 \\
136\end{array}$ & $14 \times 0$ & 3 & $\mathrm{H}_{2}$ & & $\begin{array}{r}8.8 \\
10.3 \\
4.4\end{array}$ & Dry Pressed & & 5.86 & $1 \frac{1}{2}$ & & $\mathrm{H}_{2}^{(60)}$ & 9.896 & $\cdot 9.902$ & $12,11 \frac{1}{2}$ & $5.6,6.7$ \\
\hline 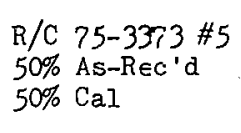 & $\begin{array}{l}096 \\
136\end{array}$ & $14 \times 10$ & 3 & $\mathrm{H}_{2}$ & & $\begin{array}{r}8.8 \\
10.3 \\
4.4\end{array}$ & Dry Pressed & . & 5.82 & 5 & . & $\mathrm{H}_{2}^{(60)}$ & 9.948 & $9.945 * * *$ & $10 \frac{1}{2}, 10$ & 9.4 .11 .2 \\
\hline $\begin{array}{l}\text { R/C } 75-3: 72 \# 6 \\
50 \% \text { As-R€c'd } \\
50 \% \mathrm{Cal}\end{array}$ & $\begin{array}{l}136 \\
136\end{array}$ & 1400 & 3 & $\mathrm{H}_{2}$ & & $\begin{array}{c}7.6-5.2 \\
8.8-6.5 \\
4.4\end{array}$ & $\begin{array}{l}\text { Dry Pressed } \\
\text { (925 Pretreat) }\end{array}$ & & 5.94 & 12 & . & $\mathrm{H}_{2}{ }^{(53)}$ & 9.941 & $9.950^{\circ}$ & $5 \frac{1}{2}, 6$ & $\begin{array}{c}53,45 \\
:\end{array}$ \\
\hline $\begin{array}{l}\text { R/C } 75-3372 \text { \#3 } \\
50 \% \text { As-Rec'd. } \\
50 \% \text { Cal }\end{array}$ & $\begin{array}{l}136 \\
136\end{array}$ & 1400 & 3 & $\mathrm{H}_{2}$ & & $\begin{array}{l}7.6-5.2 \\
8.8-6.5 \\
4.4\end{array}$ & $\begin{array}{l}\text { Dry Pressed } \\
\text { (925, Pretreat) }\end{array}$ & . & 5.99 & 5 & & $\mathrm{H}_{2}($ & 9.913 & 9.927 & 8,10 & $22,11.2$ \\
\hline $\begin{array}{l}\mathrm{R} / \mathrm{C} 75-3372 \# 4 \\
50 \% \cdot \mathrm{As}-\mathrm{Rec} \cdot \mathrm{d} \\
50 \% \mathrm{C} \equiv \mathrm{l}\end{array}$ & $\begin{array}{l}136 \\
136\end{array}$ & 1400 & 3 & $\mathrm{H}_{2}$ & & $\begin{array}{l}7.6-5.2 \\
8.8-6.5 \\
4.4\end{array}$ & $\begin{array}{l}\text { Dry Pressed } \\
\text { (925: Pretreat) }\end{array}$ & & 5.92 & $1 \frac{1}{2}$ & & $\mathrm{H}_{2}(53)$ & 9.873 & 9.883. & $-12,11$ & $5.6,7.9$ \\
\hline 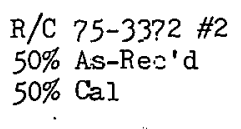 & $\begin{array}{l}136 \\
136\end{array}$ & 1400 & 3 & $\mathrm{H}_{2}$ & & $\begin{array}{l}7.6-5.2 \\
8.8-6.5 \\
4.4\end{array}$ & Dry Pressed & . & 5.96 & 12 & & $\mathrm{H}_{2}{ }^{(53)}$ & 9.928 & 9.969 & $7,6 \frac{1}{2}$ & 32,38 \\
\hline $\begin{array}{l}\text { R/C } 75-3372 ~ \# 1 \\
50 \% \text { As-Rec'd } \\
50 \% \mathrm{Cal}\end{array}$ & $\begin{array}{l}-36 \\
=36\end{array}$ & 1430 & 3 & $\mathrm{H}_{2}$ & & $\begin{array}{l}7.6-5.2 \\
8.8-6.5 \\
4.4\end{array}$ & Dry Pressed & $\therefore$ & 5.95 & $1 \frac{1}{2}$ & & $\mathrm{H}_{2}^{(53)}$ & 9.892 & $9.905^{\circ}$ & $12 \frac{1}{2}, 12 \frac{1}{2}$ & 4.7 .4 .7 \\
\hline
\end{tabular}


Spark Source Mass Spectrographic Analyses of As-Received and Calcined ( 48 Hours, $1100^{\circ} \mathrm{C}$ in Hydrogen and Air) ThO Powders

\#30125

096-03

Às-Received;

\#30129

Thoria-

Micronized

$\mathrm{SA}=8.2 \mathrm{~m}^{2} / \mathrm{gm}$

096-03

$\mathrm{H}_{2}$-Calcined

$\mathrm{SA}=4.8 \mathrm{~m}^{2} / \mathrm{gm}$

554

$\mathrm{C} \quad 554$

$\mathrm{Pb} \quad 1$

$\mathrm{Au} \leq 0.7$

Pt $\quad 0.04$

$\leq 1$

$\begin{array}{ll}\mathrm{Sr} & 0.1 \\ \mathrm{Rb} & 0.004\end{array}$

Br $\quad 0.04$

Aв $\quad 0.01$

Ca $\quad 0.002$

$\mathrm{Zn}$

$\mathrm{Cù}$

N1

Co

$\mathrm{Fe}$

Mn

$\mathrm{Cr}$

$\mathrm{V}$

Ti

Sc

Ca

K

CI

$\rightarrow \mathrm{S}$

$-\mathrm{P}$

Si

AI

$\mathrm{Mg}$

$\rightarrow \mathrm{Na}$

B $\quad 0.06$

Be $\quad 0.007$

Li $\quad 0.005$
0.01

0.08

0.2

0.04

0.03

0.1

0.05

0.01

0.04

0.009

2

0.006

2

$<0.1$

0.1

$<0.3$

$<0.01$

$=0.01$

$<0,4$

0.06

$<0.01$

0.02

, 0.1

$<3.01$

0.01

0.004

2

$<0.01$

0.06

$<0.001$

0.007

0.03

0.008

0.2

0.9

21

0.05

20

0.4

0.02

2.01

28

2

67

0.6

5

22
0.06
14

0.5

11

$n, n 1$

2

$<0.005$

140

1

30

45

0.2

$300+$

5
4

5

19

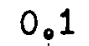

0.003

0.002
\#30126

Air-Calcined

Run 7719

$\mathrm{SA}=3.5 \mathrm{~m}^{2} / \mathrm{gm}$
096-03

\section{\#30127 \\ 136-01 \\ As-Recei ved \\ 136-01}

$\mathrm{SA}=5.5 \mathrm{~m}^{2} / \mathrm{gm}$

462

$<1$

3
1

$\leq 0.3$

0.02

$0.4 \times$

$\leq 0.3$

0.06

0.04

0.02

0.02

0.1

$0.4 *$

0.06

$0.1 *$

$0.4^{*}$

2

0.005

0.08

0.002

0.02

$0: 008$

0.02

$1 *$

$8 *$

$1400 *$

$1 *$

$190 *$

56*

$810 *$

$21 *$.

115

1

1

37

0.3

$67 *$

4

12

0.4

0.4

8*

- 0.004

0.02
2

$\leq 0.4$

$<0.01$

0.01

$\leq 0.9$

$=0.01$

< U. U1

$<0,01$

$<0.01$

0.4

0.04

0.01

0.02

0.06

3

0.005

0.05

0.001

0.03

0.003

0.002

0.09

0.7

60

0.2

11

0.5

24

0.7

1.

$<0.01$

2

0.6

2

37

80

2

0.2

23

3

0.07

0.007

0.004
$\mathrm{H}_{2}$-Calcined

$\mathrm{SA}=4.4 \mathrm{~m}^{2} / \mathrm{gm}$

$<0.1$

0.3

$<0.3$

$<0.01$

$<0.01$

$<0.5$

0.02

- 0.04

$<0.01$

0.007

0.1

$<2$

0.009

0.006

2

$<0.01$

0.03

$<0.001$

0.004

0.002

0.005

0.06

0.6

66

0.05

13

0.4

27

0.03

0.6

$<0.01$

3

0.8

25
18

0.5

$90+$

1

0.7

4

1

6

0.05

0.001

0.002

\#30128

136-01

Air-Calcined

Run 7728

$\mathrm{SA}=2.8 \mathrm{~m}^{2} / \mathrm{gm}$

$<1$

2

$\leq 1$

$<0.01$

0.6

2

$<0.01$

$<0.01$

$<0.01$

0.4

$0.2^{*}$

0.03

$0.2 *$

$1 *$

3

0.006

0.05

0.002 
Thoria and Thoria-Urania Pellets Used by WRL to Perform Diagnostic Examinations

\section{THORIA PELLETS}

\section{Pellet \\ Number}

$74-3410$

$74-3411$

$74-3412$

$74-3413$

\section{$74-3459-1$}

$\begin{array}{ll}\text { fines, } & -3 \\ \text { nscreened) } & -5 \\ -7\end{array}$

74-3460-1 $\begin{array}{ll}\text { fines, } & -3 \\ 200 \text { mesh) } & -5 \\ -7\end{array}$

$74-3461-1$ -100 mesh, -3 nscreened) -5

$74-3462-1$ -100 mesh, -3 200 mesh) -5

\section{Green \\ Sintered}

Density

64

65

65

56

59

61

64

\section{5}

57

60

67

56

58

61

$63:$

56

59

62

64.
Density

Grain Size

$\begin{array}{ccc} & 6.5 & 7.5 \\ 96.0 & 5.5 & 8.5 \\ 96.3 & 9.5 & 6.5-7.5\end{array}$

$-$

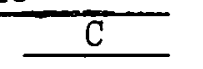

$8.5: 136$

8.5

$5.5-7 \cdot 5$

$75-136 ; 25-087$

$\left.\begin{array}{l}50-136 ; 50-087 \\ 25-136 ; 75-087\end{array}\right\}$

$1 \mathrm{w} / 0 \mathrm{CW}$

$0.2 \%$

Sterotex

\section{BINARY PELLETS - ThO $2-U^{233} \mathrm{O}_{2}$}

Blend No. 149-4-01 - Mount \#1 Long. C.S.

Blend No. 149-4-01B-Mount \#2 Inng. C..S.

$\mathrm{ThO}_{2}$ Lot \#149, UO ${ }_{2}$ Lot \#122 - 63\% G.D. . 96.9\% S.D. $2 \% \mathrm{CW}, 0.2 \%$ Sterotex 

Estimated Grain Size of $\mathrm{ThO}_{2}$ Fuel $\mathrm{P} \in \mathrm{lle}$ :s
Fabricated at WRL and Sintered at $1750^{\circ} \mathrm{C}$ for ${ }^{2} \mathrm{lz}$ Hrs in $\mathrm{H}_{2}$ (Dry)

\begin{tabular}{|c|c|c|c|c|c|c|}
\hline tion & & As-Rec $d$ & $\begin{array}{l}\text { As-Rec'd } \\
\text { Milled \& }\end{array}$ & & $\begin{array}{l}\text { Calcined } \\
\&\end{array}$ & $\begin{array}{l}\text { Maloined, } \\
\text { Milled \& }\end{array}$ \\
\hline of Grain Size & & Milled \& & Leachec \& & Calcinea & Milled \& & Jeashed, \\
\hline Determination & As-Rec'd & Leached & $\mathrm{UO}_{2}+\mathrm{P}$ & $\left(1100^{\circ} \mathrm{C}\right)$ & Leacied & $\mathrm{UO}_{2}+\mathrm{P}$ \\
\hline
\end{tabular}

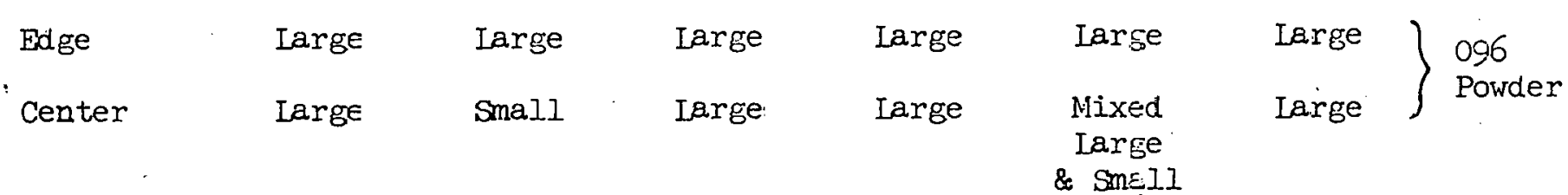

$\left.\begin{array}{lllllll}\text { Edge } & \text { Medium } & \text { Large } & \text { Large } & \text { Large } & \text { Large } & \text { Large } \\ \text { Center } & \text { Small } & \text { Small } & \text { Medium } & \text { Small } & \text { Large } & \text { Large }\end{array}\right\} \begin{aligned} & 136 \\ & \text { Powder }\end{aligned}$


TABLE 17

Spark Source Mass'Spectrographic Analysis of -Thorium Oxide and Oxalate Fowders

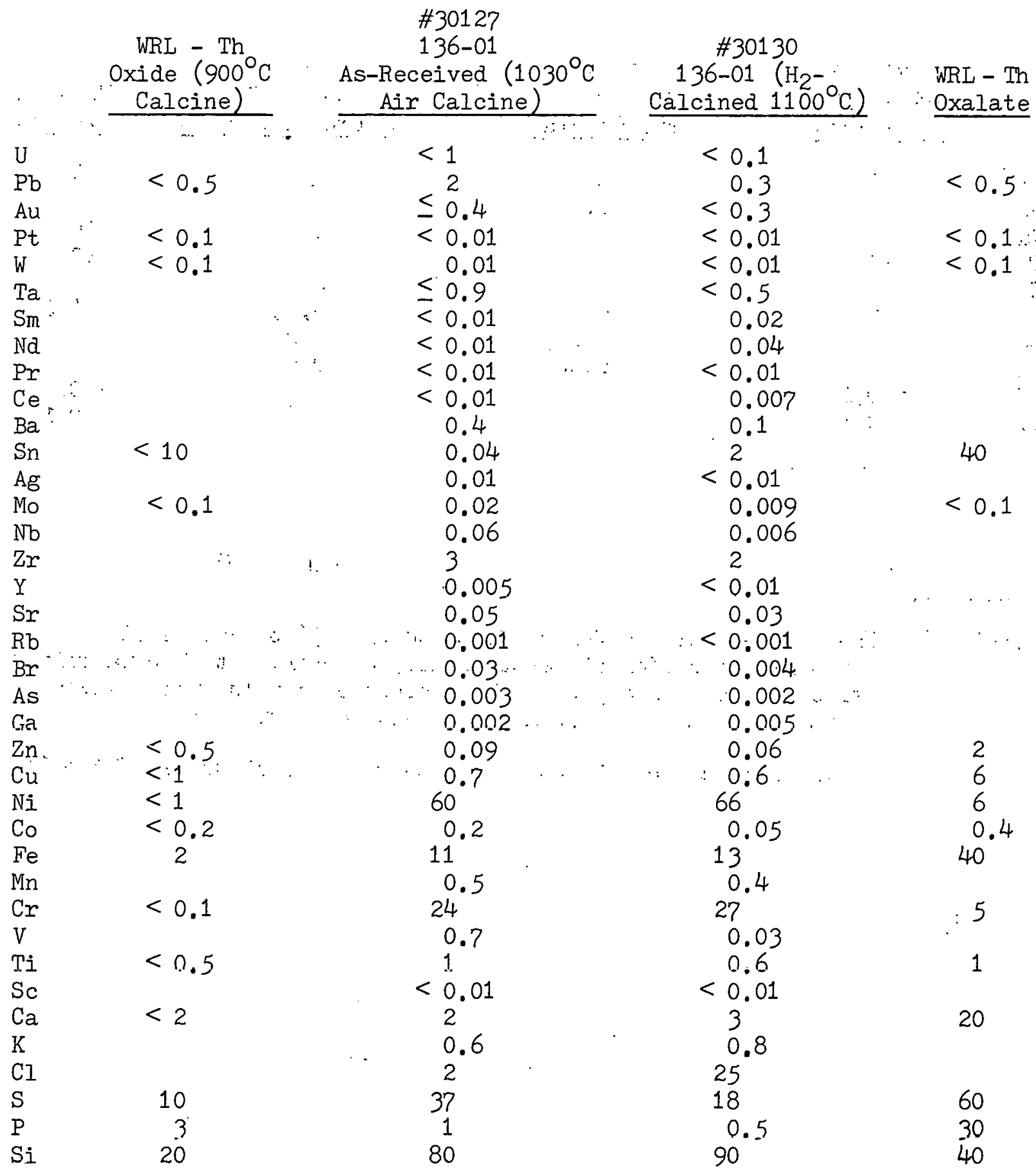


TABLI 17 (Cont'd.)

Spark Source Mass Spectrographic Analysis of Thorium Oxide and Oxalate Powders

\begin{tabular}{|c|c|c|c|c|}
\hline & $\begin{array}{l}\text { WRL }- \text { Th } \\
\text { Oxlde }\left(900^{\circ} \mathrm{C}\right. \\
\text { Calcine) } \\
\end{array}$ & $\begin{array}{c}\# 30127 \\
136-01 \\
\text { As=-Received }\left(1030^{\circ} \mathrm{C}\right. \\
\text { Air Calcine) } \\
\end{array}$ & $\begin{array}{r}\# 30130 \\
136-01\left(\mathrm{H}_{2}\right. \\
\left.\text { Ca.lcined } 1100^{\circ} \mathrm{C}\right) \\
\end{array}$ & $\begin{array}{l}\text { WRL - Th } \\
\text { oxalate }\end{array}$ \\
\hline $\mathrm{Al}$ & 0.5 & 2 & 1 & 4 \\
\hline $\mathrm{M}_{8}$ & 1 & 0.2 & 0.7 & 5 \\
\hline $\mathrm{Na}$ & 40 & 23 & 4. & 10 \\
\hline$F$ & 20 & 3 & 1 & 10 \\
\hline $\mathrm{N}$ & & 0.6 & 6 & \\
\hline B & 0.5 & 0.07 & 0.05 & 1.0 \\
\hline $\mathrm{Be}$ & & 0.007 & 0.001 & \\
\hline $\mathrm{Li}$ & & 0.004 & 0.002 & \\
\hline $\mathrm{Cd}$ & $<0.1$ & & & $<0.1$ \\
\hline $\mathrm{Bi}$ & $<0.1$ & & & $<0.1$ \\
\hline
\end{tabular}

NOTES: 1. The analyses of the WRL powders and the 136 powder were performed at different.laboratories; however, both laboratories. performed total analyses. The absence of a value for a given element indicates it was not observed to be present.

2. Additional data on 136 and 096 powders are included in Table 11. 
FIGURE I

POSTULATED DEFECT LATTICE STRUCTURE OF $\mathrm{ThO}_{2}$ \& $\mathrm{ThO}_{2}$ WITH CaO

STOICHIOMETRIC $\mathrm{THO}_{2}$

0000

$0 \cdot 0 \cdot 0 \cdot 0 \cdot 0$

$0.0 \stackrel{0}{0}: \circ \stackrel{0}{0}$

$\circ \bigcirc \square 0$

$0 \cdot 0 \cdot 0 \cdot 0 \cdot 0$

0000

(a)
"VACUUM-TREATED" $\mathrm{ThO}_{2}$ $\frac{\mathrm{PO}^{2}<10^{-10} \text { AT }}{O}$

$0 \cdot 0 \cdot 0 \cdot 0 \cdot 0$

0.000

○ $0{ }^{\ominus} \square^{\ominus} 0$

$0 \cdot 0 \cdot 0 \cdot 0 \cdot 0$

0000

(b)
WET-HYDROGEN TREATED $\mathrm{ThO}_{2}$

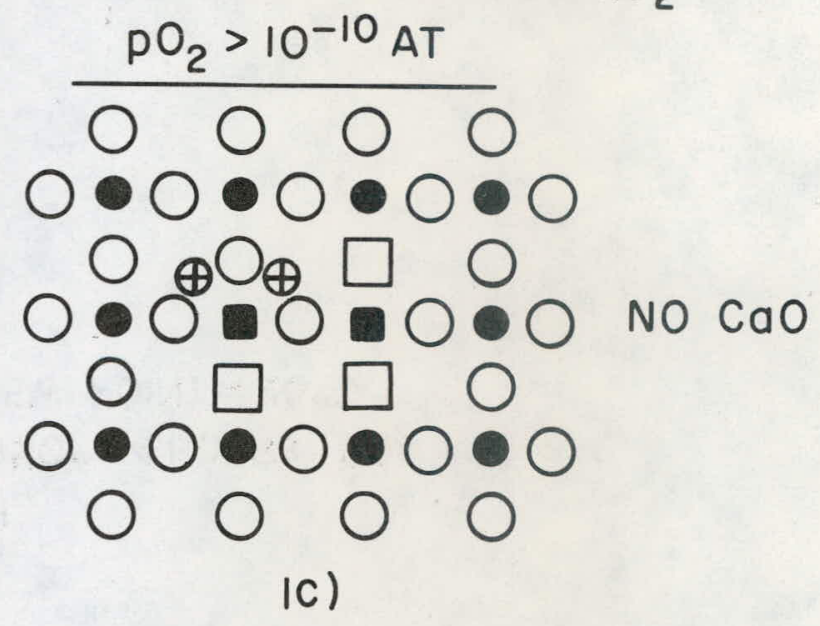

O OXYGEN ION CHARGE 2-

$\square$ OXYGEN ION LATTICE VACANCY

- thorium ion charge 4+

- thorium ion lattice VACANCY

CALCIUM ION, CHARGE $2+$

$\Theta$ FREE ELECTRON, CHARGE I-

$\oplus$ ELECTRON HOLE, CHARGE I+

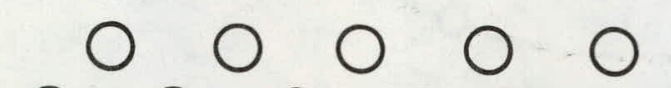
$0 \cdot 0 \cdot 0 \cdot 0 \cdot 0 \cdot 0$ O. $\begin{array}{llll}0 & 0 & \square & 0\end{array}$ $0-000 \cdot 000 \cdot 0$ $0 \square 000$ $0 \cdot 0 \cdot 0 \cdot 0 \cdot 0 \cdot 0$ o o o o 0 Id)

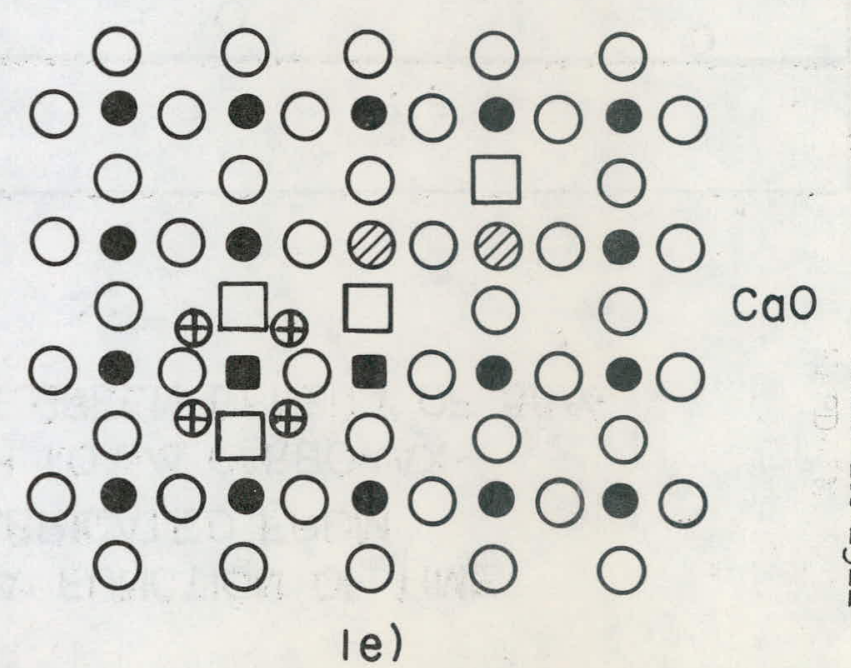


FIGURE 2

KINETIC STUDY NO.I: CHANGE IN DENSITY AS A FUNCTION OF TIME AND TEMPERATURE IN ThO $\mathrm{TH}_{2}$ PELLETS FABRICATED FROM POWDER LOT O88, L/S AGGLOMERATED WITH 1.0 W/O CARBOWAX-

0.2 W/O STEROTEX (ADDED DRY), AND PRESSED TO A GREEN DENSITY OF $55 \%$

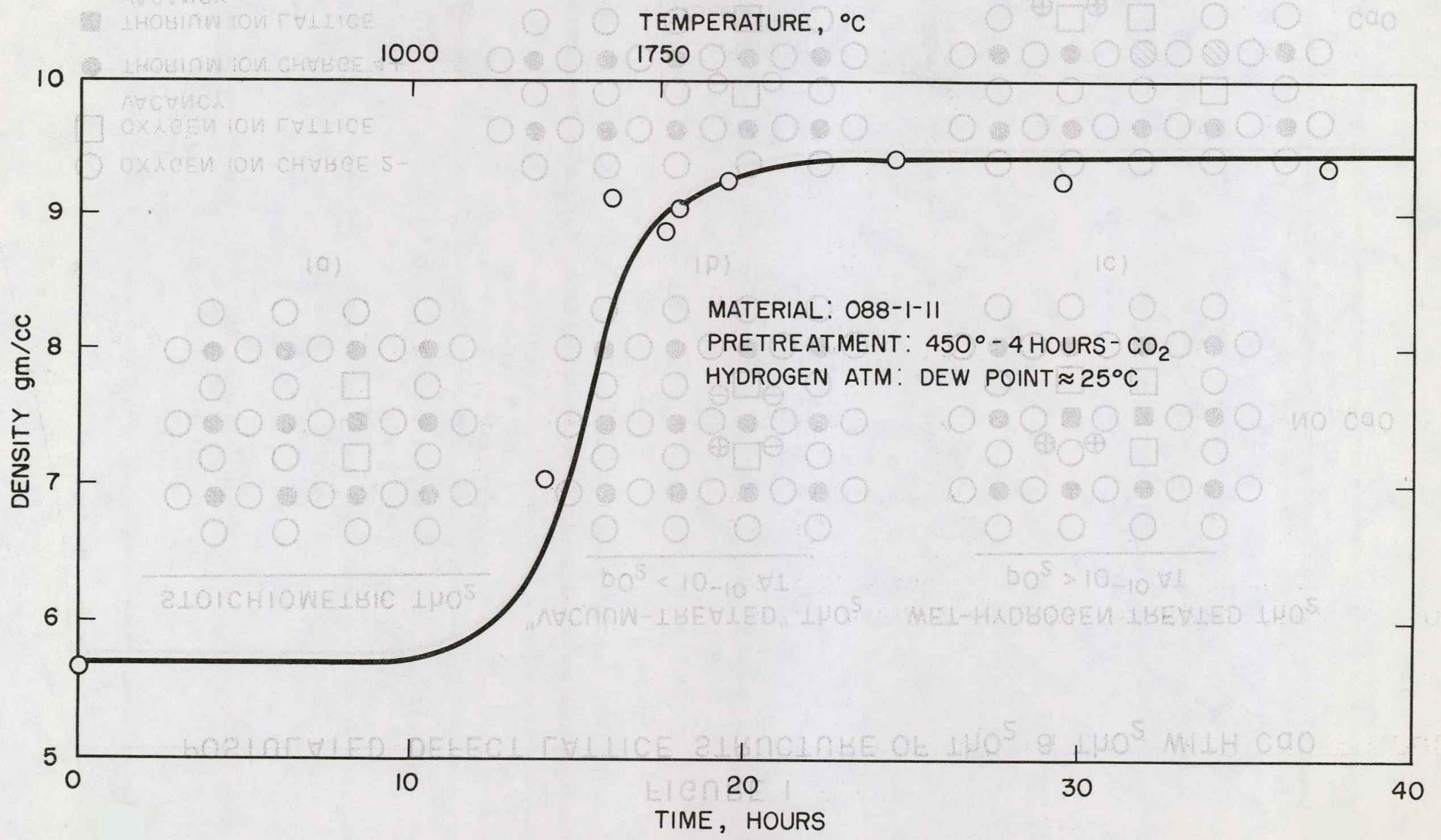


FIGURE 3

KINETIC STUDY NO.I EFFEECT OF SINTERING TIME AT $1750^{\circ} \mathrm{C}$ IN WET HYDROGEN ON.

GRAIN GROWTH IN ThO 2 PELLETS FABRICATED FROM POWDER LOT O88, L/S

AGGLOMERATED WITH 1.0 w/0 CARBOWAX - 0.2 w/o STEROTEX (ADDED DRY), AND PRESSED

TO $\triangle$ GREEN DENSITY OF $55 \%$

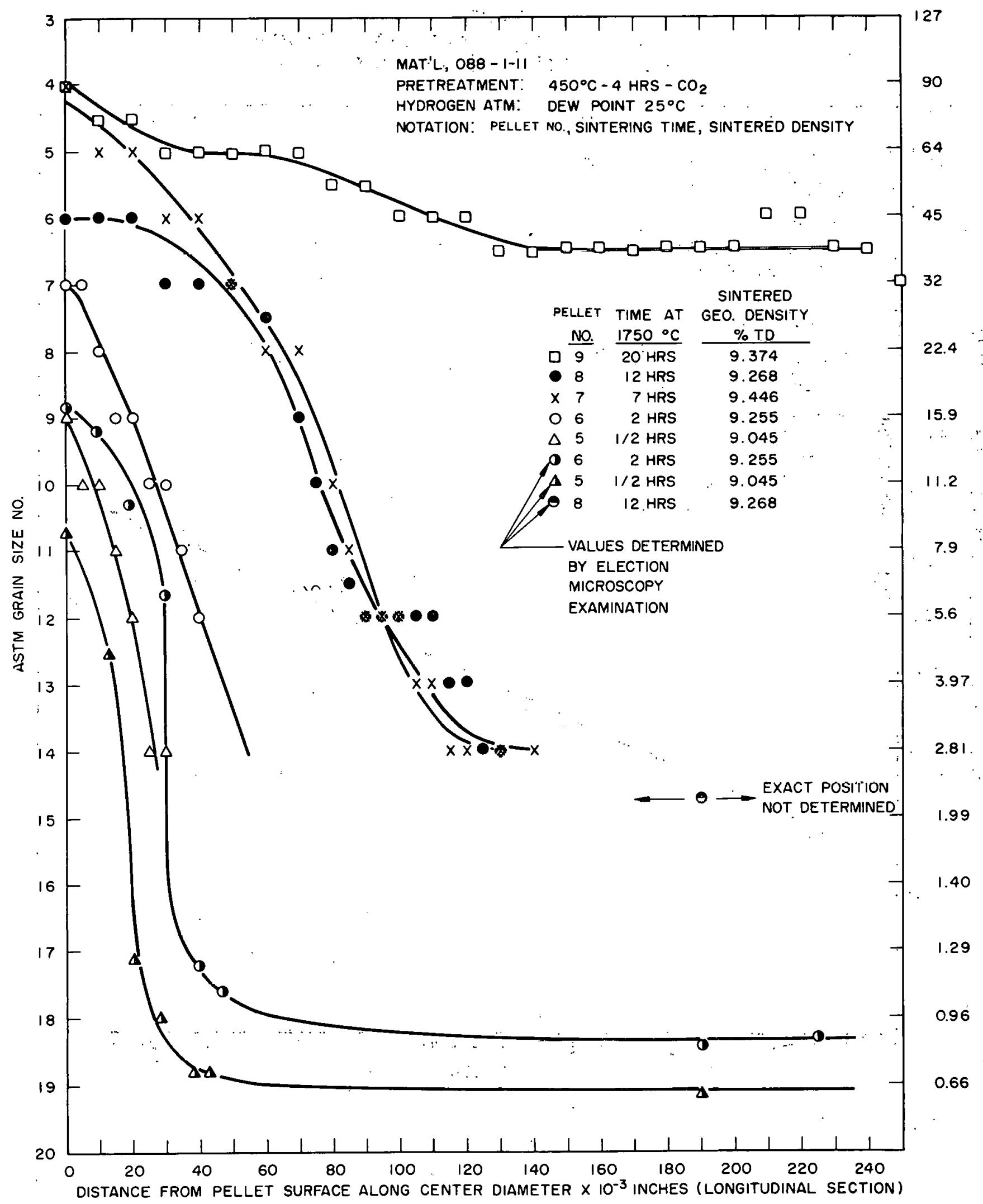


FIGURE 4

RELATIONSHIP BETWEEN GRAIN GROWTH ZONE AND TIME FOR KINETIC STUDY NO.I

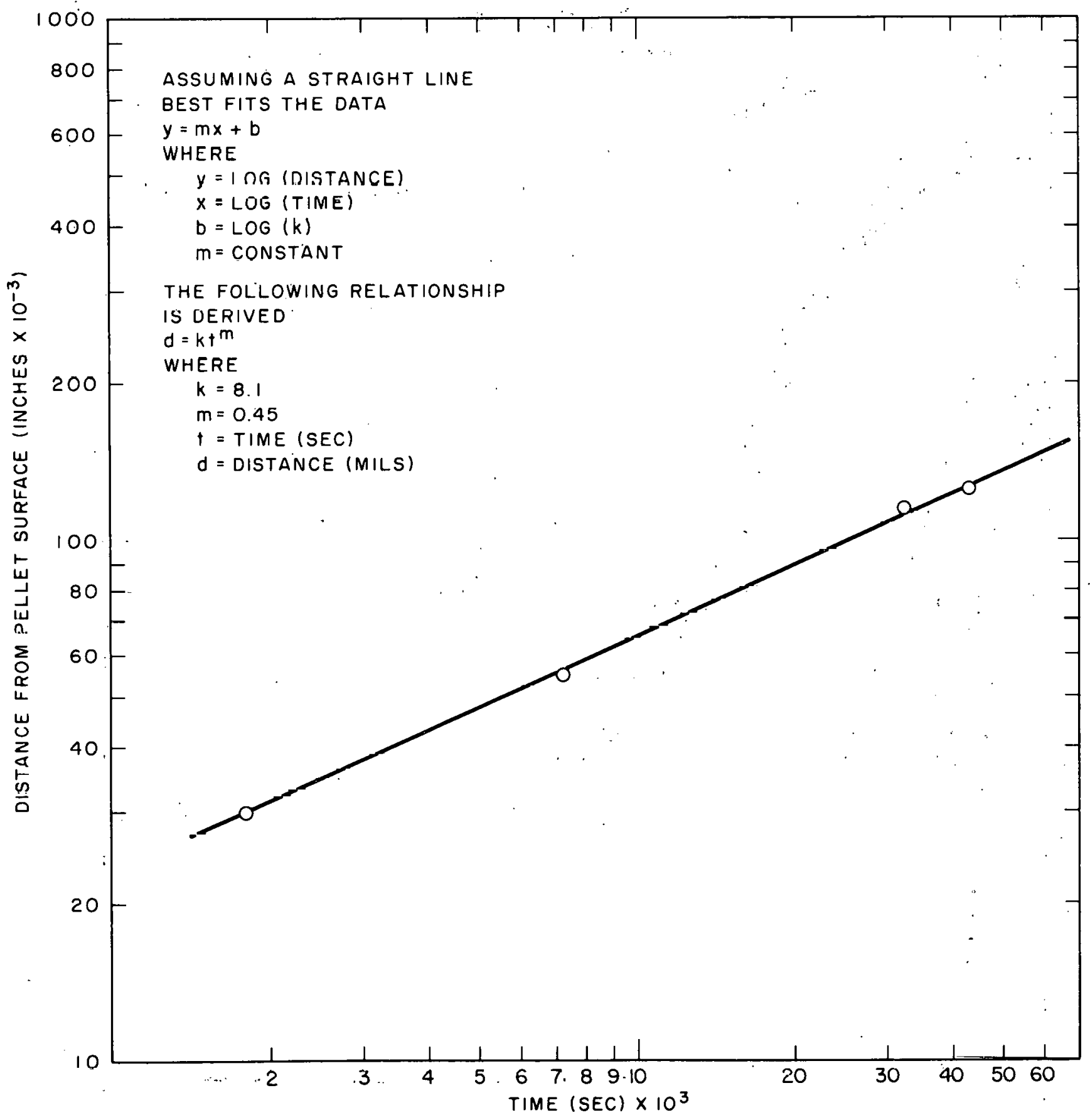




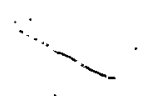

FIGURE 5

KINETIC STUDY NO. I, EFFECT OF SINTERING TIME AT $1750^{\circ} \mathrm{C}$ ON GRAIN GROWTH IN ThO 2 PELLETS FABRICATED FROM

POẄDER LOT O88, L/S AGGLOMERATED WITH 1.0 W/O CARBOWAX0.2 w/o STEROTEX (ADDED DRY), AND PRESSED TO A GREEN DENSITY OF $55 \%$

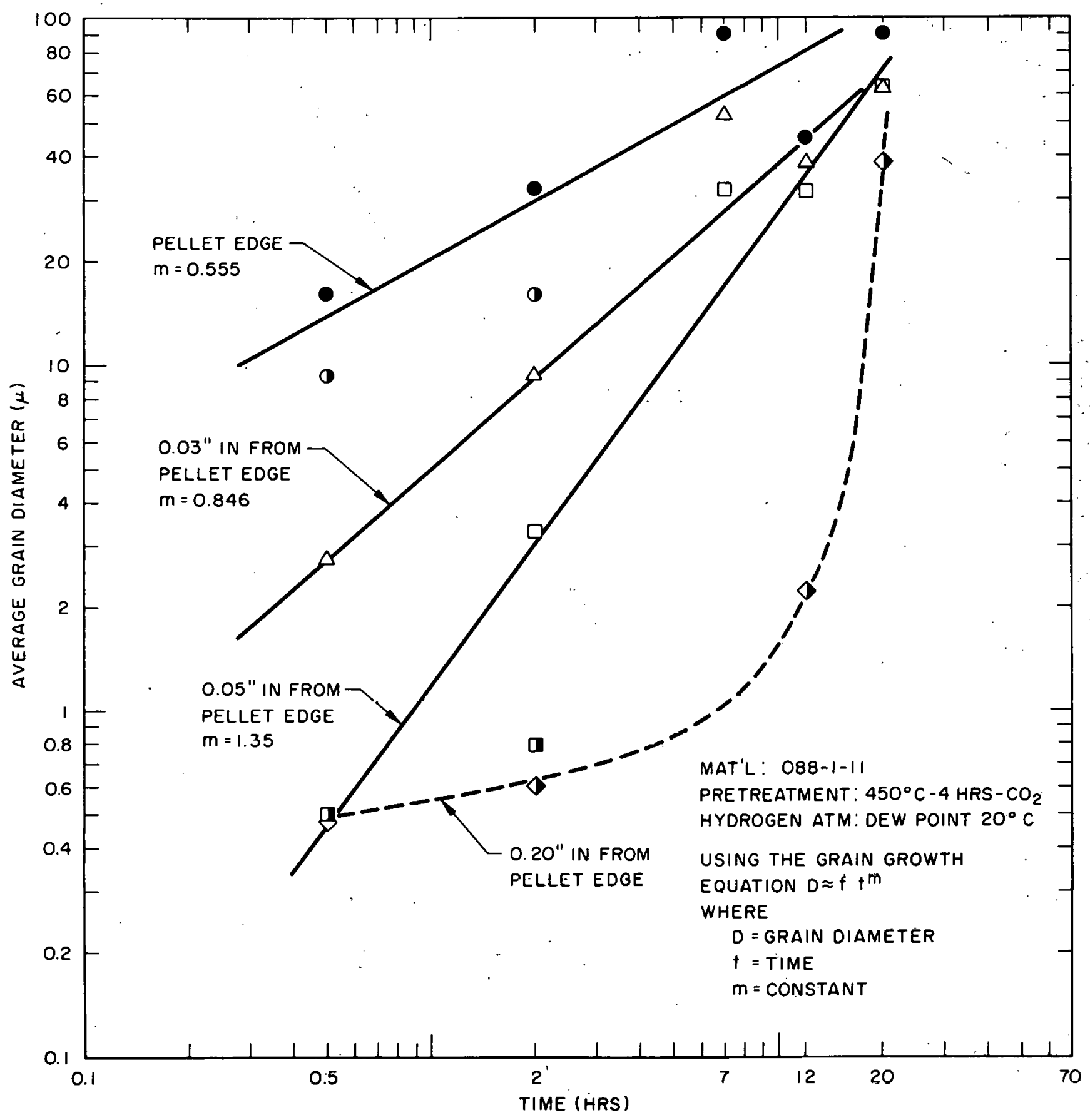


WAPD-TM-1311

FIGURE 6

KINETIC STUDY NO.I EFFECT OF SINTERING TIME AT $1750^{\circ} \mathrm{C}$ ON GRAIN GROWTH IN ThO 2 PELLETS FABRICATED FROM

POWDER LOT O88, L/S AGGLOMERATED WITH 1.0 w/O CARBOWAX 0.2 W/O STEROTEX (ADDED DRY),. AND PRESSED TO A GREEN DENSITY OF $55 \%$

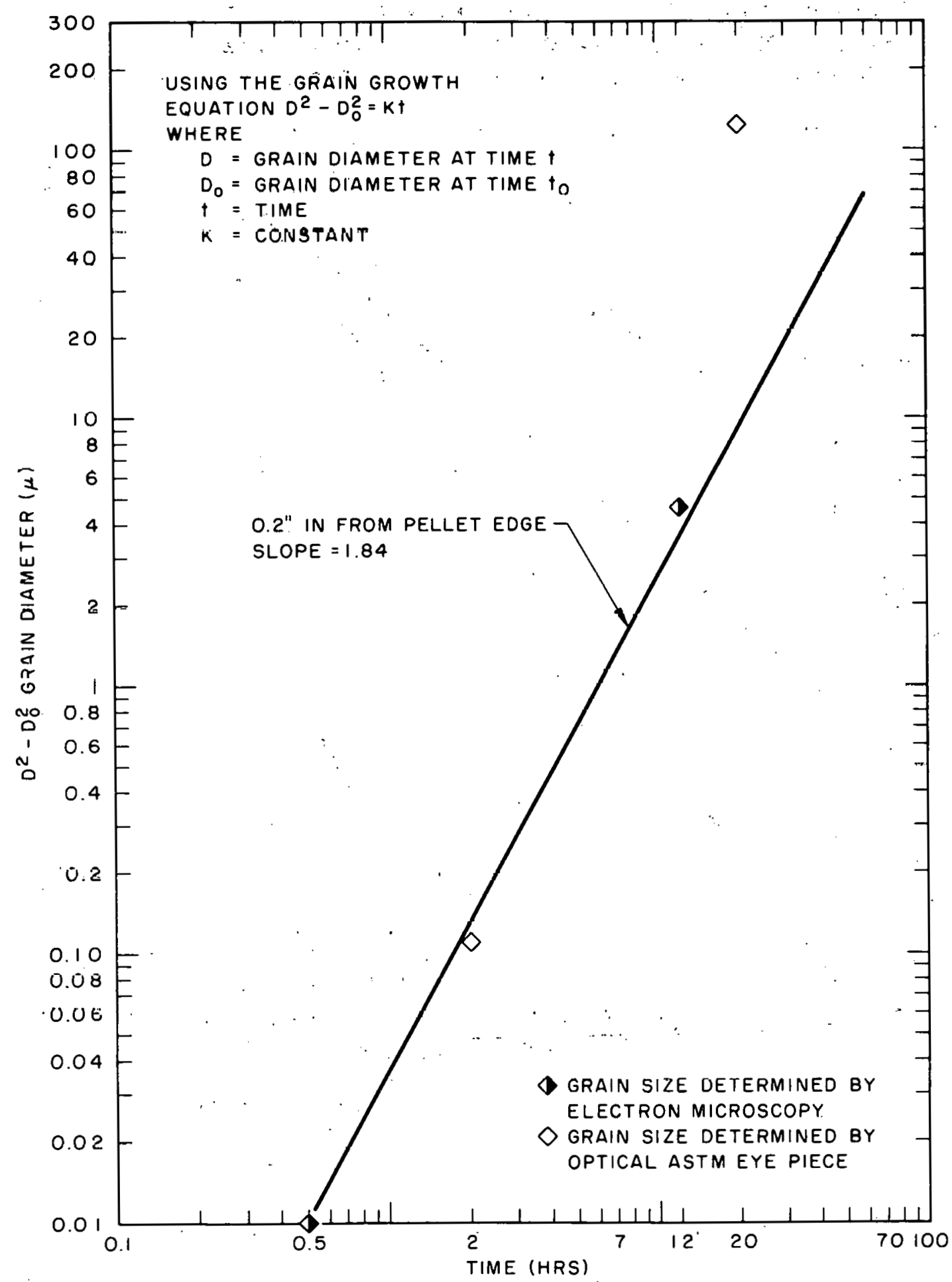




\section{FIGURE 7 :}

KINETIC STUDY NO.2: CHANGE IN DENSITY AS A FUNCTION OF TIME AND TEMPERATURE IN ThO 2 PELLETS, FABRICATED FROM POWDER LOT 097, L/S AGGLOMERATED WITH $1.0 \mathrm{~W} / 0$ CARBOWAX0.2 W/O STEROTEX (ADDED DRY), AND PRESSED TO A GREEN DENSITY OF $62 \%$

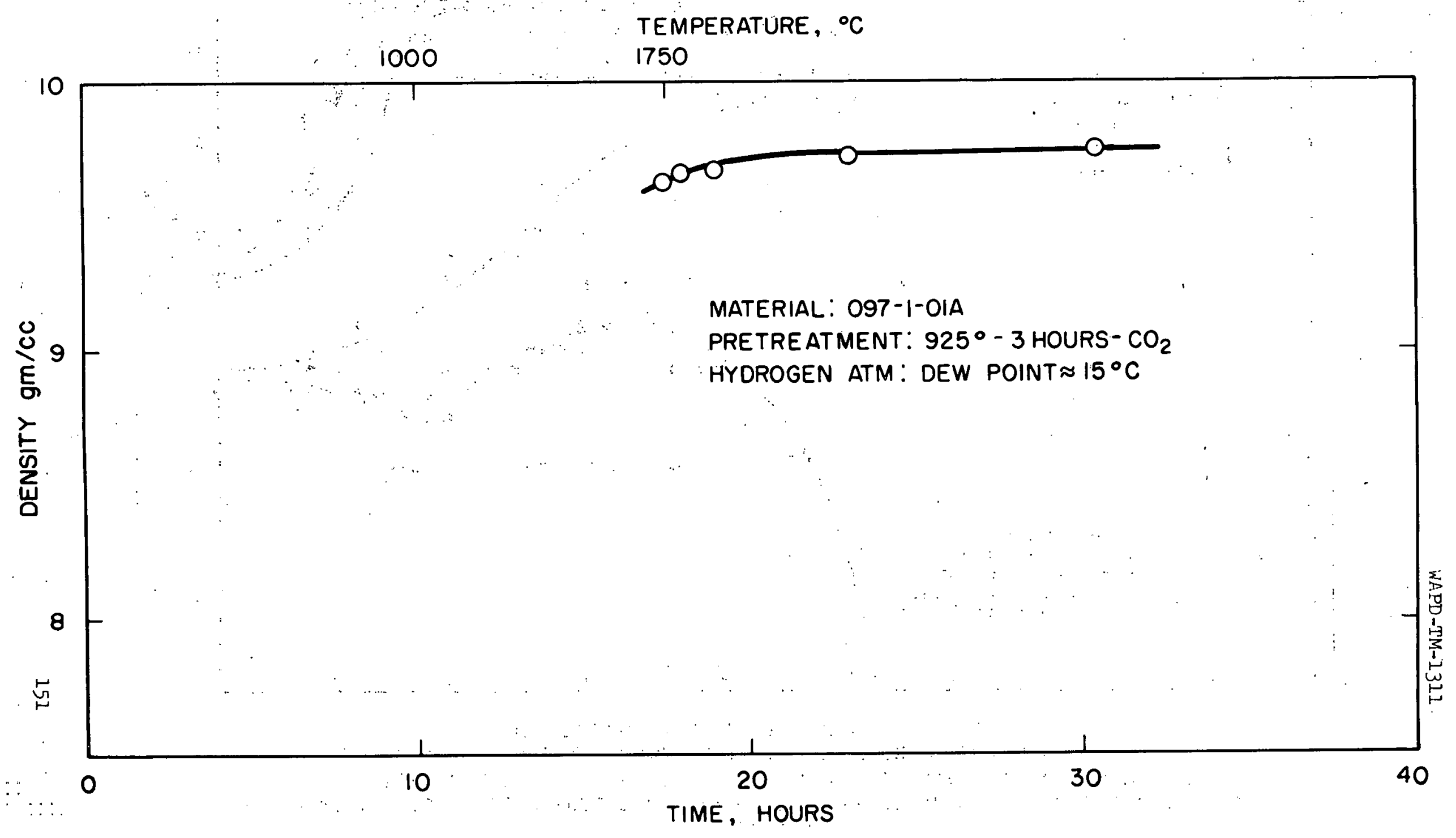


FIGURE 8

KINETIC STUDY NO. 2: EFFECT OF SINTERING TIME AT $1750^{\circ} \mathrm{C}$ DN GRAIN GROWTH IN ThO $_{2}$ PELLETS FABRICATED FROM POWDER LOT 09?, L/S AGGLOMERATED

WITH 1.0 W/O CARBCWAX - 0.2 W/O STEROTEX (ADJED DRY.), AND PRESSE[ TO A GREEN DENSITY OF $52 \%$

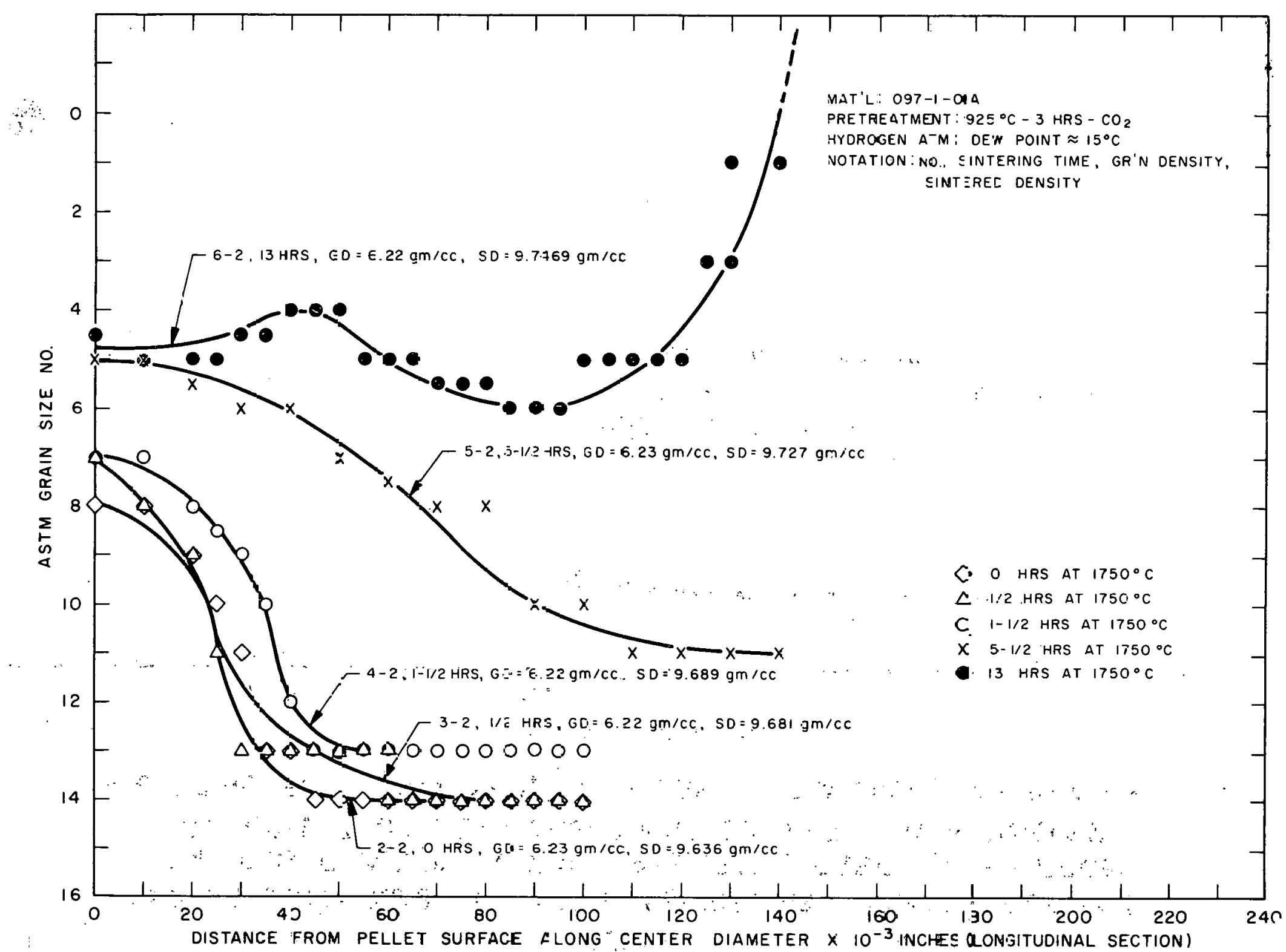




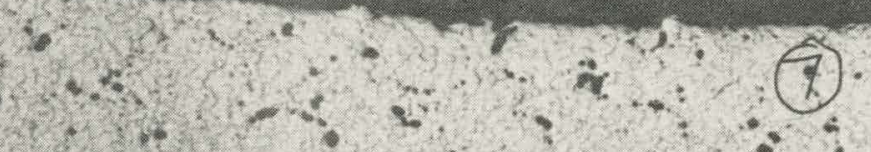

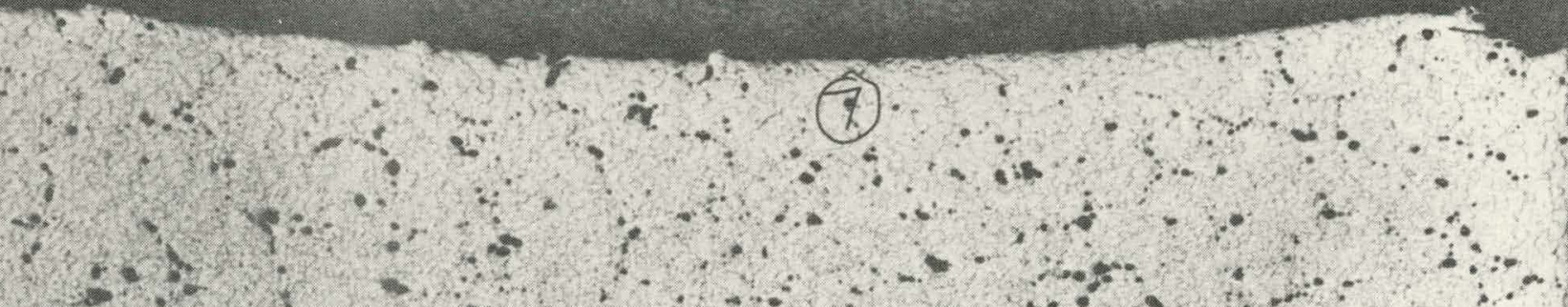

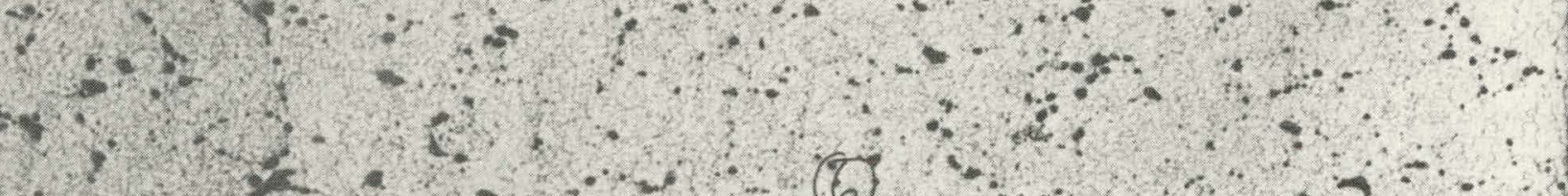

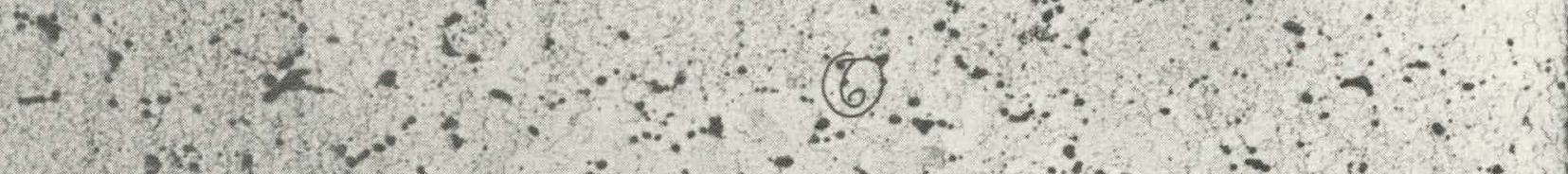

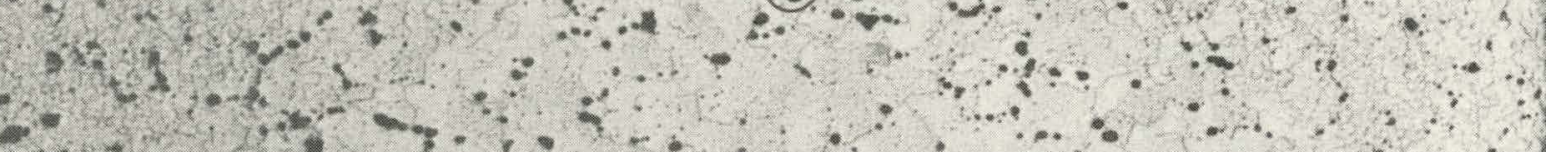

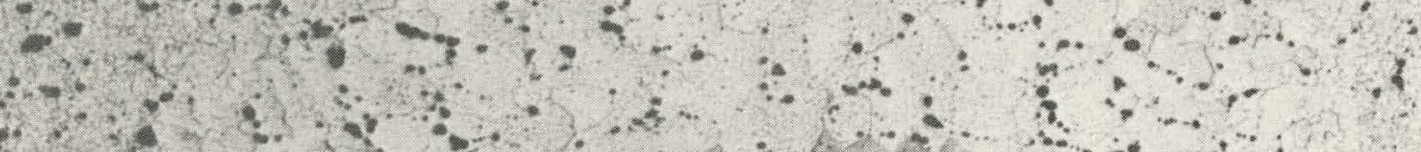

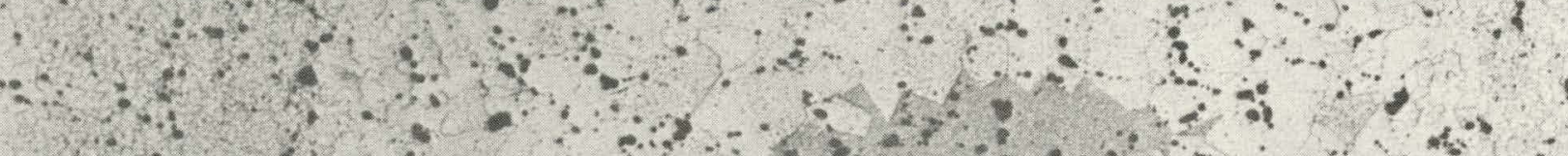

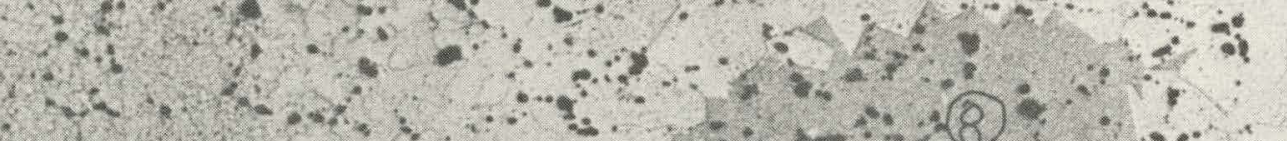

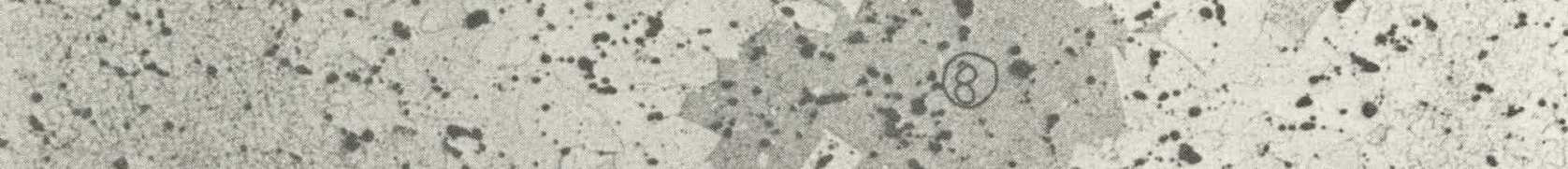

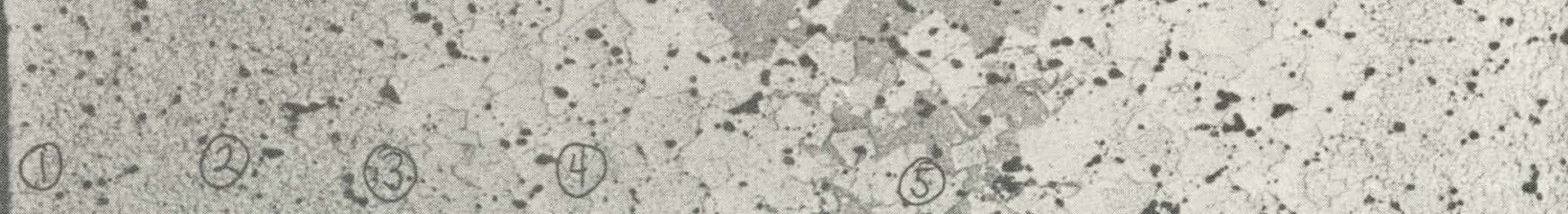
(1.3) (3) (3)

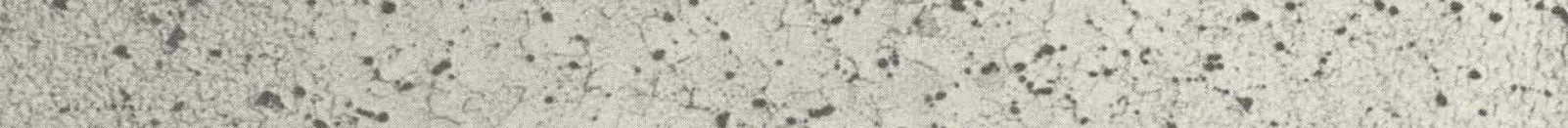

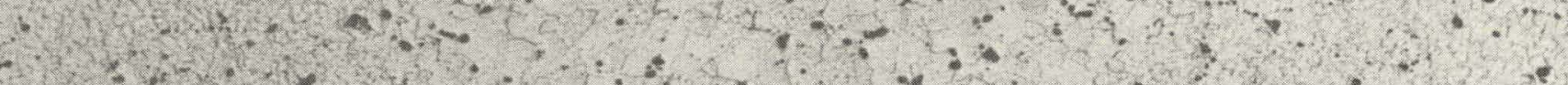

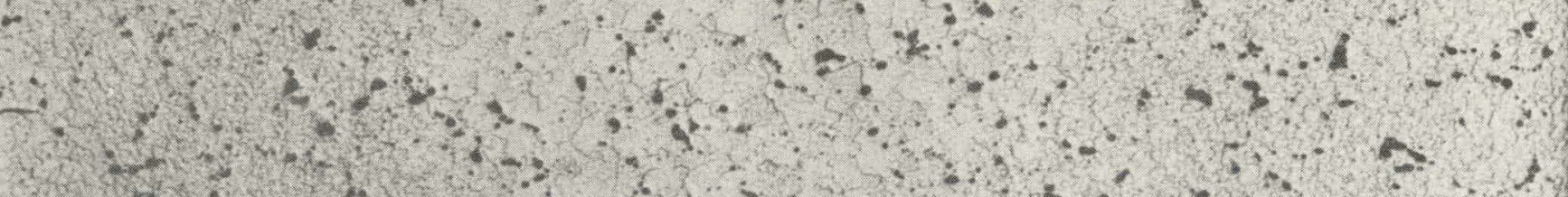

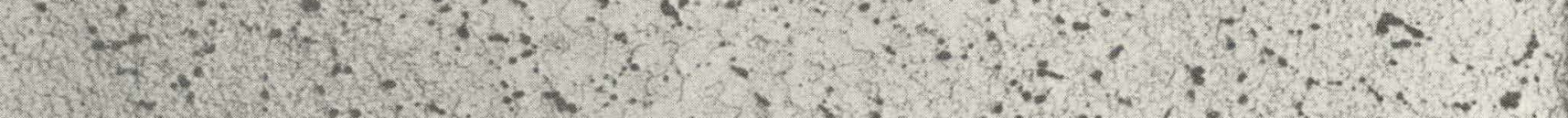

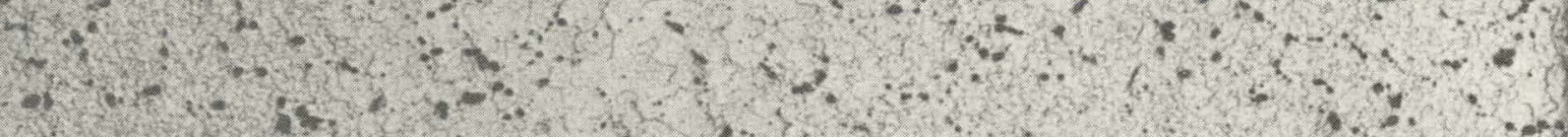

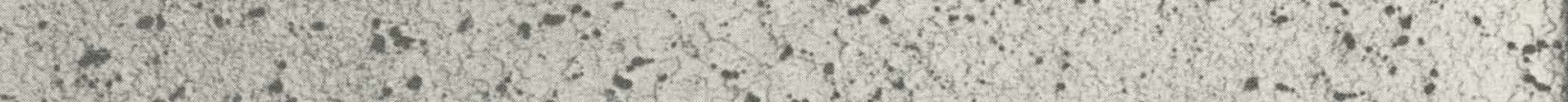

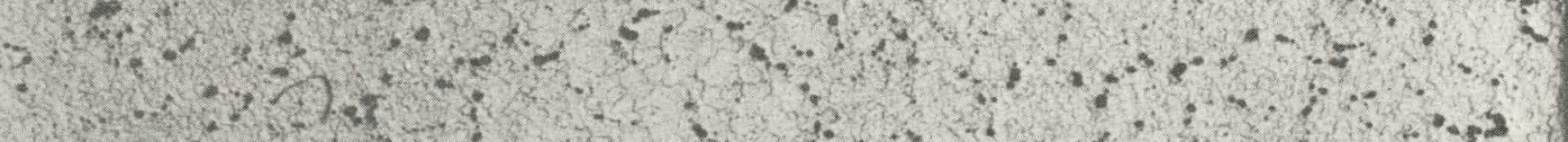

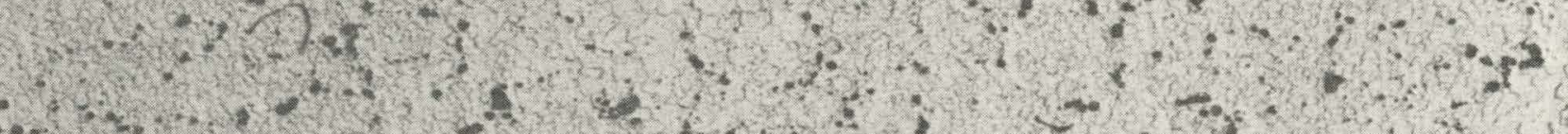

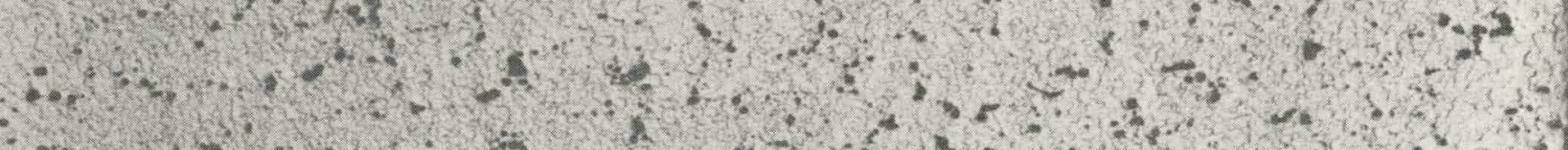

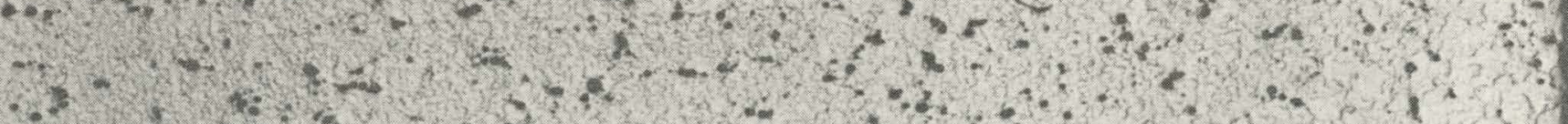

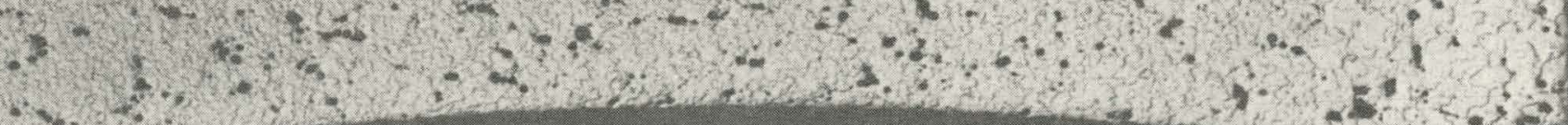

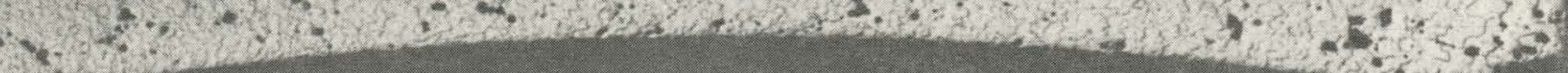


WA.PD-TM-1311

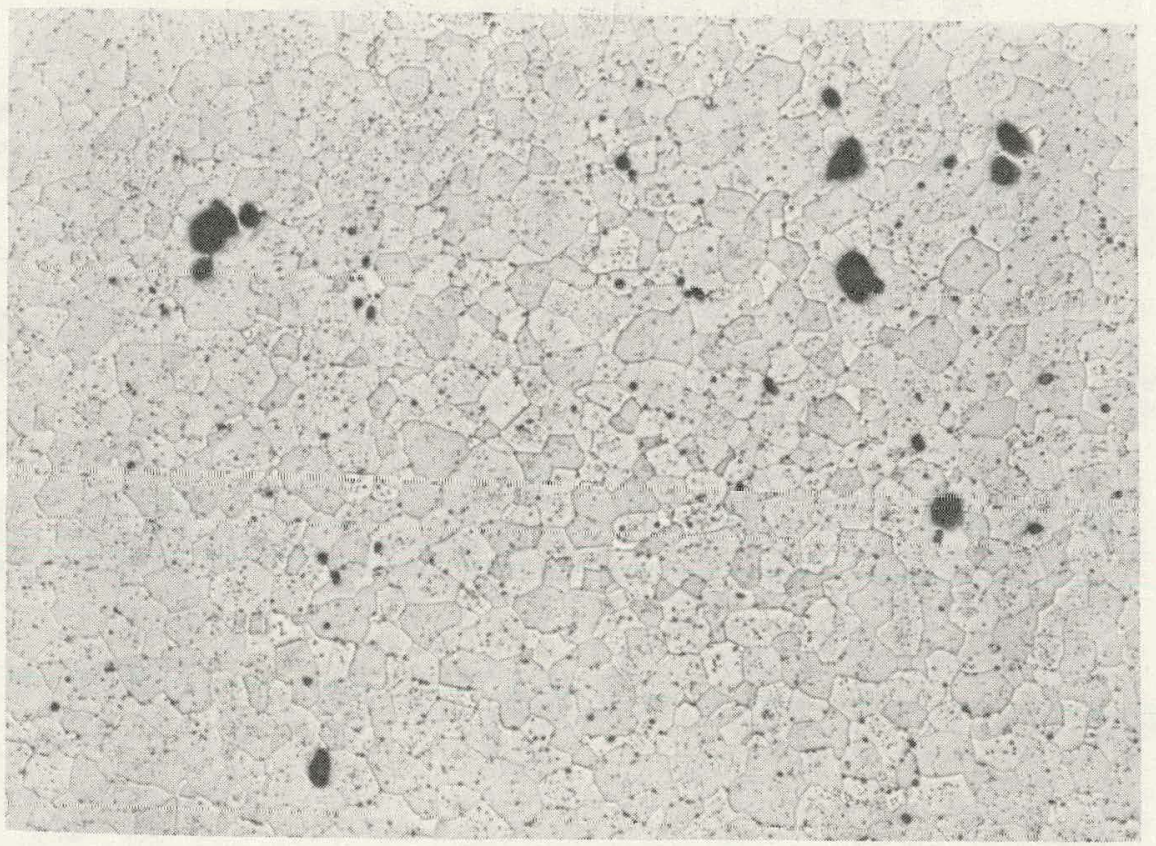

Neg. No. 51039-44

FIGURE 10. Area 1 in Figure 9 - 100X

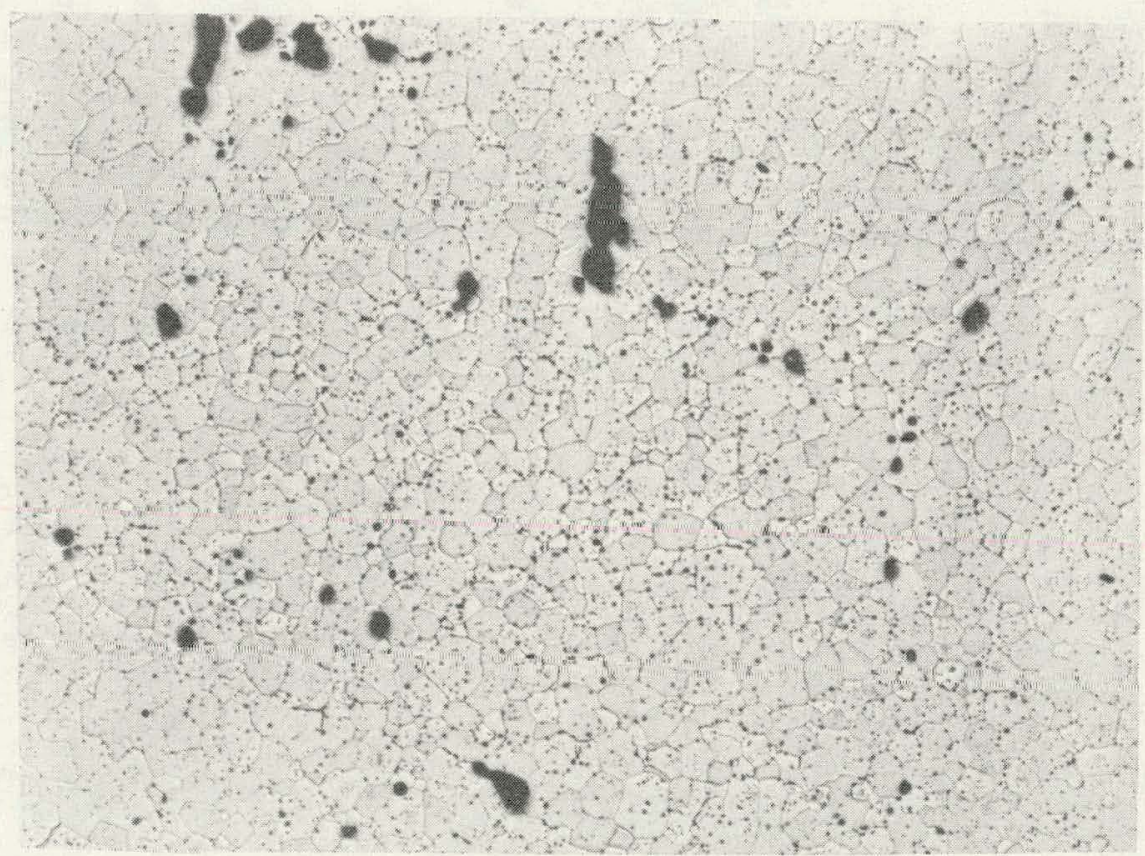

Neg. No. 51039-42

FIGURE 11. Area 2 in Figure 9 - 100X 


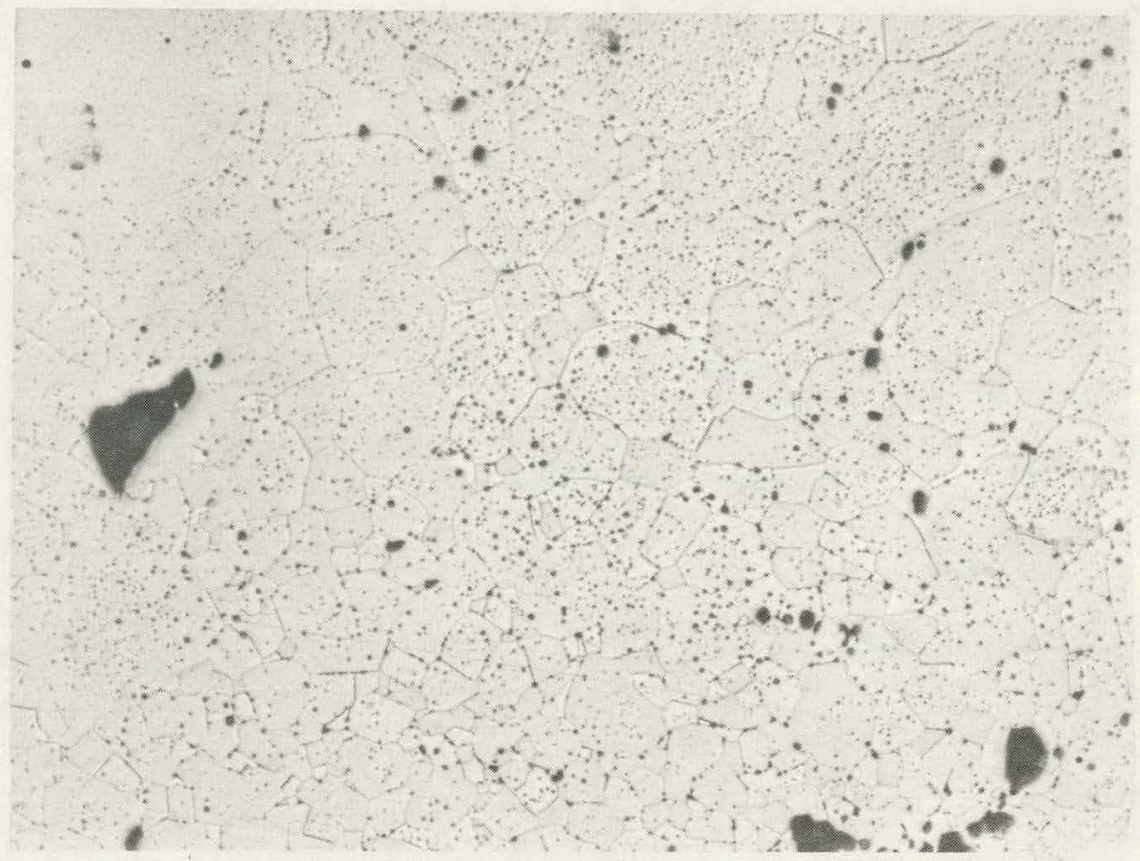

Neg. No. 51039-?

FIGURE 12. Area 3 in Figure $9-100 \mathrm{X}$

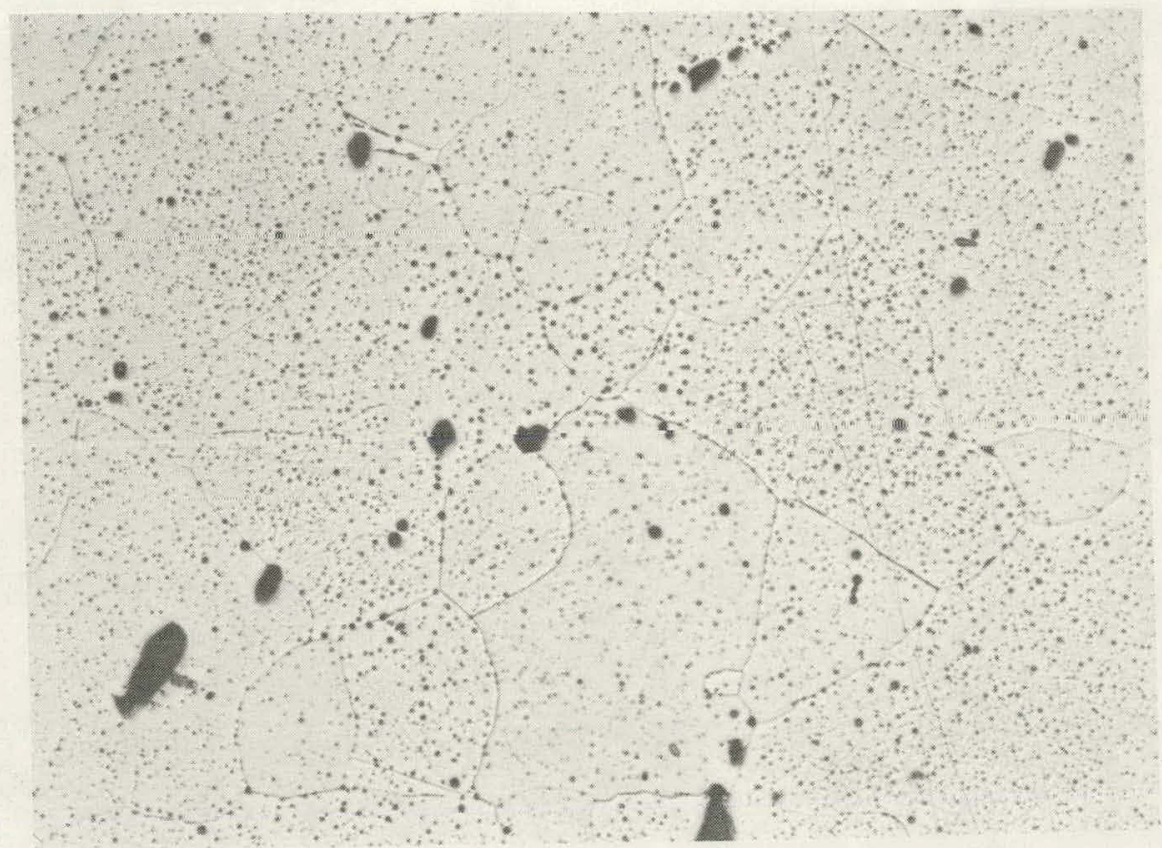

Neg. No. 51039-41

FIGURE 13. Area 4 in Figure 9 - $100 \mathrm{X}$ 
WAPD-TM-1311

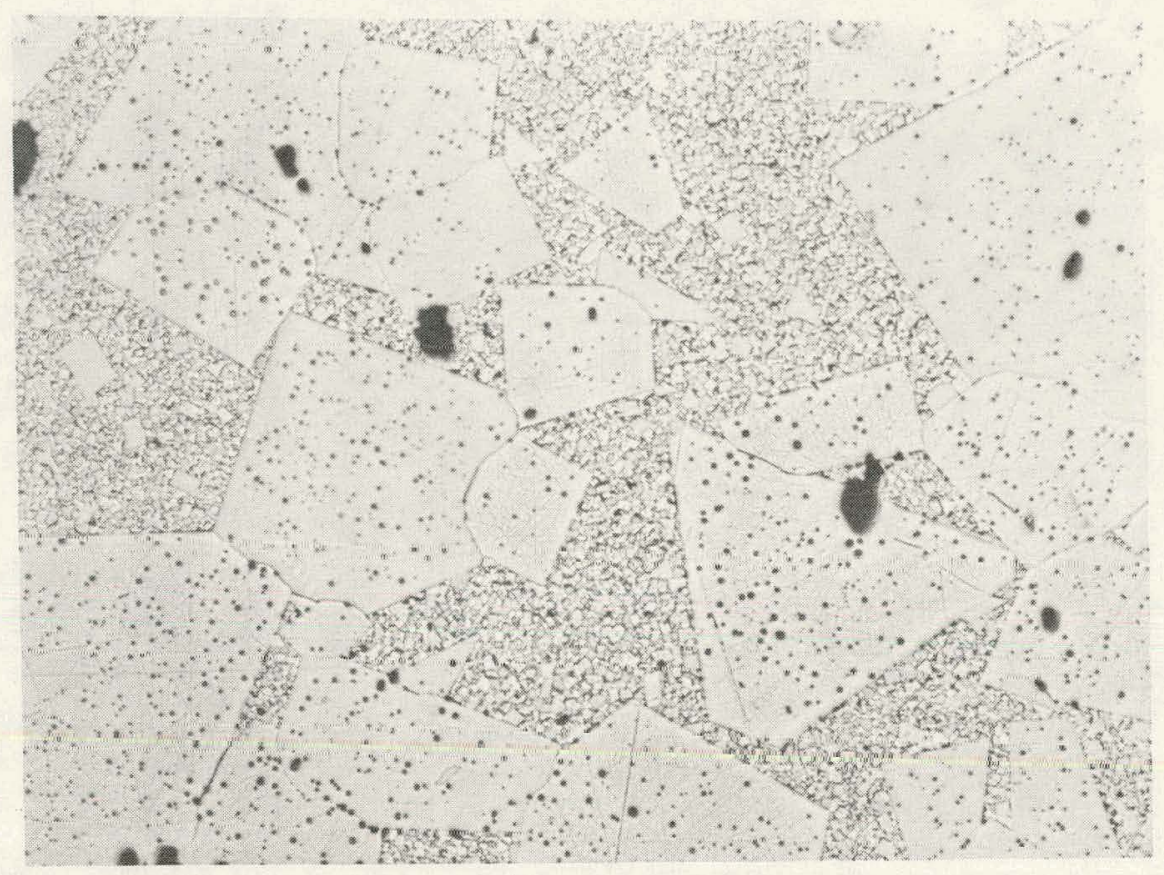

Neg. No. 51039-33

FIGURE 14. Area 5 in Figure 9-100X

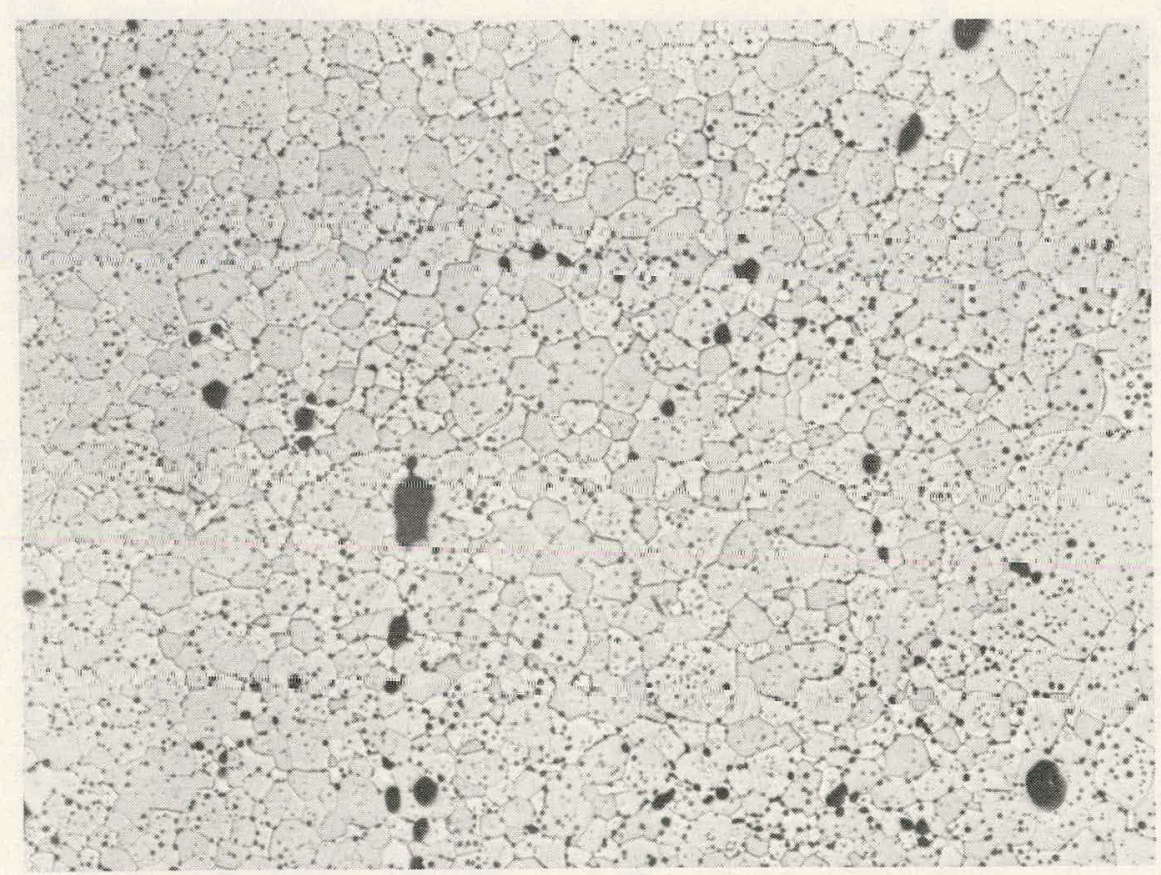

Neg. No. 51039-39

FIGURE 15. Area 6 in Figure $9-100 \mathrm{X}$ 


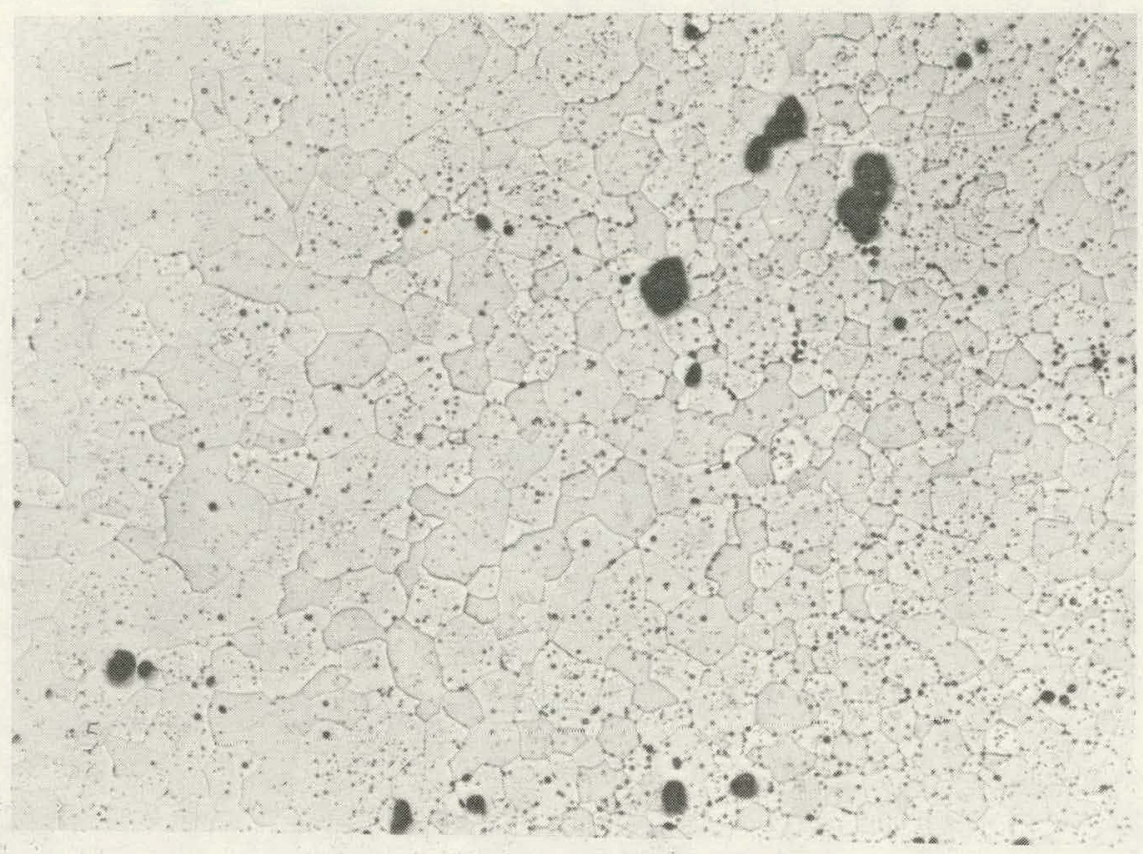

Neg. No. 51039-4

FIGURE 16. Area 7 in Figure 9 - $100 \mathrm{X}$

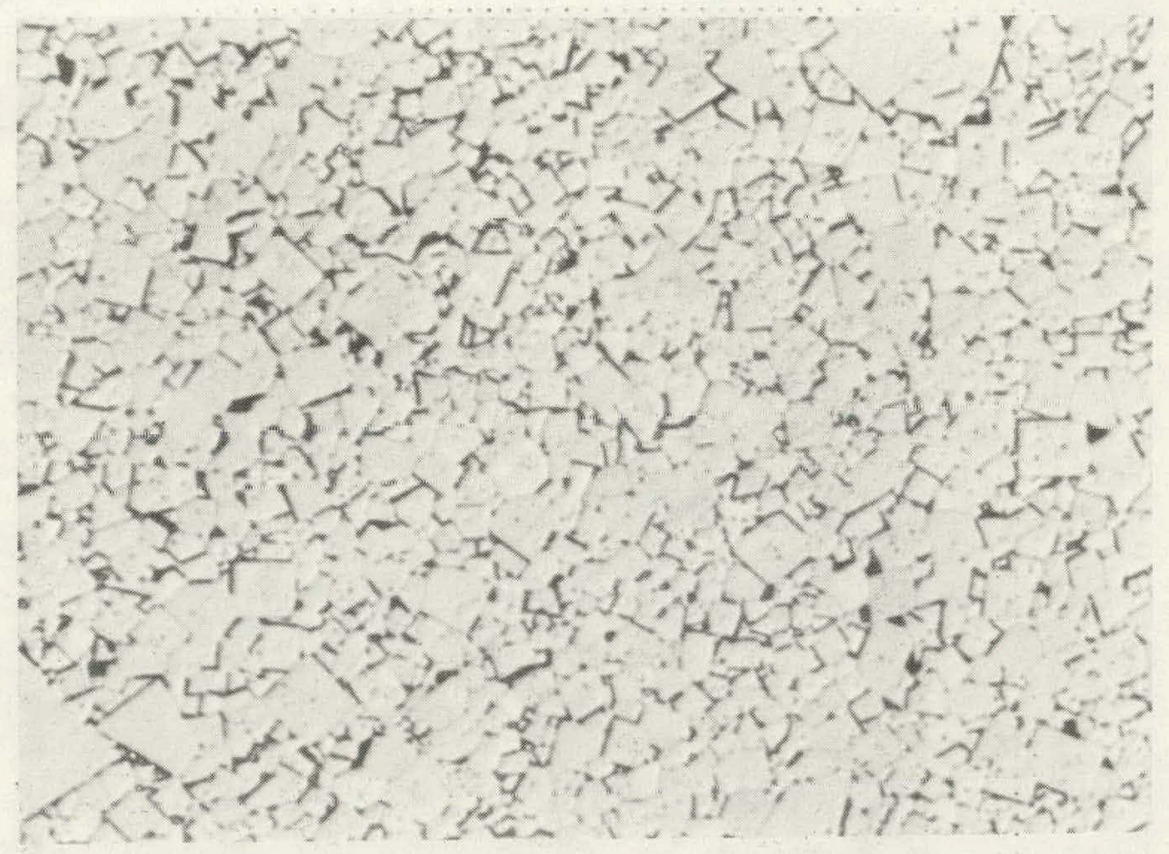

Neg. No. 51039-37

FIGURE 17. Area 8 in Figure 9 - $500 \mathrm{X}$ 
WAPD-TM-1311

FIGURE 18. Electron Microprobe Examination of $\mathrm{ThO}_{2}$ Pellet, 6-2, Blend 097-1-01A in Area of Idiomorphic Grain Structure Showing Presence of $\mathrm{Th}_{2}(0, \mathrm{~S})_{2}$ Phase: Kinetic Study \#2

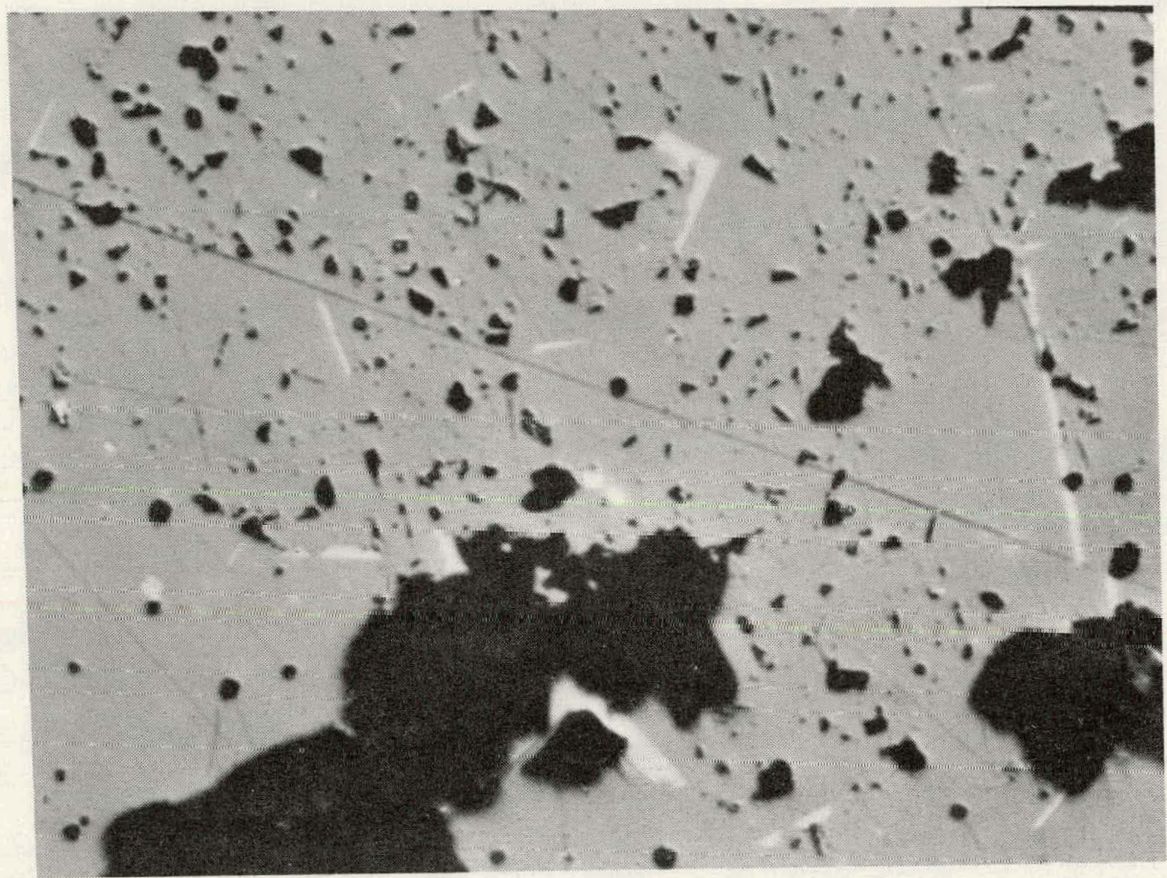

18a Opt1ud Micrograph of White, Nnnshiny, Second Phase in Area of Idiomorphic Microstructure $9578 \mathrm{~J}$ Neg. No. 51039-16 Mag. 500X

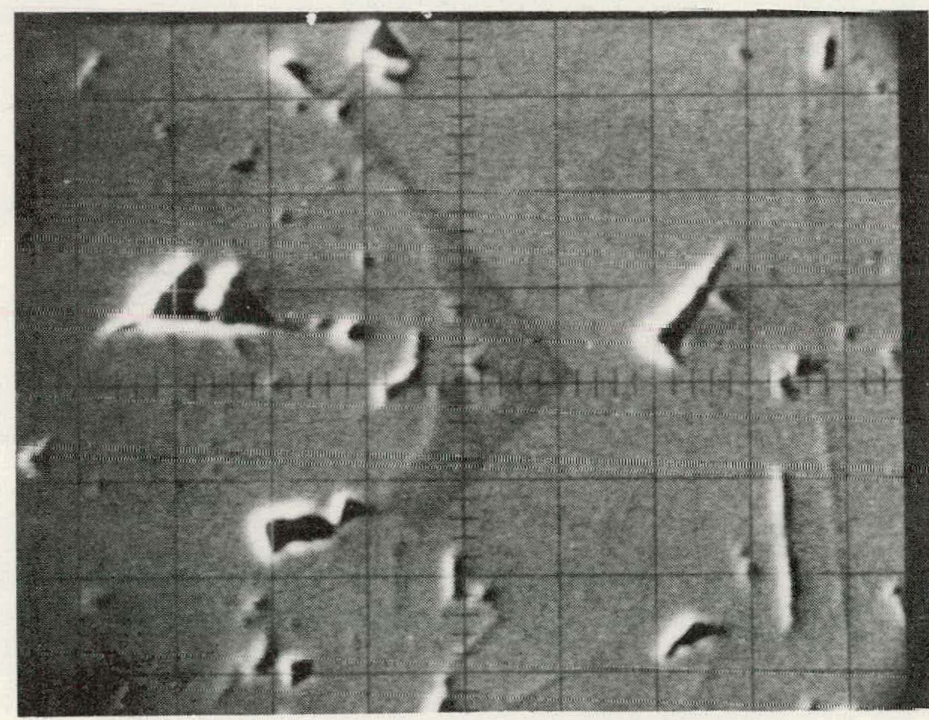

18b Electron Image of Second Phase Structure Showing Difference in Atomic Number from Matrix Phase Mag. 2000X Neg. No. 51039-23 
FIGURE 18 (Cont'd.)

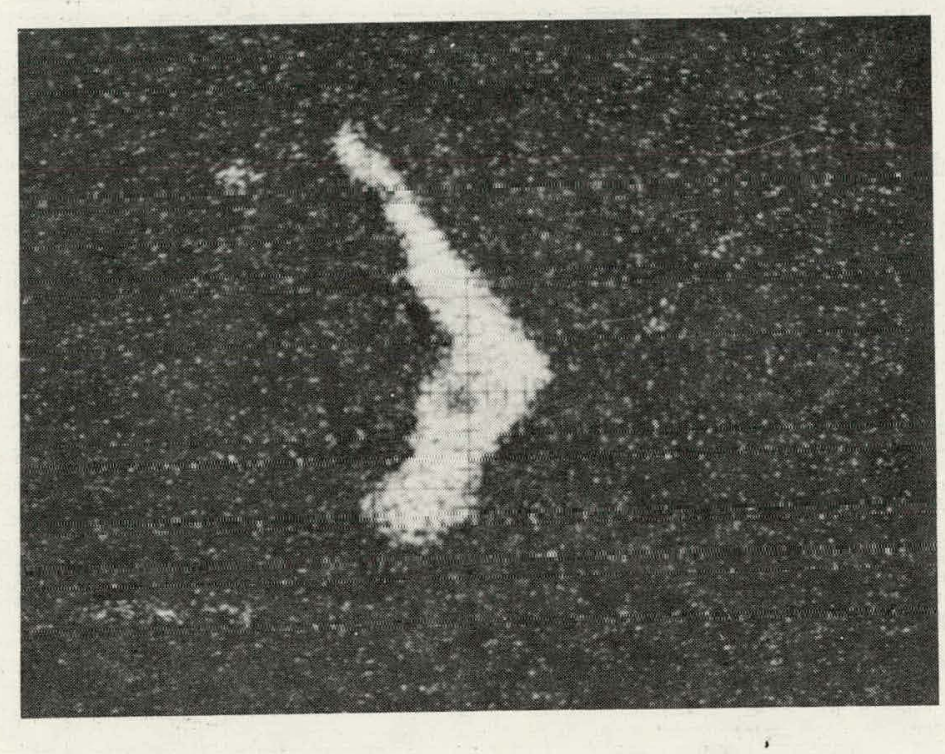

18c Sulfur $K \alpha$ X-Ray Image of Area in Figure 18b Mag. 2000X Neg. No. 51039-25

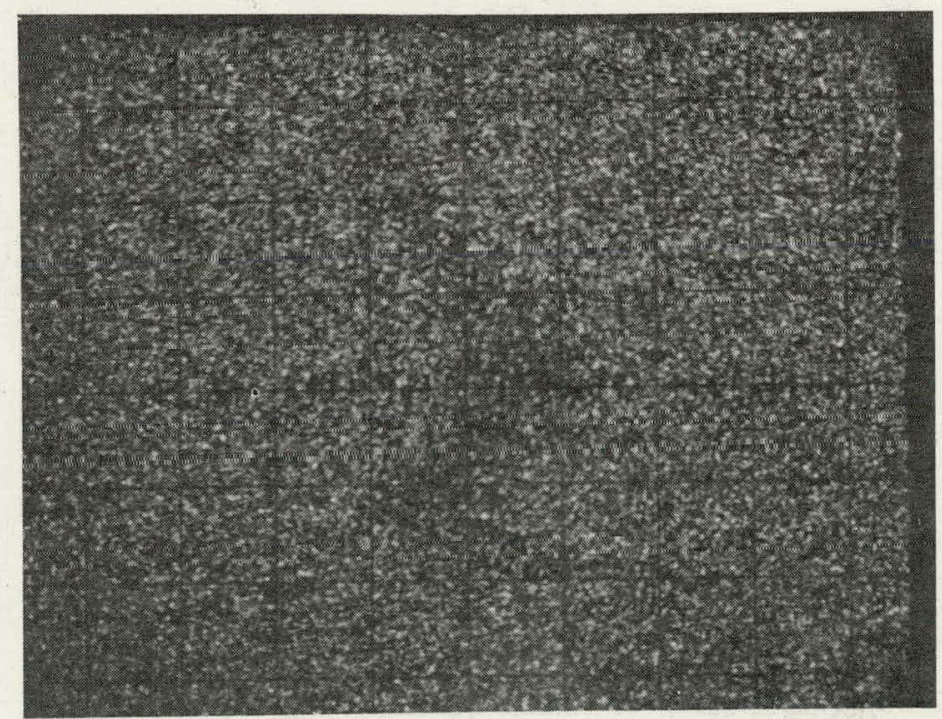

$18 \mathrm{~d}$ Oxygen $\mathrm{K} \alpha \mathrm{X}$-Ray Image of Area in Figure $18 \mathrm{c}$ Neg. No. 51039-22 Mag. 2000X 
WAPD-TM- 1311

FIGURE 19. Electron Microprobe, Semi Quantitative X-Ray
Trace of White Second Phase, Th( $(0, S)_{2}$ Shown
in Figure 18 - Kinetic Study $\# 2$

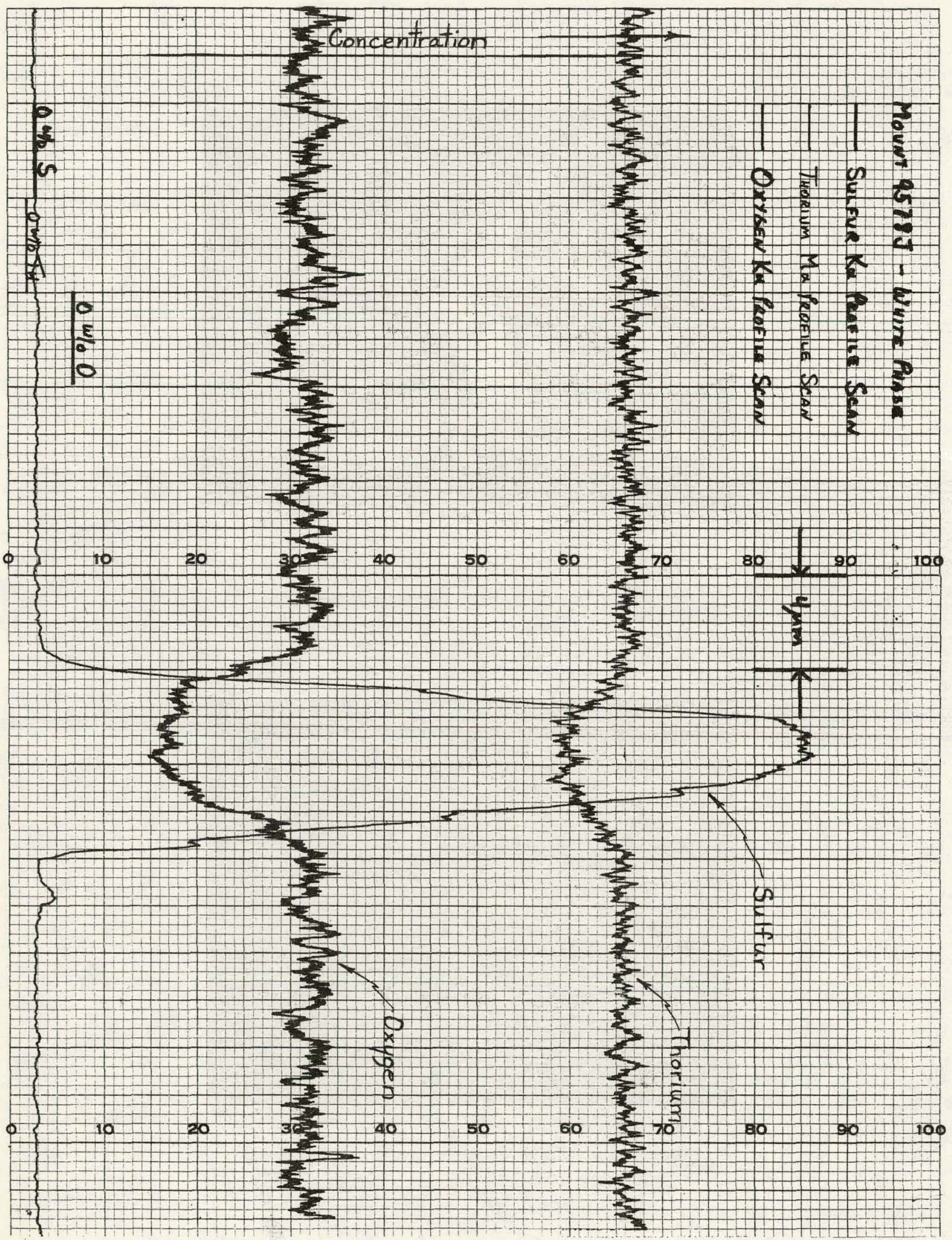

Neg. No. 51039-1 
FIGURE 20. Electron Microprobe Examination of :ThO 2 Pellet, 6-2, Blend 097-1-01A, in Area of Idiomorphic Grain Structure Showing Presence of $\operatorname{Tn}(0, S)_{2}$ Phase: Kinetic Study \#2

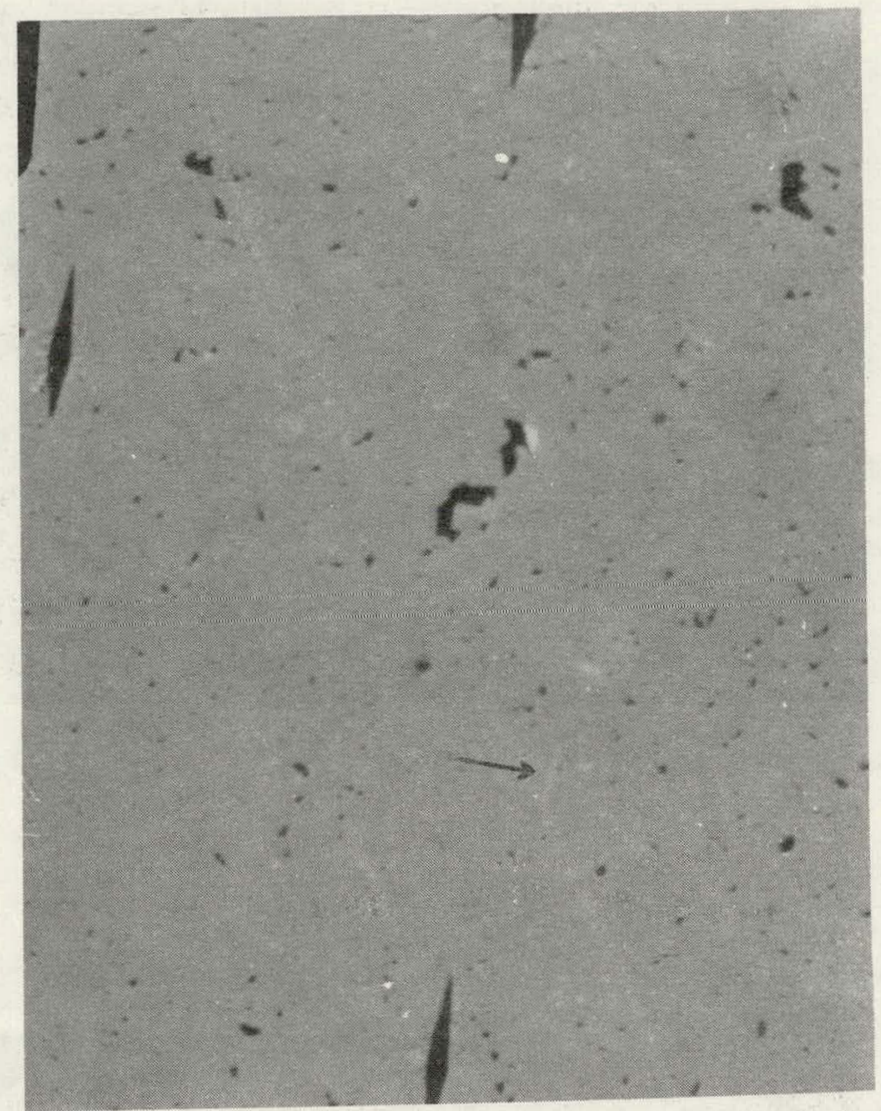

20a Optical Micrograph of Grey, Nonshiny Second Phase in Area of Idiomorphic $\begin{array}{ccc}\text { Microstructure } & 9578 \mathrm{~J} & \text { Mag. } 500 \mathrm{X}\end{array}$

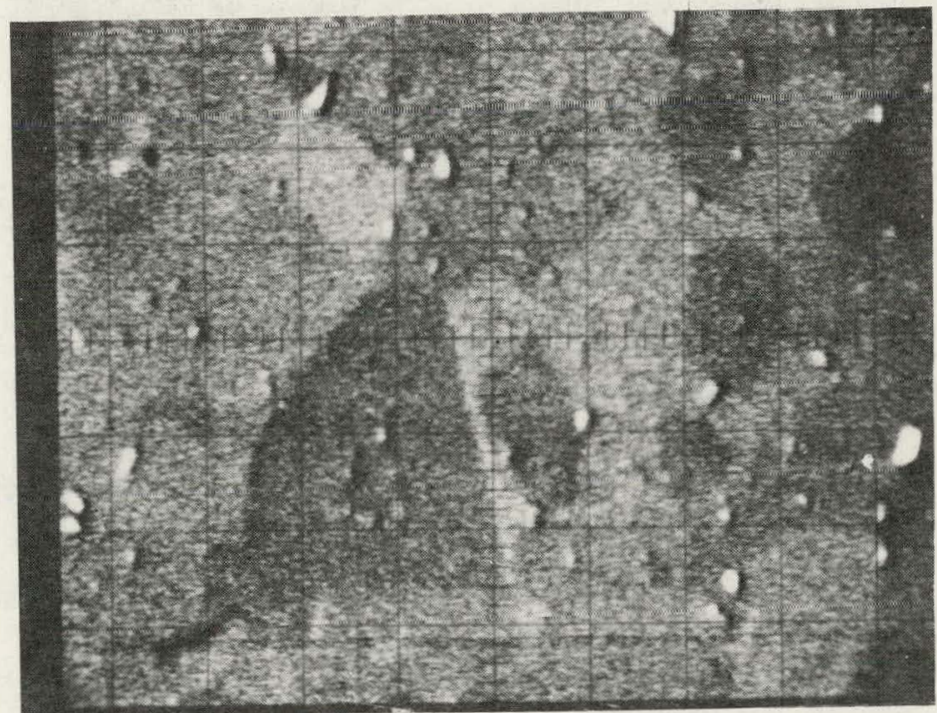

207 Electron Image of Second Phase Structure Fi gure 19a, Showing Difference in Atomic No. from Matrix Phase Mag. 2000X 
WAPD -TM-1311

FIGURE 20 (Cont'd.)

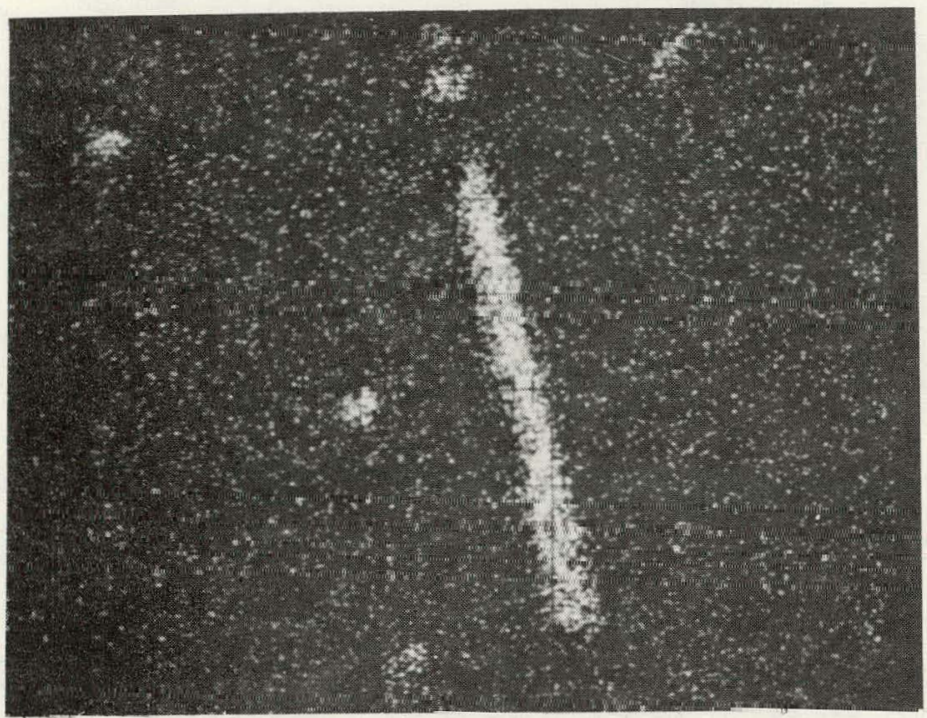

20c Sulfur Ko X-Ray Image of Area in Figure 19a Showing Presence of Sulfur in Grey Second Phase 9578 J

Neg. No. 51039-24

Mag. 3300

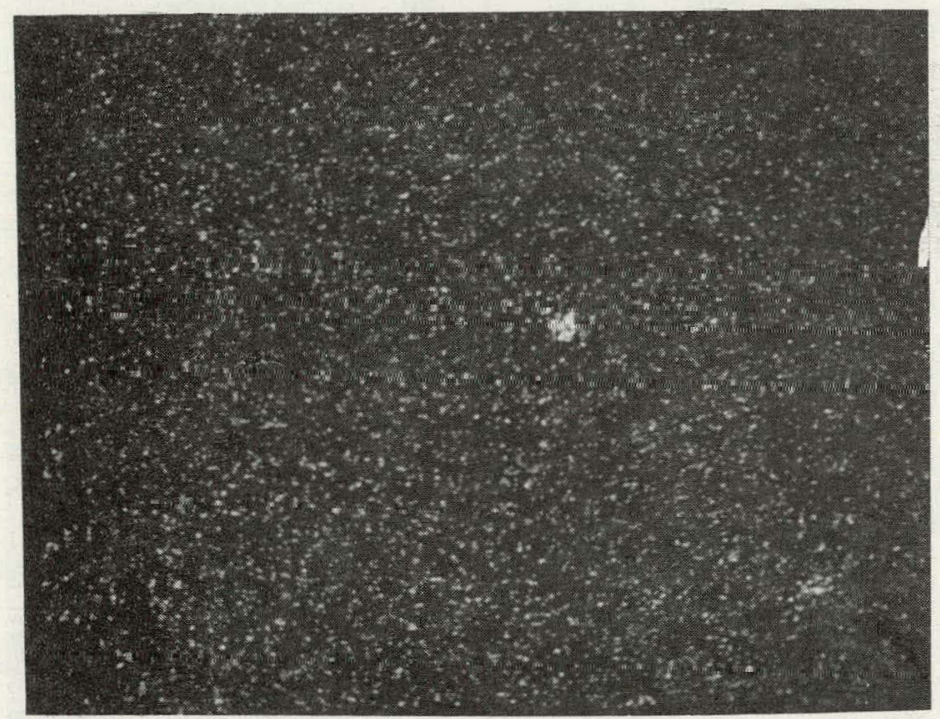

20d Chromium K $\alpha$ X-Ray Image of Area in Figure 19a Showing Absence of Chromium in Grey Second Phase 9578 J Mag. 3300

Neg. No. 51039-21 
FIGURE 21. Electron Microprobe, Semi Quantitative X-Ray

Trace of Grey Second Phase, Th $(0, S)_{2}$ Shown

in Figure 20 - Kinetic Study \#2

Mount $9578 \mathrm{~J}$ - Gray Prase

Surrur Ka Prgane Scan

Thorium Ma Pronize Scan

Oxyeren Ka Pmenes Scan

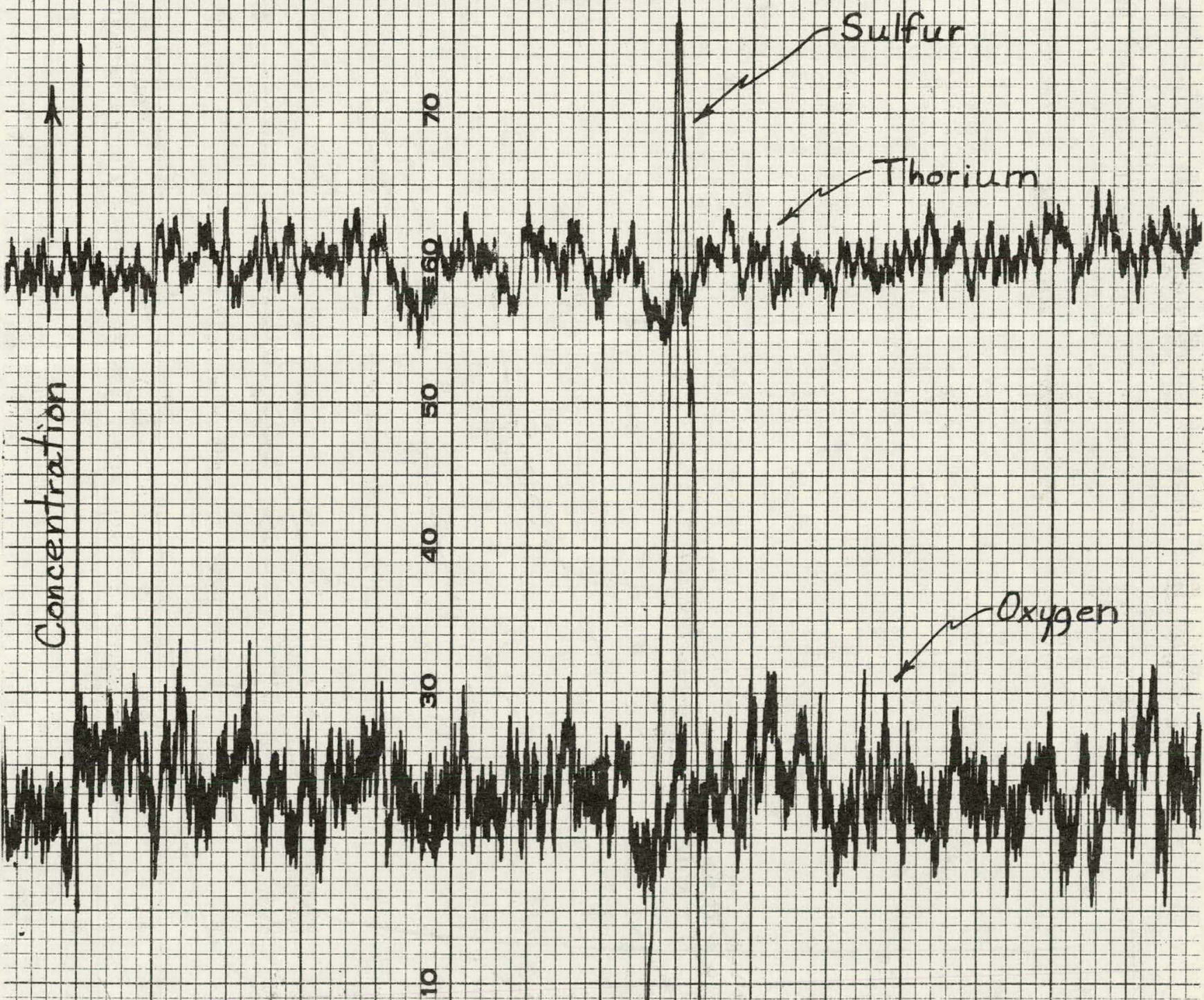

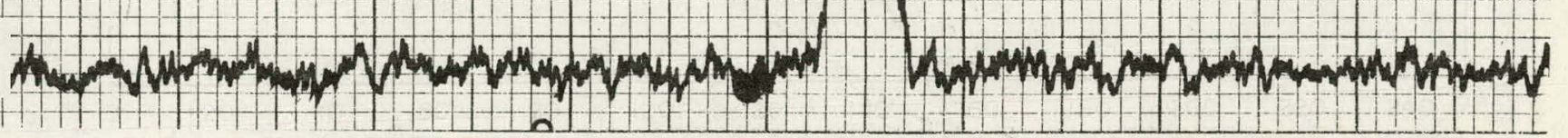

Neg. No. 51039-2 
FIGURE 22

KINETIC STUDY NO. 3: EFFECT OF SINTERING TIME AT $1800^{\circ} \mathrm{C}$ ON GRA N GROWTH IN

$\mathrm{THO}_{2}$ PE_LETS FABRICATED FROM POWDER LOT 097, L/S AGGLOMERATED

WITH 1.0 W/O CARBCWAX - 0.2 W/O STEROTEX (ADDED JRY),

AND PRESSED TO A GREEN DENSITY OF $62 \%$

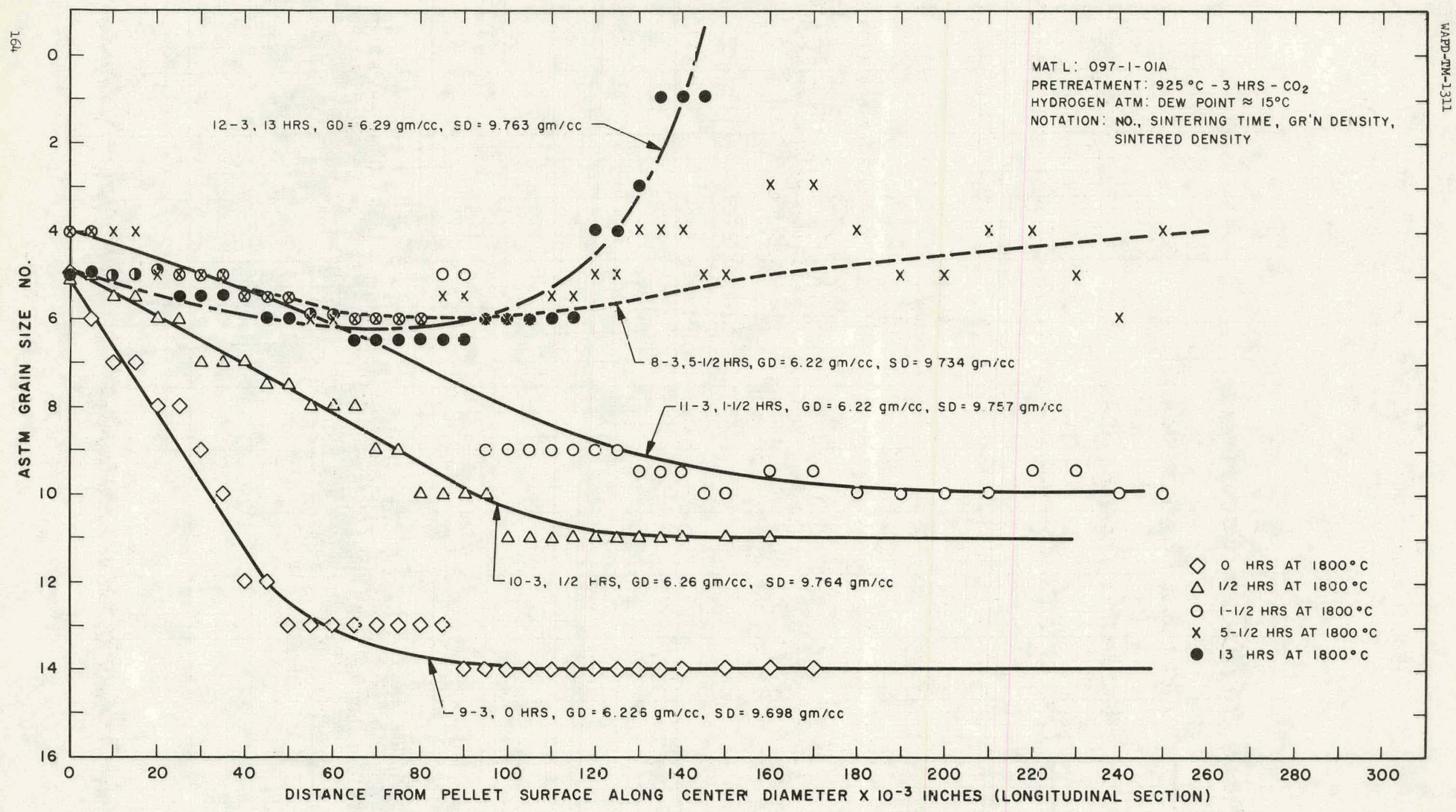




\section{FIGURE 23}

TIME DEPENDENT GRAIN GROWTH AT $1655^{\circ} \mathrm{C}$ IN ThO 2 PELLETS, $088-1-11$, AT SURFACE EXPOSED TO THE SINTERING ATMOSPHERE

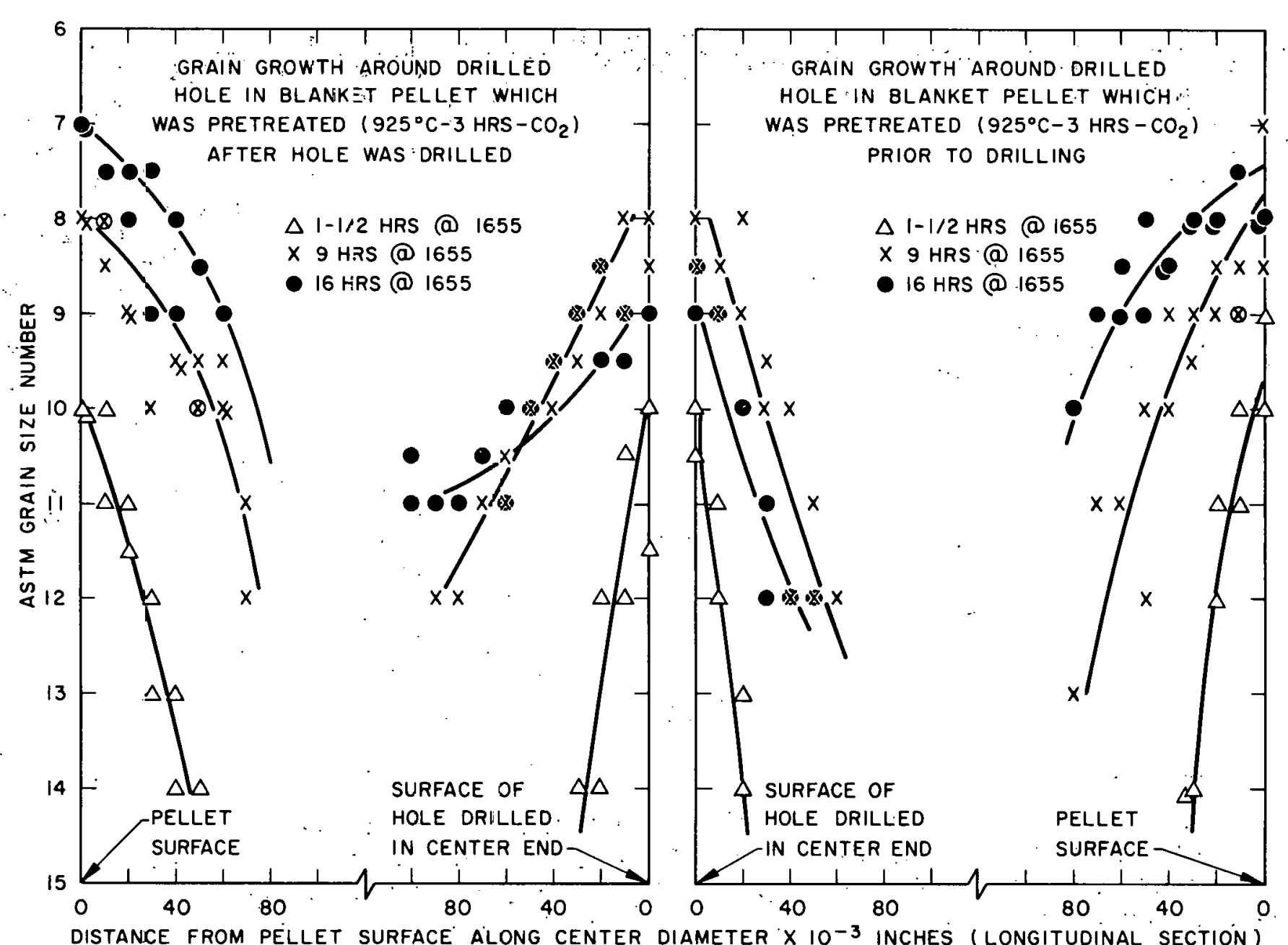


FIGURE 24

KINETIC STIUDY NO 4: EFFECT OF SINTERING TIME AT $1750^{\circ} \mathrm{C}$ IN WET HYLROȘEN ANO THE EFFECT OF A $13 \mathrm{CO}^{\circ} \mathrm{C}-48 \mathrm{HR}-\mathrm{H} \cdot \mathrm{WET}$ ) HOLD TIME ON GRAIN GROWTH IN ThO 2 PELLETS.

FABRICATED FROM POWDER LOT 097, L/S AGGLOMERATEL WITH I.O W/O CARBOWAX-

C.2 w/O STEROTEX (ADOED DRY), AND PRESSED TO A GREEN OENSITY OF $62 \%$.

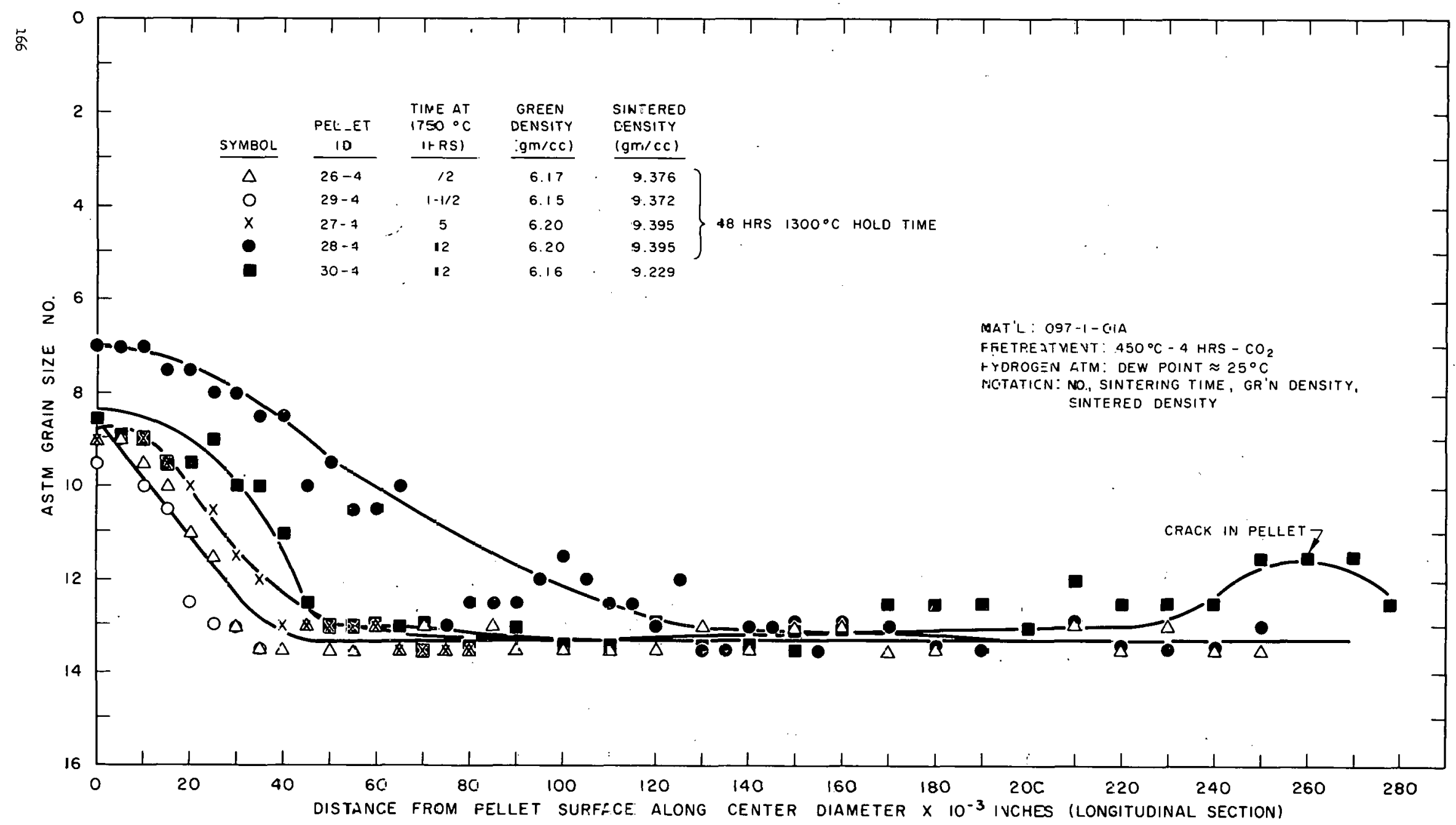




\section{FIGURE 25}

KINETIC STUDY NO. 6: EFFECT OF HEATING RATE $\left(400^{\circ} \mathrm{C} / \mathrm{HR}\right)$ AND SINTERING TIME AT $1750^{\circ} \mathrm{C}$ ON GRAIN GROWTH IN ThO 2 PELLETS FABRICATED FROM POWDER LOT 088, L/S AGGLOMERATED WITH 1.0 w/o CARBOWAX - 0.2 w/O STEROTEX (ADDED DRY), AND PRESSED TO A GREEN DENSITYY OF $55 \%$

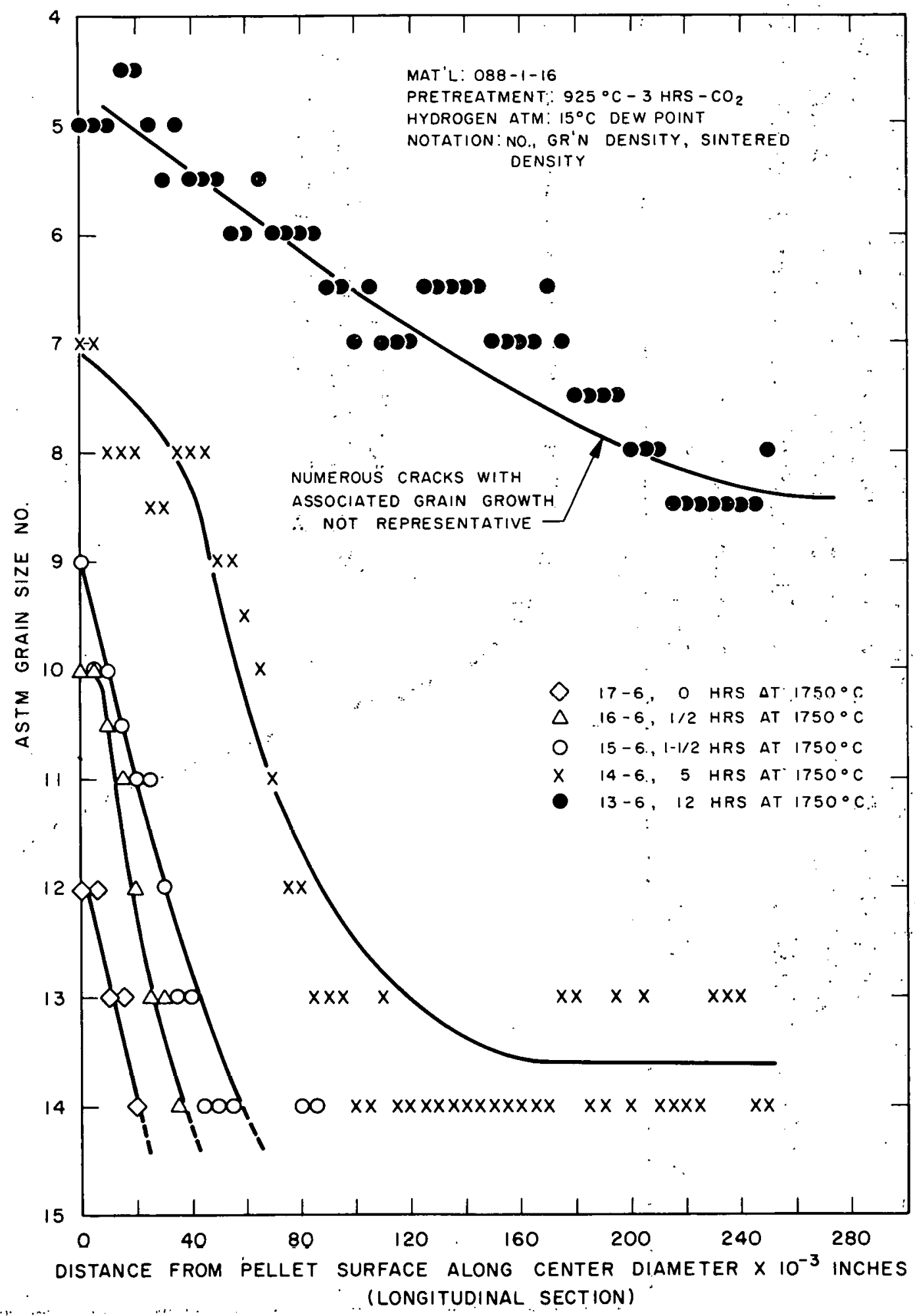


FIGURE 26

KINETIC STUDY NO.7: CHANGE IN DENSITY AS A FUNCTION OF TIME AND TEMPERATURE IN ThO 2 PELLETS FABRICATED FROM POWDER LOT 088, L/S AGGLOMERATED WITH $1.0 \mathrm{~W} / 0$ CARBOWAX0.2 w/O STEROTEX (ADDED DRY), AND PRESSED TO A GREEN DENSITY OF $55 \%$

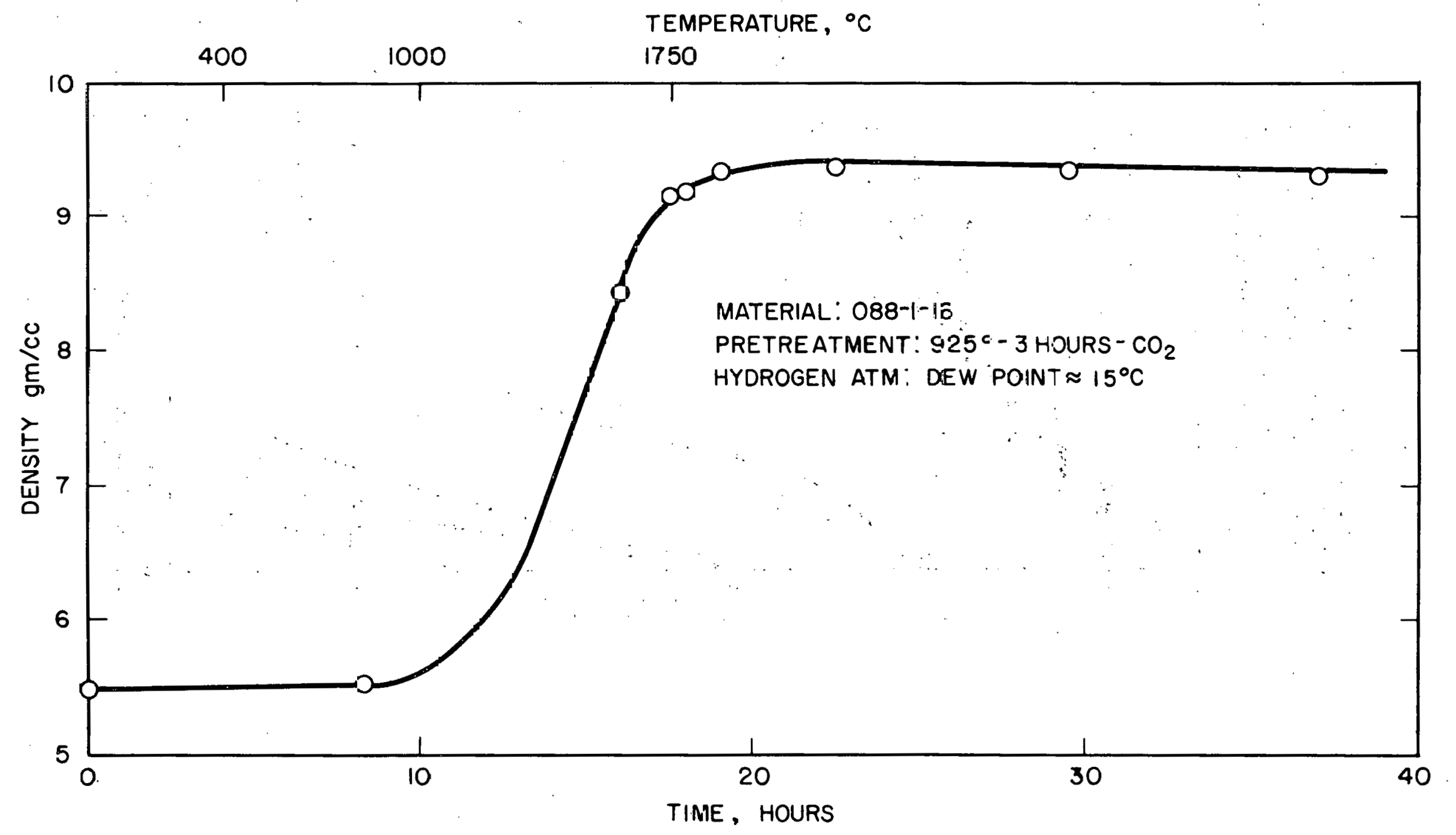


FIGURE 27

KINETIC STUDY NC. 7: EFFECT OF SINTERING TIME AT $1750^{\circ} \mathrm{C}$ ON GRAIN GROWTH IN

$\mathrm{ThO}_{2}$ PELLETS FABRICATED FROM POWDER LOT 088, L/S AGGLOMERATED

WITH I.O W/O CARBOWAX - 0.2 W/O STEROTEX (ADDED DRY).

AND PRESSED TO A GREEN DENSITY OF $55 \%$

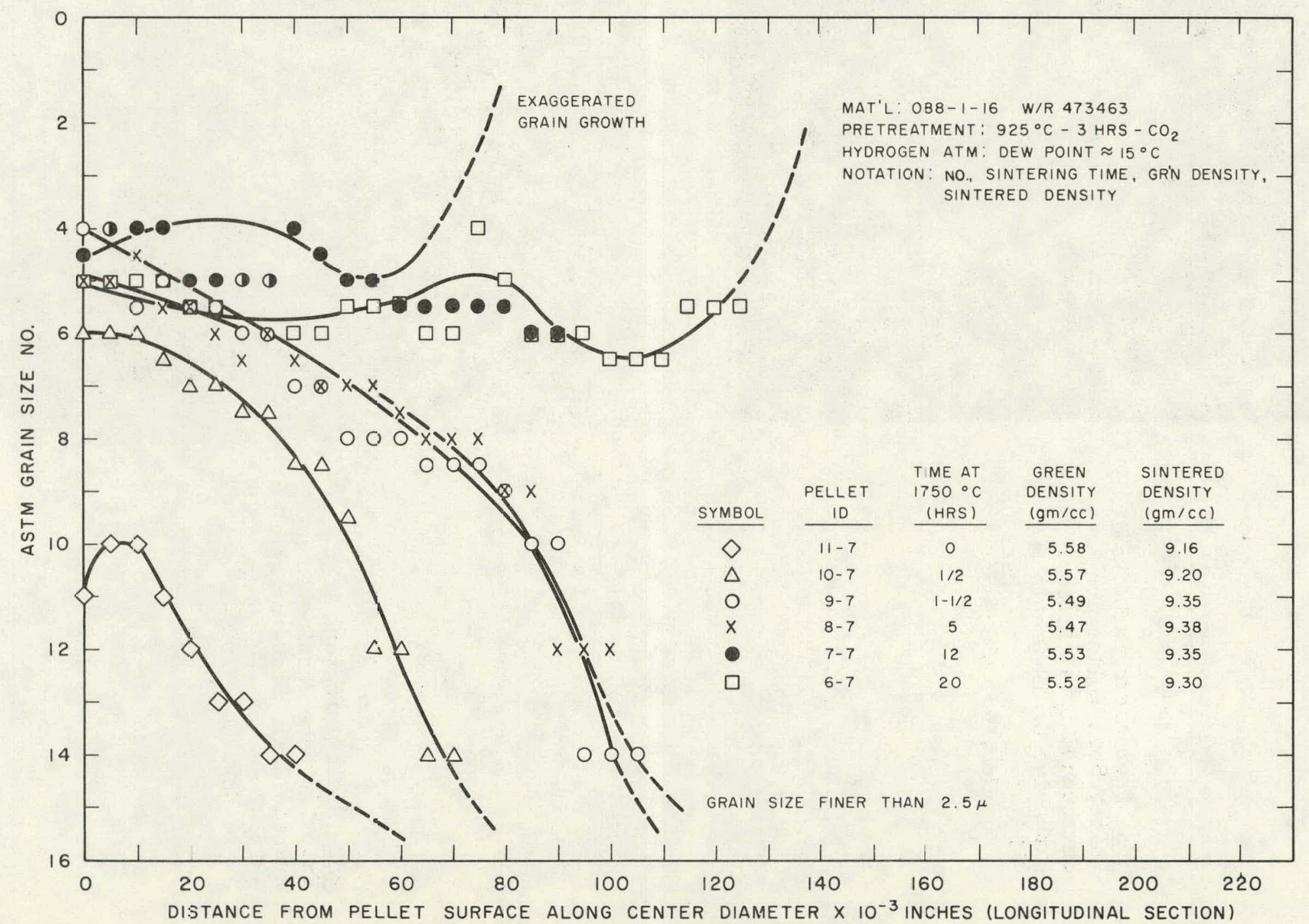


WAPD-TM-1311 FIGURE 28. Kinetic Study \#? Photomicrographs of Pellet, 8-7, Sintered Fon 5. Tre at $17500 \mathrm{C}$

28a Photomacrograph Showing White, Soft Pellet Center Surrounded by an Area of Extensive Grain Growth $9813 \mathrm{~J}-1$ Neg. No, 51039-36
Mag. $6 \mathrm{X}$

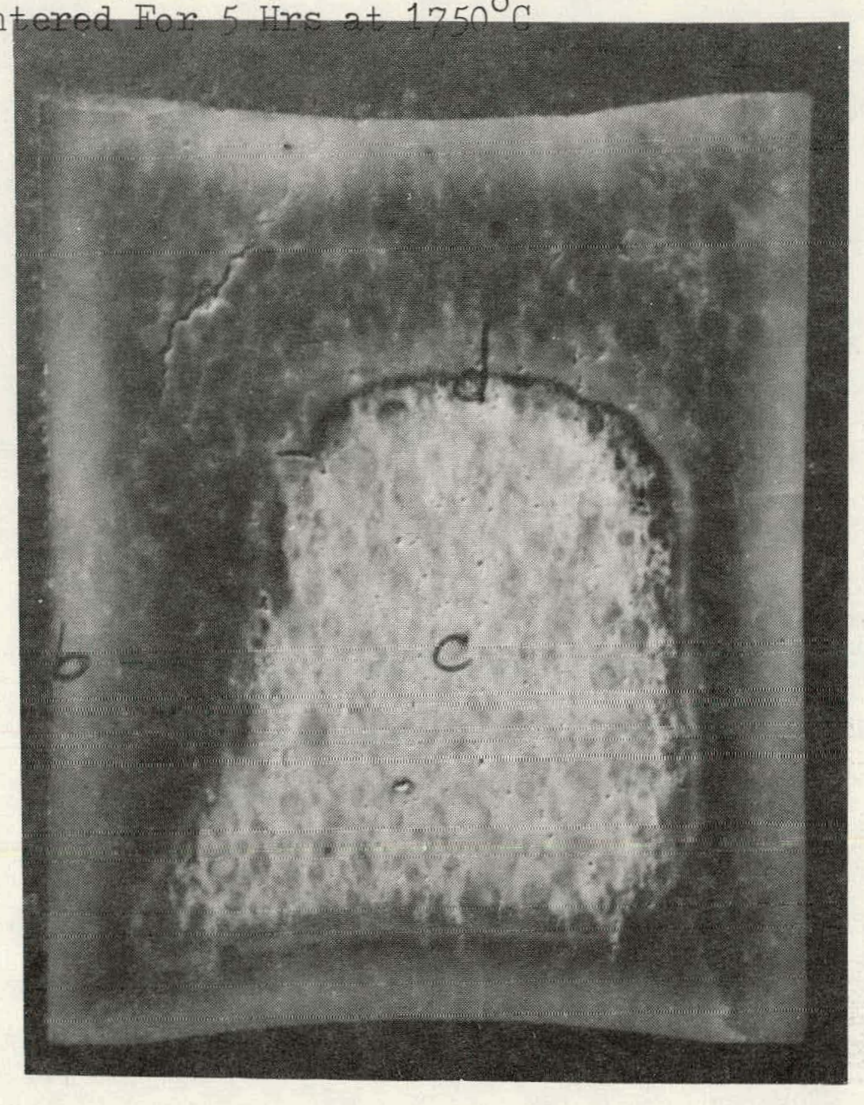

28b Photomicrograph of Fixt.erinr Fidge Showing an Average Grain Diameter of $60 \mu$ $9813 \mathrm{~J}-2$ Neg. No. $51039-28$

Mae. $100 \mathrm{X}$

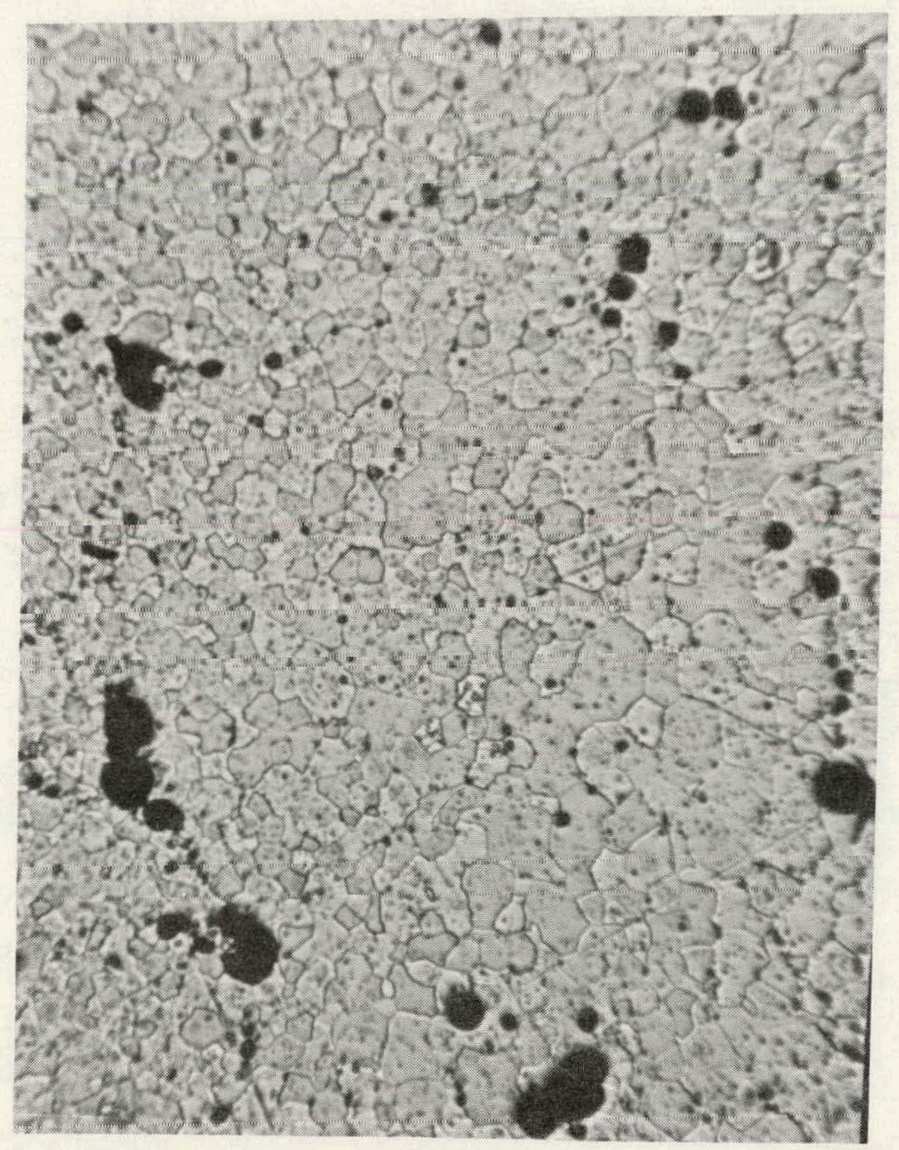



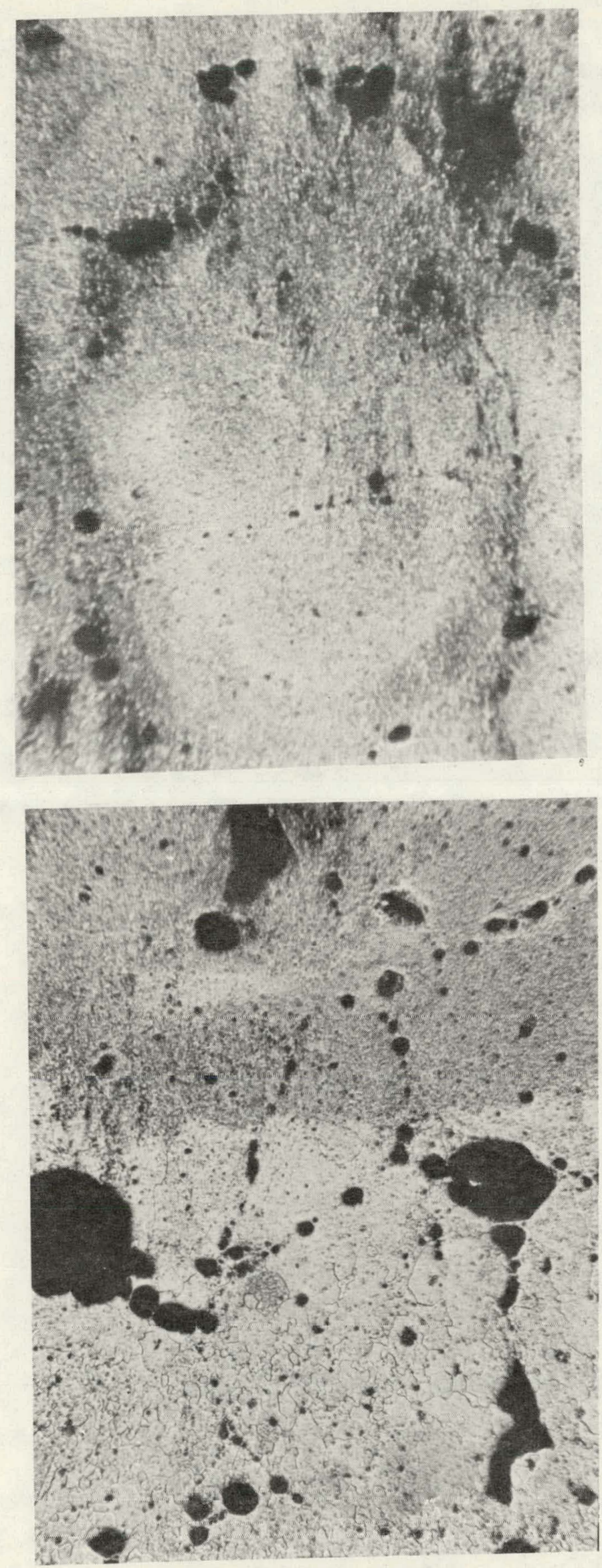

WAPD-TM-1311

28c Pellet Center Showing

Complete Lack of Grain Growth $9813 \mathrm{~J}-4$ Mag. $100 \mathrm{X}$ Neg. No. 51039-35 28d Transition Area Between Dense, Hard Phase With Extensive Grain Growth and Soft Phase With Almost No Grain Growth $9813 \mathrm{~J}-5$
Neg. No. $51039-10$ 
WAPD-TM-1311

FIGURE 29. Kinetic Study \#7: Photomicrographs of

Thoria Pellet, 6-7, Sintered for 20 Hours at $1750^{\circ} \mathrm{C}$

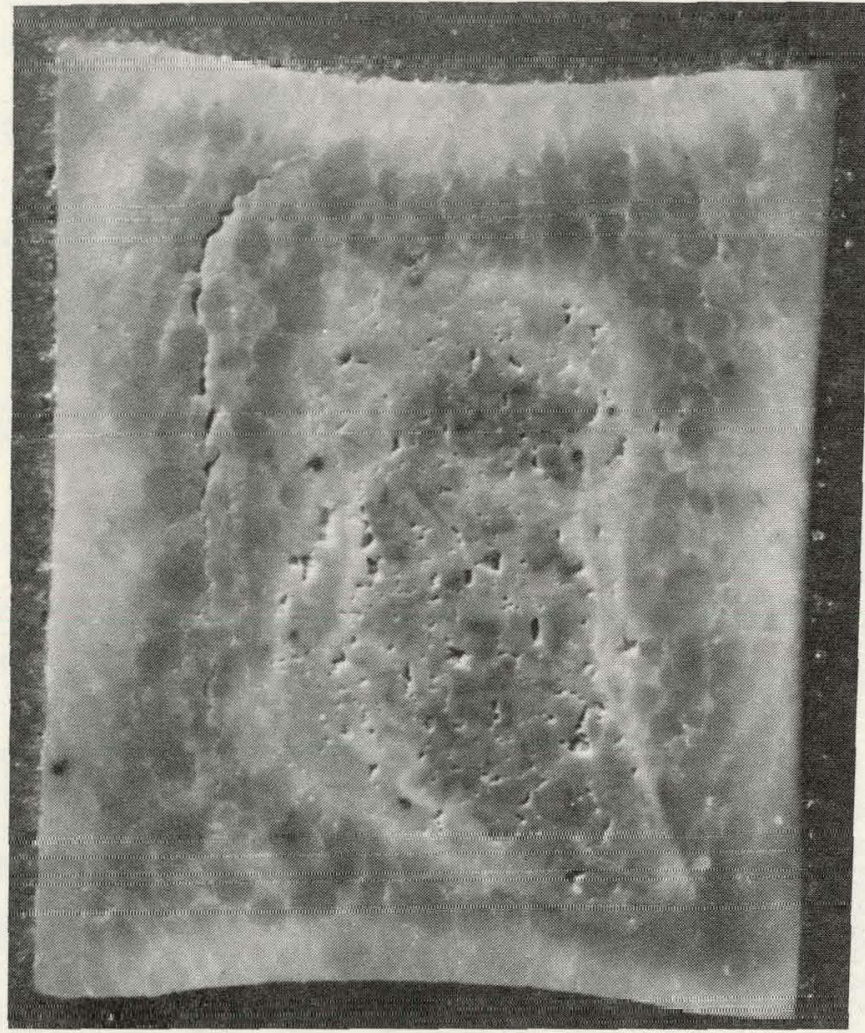

29a Photomacrograph Showing Intergranular Separation Around Pellet Center Section Which Densified After the Exterior. Large Intergranular Separations in Pellet Center. प्र818.1-1 Neg. No. 51039-30 Mag. 6Y

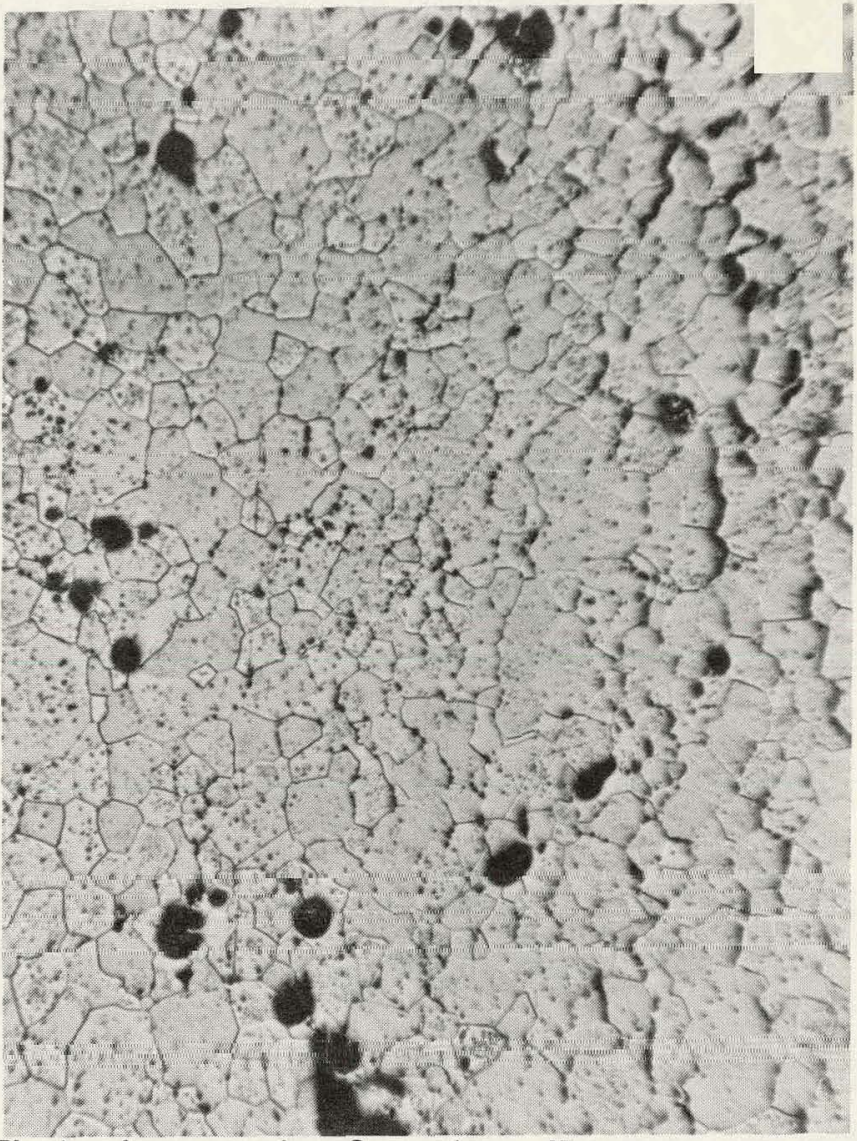

29b Photomicrograph of an Area Near the Pellet Center Showing Grain Boundary Separation (Right Hand Side of Photograph)

9818J-2 Mag. $100 \mathrm{X}$

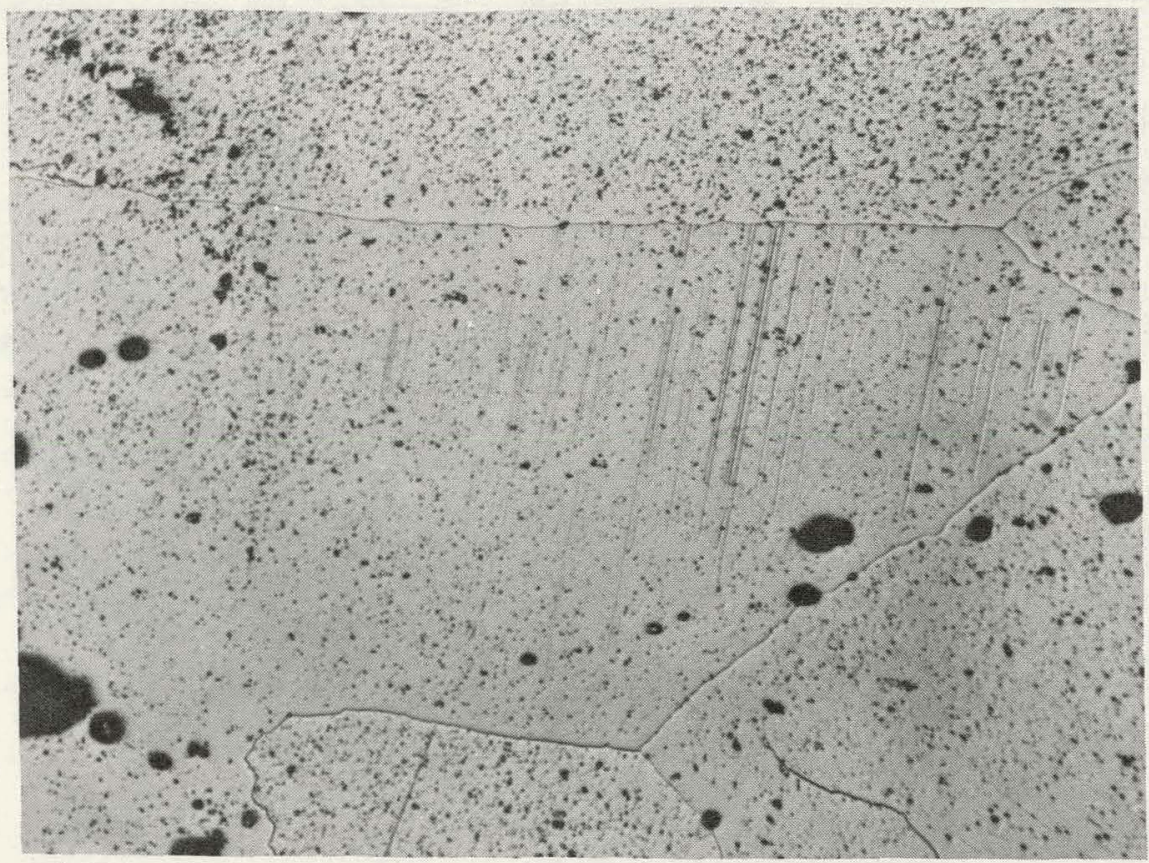

29c Photomicrograph Showing Stress Twins in Grain Exhibiting Exaggerated Growth. Also Note Large Amount of Intragranular Porosity. $\quad 9818 \mathrm{~J}-7$

Mag. 250X 
FIGURE 30

K ․--IC STUDY NO. 9: EFFECT OF SINTERING TIME AT $1750^{\circ} \mathrm{C}$ IN WET HYDROGEN ON GRAIN GROWTH IN $\mathrm{THO}_{2}$ PELLETS FABRICATED FROM POWDER LOT 088,

L/S AGGLOMERATED WITH $1.0 \mathrm{w} / 0$ CARBOWAX - 0.2 w/o STEROTEX (ADDED DRY), AND PRESSED TO A GREEN DENSITY OF $55 \%$

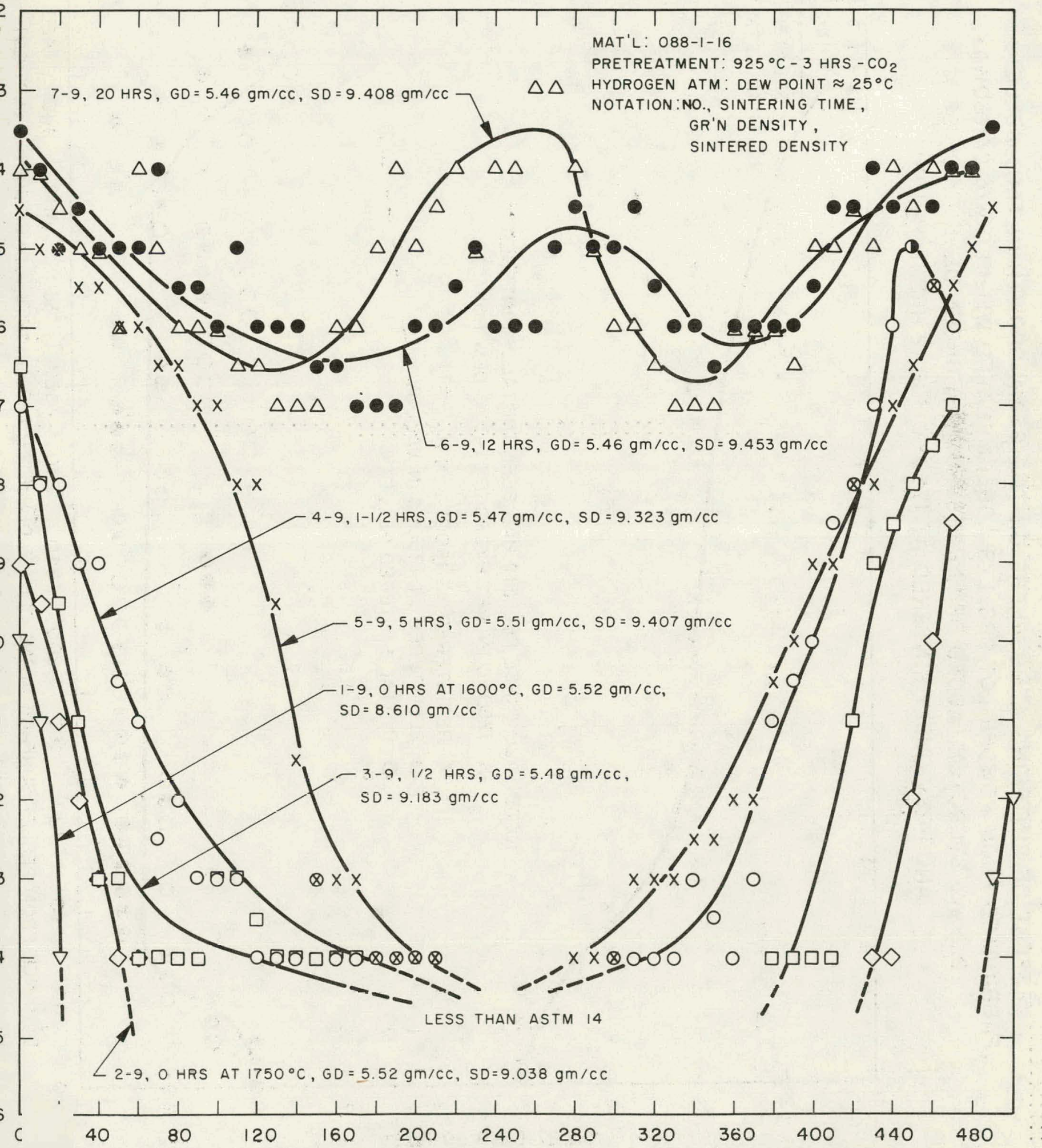

ISTANCE FROM PELLET SURFACE ALONG CENTER DIAMETER $\times 10^{-3}$ INCHES (LONGITUDINAL SECTION) 


\section{FIGURE 31}

EFFECT OF SINTERING ATMOSPHERE ON THE GRAIN GROWT I IN ThO 2 PELLETS FABRICATED FROM POWDER LOT O88, L/S AGGLOMERATED WITH 1.0 W/O CARBOWAX0.2 w/o STEROTEX (ADDED DRY), PRESSED TO A GREEN DENSITY OF $56 \%$ AND PREVIOUSLY SINTERED AT $1750^{\circ} \mathrm{C}$ FOR 12 HRS IN $\mathrm{H}_{2}$ (WET)

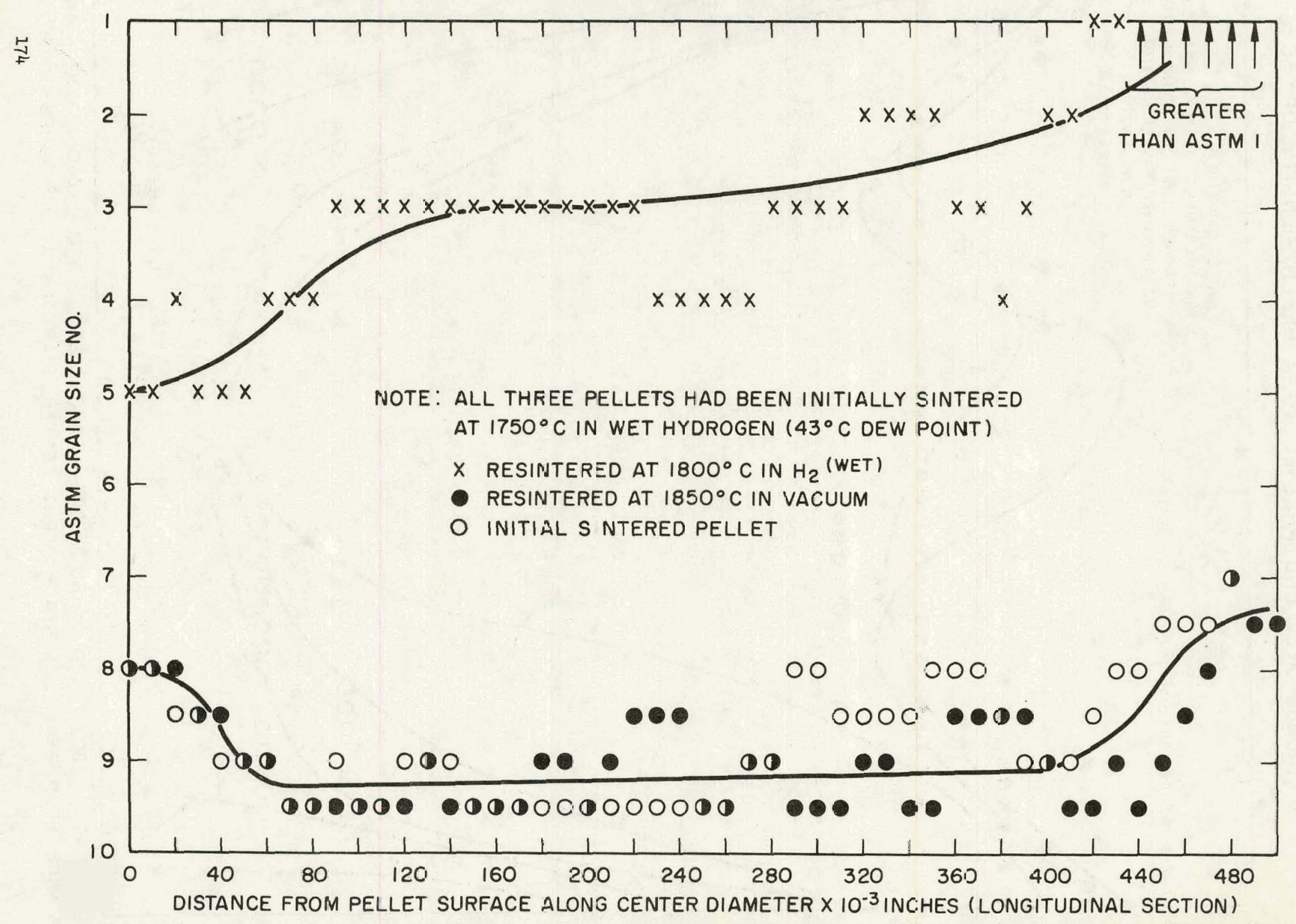


Photomicrograph of Sectioned Pellet, Powder Lot 088, Which Previously Had Been Sintered at $1750^{\circ} \mathrm{C}$ and Then Heat Treated at $1800^{\circ} \mathrm{C}$ in a Wet $\left(25^{\circ} \mathrm{C}\right)$ Hydrogen Atmosphere

Photo shows the presence of a second phase at grain boundary triple point.

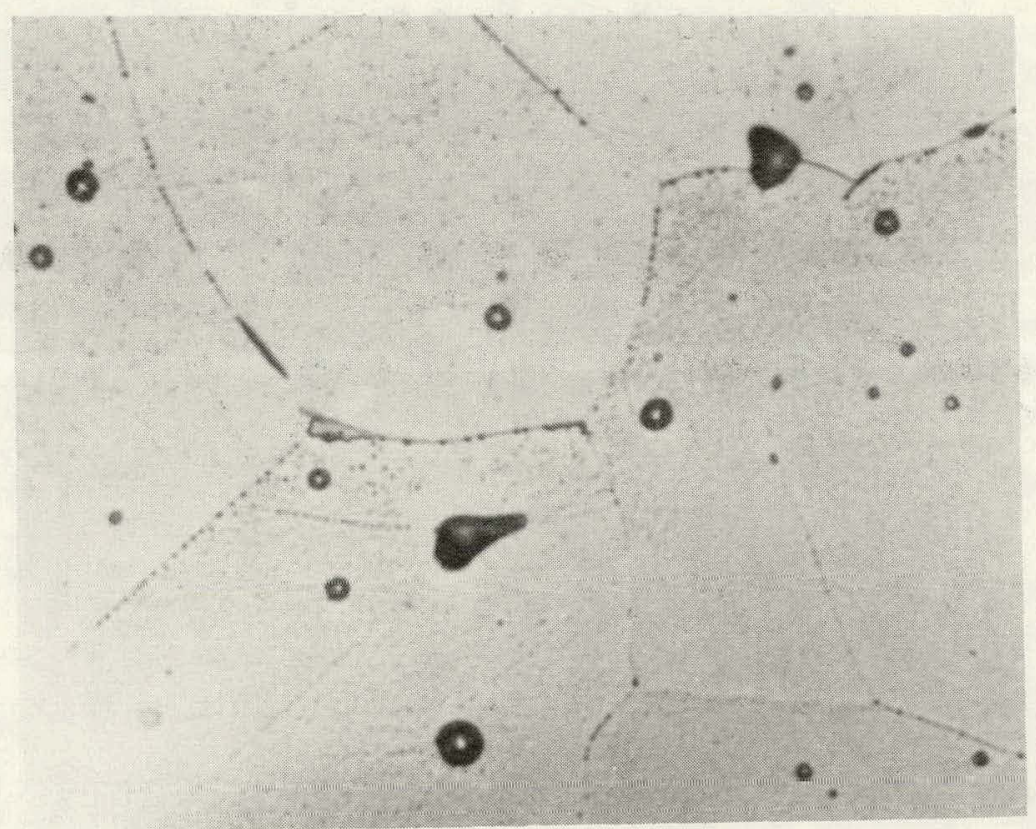

Neg. No. 51039-31

9979J-1

Mag. 1500X 
VARIATION GRAIN GROWTH AS A FUNCTION OF ThO $\mathrm{TH}_{2}$ PELLET CROSS SECTION FOR A VACUUM SINTERED PELLET FABRICATED

FROM POWDER LOT 097, L/S AGGLOMERATED WITH 1.0 W/O CARBOWAX - 0.2 W/O STEROTEX (ADDED DRY)

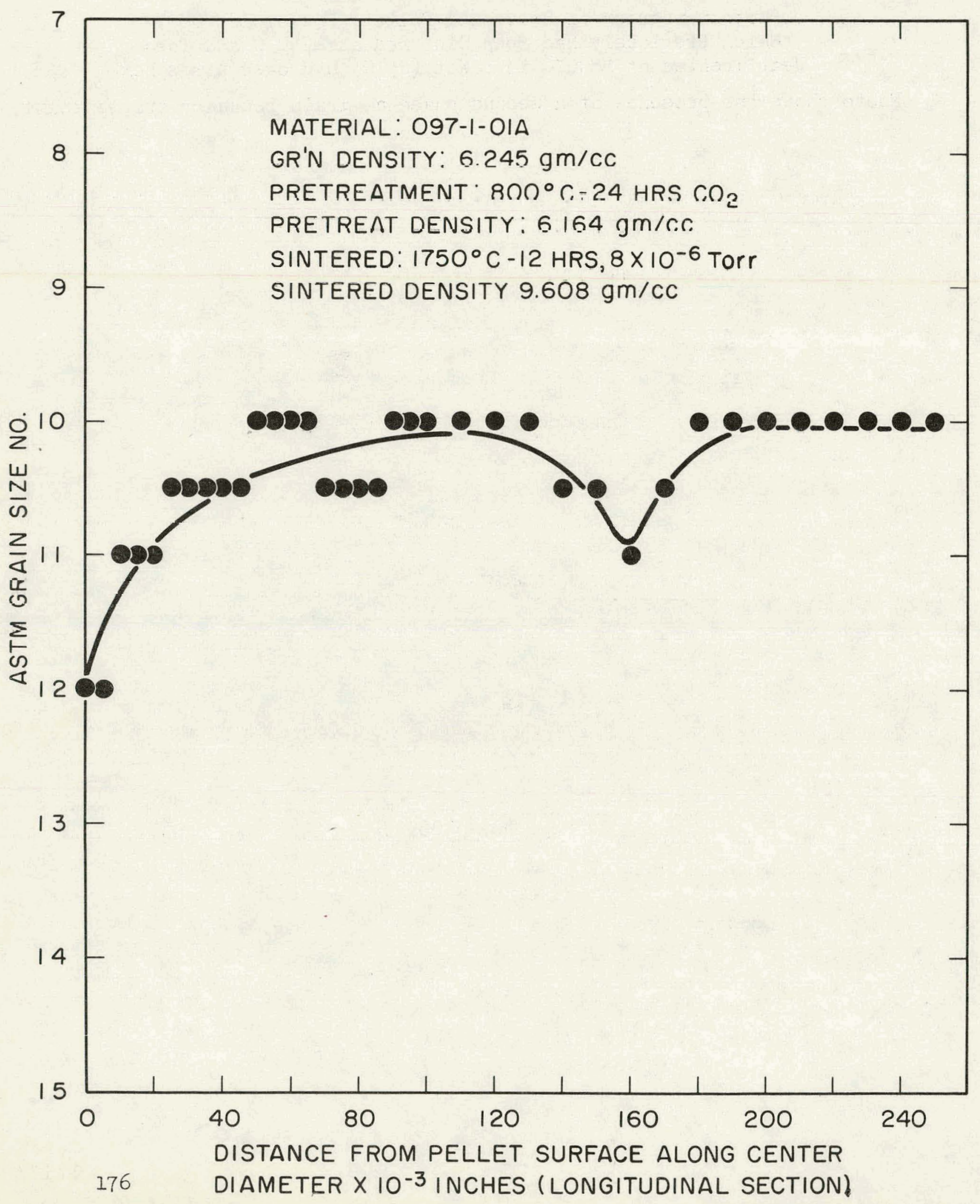




\section{FIGURE 34}

Photomicrograph Showing Recrystallized Grains in Area Plastically Deformed by Knoop Indentation

$$
\begin{array}{cc}
\text { Material: } & \mathrm{ThO}_{2} \text { Pellet } \\
087-02 & 74-3256 \mathrm{~A}
\end{array}
$$

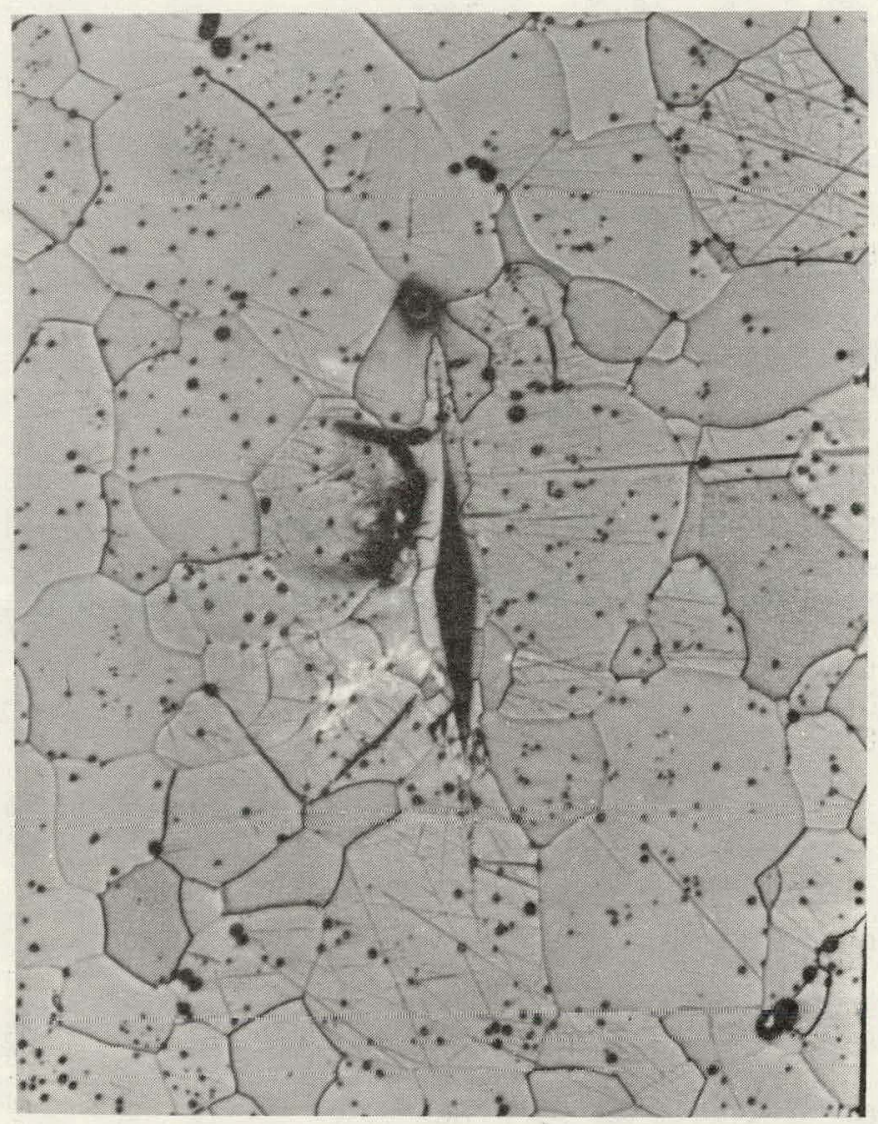

$9826 \mathrm{~J}$

Neg. No. 51039-20

Mag. $400 \mathrm{X}$ 
FIGURE 35

EFFECT OF CALCININE (II00 $\mathrm{C}-48$ HRS-AIR) AND MICRONIZING (|-DOUBLE PASS) ON GRAIN GROWTH IN ThO 2 PELLETS DRY PRESSED WITHOUT BINDER OR LUBRICANT FROM FOWDER LOT O96 AND SINTERED AT $1750^{\circ} \mathrm{C}-1-1 / 2$ HRS IN H2 ${ }^{(D R Y)}$

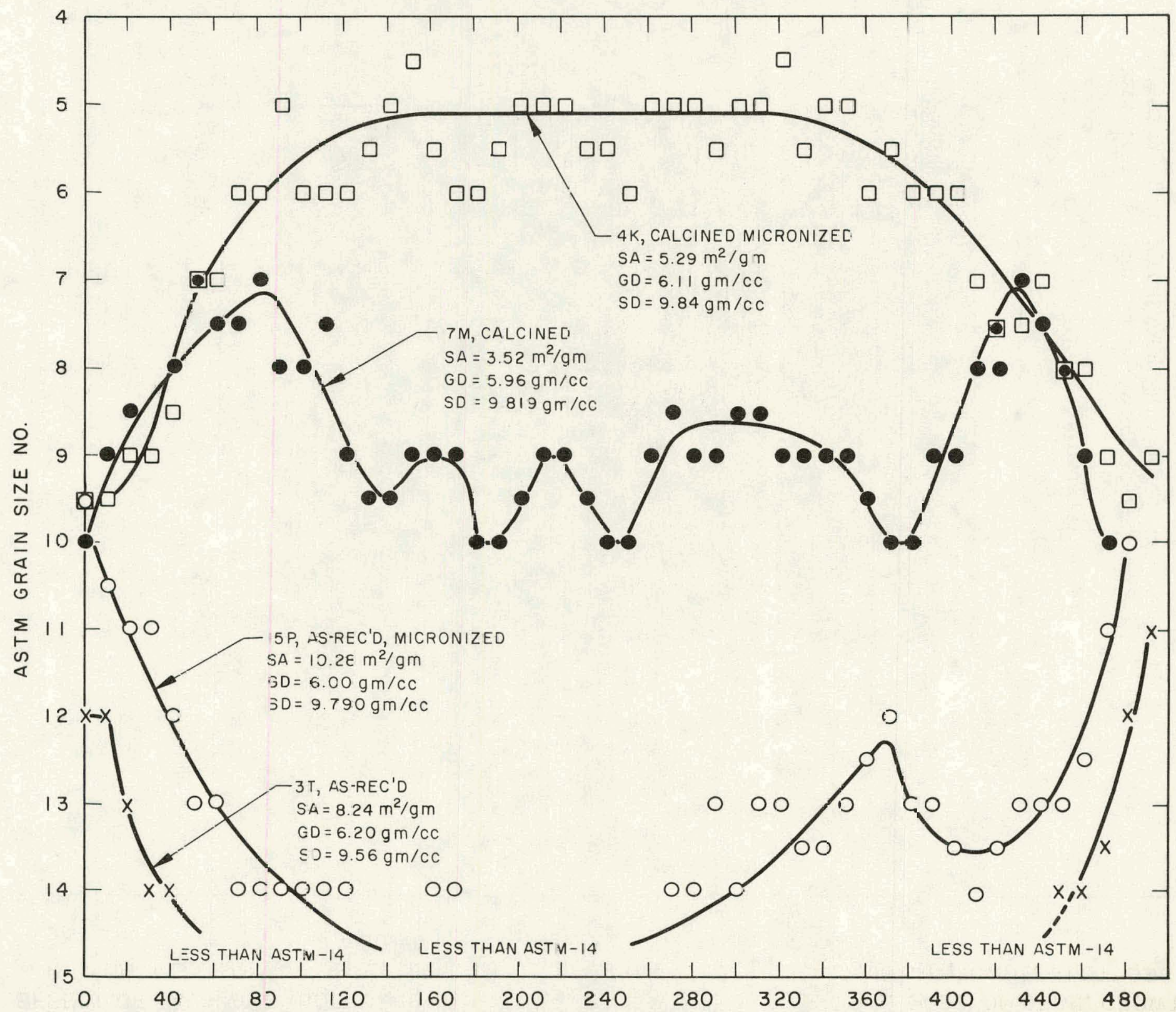


EFFECT OF CALCINING ( $11 O \mathrm{C}^{\circ} \mathrm{C}-48$ HRS-AIR) AND MICRONIZING (I-DOUBLE PASS) ON GRAIN GROWTH

IN ThO $\mathrm{T}_{2}$ PELLETS DRY PRESSED WITHOUT BINDER OR LUBRICANT FROM POWDER LOT O96 AND SINTERED AT $1750^{\circ} \mathrm{C}-12 \mathrm{HRS}-\mathrm{H}_{2}$ (DRY)

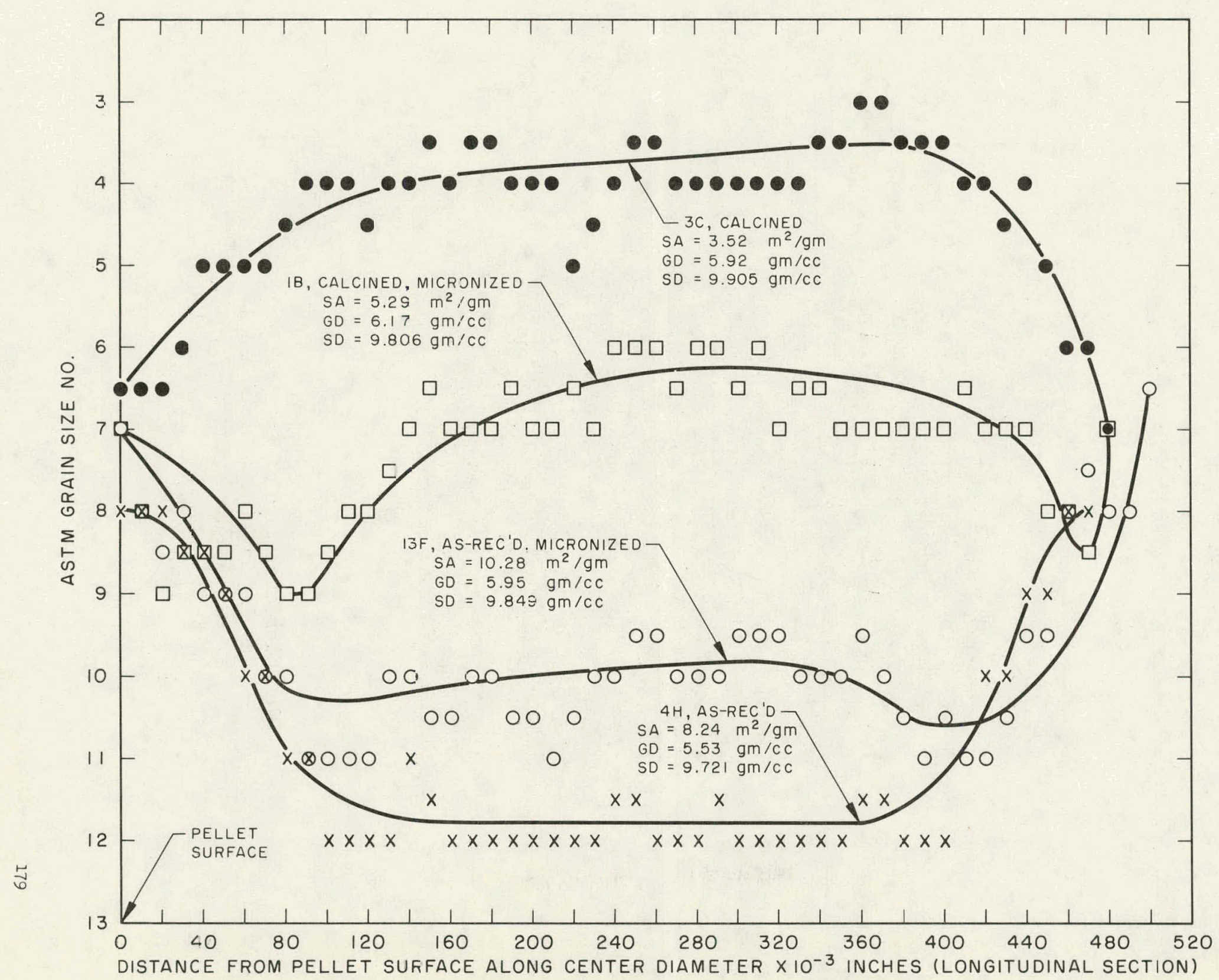


FIGURE 37. Center Microstructure Showing Intragranular Porosity

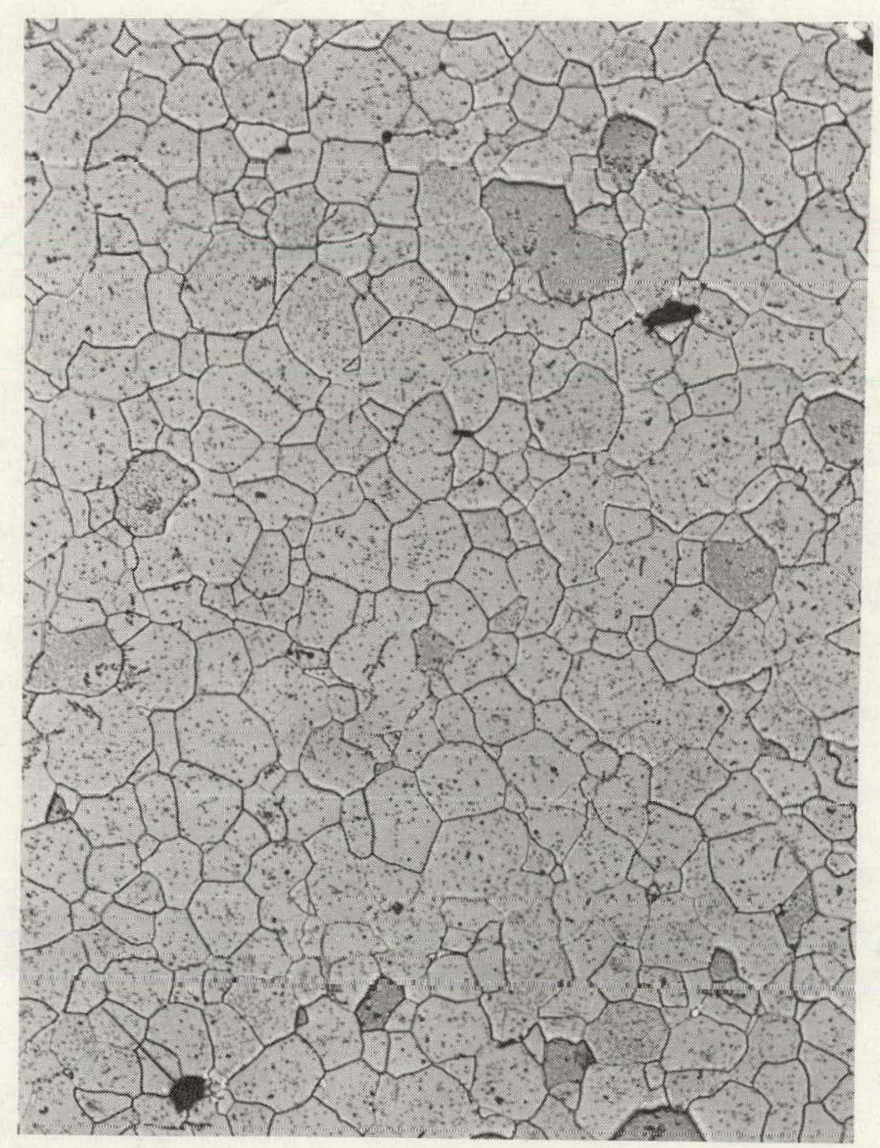

37a Mi rrnstmucture of Peliet $3 \mathrm{C}$ Showing Prominent Grain Boundaries and Intragranular Porosity $111 \mathrm{~K}-5$ Neg. No. 51039-40 Mag. 100X 

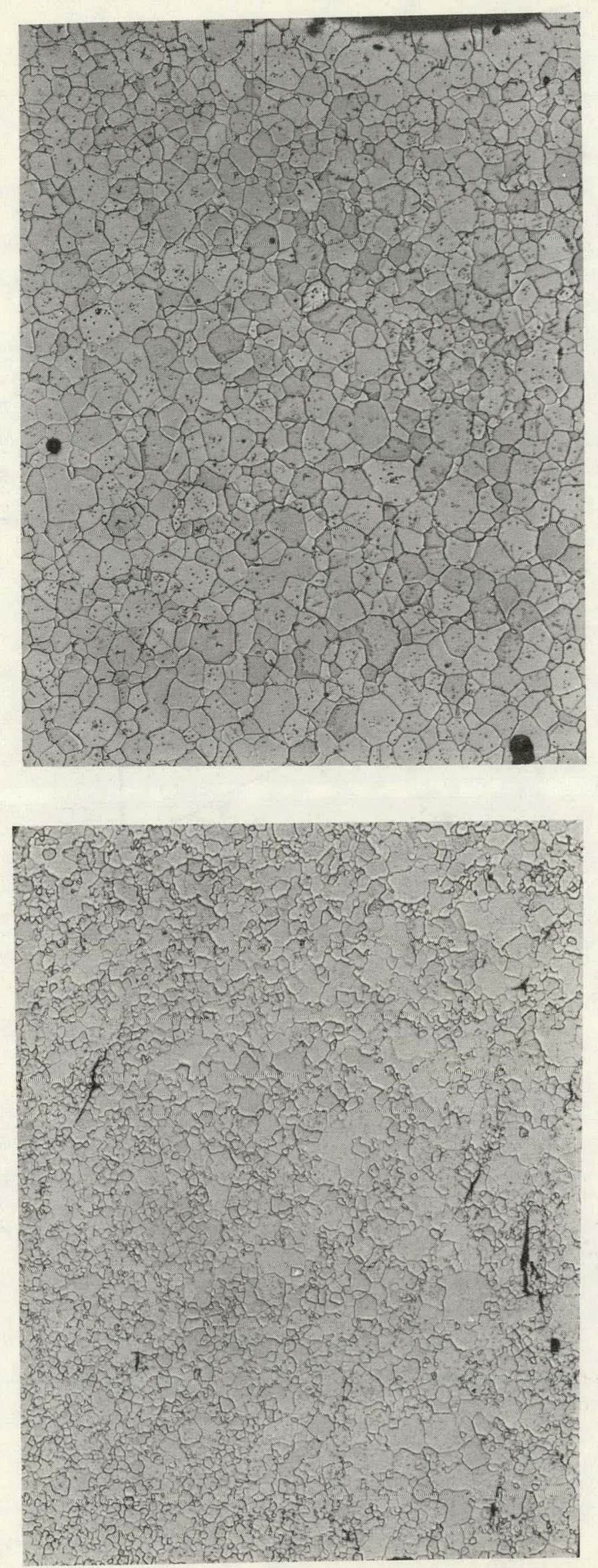

37b Microstructure of Pellet $1 \mathrm{~B}$ Showing Grain Smaller Than Shown in Pellet 3C With Less Intragranular Porosity $115 \mathrm{~K}$ Mag. $100 \mathrm{X}$ Neg. No. 51039-27 37c Microstructure of Pellet 13F Showing Poorly Formed Grain Boundaries and Very Fine Porosity $114 \mathrm{~K}-5$ Mag. $100 \mathrm{X}$ Neg. No. 51039-38 
FIGURE 38

EFFECT OF CALCINING (I100 $\mathrm{C}-48$ HRS - AIR) AND MICRONIZING (I-DOUBLE PASS)

ON GRAIN GROWTH IN ThO 2 PELLETS DRY PRESSED WITHOUT BINDER

OP LUBRICANT FROM POWDER LOT I 36 AND SINTERED AT

$1750^{\circ} \mathrm{C}-1-1 / 2$ HRS IN H $\mathrm{H}_{2}^{(D R Y)}$

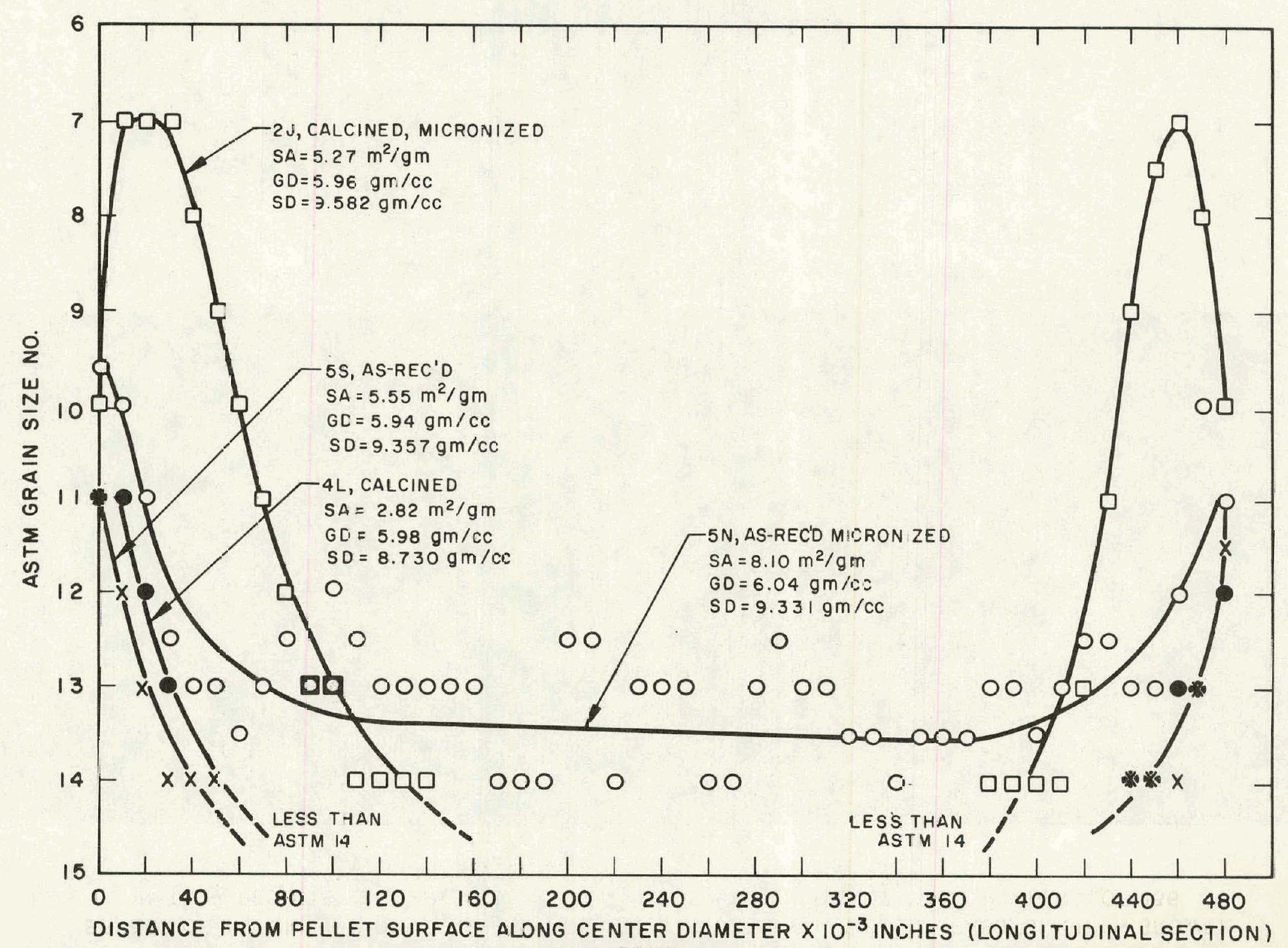


EFFECT OF CALCINING ( $1100^{\circ} \mathrm{C}-48$ HRS-AIR) AND M!CRONIZING (I-DOUBLE PASS) ON GRAIN GROWTH

IN $\mathrm{THO}_{2}$ PELLETS DRY PRESSED WITHOUT BINDER OR LUBRICANT FROM POWDER LOT I36 AND SINTERED AT $1750^{\circ} \mathrm{C}-12 \mathrm{HRS}-\mathrm{H}_{2}$ (DRY)

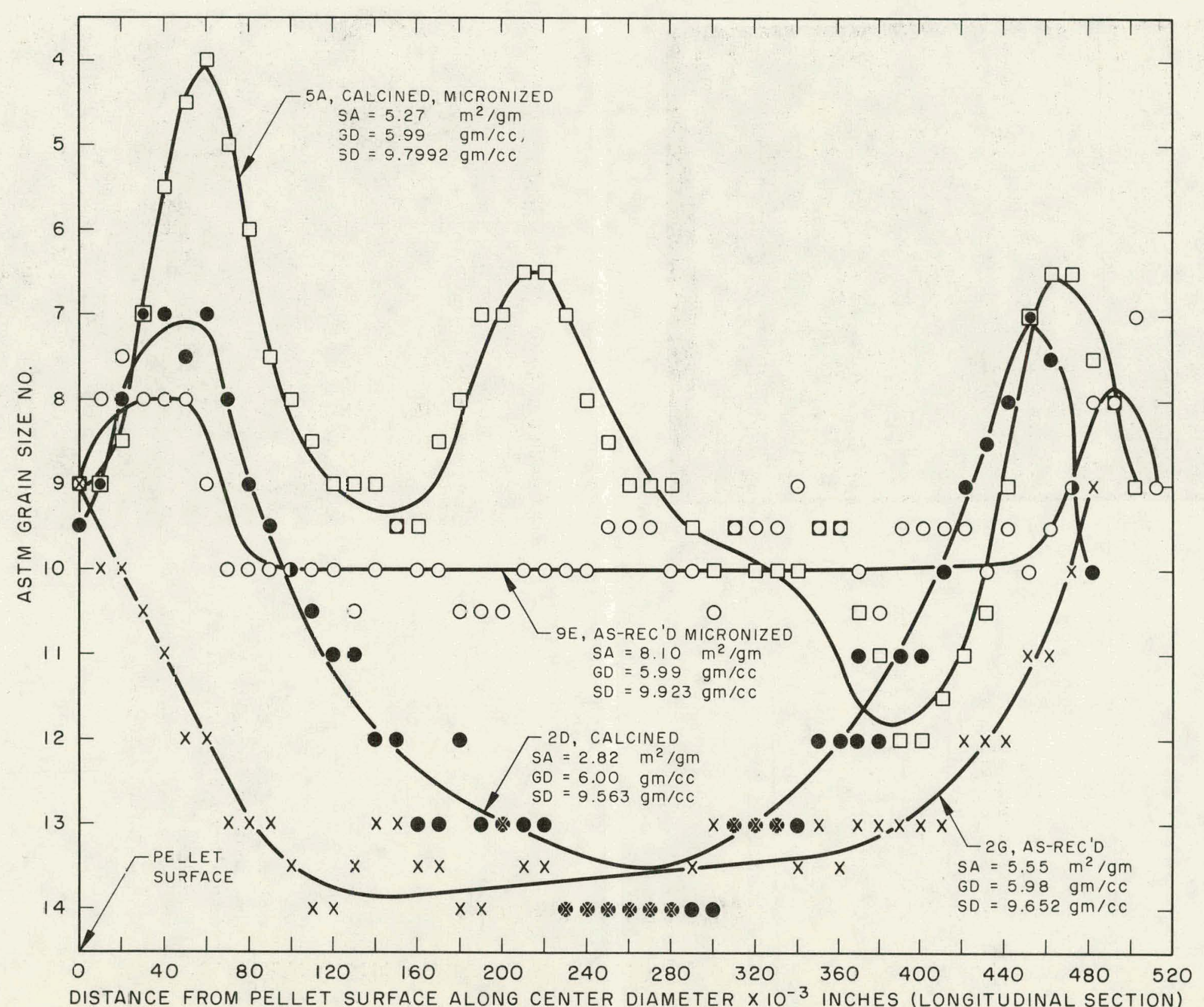


FIGURE 40. Microstructure of Slumy Agglomerated Thoria Pellets Showing Severe Granular Segregation

40a Photomacrograph of Pellet 2-1 (As-Received 136)

Showing Residua.7 Granule Structure

$255 \mathrm{~K}-4$

Ma.e. $6 X$

Neg. Nu. j1039-19

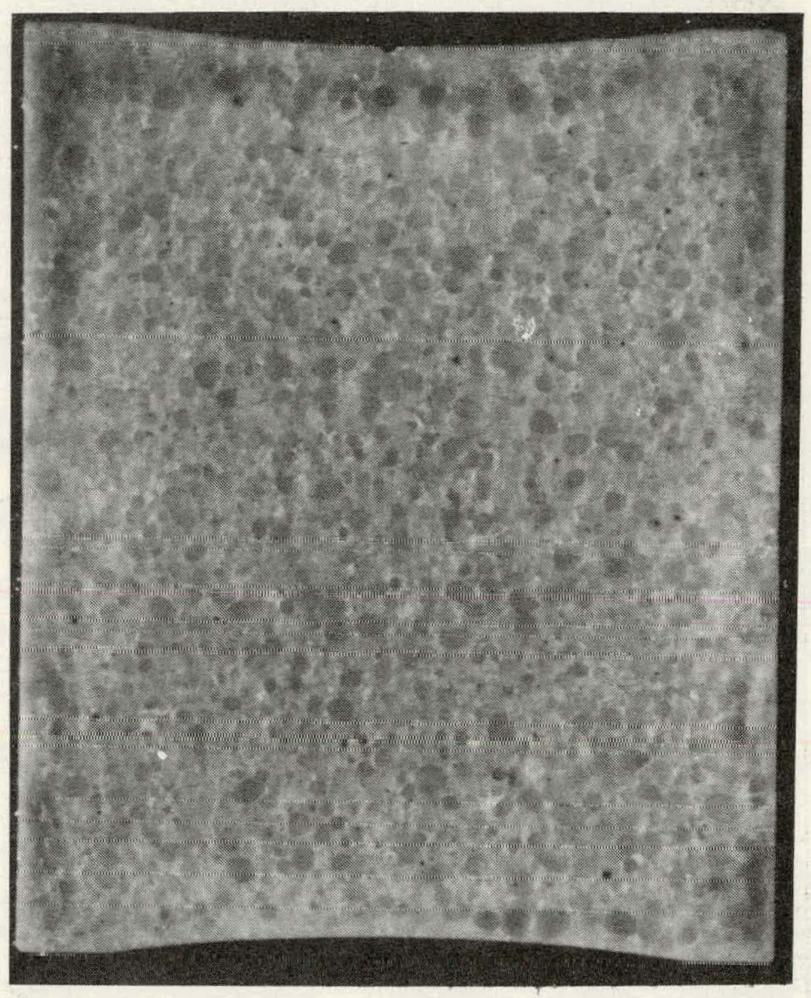

$40 \mathrm{~b}$ Photomicrograph of Pellet 2-1 Showing Porosity Associated With Granular Segregation

255K-2 Mag. 100X Neg. No. 51039-11

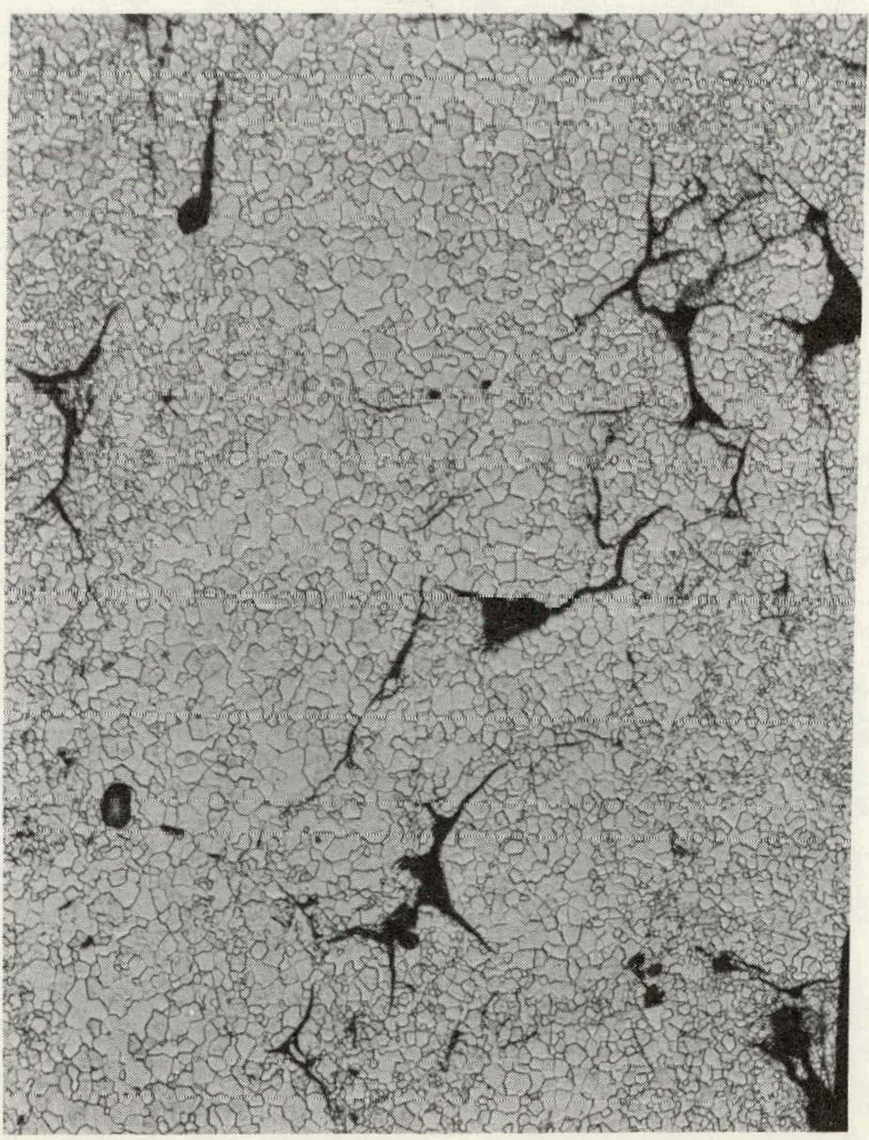




\section{FIGURE 40 (Cont'a.)}
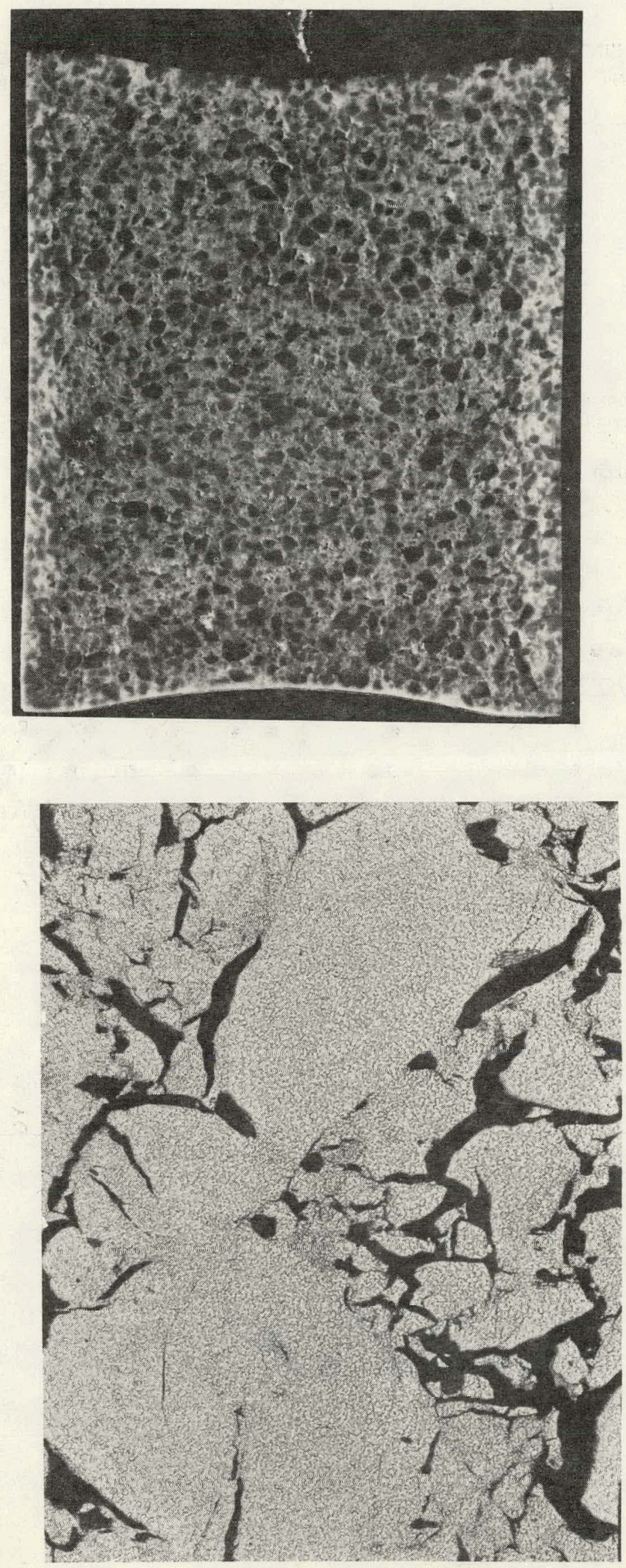

40c Photomacrograph of Pellet 3-15 (As-Calcined 096) Showing High Density Granules Which Have Not Grown Together. Note Voids Between Granules Near Top-Center of Pellet. $277 \mathrm{~K}-1$ Mag. 6X Neg. No. 51039-9 40d Photomicrograph of Pellet 3-15 Showing Almost Total Separation Between Granules $277 \mathrm{~K}-3 \quad$ Mag. 100X Neg. No. 51039-43 
FIGURE 41

EFFECT OF MICRONIZATION AND SINTERING TIME ON GRAIN GROWTH IN ThO 2 PELLETS DRY PRESSED WITHOUT BINDER OR LUBRICANT FROM CALCINED $\left(1100^{\circ} \mathrm{C}-48\right.$ HRS $\left.-\mathrm{H}_{2}{ }^{(D R Y)}\right)$, POWDER LOT O96

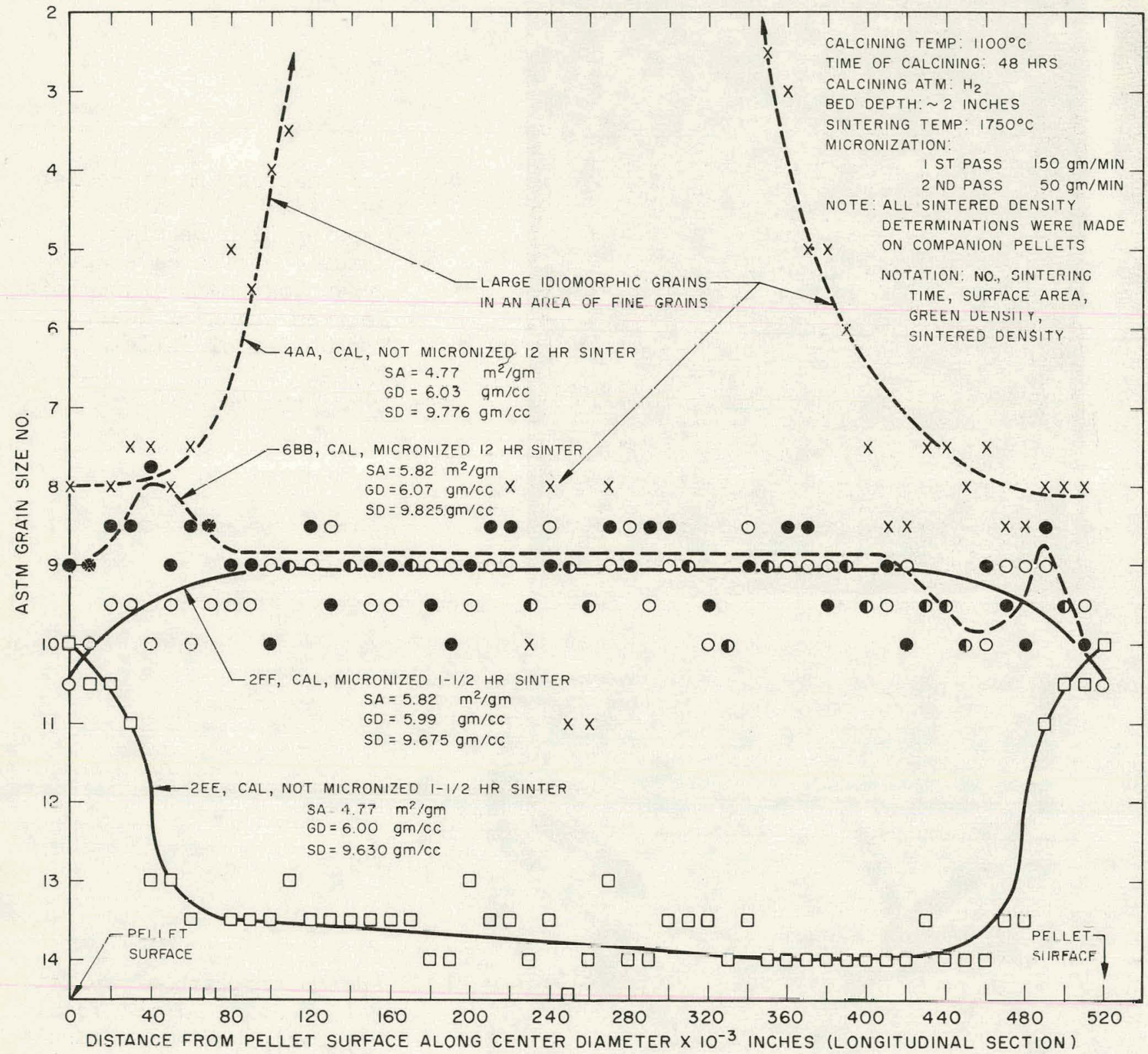


FIGURE 42, Thoria Pellet, 4AA, Dry Pressed From Calcined

$\left(1100^{\circ} \mathrm{C}-48 \mathrm{Hrs}_{2} \mathrm{H}_{2}\right.$ (Dry)) 096 Thoria. Powder and Sintered at $1750^{\circ} \mathrm{C}$ in $\mathrm{H}_{2}$ for $12 \mathrm{Hrs}$
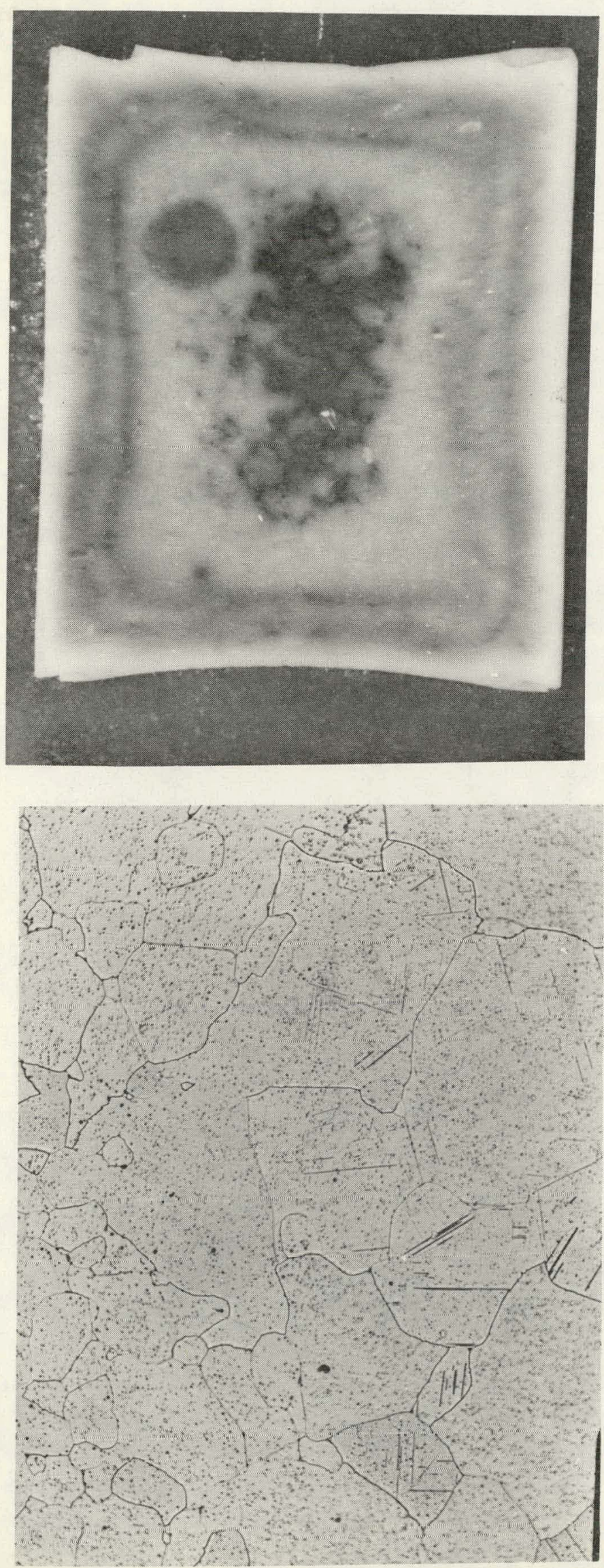

42a Photomacrograph of Pellet 4AA Showing Large Idiomorphic Grain Structure in Dark Pellet Center Observable with the Unaided Eye $240 \mathrm{~K}-1$ Mag. 6X Neg. No. 51039-32
$42 \mathrm{~b}$ Photomicrograph of Pellet $\overline{4 A A}$ Showing Large Exaggerated Grain Growth and Strain Twins $240 \mathrm{~K}-3$

Mag. 100X Neg. No. 51039-15 
42c Photomicrograph of Pellet 4AA Showing Large Idiomorphic Grains in Field of Fine Grains. Note Strain Twins May Be Present Even in the Smaller Idiomorphic Grains $2.40 \mathrm{~K}-4$ Mag. $100 \mathrm{X}$

$42 \mathrm{~d}$ Another View of the Salle Area as Shown in Figure $55 \mathrm{c}$

$240 \mathrm{~K}-5 \quad \mathrm{Mag} .100 \mathrm{X}$ Neg. No. 51039-18
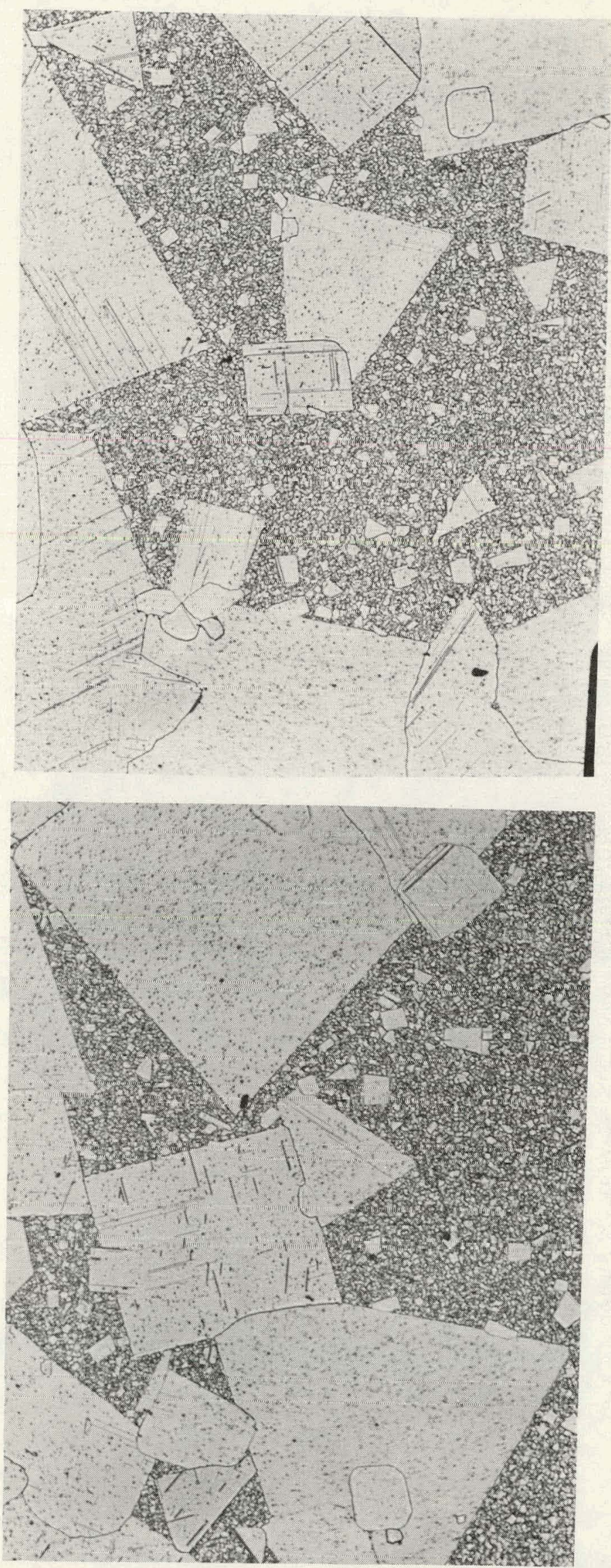
EFFECT OF MICFIONIZATION AND SINTERING TIME ON GRAIN GROWTH IN ThO 2 PELLETS DRY PRESSED WITHOUT BINDER OR LUBRICANT FROM CALCINED $\left(1100^{\circ} \mathrm{C}-48 \mathrm{HRS}-\mathrm{H}_{2}{ }^{(D R Y)}\right)$,POWDER LOT I36

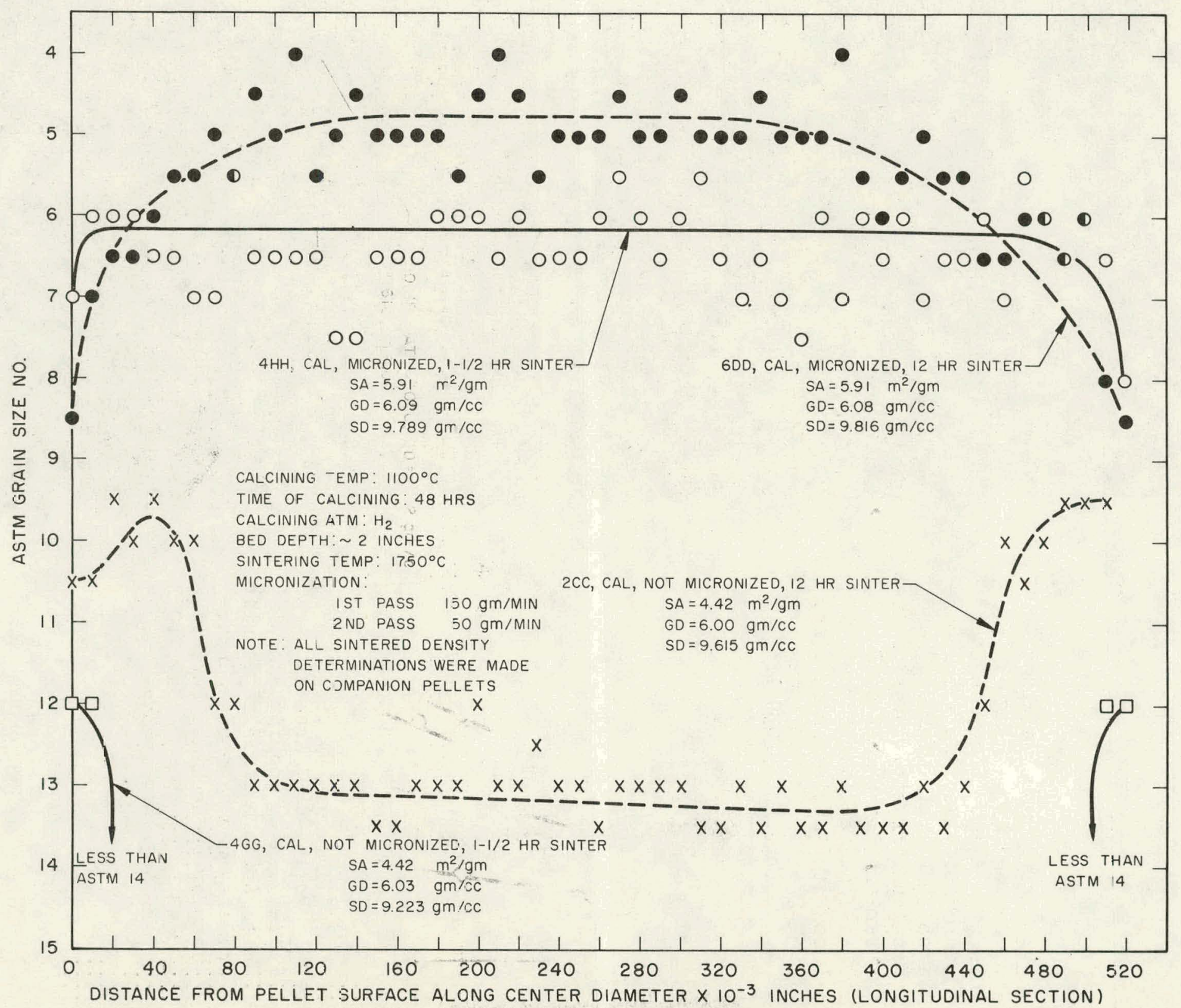


FIGURE 44. Porosity Distribution in Thoria Pellets Fabricated From Calcined $\left(1100^{\circ} \mathrm{C}-48 \mathrm{Hrs}-\mathrm{H}_{2}\right)$ Powder

$44 a$ Pellet 6DD, Calcined, Micronized 136, $12 \mathrm{Hr}$ Sinter, Showing Almost Complete Lack of Pornsity Near Exterior Surface (Left Half of Photo) and Necklace Porosity Toward Pellet Interior (Right Half of Photo). Note That Necklace Porosity Does Not Diminish Grain Size. $243 \mathrm{~K}-2$ Neg. No. 51039-12

Mag. $100 \mathrm{X}$

44b Pellel CiDل, Area at

Pel let Center Showing Almost Total Absence of Intragranular Porosity and Extensive Intergranular or Necklace Porosity $243 \mathrm{~K}-3$

Mag. $100 \mathrm{X}$ Neg. No. 51039-17
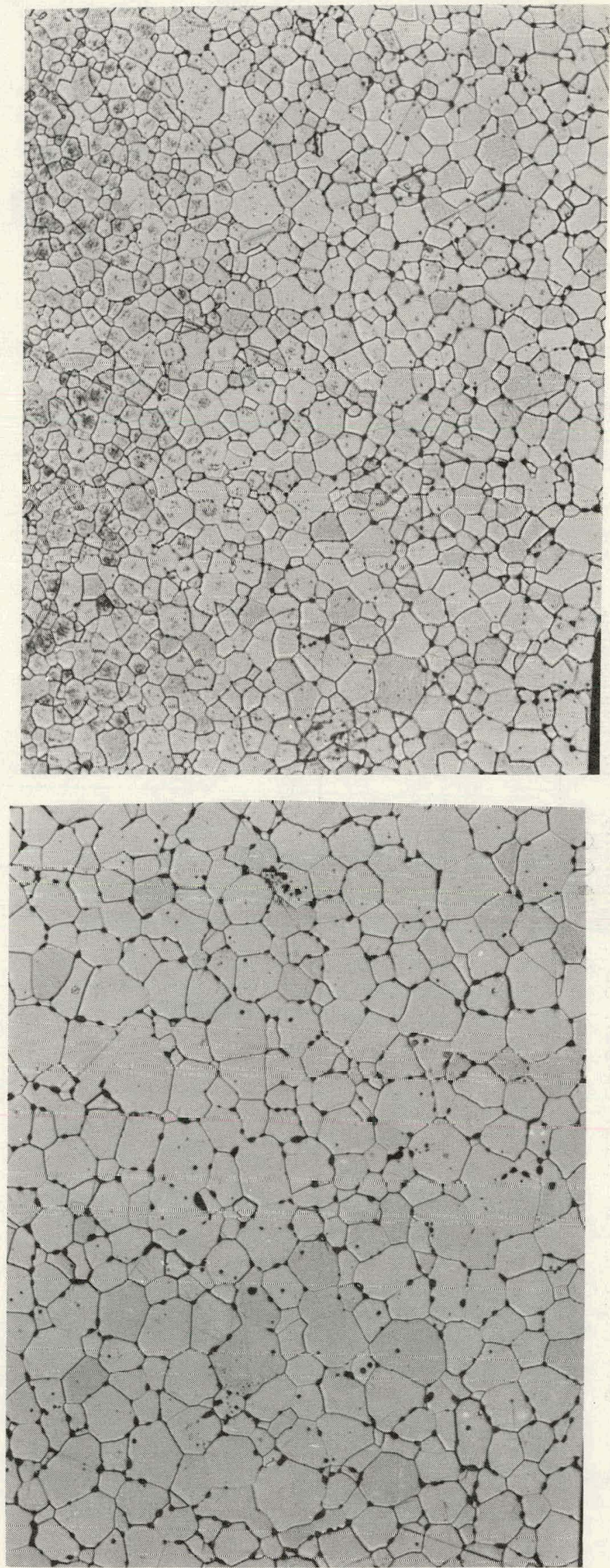


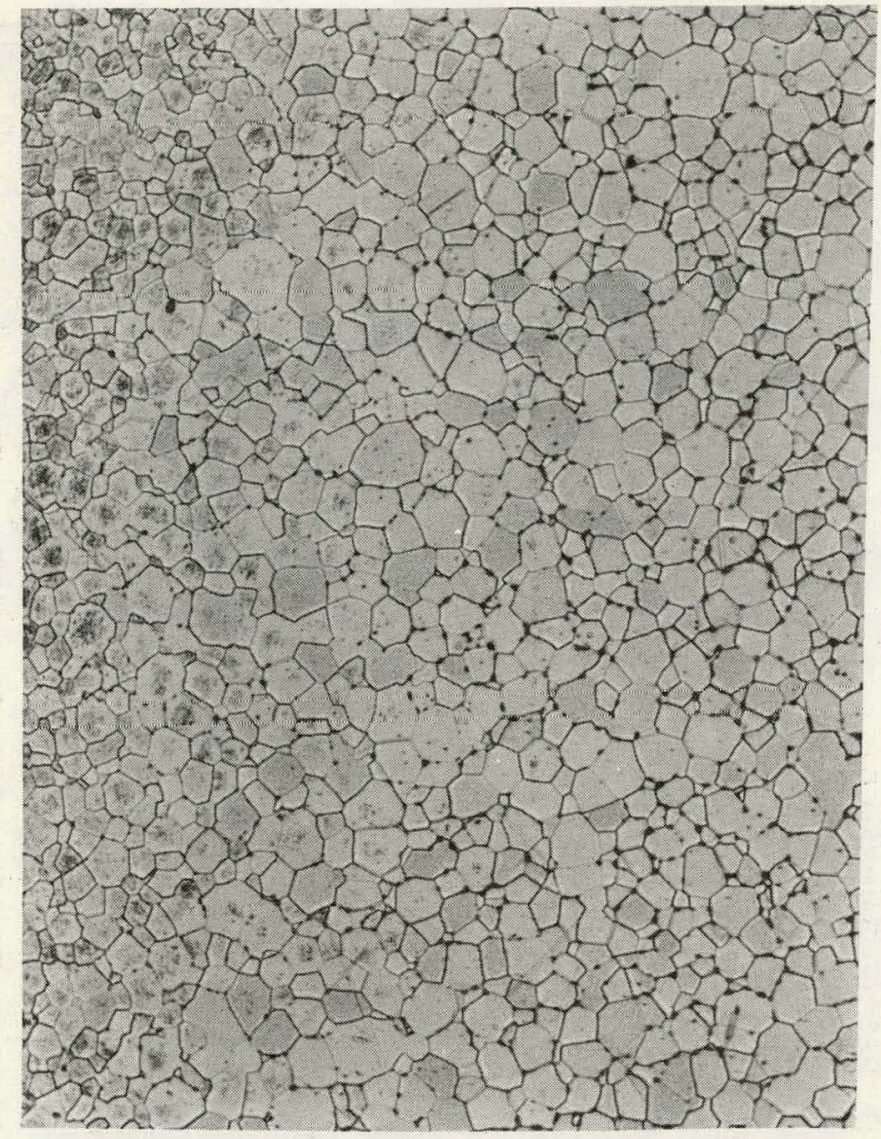

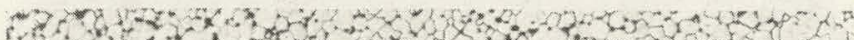

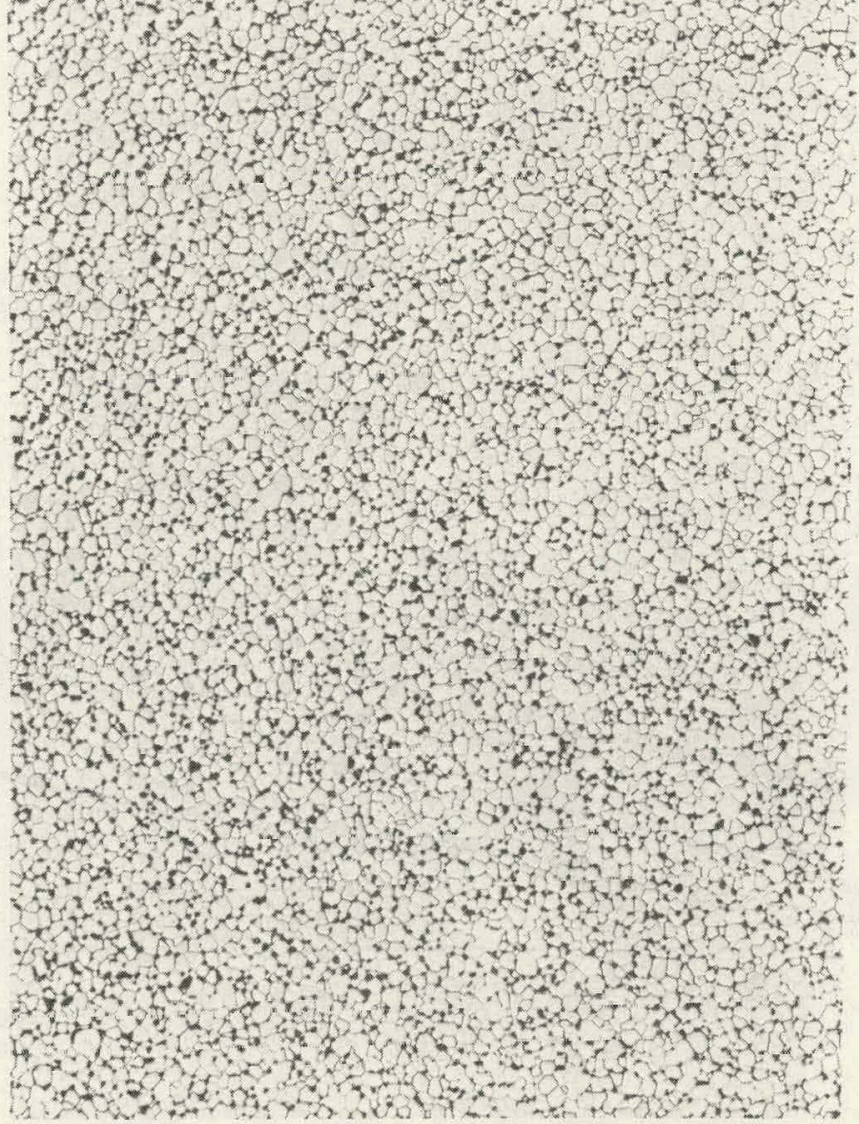

44c Pellet 4HH, Calcined, Micronized 136, $1 \frac{1}{2} \mathrm{Hr}$ Sinter, Showing That Duplex Porosity Distribution Happens Early in Sintering Cycle $247 \mathrm{~K}-2$ Mag. $100 \mathrm{X}$ Neg. No. 51039-13
$44 \mathrm{~d}$ Pellet 2FF, Calcined,

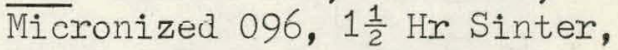
Showing Considerable Necklace Porosity Even When Grain Growth Was Not Extensive $245 \mathrm{~K}-4$ $100 \mathrm{X}$ Neg. No. 51039-5 
FIGURE 45

EFFECT OF SINTERINS TIME AT $1750^{\circ} \mathrm{C}$ ON GRAIN GROWTH IN ThO 2 PELLETS FABRICATED FROM POWDER LOT 096, MICRONIZED, CALCINED (II00 ${ }^{\circ} \mathrm{C}-48$ HRS $\left.-\mathrm{H}_{2}{ }^{(D R Y)}\right)$, SLURRY AGGLOMERATED WITH I.75 W/O CARBOWAX - 0.2 w/O STEROTEX (ADDED DRY) AND PRESSED TO A TARGET GREEN DENSITY OF $57 \%$

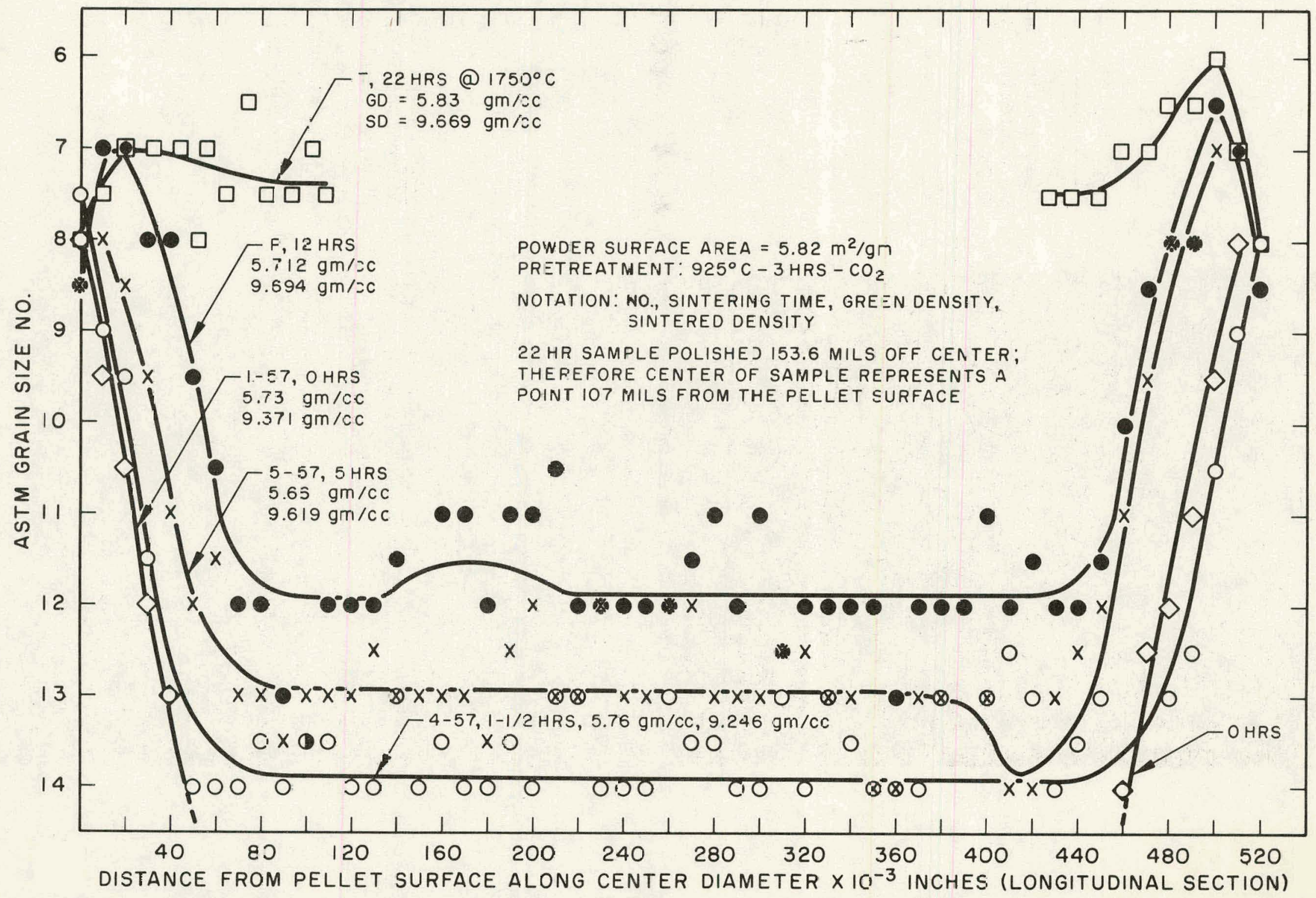




\section{FIGURE 46}

EFFECT OF SINTERING TIME AT $1750^{\circ} \mathrm{C}$ ON GRAIN GROWTH IN ThO 2 . PELLETS FABRICATED FROM POWDER LOT 096, MICRONIZED; CALCINED ( $\left.1100^{\circ} \mathrm{C}-48 \mathrm{HRS}-\mathrm{H}_{2}^{(D R Y)}\right)$,SLURRY AGGLOMERATED WITH I.75 W/O CARBOWAX - 0.2 w/o STERCTEX (ADDED DRY) AND PRESSED TO A TARGET GREEN DENSITY OF $61 \%$

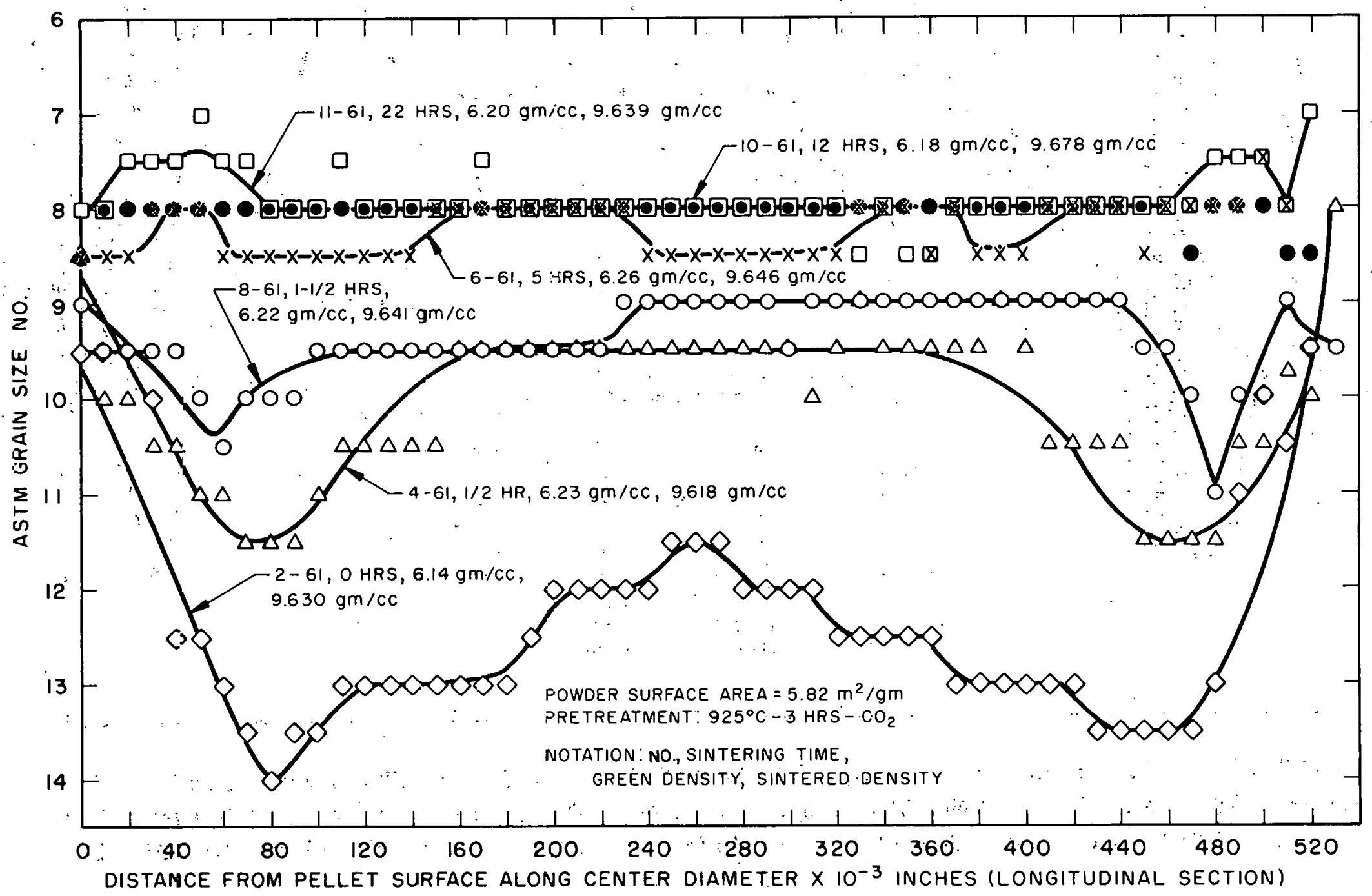


FIGURE 47

EFFECT OF SINTERING TIME AT $750^{\circ} \mathrm{C}$ ON GRAIN GROWTH IN THO 2 PELLETS FABRICATED

FROM POWDER LOT 136 , CALCINED $\left(1100^{\circ} \mathrm{C}-48 \mathrm{HRS}-\mathrm{H}_{2}{ }^{(D R Y)}\right)$, MICRONIZED, SLURRY AGGLOMERATED

WITH 1.75 W/O CARBOWAX - 0.2 w/0 STEROTEX (ADDED DRY), AND PRESSED TO A GREEN TARGET DENSITY OF 57\%

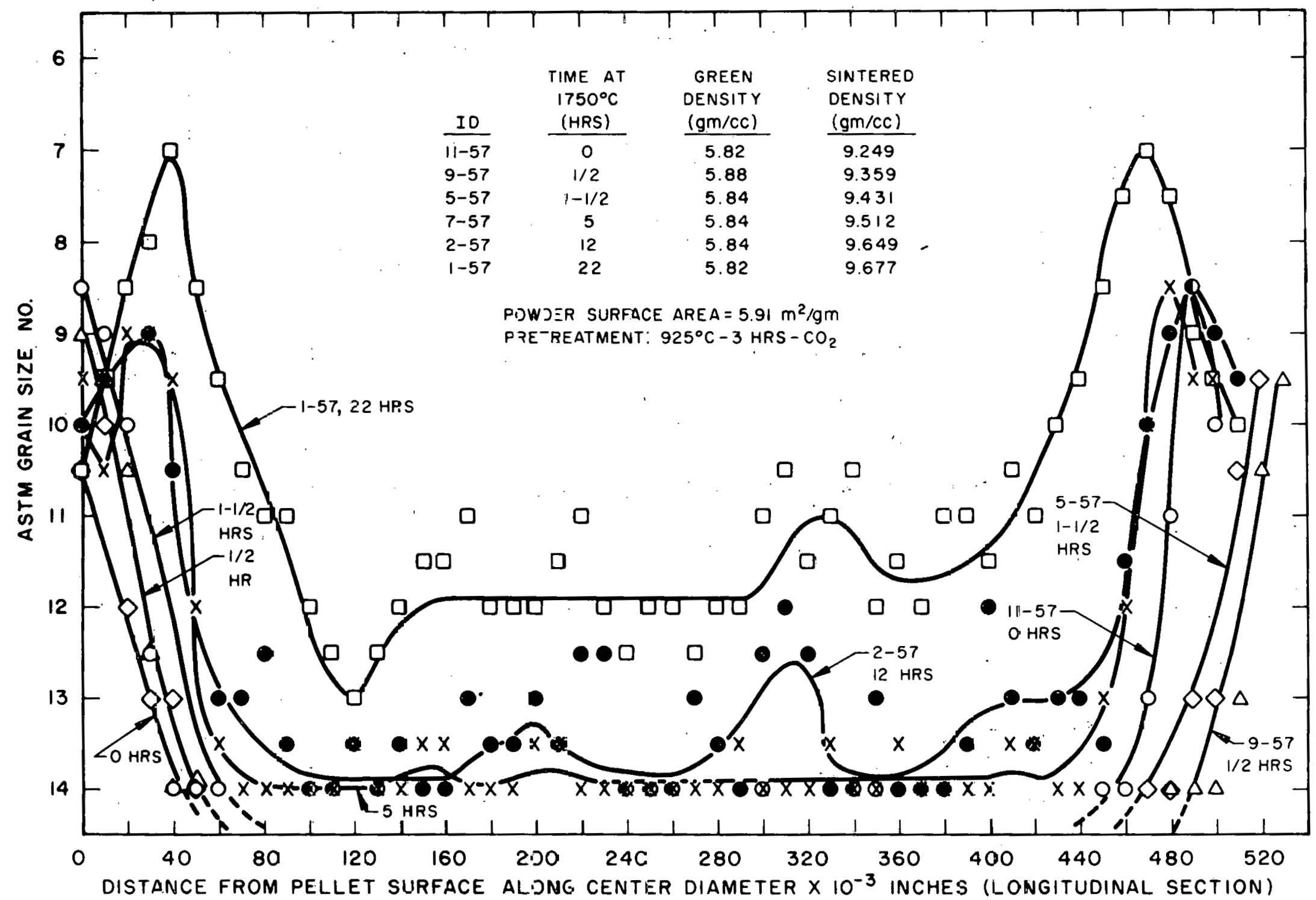


EFFECT OF SINTERING TIME AT $1750^{\circ} \mathrm{C}$ ON GRAIN GROWTH IN ThO 2 PELLETS FABRICATED FROM POWDER LOT 136, CALCINED $\left(1100^{\circ} \mathrm{C}-48 \mathrm{HRS}-\mathrm{H}_{2}{ }^{(D R Y)}\right)$, MICRONIZED, SLURRY AGGLOMERATED WITH 1.75 w/o CARBOWAX-0.2w/0 STEROTEX (ADDED DRY), AND PRESSED.TO A GREEN TARGET DENSITY OF $61 \%$

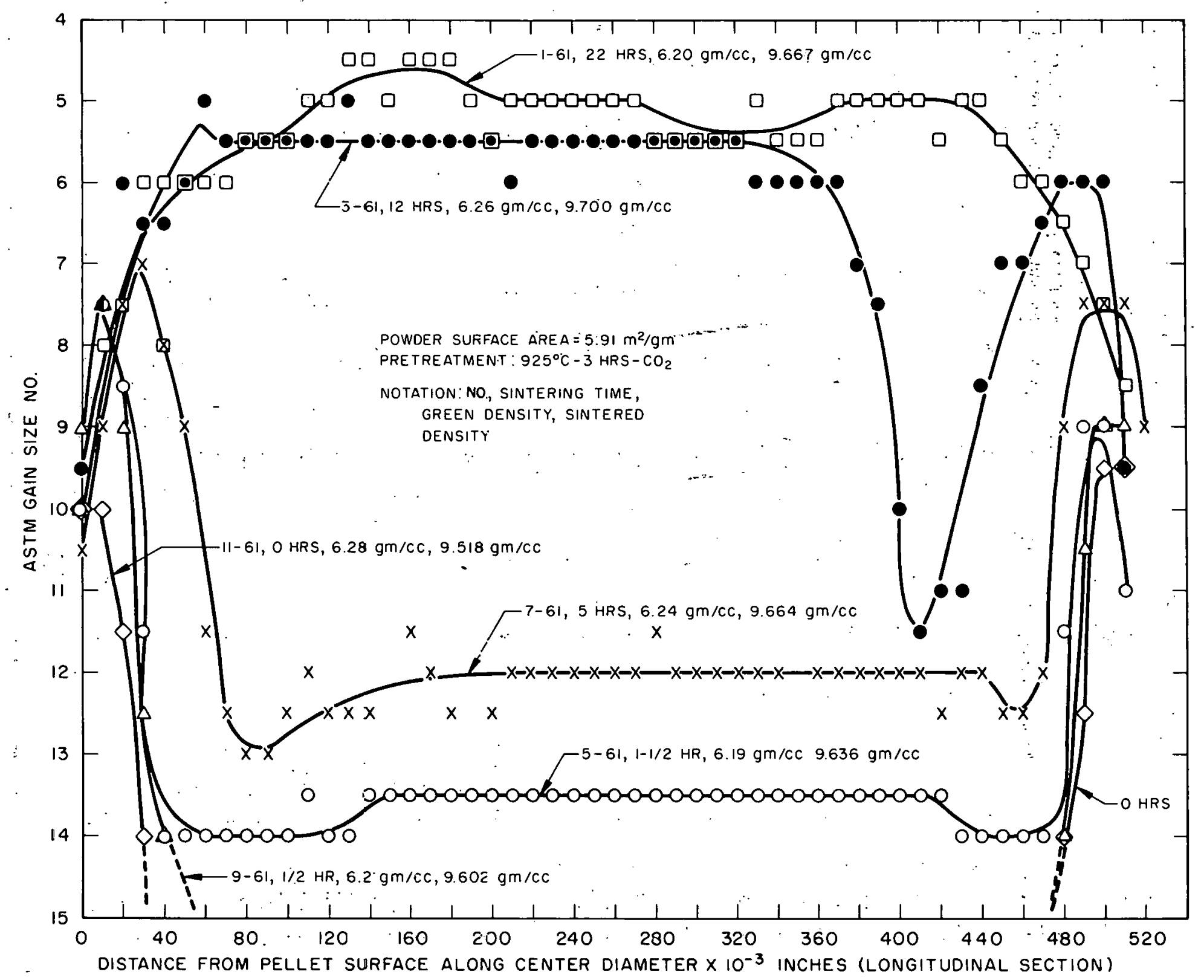


FIGURE 49

EFFECT OF PRESSED DENSITY ON GRAIN GROWTH IN ThO 2 PELL $\equiv T S$ PRESSED FROM $1100^{\circ} \mathrm{C}-$

48 HRS-H ${ }_{2}^{\text {(DRY) }}$ CALCINED, MICRONIZED, POWDER LOT 096 SLURRY AGGLOMERATED WITH 1.75 W/0

CARBOW'AX- 0.2 W'O STEROTEX (ADDED DRY) AND SINTERED AT $1750^{\circ} \mathrm{C}$ FOR 12 HOURS

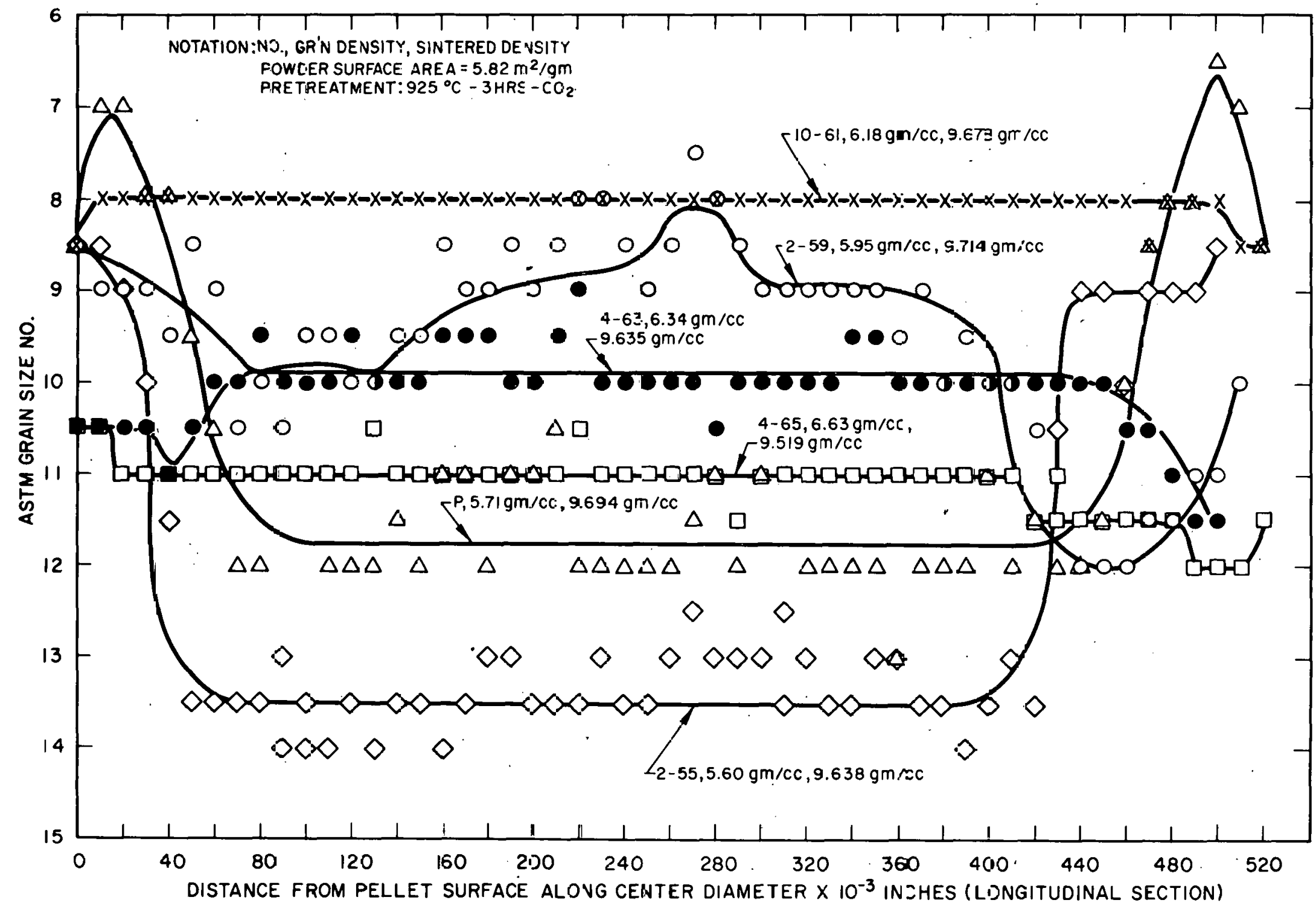




\section{FIGURE 50}

EFFECT OF PRESSED DENSITY ON GRAIN GROWTH IN ThO 2 PELLETS PRESSED FROM $1100^{\circ} \mathrm{C}-48 \mathrm{HRS}-\mathrm{H}_{2}$ (DRY) CALCINED, MICRONIZED, POWDER LOT 136 SLURRY AGGLOMERATED WITH

1.75 w/o CARBOWAX -0.2 w/O STEROTÉX (ADDED DRY) AND SINTERED AT $1750^{\circ} \mathrm{C}$ FOR 12 HRS

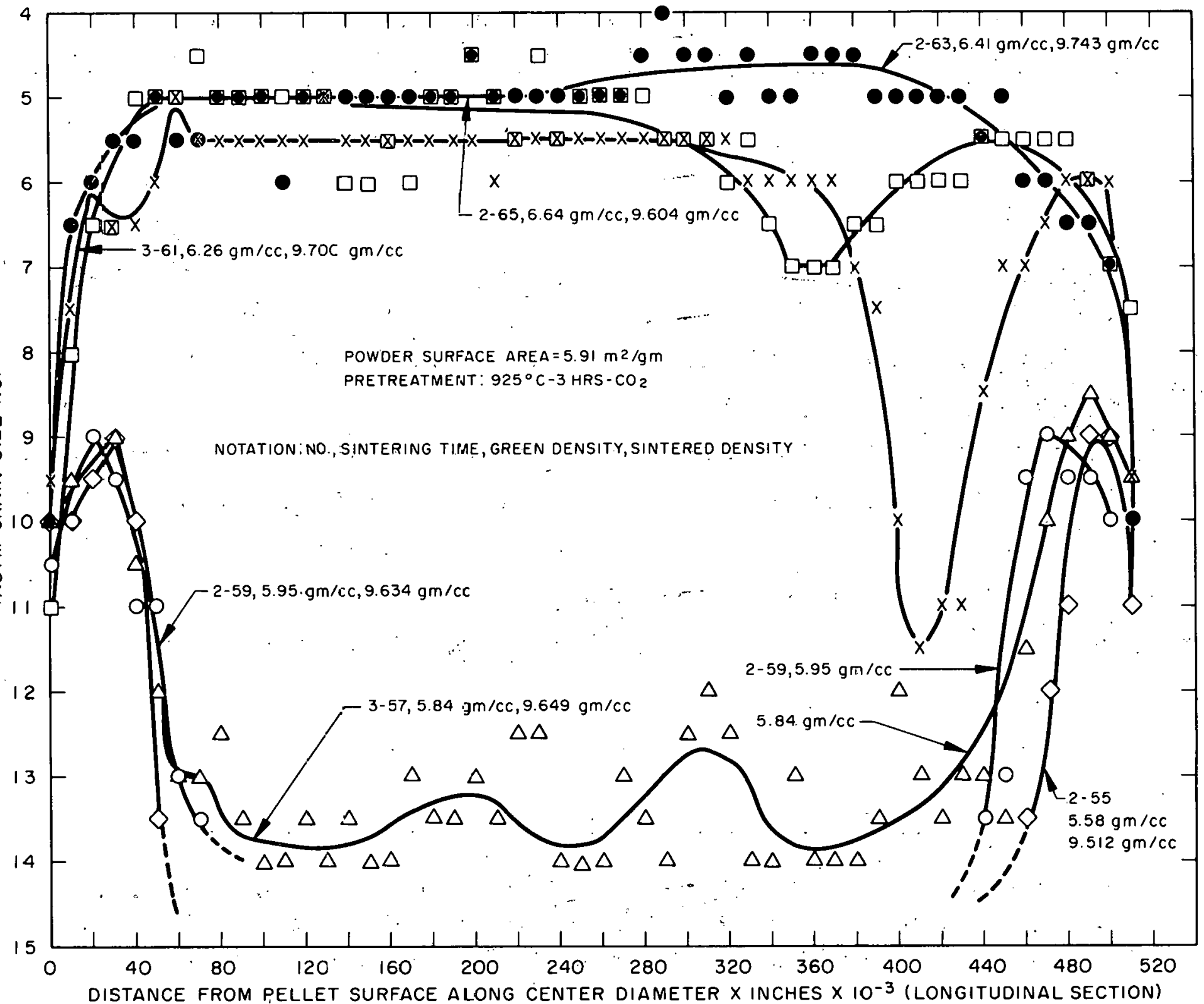


FIGURE 51

EFFECT OF PRESSED DENSITY ON GRAIN GROWTH IN ThO 2 PELLETS PRESSED FROM MICRONIZED, AS-RECEIVED POWDER LOT 096, SLURRY AGGLOMERATED WITH 1.75 w/0 CARBOWAX-0.2 w/o STEROTEX (ADDED DRY) AND SINTERED AT $1750^{\circ} \mathrm{C}$ FOR $12 \mathrm{HRS}$

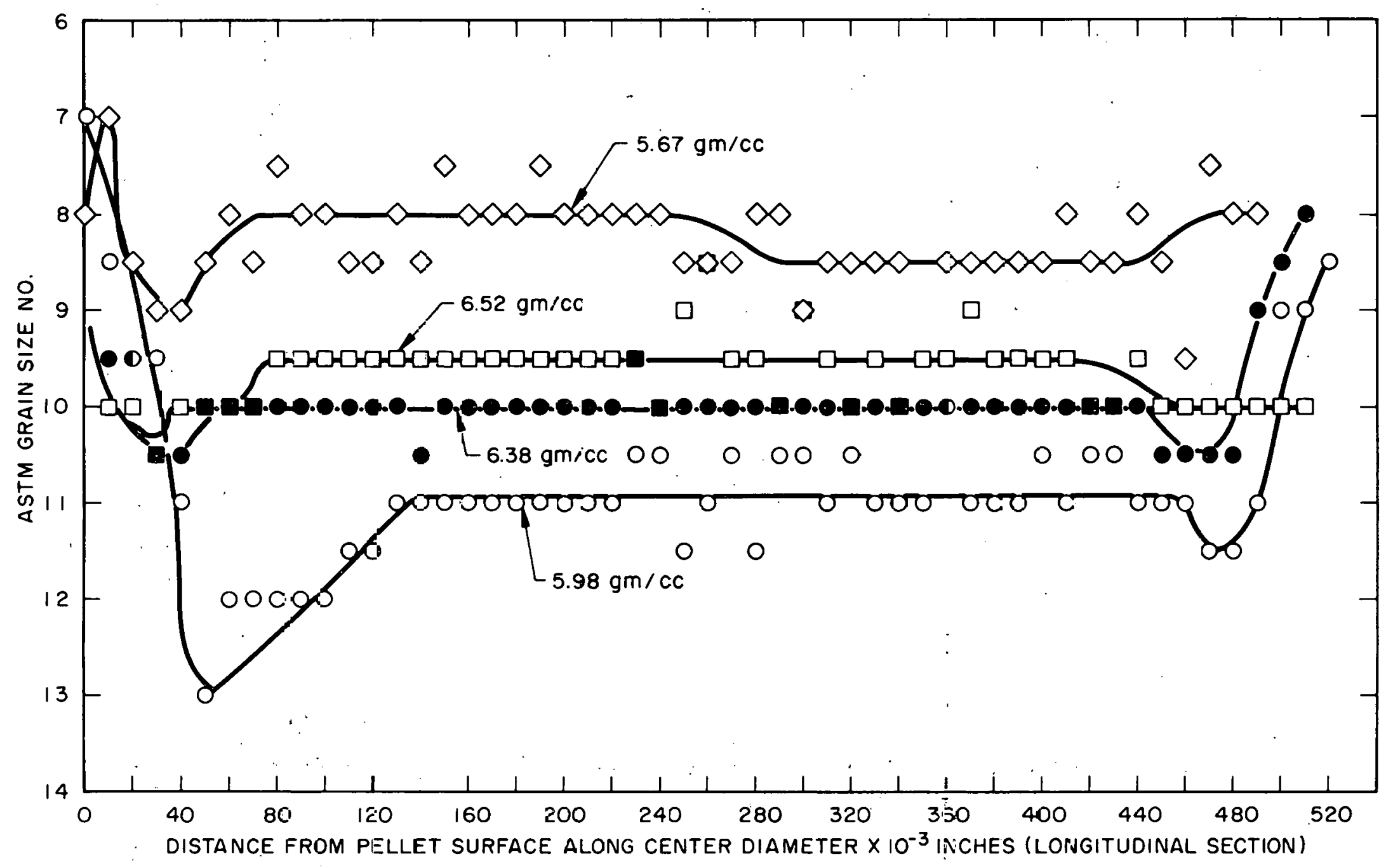


FIGURE 52

EFFECT OF CALCINING TIME AND TEMPERATURE ON GRAIN GROWTH IN ThO 2 PELLETS FABRICATED WITHOUT BINDER FROM POWDER LOT 136, AND DRY PRESSED TO A GREEN DENSITY OF $60 \%$ SINTERING CONDITION: $1750^{\circ} \mathrm{C}-1-1 / 2$ HRS $-\mathrm{H}_{2}$ (DRY)

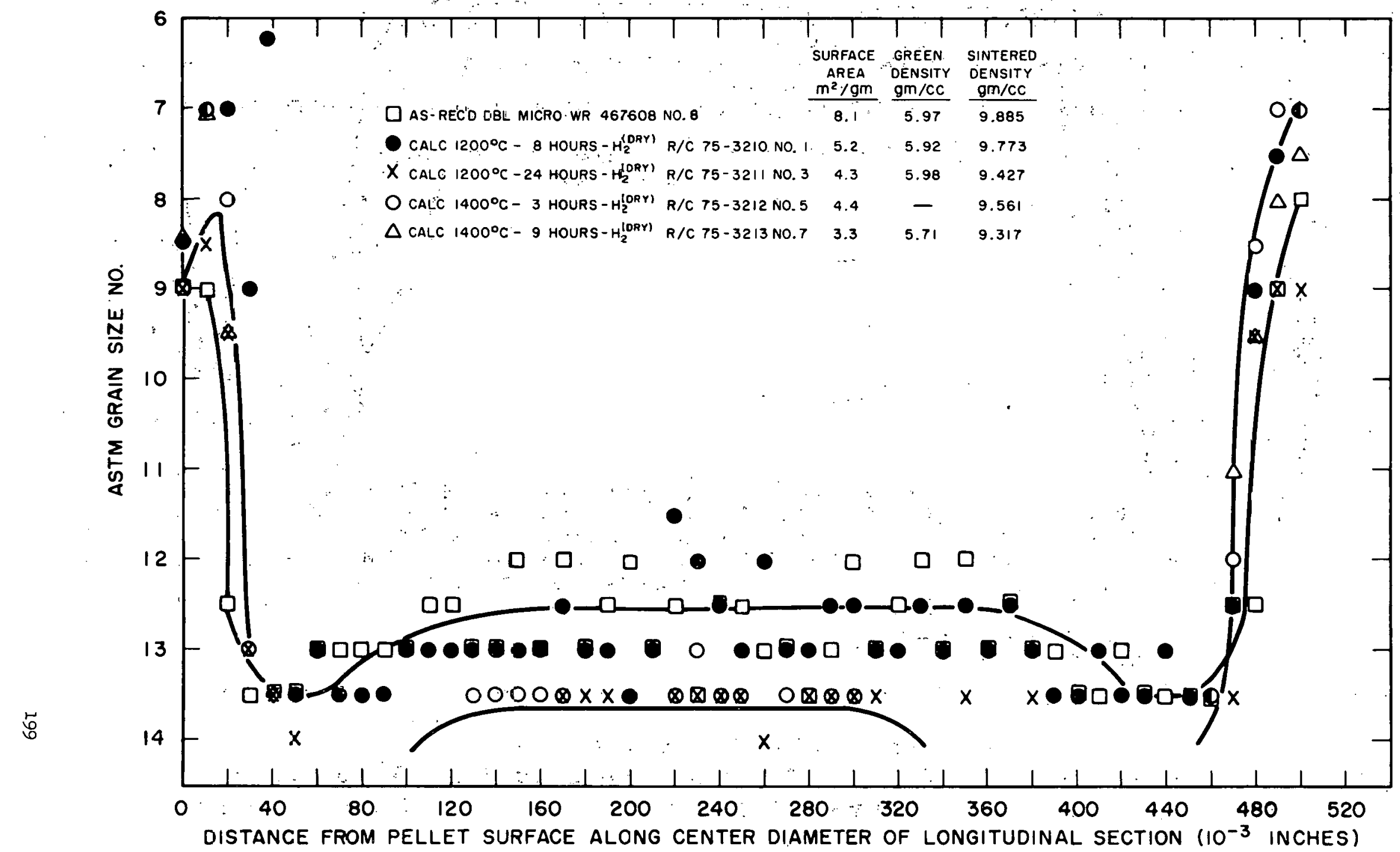


FIGURE 53

EFFEC'T OF CALCINING TIME AND TEMPERATURE ON GRAIN GROWTH IN ThO 2 PELLETS FABRICATED WITHOUT BINDER FROM POWDER LOT 136 AND DRY PRESSED TO A GREEN DENSITY OF $60 \%$ SINTERING CONDITIONS: $1750^{\circ} \mathrm{C}-12$ HRS $-\mathrm{H}_{2}^{(D R Y)}$

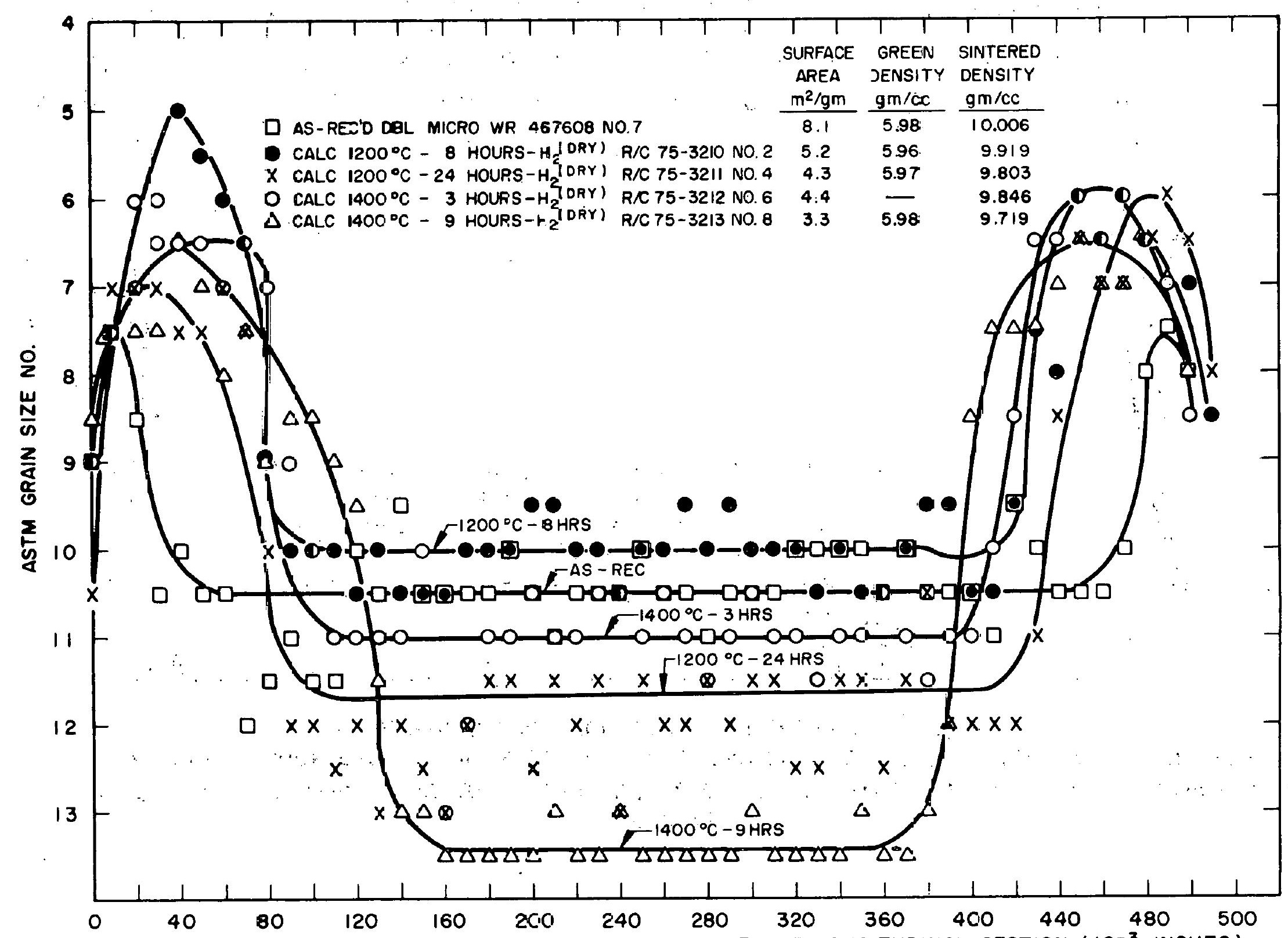


FIGURE 54

EFFECT OF CALCINING TIME AND TEMPERATURE ON GRAIN GROWTH IN PRETREATED (925 $5^{\circ} \mathrm{C}-3 \mathrm{HRS}^{-\mathrm{CO}} \mathrm{2}$ ) $\mathrm{ThO}_{2}$ PELLETS FABRICATED WITHOUT BINDER FROM POWDER LOT 136, DRY PRESSED TO

A GREEN DENSITY OF $60 \%$ AND SINTERED AT $1750^{\circ} \mathrm{C}$ IN H ${ }_{2}^{(D R Y)}$ FOR I-I/2 HRS.

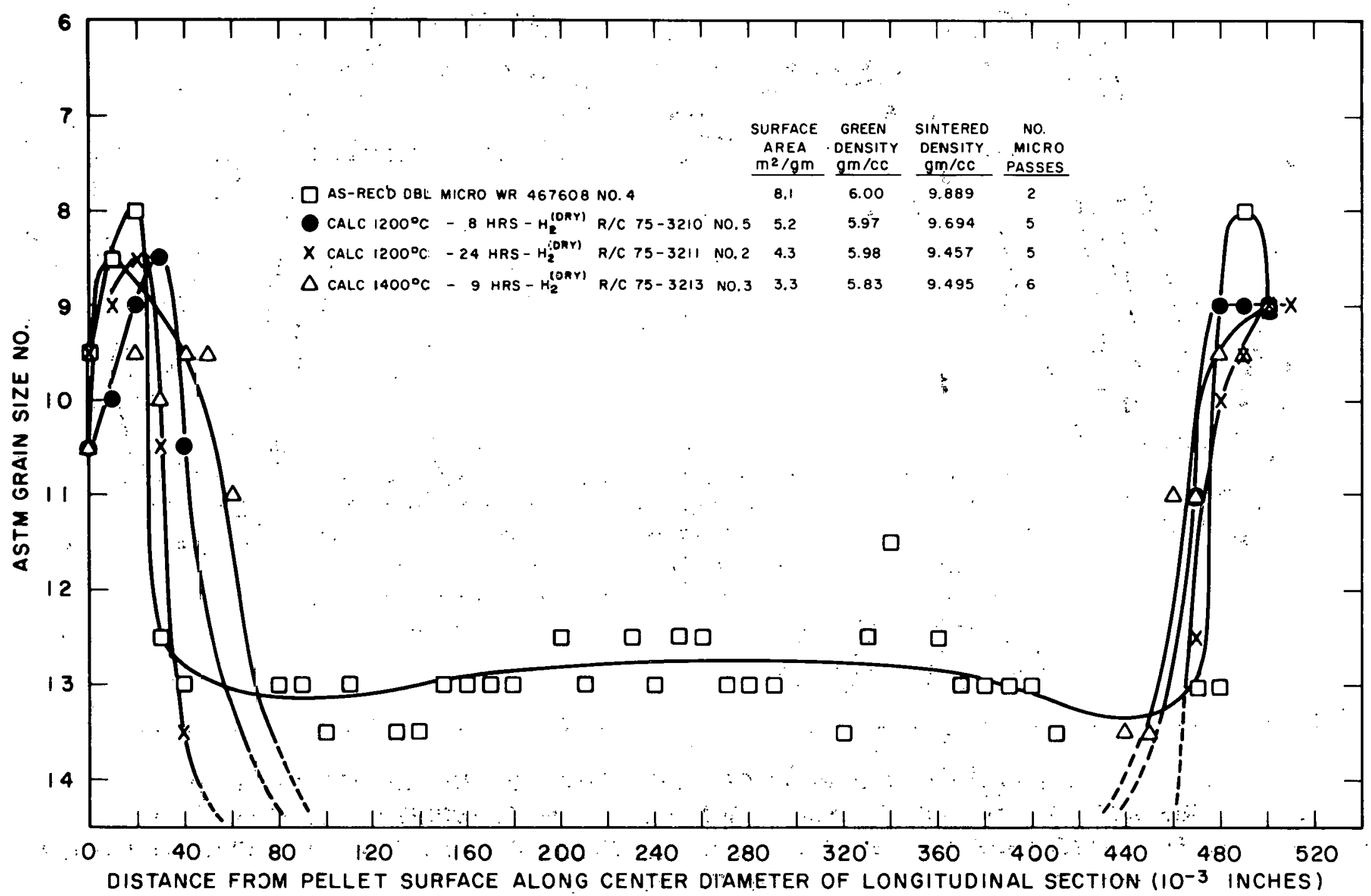


FIGURE 55

EFFECT OF CALCINING TIME AND TEMPERATURE ON GRAIN GROWTH IN PRETREATED $\left(925^{\circ} \mathrm{C}-3 \mathrm{HRS}-\mathrm{CO}_{2}\right)$ $\mathrm{THO}_{2}$ PELLETS FABRICATED WITHOUT BINDER FROM POWDER LOT 136, DRY PRESSED TO A GREEN DENSITY OF $60 \%$ AND SINTERED AT $1750^{\circ} \mathrm{C}$ IV $\mathrm{H}_{\varepsilon}{ }^{(D R Y)}$ FOR 12 HRS

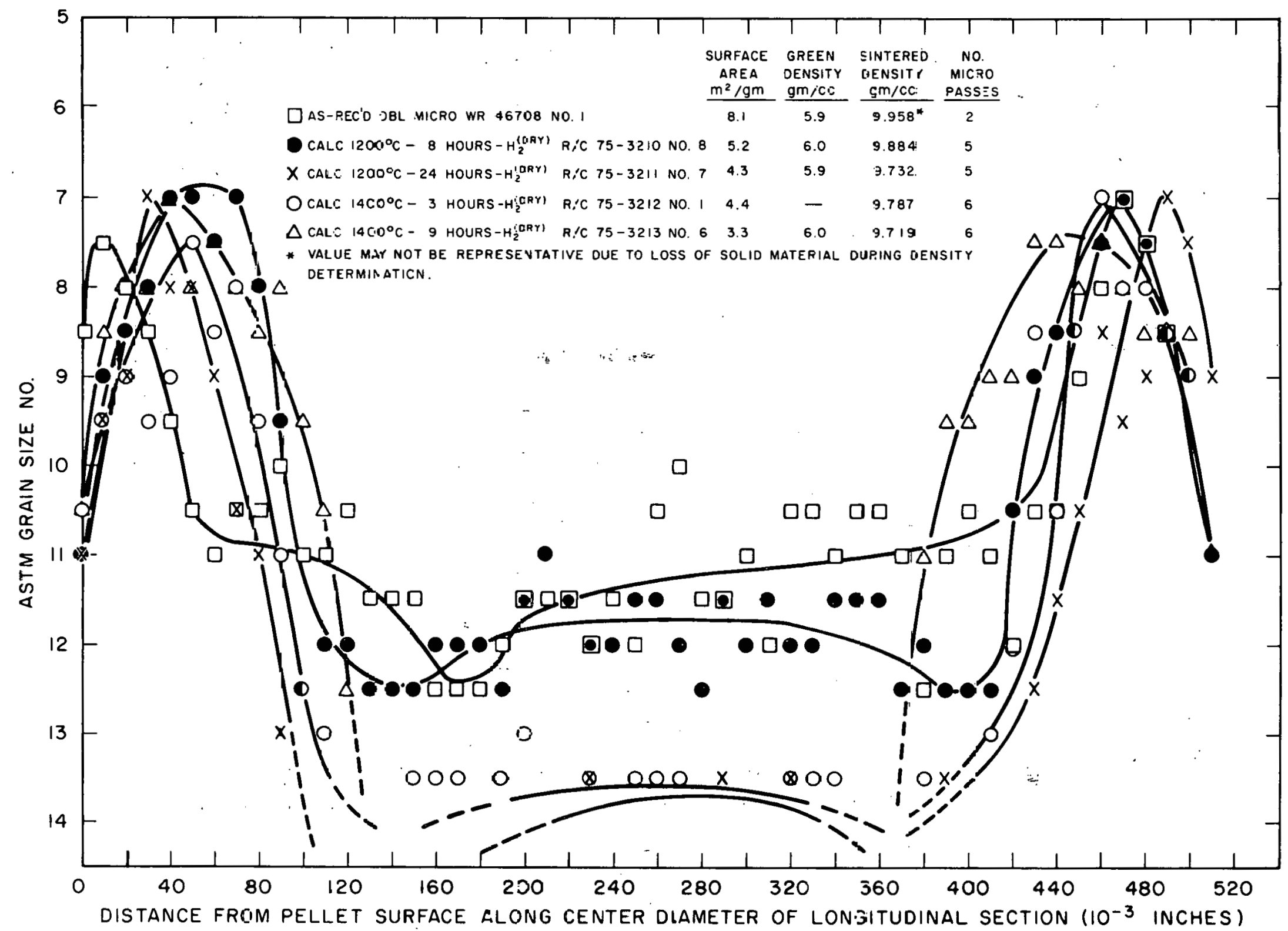


FIGURE 56

EFFECT OF SINTERING TIME AT $1750^{\circ} \mathrm{C}-\mathrm{H}_{2}{ }^{\text {(DRY) }}$ ON GRAIN GROWTH IN ThO ${ }_{2}$ PELLETS FABRICATED

FROM POWDER LOT 136, MICRONIZED, CALCINED (i $200^{\circ} \mathrm{C}-8 \mathrm{HRS}-\mathrm{H}_{2}$ (ORY)), L/S AGGLOMERATED WITH 1.5 W/o CARBOWAX - 0.2 w/o STEROTEX (ADDED DRY), AND PRESSED TO A GREEN DENSITY OF $60 \%$

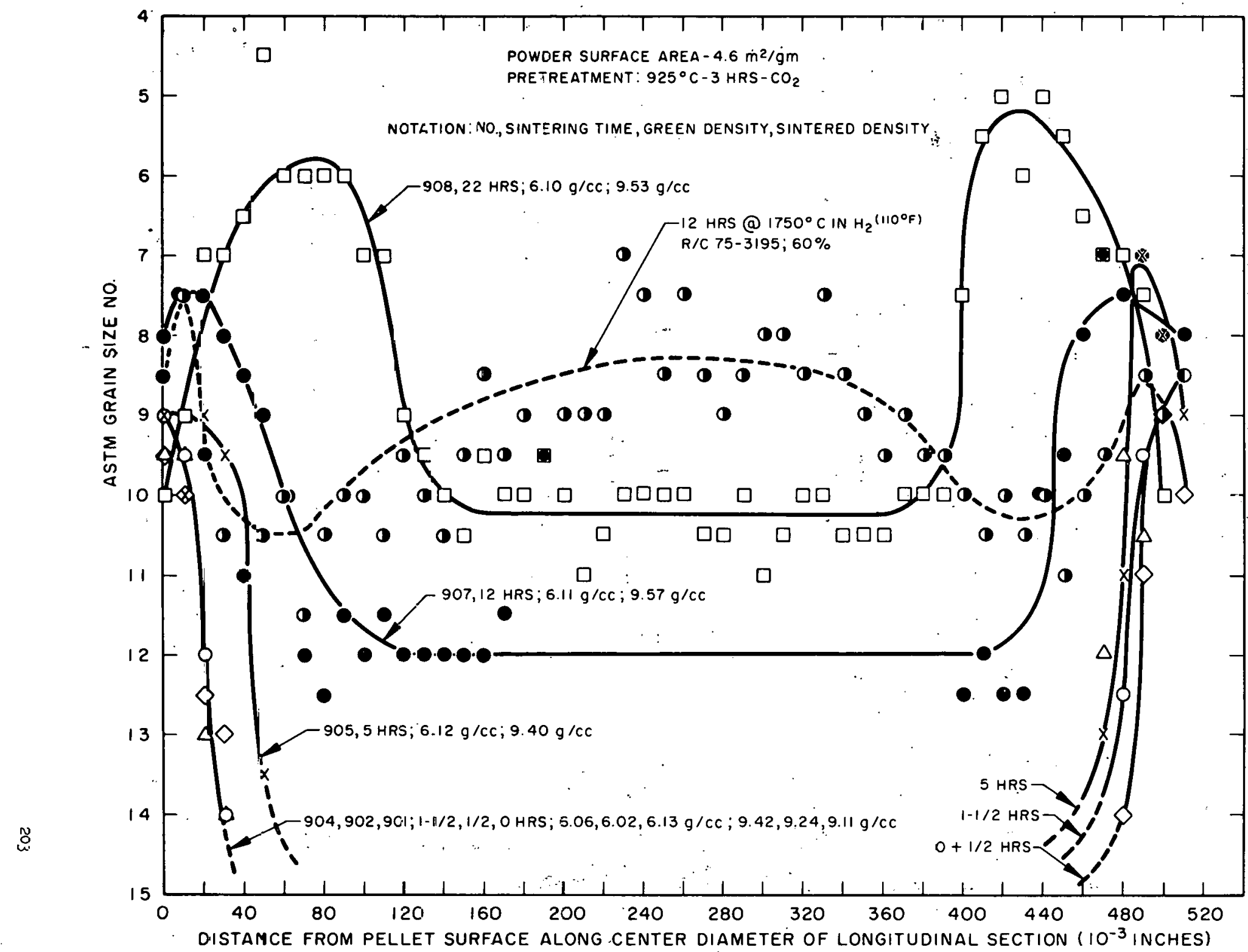


WAPD-TM-1311

FIGURE 57

EFFECT OF SINTERING TIME AT $1750^{\circ} \mathrm{C}-\mathrm{H}_{2}{ }^{\text {(DRY) }}$ ON GRAIN GROWTH IN ThO ${ }_{2}$ PELLETS

FABRICATED FROM POWDER LOT 136, MICRONIZED, CALCINED $\left.\left(1200^{\circ} \mathrm{C}-8 \mathrm{HRS}-\mathrm{H}_{2}{ }^{(D R Y}\right)\right)$,

L/S AGGLOMERATED WITH 1.5 W/O CARBOWAX - 0.2 w/O STEROTEX (ADDED DRY), AND PRESSED TO A GREEN DENSITY OF $62 \%$

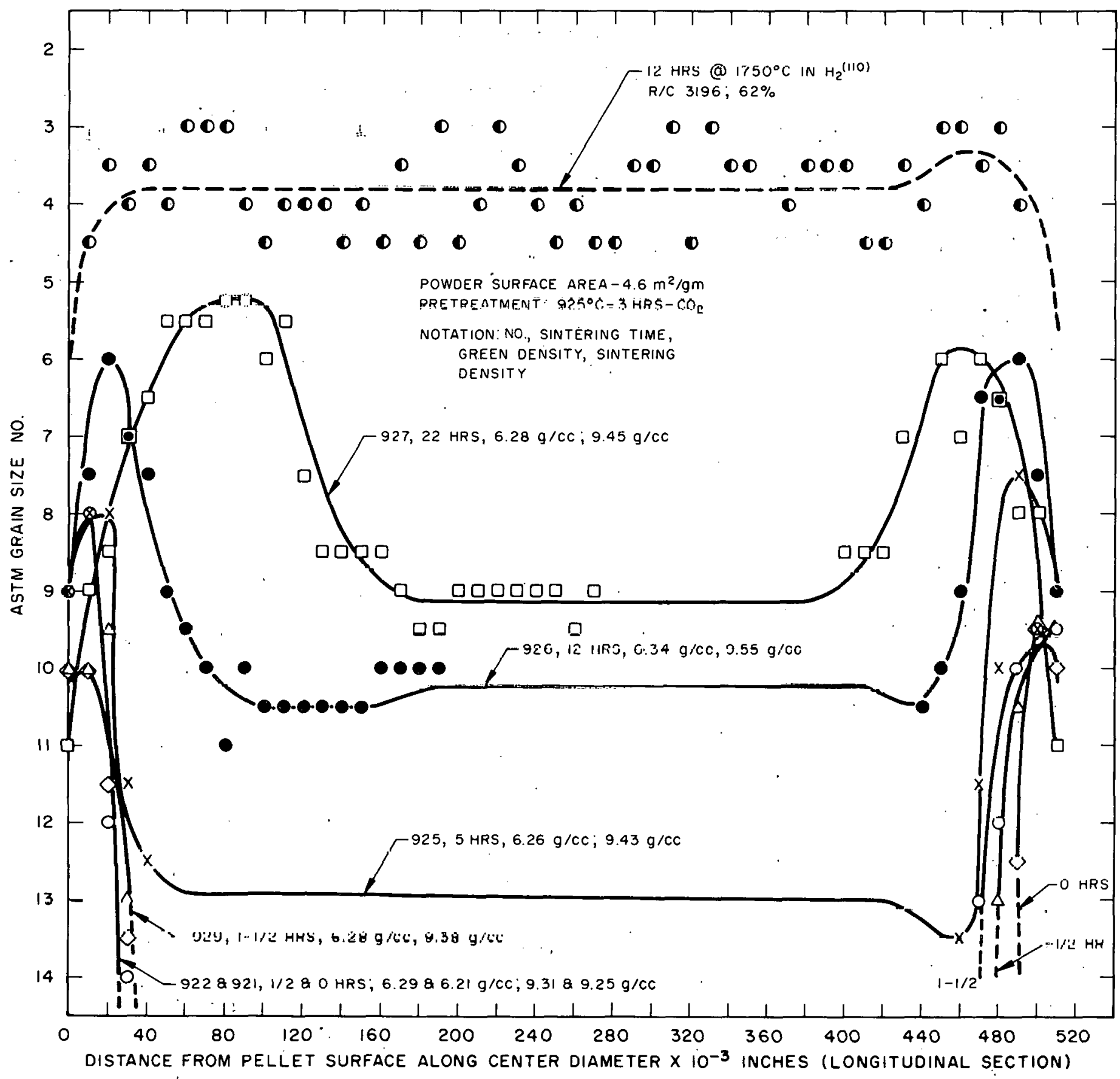


FIGURE 58

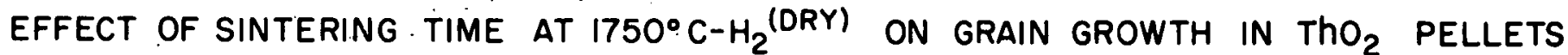
FABRICATED FROM POWDER LOT I36 MICRONIZED, CALCINED $\left(1400^{\circ} \mathrm{C}-3 \mathrm{HRS}-\mathrm{H}_{2}(\mathrm{DRY}), \mathrm{L} / \mathrm{S}\right.$ AGGLOMERATED WITH 1.5 W/O CARBOWAX - 0.2 W/O STEROTEX (ADDED DRY), AND PRESSED TO A GREEN DENSITY OF $60 \%$

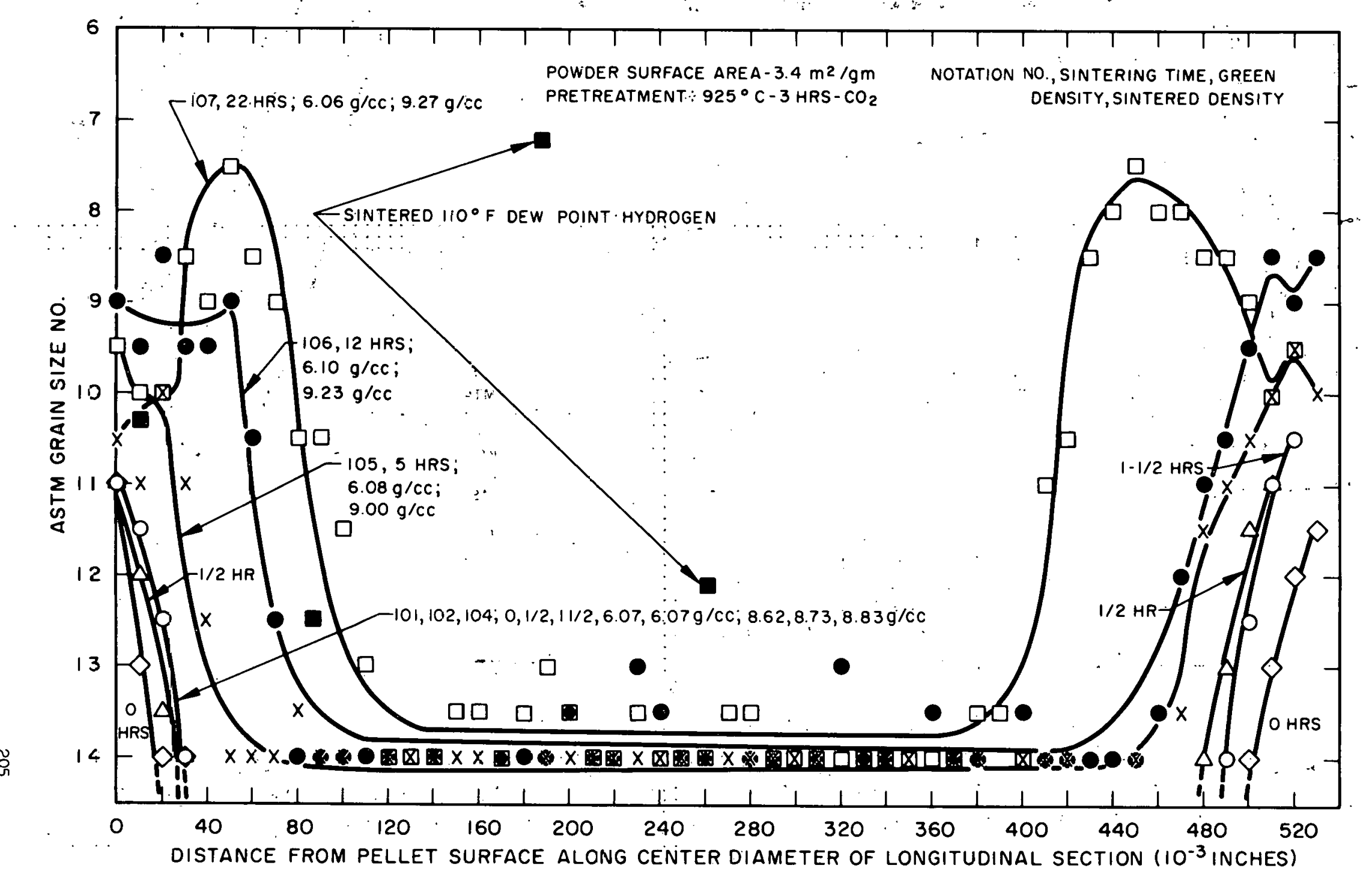


F GURE 59

EFFECT OF SINTERING TIME AT $1750^{\circ} \mathrm{C}-\mathrm{H}_{2}{ }^{(\mathrm{DRY})}$ ON GRAIN GROWTH IN ThO 2 PELLETS FABRICATED FRCM. POWDER LOT 136, MICRONIZED, CALCINED $\left(140 \mathrm{C}^{\circ} \mathrm{C}-3 \mathrm{HRS}-\mathrm{H}_{2}(\mathrm{DRY})\right.$ ) L/S AGGLOMERATED WITH 1.5 wio SARBOWAX-0.2. W/0 STEROTEX (ADDED DRY), AND PRESSED TO A GREEN DENSITY OF $65 \%$

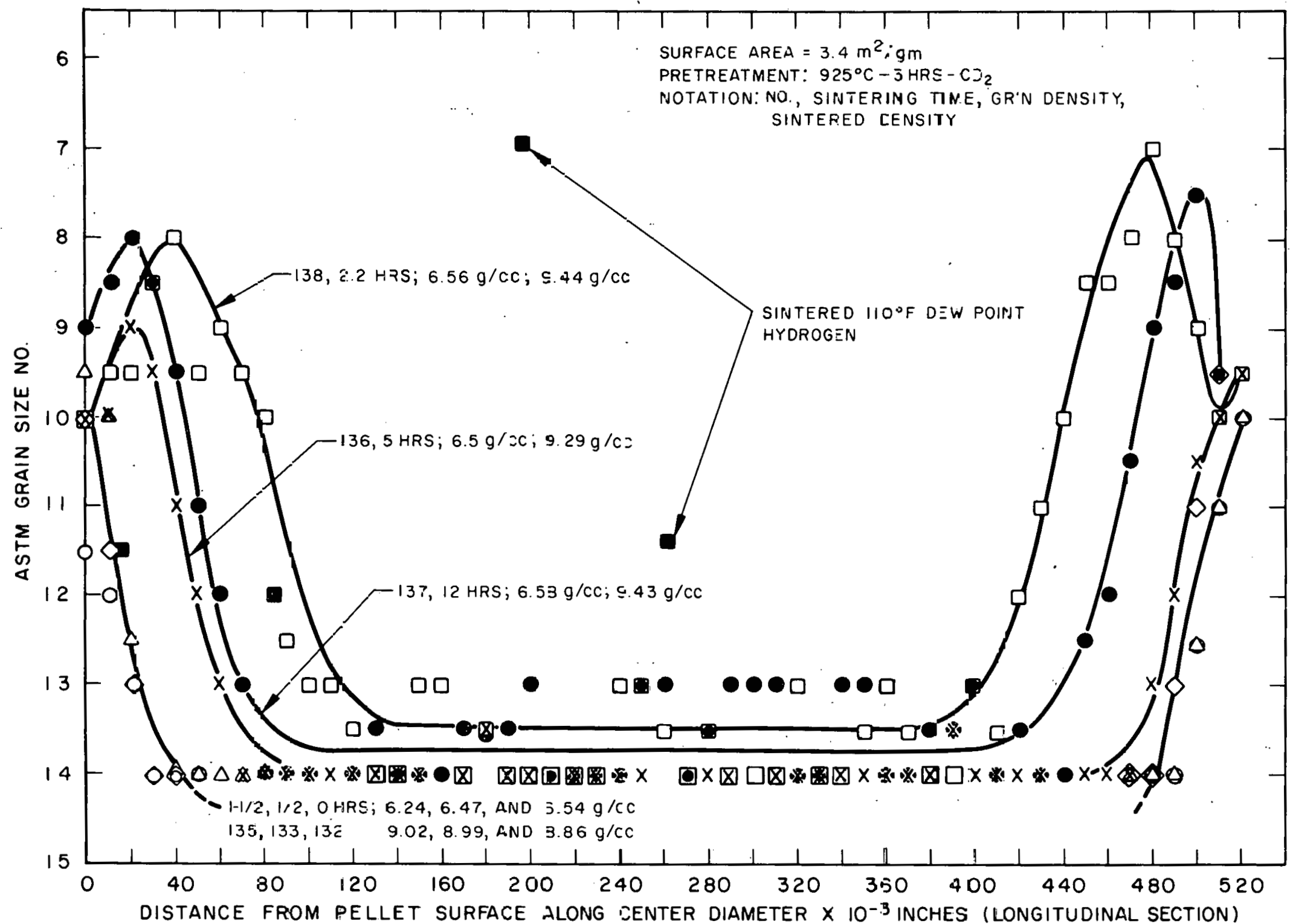




\section{FIGURE 60}

EFFECT OF BLENDING CALCINED AND AS-RECEIVED 136 POWDER ON GRAIN GROWTH IN ThO 2 PELLETS DRY PRESSED WITHOUT BINDER AT $60 \%$ GREEN DENSITY AND SINTERED AT $1750^{\circ} \mathrm{C}$ IN H${ }^{(D R Y)}$ FOR I-I/2 HRS

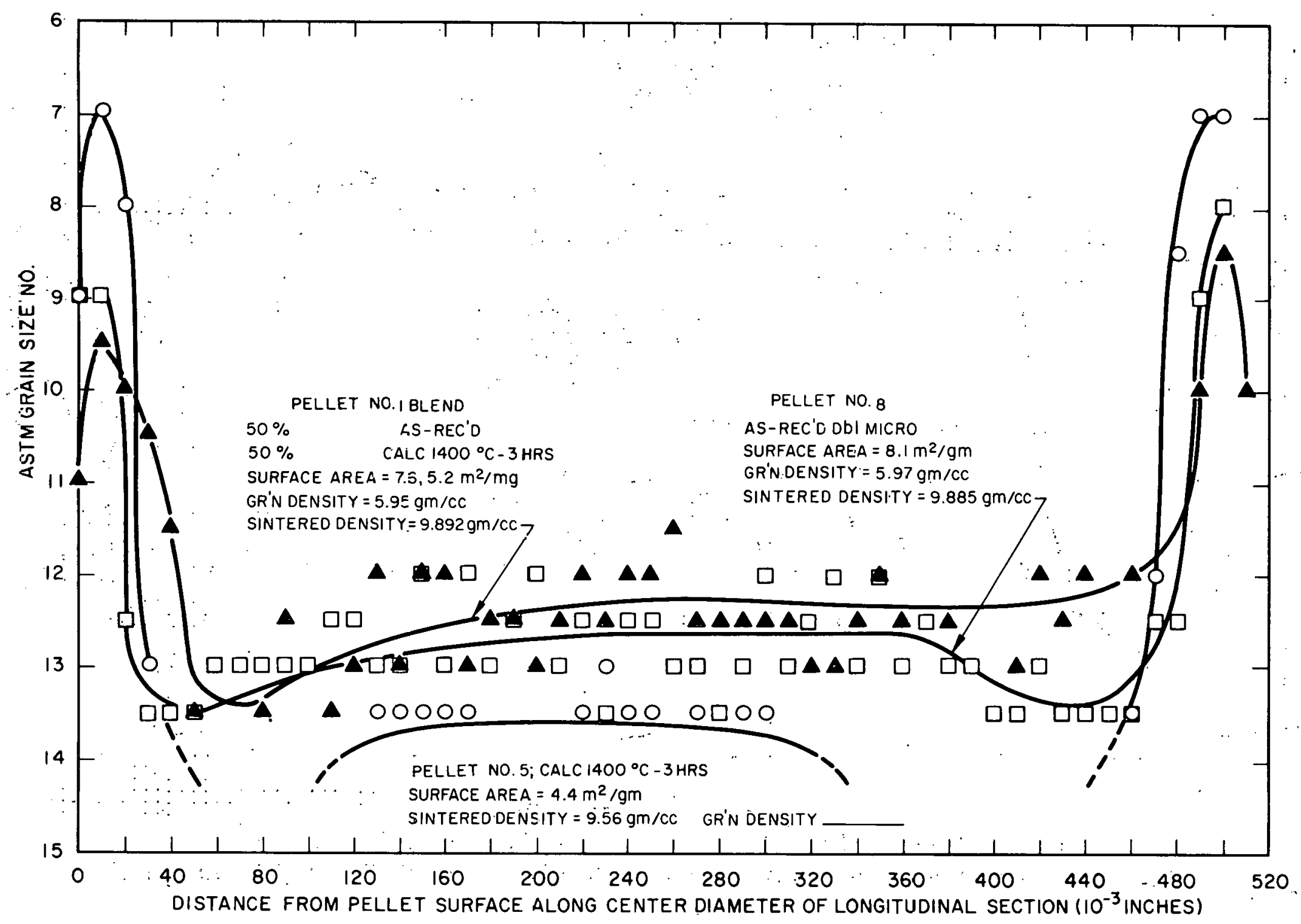


FIGURE 61

EFFECT OF BLENDING CALCINED AND AS-RECEIVED I36 POWDERS ON GFAIN GROWTH IN ThO 2 PELLETS DRY PRESSED WITHOUT BINDER AT $60 \%$ GREEN DENSITY AND SINTERED AT $17500^{\circ} \mathrm{C} I \mathrm{~N} \mathrm{H}_{2}{ }^{\text {(DRY) }}$ FOR 12 HRS

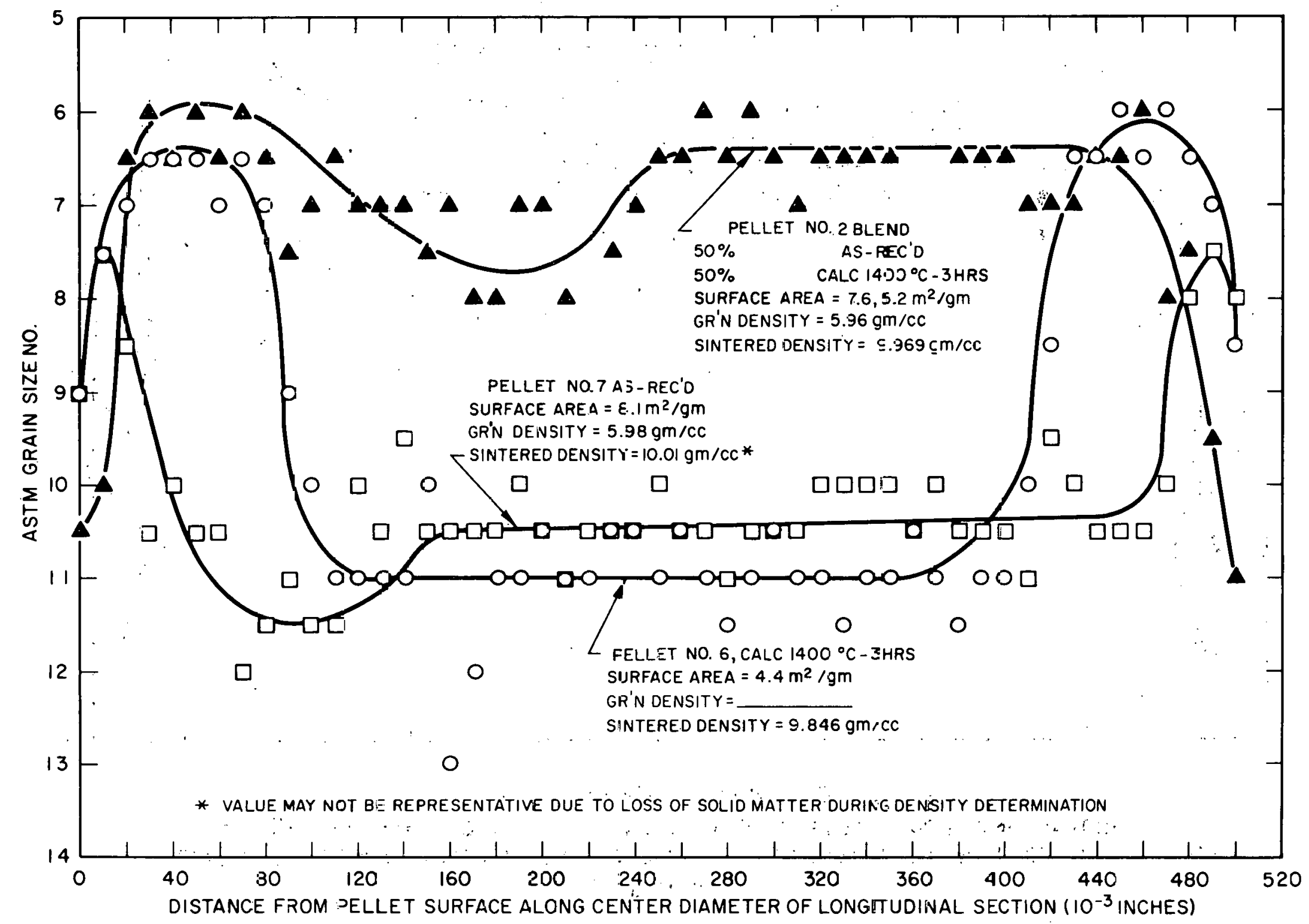


FIGURE 62

EFFECT OF SINTERING TIME AT $17500^{\circ} \mathrm{C}$ IN H2 (DRY) ON GRAIN GROWTH IN PRETREATED $\left(925{ }^{\circ} \mathrm{C}-3 \mathrm{HRS}-\mathrm{CO}_{2}\right)$ $\mathrm{ThO}_{2}$ PELLETS DRY PRESSED WITHOUT BINDER FROM A BLEND OF CALCINED AND AS-RECEIVED I36 POWDER

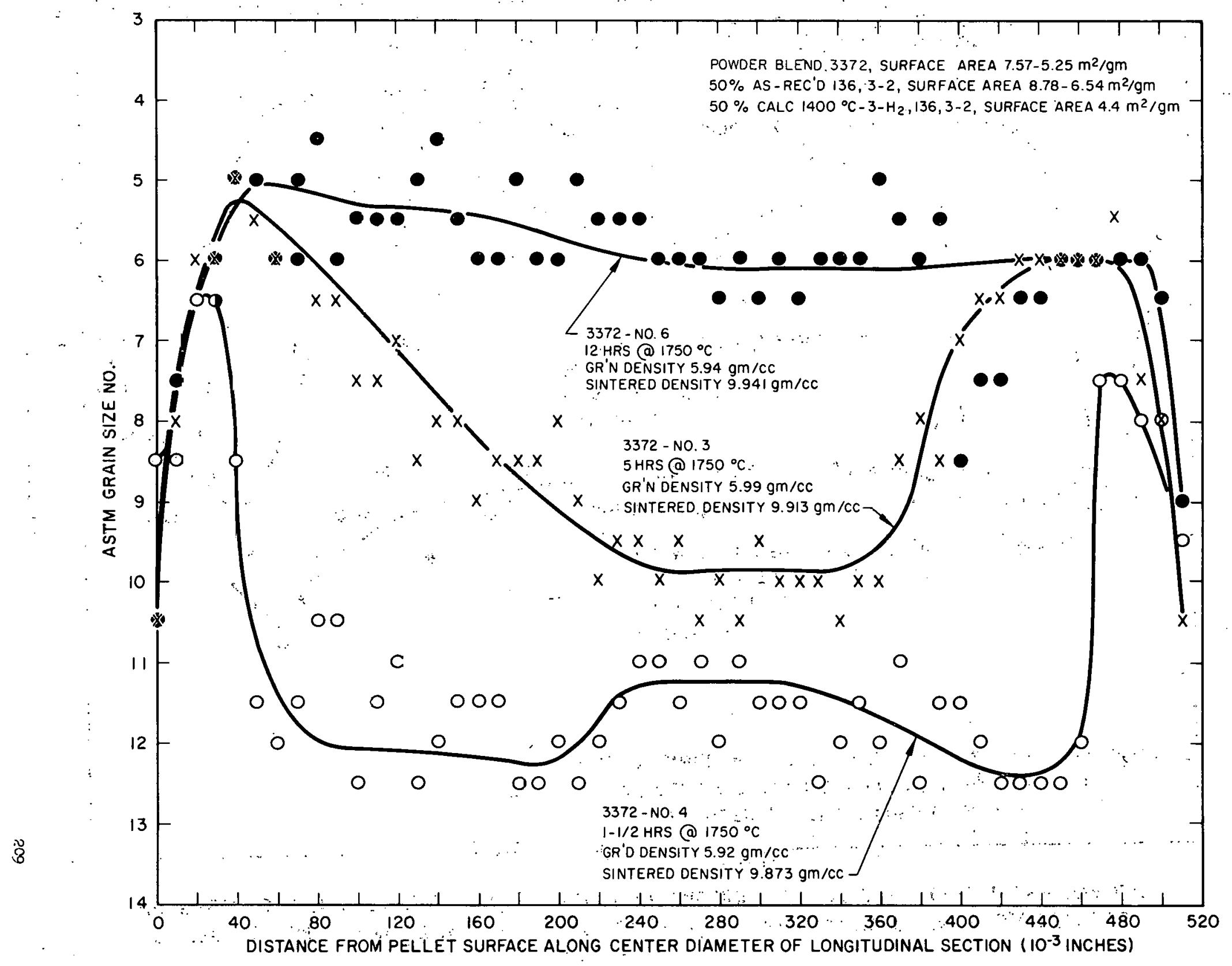


FIGURE 63

EFFECT OF SINTERIYIG TIME AT $1750^{\circ} \mathrm{C}$ IN H2 ${ }^{(D R Y)}$ ON GRAIN GRDWTH IN ThO 2 PELLETS

DRY PRESSED WITHOUT BINDER FRDM A BLEND OF CALCINED I36 AND AS-RECEIVED 096 POWDER

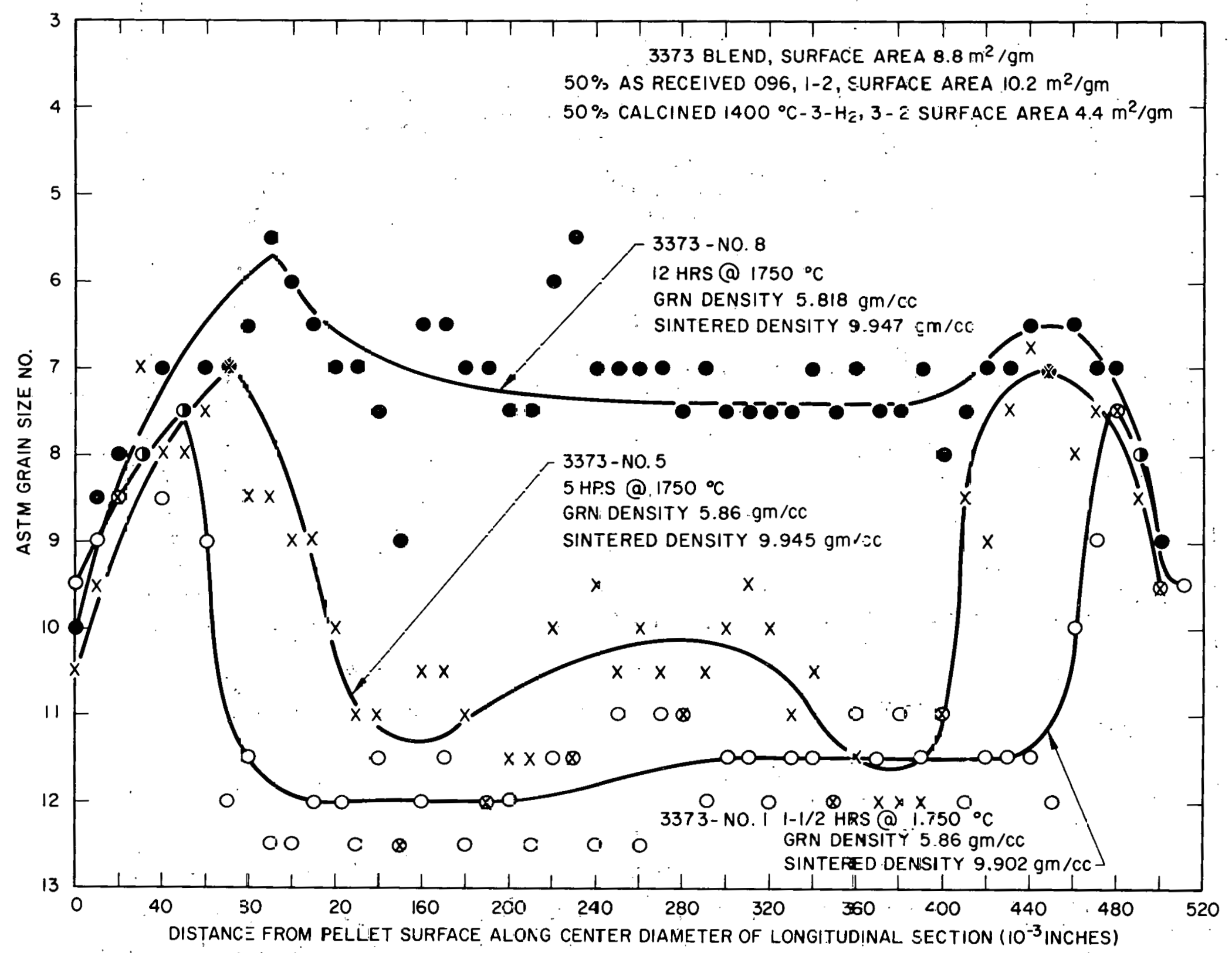


FIGURE 64

EFFECT OF BLENDING CALCINED I36 AND AS-RECEIVED 096 POWDER ON GRAIN GROWTH IN

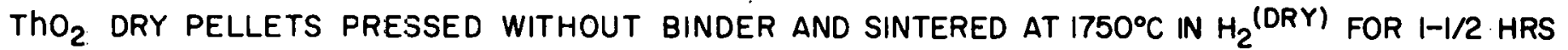

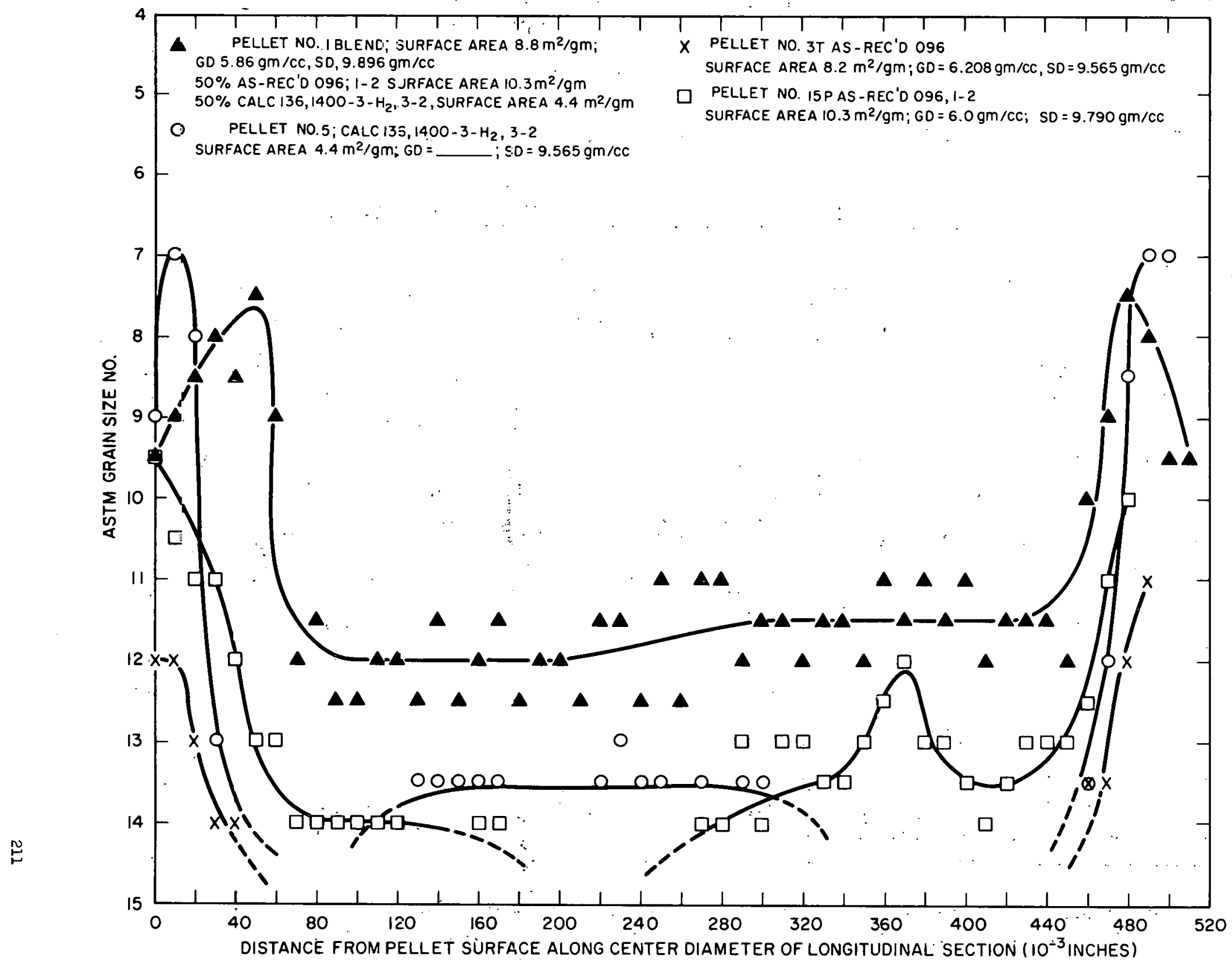


FIGURE 65

EFFECT OF 3LENDING CALCINEC 136 AND AS-RECEIVED 096 PO'NDER ON GRAIN GROWTH IN $T_{2} \mathrm{O}_{2}$ PEILLETS C.RY PRESSED WITHOUT BINDER AND SINTERED AT $1750^{\circ} \mathrm{C} \mathrm{N} \mathrm{H}_{2}$ (DRY) FOR 12 HRS

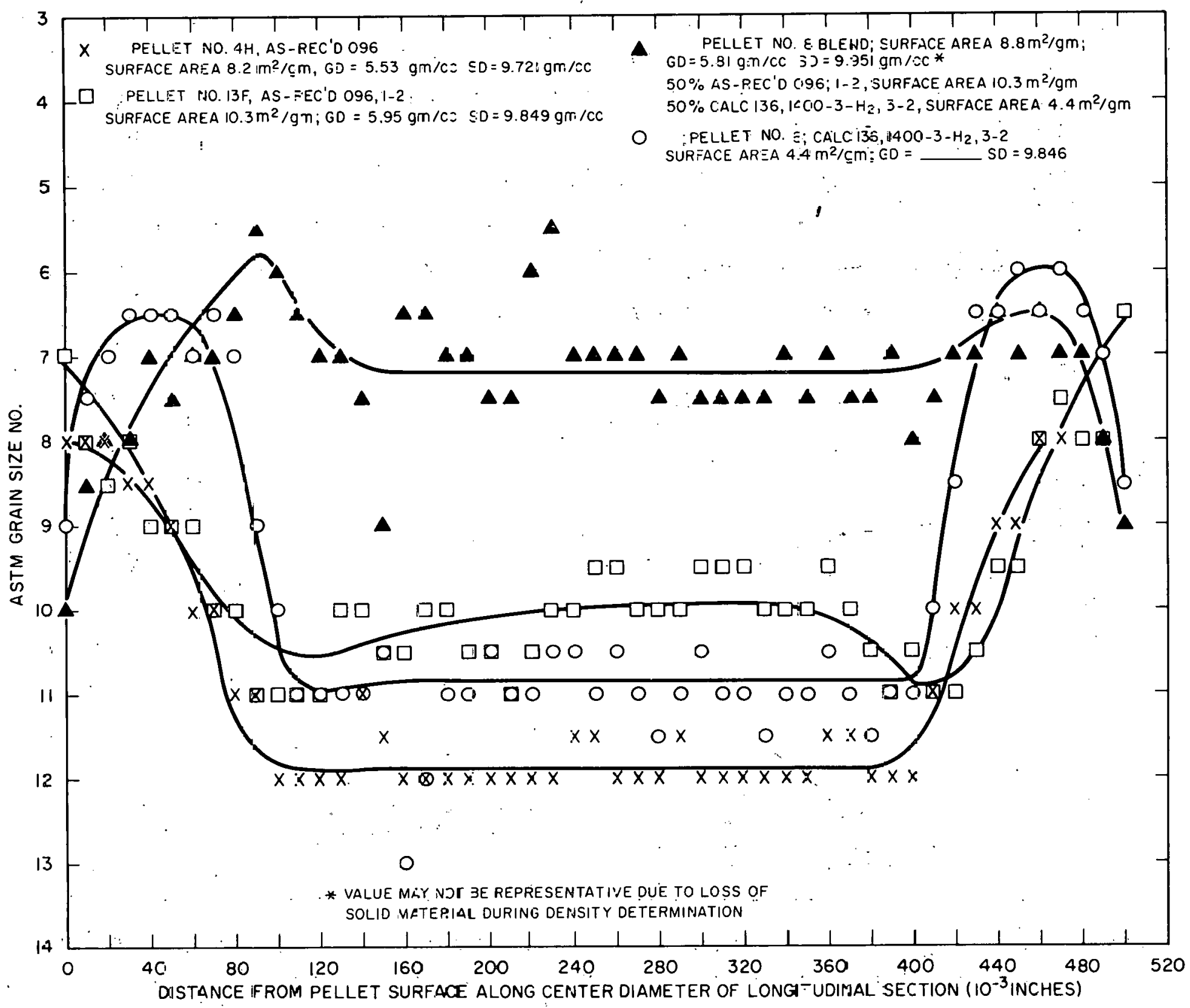



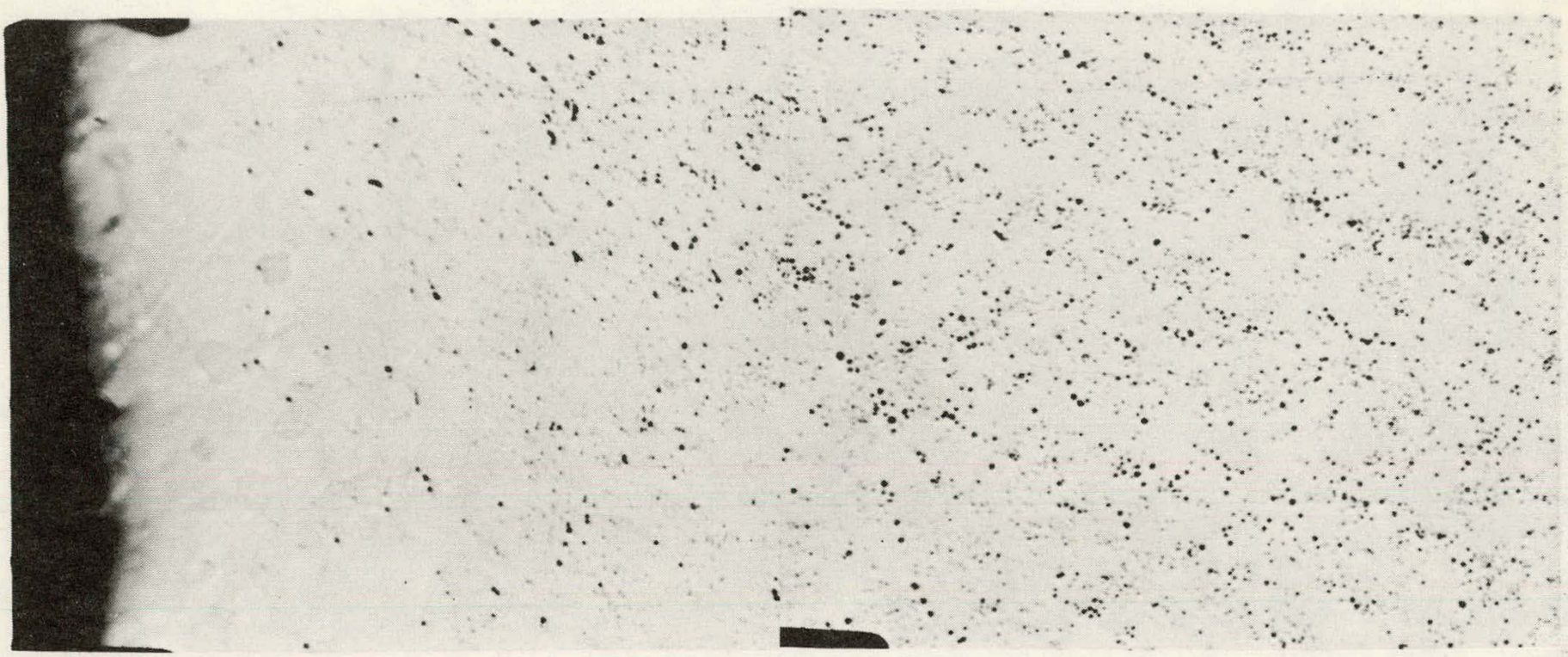

FIGURE 6\%a - Metallographic section at the surface along the diameter of the thoria pellet fabricated without binder from equal quantities of calcined $\left(1400-3 \mathrm{hrs}_{2} \mathrm{H}_{2}\right)$, micronized and as-received, micronized thoria 136 powder. Sintering temperature $1750^{\circ} \mathrm{C}-1 \frac{1}{2}$ hrs $-\mathrm{H}_{2}$. 
FIGURE 68

VARIATION IN POROSITY ALONG THE DIAMETER OF A THORIA PELLET

FABRICATED WITHOUT BINDER FROM EQUAL QUANTITIES OF CALCINED

AND AS-RECEIVED I36 POWDER SINTERED AT $1750^{\circ} \mathrm{C}$ IN H

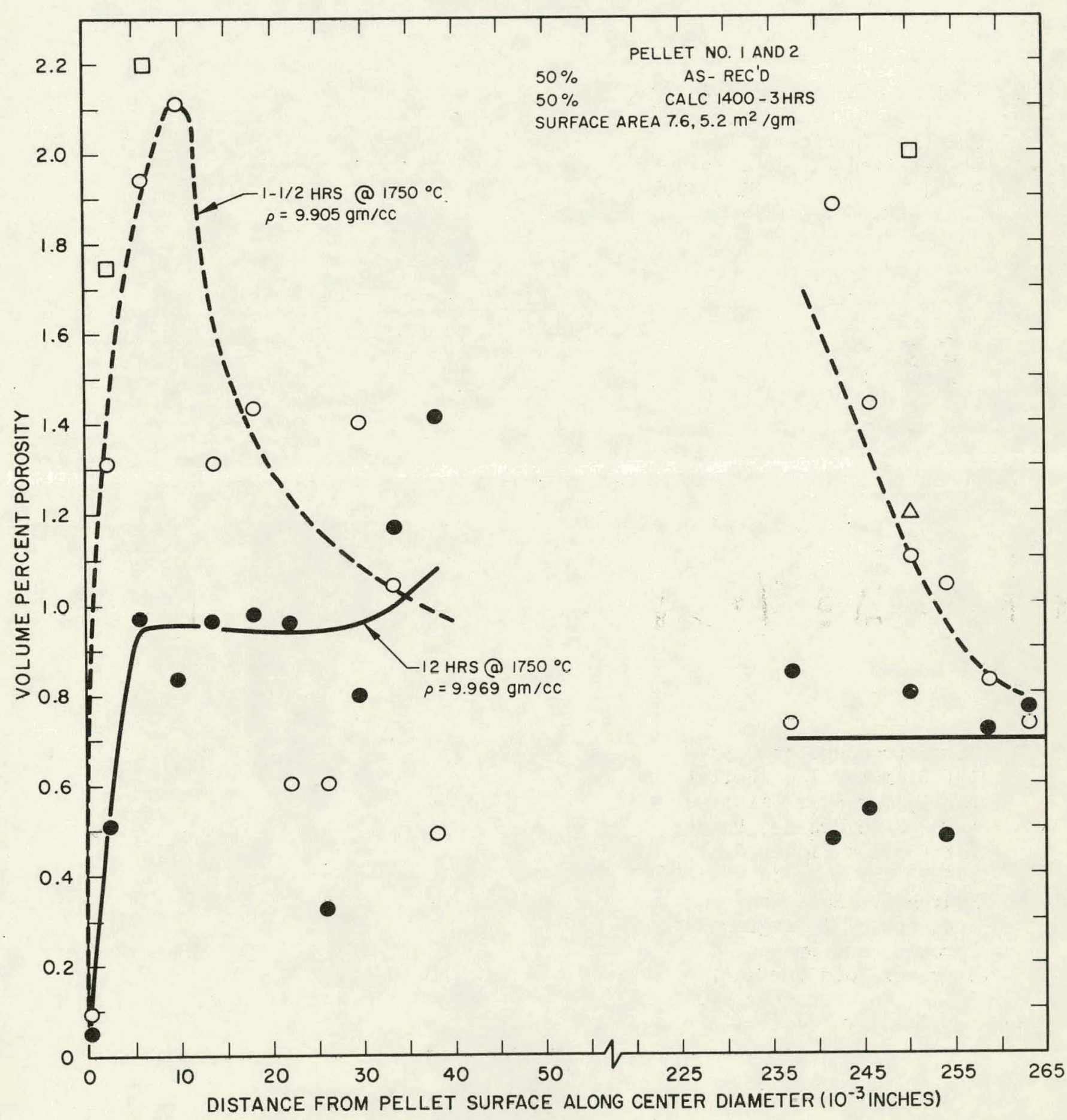


FIGURE 69. Grain Boundary Curvature at a Free Surface

69a Typical Sterotex Void As Observed in Micrograph of a Pellet Fabricated From As-Received $136 \mathrm{ThO}_{2}$ Powder $9978 . T$ vag. $400 \mathrm{X}$ Neg. No. $51039-45$

$69 \mathrm{~b}$ Microstructure of 0.53 In. Diameter ThO Pellet Fabricated From Calcined $\left(1100^{\circ} \mathrm{C}-48 \mathrm{Hrs}-\mathrm{H}_{2}\right.$ ) Powder Lot 136 and Sintered at $1750^{\circ} \mathrm{C}$ For $\frac{1}{2}$ Hr in Hydrogen. Note The Presence of Intragranular Porosity and Smooth Sterotex Void Surface. $395 \mathrm{~K}$ Mag. $400 \mathrm{X}$ Neg. No. 51039-6
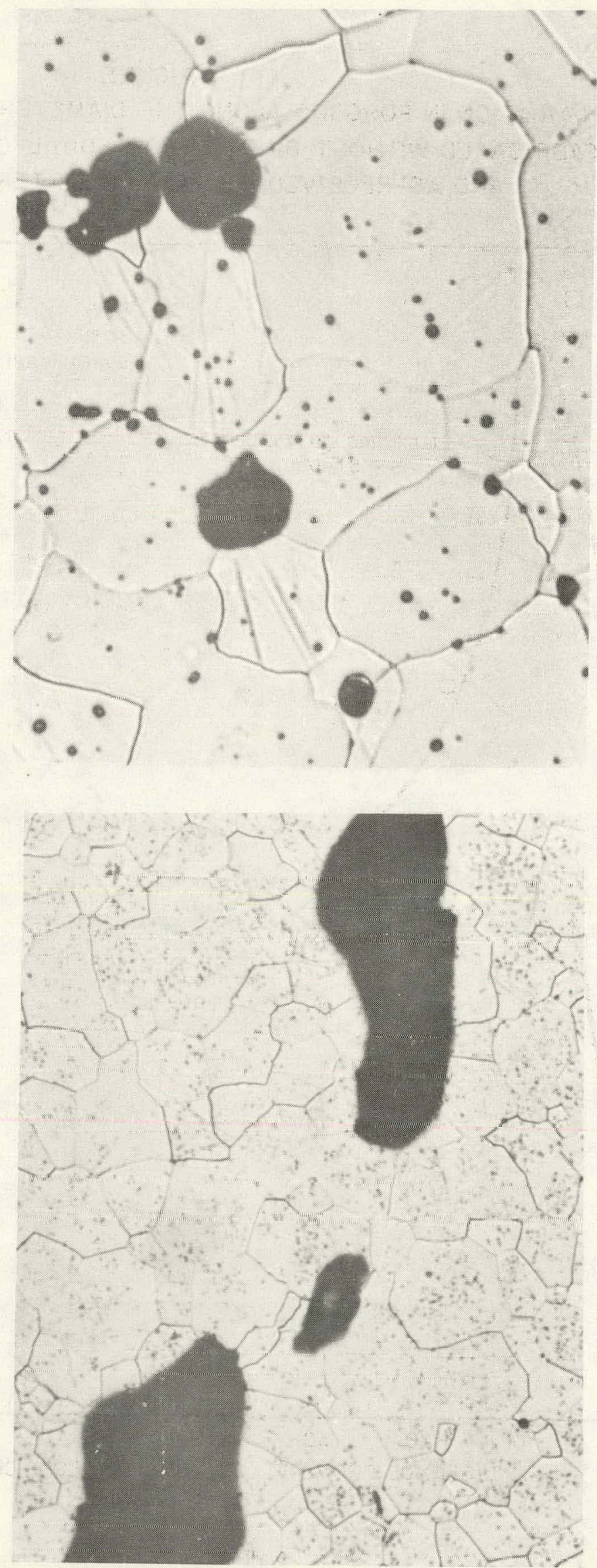


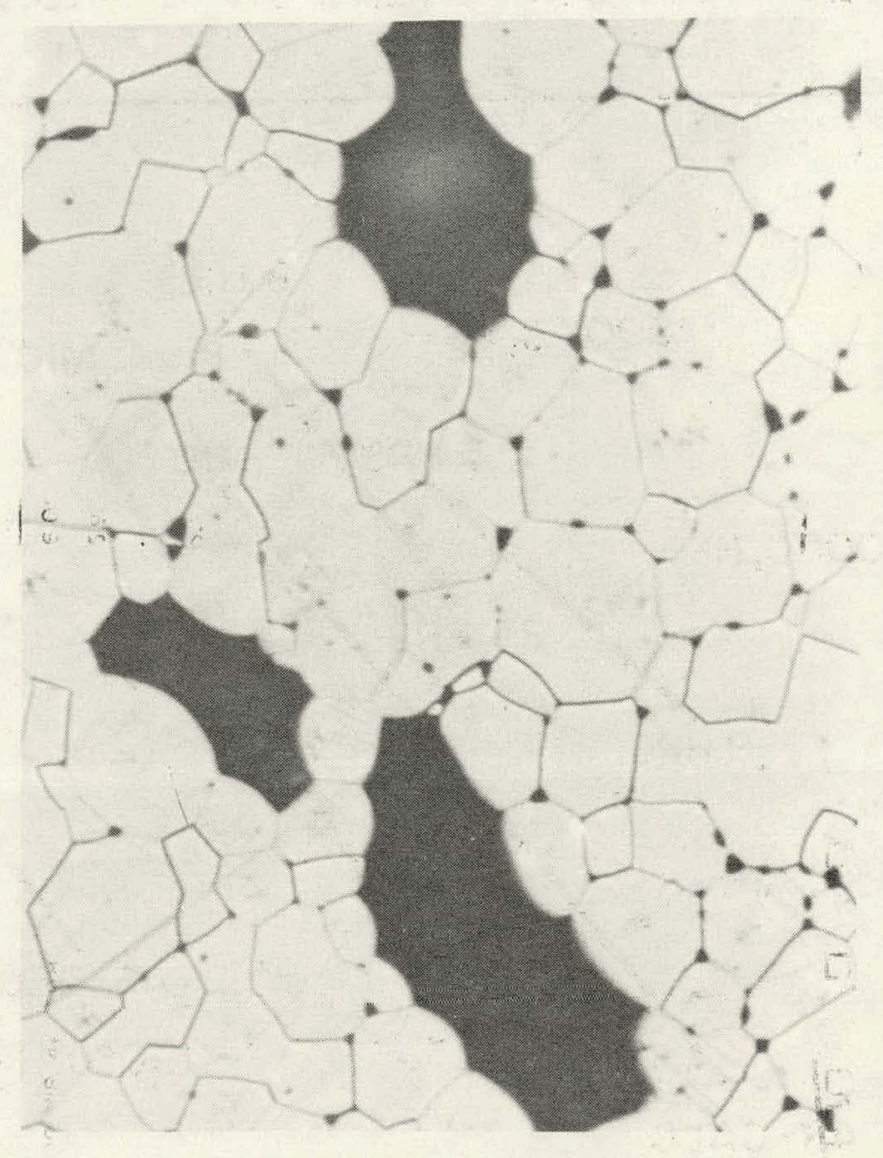

69c Same Pellet Composition As 69b Above Except the Pellet Was Sintered at $1750^{\circ} \mathrm{C}$ For $12 \mathrm{Hrs}$. Note Lack of Intragranular Porosity and Irregular Sterotex Void Surface Resulting From the Movement of Grain Boundaries Into the Free Surface. $417 \mathrm{~K}$ Mag. $400 \mathrm{X}$ Neg. No. 51039-46 
FIGURE 70

EFFECT OF CALCINING TEMPERATURE AND SURFACE AREA ON THE SINTERED DENSITY OF BINDERLESS $\mathrm{ThO}_{2}$ PELLETS (LOT 136) SINTERED FOR 12 HRS AT $1750^{\circ} \mathrm{C}$ IN DRY $\mathrm{H}_{2}$

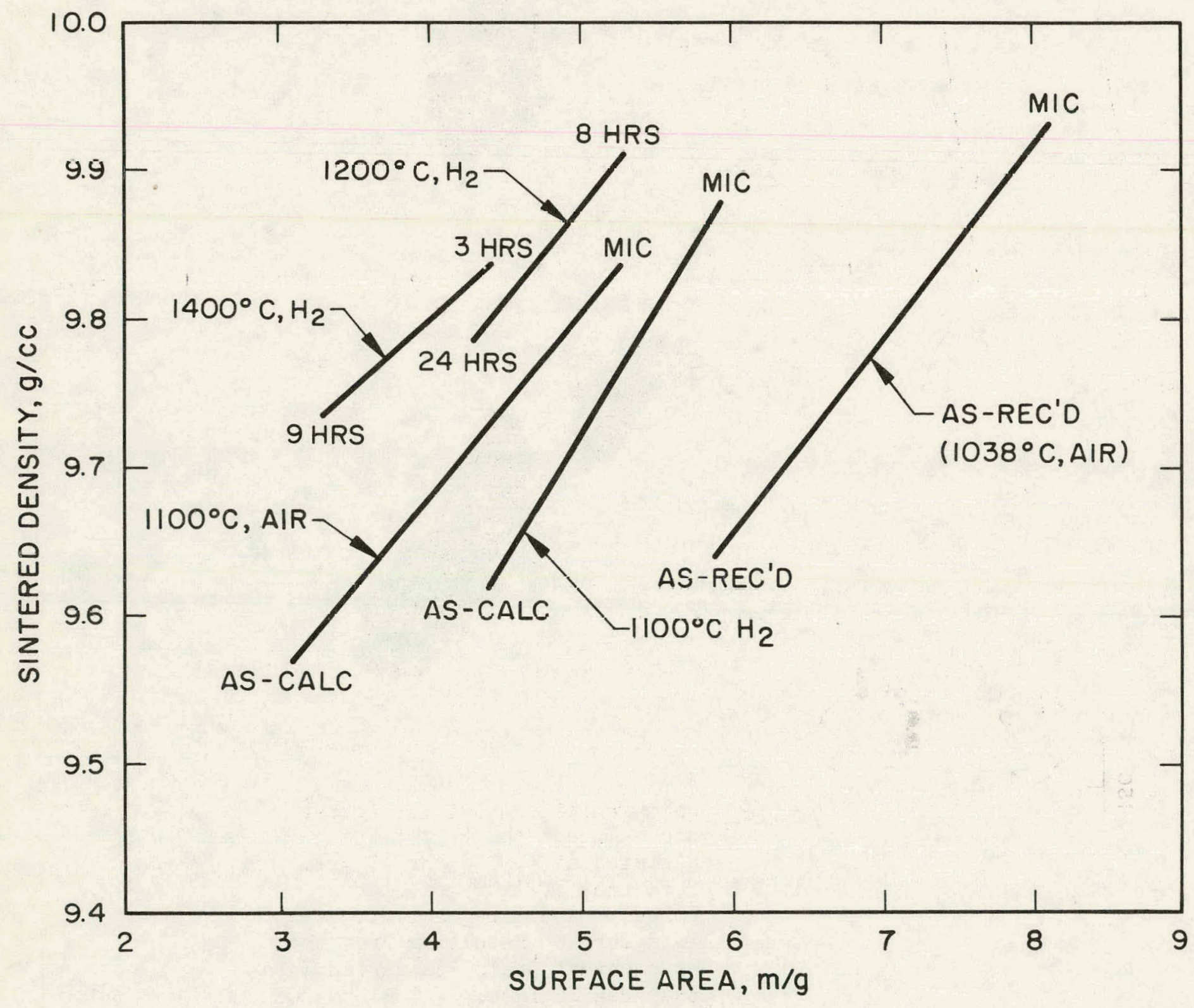


FIGURE 71

EFFECT OF SURFACE AREA AND CALCINATION

ON GRAIN GROWTH IN ThO 2 PELLETS

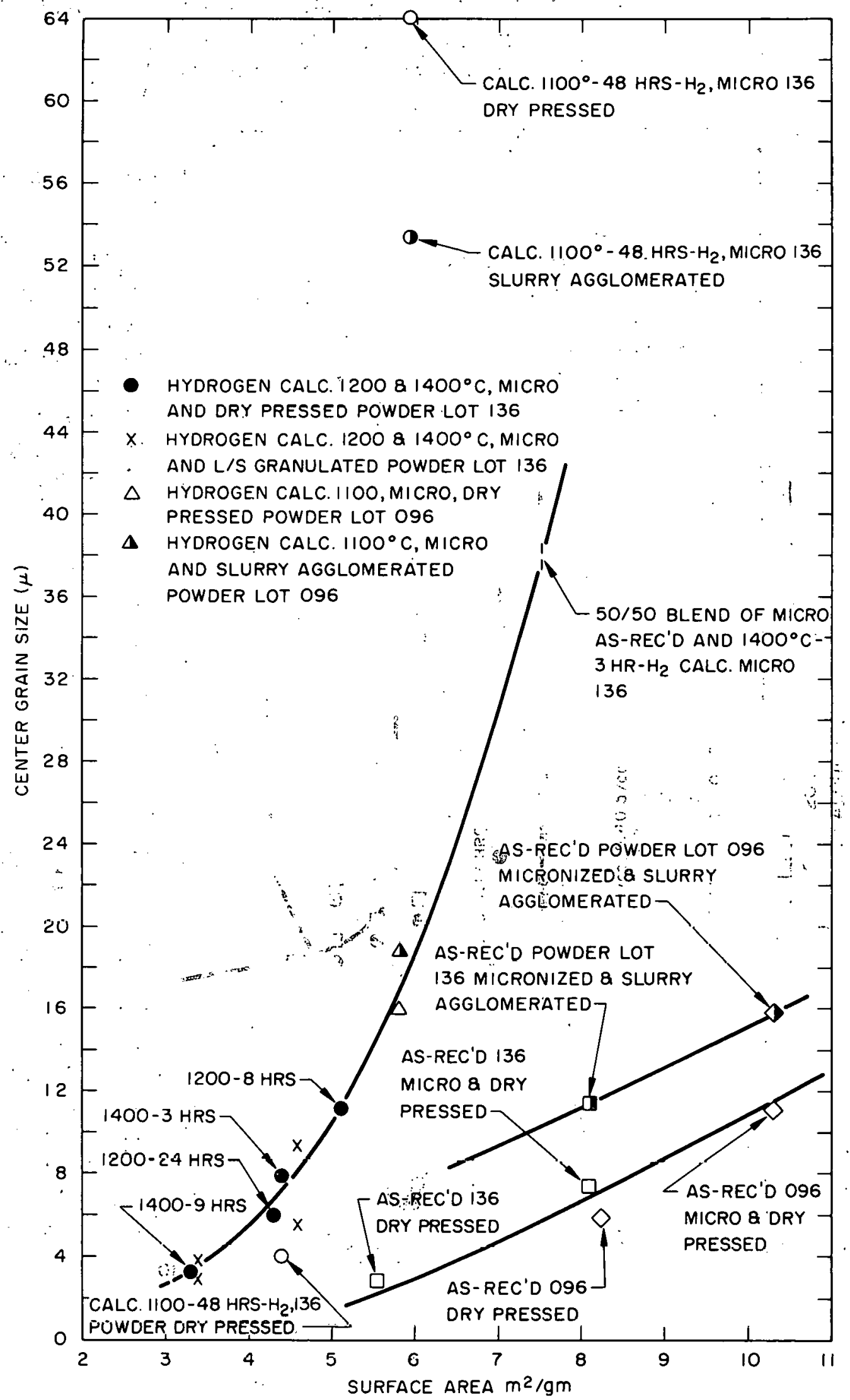


FIGURE 72

EFFECT OF SURFACE AREA AND CALCINATION

ON GRAIN GROWTH IN ThO 2 PELLETS

SINTERED AT $1750^{\circ} \mathrm{C}$ IN H $\mathrm{H}_{2}$ FOR 12 HRS

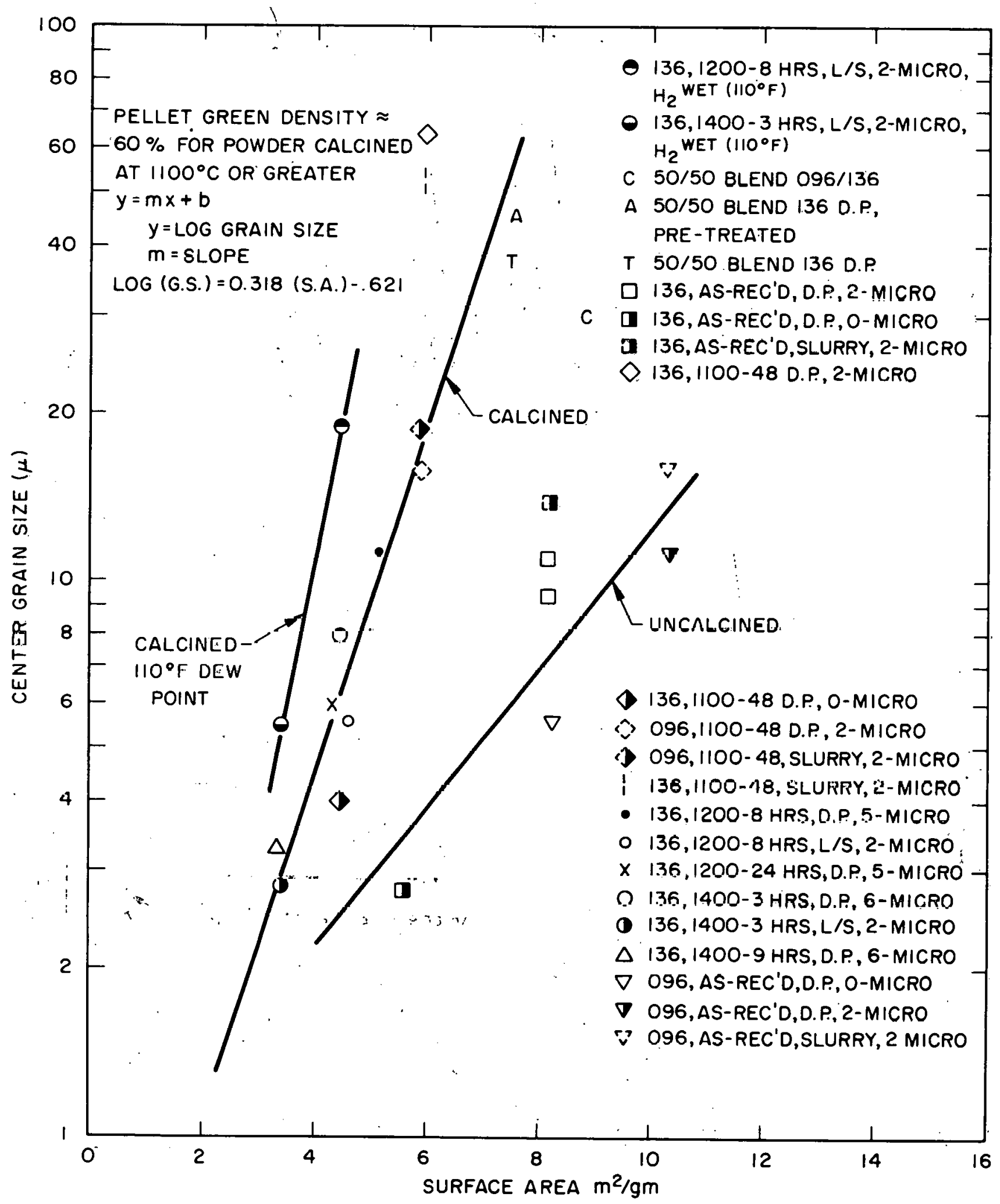




\section{$\underline{A P P E N D I X} \underline{A}$ \\ GRAIN GROWTH IN SLURRY AGGLOMERATED ThO 2 PELLETS}

Extensive granular segregation was observed in the microstructure of thoria pellets fabricated from micronized-as-received and micronized $-1100^{\circ} \mathrm{C}-48$ hour air-calcined powder lots 096 and 136 by the slurry agglomeration process, Section VII. It was theorized that the sintering atmosphere was able to penetrate the pellet structure through separations between granules and vaporize the grain growth inhibiting impurity. Consequently, the grain size data presented in Figures A-1 - A-12 may not be representative and should be used with discretion. 
FIGURE A-1

EFFECT OF SINTERING TIME AT $1750^{\circ} \mathrm{C}$. ON GRAIN GROWTH IN THO 2 PELLETS

FABR:CATEC FROM POWDEZ LOT O96, MICRONIZED, AS-RECEIVED, SLURRY AGGLOMERATED WITH:I.75 w/O CARBOWAX - 0.2 w/o STEROTEX (ADDED DRY)

AND PRESSED TO A GREEN TARGET DENSITY OF $57 \%$

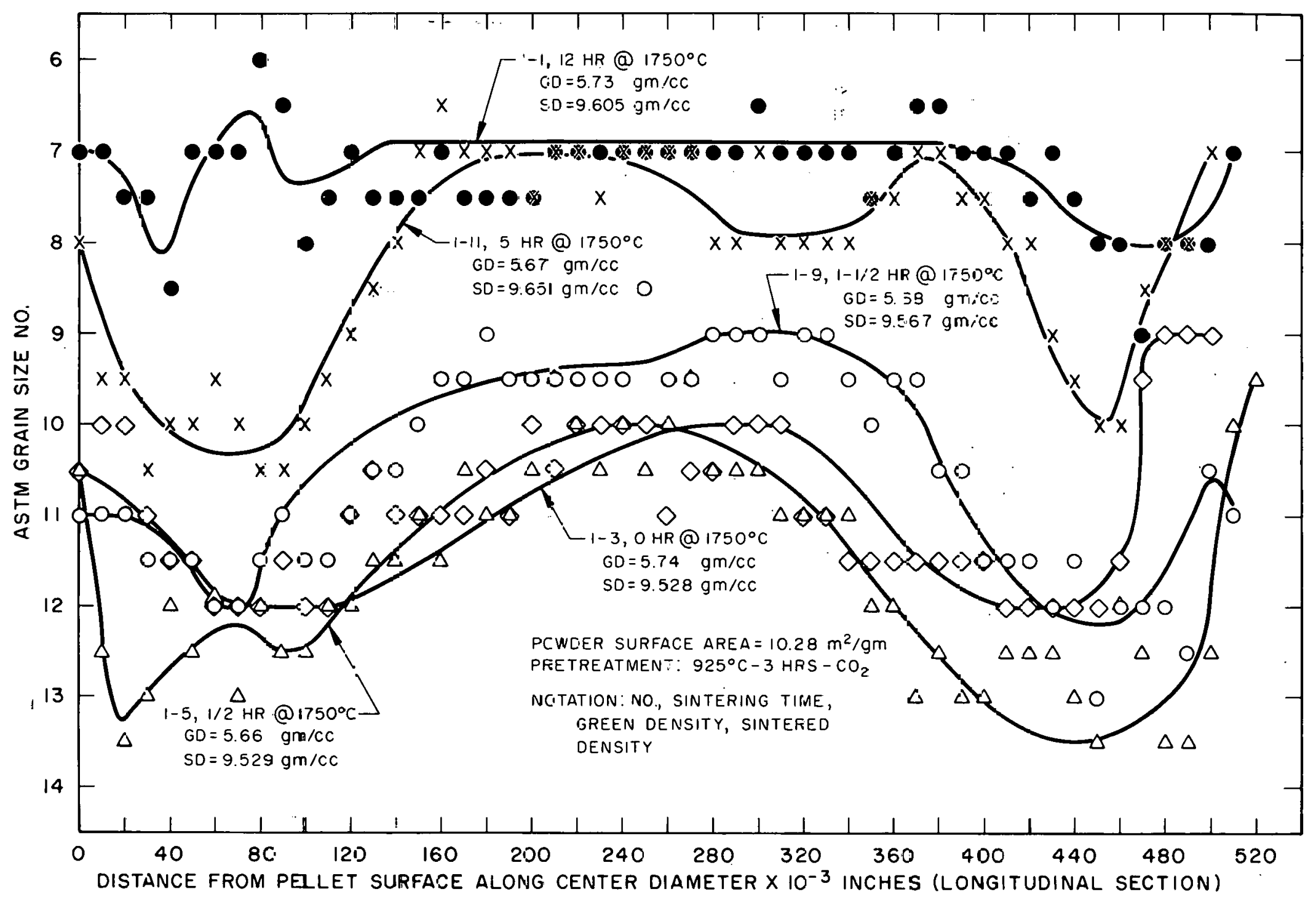


FIGURE-":A-2

EFFECT OF SINTERING TIME AT $1750^{\circ} \mathrm{C}$ ON GRAIN GROWTH IN ThO ${ }_{2}:$ PELLETS

FABRICATED FROM POWDER LOT 096 AIR CALCINED AT $1100^{\circ} \mathrm{C}$ FOR

48 HRS, MICRONIZED, SLURRY AGGLOMERATED WITH 1.75 w/o CARBOWAX -

0.2 w/o STEROTEX (AIDDED DRY) AND PRESSED TO A GREEN TARGET DENSITY OF $57 \%$

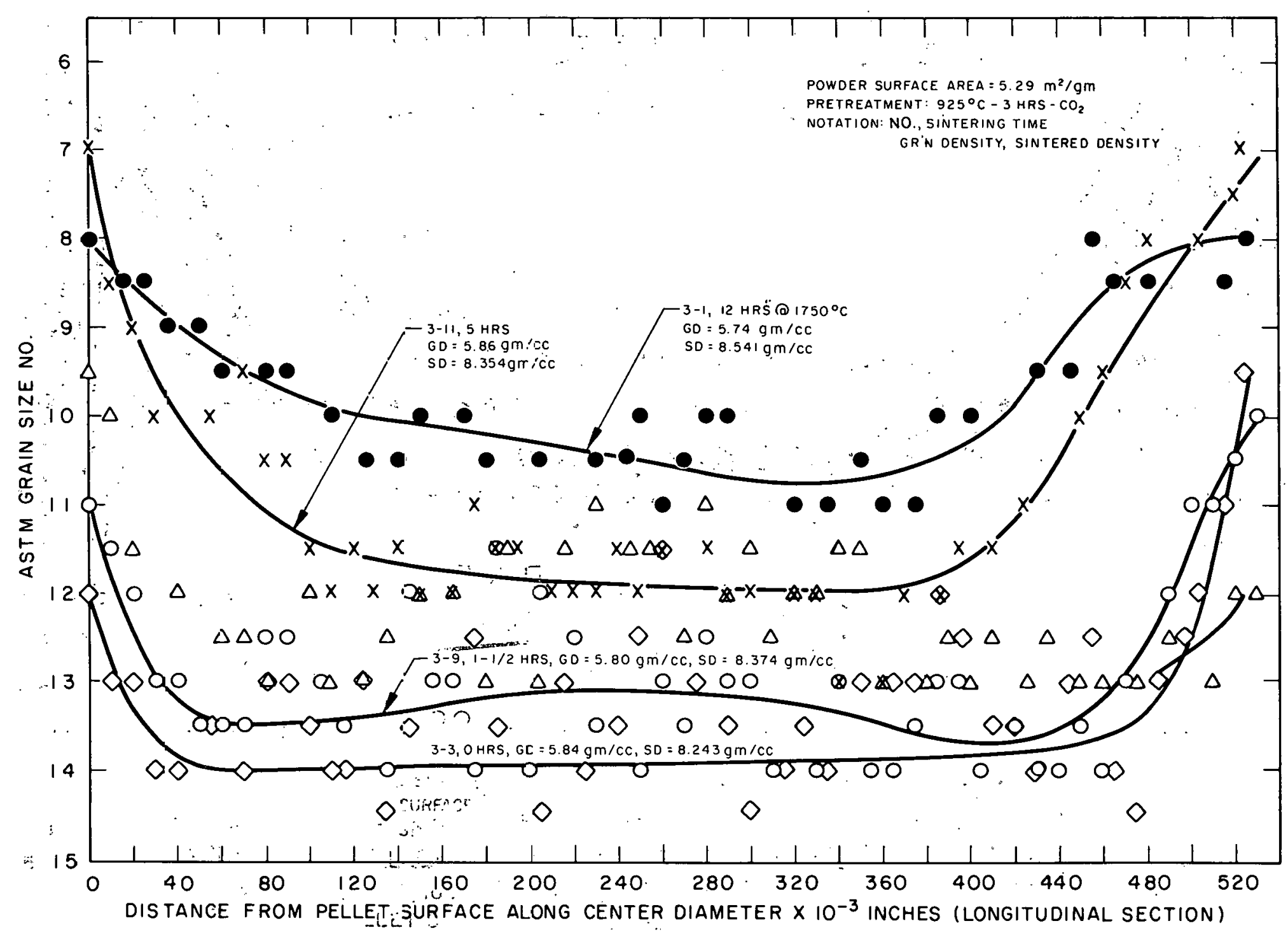

DISTANCE FROM PELLET: STURFACE ALONG CENTER DIAMETER $\times 10^{-3}$ INCHES (LONGITUDINAL SECTION) 
FIGURE A-3

EFFECT OF SINTERING TIME AT $1750^{\circ} \mathrm{C}$ ON GRAIN GROWTH IN ThO 2 PELLETS

FABRISATED FROM POWLER LOT 096; MICRONIZED, AS-REC.EIVED, SLURRY

AGGLCMERATED WITH 1.75 w/o CARBOWAX - 0.2 w/0 STEROTEX (ADDED DRY)

ANC PRESSED TO A GREEN TARGET DENSITY CIF $61 \%$

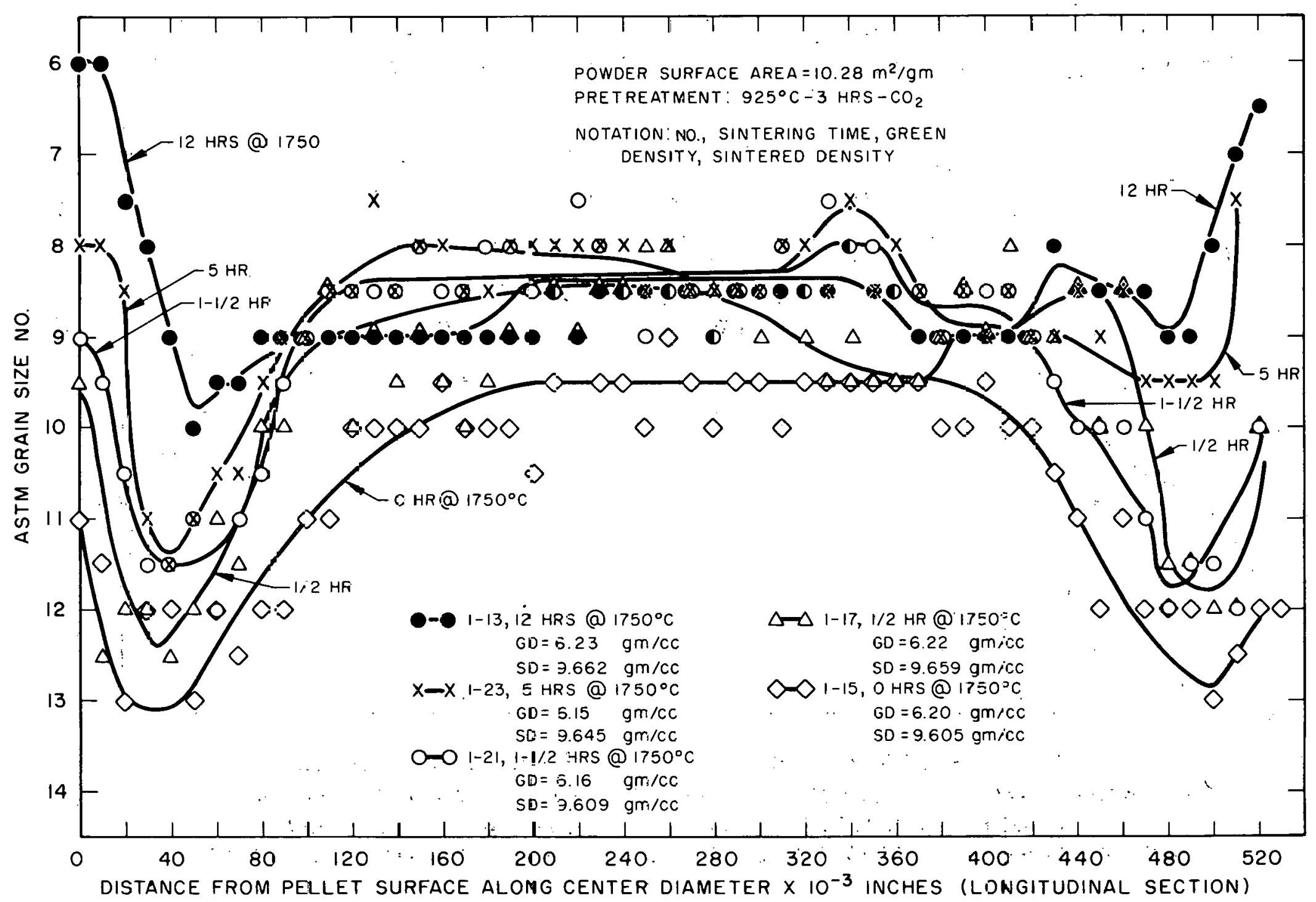


FIGURE A-4

EFFECT OF. SINTERING TIME AT $1750^{\circ} \mathrm{C}$ ON GRAIN GROWTH IN ThO 2 PELLETS

'FABRICATTED FROM POWDER LOT 096 AIR CALCINED AT $1100^{\circ} \mathrm{C}$ FOR

48;HRS, MICRONIZED, SLURRY AGGLOMERATED WITH 1.75 w/o CARBOWAX

$0.2 . w \%$ STEROTEX (ADDEDDRY) AND PRESSED TO A GREEN TARGET DENSITY OF $61 \%$

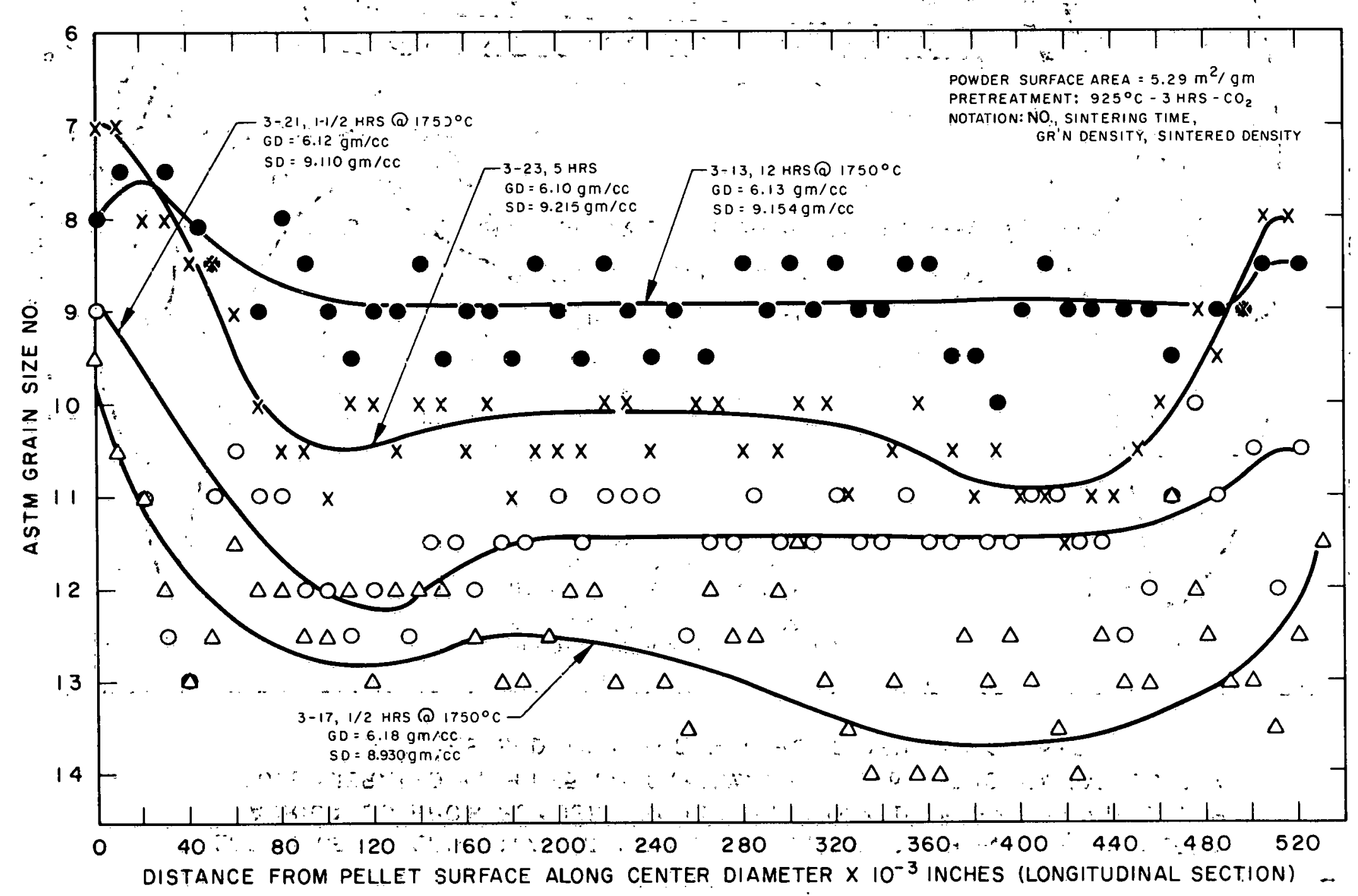


FIGURE . A-5

EFFEOT OF SINTERING TIME AT $1750^{\circ} \mathrm{C}$ ON GRAIN GROWTH IN ThO 2 PELLETS FABRICATED FROM POWDER. LOT 136, MICRONIZED, AS -RECEIVED, SLURRY AGGLOMERATED WITH 1.75 w/o CARBOWAX - 0.2 w/o STERDTEX (ADDED DRY)

AND PRESSED TO A GREEN TARGET DENSITY OF $57 \%$
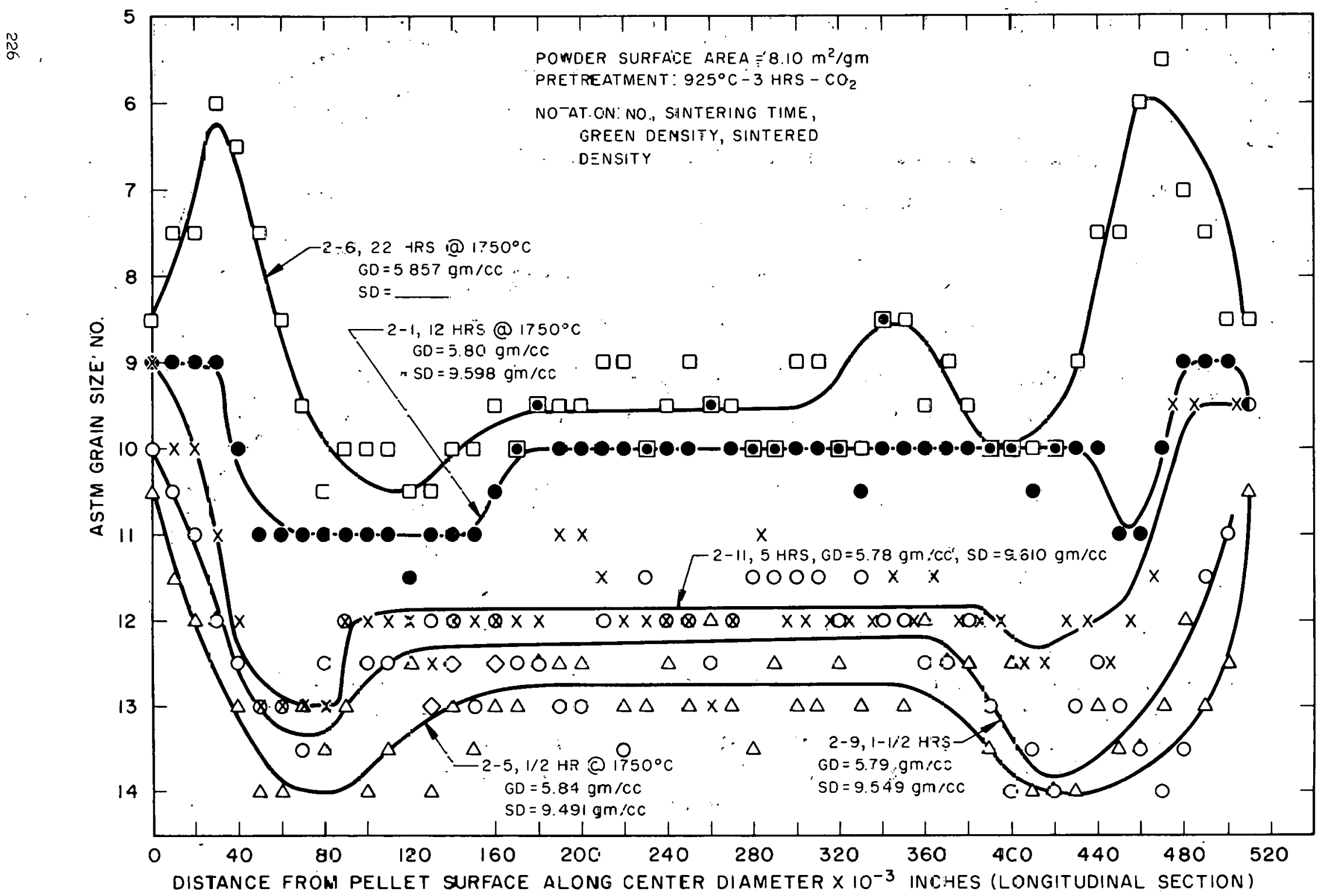
FIGURE A-6

EFFECT OF SINTERING TIME AT $1750^{\circ} \mathrm{C}$ ON GRAIN GROWTH IN ThO 2 PELLETS FABRICATED

FROM POWDER LOT 136 AIR CALCINED AT $1100^{\circ} \mathrm{C}$ FOR 48 HRS, MICRONIZED, SLURRY

AGGLOMERATED WITH 1.75 W/O CARBOWAX-0.2 W/O STEROTEX (ADDED DRY) AND PRESSED

TO A GREEN TARGET DENSITY OF $57 \%$

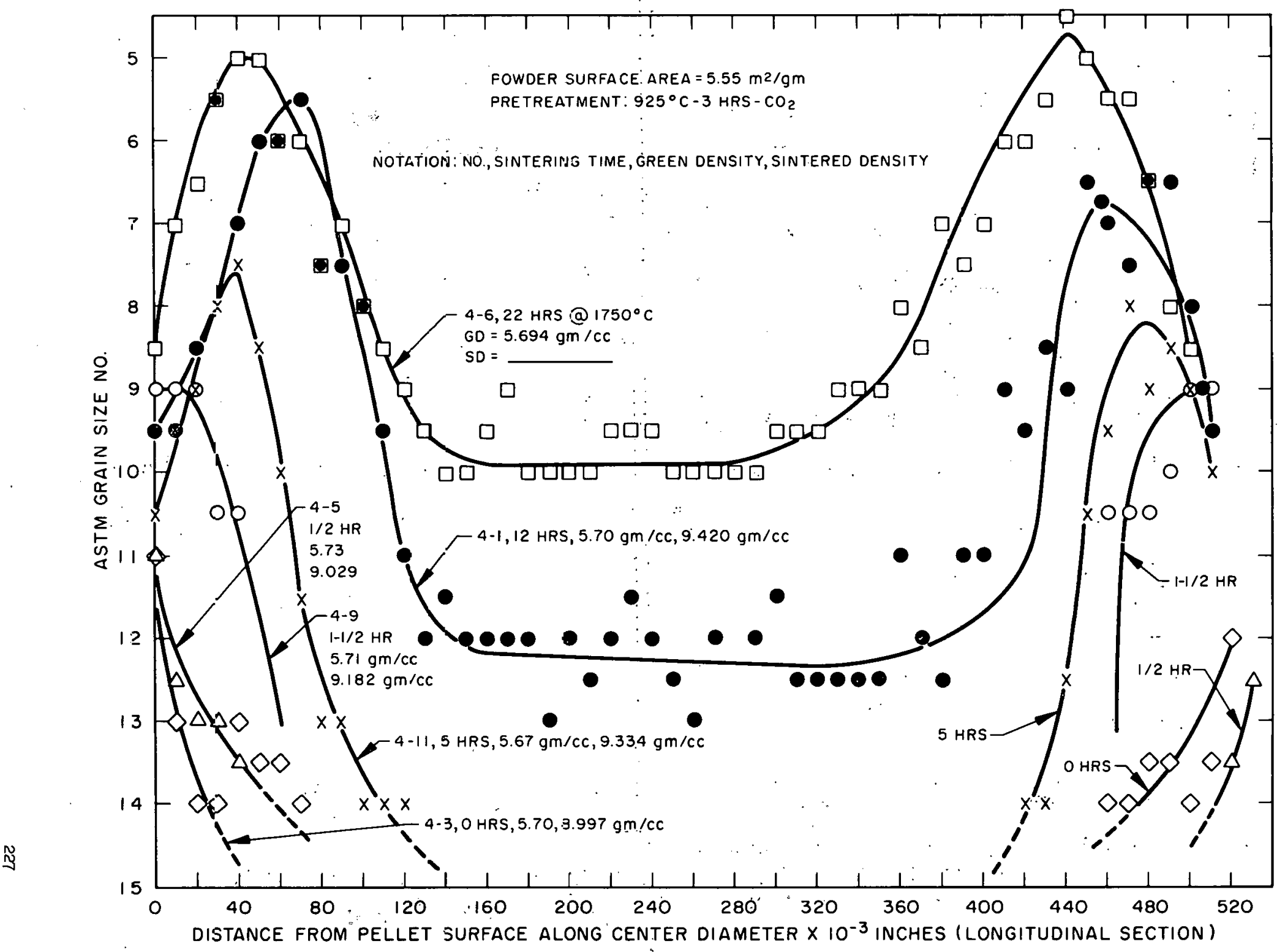


FIGURE A-?

EFFECT OF SINTERING TIME AT $1750^{\circ} \mathrm{C}$ ON GRAIN GROWTH IN THO 2 PELLETS FABRICATED FROM POWDER LOT 135, MICRONIIZED, AS-RECEIVED, SLURRY AGGLOMERATED WITH I.75 W/0 CARBOWAX -

0.2 w/o STEROTEX (ADDED DRY) AND PRESSED TO A GREEN TARGE T:DENSITY OF: $61 \%$.

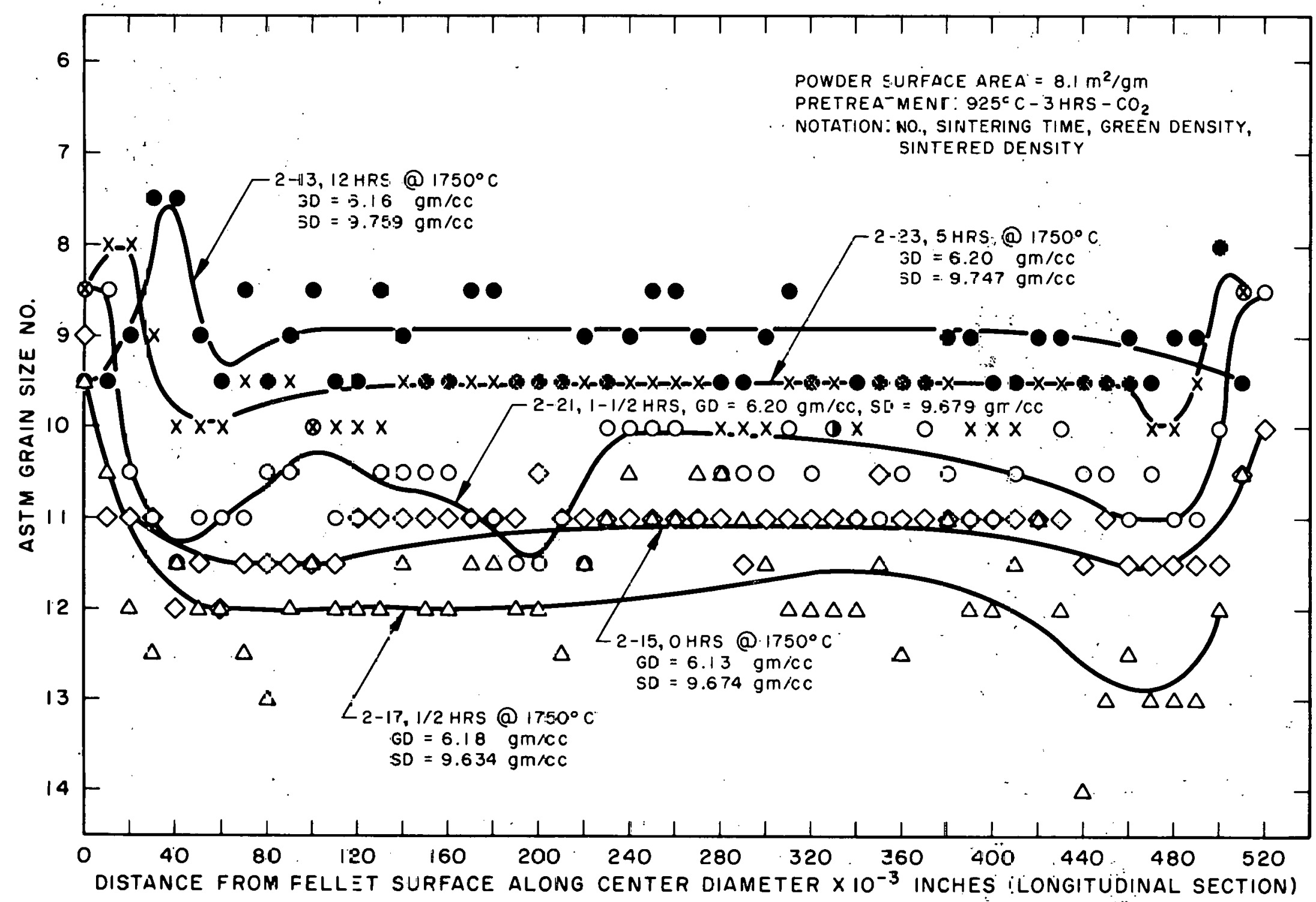


FIGURE A-8

EFFECT C.F SINTERING TIIAE AT $1750^{\circ} \mathrm{C}$ ON GRAIN GROWTH IN ThO 2 PELLETS FABRICATED FROM POWDER LOT 136 AIR CALCINED AT $110^{\circ} \mathrm{C}$ FOR 48 HRS, MICRONIZED, SLURRY AGGLOMERATED WITH

1.75 w/o CARBOWAX -0.2 w/o STEROTEX (ADDED DRY) AND PRESSED TO A GREEN DENSITY OF $61 \%$

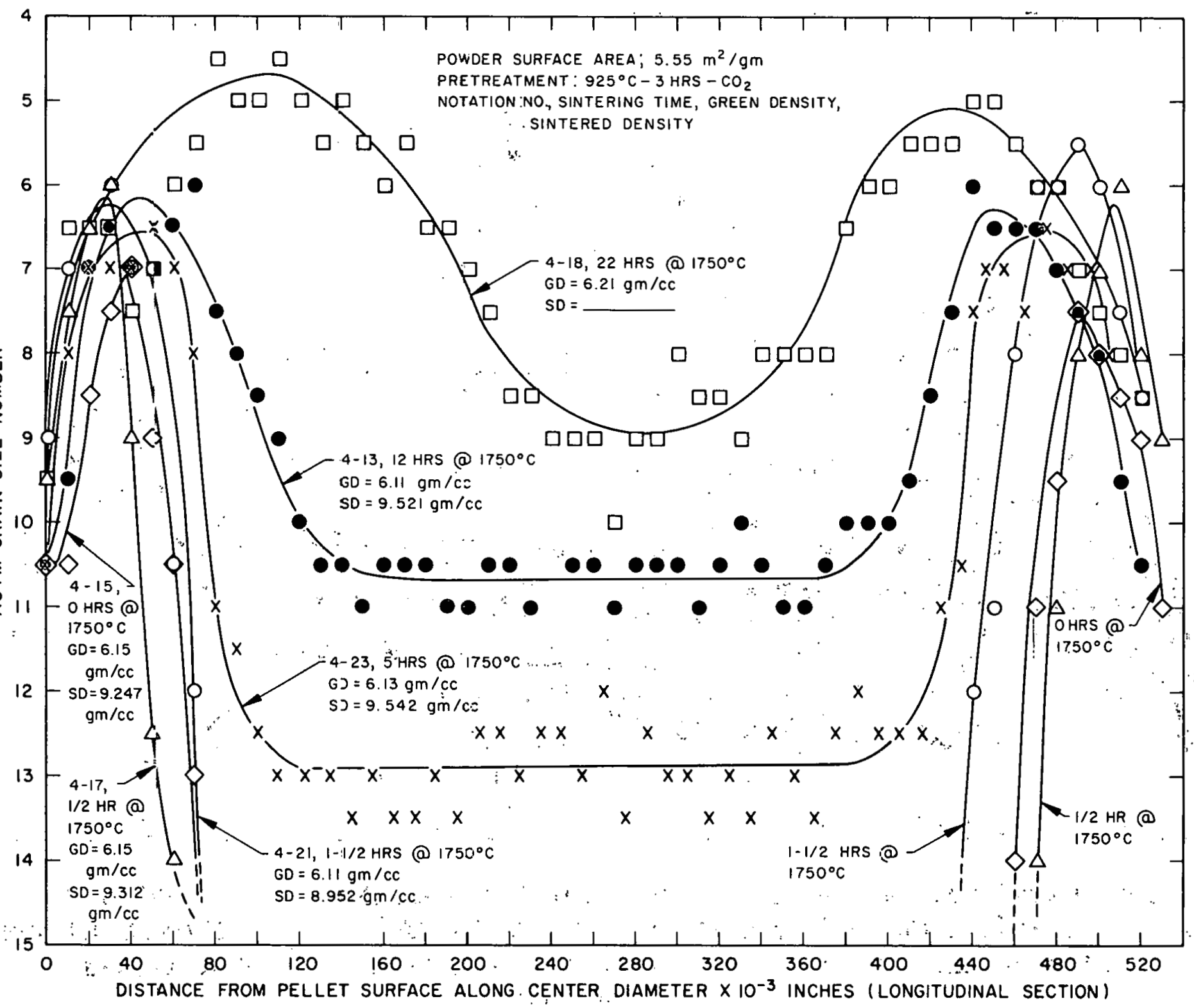


FIGURE A-9

EFFECT OF PRESSED DENSITY ON GRAIN GROWTH IN ThO 2 PELLETS: PRESSED

FROM MICRONIZED, AS-RECEIVED POWDER LOT O96 SLURRY AGGLOMERATED WITH I.75 W/O

CARBOWAX - 0.2 W/O STEROTEX :ADDED DRY) AND SINTERED AT $1750^{\circ} \mathrm{C}$ FOR $12 \mathrm{HRS}$

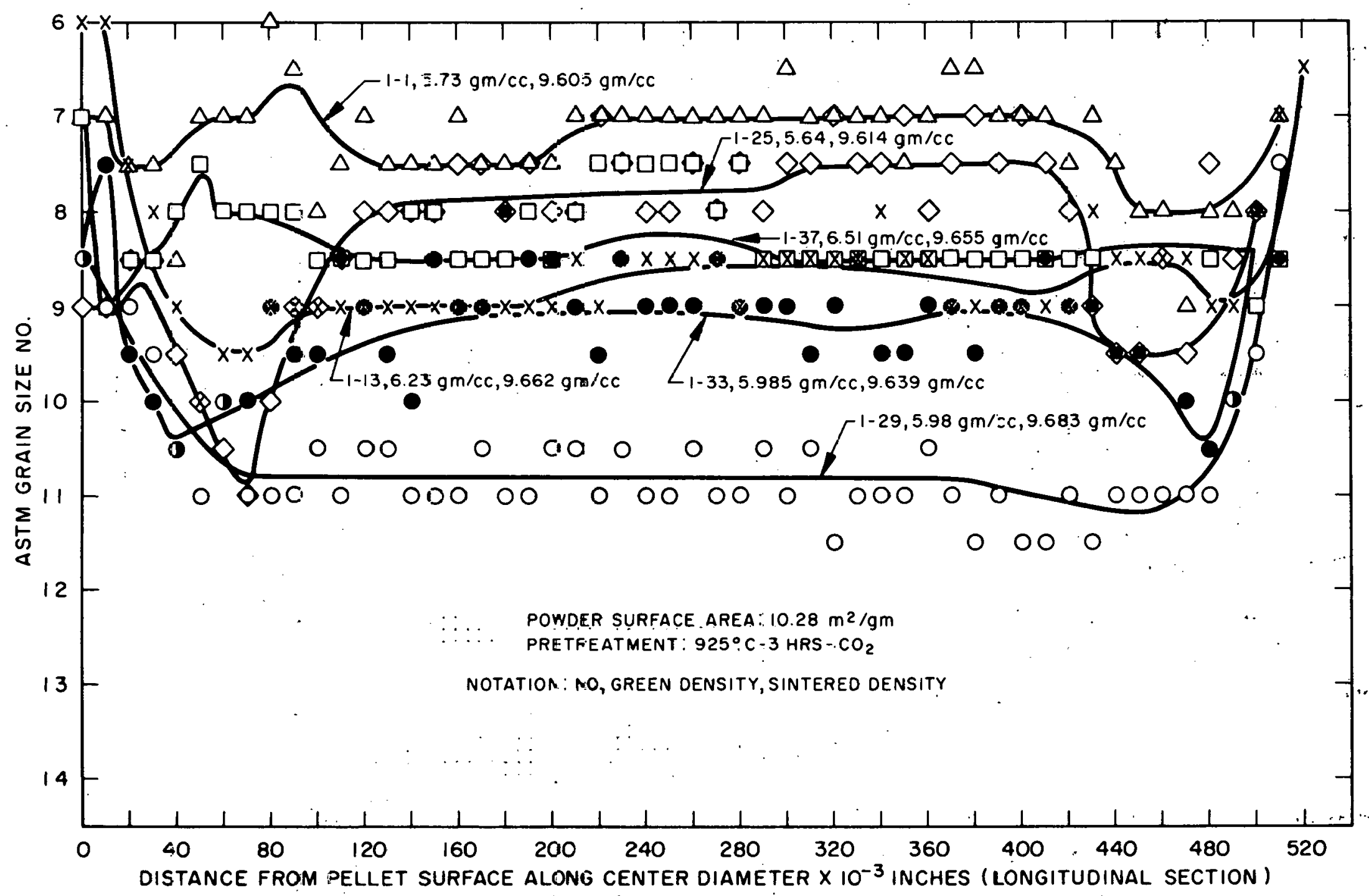


FIGURE A-10

EFFECT OF PRESSED DENSITY ON GRAIN GROWTH IN ThO 2 PELLETS PRESSED FROM $1100^{\circ} \mathrm{C}-48 \mathrm{HRS}$ AIR CALCINED; MICRONIZED POWDER LOT 096 SLURRY AGGLOMERATED WITH 1.75 w/o CARBOWAX - 0.2 w/o STEROTEX (ADDED DRY) AND SINTERED AT $1750^{\circ} \mathrm{C}$ FOR I2 HRS

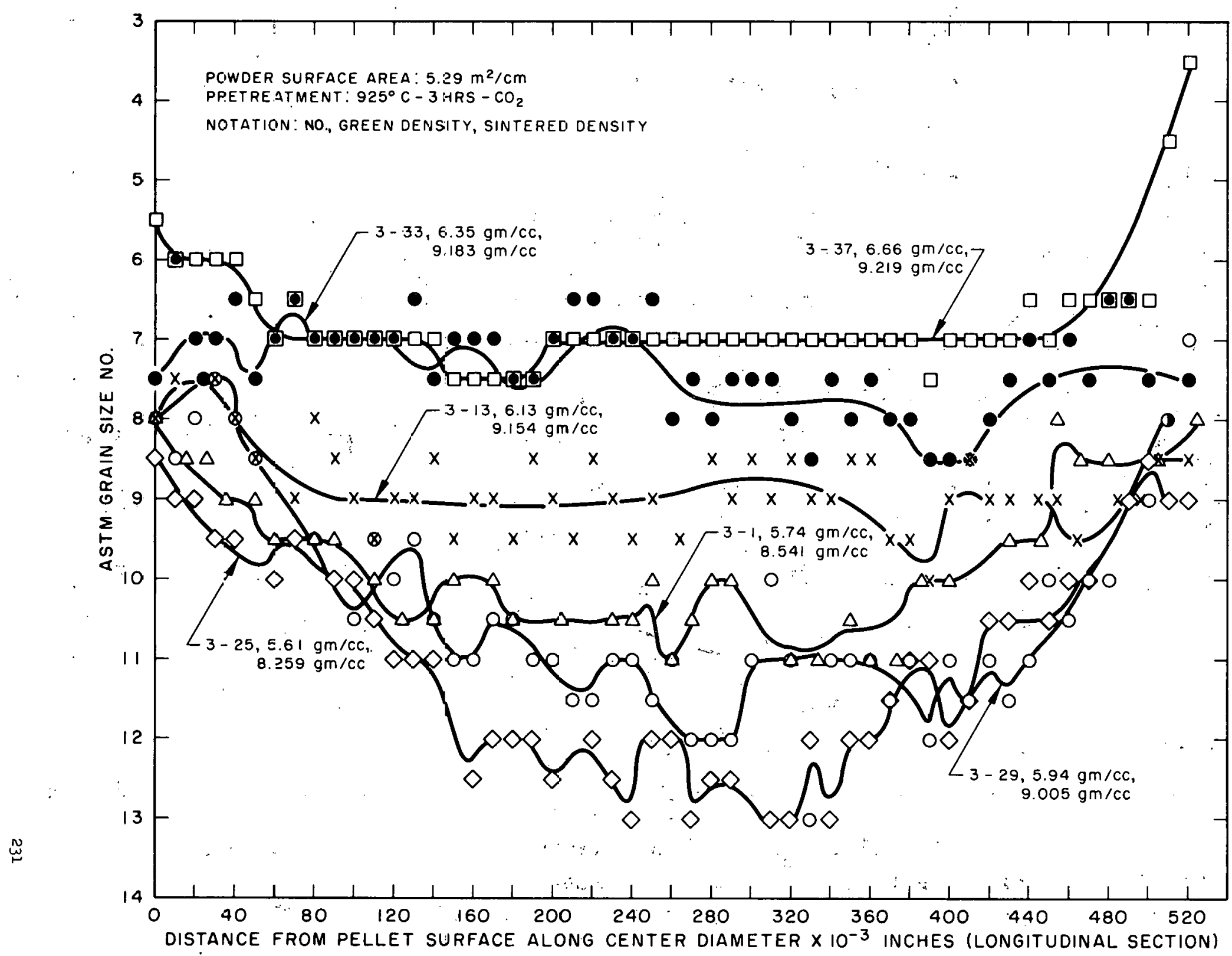


FIGURE A-11

EFFECT OF PRESSED DENSITY ON GRAIN GROWTH IN ThO 2 PELLETS PRESSED FROM MICRONIZED AS.-RECEIVED PJWDER LOT 136 SLURRY AGGLOMERATED WITH I.75 W/O

CARBOWAX - 0.2 w/O STEROTEX (ADDED DRY) AND SINTERED AT $1750^{\circ} \mathrm{C}$ FOR 12 HRS

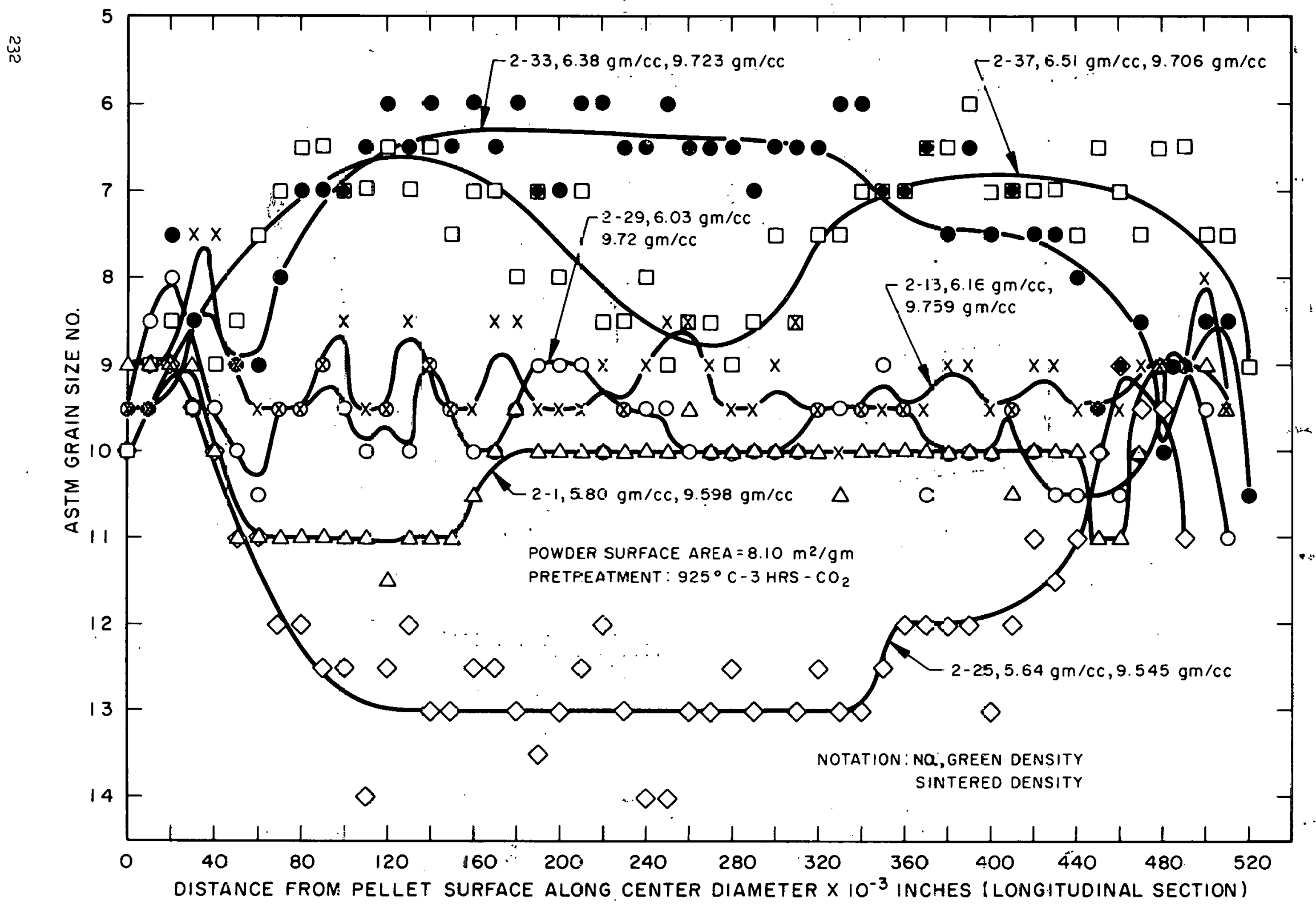


FIGURE A-12

EFFECT OF PRESSED DENSITY ON GRAIN GROWTH IN ThO 2 PELLETS PRESSED

FROM AIR CALCINED $1100^{\circ} \mathrm{C}-48$ HRS, MICRONIZED POWDER LOT 136 , SLURRY AGGLOMERATED WITH

I.?5 w.o CARBOWAX-0.2 w/o STEROTEX (ADDED DRY) AND SINTERED AT $1750^{\circ} \mathrm{C}$ FOR 12 HRS

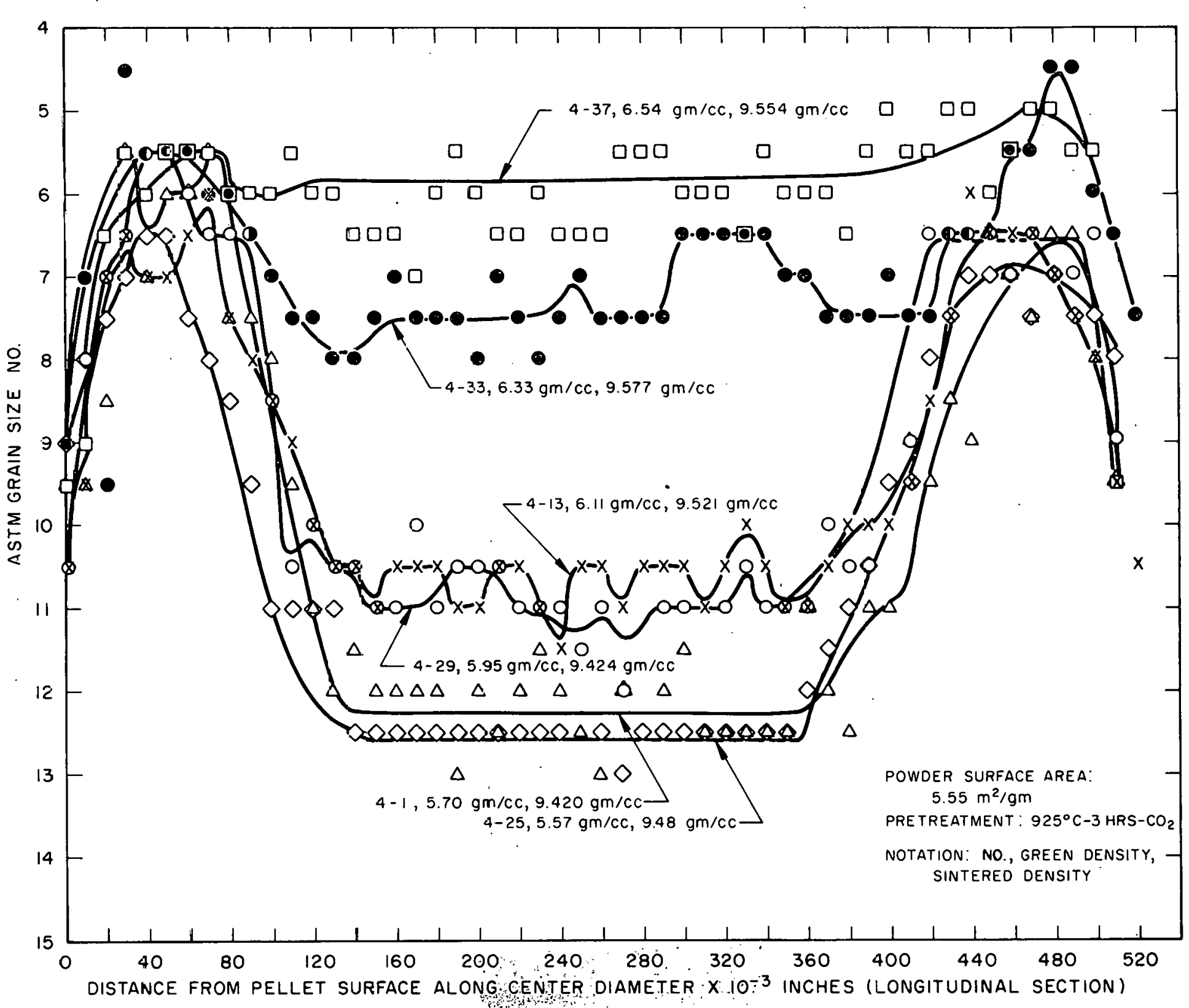

